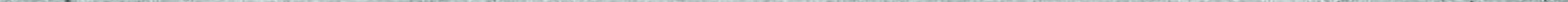




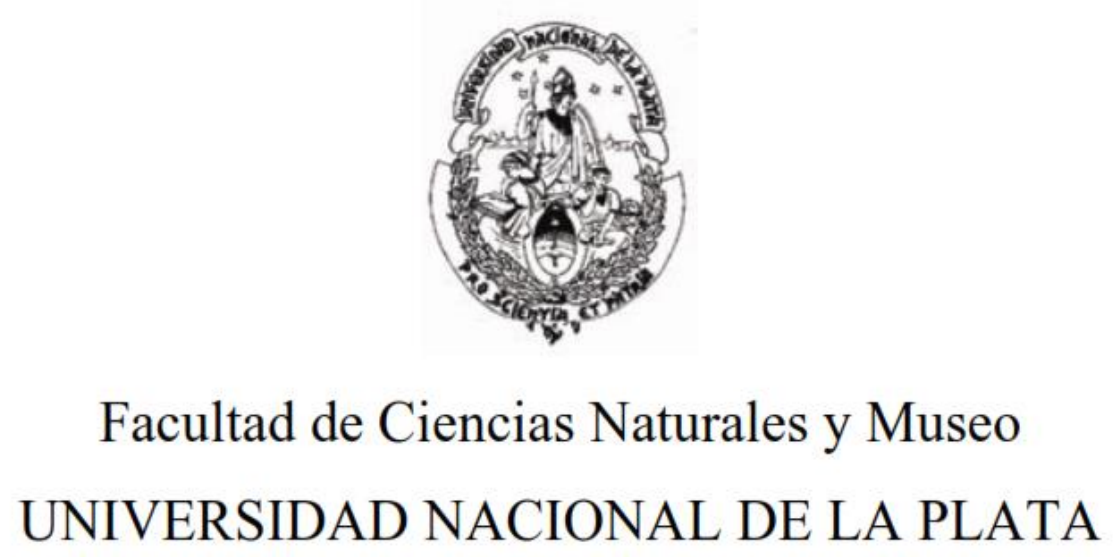

Carrera del Doctorado en Ciencias Naturales

\title{
Anatomía y Sistemática de los Toxodontidae (Notoungulata) de la Formación Santa Cruz, Mioceno Temprano, Argentina.
}

\author{
Tesis doctoral por:
}

Lic. Santiago Hernández Del Pino

Dra. Ma. Esperanza Cerdeño Serrano

Directora
Dr. Sergio F. Vizcaíno

Director

TOMO I

La Plata - Argentina 


\section{Dedicatoria}

A mi familia, por haberme impulsado en todo momento a perseguir mis aspiraciones. Especialmente a mi vieja; por haber sido el pilar fundamental, por todo su esfuerzo y perseverancia, por todas sus palabras de aliento, el apoyo incondicional y la motivación constante que me brindó durante todas las etapas de mi vida. 
"When there is freedom from mechanical conditioning, there is simplicity. The classical man is just a bundle of routine, ideas, and tradition. If you follow the classical pattern, you are undestanding the routine, the tradition, the shadow-you are not understanding yourself",

-Bruce Lee 


\section{Agradecimientos}

En estos breves comentarios, expreso mi agradecimiento a todas las personas que colaboraron, de alguna u otra manera, con el desarrollo y finalización de esta tesis.

En primer lugar, a la Educación Pública y gratuita porque sin ella no hubiese podido acceder a la universidad, ni a la oportunidad de realizar un postgrado.

A mi directora, Dra. Esperanza Cerdeño; en primer lugar, por haberme aceptado como su estudiante, por abrirme las puertas a su grupo de trabajo y haberme acompañado en el desarrollo de mi beca doctoral, brindándome su apoyo, experiencia y excelente predisposición desde que el primer momento que pisé Mendoza. También por su paciencia (especialmente en los últimos meses) y sus valiosos consejos que han mejorado de manera notable esta tesis doctoral y mí desempeño en general.

A mi director, Dr. Sergio Vizcaíno, también por haberme aceptado como su estudiante, por invitarme a participar en su proyecto de investigación y el trabajo de campo en la provincia de Santa Cruz y por su orientación durante estos años.

Al Dr. Guillermo Cassini, por su predisposición, por acompañarme durante mi beca doctoral, por su guía y aporte de ideas; por invitarme a participar en sus proyectos, su colaboración con los análisis de morfometría geométrica utilizados en esta tesis y por facilitarme sus bases de datos de medidas lineales y landmarks para la realización de los análisis de morfoespacio teórico. También, por facilitarme la posibilidad de utilizar el software Agisoft Photoscan para la realización de los modelos tridimensionales a partir de fotogrametría, cuya licencia no habría podido adquirir por mi cuenta.

Al Dr. Ross MacPhee, por su calidez y excelente predisposición, por haberme abierto las puertas de su oficina durante mi estadía en el American Museum, por los valiosos consejos y discusiones sobre diversas temáticas, por brindarme la chance de colaborar en sus proyectos de investigación. Por realizar las microtomografías que permitieron un análisis mucho más detallado del que podría haber realizado.

A la Dra. Analía Forasiepi, por su constante motivación, por facilitarme bibliografía, compartir discusiones sobre ontogenia, anatomía y filogenia, por invitarme a participar de sus proyectos de investigación y por su colaboración en las investigaciones que desarrollo.

A la Dra. Gabriela Schmidt, por su amabilidad, por compartir conmigo su experiencia sobre los ungulados sudamericanos, por sus charlas, su confianza y los valiosos consejos que facilitaron la realización de esta tesis. 
Al Dr. Federico Agrain, por su sencillez y buena onda, sus consejos en materia de filogenia y cladismo. Por siempre estar bien predispuesto para dar una mano.

Al Lic. Sergio L. Mosconi y a la FUESMEN (Mendoza), por brindarme la posibilidad de realizar las tomografías computadas, a partir de las cuales se hicieron la mayor parte de las reconstrucciones de cavidades presentadas en esta tesis.

A la Dra. Susana Bargo y el Dr. Juan Carlos Fernicola, por invitarme a participar en sus proyectos de investigación, por su asistencia en las campañas a Santa Cruz y la gestión para que pudiera acceder al material sobre el que se desarrolló esta tesis.

A todos aquellos que permitieron el acceso a las colecciones bajo su cuidado: al Dr. Marcelo Reguero de la Colección de Paleontología de Vertebrados del Museo de La Plata; al Dr. Alejandro Kramarz y a Stella Maris Álvarez de la Colección de Paleontología de Vertebrados del Museo Argentino de Ciencias Naturales; a Judith Galkin y a Ruth O’Leary de la Colección de Mamíferos Fósiles del American Museum of Natural History de Nueva York; al Dr. Ross MacPhee y a Eileen Westwig de la Colección de Mastozoología del American Museum of Natural History de Nueva York; al Dr. Chris Norris y a Daniel Brinkman de la Colección de Paleontología del Yale Peabody Museum de New Haven.

A Marcelo Bourguet y Cristian Sancho, por la preparación de parte del material estudiado en esta tesis, su asistencia durante los viajes de campo y todos los asados.

Al Lic. Leonel Acosta, por la preparación del material y por su asistencia durante las campañas; al Dr. Néstor Toledo, la Dra. Laura Chonogubsky, la Dra. Verónica Krapovickas, el Dr. Nahuel Muñoz y todos aquellos que me brindaron su asistencia en las campañas en la provincia de Santa Cruz.

A quienes me alojaron en sus casas durante mis viajes en el transcurso de estos años: Lean C., Pancho, Penny, Mati Armella, Leo Scarpa y Juan Diederle.

A mi familia, mis viejos y mi hermano que me han brindado todo su apoyo y cariño durante el desarrollo de este trabajo. Especialmente a mi vieja que siempre estuvo pendiente y brindándome su apoyo incondicional. A Ciro, el último en llegar, que con cada pasito y mueca me arranca una sonrisa.

A los amigos: Juli y Lauta que no solo me abrieron las puertas de su casa, sino que colaboraron de manera constante con el desarrollo de esta tesis, desde unos mates, una charla hasta la traducción de textos y el dibujo de la portada. Al Chino, Noe, Juli y Lu, por hacerme el aguante durante los momentos complicados, por las cenas y las charlas, por ser tan buena gente y por dejarme compartir tantos ratos con ustedes. A los chicos de la Sala, 
Meli y Lucho por hacerme el aguante en La Plata, sin fallar, y aguantar mi pésimo humor una y otra vez. A “Aroncito” y al Dami por su humor rancio y huraño que me alegró cada vez que estaba bajoneado y por no dejarme pagando cuando necesitaba donde quedarme. A Juanpi, por hacerme el aguante sin dudar aun en los momentos más difíciles. A Anita por ser mi "compañera de finalización de tesis" compartir los altibajos y tomarse mis mates lavados. A Leo, al Ale S., Ale dP., Sabi, Jupi, Pato, Bel, Lean A., Lean V., Sil, Emma, Ceci y Fede.

A todos ellos y a muchos más de los que seguro me estoy olvidando... SIMPLEMENTE GRACIAS.

El desarrollo de esta tesis fue posible gracias a una beca doctoral del CONICET y el apoyo de los proyectos de investigación ANPCyT - PICT 2010-1805 y CONICET- PIP 0075, dirigidos por la Dra. Esperanza Cerdeño; al CONICET- PIP 00781 a cargo del Dr. Juan Carlos Fernicola; a los proyectos UNLP N750 y ANPCyT - PICT 0389 a cargo del Dr. Sergio Vizcaíno; y por a los proyectos National Science Foundation grants EAR0851272, EAR1348259, National Geographic Society 9167-12 a cargo del Dr. Richard Kay. 


\section{Resumen}

Dentro del grupo conformado por los Ungulados Nativos Sudamericanos, los Notoungulata constituyen el clado más diverso y abundante, mostrando una amplia diversidad de formas. Uno de los grupos más exitosos de notoungulados fue el de los toxodóntidos, comprendido por herbívoros de mediano a gran tamaño con una dentición anterior especializada, caracterizada por la presencia de incisivos hipsodontes y una dentición yugal protohipsodonte a hipselodonte. Los Toxodontidae abarcan un lapso temporal desde el Oligoceno tardío (Edad Mamífero Deseadense) hasta el PleistocenoHoloceno y se distribuyeron por toda América del Sur, incluso llegando a alcanzar el Sur de América del Norte. Toxodon platensis, caracterizado por Owen en el año 1837, fue el primer taxón del grupo en ser descrito y llamó particularmente la atención de este autor por la conformación peculiar de su cráneo. Esto llevó a Owen a considerar a Toxodon como una forma transicional entre los roedores y los elefantes. Tras las interpretaciones de Owen, diversos autores han señalado la similitud de los toxodóntidos con rinocerontes e hipopótamos, dado su tamaño y la forma del cráneo, aventurándose a considerarlos como análogos ecológicos.

Existen alrededor de 40 géneros descriptos para la familia, distribuidos mayormente en dos subfamilias, Nesodontinae y Toxodontinae. La subfamilia más pequeña, Nesodontinae, objeto de estudio en esta tesis, consta de dos géneros, Adinotherium y Nesodon, y solo tres especies, Adinotherium ovinum, Nesodon imbricatus y Nesodon taweretus. Los nesodontinos son toxodóntidos de mediano a gran tamaño, con una masa corporal promedio de $75 \mathrm{~kg}$ para A. ovinum y un peso mayor a la media tonelada para $N$. imbricatus. En líneas generales, presentan cráneos largos y bajos, dentición yugal de corona compleja, en contrapartida con las formas de toxodontinos que presentan cráneos cortos y altos, y dentición yugal con el patrón oclusal simplificado. A Nesodontinae se le han atribuido otros taxones, pero o bien se trata de miembros de la subfamilia Toxodontinae o constituyen sinónimos de Adinotherium o Nesodon.

Los nesodontinos A. ovinum y N. imbricatus constituyen componentes importantes y muy abundantes de las faunas del Mioceno temprano de la Formación Santa Cruz. Su registro ha permitido la descripción de esqueletos casi completos y ha posibilitado el desarrollo de numerosos estudios que involucran diversos aspectos paleobiológicos. Sin embargo, su abundancia también ha generado que la literatura se poblara de nombres a 
causa de la enorme variabilidad que pudo documentarse a partir de los ejemplares disponibles.

Se ha hallado otro toxodonte en los depósitos de la Formación Santa Cruz, Hyperoxotodon speciosus, un toxodontino del que se tiene registro de un único ejemplar, y que es típico de sedimentos con edades más jóvenes (Edades Mamífero Friasense y Colloncurense).

Esta tesis consiste en la revisión taxonómica, actualización del conocimiento anatómico del cráneo, relaciones filogenéticas (a partir de un análisis cladístico) y un análisis paleobiogeográfico de los Toxodontidae (Notoungulata) de la Formación Santa Cruz (Mioceno temprano).

Aquí se lleva a cabo una revisión de los más de setenta nombres atribuidos a los toxodóntidos de la Formación Santa Cruz, listando autoría de los nombres, un resumen de las descripciones originales, destacando los caracteres diagnósticos utilizados, e ilustraciones de los ejemplares tipo más relevantes.

En esta contribución se incluye una revisión detallada de la anatomía externa del cráneo de los Nesodontinae de la Formación Santa Cruz, estableciendo algunas comparaciones con otros Nesodontinos (Nesodon taweretus), otros miembros de la familia Toxodontidae (Proadinotherium muensteri) y miembros de otras familias del suborden Toxodontia (Notohippus toxodontoides y Homalodotherium). Además, se evalúan aspectos de la anatomía poco conocidos o no descriptos hasta la fecha.

Por otro lado, dada la cantidad de materiales a disposición, se realiza un análisis cuantitativo a partir de morfometría tradicional y morfometría geométrica para establecer el morfoespacio teórico (principalmente del cráneo) de los nesodontinos de la Formación Santa Cruz. Los análisis de morfometría tradicional se hacen a partir de una muestra de 27 variables, 20 de ellas correspondientes al cráneo y las restantes 7 a la mandíbula, en 110 especímenes de nesodontinos de la Formación Santa Cruz. A partir de ellas se calcularon medidas de tendencia central para establecer un panorama de la variación (intraespecífica y ontogenética) de talla de las distintas partes del cráneo y la mandíbula; además, en los casos que el tamaño muestral lo permite, se realiza un análisis de componentes principales para identificar cuáles son las variables que hacen el mayor aporte la variación de la forma del cráneo de los nesodontinos. Para el caso de los análisis morfogeométricos, a las configuraciones de landmarks se les ejecuta un análisis de retrodeformación y se comparan los resultados de los diferentes análisis para las muestras deformadas y las retrodeformadas. Por último, se realizan regresiones de los componentes principales contra 
el tamaño del centroide para evaluar el rol del tamaño corporal como estructurador de la variación de la forma del cráneo.

Para la realización de los análisis cladísticos, se utiliza una matriz de 66 taxa terminales y 180 caracteres a partir de datos morfológicos discretos. Se efectuaron análisis bajo pesos iguales y pesos implicados sobre dicha matriz, además de realizarse un calibrado en el tiempo para los árboles resultantes. También se utiliza una matriz mixta con los datos de la matriz anterior y la configuración de landmarks para nueve de los 66 taxones (Adinotherium ovinum, Nesodon imbricatus, Nesodon taweretus, Proadinotherium muensteri, Toxodon platensis, Trigodon gaudryi, Gualta cuyana, Leontinia gaudryi, Thomashuxleya externa).

En esta tesis, se lleva a cabo por primera vez un análisis cuantitativo para evaluar la historia biogeográfica de la familia a partir de los árboles obtenidos del análisis filogenético bajo pesos iguales sobre la matriz morfológica discreta.

La revisión detallada de todos los nombres disponibles en la literatura permite proponer las siguientes nuevas sinonimias: Atryptherium Ameghino 1887a Nov. syn. de Adinotherium Ameghino 1887a; Adinotherium splendidum Ameghino 1887a Nov. syn. de Adinotherium ovinum (Owen 1853), Atryptherium bifurcatum Ameghino 1887a Nov. syn. de Adinotherium ovinum (Owen 1853), Nesodon bifurcatus Mercerat 1891 Nov. syn. de Adinotherium ovinum (Owen 1853), Acrotherium stygium Ameghino 1891 Nov. syn. de Adinotherium ovinum (Owen 1853), Adinotherium rotundidens Ameghino 1899 Nov. syn. de Adinotherium ovinum (Owen 1853), Adinotherium corriguenense Ameghino 1907 Nov. syn. de Adinotherium ovinum (Owen 1853), Noaditherium splendidum Ameghino 1907 Nov. syn. de Adinotherium ovinum (Owen 1853); Protoxodon conspurcatus Ameghino 1887a Nov. syn. de Nesodon imbricatus Owen 1847, Nesodon rutimeyeri Mercerat 1891 Nov. syn. de Nesodon imbricatus Owen 1847, Nesodon conspurcatus (Ameghino 1887a) Nov. syn. de Nesodon imbricatus Owen 1847, Nesodon brachycephalus Ameghino 1894a Nov. syn. de Nesodon imbricatus Owen 1847, Nesodon cornutus Scott 1912 Nov. syn. de Nesodon imbricatus Owen 1847.

Los siguientes nombres no pudieron ser evaluados debidamente por lo que se mantiene su estatus como Nomina dubia: Toxodon patagonensis Moreno (nomen nudum) 1882, Adelphotherium ligatum Ameghino 1887a, Gronotherium decrepitum Ameghino1887a, Phobereotherium sylvaticum Ameghino 1887a, Rhadinotherium limitatum Ameghino 1887a, Protoxodon patagonensis (Moreno) Ameghino 1887b, Acrotherium intermedium Mercerat 1891, Adinotherium antiquum Mercerat 1891, 
Adelphotherium rothi Mercerat 1891, Nesotherium patagonense (Moreno) Mercerat 1891, Paleolithops praevium Ameghino 1891, Nesodon impinguatus Ameghino 1899.

El análisis morfológico cualitativo, además de haber contribuido a la revisión taxonómica y a complementar las diagnosis de las especies válidas, permitió la caracterización del petroso, el oído interno y la cavidad endocraneana. A partir de esos datos, se generaron 19 caracteres de la cavidad y se logró la codificación de taxones para otros caracteres de la anatomía interna disponibles en la literatura.

Los análisis del morfoespacio teórico permitieron el establecimiento de un marco conceptual cuantitativo para la comparación de la morfología craneana entre los toxodóntidos santacrucenses y otros miembros de Notoungulata. Además, posibilitaran la comparación de su morfoespacio con el de especies actuales para así poder corroborar la viabilidad de las hipótesis taxonómicas propuestas aquí. Entre los resultados, se destaca, la bimodalidad que presentan algunas de las variables craneanas en los adultos de Adinotherium ovinum (que podría atribuirse a un carácter sexual secundario físico), el aporte que realizan las variables relacionadas con el largo del rostro a la variación registrada en el cráneo de los nesodontinos, la similitud de la forma del cráneo que presentan los ejemplares juveniles de Nesodontinae con los adultos de los Toxodontinae más derivados, y la mayor relación del cráneo de los ejemplares juveniles de ambas especies de nesodontinos que con sus respectivos estadios adultos. Además, las regresiones contra el tamaño del centroide permitieron detectar la escasa influencia del tamaño corporal como regulador de la forma del cráneo.

Los análisis filogenéticos recuperaron arreglos macrosistemáticos similares a los obtenidos en análisis previos disponibles en la literatura. Los nuevos caracteres formulados a partir de la anatomía interna no resultaron útiles para establecer arreglos entres los taxones bajo estudio y, por ello, debieron obviarse, pero pueden constituir una fuente útil de caracteres una vez sea posible aumentar el muestreo taxonómico.

De acuerdo a los resultados obtenidos, Proadinotherium no constituiría un grupo monofilético, y Proadinotherium leptognathum constituye el taxón más basal de la familia. A partir de él, el clado Toxodontidae diverge en dos grupos, por un lado los Nesodontinae y por otro Proadinotherium muensteri y los Toxodontinae. Dentro de los nesodontinos, Nesodon constituye un grupo monofilético. En el caso de Hyperoxotodon speciosus, se recuperó como el taxón hermano de Nonotherium hennigi, en un clado que se desprende tempranamente en la base de los Toxodontinae. 
Los resultados de los análisis paleobiogeográficos realizados indican que el área ancestral más probable para los tres eventos de diversificación de la familia habría sido Patagonia. Dichos resultados deben ser revaluados en un contexto que incluya un muestreo taxonómico más amplio. 


\begin{abstract}
Within the group of the South American Native Ungulates, the Notoungulata constitute the most diverse and abundant clade, showing a wide diversity of forms. Toxodontids were one of the most successful groups of notoungulates; they comprise small to large herbivores, with specialized anterior dentition and protohypsodont to hypselodont cheek teeth. The temporal range of Toxodontidae goes from the late Oligocene (Deseadan Mammal Age) to Pleistocene-Holocene; they were distributed throughout South America, even reaching the south of North America. The first taxon of this group to be described was Toxodon platensis, characterized by Owen in 1837, He was surprised by the particular morphology of its cranium and considered Toxodon as a transitional form between rodents and elephants. After that, several authors pointed out the similarity of toxodontids with rhinos and hippos, given their size and skull shape, and even venturing to consider them as ecological analogs.

There are approximately 40 genera described for the family, mostly distributed among two subfamilies, Nesodontinae and Toxodontinae. Nesodontinae, the smallest of the two and object of study in this thesis, comprises two genera, Adinotherium and Nesodon, and only three species, Adinotherium ovinum, Nesodon imbricatus and Nesodon tawaretus.
\end{abstract} The nesodontines are medium to large sized toxodontids, with an average body mass of 75 $\mathrm{kg}$ for A. ovinum, and more than half a ton for $N$. imbricatus. In general, they present long and low skulls, and cheek teeth with a complex crown, unlike the toxodontines, which present short and high skulls, and cheek teeth dentition with simplified crowns. Some other taxa have been attributed to Nesodontinae, but they either refer to members of the Toxodontinae subfamily or to synonyms for Adinotherium or Nesodon.

The nesodontines $A$. ovinum and $N$. imbricatus constitute important and frequent components of the early Miocene fauna of the Santa Cruz Formation. Their occurrence has allowed the description of nearly complete skeletons, and has made possible to develop a lot of studies that involve several paleobiological aspects. Nonetheless, their abundance has allowed the proliferation of synonymous names in the literature, as a result of the great amounts of specimens available.

Another toxodont species has been found in the Santa Cruz Formation, Hyperoxotodon speciosus, a toxodontine only known by one specimen, which is better known from more recent sediments (Friasian and Colloncuran Mammal Ages).

This thesis aims to perform a taxonomic revision, the actualization of the anatomic knowledge of the skull, phylogenetic relationships (carried out by the means of a cladistic 
analysis) and a paleobiogeographic analysis of the Toxodontidae (Notoungulata) found in the early Miocene Santa Cruz Formation.

More than 70 names attributed to toxodontids from the Santa Cruz Formation have been revisited here, listing the authorship of the names, a summary of the original descriptions, highlighting the diagnostic characteristics used, and illustrations of the most relevant type specimens.

Along this contribution, a detailed revision on the external anatomy of the skull of the Nesodontinae is included, establishing some comparisons with other nesodontines (Nesodon taweretus), other members of the Toxodontidae (Proadinotherium muensteri), and members from other families within the suborder Toxodontia (Notohippus toxodontoides and Homalodotherium). Additionally, several aspects of the anatomy that remained unrenowned or not described are evaluated.

Furthermore, given the amount of available material, a quantitative analysis has been performed using traditional morphometrics and geometric morphometrics to establish the theoretical morphospace (mainly of the skull) of the nesodontines found in the Santa Cruz Formation. The traditional morphometrics analyses are made on a 27 variables sample, 20 of them from the skull and the remaining 7 from the mandible, measured in 110 specimens of nesodontines from the Santa Cruz Formation. From these variables, measures of central tendency are calculated to establish a general view of the variation (intraspecific and ontogenetic) in the size of the different parts of the skull and jaw; in addition, in cases where the sample size allowed it, an analysis of principal components is carried out to identify which variables make the greatest contribution to the variation of the shape of the skull of the nesodontines. Regarding the geometric morphometrics analyses, retrodeformation analyses are performed on the landmarks configurations, and then, the results are compared to the ones observed in deformed and retrodeformed samples. And last, to evaluate the role of body size as a regulator of the shape variation, regressions of the principal components versus the centroid size are performed.

For the cladistic analysis, a matrix of 66 terminal taxa and 180 characters from morphological discrete data was used. The analyses were performed under equal weights and implied weights over the matrix, in addition to a time calibration for the resultant trees. Also, a mixed matrix was used with the combined data of the first matrix and the landmarks of nine out of the 66 taxons (Adinotherium ovinum, Nesodon imbricatus, Nesodon taweretus, Proadinotherium muensteri, Toxodon platensis, Trigodon gaudryi, Gualta cuyana, Leontinia gaudryi, Thomashuxleya externa). 
In this thesis, for the first time, a quantitative analysis is implemented to evaluate the paleobiogeographical history of the family, based on the trees obtained from the phylogenetic analysis under equal weights over the discrete morphological matrix.

The detailed revision of every name available in literature allows postulating the following new synonymies: Atryptherium Ameghino 1887a Nov. syn. of Adinotherium Ameghino 1887a; Adinotherium splendidum Ameghino 1887a Nov. syn. of Adinotherium ovinum (Owen 1853), Atryptherium bifurcatum Ameghino 1887a Nov. syn. of Adinotherium ovinum (Owen 1853), Nesodon bifurcatus Mercerat 1891 Nov. syn. of Adinotherium ovinum (Owen 1853), Acrotherium stygium Ameghino 1891 Nov. syn. of Adinotherium ovinum (Owen 1853), Adinotherium rotundidens Ameghino 1899 Nov. syn. of Adinotherium ovinum (Owen 1853), Adinotherium corriguenense Ameghino 1907 Nov. syn. of Adinotherium ovinum (Owen 1853), Noaditherium splendidum Ameghino 1907 Nov. syn. of Adinotherium ovinum (Owen 1853); Protoxodon conspurcatus Ameghino 1887a Nov. syn. of Nesodon imbricatus Owen 1847, Nesodon rutimeyeri Mercerat 1891 Nov. syn. of Nesodon imbricatus Owen 1847, Nesodon conspurcatus (Ameghino 1887a) Nov. syn. of Nesodon imbricatus Owen 1847, Nesodon brachycephalus Ameghino 1894a Nov. syn. of Nesodon imbricatus Owen 1847, Nesodon cornutus Scott 1912 Nov. syn. of Nesodon imbricatus Owen 1847.

The following names could not be properly evaluated, and they are considered as Nomina dubia: Toxodon patagonensis Moreno (nomen nudum) 1882, Adelphotherium ligatum Ameghino 1887a, Gronotherium decrepitum Ameghino1887a, Phobereotherium sylvaticum Ameghino 1887a, Rhadinotherium limitatum Ameghino 1887a, Protoxodon patagonensis (Moreno) Ameghino 1887b, Acrotherium intermedium Mercerat 1891, Adinotherium antiquum Mercerat 1891, Adelphotherium rothi Mercerat 1891, Nesotherium patagonense (Moreno) Mercerat 1891, Paleolithops praevium Ameghino 1891, Nesodon impinguatus Ameghino 1899.

The morphological qualitative analysis contributed to the taxonomical revision, and to complement the diagnosis of valid species, while simultaneously allowing the characterization of the petrosal, inner ear and endocranial cavity. From this data, 19 characters for the cavity were generated, which permitted the codification of taxa for other internal anatomy characters present in the literature.

The theoretical morphospace analysis allowed the definition of a conceptual quantitative framework for the comparison of the cranial morphology between the Santacrucian toxodontids and other notoungulate family members. It will enable, as well, 
the comparison of their morphospace with those of extant species, so the plausibility of the taxonomic hypothesis asserted in this thesis can be corroborated. Among the results, it is noteworthy, the bimodality of some of the cranial variables in adults of Adinotherium ovinum (which could be attributed to a secondary sexual physical character), the contribution made by the variables related to the length of the rostrum to the registered variation in the skull of the nesodontines, the similarity of the skull between the specimens of young Nesodontinae and the adults of more derived Toxodontinae; the closer affinity between the young specimens of both species of nesodontines than between them and their respective adults specimens. In addition, the regressions against the centroid size allowed the detection of the scarce influence of the body size as a shape regulator.

The phylogenetic analysis recovered similar macrosystematic arrangements to those found in previous analyses in the literature. The new characters formulated from the internal anatomy were not helpful to establish arrangements among the taxa under study, and they had to be removed from the analysis, but they could still constitute a strong and useful source of characters when the taxonomic sampling is increased.

According to the results obtained through this study, Proadinotherium would not constitute a monophyletic group, and Proadinotherium leptognathum constitutes the most basal taxon within the family. From it, the Toxodontidae clade diverges in two groups, on one side there is the Nesodontinae, and on the other, Proadinotherium muensteri plus the Toxodontinae. Among the nesodontines, Nesodon constitutes a monophyletic group. Hyperoxotodon speciosus was recovered as the sister taxon of Nonotherium hennigi, in a clade that splits early in the base of the Toxodontinae.

The paleobiogeographical results point out Patagonia as the ancestral area in which the three events of diversification of the family would have likely occurred. Still, these results need to be reevaluated in a context that includes a broader taxonomic sample. 


\section{Índice}

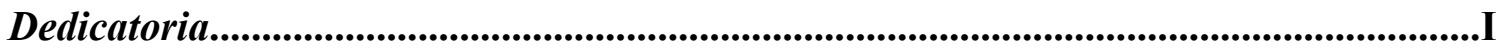

Agradecimientos...................................................................................................................................III

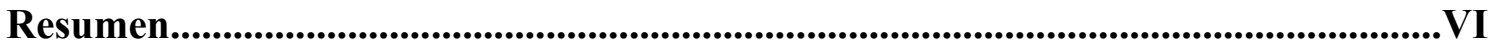

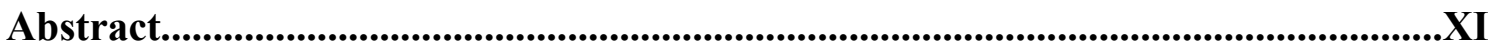

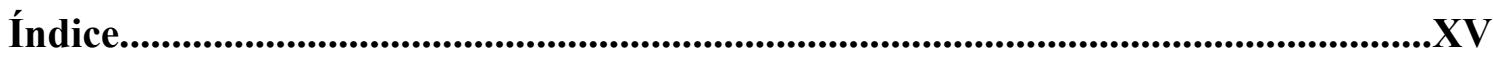

Capítulo I. Introducción..................................................................................................1

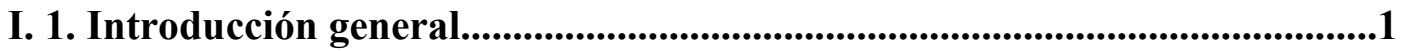

I. 2. Objetivos e hipótesis.....................................................................................................11

I. 2.1 Objetivos....................................................................................................................12

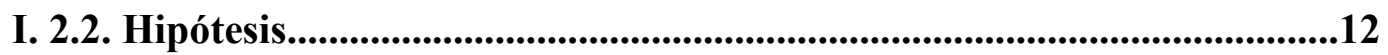

I. 3. Antecedentes sistemáticos para la Familia Toxodontidae y la Subfamilia

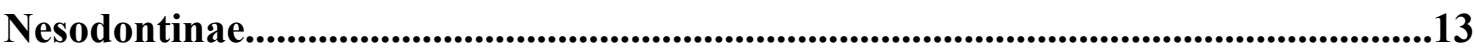

I. 4. La Formación Santa Cruz y la Edad Mamífero

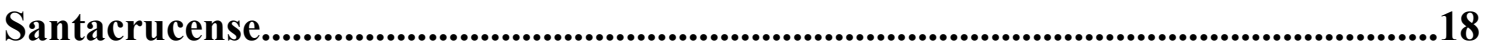

I. 4.1 Marco geológico y temporal............................................................................21

I. 4.2 Contenido faunístico, aspectos paleoambientales y paleoecológicos de la

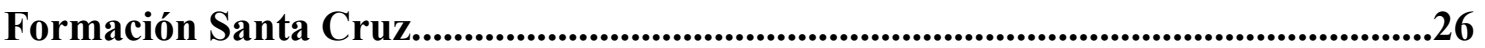

Capítulo II. Materiales y Métodos.......................................................................29

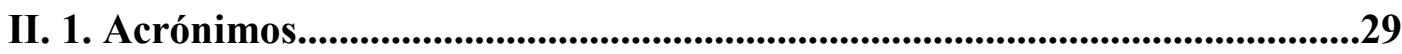

II. 2. Lista de especímenes consultados.........................................................................30

II. 3. Determinación taxonómica y descripción anatómica.....................................39

II. 4. Cuantificación de la forma y Paleontología virtual......................................42

II. 4.1. Marco teórico relacionado con la cuantificación de la forma y la morfometría geométrica..........................................................................................42

II. 4.2. Morfología virtual.....................................................................................45

II. 4.3. Protocolo utilizado para la obtención de modelos tridimensionales a partir de imágenes digitales..........................................................................52

II. 4.4. Análisis de Retrodeformación......................................................................54

II. 4.5. Estimación del morfo espacio teórico..........................................................55

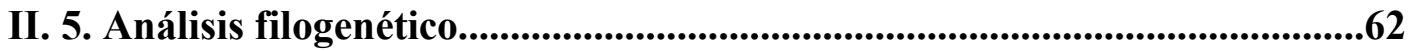

II. 5.1. Morfología y morfometría tradicional....................................................62 


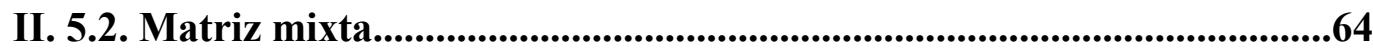

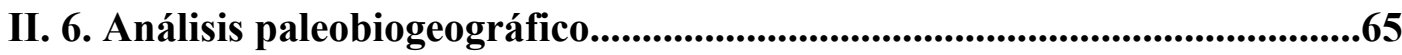

Capítulo III. Revisión taxonómica y estatus nomenclatural de los toxodontes del

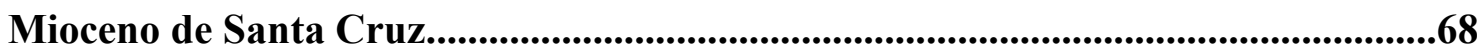

III. 1. Toxodontidae y Nesodontinae......................................................................68

III. 2. Toxodóntidos santacrucenses.....................................................................74

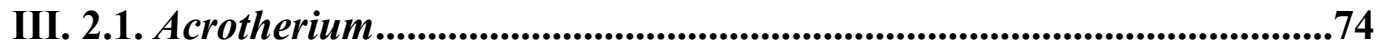

III. 2.2. Adelphotherium ..................................................................................82

III. 2.3. Adinotherium. .....................................................................................87

III. 2.4. Atryptherium ...........................................................................................................100

III. 2.5. Gronotherium .....................................................................................101

III. 2.6. Hyperoxotodon........................................................................................102

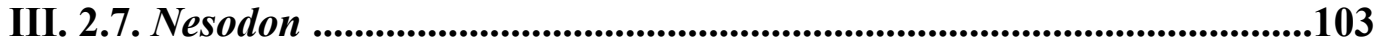

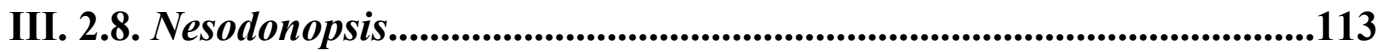

III. 2.9. Nesotherium ..............................................................................................114

III. 2.10. Noaditherium ................................................................................121

III. 2.11. Phobereotherium .........................................................................................122

III. 2.12. Protoxodon ..................................................................................................123

III. 2.13. Rhadinotherium .............................................................................................129

III. 2.14. Scophotherium ........................................................................................130

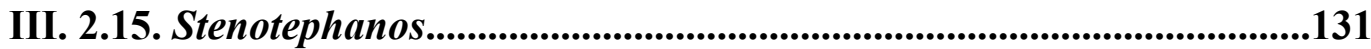

III. 3. Estatus taxonómico de las especies de Nesodontinae de la Formación Santa Cruz

III. 3.1. Consideraciones sobre los caracteres utilizados en la literatura para la diferenciación de especies de Nesodontinae..................................................132

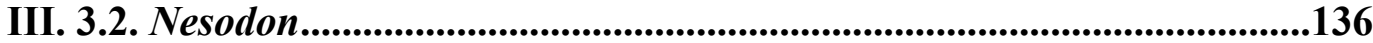

III. 3.3. Adinotherium .....................................................................................139

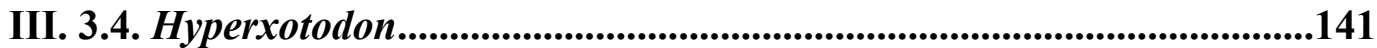

III. 3.5. Nomina dubia.......................................................................................142

Capítulo IV. Descripción anatómica................................................................144

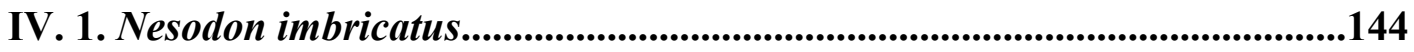

IV. 2. Adinotherium ovinum ...................................................................................182

IV. 3. Nesodontinos no santacrucenses y otros taxa santacrucenses relacionados con los Nesodontinae. 


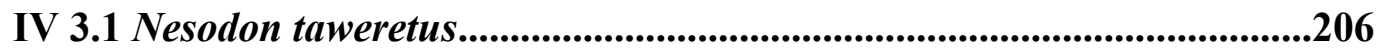

IV 3.2 Proadinotherium muensteri .....................................................................217

IV 3.3 Notohippus toxodontoides.................................................................225

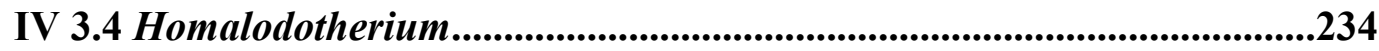

IV. 4. Discusión................................................................................................................239

IV 4.1 Anatomía interna de los nesodontinos.................................................239

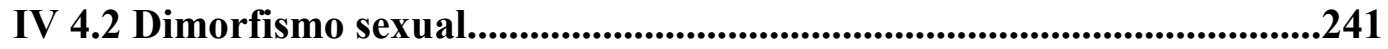

Capitulo V. Cuantificación del morfoespacio teórico...............................................245

V. 1. Morfometría tradicional...........................................................................245

V.1.1 Nesodon imbricatus.................................................................................246

V. 1.2 Adinotherium ovinum....................................................................256

V. 2. Morfometría geométrica..........................................................................264

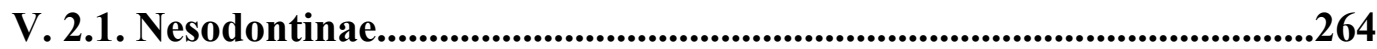

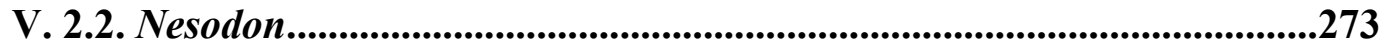

V. 2.3. Adinotherium ovinum ...............................................................................281

V. 3. Rol del tamaño corporal como estructurador de la variación.................288

V. 4. Análisis de parsimonia a partir de landmarks.........................................296

V. 5. Discusión.....................................................................................298

Capítulo VI. Análisis filogenético y paleobiogeográfico.........................................303

VI. 1. Análisis filogenético............................................................................303

VI. 1.1 Morfología y morfometría tradicional..............................................303

VI. 1.2 Morfometría geométrica............................................................313

VI. 2. Análisis biogeográfico....................................................................316

VI. 3. Discusión...............................................................................................321

Capítulo VII. Consideraciones finales y perspectivas futuras...................................329

VII. 1. Taxonomía.........................................................................................329

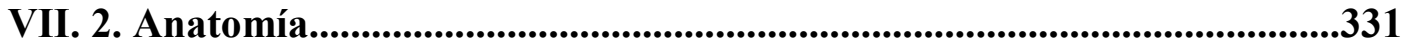

VII. 3. Historia evolutiva..........................................................................334

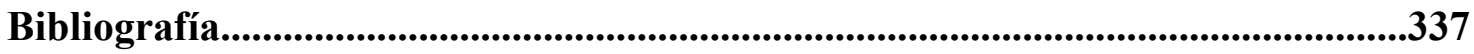

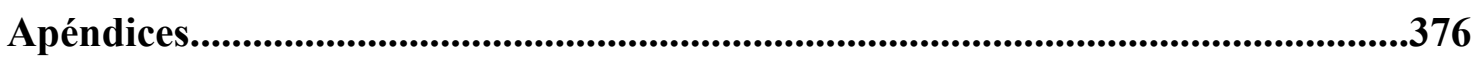

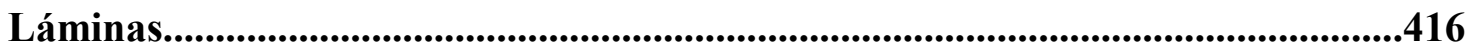




\section{Capítulo I. Introducción}

\section{1. Introducción general}

Sin duda, uno de los hitos en la evolución de los mamíferos placentarios se dio mientras América del Sur se encontraba aislada de otros continentes, desde su separación de Antártida hace unos 55 Ma. hasta gran parte del Plioceno (e.g. Iturralde-Vinent 2006, Montes et al. 2012, Reguero et al. 2014). Durante este lapso temporal, se desarrolló una gran radiación de varios órdenes de mamíferos conocidos en conjunto como "Ungulados Nativos Sudamericanos" (UNS). Este grupo fue sumamente exitoso y sus últimos integrantes se extinguieron en el Cuaternario.

Los UNS comprenden cinco órdenes: Astrapotheria, Litopterna, Pyrotheria, Xenungulata y Notoungulata. Según McKenna (1975), ellos conformarían el superorden Meridiungulata, a partir de la premisa de que todos estos grupos comparten un origen común, probablemente relacionado a algún condilartro basal (didolodóntido o mioclaénido). Los UNS son grupos netamente de América del Sur, aunque se han encontrado algunos en la Península Antártica (Reguero et al. 2002) e incluso ciertos taxones lograron dispersarse hacia América del Norte. Aun cuando este superorden no contaba con caracteres claramente definidos, se mantuvo de manera general hasta la hipótesis filogenética propuesta por de Muizon y Cifelli (2000). En un análisis cladístico de los caracteres dentarios de varios grupos de condilartros y algunos miembros del orden Litopterna, estos autores propusieron que los mioclaénidos, los didilodóntidos y los Litopterna constituían un grupo monofilético al que llamaron Panameriungulata, pero no se refirieron a la posibilidad de que el resto de los órdenes de Meridiungulata conformaran o no un clado.

Más recientemente, O’Leary et al. (2013) revaluaron (Fig. I. 1) las relaciones filogenéticas dentro de los placentarios y reconstruyeron su ancestro hipotético. Su análisis no recuperó los UNS como grupo monofilético, sino que planteó la hipótesis de un doble origen para los miembros del grupo. Por un lado Thomashuxleya (notoungulado "Isotemnidae") y Carodnia (xenungulado) como sucesivos grupos hermanos del clado Tethytheria (Proboscidea+Sirenia) que, junto con los hyracoideos, conformarían el clado Paenungulata (Lavergne et al. 1996; Springer et al. 1999; Shoshani and McKenna 1998; Asher et al. 2009). En el otro extremo del árbol, el linaje de los Litopterna aparece por fuera de los Afrotheria y se encuentra dentro de un clado conformado por varios grupos de condilartros como sucesivos 
grupos hermanos del clado Euungulata (Cetartiodactyla+Perissodactyla). En este arreglo, Protolipterna (un Litopterna basal) aparece relacionado con los condilartros didolondóntidos (en concordancia con la hipótesis de Muizon y Cifelli citada anteriormente).

Posteriormente, los avances en la obtención de material genético a partir de fósiles favorecieron la realización de filogenias basadas en proteínas que incluyen miembros de los UNS (e.g. Buckley 2015). En ellas, a partir de la secuenciación de proteínas de colágeno, Buckley (2015) y Welker et al. (2015) recuperaron a los Nototungulata y Litopterna (representados por Toxodon y Macrauchenia, respectivamente) como un grupo monofilético y grupo hermano de Perissodactyla, formando el clado Panperissodactyla; sin embargo, la monofilia de los UNS no pudo ponerse a prueba debido a la imposibilidad de obtener material genético de representantes de los restantes ordenes de ungulados nativos (Astrapotheria, Xenungulata y Pyrotheria). La hipótesis de la existencia del clado Panperissodactyla ha sido parcialmente respaldada por análisis filogenéticos más recientes, basados en ADN (Westbury et al. 2017), que situan a Macrauchenia como grupo hermano de los Perissodactyla.

Kramarz et al. (2017) han realizado recientemente un análisis filogenético a partir de dos conjuntos de datos morfológicos utilizados por de Muizon et al. (2015) y Billet et al. (2015), para testear las relaciones filogenéticas de un astrapoterio en el contexto de los Meridiungulata. En uno de los resultados obtenidos a partir de la modificación de la matriz utilizada por de Muizon et al. (2015), en donde no fueron forzadas las monofilias de los grandes grupos de placentarios, se ubica Paenungulata como grupo hermano de Pyrotheria. A su vez, ese conjunto forma una politomía con algunos miembros del orden Notoungulata. Por tanto, Notoungulata no constituiría un grupo natural (en la definición de Roth 1903) a menos que se incluyera a Pyrotheria+Paenungulata. La hipótesis filogenética de Kramarz et al. (2017) reforzaría la idea planteada por O' Leary (2013), esbozada también por Agnolin y Chimento (2011), sobre la relación cercana de parentesco entre Notoungulata y Afrotheria, a la par que apoyaría la existencia de relaciones filogenéticas cercanas entre Pyrotheria y Notoungulata, tal como propuso Billet (2011). Aun cuando la hipótesis de Agnolin y Chimento (2011) coincide con los resultados mencionados anteriormente; cabe destacar que, varios de los argumentos que sustentaron su hipótesis han sido rechazados por diversos autores (e.g. Billet y Martin 2011, Bond et al. 2011, Lorente et al. 2011, Gelfo y Lorente 2012, Kramarz y Bond 2014, Kramarz et al. 2011, 2017), tal y como se verá al tratar brevemente el orden Notoungulata. 
A continuación, se da una caracterización breve de los diferentes órdenes de UNS, haciendo énfasis en los Notoungulata, orden del cual es miembro la subfamilia estudiada en esta tesis.

El orden Astrapotheria es uno de los grupos más enigmáticos de UNS e incluye a las especies más grandes dentro de este grupo (e.g. Parastrapotherium). Entre las características más distintivas del grupo se encuentra la retracción de los nasales (lo que sugiere la presencia de una proboscis, al menos en las formas más derivadas), caninos alargados y bien desarrollados, y la presencia de yugales braquiodontes similares a los de un rinoceronte (Ameghino 1894b, Scott 1937, Kramarz et al. 2011). Se reconoce desde el Paleoceno medio hasta el Mioceno tardío, alcanzó su máxima diversidad durante el Mioceno temprano (Edades Mamífero-EM-Colhuehuapense y Santacrucense) y está constituido por unos pocos taxones, menos de 10 géneros de acuerdo a Cifelli (1993), de los cuales Astrapotherium es el mejor conocido.

El orden Litopterna comprende varias familias y es el segundo grupo más diverso de ungulados nativos (Cifelli 1983, 1993, Cifelli y Soria 1983, Bond 1986, 1999, Bond et al. 1995, 2001, Cifelli y Guerrero 1997; Soria 1981, 2001, Scherer et al. 2009; Schmidt y Ferrero 2014). Su registro abarca desde el Paleoceno temprano (Bonaparte y Morales 1997) hasta principios del Holoceno (Tonni 1990, Bond 1999, Schmidt y Ferrero 2014). Se han encontrado, incluso, en el Eoceno de Antártida (Gelfo et al. 2015). Las relaciones filogenéticas dentro del orden Litopterna (Cifelli 1993, Rose 2006, Forasiepi et al. 2016) y con el resto de los órdenes de ungulados nativos aún no están claras, pero Muizon y Cifelli (2000) propusieron un agrupamiento a nivel de orden que combinaba a Mioclaenidae, Didolodontidae y Litopterna, grupo al que llamaron Panameriungulata. De acuerdo a Gelfo y Lorente (2012), los resultados de este trabajo deben ser tomados con cautela, dado que el análisis no incluyó un gran número de representantes y entre sus resultados no contaba con caracteres derivados que dieran soporte al clado Panameriungulata. Las dos familias de Litopterna que presentan mayor número de representantes y cuyo conocimiento está más refinado son: Protherotheriidae Ameghino 1887a y Macraucheniidae Gervais 1855 (ver Schmidt, 2013, 2015, Forasiepi et al. 2016 y referencias incluidas). Protherotheriidae se caracteriza por cráneos con la cresta sagital conspicua, alta y fina, además de una cavidad craneana moderadamente desarrollada; si bien los nasales pueden estar reducidos, nunca alcanzan el nivel de reducción presente en la otra familia; formula dentaria completa en formas basales con una tendencia a la reducción en formas derivadas; pies tridáctilos con los dedos laterales muy reducidos, con la expresión máxima de reducción en el género 
Thoatherium, el cual presenta solo rudimentos de los metapodos II y IV. Macraucheniidae se caracteriza por taxones de cuello alargado, con cráneos largos, estrechos y bajos, cresta sagital pobremente desarrollada o ausente y cavidad craneana pequeña; en las formas más derivadas, puede observarse que la región nasal está muy modificada, con las narinas externas situadas muy posteriormente; miembros tridáctilos, mesaxónicos, con ulna y radio co-osificados en toda su extensión, y tibia y fíbula fusionados en los extremos.

El orden Pyrotheria incluye ungulados de gran tamaño representados temporalmente desde la EM Casamayorense (Eoceno medio) hasta la Deseadense (Oligoceno tardío). Este grupo se encuentra ampliamente representado en América del Sur (e.g. Anthony 1924, Patterson 1942, Hoffstetter 1970, Salas et al. 2006). En un principio, Ameghino los relacionó filogenéticamente con los ungulados (Ameghino 1888), pero más tarde les atribuyó relaciones con los Proboscidea (Ameghino 1894c, 1897), aunque no los incluyó dentro de este orden por diferencias en el astrágalo. Las relaciones filogenéticas de los piroterios han sido objeto de numerosos estudios y diversos autores los han relacionado con varios grupos de mamíferos diferentes, tales como los marsupiales diprotodontes (Lydekker 1893, Loomis 1921), proboscídeos (Loomis 1914, Lydekker 1896), pantodontes (Zittel 1893), notoungulados (Osborn 1910, Scott 1913, Patterson 1977) y xenungulados (Simpson 1945, Cifelli 1983; Schoch y Lucas 1985, Lucas 1986, 1993, Gelfo et al. 2008). La hipótesis de que Pyrotheria se encuentra dentro de Notoungulata se vio apoyada por algunos análisis filogenéticos realizados en los últimos años (Billet 2011, Billet et al. 2015, de Muizon et al. 2015, Kramarz et al. 2017); sin embargo, algunos de los trabajos más recientes vuelven a considerarlo como un orden aparte (Koenigswald et al. 2015, Cerdeño y Vera 2017). 


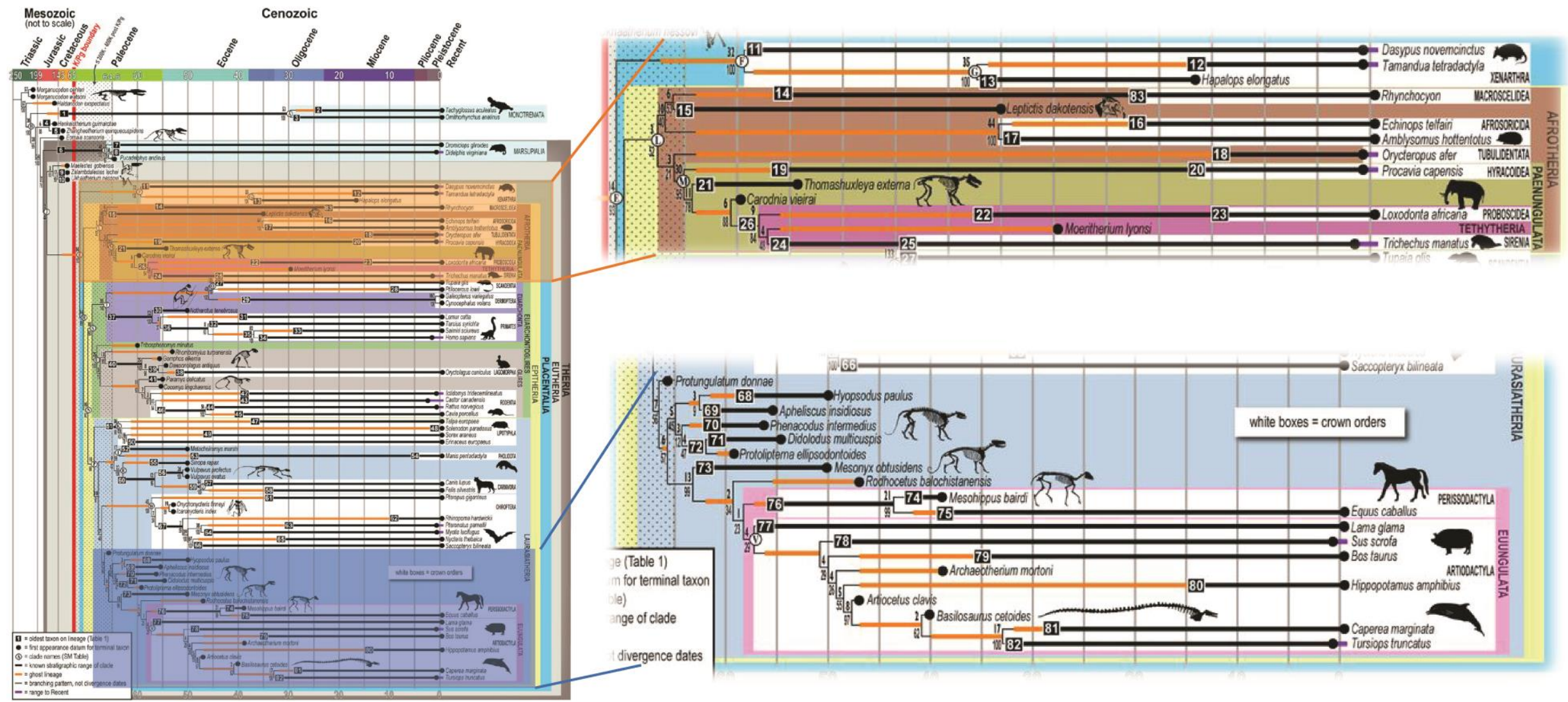

Fig. I. 1. Árbol filogenético presentado por O’Leary et al. 2013 con el detalle del agrupamiento de los UNS: posición de Notoungulata (Thomasxuleya externa) dentro del clado Afrotheria (Arriba) y posición de Litopterna y Condylarthra dentro de Laurasiatheria y como sucesivos grupos hermanos de Euungulata (Abajo). 

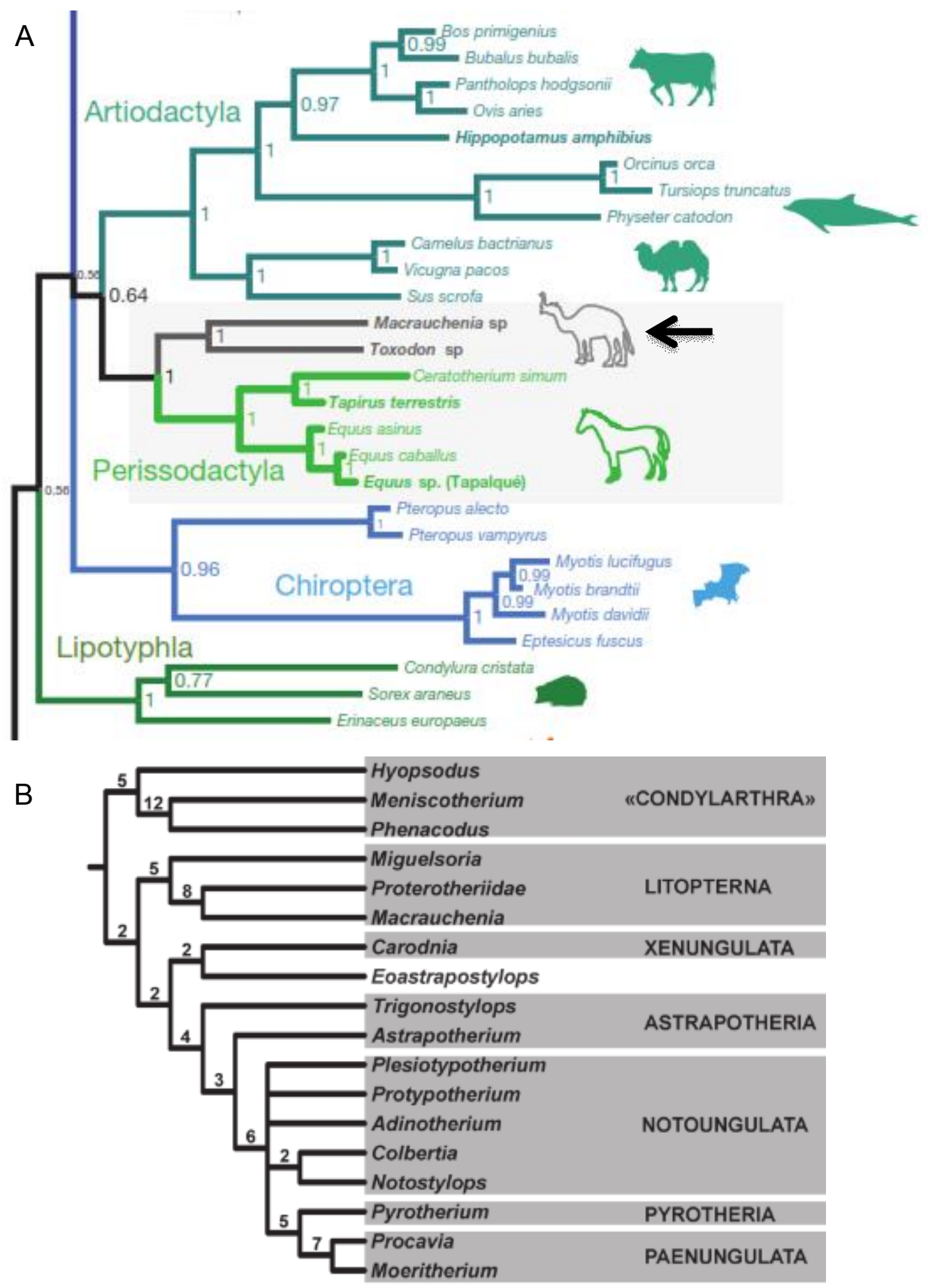

Fig. I. 2. Hipótesis filogenéticas recientes para los Ungulados Nativos de América del Sur: hipótesis filogenética presentada por Buckley (2015) a partir de datos moleculares (A) e hipótesis filogenética presentada por Kramarz et al. (2017) a partir de datos morfológicos (B).

El orden Xenungulata probablemente sea uno de los grupos de UNS más enigmático; su registro fósil es escaso (y en consecuencia también lo es el conocimiento sobre el grupo) y se encuentra restringido temporalmente al Paleoceno temprano-Eoceno temprano de Patagonia, Brasil y Colombia (Simpson 1935, Paula Couto 1952, Villarroel 1987, Gelfo et al. 2008, 
Clyde et al. 2014, Woodburne et al. 2014a, b, Antoine et al. 2015). Como se ha mencionado antes, Scoch y Lucas (1985) consideraron a los xenungulados como un grupo dentro de Pyrotheria, vinculando a este último con los Dinocerata, en un grupo que recibió el nombre de Uintatheriomorpha, hipótesis que no se ha respaldado posteriormente. Dentro de Xenungulata se reconocen dos familias, Carodniidae y Etayoidae, ambas con una diversidad muy baja. Carodniidae es una familia monotípica, que incluye al género Carodnia (con tres especies, $C$. feruglioi Simpson 1935, C. vierai Paula Couto 1952 y C. inexpectans Antoine et al. 2015), mientras que la familia Etayoidae incluye los géneros Etayoa y Notoetayoa. Poseen yugales bilofodontes, rasgo que permitió a algunos autores relacionarlos con los Pyrotheria; sin embargo, la dentición del género más basal del grupo, Etayoa, sugiere que podrían estar más relacionados con los Astrapotheria (e.g. Villaroel 1987, Croft 1999, entre otros), pero Gelfo et al (2008) interpretaron las similitudes dentarias como convergencias entre ambos grupos.

Notoungulata es el orden más diverso de UNS e incluye la subfamilia objeto de estudio en esta tesis. En términos de diversidad, el Orden Notoungulata ha sido el más exitoso de todos los UNS con más de 150 géneros y 14 familias: Henriscosborniidae, Notostylopidae, Isotemnidae, Leontiniidae, Notohippidae, Toxodontidae, Homalodotheriidae, Archaeopithecidae, Notopithecidae (revalidada recientemente por Vera 2015, 2017), Oldfieldtomasiidae, Interatheriidae, Mesotheriidae, Archaeohyracidae y Hegetotheriidae (sensu McKenna y Bell 1997). Además, en la década de 1980 se propuso la familia "Campanorcidae", pero no fue definida nunca formalmente y, por tanto, no constituye un nombre válido; incluía únicamente a Campanorco inauguralis, del Eoceno de Salta, considerado un notoungulado basal dentro de Typotheria (e.g. Reguero et al. 2010).

Los notoungulados tienen un registro temporal que abarca desde el Paleoceno temprano (Muizon y Cifelli 2000) hasta aproxidamente 8500 años antigüedad (Tonni et al. 1992). Roth (1903) definió el orden Notoungulata a partir de la organización particular de los huesos de la región temporal del cráneo. Su trabajo fue ampliado por Simpson (1936) y Patterson (1932, 1936, 1977). En términos sistemáticos, Ameghino (1895, 1897, 1902) había incluido a diversos grupos de estos notoungulados con diferentes órdenes de mamíferos placentarios (e.g. homalodotéridos junto a los Chalicotheriidae o Archeohyrax como un hiracoideo basal). Madden (1990), basándose en los trabajos de Roth (1903), Simpson (1961), Radinsky (1981) y Cifelli (1993), definió a los miembros del orden Notoungulata por la presencia de:

“ un surco silviano oblicuo y prominente, un lóbulo temporal expandido, bulla timpánica y seno hipotimpánico inflados, seno epitimpánico del escamoso bien desarrollado, senos venosos y vagina processus hyoidei prominentes, meato auditivo osificado frecuentemente 
con cresta, órbita abierta, cigoma fuerte y alto posteriormente, pie ungulado (excepto Homalodotheriidae), astrágalo con tróclea superficial interrumpida por el foramen astragalar y con surco posterolateral, protuberancia media tibial, facetas sustentacular y navicular en contacto, dentición completa, molares lofodontes, molares inferiores bicrescentiformes, el entocónido formando un entolófido transverso, molares superiores con ectolofo, protolofo y un corto metalofo transverso, y premolares molarizados."

Un análisis filogenético realizado por Billet (2010) recuperó las siguientes sinapomorfías no ambiguas para el clado Notoungulata (incluyendo a Pyrotheria): la presencia, en la dentición yugal inferior, de un entocónido expandido transversalmente en un entolófido; y la presecia de una cresta mesiodistal pequeña del metalófido en los dientes yugales inferiores. En su análisis, Billet, no pudo recuperar sinapomorfias del cráneo que no fueran ambiguas, pero tras realizar una optimización de transformación acelerada (Acctran) logró recuperar un conjunto de sinapomorfías craneanas ambiguas para los Notoungulata (algunas de ellas coincidentes con las presentes en la diagnosis realizada por Madden 1990): Cavidad craneana más de dos veces el tamaño del rostro; sutura entre el premaxilar y maxilar transversa medialmente en vista palatal; presencia de procesos nariales en los premaxilares; apertura externa del tubo de Eustaquio (auditivo) lateral al foramen oval o la fisura esfenotimpánica; la presencia de una bula timpánica inflada bien ligada al basicráneo; la presencia de una crista meatal; la presencia de un meato auditivo externo tubular y osificado; la presencia de un receso timpanohial (ver Billet et al. 2009 para mayores detalles) en el extremo posterolateral de la bula timpánica; la presencia de un seno epitimpánico en la parte posterodorsal del escamoso; margen medial de la cara timpánica del petroso expandido y en forma de abanico, bien separado del promontorio; pars mastoidea del petroso reducida a una pequeña barra de hueso ubicada entre el escamoso y el exoccipital, no continua con la superficie no mastoidea del petroso; la presencia de un foramen mastoideo abriendo lateralmente al petroso.

Se han propuesto varias hipótesis sobre las relaciones filogenéticas de Notoungulata con el resto de los clados de UNS. Los aportes realizados por Simpson $(1934,1945,1948,1967)$ contribuyeron enormemente al entendimiento de su anatomía y al planteamiento de las relaciones de parentesco dentro del grupo. La primera propuesta de relaciones filogenéticas para el orden mediante un análisis cladístico fue elaborada por Cifelli (1993); su trabajo recuperó dos de los subórdenes que tradicionalmente se han considerado como notoungulados, Typotheria y Toxodontia sensu lato (incluyendo Isotemnidae y Homalodotheriidae), y argumentó en favor de la parafilia de Notioprogonia (Henricosborniidae + Notostylopidae) y Entelonychia (Isotemnidae + Homalodotheriidae). Si 
bien el trabajo de Cifelli fue un estudio pionero sobre las relaciones filogenéticas de Notoungulata, el muestreo taxonómico solo incluyó 13 taxa, uno por cada familia considerada, muchas de las cuales (e.g. Isotemnidae, Oldfieldthomasiidae, Notohippidae) han resultado parafiléticas en trabajos más recientes.

Agnolin y Chimento (2011) sugirieron que Notoungulata y Astrapotheria se encontrarían relacionados con los Afrotheria, basándose en la presencia compartida de tres caracteres: el número de vertebras torácico-lumbares (más de 19), la erupción dentaria retrasada en relación al crecimiento craneano y la presencia de fosa cotilar en el astrágalo. Como fue mencionado anteriormente, diversos autores han rechazado los argumentos utilizados por estos autores para establecer una relación genealógica entre Notoungulata y Afrotheria; en las siguientes líneas, a modo de ejemplo, se referirán algunos de los argumentos rechazados. Billet y Martin (2011) manifestaron que no existen evidencias para inferir un retraso en la erupción dentaria en los notoungulados y tampoco para establecer que el retraso en la erupción sea el estado basal para ese carácter. Asimismo, respecto a la presencia de fosa cotilar en el astrágalo, Salton y Szalay (2004) señalaron que este rasgo no puede establecerse como un carácter derivado en los Afrotheria, ya que no se encuentra presente en crisoclóridos y varios tenrécidos. En cambio, esta característica se encuentra presente en integrantes de distintos grupos de mamíferos como algunos primates, condilartros laurásicos (e.g. Meniscotherium), dinocerátidos (e.g. Probathyopsis), notoungulados (e.g. Nesodon) y macropódidos (Zack et al. 2005, Lorente et al. 2011, Gelfo y Lorente 2012).

Billet (2011) volvió a revaluar las relaciones filogenéticas dentro del orden Notoungulata por medio de un análisis cladístico, con un muestreo taxonómico mucho más grande (50 géneros) y 133 caracteres morfológicos. Entre los resultados obtenidos, Pyrotheria volvía a estar dentro del orden Notoungulata y los subórdenes Typotheria y Toxodontia fueron recuperados como clados; dentro de Toxodontia, las familias "Isotemnidae" y "Notohippidae" no se recuperaron como grupos monofiléticos, mientras que las familias Homalodotheriidae, Leontiniidae y Toxodontidae sí resultaron monofiléticas. Billet et al. (2015) presentaron una nueva matriz con 48 taxones en el ingroup y un total de 156 caracteres, diseñada para testear las relaciones filogenéticas entre los grupos de UNS y no sus relaciones con otros taxones de Placentalia; los resultados obtenidos para Notoungulata fueron similares a los de Billet (2011). Esta matriz fue modificada por Deraco y García-Lopez (2016) para el análisis de las relaciones filogenéticas de un Toxodontia del Eoceno del Noroeste de Argentina; estos autores añadieron tres caracteres nuevos y modificaron la codificación de algunos de los originales (quedando 146 caracteres en total), incorporando además siete taxa nuevos a la 
matriz, con un total de 68 taxa. A la fecha, esta matriz es la última que ha sido utilizada para testear las relaciones filogenéticas dentro de Notoungulata y de éstos con respecto a los ordenes Astrapotheria y Pyrotheria (que en este estudio aparece en una politomía en la base del orden Notoungulata). Los resultados obtenidos no difieren en gran medida de los de Billet en sus contribuciones anteriores.

Dentro del Suborden Toxodontia, la Familia Toxodontidae incluye herbívoros de tamaño mediano a grande, caracterizados por la presencia de incisivos hipselodontes (formando defensas) y molares hipsodontes o hipselodontes, que tuvieron una gran representación a lo largo del Cenozoico en América del Sur (e.g. Brasil, Paula Couto 1956, 1981, 1982; Perú, Spillmann 1949, Willard 1966; Ecuador, Repetto 1977; Venezuela, Hopwood 1928, Bond et al. 2006, Rincón et al. 2016; Bolivia, Hofftetter 1986, Villarroel 1977, Colombia, Madden 1990, 1997; Chile, Bond y García 2002; Argentina, Ameghino 1887a, 1889, 1894a, b, Scott 1912, Bond et al. 1995, Nasif et al. 2000, Miño Boilini et al. 2006, Forasiepi et al. 2015), con algunos taxa que llegaron incluso a dispersarse hacia América Central y América del Norte en el Pleistoceno tardío (Lundelius et al. 2013). Se registran a partir del Oligoceno tardío (EM Deseadense, Ameghino 1894a, 1897, Shockey y Anaya 2008, Hernández Del Pino et al. 2017) y presentaron su pico de diversidad durante el Mioceno (Cifelli 1985, Marshall y Cifelli 1990, Nasif et al. 2000, Forasiepi et al. 2015). De acuerdo a los últimos trabajos sobre el grupo, durante el Mioceno temprano y el Mioceno medio los toxodóntidos estuvieron representados por los siguientes taxones: Nesodon imbricatus, N. conspurcatus, N. cornutus, $N$. taweretus (EM Santacrucense en Argentina y Chile); Adinotherium ovinum and A. robustum (EM Santacrucense en Argentina); Proadinotherium muensteri (EM Colhuehuapense en Argentina); Palyeidodon obtusum (Edades mamífero Santacrucense, Friasense s.s y Colloncurense en Argentina, Bolivia y Chile), Hyperoxotodon speciosus (EM Santacrucense-Colloncurense en Argentina y Chile) y Pericotoxodon platignathus (EM Laventense en Colombia) (e.g. Pascual 1954, Marshall et al. 1983, Madden 1990, 1997; Nasif et al. 2000, Croft et al. 2003, 2004, 2009, Kramarz et al. 2005, Croft 2007).

Los detalles sobre las diferentes posturas filogenéticas para familia Toxodontidae y la subfamilia Nesodontinae se dan algunos párrafos más adelante. 


\section{2. Objetivos e hipótesis}

En esta tesis se pretende realizar una revisión sistemática de los taxones de toxodóntidos presentes en la Formación Santa Cruz, con énfasis en los Nesodontinae. La taxonomía de este grupo fue objeto de diversos estudios a partir de diversas campañas a la Patagonia entre finales del siglo XIX y principios del XX (entre otros, por Carlos Ameghino; ver compilación completa en Vizcaíno et al. 2012), que devinieron en el establecimiento de varios nombres para los taxa de esta subfamilia. Ameghino (1887a, 1891, 1894a, b, 1907), Mercerat (1891), Lydekker (1893) y Scott (1912), entre otros autores, dedicaron varios trabajos al entendimiento y la discusión sobre aspectos taxonómicos del grupo, aun cuando prácticamente la totalidad de los nombres asignados fueron identificados como sinónimos de los taxones más conocidos de la subfamilia, Adinotherium ovinum y Nesodon imbricatus (Ameghino 1894a, Scott 1912, Tauber 1994). La multitud de nombres, la perdida de especímenes tipo y la relativamente escasa información anatómica, geográfica y estratigráfica presente en las descripciones originales fueron lo que motivó la realización de este trabajo de revisión sistemática. Además, se incluye un gran número de ejemplares nuevos del Museo Padre Jesús Molina, con información geográfica y estratigráfica precisa, para las comparaciones con los materiales de nesodontinos de las viejas colecciones del Santacrucense. Esta revisión evalúa la existencia de variaciones intraespecíficas en el cráneo de los toxodóntidos santacrucenses, en particular asociadas a distintos estadios ontogenéticos (Cassini et al. 2012a). Las variaciones ontogenéticas se han subestimado en muchas ocasiones en distintos grupos de mamíferos fósiles (poder establecer series ontogenéticas resulta extremadamente difícil en paleontología), dando lugar a una proliferación de taxones basados en morfologías que, entre otros aspectos, dependen del grado de desgaste dentario, número de piezas dentarias y proporciones relativas de las diferentes partes del cráneo. Esta variación se ha puesto de manifiesto recientemente en algunos grupos de notoungulados (e.g. Billet et al. 2008, Cerdeño et al. 2010, Cassini et al. 2011, 2012a) e incide directamente en las interpretaciones taxonómicas. Además de la variación ontogenética, se pretende evaluar si existen rasgos que presenten variación a nivel sexual, para lo que se recurre a comparaciones con taxones actuales de hábito similar. En este trabajo, además, se realiza una evaluación de las relaciones filogenéticas en el marco de Toxodontidae y Notoungulata. Finalmente, se realiza un análisis biogeográfico para interpretar la historia paleobiogeográfica de los Toxodontidae. 


\section{2.1 Objetivos}

\section{-Objetivo general}

Revaluar y establecer la diversidad de la familia Toxodontidae (Notoungulata) representada en los niveles de la Formación Santa Cruz (FSC de aquí en adelante), Mioceno temprano, provincia de Santa Cruz, Argentina, y las relaciones filogenéticas de los taxones reconocidos con el resto de los toxodóntidos sudamericanos.

\section{-Objetivos particulares}

1. Revisar la sistemática de los géneros y especies de toxodóntidos presentes en la FSC y compararlos con otros Toxodontidae conocidos en Argentina y otras regiones de América del Sur.

2. Cuantificar y cualificar la forma del cráneo de los toxodóntidos de Santa Cruz, con énfasis en los Nesodontinae.

3. Establecer las relaciones filogenéticas de los taxones reconocidos dentro de la Familia Toxodontidae, contrastando las hipótesis previas de la existencia de grupos monofiléticos de géneros (subfamilias).

4. Precisar la distribución paleogeográfica de los toxodóntidos identificados en la Formación Santa Cruz.

\section{2.2. Hipótesis}

\section{-Hipótesis generales}

1. La diversidad específica de los Toxodontidae de la Formación Santa Cruz está sobreestimada.

2. Los toxodóntidos presentes en la Formación Santa Cruz comparten caracteres que los relacionan como un grupo monofilético basal dentro de la Familia Toxodontidae. El origen de la familia fue en el Oligoceno de Patagonia, y desde donde se dispersó al resto de América del Sur hasta alcanzar el sur de América del Norte.

\section{-Predicciones}

1a. La mayor parte de las especies de nesodontinos nominadas para la Formación Santa Cruz fueron definidas a partir de material cuyas diferencias corresponden a rasgos con variación individual para Adinotherium ovinum y Nesodon imbricatus. 
1b. Existe dimorfismo sexual en ambas especies de nesodontinos santacrucenses, evidenciado por dos morfotipos craneanos diferentes y una leve diferencia de tamaño, relativamente menos acentuada en el género Nesodon que en Adinotherium.

\section{3. Antecedentes sistemáticos para la Familia Toxodontidae y la Subfamilia} Nesodontinae

Esta sección pretende resumir los antecedentes sistemáticos relacionados con los toxodóntidos santacrucenses, los que luego son evaluados en el Capítulo VI de esta tesis. Los antecedentes del grupo se comentan con mayor detalle en el Capítulo III de esta tesis.

Entre los Toxodontidae santacrucenses, se han descripto detalladamente los géneros Adinotherium y Nesodon, cada uno de ellos con varias especies, si bien solo dos, A. ovinum y N. imbricatus, fueron bien caracterizadas (Scott 1912). Algunas de las especies, pertenecientes de estos géneros definidas para la Formación Santa Cruz son Adinotherium robustum, A. nitidum, A. karaikense, A. splendidum, Nesodon cornutus y N. conspurcatus. Sin embargo, su caracterización se ha realizado sobre materiales escasos y poco significativos, a pesar de lo cual algunas han sido reconocidas en trabajos recientes (Tauber 1999, Croft et al. 2003, López et al. 2011). Al mismo tiempo, autores como Marshall et al. (1983) o Madden (1990) incluyeron en la lista faunística de la Formación Santa Cruz al toxodonte Hyperoxotodon speciosus, taxón típico de la EM Colloncurense (Mioceno medio). Estas referencias solo mencionan alrededor de una décima parte de los nombres que se le han atribuido a los toxodóntidos de la Formación Santa Cruz y es una de las principales cuestiones que pone de manifiesto la necesidad de realizar una revisión sistemática profunda.

En su noción tradicional (i.e. incluyendo a los géneros Proadinotherium, Adinotherium y Nesodon) y tal como se considera en este trabajo, la subfamilia Nesodontinae tiene un registro temporal que abarca desde el Oligoceno tardío (EM Deseadense) al Mioceno medio de Patagonia, San Juan y Mendoza, Argentina (López et al. 2011, Forasiepi et al. 2015, Hernández Del Pino et al. 2017), el Oligoceno tardío (Deseadense) de Bolivia (Shockey y Anaya 2008) y el Mioceno temprano de Chile (Croft et al. 2004). Según Madden (1990), la distribución de este taxón podría expandirse hasta Colombia y Brasil, aun cuando el registro en este último país no haya sido confirmado en trabajos subsiguientes. Actualmente, se considera a Adinotherium y Nesodon, excluyendo a Proadinotherium, como miembros de la 
subfamilia (Nasif et al. 2000, Forasiepi et al. 2015); sin embargo, Nasif et al. (2000) señalaron que la sinapomorfía que reúne Adinotherium y Nesodon es un carácter faltante en Proadinotherium y sería necesario contar con nuevos restos para confirmar su pertenencia a Nesodontinae. Si bien se acepta la clasificación propuesta por Nasif et al (2000) acorde a su resultado filogenético, en el contexto de esta tesis es pertinente incluir comentarios y comparaciones con Proadinotherium.

De los tres géneros mencionados, el menos conocido es Proadinotherium, que se encuentra presente en la EM Deseadense (Oligoceno tardío) y la EM Colhuehuapense (Mioceno temprano). El primer taxón descripto fue Proadinotherium leptognathum Ameghino 1894a, proveniente de localidades fosilíferas del Oligoceno tardío de las provincias de Chubut y Santa Cruz. Años más tarde, Ameghino $(1897,1902)$ describió dos especies más para este género procedentes de niveles colhuehuapenses: Proadinotherium angustidens Ameghino 1897, Proadinotherium muensteri Ameghino 1902. El género Proadinotherium también se ha registrado en las localidades deseadenses de Quebrada Fiera, Mendoza, Argentina (Hernández Del Pino et al. 2017) y Salla, Bolivia; en esta última se definió la especie P. saltoni Shockey y Anaya 2008. Madden (1990: 286) también señaló registros extra-patagónicos del género Proadinotherium, en Tremembé (Brasil) y Chaparral (Colombia); este último fue identificado tentativamente como Proadinotherium cf. $P$. leptognathum, sin mayores comentarios. En el caso del registro de Brasil, no ha sido confirmado en trabajos subsiguientes como el de Berqvist y Ribeiro (1998).

La gran cantidad de nombres que se ha generado en los taxones de nesodontinos santacrucenses (Adinotherium y Nesodon) complicó en gran medida la historia nomenclatorial del grupo (ver detalles en el Capítulo III). Esto llevó a Lydekker (1893), Ameghino (1894a) y, posteriormente, a Scott (1912) a realizar una amplia revisión y establecer sinonimias entre los taxones reconocidos hasta ese momento. El primero de ellos (Lydekker 1893, p: 26) se refirió a la cantidad de nombres atribuidos a la especie Nesodon imbricatus de la siguiente manera:

"En toda la literatura zoológica, no creo que haya algo que se pueda comparar con la sinonimia aterradora de esta especie y de las que siguen, que han recibido un numero casi incontable de nombres específicos arreglados bajo la cubierta de términos genéricos mencionada más arriba, según el antojo de sus descriptores."

Ameghino (1891, 1894a), Lydekker (1893) y Scott (1912) recalcaron la enorme variabilidad presente en Nesodon, dependiendo del estadio ontogenético en el que se encontrase, especialmente en la apariencia de la dentición. Sin la existencia de una serie ontogenética más o menos completa, resulta complicado reconocer que los estadios más 
extremos de la serie pertenecen al mismo taxón. La revisión de Scott (1912) estableció tres especies de Nesodon y cinco de Adinotherium como válidas, taxones que se utilizan en esta tesis como punto de partida para analizar la problemática taxonómica del grupo. Se tuvo en cuenta, además, la recopilación nomenclatural presentada por Mones (1986).

Con respecto a las relaciones filogenéticas de los toxodóntidos, el primero en realizar un análisis filogenético para la familia Toxodontidae fue Madden (1990) en su trabajo de tesis doctoral. Analizó las relaciones de 31 toxodóntidos, incluyendo nueve notoungulados no toxodóntidos como grupos externos y una matriz de 39 caracteres, la mayoría de los cuales eran dentarios. Realizó diversas búsquedas de árboles de máxima parsimonia utilizando diferentes configuraciones de taxones (comenzó con aquellos mejor definidos y fue agregando taxones conocidos más parcialmente a medida que progresaba en el análisis). Entre los aspectos más destacables, se puede ver que en ninguno de sus consensos se recuperaron a las cinco subfamilias definidas tradicionalmente. En su trabajo, Madden señaló que la subfamilia Nesodontinae está definida mayormente por caracteres plesiomórficos de la dentición y que dicho grupo no podría ser defendido en el contexto de una clasificación filogenética estricta, ya que no presentaría sinapomorfías. Asimismo, destacó que el escaso material asignado a las especies del género Proadinotherium dificulta el establecimiento de caracteres derivados para esta subfamilia. Aun así, retuvo a esta subfamilia teniendo en consideración el precedente histórico y la preservación de la estabilidad en la clasificación.

Más tarde, Madden (1997) presentó una nueva matriz de caracteres al describir formalmente la especie Pericotoxodon platignathus del Mioceno medio-tardío de Colombia, taxón que ya había introducido en su trabajo de tesis. En esta ocasión, la matriz se encontraba conformada por un total de 14 taxones (11 Toxodontidae y tres notoungulados no toxodóntidos) y 42 caracteres dentarios y mandibulares. El árbol filogenético obtenido mostró muchas politomías, pero, en este caso, se recuperó a los Nesodontinae como un grupo monofilético, aunque no se resolvían las relaciones entre ellos. 
A

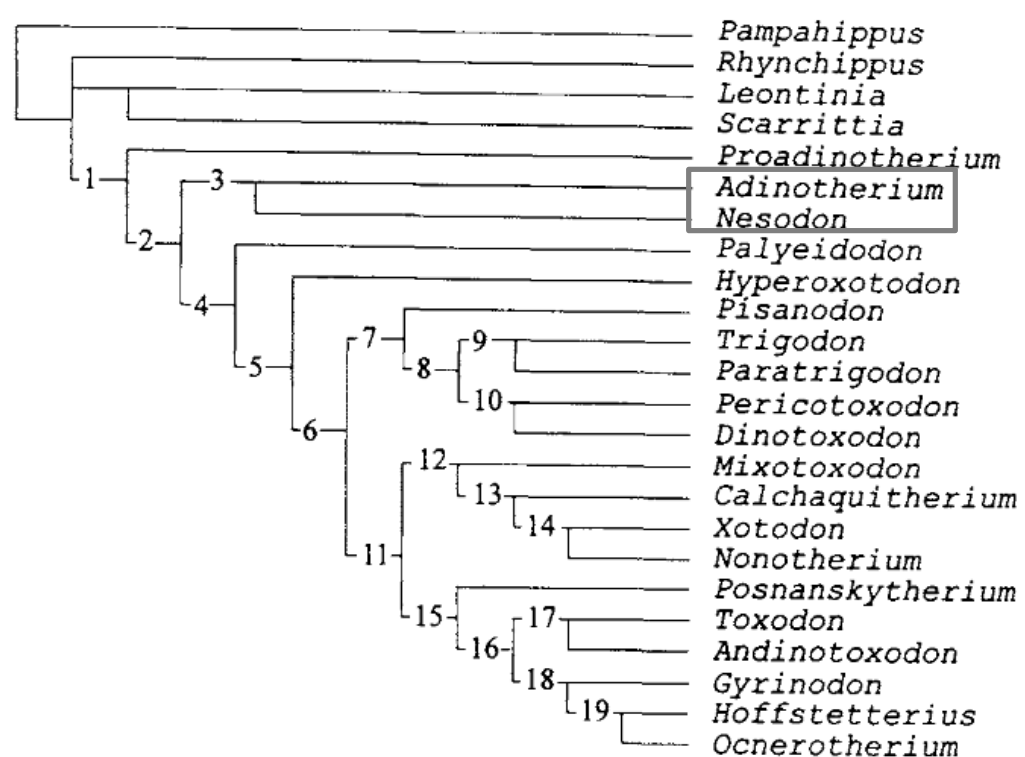

$\mathrm{B}$

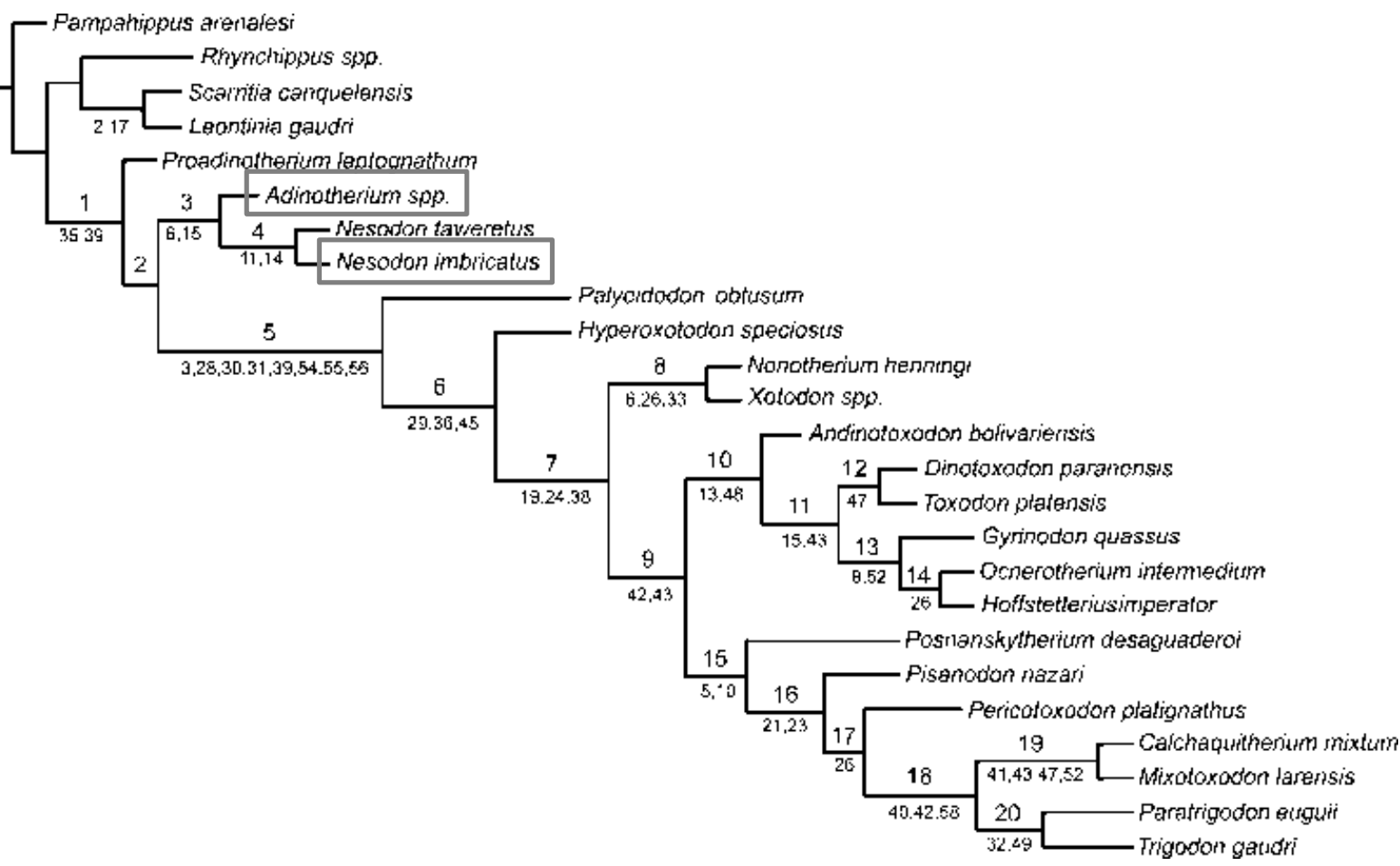

Fig. I. 3. Hipótesis filogenéticas para las relaciones de los Toxodontidae, resaltando la posición de los géneros de nesodontinos de la Formación Santa Cruz: hipótesis presentada en el trabajo de Nasif et al. 2000 (A), hipótesis presentada en el trabajo de Forasiepi et al. 2015 (B).

El análisis de Nasif et al. (2000), realizado a nivel genérico, ha sido el que ha servido de base para los estudios que han tenido más preponderancia en los últimos años. Estos autores realizaron un muestro de 59 caracteres para 24 taxones del suborden Toxodontia. Para la realización del análisis, seleccionaron cuatro taxones como grupos externos: dos Notohippidae, Pampahippus y Rhynchippus, y dos Leontiniidae, Leontinia y Scarritia En la filogenia resultante, Adinotherium y Nesodon conformaron un grupo monofilético, pero las 
relaciones con el taxón más antiguo dentro de Toxodontidae, Proadinotherium (a priori considerado dentro de la subfamilia Nesodontinae), resultaron ser parafiléticas. En dicho estudio tampoco se recuperaron las otras cuatro subfamilias definidas para la familia Toxodontidae y se concluyó que las características sobre las cuales fueron definidos esos grupos no constituirían caracteres sinapomórficos, sino que se trataba de caracteres homoplásicos. A raíz de esos resultados, los autores propusieron una nueva clasificación, en la que situaron a Proadinotherium como un toxodóntido basal sin rango subfamiliar y consideraron dos subfamilias: Nesodontinae, incluyendo a Adinotherium y Nesodon, y Toxodontinae, agrupando al resto de los toxodóntidos postsantacrucenses. Asimismo, reconocieron que el clado Toxodontinae se encuentra conformado por tres grupos principales de géneros relacionados (Fig. I. 3A).

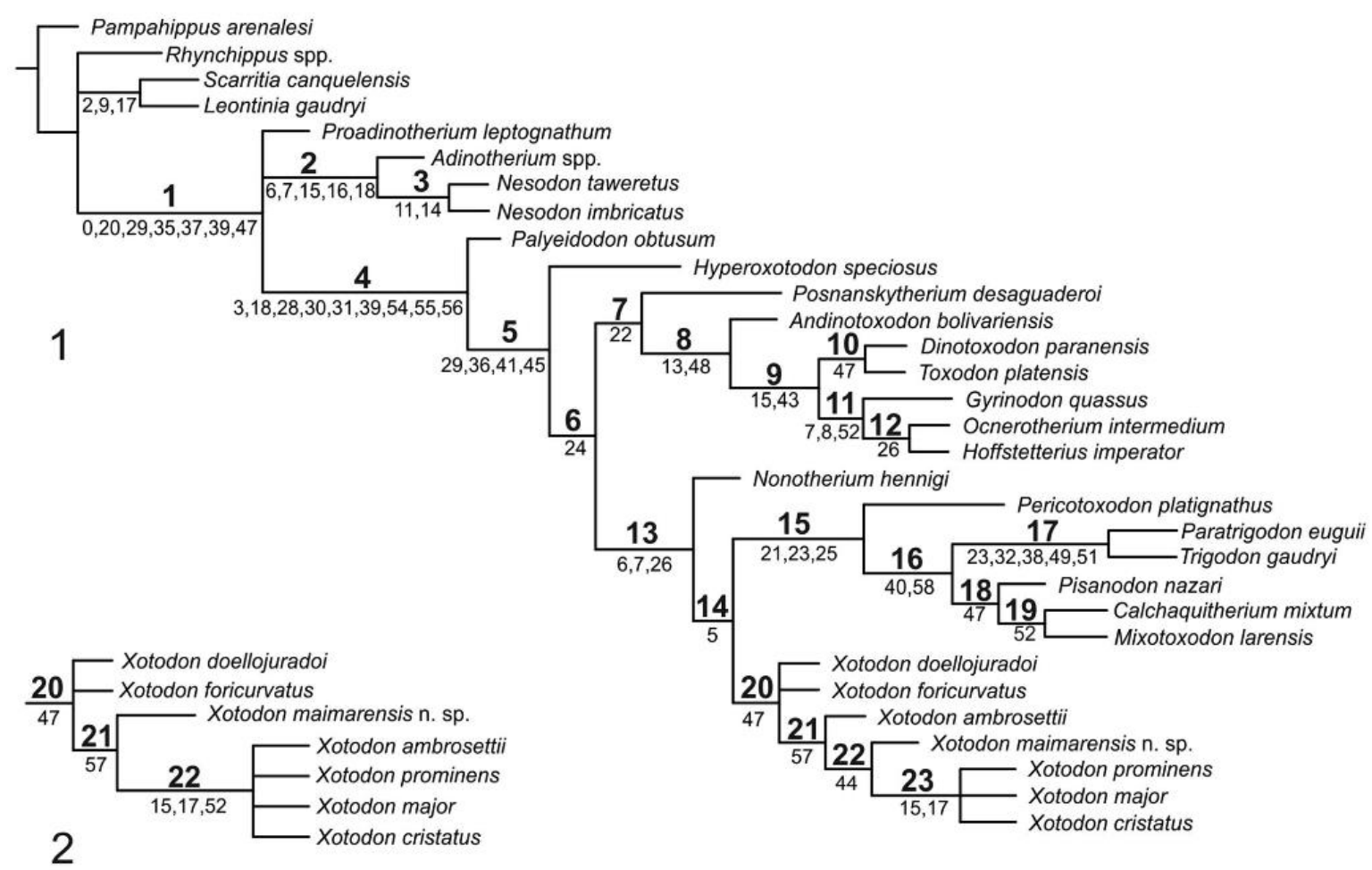

Fig. I. 4. Hipótesis filogenética para Toxodontidae presentada por Bonini et al. 2017.

Forasiepi et al. (2015), al describir una especie nueva de Nesodon de la Formación Aisol (Mioceno temprano), en la provincia de Mendoza, realizaron una nueva filogenia para la familia Toxodontidae a partir de la modificación de la matriz de caracteres de Nasif et al. (2000) y utilizando un algoritmo diferente para la búsqueda heurística. Los autores obtuvieron los mismos resultados en lo concerniente a la definición tradicional de Nesodontinae, con Proadinotherium quedando como taxón basal, grupo hermano del resto de los toxodóntidos. 
En cambio, la topología resultó diferente para las relaciones internas dentro de la subfamilia Toxodontinae (Fig. I. 3B).

Bonini et al. (2017) describieron recientemente una especie nueva de Xotodon procedente de Maimará, provincia de Jujuy, y presentaron un nuevo análisis filogenético, a partir de la matriz modificada por Forasiepi et al. (2015), aumentando el muestreo de taxones, más precisamente dentro del género Xotodon. Hasta la fecha, es el trabajo publicado más reciente sobre las relaciones filogenéticas de la familia Toxodontidae (Fig. I. 4).

\section{4. La Formación Santa Cruz y la Edad Mamífero Santacrucense}

En el año 1845 se llevaron a cabo las primeras colectas de fósiles en la Formación Santa Cruz, a cargo del Capitán Bartholomew Sullivan, antiguo compañero de tripulación de Charles Darwin en el HMS Beagle. Sullivan colectó varios especímenes que encontró en bloques caídos, que más tarde fueron enviados a Darwin, quien a su vez se los envió a Richard Owen para su estudio. Hacia fines del siglo XIX, Carlos Ameghino realizó numerosas exploraciones en la zona, siendo su hermano Florentino quien formalizó los aportes científicos de estas expediciones (e.g. Ameghino 1887a, b, 1889, 1904, Marshall 1976; ver una compilación pormenorizada en Vizcaíno et al. 2013).

En 1889, F. Ameghino definió la Formación Patagónica (ver párrafo siguiente), estableciendo una diferenciación temporal entre estos depósitos y los más jóvenes que reconoció como Formación Entrerriana, en Paraná (provincia de Entre Ríos). Ambos depósitos corresponden a transgresiones marinas (Patagoniense y Entrerriense respectivamente) representadas por la sucesión de estratos de sedimentos marinos depositados en áreas continentales durante un cierto periodo de tiempo. La Transgresión Patagoniense fue uno de los eventos de ingresión marina de mayor calibre registrados para el Cenozoico de América del Sur y los registros sedimentarios de este evento pueden encontrarse desde Tierra del Fuego (Malumián y Náñez 2011) hasta el norte de la cuenca Chacoparanaense (Marengo 2015) y también en algunas localidades de la costa de Brasil (Rossetti et al. 2013). 

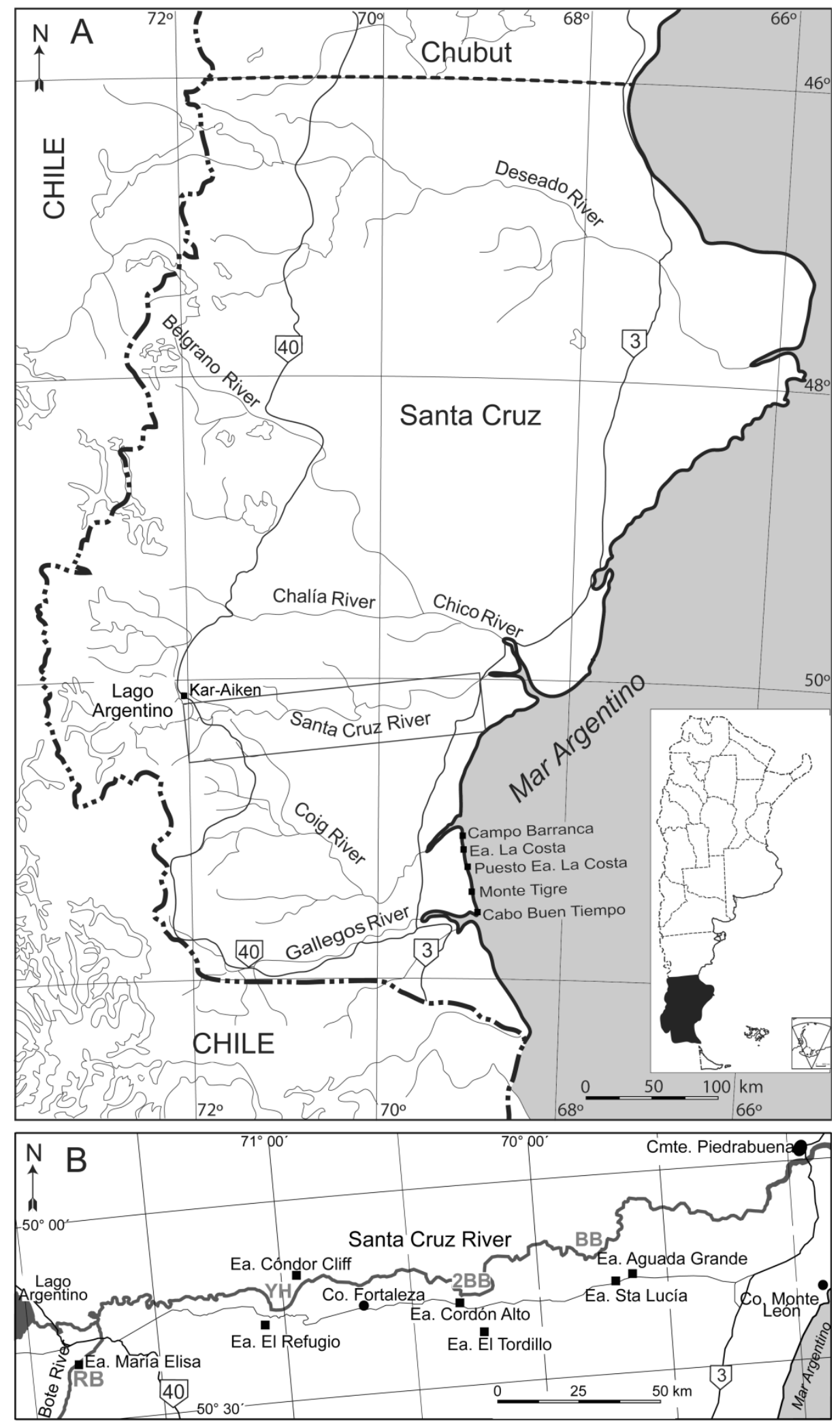

Fig. I. 5. Mapa de la provincia de Santa Cruz con el detalle de algunas de las localidades fosilíferas al sur de la costa Atlántica márgenes(A), detalle algunas de las localidades fosilíferas en las márgenes del Río Santa Cruz de donde provienen algunos de los materiales estudiados en esta tesis (B). BB, Barrancas Blancas; 2BB, Segundas Barrancas Blancas; YH, Yatén-Huageno; RB, Río Bote. 
En el trabajo citado Ameghino (1889) reconoció una Formación Santacruceña que constaría de dos pisos, un Piso Sub-Patagónico, de origen marino, y un Piso Santacruceño con depósitos continentales. Cabe aclarar que, según Tonni (2009), la concepción que Florentino Ameghino tenía de una formación correspondía a una unidad de tiempo inferida a partir de su contenido fosilífero, donde la litología no era el elemento principal ni mucho menos el único criterio para su definición. Ameghino dividía a sus formaciones en pisos (étages) u horizontes. Más tarde, Ameghino (1898) propuso la división en dos partes de los depósitos de la Formación Patagónica en la provincia de Santa Cruz: una inferior, a la que denominó Piso Juliense, y una superior, denominada Piso Leonense. Sobre los depósitos del piso Leonense se habría producido un breve periodo erosivo y, más tarde, se depositarían los sedimentos correspondientes a la formación Santacruceña (Ameghino 1900-1902). En estos trabajos, la asignación temporal que Ameghino dio para los depósitos santacruceños correspondía a un Eoceno superior, mientras que la Formación Patagónica la situaba en el Eoceno inferior.

Los trabajos de los hermanos Ameghino alentaron el desarrollo de varias expediciones lideradas por la Universidad de Princeton (EEUU), a cargo de John B. Hatcher, cuyos fósiles fueron objeto de descripciones detalladas y excelentes ilustraciones en los volúmenes que esta misma institución publicó sobre la Formación Santa Cruz (Scott 1910, 1912, Sinclair 1909, entre otros). Una de las conclusiones a las que se llegó, a partir de comparaciones de la fauna santacrucense con faunas holárticas, fue que la asignación temporal propuesta por Ameghino para estos depósitos era errónea y que el contenido faunístico indicaba que una edad mucho más joven, correspondiente a un Mioceno inferior. Asimismo, estos autores criticaron fuertemente la división sostenida por Ameghino para los depósitos de la Formación Patagónica y que los pisos Leonense y Juliense constituirían ambientes locales o facies de la Formación Patagónica (Camacho 1974).

Actualmente, las localidades fosilíferas mejor conocidas de la Formación Santa Cruz son las que afloran en la costa atlántica de la provincia homónima, desde la localidad de Monte León, al norte de la provincia, hasta Río Gallegos hacia el sur (Vizcaíno et al. 2012a). Sin embargo, las investigaciones recientes también han propiciado la exploración de un conjunto de localidades alejadas de la costa, que hasta ahora no habían recibido demasiada atención (Fernicola et al. 2014, Fig. I. 5). 


\section{4.1 Marco geológico y temporal}

Los depósitos del Mioceno temprano de la Formación Santa Cruz se encuentran ampliamente distribuidos a lo largo de la Cuenca Austral (Patagonia, Argentina) (Raigemborn et al. 2015) (Fig. I. 6). Desde hace más de un siglo, estos depósitos han proporcionado numerosos restos de mamíferos miocenos caracterizados por su buena preservación y el hecho de encontrarse muchos esqueletos prácticamente completos. Estos afloramientos se encuentran compuestos por depósitos de origen fluvial de material mayormente volcaniclástico (Tauber 1994, 1997a, Kay et al. 2008, entre otros). La Formación Santa Cruz constituye el yacimiento paleontológico más diverso y de mayor extensión de los depósitos continentales de edad cenozoica que se encuentran presentes en Patagonia (Tauber 1994, Tejedor et al. 2006, Vizcaíno et al. 2006, 2010).

La Formación Santa Cruz fue definida formalmente por Furque y Camacho (1972), aproximadamente a $300 \mathrm{~km}$ de la costa, en las proximidades del Lago Argentino. Desde el punto de vista sedimentario, estos autores y Furque (1973) reconocieron tres miembros diferentes para esta formación: Miembro Los Dos Mellizos, con $250 \mathrm{~m}$ de espesor de arcillas grises, amarillentas y verdegrisáceas; Miembro Bon Acord, con 150 m de espesor de areniscas conglomerádicas y tobas azuladas; y Miembro Los Huelguistas, con $95 \mathrm{~m}$ de espesor de areniscas y conglomerados (Matheos y Raigemborn 2012).

Mas tarde, Tauber (1994, 1996, 1997a, b) ubicó el contenido fosilífero de las unidades de la costa en un contexto sedimentario y estratigráfico, proponiendo dos miembros diferentes de la Formación Santa Cruz: el inferior, denominado Miembro Estancia La Costa, en donde registró 19 niveles fosilíferos, y el miembro superior, denominado Estancia Angelina, en el que reconoció cuatro niveles fosilíferos más. Los afloramientos de la Formación Santa Cruz mapeados por Tauber (1994) entre el Río Coyle y el Río Gallegos totalizaban un espesor de $223,5 \mathrm{~m}$ para toda la unidad (120 m de espesor para el miembro inferior y $103 \mathrm{~m}$ para el miembro superior). De acuerdo a la similitud entre litologías, Tauber (1994) sugirió que los Miembros Estancia La Costa y Estancia La Angelina podrían ser equivalentes a los Miembros Bon Acord y Los Huelguistas, respectivamente, definidos cerca del Lago Argentino (Furque y Camacho 1972).

Desde las contribuciones de Tauber, se han realizado numerosos aportes sobre la sedimentología (Matheos et al. 2008, 2010, Matheos y Raigemborn 2012, Raigemborn et al. 2012, 2015) y la geocronología (Fleagle et al. 2012, Perkins et al. 2012, Cuitiño et al. 2012, 2016) de la Formación Santa Cruz. También se han realizado numerosas contribuciones 
relacionadas con aspectos icnológicos (Krapovickas 2012, Krapovickas et al. 2013, Zapata et al. 2013, 2016) y paleobotánicos (Brea et al. 2012, 2017) que se suman a las contribuciones en materia de bioestratigrafía antes mencionadas para esta unidad. Gran parte de la información existente hasta el año 2012 fue compilada por Vizcaíno et al. (2012a), contribuyendo al entendimiento de la sucesión temporal y paleoambiental de las exposiciones costeras de la Formación Santa Cruz que afloran desde el Río Coyle hasta el Río Gallegos.

En las siguientes líneas, se presenta un breve resumen de los últimos resultados en materia de sedimentología y estratigrafía de la Formación Santa Cruz, basado principalmente en los aportes de Matheos y Raigemborn (2012), Raigemborn et al. (2015) y Cuitiño et al. (2016).

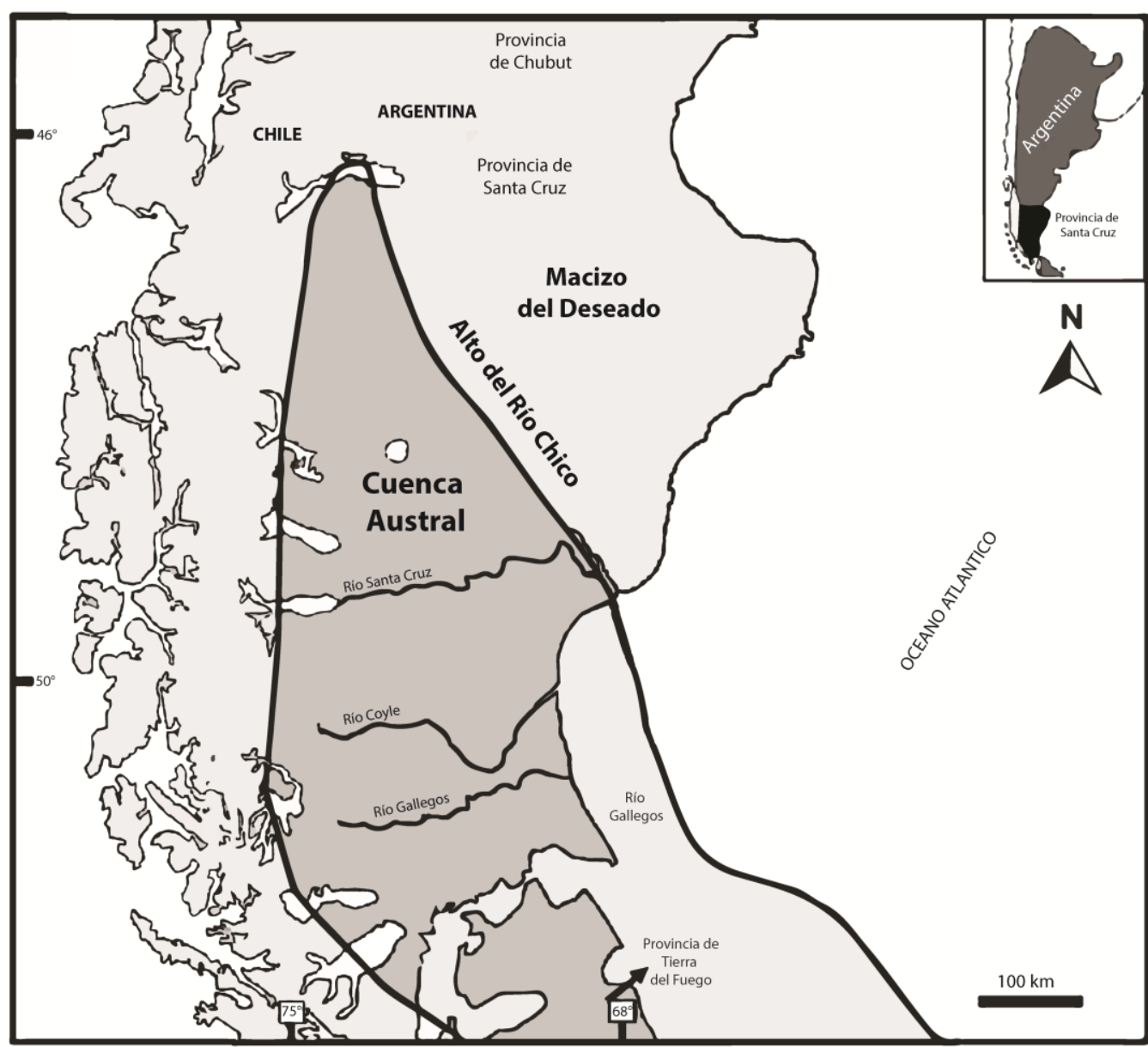

Fig. I. 6. Mapa de la provincia de Santa Cruz con la ubicacion de los depósitos de la Cuenca Austral (Modificado de Raigemborn et al. 2015).

Como se mencionó al principio de este apartado, los depósitos de la Formación Santa Cruz forman parte de la secuencia sedimentaria neógena de la Cuenca Austral (también conocida como Cuenca Magallanes). Esta cuenca se encuentra localizada en la costa y el 
centro del sur de Argentina y Chile (i.e. sur de Patagonia). Está limitada por los Andes al Oeste (cordillera Patagónica y Fueguina hacia el extremo sur) y el alto del Río Chico al Este, extendiéndose hasta el macizo del Deseado hacia el Noroeste y Noreste, y hasta la cuenca de Malvinas, al Sudeste, y el cinturón corrido y plegado, al Sur (Fig I. 6).

Las cuencas Austral y Malvinas forman parte de la placa sudamericana. Su historia geológica comienza con el inicio del rifting entre América del Sur y África en el Triásico (Biddle et al. 1986). El relleno sedimentario pre-cenozoico de la Cuenca Austral contiene unidades sedimentarias correspondientes tanto a ambientes marinos profundos como continentales e incluso depósitos volcaniclásticos, que se extienden desde el Jurásico tardío hasta el Cretácico tardío (e.g. Sacomani y Panza 2012, Raigemborn et al. 2015). Desde el Cretácico temprano hasta el Mioceno, la cuenca experimentó repetidos eventos marinos transgresivo-regresivos. La Formación Palermo Aike (Campaniano-Maastrichtiano) y la sucesión estratigráfica Paleógeno-Neógeno, aflorantes en el norte, se encuentran compuestas de unidades marinas que fueron depositadas durante eventos de transgresión, intercaladas con intervalos de no depositación, erosión y depositación continental (Malumian 1999). Estos eventos transgresivos se agruparon con el nombre de Patagoniense y ocurrieron en tres grandes episodios que fueron nombrados por Ameghino (1898) como: Juliense, correspondiente a los depósitos de la Formación San Julián (Eoceno tardío-Oligoceno temprano); Leonense, correspondiente a los depósitos de la Formación Monte León (Oligoceno tardío-Mioceno temprano) (ver Bertels 1970); y Superpatagónico, correspondiente a la parte más alta de la Formación Monte León, sobre la cual yace en conformidad la Formación Santa Cruz (Fig. I. 7B). Finalmente, por encima de los depósitos de la FSC, se encuentran las terrazas marinas del Plioceno y los depósitos continentales de Rodados Patagónicos (Pleistoceno tardío-Cuaternario) (Uliana et al. 1985, Corbella 2002, Peroni et al. 2002).

Los depósitos continentales de la Formación Santa Cruz en el área de la costa tienen un espesor aproximado de $225 \mathrm{~m}$, yacen en conformidad por encima de los depósitos de la Formación Monte León (que consiste mayormente en depósitos marinos costeros con una edad que abarcaría desde el Oligoceno tardío, $25 \mathrm{Ma}$, hasta el Mioceno temprano, $18 \mathrm{Ma}$, para el conjunto de las formaciones San Julián y Monte León; Tauber 1997a). Litológicamente, los depósitos de la Formación Santa Cruz están compuestos mayormente por fangolitas, areniscas de origen volcaniclástico de grano fino a medio y toba de tonalidades claras, que contienen paleosuelos inmaduros con la presencia de cuerpos arenosos que cortan la secuencia, que representan paleocanales (Matheos y Raigemborn 2012). Como se mencionó anteriormente, 
Tauber (1994) reconoció dos miembros diferentes, separados por una discontinuidad erosiva local, en los afloramientos de la Formación Santa Cruz en el margen costero al sur del Río Coyle. El Miembro Estancia La Costa tiene predominancia de arcillitas y fangolitas de origen piroclástico, mientras que el Miembro Estancia La Angelina está compuesto mayormente por arcillitas piroclásticas, fangolitas y areniscas.

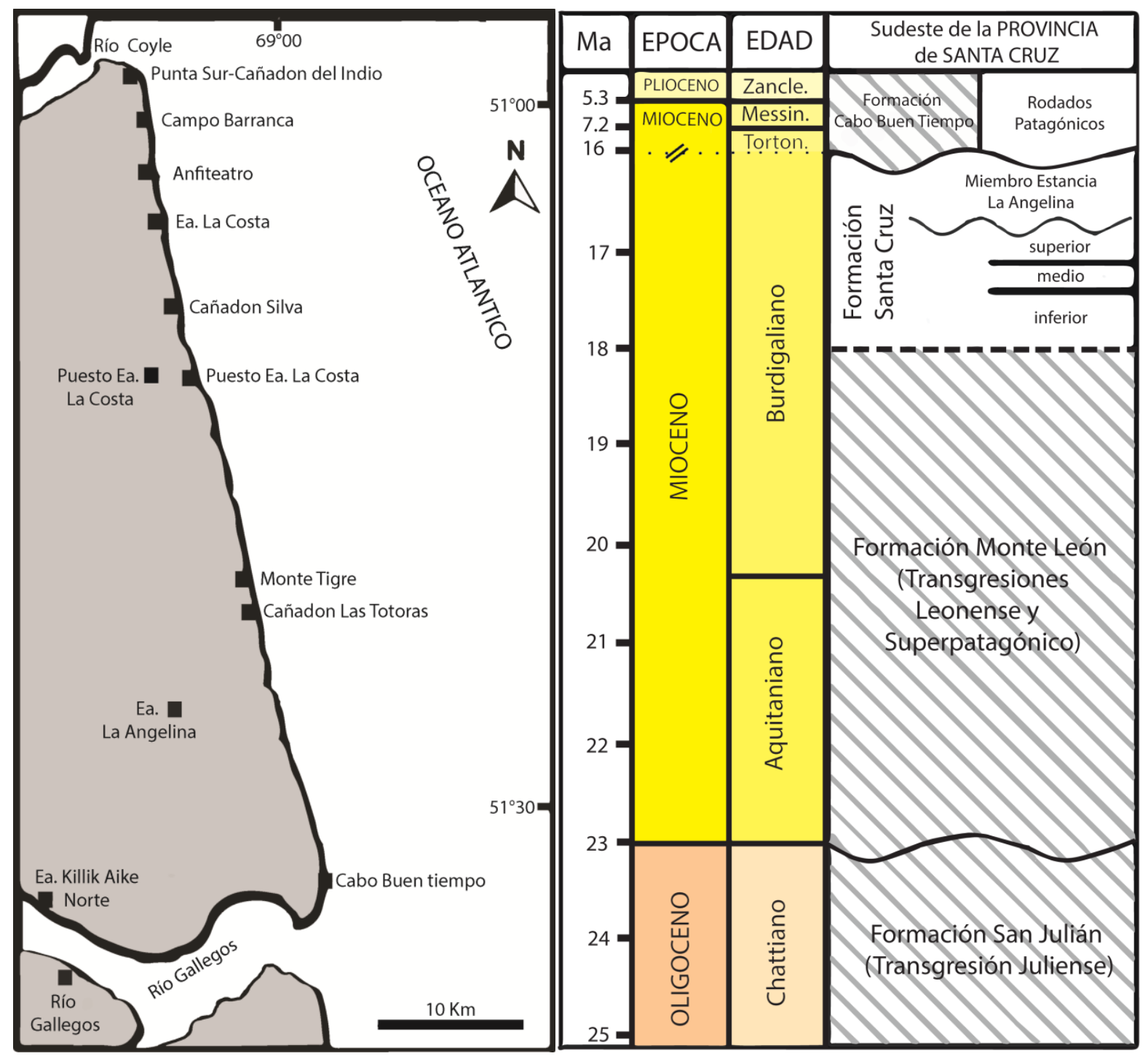

Fig. I. 7. A. Mapa con el detalle de las localidades del margen sudeste de la provincia de Santa Cruz (modificado de Raigemborn et al. 2015). B. Cuadro estratigráfico correspondiente a esa zona (modificado de Raigemborn et al. 2015).

Matheos y Raigemborn (2012) propusieron un nuevo esquema sedimentario informal para el Miembro Estancia La Costa, diferenciándolo en tres niveles de acuerdo a sus caracteristicas litológicas. La sección inferior de la secuencia presenta abundante material piroclástico, con escasos paleosuelos e intercalaciones de areniscas y fangolitas. La sección 
media presenta un incremento en las facies gruesas que sugerirían mayor energía del agente fluvial en la base de la unidad, aunque hacia la parte superior se registra un aumento del material piroclástico, fangolitas y paleosuelos más desarrollados que en el nivel anterior; esto indicaría un descenso de la energía del agente y una tasa de sedimentación más baja para la porción superior de este nivel. La sección superior, está caracterizada por la presencia de mayor cantidad de areniscas y fangolitas, y la ausencia de material piroclastico, indicando un agente con mayor energía que el de las secciones anteriores; en la parte basal de esta sección existen paleosuelos de coloración clara con concreciones calcáreas y grietas de desecación.

Los depósitos de la Formación Santa Cruz que se encuentran presentes en la costa atlántica subyacen en disconformidad con los depósitos marinos y glaciofluviales de la Formación Cabo Buen Tiempo (“Cape Fairweather beds" de Hatcher 1897) y con los Rodados Patagónicos, cuya edad abarca desde el Mioceno tardío al Pleistoceno (Fig. I. 7B).

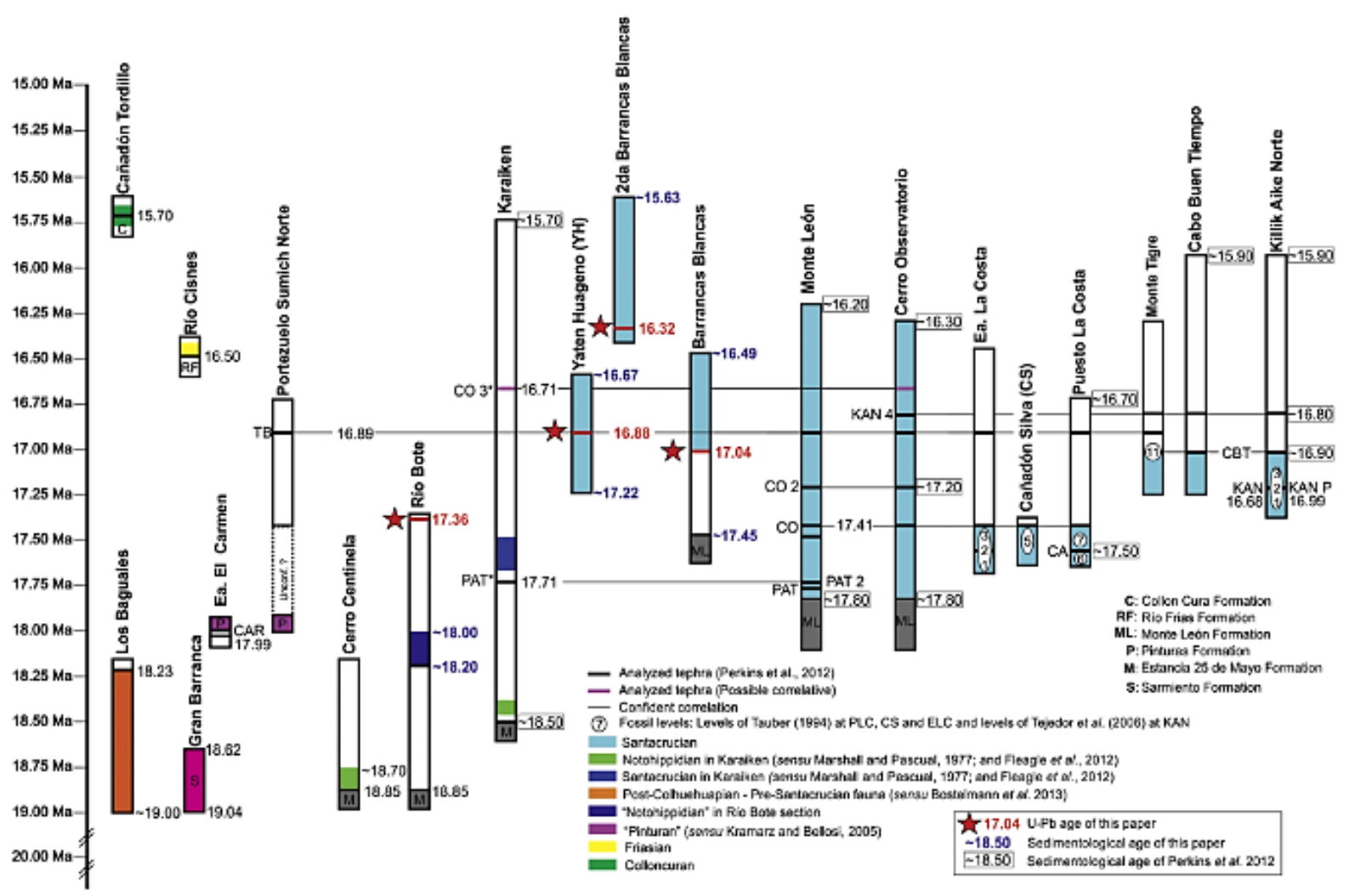

Fig. I. 8. Correlaciones temporales entre las diferentes localidades que presentan depósitos de la Formación Santa Cruz (tomado de Cuitiño et al. 2016).

La edad absoluta de los depósitos de la formación Santa Cruz ha sido objeto de múltiples estudios durante los últimos 30 años (e.g. Marshall et al. 1986, Bown y Fleagle 1993, Fleagle et al. 1995, Blisniuk et al. 2005). En años recientes, Perkins et al. (2012) y Fleagle et al. 
(2012) indicaron que los depósitos costeros de la formación abarcan un intervalo de $\sim 17,9$ a 16,2 Ma, mientras que los depósitos correspondientes a la región andina ocuparían un intervalo algo mayor, entre $\sim 19$ y $\sim 14$ Ma. Cuitiño et al. (2016) ampliaron el esquema estratigráfico propuesto por Perkins et al. (2012), incluyendo algunas de las localidades del Río Santa Cruz y el Oeste de la provincia, cuyo resultado se muestra en la Figura I. 8.

\section{4.2 Contenido faunístico y aspectos paleoambientales y paleoecológicos de la Formación Santa Cruz}

Sobre la base de su contenido fósil, Ameghino (1906) reconoció dos pisos para lo que él denominó Formación Santa Cruz: el Piso Notohippidiense y el Piso Santacrucense. El primero de ellos estaba caracterizado por la presencia de una fauna menos especializada que la fauna santacrucense, a la que reconoció como fauna de Notohippus, siendo este notoungulado uno de los taxones más representativos de la asociación; esta fauna se encontraría representada típicamente en la localidad Karaiken, próxima al Lago Argentino. El Piso Santacrucense estaba representado en los depósitos de la FSC que se encuentran al Este de la provincia y sería más joven que el Piso Notohippidense. Tras los trabajos de F. Ameghino, el Piso Notohippidiense ha recibido poca atención y resulta necesaria una revaluación en detalle del contenido faunístico propuesto para esta unidad (González Ruiz y Scillato-Yané 2009), que se está llevando a cabo en el marco de investigaciones en curso (Fernicola et al. 2014, Cuitiño et al. 2016).

La importancia de la fauna santacrucense ha sido destacada en el contexto de la evolución de las faunas terciarias sudamericanas por varios autores (e.g. Pascual et al. 1965, Simpson 1980, Vizcaíno et al. 2012a, b). La riqueza fosilífera de la Formación Santa Cruz llevó a Pascual et al. (1965) a definir la Edad Mamífero Santacrucense, constituyendo una de las asociaciones más diversas de América del Sur previas al Gran Intercambio Biótico Americano (GIBA-GABI en inglés- e.g. Stehli y Webb 1985, Woodburne 2010, Cione et al. 2015), en el límite Plio-Pleistoceno, tras la formación del istmo de Panamá.

En la década de 1990, se realizaron nuevas expediciones que aportaron en materia de sedimentología y la paleontología de la Formación Santa Cruz (Tauber 1996, 1997a, b, 1999). En términos de diversidad, Tauber reconoció un total de 12 ordenes, 27 familias, 45 géneros y 64 especies, mayormente representados por taxones de mamíferos, habiendo registrado además anfibios y aves (Tauber, 1999). En 21 de los 23 niveles fosilíferos reconocidos por este autor, logró identificar vertebrados a nivel específico. 
A partir del registro paleontológico, Tauber (1999) reconoció cuatro conjuntos faunísticos diferentes: el primero correspondería a faunas de ambientes cálidos o templado-cálidos (e.g. el anfibio Caudiverbera, actualmente considerado sinonimo del género Calyptocephalella), registrado entre los niveles fosilíferos inferiores (1 a 6); el segundo conjunto comprende mamíferos de talla reducida con hábitos presumiblemente arborícolas o semi-arborícolas (e.g. metaterios Microbiotherium patagonicum y Palaeothentes minutus, y el primate Homunculus patagonicus), también reconocidos en los niveles fosilíferos inferiores; el tercer conjunto, de diversidad reducida de xenartros Megatheridae y Megalonychidae, identificado entre los niveles superiores (8.1 a 10); y el cuarto caracterizado por la presencia del único roedor Octodontidae presente en la Formación Santa Cruz y que indicaría unas condiciones climáticas más áridas en la sección baja del Miembro Ea. La Angelina. A partir de sus datos, Tauber (1997b) infirió que, durante el proceso de acumulación del miembro Ea. La Costa y la parte baja del miembro Ea. La Angelina, habría disminuido el nivel de humedad, pasando de condiciones más uniformes, cálidas y húmedas, a condiciones más secas, con una estacionalidad marcada. Durante este proceso de desecación, se habría producido un reemplazo de ambientes con abundante vegetación arbórea y arbustiva por ambientes más abiertos con predominio de vegetación herbácea (tipo sabana o estepa).

Desde el año 2003 hasta la fecha, en el marco de nuevos proyectos de investigación sobre la Formación Santa Cruz, se realizaron sucesivas expediciones, bajo la dirección de los doctores S. Vizcaíno y S. Bargo, que contribuyeron principalmente a la reconstrucción paleobiológica de la asociación faunística santacrucense (e.g. Vizcaíno et al. 2012a, y bibliografía incluida, Cassini 2013, Toledo et al. 2017). Kay et al. (2012) revisaron las interpretaciones paleoambientales y paleoecológicas para la Formación Santa Cruz y propusieron una nueva reconstrucción paleoecológica para el Miembro Estancia La Angelina, concentrándose principalmente en los siete primeros niveles fosilíferos definidos por Tauber (1994) (considerados por estos autores como contemporáneos). Kay et al. (2012) realizaron un corolario a partir de los datos sedimentarios y paleobiológicos presentados en el volumen de Vizcaíno et al. (2012a) para proponer una reconstrucción climática para la Formación Santa Cruz en la que el clima era más húmedo (promediando alrededor de $1000 \mathrm{~mm}$ de precipitación anual) y cálido que en la actualidad, con temperaturas medias anuales que superarían los $14^{\circ} \mathrm{C}$ y estacionalidad marcada, con inviernos húmedos y veranos secos. El tipo de ambiente inferido correspondería a un mosaico de bosques húmedos y semiáridos, similares a los que pueden encontrarse actualmente en los Andes y el Piedemonte patagónicos, que habrían coexistido con porciones de pastizales que habrían presentado tanto 
Hernández Del Pino, S.

cuerpos de agua transitorios como permanentes que incluso podrían haber promovido la formación de pantanos. 


\section{Capítulo II. Materiales y Métodos}

\section{1. Acrónimos}

Abreviaturas institucionales.-AMNH, American Museum of Natural History, Nueva York; EEUU; FMNH, Field Museum of Natural History, Chicago, EEUU; MACN, Museo Argentino de Ciencias Naturales 'B. Rivadavia', Buenos Aires, Argentina; MCNAM-PV, Museo de Ciencias Naturales y Antropológicas 'J. C. Moyano', Colección de paleontología de vertebrados, Mendoza, Argentina; MLP, Museo de La Plata, La Plata, Argentina; MPEF, Museo Paleontológico Egidio Feruglio, Trelew, Argentina; MPM, Museo Regional Provincial Padre M. Jesús Molina, Río Gallegos Argentina; NM-GPA, Nemzeti Muzeum Geologie und Paläontologie Abteil, Budapest, Hungría; RCS, Royal College of Surgeons, Londres, Reino Unido; YPM, Yale Peabody Museum of Natural History, New Haven, USA.

Abreviaturas anatómicas. - aco, acueducto coclear; acv, acueducto vestibular; ae, aliesfenoides; amp, ámpula posterior; an, abertura nasal anterior; ba, basioccipital; be, basiesfenoides; bo, bulbo olfatorio; bt, bulla timpánica; ce, cavidad encefálica; cec, cresta ectopterigoidea; cm; crista meatal; cmb; cresta media del basioccipital; cmp, cresta medial del paladar; cn, cresta nucal; co, cóndilo occipital; coa, coana; coc, cóclea; cot, canal orbitotemporal; cpf, comisura prefacial; cpmx, cresta del premaxilar; cpt, canal postemporal; cpre, osificación tentoria de la cresta petrosa; crc, crus commune; cs, cresta sagital; csa, canal semicircular anterior; csl, canal semicircular lateral; csp, canal semicircular posterior; erm, espacio retromolar de la mandíbula; es, escamoso; f, frontal; fam, flanco anteromedial; fc, fenestra coclear; fci, fisura circular; fe, fosa escafoidea; fem, foramen estilomastoideo; feo, fisura esfeno-orbitaria; ff, foramen nutricio del frontal; ffs, foramen facial secundario; fg, fosa glenoidea; fgl, fisura glaseriana; fh, foramen hipogloso; fi, foramen incisivo; fio, foramen infraorbitario; fl, foramen lacrimal; fm, foramen mentoniano; fma, foramen magnum; fme, fosa para el musculo estapedial; fo, foramen oval; fp, fenestra piriforme; fpg, foramen postglenoideo; fr, fisura rinal; fsa, fosa subarcuata; fv, fenestra vestibular; fy, foramen yugular; h, hipófisis; ha, hamulus; hc, hemisferio cerebral; hcl, hemisferio cerebelar; hF, hiatus Fallopii; l, lacrimal; laa, ámpula lateral; lep, lámina espiral primaria; les, lámina espiral secundaria; Ip, lóbulo piriforme; It, línea temporal; MAE, meato auditivo externo, MAI, meato auditivo interno; mo, medula oblonga; ms, muesca sigmoidea; mx, maxilar; n, 
nasal; NC, nervio craneano; p, parietal; pa, palatino; pae, proceso articular del escamoso; pan, proceso angular de la mandíbula; pc, proceso cigomático del escamoso; pcm, proceso condilar de la mandíbula; pco, proceso coronoideo de la mandíbula; pe, proceso estiliforme del ectotimpánico; pet, petroso; pf, paraflóculo; pfn, proceso frontal del nasal; pmx, premaxilar; po, pons; ppc, proceso paracondilar del exoccipital; ppg, proceso postglenoideo; ppm, proceso palatino medio del premaxilar; ppo, proceso postorbital del frontal; ppt, proceso posttimpánico del escamoso; pr, promontorio; pre, preesfenoides; pt, pterigoides; qo, quiasma óptico; ra, rama ascendente de la mandíbula, re, receso epitimpánico; rh, receso hioideo; rho, rama horizontal de la mandíbula; rt, rami temporalis; sf, surco facial; sfr, seno frontal; sm, sínfisis mandibular; sss; seno sagital superior; st, seno transverso; su, sutura; sum, sulco medial; tb, tubérculo del basioccipital; te, teca epitimpánica; to, tracto olfatorio; v, vermis cerebelli; ve, vestíbulo; y, yugal.

Otras abreviaturas._-ACP, análisis de componentes principales; F.D., formula dentaria; FSC, Formación Santa Cruz; ECC, complejidad de las crestas del esmalte; EQ, índice de encefalización; HI, índice de hipsodoncia; mc, masa corporal;

\section{2. Lista de especímenes consultados}

En este apartado se brinda un listado de los especímenes que fueron utilizados por los diferentes autores para establecer los nombres asignados a los toxodóntidos santacrucenses (basado mayormente en el catálogo de Mones 1986). Se listan en orden alfabético y, para cada taxón, se detalla su número de inventario, breve descripción de la pieza y procedencia geográfica. La especie tipo de cada género (colocada en primer lugar en cada caso) y los ejemplares tipo establecidos para cada nombre se encuentran resaltados con letra "negrita". Aquellos especímenes que fueron consultados solo a partir de la literatura disponible se diferencian del resto utilizando un asterisco $\left(^{*}\right)$ detrás del número de inventario. En los casos en los que aparece la sigla de la institución seguida de un signo de interrogación (e.g. MLP ?) se trata de material no localizado que tampoco pudo ser consultado por Mones (1986).

El listado completo de los especímenes fósiles y actuales utilizados en esta tesis se presenta en el Apéndice I. En las siguientes líneas, se detallan los especímenes de la Formación Santa Cruz que fueron utilizados para la fundación de nuevos taxones de toxodóntidos. 
-Acrotherium Ameghino 1887a

Acrotherium rusticum Ameghino 1887a, Río Santa Cruz: MLP 12-42, fragmento de paladar derecho con los últimos seis yugales con un grado de desgaste avanzado; MLP 12-50, fragmento de cráneo con el I2 y un premolar derechos; MLP 12-925, fragmento de paladar con un molar preservado.

Acrotherium australe Mercerat 1891: MLP ? (no localizado).

Acrotherium intermedium Mercerat 1891: MLP ? (no localizado).

Acrotherium karaikense Ameghino 1891a, Patagonia austral: MACN A 947 (no localizado)*; MACN A 5366, fragmento de mandíbula con p2-m1.

Acrotherium mutabile Mercerat 1891, Río Santa Cruz: MLP 12-55, fragmento de paladar con todos los molares; MLP 12-71, fragmento de paladar con los primeros dos molares derechos y el último premolar.

Acrotherium patagonicum Mercerat 1891, Río Santa Cruz: MLP 12-4, cráneo completo y fragmento de mandíbula; MLP 12-44, fragmento de maxilar con P2-M3.

Acrotherium stygium Ameghino 1891b, sin datos de localidad: MACN A 5358, fragmento de premaxilar y un incisivo; MACN A 1692, fragmento de mandíbula izquierda, con p3-m3; MACN A 1693, fragmento de mandíbula derecha, con p2-m2, quizá del mismo individuo que el ejemplar anterior.

Acrotherium variegatum Mercerat 1891, Río Santa Cruz: MLP 12-62, fragmento de paladar izquierdo con los primeros dos molares y el último premolar deciduo roto.

-Adelphotherium Ameghino 1887a

Adelphotherium ligatum Ameghino 1887a: MLP ? (no localizado). 
Adelphotherium lutarium Mercerat 1891, Río Santa Cruz: MLP 12-20 (no localizado); MLP 12-24 (no localizado); MLP 12-26, fragmento de cráneo conservando el rostro y parte del paladar con algo de la dentición yugal rota; MLP 12-64 (no localizado).

Adelphotherium pumilum Mercerat 1891: MLP ? (no localizado); MLP 12-25, fragmento de cráneo conservando el rostro, paladar y los molares fragmentarios, Río Santa Cruz.

Adelphotherium repandum Mercerat 1891, Río Santa Cruz: MLP 12-10, fragmento de cráneo conservando el rostro, paladar y yugales de un individuo joven.

Adelphotherium rothi Mercerat 1891: MLP ? (no localizado).

Adelphotherium trivium Mercerat 1891, Río Santa Cruz: MLP 12-8, fragmento de rostro y paladar casi completo con gran parte de la dentición yugal; MLP 12-40, fragmento de paladar derecho con los últimos cinco yugales; MLP 12-41, fragmento de paladar izquierdo con los últimos cuatro yugales.

- Adinotherium Ameghino 1887a

Adinotherium magister Ameghino 1887a, sin datos de localidad: MLP ? (no localizado)*, cráneo completo; MACN A 923, cráneo completo con casi toda la dentadura,; MACN A 929, fragmento de cráneo con gran parte de la dentadura; Corriguen-kaike: MACN A 1666, mandíbula incompleta, en dos fragmentos, y dientes aislados,.

Adinotherium antiquum Mercerat 1891: MLP ? (no localizados)*, maxilares y premaxilares de seis ejemplares diferentes, Monte León y Barrancas del Río Santa Cruz.

Adinotherium corriguenense Ameghino 1907, Corriguen-kaike: MACN A 11689, cráneo.

Adinotherium ferum Ameghino 1887a: MLP ? (no localizado)*; Corriguen-kaike: MACN A 5352, cráneo bastante completo; MACN A 5353, mandíbula.

Adinotherium haplodontoides Ameghino 1891a, Patagonia: MACN ? (no localizado)*, piezas dentarias superiores. 
Adinotherium karaikense (Mercerat) 1891 (ver Acrotherium karaikense).

Adinotherium kobyi Mercerat 1891, Monte León: MLP 12-27 y MLP ? (no localizados)*, cráneo incompleto y cuatro fragmentos de maxilares.

Adinotherium nitidum Ameghino 1887a, sin datos de localidad: MACN A 946, varios fragmentos de hueso, uno de ellos correspondiente a una mandíbula sin preparar que podría corresponder a un ejemplar juvenil; Sehuen: MACN A 5360, cráneo de un individuo bastante joven.

Adinotherium ovinum Owen 1853, sin datos de localidad: MACN A 926, cráneo de un individuo joven.

Adinotherium proximum Ameghino 1887a, sin datos de localidad: MLP 12-259, mandíbula con la serie molar completa.

Adinotherium pulchrum Mercerat 1891, Santa Cruz: MLP 12-32, cráneo incompleto, barrancas del Río Santa Cruz; MLP 55-XII-12-5, fragmento de paladar derecho con los últimos seis yugales rotos.

Adinotherium robustum Ameghino 1891a, sin datos de localidad: MACN A 924 (no localizado); MACN A 407, porción anterior del cráneo; MACN A 865, maxilar con dientes.

Adinotherium rotundidens Ameghino 1899, sin datos de localidad: MACN 5956, dos fragmentos de mandíbula con molares y otros dientes aislados; MACN A 10377, dos fragmentos de molar inferior; MACN A 11609, un molar; MACN A 11612, varios restos de molares.

Adinotherium silvaticum (Ameghino) 1887a (ver Phobereotherium silvaticum).

Adinotherium splendidum Ameghino 1887a, Río Santa Cruz: MLP 12-46 (no localizado); MLP 12-147, fragmento de paladar con todos los molares; MLP 12-280, fragmento de mandíbula izquierda con los molares; sin datos de localidad: MLP 12-985, mandíbula bastante completa con parte de la dentición perteneciente a un individuo viejo; MACN A 
Hernández Del Pino, S.

1116, fragmento de maxilar con tres molares; MACN A 1117, fragmento de mandíbula derecha con $\mathrm{p} 2-\mathrm{m} 4$.

-Atryptherium Ameghino 1887a

Atryptherium bifurcatum Ameghino 1887a, sin datos de localidad: MACN A 926, cráneo completo.

—Gronotherium Ameghino 1887a

Gronotherium decrepitum Ameghino 1887a: MLP 12-233 (no localizado).

—Hyperoxotodon Mercerat 1891

Hyperoxotodon speciosus (Ameghino 1887a) Santa Cruz: MLP 12-53 (no localizado)*, fragmento de mandíbula; MLP 12-59, fragmento de maxilar con M1-M3.

—Nesodon Owen 1847

Nesodon imbricatus Owen 1847: RCS 2222 (perdido)* fragmento de mandíbula de un individuo joven.

Nesodon andium Ameghino 1891a: MACN A 885 (no localizado)*; Karaiken: MACN A 859, porción anterior de un cráneo con algunas piezas dentarias muy fragmentarias; MACN A 887, fragmento de mandíbula con los últimos cuatro yugales rotos; MACN A 888, fragmento de mandíbula derecha con $\mathrm{m} 2$ y $\mathrm{m} 3$.

Nesodon bifurcatus (Ameghino) 1887a (ver Atryptherium bifurcatum).

Nesodon brachycephalus Ameghino 1894a; Corriguen-kaike: MACN A 5305, cráneo bastante completo con casi toda la dentición; Monte Observación: MACN A 5311, varios fragmentos de un paladar; MACN A 5312, mandíbula casi completa; MACN A 5315, fragmento de mandíbula derecha; MACN A 5316, fragmento de mandíbula izquierda. 
Nesodon cavifrons Ameghino 1894a, Monte Observación: MACN A 5306, porción anterior del cráneo y mandíbula en oclusión, Monte Observación.

Nesodon conspurcatus Ameghino 1887a, Santa Cruz: MLP ? (no localizado)*, fragmento de paladar con P3-M3 de un ejemplar viejo.

Nesodon cornutus Scott 1912, Lago Pueyrredón: YPM-PU 16012, cráneo en buen estado de preservación, pero con la dentición severamente dañada, asociado a una mandíbula y algunos elementos postcraneales.

Nesodon imbricatus maior Kretzoi 1941, Patagonia: NM-GPA P.V. 21*, dos fragmentos de paladar.

Nesodon impinguatus Ameghino 1899: MACN ? (no localizado). La única información encontrada sobre este ejemplar corresponde al catálogo de Mones (1986); no existen referencias en las colecciones paleontológicas del Museo Argentino de Ciencias Naturales ni en las demás instituciones visitadas para la realización de este trabajo.

Nesodon ovinus Owen 1853 (ver Adinotherium ovinum).

Nesodon oweni Mercerat 1891, Río Santa Cruz: MLP 12-926 (no localizado); MLP 12962 (no localizado); MLP 12-1030, fragmento de mandíbula. Mercerat fundó esta especie a partir de dos fragmentos de maxilar del mismo individuo.

Nesodon patagonicus Moreno fide Ameghino 1894a (ver Protoxodon patagonensis).

Nesodon rutimeyeri Mercerat 1891, Río Santa Cruz: MLP 12-68, fragmento de maxilar con yugales de un individuo joven; Monte León: MLP 12-978, fragmento de mandíbula con dientes deciduos; MLP 12-1046 (no localizado). Mercerat fundó esta especie a partir de una mandíbula incompleta y dos fragmentos de maxilar.

Nesodon sulivani Owen 1847: RCS ? 
Hernández Del Pino, S.

Nesodon typicus Mercerat 1891, Santa Cruz: MLP 12-65, fragmento de maxilar con algunos dientes; MLP 12-272 (no localizado).

\section{—Nesodontopsis Roth 1899}

Nesodontopsis speciosus (Ameghino 1887a) (ver Hyperoxotodon speciosus).

\section{—Nesotherium Mercerat 1891}

Nesotherium carinatum Mercerat 1891, Río Santa Cruz: MLP 12-3, cráneo y mandíbula incompleta pertenecientes al mismo individuo.

Nesotherium argentinum Mercerat 1891, Santa Cruz: MLP 12-16 (no localizado); MLP 12-28, porción anterior del cráneo con parte de la dentición conservada; MLP 12-86, fragmento de mandíbula con un m3; MLP 12-967 (no localizado); MLP 12-1028, fragmento de mandíbula derecha con gran parte de la dentición; MLP 12-1043 (no localizado).

Nesotherium burmeisteri Mercerat 1891, Monte León: MLP ? (no localizado)*, Mercerat fundó el taxón a partir de dos cráneos incompletos.

Nesotherium elegans Mercerat 1891, Río Santa Cruz: MLP 12-1050, fragmento de mandíbula con gran parte de la dentición.

Nesotherium nehringi Mercerat 1891, Monte León: MLP ? (no localizado)*, especie fundada a partir de un cráneo en buen estado de preservación y otros fragmentos craneanos y mandibulares.

Nesotherium patagonense Mercerat 1891 (Ver Protoxodon patagonicus, Protoxodon sullivani).

Nesotherium rufum Mercerat 1891, Río Santa Cruz: MLP ? (no localizado)*, fragmento de mandíbula derecha. 
Nesotherium rutilum Mercerat 1891, Monte León: MLP 12-58, fragmento de maxilar con los molares; MLP 12-1029 (no localizado); MLP 12-1039, fragmento de mandíbula izquierda con M2-M3; MLP 12-1045 (no localizado).

Nesotherium studeri Mercerat 1891, Río Santa Cruz: MLP ? (no localizado)*, cráneo y mandíbula correspondiente al mismo individuo.

Nesotherium turgidum Mercerat 1891, Monte León: MLP 12-29, fragmento anterior de cráneo. De acuerdo a Mercerat, también había un resto mandibular, pero no fue localizado.

\section{—Noaditherium Ameghino 1907}

Noaditherium splendidum (Ameghino 1887a) (ver Adinotherium splendidum)

\section{—Phobereotherium Ameghino 1887a}

Phobereotherium silvaticum Ameghino 1887a: MLP?

\section{_Protoxodon Ameghino 1887b}

Protoxodon patagonensis Ameghino 1887b ex Moreno 1882: MLP ? (no localizado).

Protoxodon americanus Mercerat 1891, Río Santa Cruz: MLP 12-981, fragmento de mandíbula con dientes rotos; MLP 12-982, fragmento de mandíbula con molares; MLP 121040 (no localizado).

Protoxodon clemens Mercerat 1891, Río Santa Cruz: MLP 12-838 (no localizado)*, fragmento de cráneo; MLP 12-847, fragmento de mandíbula con tres dientes.

Protoxodon conspurcatus Ameghino 1887a (ver Nesodon conspurcatus).

Protoxodon evidens Mercerat 1891, Río Santa Cruz: MLP 12-23, fragmento anterior de cráneo. 
Hernández Del Pino, S.

Protoxodon henseli Mercerat 1891, Río Santa Cruz: MLP ? (no localizado)*, mandíbula incompleta y un fragmento de cráneo.

Protoxodon marmoratus Ameghino 1887b, Río Santa Cruz: MLP 12-250 (no localizado); MLP 12-263, fragmento de mandíbula con gran parte de la dentición; MLP 12969, fragmento de mandíbula derecha con un $\mathrm{m} 3$.

Protoxodon obliteratus Ameghino 1887b, Río Santa Cruz: MLP 12-851 (no localizado)*, mandíbula con parte de la dentición perteneciente a un individuo viejo; MLP 12-940, fragmento de mandíbula derecha con un $\mathrm{m} 3$.

Protoxodon speciosus Mercerat 1891, Río Santa Cruz: MLP 12-158 (no localizado)*, fragmento de mandíbula derecha.

Protoxodon trouessarti Mercerat 1891, Monte León: MLP 12-1051 (no localizado)*, cráneo con un fragmento de mandíbula.

\section{—Rhadinotherium Ameghino 1887a}

Rhadinotherium limitatum Ameghino 1887a, Santa Cruz: MLP ? (no localizado)*, fragmento de mandíbula con dientes.

\section{Scophotherium Ameghino 1887a}

Scophotherium cyclops Ameghino 1887a, Río Santa Cruz: MLP 12-1054, fragmento de mandíbula con la dentición severamente dañada.

\section{—Stenostephanus Ameghino 1887a emend. Lydekker 1893}

Stenostephanus speciosus Ameghino 1887a (ver Hyperoxotodon speciosus). 


\section{3. Determinación taxonómica y descripción anatómica}

Para la determinación taxonómica, se realizaron comparaciones con diferentes taxones dentro de la familia Toxodontidae y con los taxones supragenéricos más cercanos filogenéticamente a la familia, siguiendo las hipótesis filogenéticas de Nasif et al. (2000), Billet (2011), Forasiepi et al. (2015) y Deraco y García-López (2016), enfocándas mayormente en la anatomía del cráneo y la mandíbula, dando solo una descripción superficial de los elementos dentarios, que ya han sido tratados en detalle por otros autores en trabajos previos (e.g. Madden 1990, 1997).

Fuera de la Formación Santa Cruz, son pocas las asociaciones asignadas a la EM Santacrucense. En este sentido, se incluye especialmente la comparación con toxodóntidos de otras áreas reconocidos como los mismos géneros o afines. Por ejemplo, Croft et al. (2003) reconocieron Nesodon conspurcatus en la Formación Cura Mallín (Chile) y Flynn et al. (2002) y Croft et al. (2004) identificaron Nesodon y Adinotherium en la Formación Pampa Castillo y Chucal (Chile), respectivamente. Más recientemente, en el centro-oeste argentino se han recuperado restos asignados a $N$. conspurcatus en la Formación Chinches, en San Juan (López et al. 2011) y a Nesodon taweretus y cf. Palyeidodon en la Formación Aisol, en Mendoza (Forasiepi et al. 2015). En todos los casos, se ha establecido una edad correspondiente al Mioceno temprano, contemporánea de la Formación Santa Cruz (Forasiepi et al. 2011, López et al. 2011, Garrido et al. 2012), contemporánea de la Formación Santa Cruz. Además, Lopez et al. (2016) han citado la presencia de Nesodon en la Fm. Cullén, considerada una extensión de la Fm. Santa Cruz en Tierra del Fuego.

Con propósitos comparativos y su inclusión en los análisis filogenéticos, solo se utilizan los taxones más conocidos del género Proadinotherium (P. leptognathum y P. muensteri), de las EMs Deseadense-Colhuehuapense, dado que son aquellos cuya entidad específica es menos debatida y de los que se cuenta con mayor información (especialmente de $P$. muensteri). Proadinotherium saltoni (Shockey y Anaya 2008) no pudo incorporarse a la matriz dado que no fue posible acceder al material y la información bibliográfica fue insuficiente para su correcta codificación. El género Pronesodon fue definido por Ameghino (1891) para materiales de la EM Deseadense provenientes de la localidad de La Flecha, en Santa Cruz. Sin embargo, dicho nombre ha permanecido ausente de la literatura por muchísimo tiempo y los ejemplares sobre los cuales fue definido se han asignado informalmente, por diferentes autores, a Proadinotherium o a taxones pertenecientes a Leontiniidae. Si bien la revisión de este taxón es necesaria y debería ser incluido en los 
análisis filogenéticos, este género fue definido a partir de material postcraneano (ver Hernández Del Pino et al. 2017) y el presente estudio se basa mayormente en la morfología craneana y mandibular de los Nesodontinae. A esto se suma que los estudios sobre los elementos postcraneales de Notoungulata son escasos; por todo ello, se decidió no utilizar el género Pronesodon en los análisis filogenéticos.

La mayoría del material fue observado directamente; sin embargo, para los casos especiales en los que no se tuvo acceso a los fósiles, se recurrió únicamente a la bibliografía.

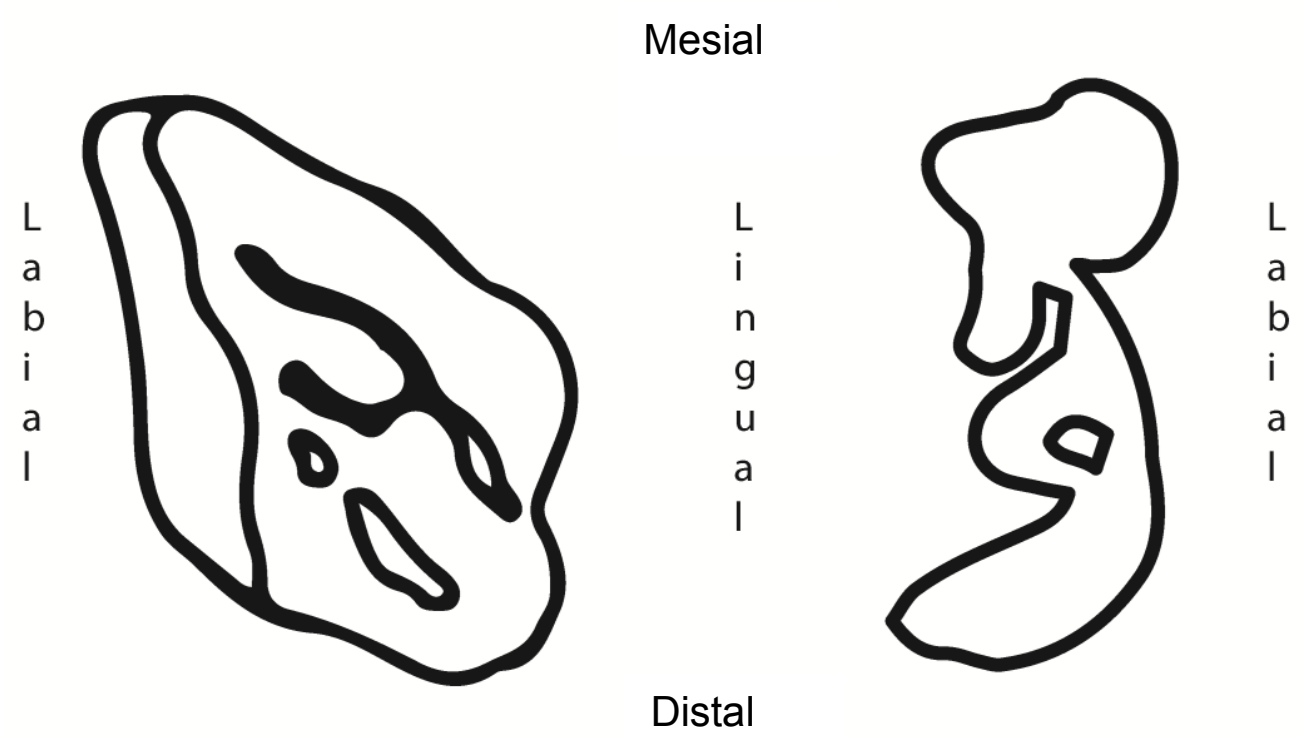

Fig. II. 1. Orientación de los dientes superiores (izquierda) e inferiores (derecha) (tomado de Cassini et al. 2012b).

Las descripciones provistas en esta tesis se enfocan mayormente en la anatomía craneana y mandibular de los toxodóntidos santacrucenses. La dentición se describe de forma más concisa y se pueden encontrar más detalles en el trabajo de Scott (1912), sobre los Toxodontia de la Formación Santa Cruz, o en la revisión taxonómica realizada por Madden (1990) de los toxodóntidos miocenos de Colombia, Ecuador y Chile. A fines comparativos, se han incluido algunas descripciones breves de algunos taxones de toxodóntidos no santacrucenses (e.g., Nesodon taweretus y Proadinotherium muensteri), así como de algunos taxa filogenéticamente cercanos que se encuentran presentes en la Formación Santa Cruz (e.g. Notohippus toxodontoides, Homalodotherium sp.). Para la descripción craneana, se sigue el protocolo planteado por Wible y Gaudin (2004), que consiste en dividir al cráneo en cinco grandes regiones: naso-facial, palatal, orbito-temporal, basicráneo y región auditiva, y región 
occipital; a esto se añaden aspectos de las cavidades internas a partir de moldes endocraneanos y moldes del laberinto óseo del oído interno.
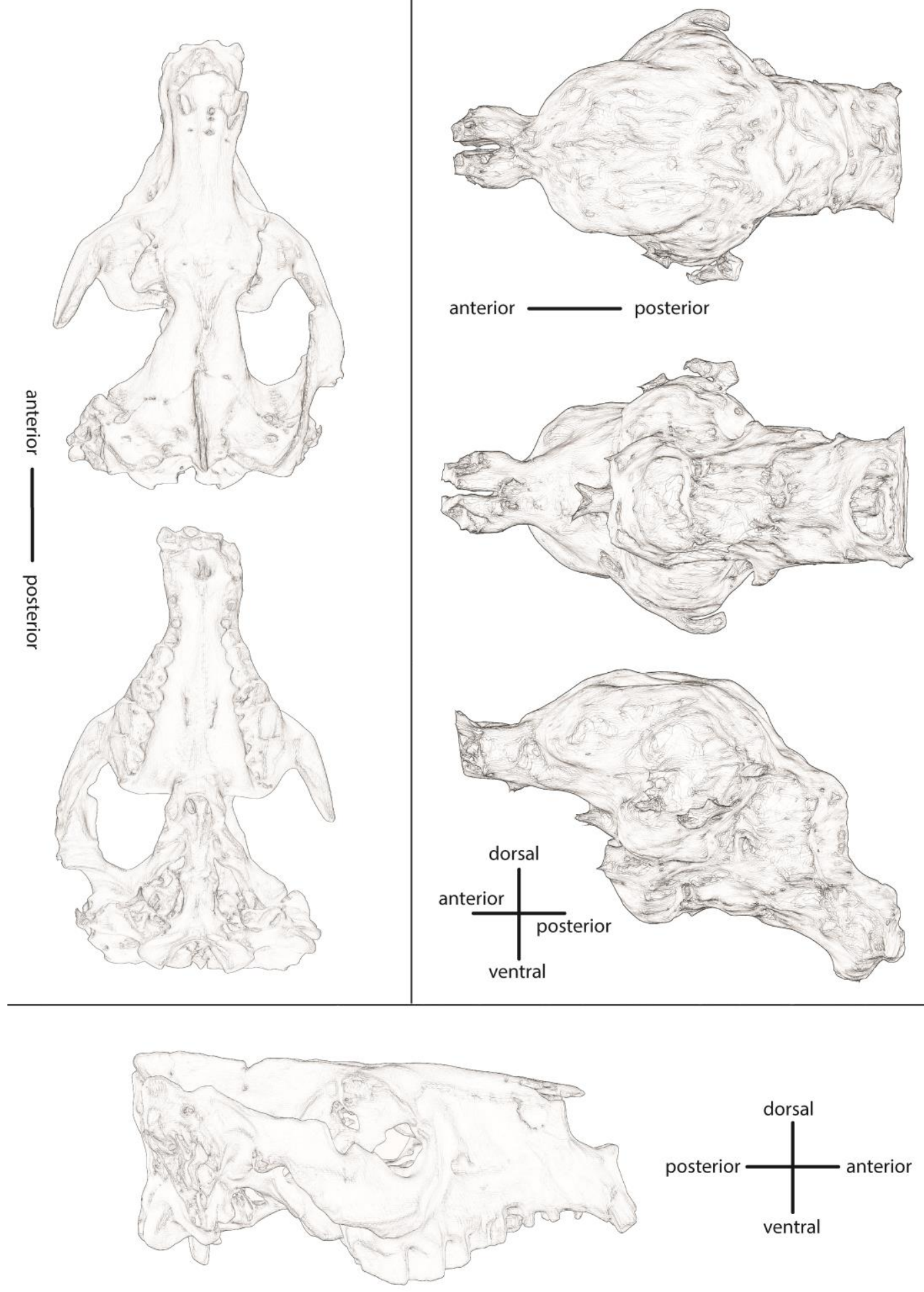

Fig. II. 2. Orientación del cráneo y el molde de la cavidad endocraneana. 
Para la nomenclatura anatómica, se siguieron los trabajos de Wible (2003, 2008), Wible y Gaudin (2004) y MacPhee (2014). La terminología asociada a la cavidad endocraneana sigue a Macrini et al. (2007a, b, c); para el petroso y el oído interno, a Macrini et al. (2010) y Billet et al. (2015). La terminología utilizada para las piezas dentarias se basa en diversos trabajos previos sobre notoungulados toxodóntidos (e.g., Madden 1990, Nasif et al. 2000, Billet 2011). La orientación de los elementos dentarios y craneanos se ejemplifica en las Figuras II. 1 y II. 2 , respectivamente.

\section{4. Cuantificación de la forma y Paleontología virtual}

La cuantificación de la forma puede realizarse desde dos enfoques. El tradicional consiste en el uso de un conjunto de medidas de ciertos aspectos o estructuras relevantes como, por ejemplo, el largo y el ancho de un molar. El geométrico involucra el uso de coordenadas en el espacio para evaluar aspectos de la forma de los organismos.

El advenimiento de nuevas tecnologías no solo ha permitido avances en el estudio de la forma de los organismos, sino que también ha posibilitado el desarrollo de nuevas técnicas para el estudio de los materiales fósiles. Una de las disciplinas que está tomando mayor importancia en el estudio de los fósiles es la Paleontología Virtual. Esta disciplina reúne un conjunto de técnicas que posibilitan la generación de modelos tridimensionales que facilitan el estudio de los ejemplares, pudiendo en algunos casos acceder a aspectos de la anatomía interna de los organismos sin la necesidad del uso de métodos de preparación invasivos.

En el siguiente apartado, se comentan algunos aspectos metodológicos relevantes de estas dos disciplinas, que facilitarán la comprensión de algunas secciones claves de este trabajo de tesis.

\section{4.1. Marco teórico relacionado con la cuantificación de la forma y la morfometría geométrica}

La forma, de acuerdo a Bock y von Whalert (1965), se define como "la apariencia, configuración o composición de un rasgo", entendiéndose por rasgo a cualquier aspecto de un organismo, ya sea morfológico, comportamental, fisiológico, etc. Para cuantificar la forma, se deben transformar esas características en variables que puedan ser medidas y así obtener una matriz de atributos numéricos. Para ello, en esta tesis se ha recurrido a diferentes dispositivos (calibres, brazo digitalizador 3D, cámaras fotográficas digitales, tomógrafos y microtomógrafos) y al uso de programas especializados (Image-J, 3D Slicer, VGStudio, 
Agisoft-Photoscan, Landmark editor, R), de acuerdo a las necesidades de cada enfoque de estudio y los objetivos planteados.

Para la cuantificación de la forma, se plantearon los dos enfoques mencionados: morfometría clásica y morfometría geométrica. Antes de describir en detalle el protocolo utilizado para la transformación de estas variables en medidas, resulta necesario dar algunas precisiones sobre el concepto de morfología y otros conceptos relacionados, tales como rasgo, forma, silueta, etc.

Se entiende por morfología al estudio de la forma (incluyendo el tamaño) y estructura de los organismos. También involucra al valor funcional de dichas estructuras (binomio formafunción o Ley de la correlación orgánico-funcional de Cuvier) (Vizcaíno et al. 2016).

A continuación, se describen una serie de términos relacionados con la morfología funcional que, si bien no forman parte del eje principal de este trabajo de tesis, serán utilizados al momento de referirse a la variación de la forma entre los diferentes taxones (ya sea a nivel intraespecífico, interespecífico o supragenérico). Dichos términos han sido tomados de Vizcaíno et al. (2016), quienes, a su vez, se basaron en los aportes de Bock y von Wahlert (1965) y Plotnick y Baumiller (2000). Estos conceptos son útiles a la hora de entender ciertos aspectos relacionados con los análisis del morfoespacio teórico de las diferentes especies de nesodontinos.

Rasgo: cualquier parte, atributo o carácter de un organismo, sea morfológico, de comportamiento, fisiológico, etc. Las estructuras de un organismo son sus rasgos morfológicos.

Forma: es la apariencia, configuración o composición de un rasgo, incluyendo el tamaño. Las expresiones figura, silueta o contorno refieren a la forma con exclusión del tamaño.

Función: es lo que un rasgo hace o cómo funciona. Incluye las propiedades físicas y químicas emergentes de su forma.

La cuantificación de la forma puede realizarse en el marco de dos metodologías: la morfometría clásica, que utiliza un conjunto de medidas entre puntos anatómicos considerados homólogos, y la morfometría geométrica, en la que se recurre al uso de coordenadas en un espacio bi o tridimensional para un conjunto de hitos anatómicos o landmarks que describen una estructura en particular (Vizcaíno et al. 2016).

Muchos de los problemas con los que se han encontrado los sistemáticos a la hora de utilizar datos morfológicos (tanto continuos como discretos) en los análisis filogenéticos derivan de la naturaleza compleja de esta clase de datos que, en muchos casos, imposibilita una descripción precisa. Difícilmente uno puede abstraer y trasladar la complejidad del 
arreglo estructural de los seres vivos a valores escalares (tales como largo, ancho, profundidad, etc) utilizando morfometría tradicional (MacLeod y Forey 2002). Sumado a ello, los conceptos geométricos (como tamaño y forma), comúnmente utilizados en las ciencias biológicas, han probado ser mucho más complicados de modelar que lo esperado y requieren herramientas de análisis mucho más complejas. Una disciplina que ha servido para sobrellevar la dificultad de la modelización de la forma en dos y tres dimensiones es la morfometría geométrica.

De acuerdo con Bookstein (1993), la morfometría geométrica representa una síntesis cuantitativa de dos temáticas que han dominado el estudio de la forma por más de un siglo. La primera y más antigua de ellas tiene sus raíces en el Renacimiento, desde los estudios de la forma llevados a cabo por artistas de la época (e.g. Alberto Durero, Leonardo da Vinci, Miguel Ángel), y fue introducida en la literatura científica moderna a partir de los trabajos de D’Arcy Thompson (1917). Este enfoque visualiza el cambio morfológico como si se tratase de pequeñas transformaciones registrables entre estadios iniciales y finales. Thompson estaba abocado particularmente a la interpretación de cómo pequeños patrones de deformación se combinaban con geometrías de organismos y generaban resultados complejos. Para poder expresar esto de manera gráfica, implementó el uso de una grilla cartesiana, donde las líneas de la grilla representarían (o se corresponderían con) landmarks tanto en la forma inicial como la final. El segundo tópico enmarcado en esta síntesis morfométrica surgió a partir de los trabajos sobre el análisis de regresiones biométricas de Francis Galton (1889), a partir de la distinción de aspectos lineares en el apareamiento entre pares de variables morfométricas (estimadas a partir de la covarianza o correlación de los elementos de la muestra) y el aspecto no linear de este apareamiento (medido a partir de la distribución de los residuos alrededor de la línea de regresión). A partir de ellos, se buscó la abstracción de componentes lineales artificiales, definidos a partir de la covarianza o correlación de matrices que pueden ser pensadas como vectores que existen en un espacio multidimensional definido a partir de las variables originales.

La morfometría geométrica combina los dos tópicos mencionados anteriormente para conformar un programa de análisis morfológico enfocado en los siguientes aspectos: 1) la representación de configuraciones de landmarks (=geometrías) como variables, 2) el registro de esas geometrías a partir de especímenes para la remoción de las diferencias de tamaño y orientación, y 3) formalizar las transformaciones de Thompson a partir del uso de dispositivos gráficos conocidos como thin-plate spline. Los aportes que detallan las variadas metodologías que incluye la morfometría geométrica son numerosos (e.g. Rohlf y Bookstein 1990, 
Bookstein 1986, 1991, 1996, Reyment 1991, Marcus et al. 1993, 1996, MacLeod y Forey 2002).

En síntesis, la morfometría geométrica provee un conjunto de herramientas que pueden detectar, representar y describir morfologías en un modo analíticamente superior a los métodos previos que se han utilizado para el estudio anatómico. También posibilita la revisión de numerosos problemas con los que el sistemático se encuentra a la hora de la interpretación y el uso de los datos morfológicos en el contexto de los análisis filogenéticos. En última instancia, las técnicas de morfometría geométrica pueden describir la forma de manera precisa a partir del uso del lenguaje matemático y pueden impactar de manera significativa tanto en la teoría como en la práctica de la caracterización morfológica (MacLeod y Forey 2002).

\section{4.2. Morfología virtual}

Al igual que en la sección anterior, aquí se detallan sucintamente algunos conceptos importantes para comprender en qué se basa la disciplina de la morfología virtual y la manera en que la información es procesada en el marco de varias metodologías para la obtención de imágenes digitales. También se desarrollan brevemente algunos conceptos relacionados con uno de los posibles resultados del uso de imágenes digitales, los modelos tridimensionales, uno de los insumos utilizados en esta tesis para la ubicación de landmarks y el posterior análisis utilizando morfometría geométrica.

La morfología virtual enmarca una serie de técnicas computacionales que permiten el análisis y la visualización de los organismos (tanto fósiles como actuales) en tres dimensiones y constituye una poderosa herramienta para el estudio de la historia de la vida. El uso de técnicas para la edición y manipulación de modelos 3D permite el estudio en detalle de aspectos anatómicos previamente desconocidos para varios grupos de organismos y trazas fósiles. Otra de sus ventajas en paleontología es que pueden ser aplicados a un amplio rango de tamaños y tipos de preservación de los especímenes analizados; además, provee una alternativa no invasiva que permite la preservación y protección de especímenes delicados (Rahman y Smith 2014). Más precisamente, el uso de este tipo de información elimina la necesidad de manipular constantemente los fósiles grandes, frágiles o raros; además, posibilita el intercambio de datos a largas distancias sin la necesidad de que el material original sea transportado (i.e. prácticamente permite el acceso a la información para cualquiera que lo solicite). 
Existen varios métodos para la obtención de sets de datos tridimensionales como, por ejemplo, escáneres láser, escáneres de luz reflectante o tomografías computadas (Mallison y Wings 2014). El uso de estos modelos 3D permite realizar análisis de cuantificación de la forma y el estudio de diversos aspectos morfofuncionales como, por ejemplo, el análisis de elementos finitos. Sutton et al. (2014) efectuaron una revisión completa de los métodos utilizados actualmente en la Paleontología Virtual, de los cuales cuatro se han aplicado en el desarrollo de varios aspectos de este trabajo y se comentan brevemente a continuación.

\section{-Brazo digitalizador 3D}

Un brazo digitalizador 3D es un dispositivo articulado que permite referenciar en un sistema de coordenadas tridimensionales las posiciones de cada punto homólogo (landmark) de una estructura biológica bajo estudio.

\section{—Tomografía computada (TC) y Microtomografía ( $\mu$ TC) de Rayos X}

Existe un amplio rango de métodos para la obtención de imágenes bidimensionales a partir de una estructura tridimensional y la posterior reconstrucción de especímenes digitales tridimensionales a partir de ese conjunto de imágenes. Uno de ellos es el uso de tomografías computadas (CT por sus siglas en ingles) de rayos X (agrupando a TC médicas, Micro-TC $\mu \mathrm{TC}-\mathrm{y}$ tomografías de sincrotrón). Estos métodos generan imágenes que representan mapas de atenuación de rayos $\mathrm{X}$.

Una tomografía es la representación de una estructura tridimensional en una serie de imágenes bidimensionales formadas por secciones paralelas (tomogramas). Un tomograma está constituido por una única imagen que representa una sección del objeto. Las tomografías proveen un medio efectivo para representar la estructura interna de un fósil y no sufren los problemas asociados a la perdida de datos por las técnicas de preparación. Esta clase de archivos pueden ser estudiados por observación directa de los tomogramas o como insumo para reconstruir un modelo tridimensional de la estructura original. Un tomógrafo es el dispositivo que permite la obtención y preparación de un conjunto de datos tomográficos (una serie de tomogramas). Aquellos conjuntos de datos que cuenten con escala, resolución y espaciado de corte constante entre imágenes pueden ser tratados como volúmenes, en donde los píxeles de los tomogramas corresponden a voxels (elementos volumétricos o volumetric pixels) que constituyen atributos espaciales (entre otras propiedades) de un punto en una grilla tridimensional (Sutton 2008). 
Los escáneres de TC médicos están optimizados para objetos a escala humana y han sido utilizados para realizar estudios en Paleontología desde principios de la década de 1980 (e.g. Tate y Cann 1982, Conroy y Vannier 1984, Sutton, 2008).

Uno de los métodos más comunes para la toma de este tipo de datos en paleontología es la utilización de tomografías computadas volumétricas (Volume CT), donde la fuente de rayos $\mathrm{X}$ dirige los haces a través de la muestra hacia el detector, que es un dispositivo de carga acoplada bidimensional (CCD por sus siglas en inglés), para capturar radiografías de la muestra en varias posiciones rotacionales, típicamente a cada grado de una rotación de $180^{\circ}$. Los tomogramas perpendiculares al eje de rotación se derivan de los datos obtenidos a partir del uso de algoritmos especializados. El detalle de las diversas variantes que existen para la obtención de conjuntos de datos tomográficos se puede consultar en los trabajos de Ketcham y Carlson (2001) y Kalender (2006).

Aun cuando los TC médicos proveen información muy valiosa, éstos se han utilizado normalmente para el estudio de vertebrados de gran tamaño, dado que su tamaño mínimo de voxel varía de varios milímetros a algo menos de $1 \mathrm{~mm} \mathrm{y}$, por tanto, no constituyen la herramienta adecuada para el estudio de organismos de pequeño tamaño (e.g. micromamíferos). Otra de las limitaciones que presentan este tipo de estudios es la cantidad de voxels (voxel count) que se pueden obtener; en el caso de los escáneres médicos para un conjunto de datos axial, el conteo de voxels es directamente proporcional a la resolución del detector.

Para subsanar las limitaciones de resolución y de separación entre cortes que acarrean los escáneres médicos, se recurre a otro tipo de dispositivo para la obtención de tomogramas, los microtomógrafos de rayos X, que básicamente aplican el método de TC axial a una escala de resolución mucho más alta. Estos escáneres fueron diseñados inicialmente para aplicaciones en ingeniería y física de los materiales, pero han resultado ser útiles para analizar fósiles pequeños (Sutton 2008).

Uno de los conceptos que vale la pena aclarar a la hora del tratamiento de los datos tomográficos es el concepto de segmentación, que consiste en la diferenciación semiautomática o manual de una serie de voxels (píxeles tridimensionales) de una región de interés. 


\section{-Conjuntos de imágenes}

Los conjuntos de imágenes utilizados consistieron en:

a) para el caso de las imágenes obtenidas a partir de tomógrafos médicos, el formato de imagen utilizado fue el original (DICOM) con una distancia entre cortes de $0.6 \mathrm{~mm}$ y una resolución de 500 x 500 píxeles;

b) para el caso de las imágenes obtenidas a partir de microtomógrafos, los archivos fueron convertidos a imágenes TIFF de 4900 x 4900 pixeles, con una distancia de corte variable entre 0,01 y $0,056 \mathrm{~mm}$. Estas últimas tuvieron que ser re-escaladas y remuestreadas para poder estudiarlas con el equipamiento disponible (los archivos muy pesados requieren un poder computacional muy superior al disponible).

\section{-Metadatos}

Los conjuntos de imágenes no son el único insumo necesario para dar el mejor uso a la información que contienen. El tamaño de voxel y el espaciado entre imágenes no se encuentran incluidos como datos en la mayoría de los formatos de imagen. En el caso particular de los archivos tipo DICOM, esta información está contenida en los archivos y se puede acceder a ella con el uso de un programa especializado. En el caso en que las imágenes se brinden en formato que no contenga los datos del protocolo de obtención de datos, deben acompañarse de un archivo que especifique cómo fueron adquiridas esas imágenes (incluyendo los parámetros definidos para realizar el escaneo), el tamaño de voxel y el espaciado.

\section{-Fotogrametría}

La Estereofotogrametría o Fotogrametría consiste en la derivación de información tridimensional en puntos, líneas o áreas de objetos en el terreno a partir de secuencias de imágenes fotográficas (Mallison y Wings 2014). Se trata de una técnica no invasiva que permite la creación de modelos tridimensionales texturados (Fig. II. 3).

Los modelos digitales obtenidos a partir de esta metodología permiten simulaciones computacionales con diversos propósitos como, por ejemplo, el análisis de la locomoción y el rango de movimiento en biomecánica o el análisis de elementos finitos. La información generada a partir de estos métodos puede utilizarse en diversos estudios (morfométricos, morfogeométricos), además de proveer información espacial y permitir la cuantificación de otras variables como tamaño y volumen. En última instancia, el uso de estas técnicas permite 
la realización de impresiones 3D para crear copias de los objetos originales y así preservarlos del desgaste de la manipulación.

El proceso para la obtención de modelos tridimensionales a partir de fotogrametría consta de tres pasos importantes (Mallison y Wings 2014):

1) Toma de fotografías

2) Edición de las imágenes (puede no ser necesario)

3) Generación del modelo tridimensional, que incluye, a su vez, otros pasos:

3.1) Acondicionamiento de los datos desde el programa

3.2) Alineación y generación de la capa de la nube de puntos

3.3) Generación de la nube densa de puntos (puede ser omitido)

3.4) Generación de la malla poligonal

3.5) Generación de la textura

Finalmente, se procede a exportar los datos para ser utilizados en los diferentes análisis o completar la edición de la malla poligonal.

Existen dos maneras para realizar la toma de fotografías para realizar fotogrametría. La primera consiste en utilizar una placa giratoria, donde se encuentra apoyado el espécimen a fotografiar, manteniendo la cámara fotográfica estática en un trípode e ir tomando fotografías sucesivas del espécimen a medida que la placa es rotada en pequeños ángulos. El resultado es una serie de fotografías que describen un círculo perfecto alrededor de la pieza, siempre con la cámara apuntando hacia el eje vertical de la placa giratoria. Sin embargo, una única "vuelta" no es suficiente para poder cubrir toda la superficie de objetos cuya geometría es compleja, razón por la cual, usualmente, es necesario variar la altura de la cámara y su posición en relación al espécimen y tomar nuevas fotografías, repitiendo el proceso mencionado. También se puede mantener la cámara en una posición fija, mientras se rota la posición del espécimen al terminar cada vuelta. Las ventajas que presenta este método es que uno es capaz de controlar la luz del entorno, la posibilidad de tomar una serie de fotografías rápidamente y el control que uno tiene sobre el fondo. En contrapartida, el factor más limitante de este método es la maniobrabilidad del material, ya que el espécimen tiene que poder moverse con relativa libertad; además, en su mayoría, las placas giratorias presentan un límite de peso, por lo que no pueden usarse con elementos de gran tamaño o con fósiles cuya matriz sea muy pesada. Para aquellas fotografías en las que no se pudo utilizar un fondo uniforme, se realizó un procedimiento de "enmascarado" manual que consiste en indicarle al programa que desestime el fondo para realizar las reconstrucciones. 
El segundo método consiste en realizar lo opuesto al anterior; la cámara se mueve, mientras que el espécimen permanece estático. Esencialmente, hay que caminar alrededor de un ejemplar tomando una serie de fotografías desde diferentes ángulos y distancias. Las ventajas de este método es que permite tomar fotografías de elementos pesados o de gran tamaño sin la necesidad de moverlos. La desventaja es que no puede controlarse la iluminación ni el fondo y, en muchos casos, es necesario ajustar la configuración de la cámara para la toma de las diferentes fotografías. Una de las cuestiones a tener en cuenta es que, al utilizar este método, el usuario tiene que juzgar correctamente si la cantidad y la posición de las fotos tomadas han sido suficientes para cubrir toda la superficie del espécimen.
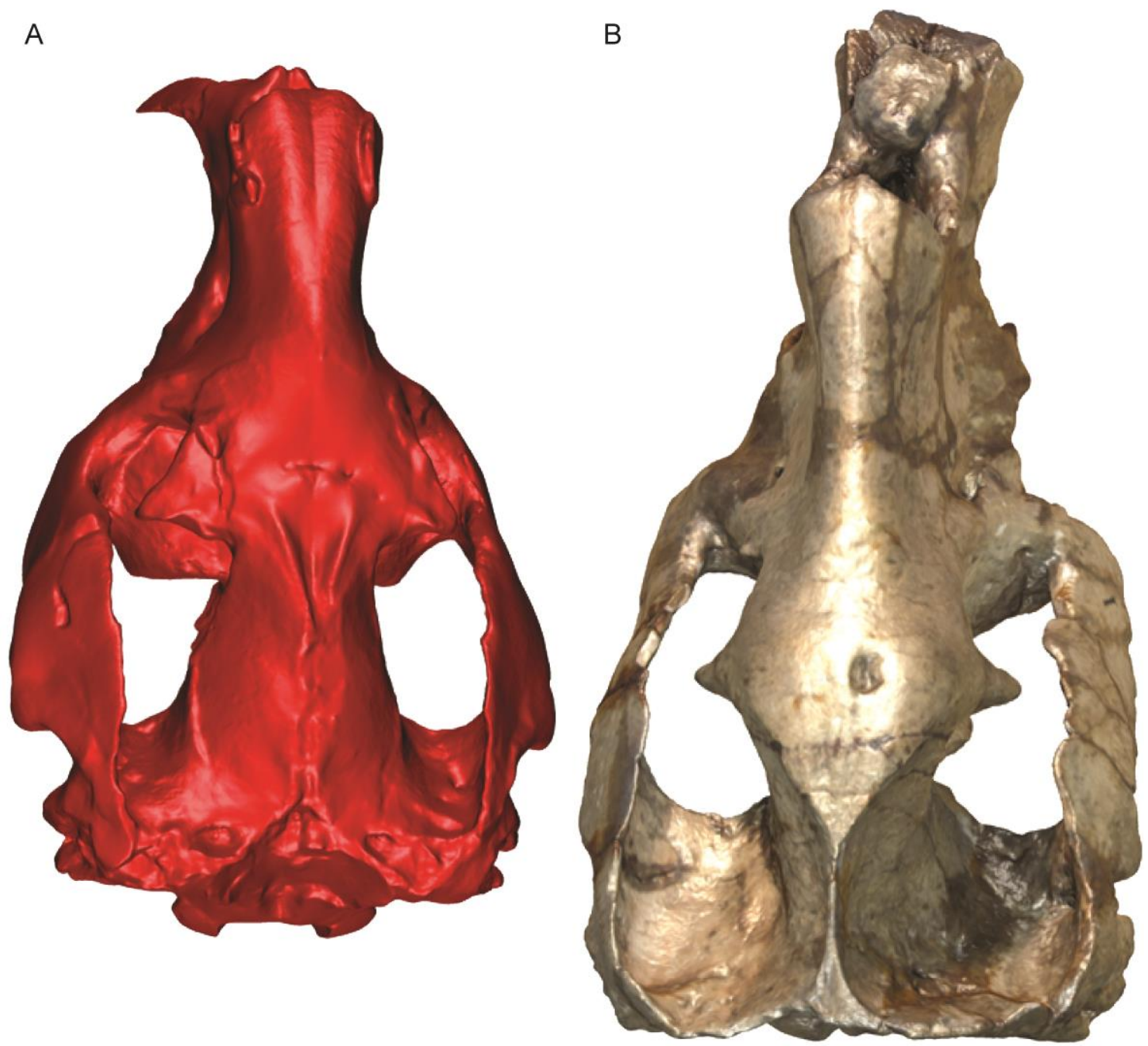

Fig. II. 3. Reconstrucciones de craneos obtenidas a partir del uso de fotogrametría: Vista dorsal de una reconstruccion sin textura (A). Vista dorsal de una reconstrucción con textura (B). 


\section{—Modelos tridimensionales}

En el caso de las dos metodologías expuestas anteriormente (Tomografías de rayos X y Fotogrametría), el resultado final es la reconstrucción tridimensional de una o varias estructuras (Fig. II. 4). Generalmente, estos modelos consisten en mallas de geometría triangular generadas a partir de la unión de superficies con igual valor (isosurfacing); los modelos generados a partir de estos métodos reciben el nombre de "modelos de superficie". Estos modelos pueden ser modificados luego de su obtención; uno de los ejemplos más comunes es el uso del suavizado de superficies (smoothing) o el uso de diferentes algoritmos para identificar y reparar las mallas para su uso en análisis de elementos finitos o impresión $3 \mathrm{D}$.

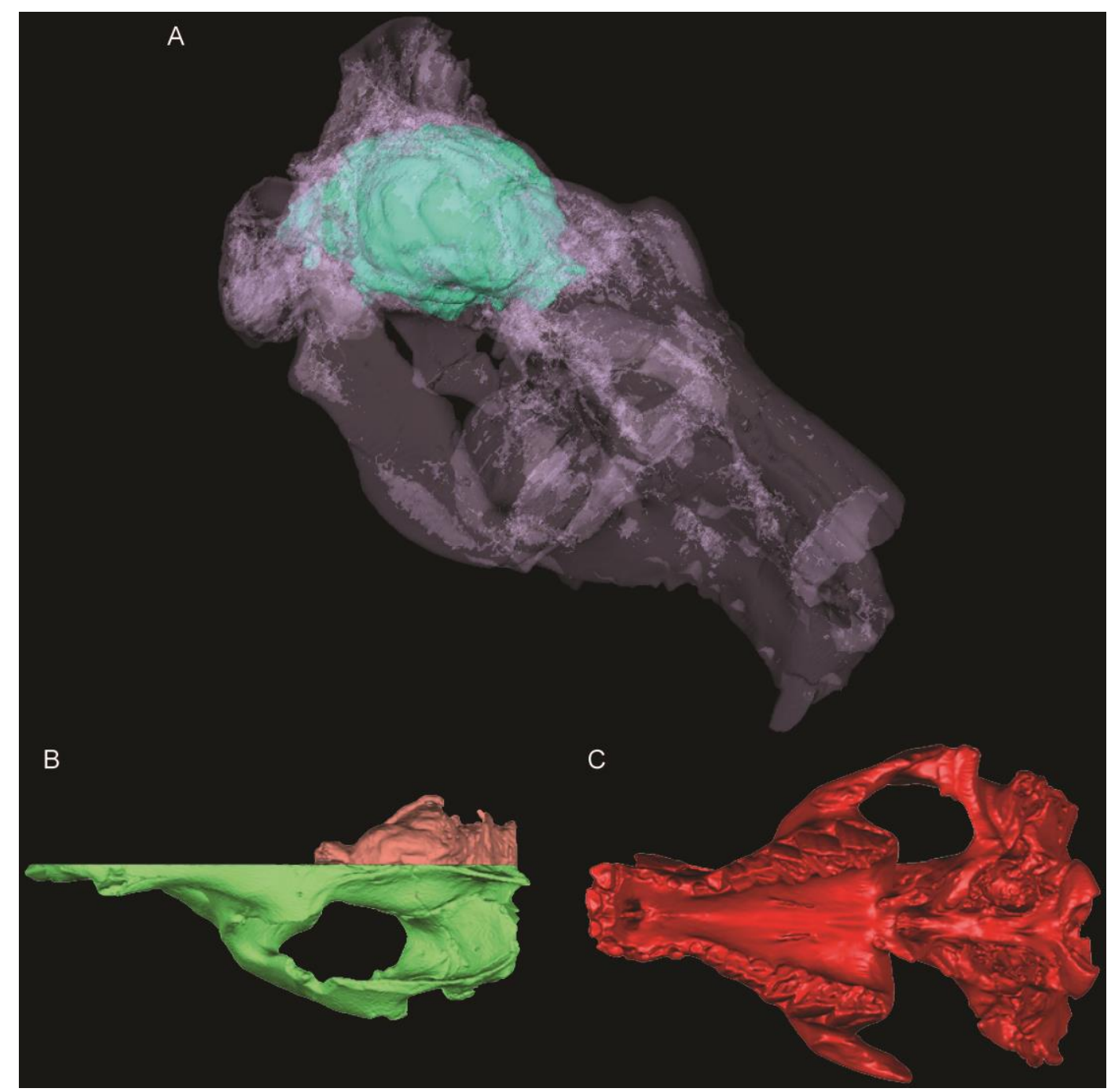

Fig. II. 4. Diferentes reconstrucciones del craneo de Adinotherium a partir de estudios de TC: Craneo y molde endocraneano del MPM-PV RB2-SFV-14-9 (A), mitad del craneo del MPM-PV 3532 con la reconstruccion de la cavidad endocraneana (B), vista ventral del craneo del MPM-PV 3532 (C). 


\section{4.3. Protocolo utilizado para la obtención de modelos tridimensionales a partir de imágenes digitales}

Raramente los conjuntos de datos utilizados para hacer una reconstrucción tridimensional se utilizan sin haber realizado alguna modificación a los datos originales (e.g. re-escalar las imágenes para disminuir su resolución, recortar el fondo de una serie de imágenes, ajustes en el contraste de las imágenes para separar nuestro objeto de interés del fondo, conversión de las imágenes a un formato diferente). Este apartado resume los protocolos seguidos a la hora de la obtención de modelos tridimensionales utilizando las diferentes metodologías comentadas anteriormente, debido a que todo el procesado de imágenes resulta subjetivo en cierta medida. En el caso de los conjuntos de datos en paleontología, usualmente requieren una intervención manual extensa a fin de poder extraer la mayor cantidad de información a partir de los datos originales.

\section{$-\mathrm{TC} \mathrm{\mu TC}$}

Las reconstrucciones tridimensionales a partir de tomografías computadas (ya sean médicas o micro-TC) se realizaron utilizando el software 3DSlicer (Fedorov et al. 2012). La mayoría de los ejemplares analizados fueron escaneados a partir de tomógrafos médicos (resolución de imagen de 500x500px y distancia de corte de 0,6mm), a excepción de los ejemplares AMNH 9276 y FMNH-13590 escaneados en microtomógrafo (resolución de imagen desde 1000x1000 a 1900x1900px y distancia de corte de 0,078mm).

Una vez cargadas las imágenes en el programa, se modificó el contraste de las mismas con la finalidad de mejorar la visibilidad de las diferentes estructuras en la medida que fue necesario (cada uno de los conjuntos de imágenes requirió diferentes parámetros en función de la preservación y la preparación del material). Para las reconstrucciones del cráneo y la mandíbula, por lo general, bastó con recurrir a la herramienta de umbral (treshold) para realizar la segmentación y posteriormente la reconstrucción del cráneo; los umbrales utilizados variaron enormemente, debido a las condiciones de preservación y también a la preparación a la que se había sometido el material. Fueron raros los casos en los que hubo que intervenir manualmente para la realización del modelado tridimensional.

Las reconstrucciones de la cavidad endocraneana y otros elementos del cráneo (e.g. petroso) también se realizaron con el mismo programa, pero en este caso hubo que recurrir a una alta intervención manual, ya que la herramienta de umbral raramente se ajustaba bien a la segmentación requerida. 


\section{-Fotogrametría}

La obtención de las fotografías se llevó a cabo por medio de los dos métodos antes mencionados. Para el caso de la placa giratoria se tomaron fotografías en vista lateral, ventral y cenital, realizando una vuelta (serie) por vista; el número total de fotografías obtenidas a partir de este método ronda las 200 por espécimen.

En los casos en que el material era demasiado grande o frágil para su manipulación, o simplemente por no disponer de una placa giratoria, se realizó la toma de fotografías desde diferentes ángulos en diferentes vistas, dejando los especímenes fijos. Al igual que en el caso anterior, el número de fotografías por vista rondó las 65-70, alcanzando un promedio de 200 por ejemplar para realizar las reconstrucciones.
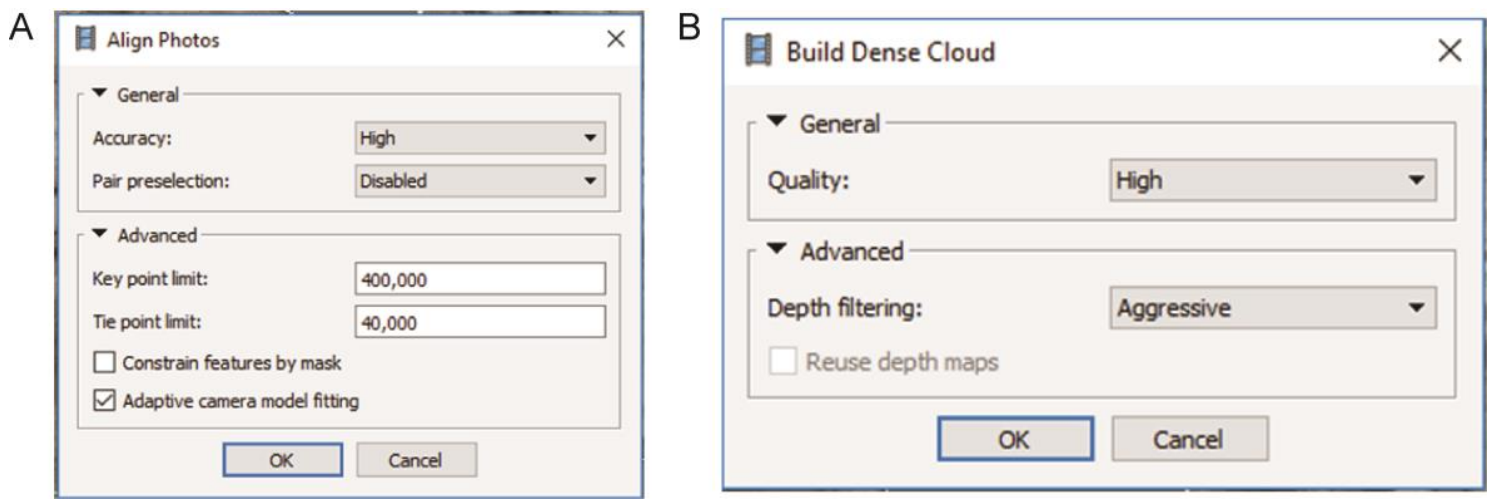

Fig. II. 5. Diferentes cuadros de diálogo espeficando los parámetros utilizados para realizar las reconstrucciones 3D con el programa Agisoft Photoscan: Parámetros para el alineamiento de fotografias (A), parámetros para la creacion de la nube densa $(\mathbf{B})$.

Para poder alinear las fotografías, hubo que realizar un proceso de enmascarado de las mismas para eliminar el fondo de la reconstrucción, sin excepción. Una vez enmascaradas, se procedió a la alineación de las fotografías utilizando el programa Agisoft Photoscan, utilizando los parámetros detallados en la figura II. 5A. Una vez alineadas las fotografías, se realizó una limpieza manual de la nube puntos (básicamente consiste en eliminar los puntos en el espacio que fueron mal reconocidos por el programa y los puntos remanentes que correspondan al fondo). Al finalizar la limpieza, se continuó con el armado de la nube de puntos densa, utilizando los parámetros detallados en la figura II. 5B, insumo indispensable para la realización de la malla poligonal 3D.

Finalmente, una vez realizada la nube densa de puntos, nuevamente se realizó una limpieza para eliminar aquellos puntos que son inconsistentes con la reconstrucción que se desea realizar (puntos que estén flotando en el espacio o que correspondan al fondo) para 
luego hacer la reconstrucción tridimensional usando los parámetros detallados en la figura II. 6.

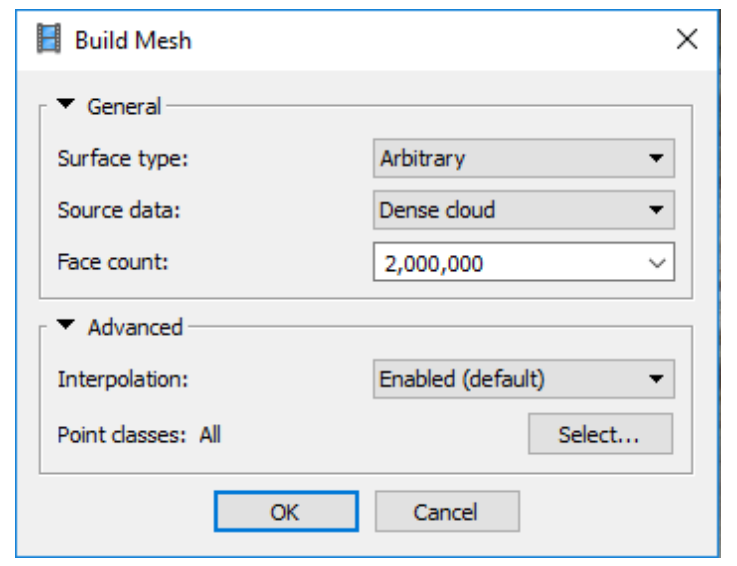

Fig. II. 6. Cuadro de diálogo espeficando los parámetros utilizados para realizar la malla poligonal con el software Agisoft Photoscan.

El proceso de creación de las texturas fue opcional para los objetivos de esta tesis y, al realizar la nube densa de puntos, raramente fue necesaria la creación de texturas como un auxiliar para la colocación de los landmarks en los modelos tridimensionales.

\section{4.4. Análisis de Retrodeformación}

Durante la diagénesis, los huesos pueden sufrir numerosos procesos de deformación como, por ejemplo, el achatamiento debido a la presión litostática o la curvatura por tensión que afectan la simetría bilateral del animal. El método utilizado para reconstruir la forma original del animal antes de su muerte se conoce como retrodeformación. En este caso, el método que se utiliza para la retrodeformación consiste en una "simetrización" (symmetrization), del cual existen numerosas variantes, siendo la técnica estándar la de reflejar los landmarks a lo largo del plano sagital y calcular el promedio de cada uno de esos landmarks con su "reflejo". Este método fue implementado por Gunzt et al. (2009) para revertir los efectos moderados de cizalla introducidos artificialmente. Sin embargo, este tipo de método no revierte los efectos de la curvatura y la compresión (Tallman et al. 2014). Se han desarrollado numerosas alternativas para poder suplir estas falencias (e.g. Motani 1997, Zollikofer y Ponce de León 2005, Amenta y Kazhdan 2010, Subsol et al. 2013); sin embargo, ninguna de ellas permite la evaluación de cuán precisa es la retrodeformación (Tallman et al. 
2014). El algoritmo utlizado en esta tesis para realizar la retrodeformacion de las configuraciones de landmarks fue creado por Ghosh et al. (2010).

El algoritmo de Ghosh et al. (2010) toma como punto de partida un set de pares de puntos correspondientes entre sí; en el resultado final, los puntos correspondientes entre sí deberían disponerse de manera tal de tener simetría bilateral entre sí.

En primera instancia, el algoritmo estima la transformación (para cada uno de los pares de puntos) en la cual se produce una aproximación a la simetría bilateral local con los puntos vecinos. Como en este caso se utilizó la variante para modelos comprimidos (y no la de modelos articulados), se estima el estiramiento mínimo que corrige la compresión sufrida por el espécimen, a la par que se establece la simetría local de los dos vecinos bilateralmente simétricos. La formulación de este primer paso está basada en el trabajo de Kazhdan et al (2009).

En el segundo paso, se aplican las transformaciones del paso anterior y se combinan las simetrías locales en una deformación. Como resultado, los pares de puntos se vuelven exactamente simétricos a lo largo de un único plano global mientras se preserva, de la mejor manera posible en términos de los minimos cuadrados, la figura (shape) en las regiones cercanas.

\section{4.5. Estimación del morfo espacio teórico}

Para la realización de los análisis de cuantificación del morfoespacio teórico se recurrió al uso de morfometría tradicional y morfometría geométrica.

En el primero de los enfoques, se tomaron 27 medidas, de las cuales 20 corresponden al cráneo (Tabla II.1 y Fig. II. 7) y las restantes siete a la mandíbula (Tabla II.2 y Fig. II. 7), utilizando como base los trabajos y base de datos de Cassini (2011) y Cassini et al. (2012a), que a su vez se basan en las contribuciones de Abdala et al. (2001), Giannini et al. (2004) y Flores et al. (2006). Se midieron 110 ejemplares de Nesodontinae, elegidos por el estado de preservación de cráneo y mandíbula; o en el caso de algunos ejemplares incompletos o deformados, debido a su importancia para la discusión taxonómica.

La ubicación de los landmarks 3D para la estimación del morfoespacio teórico se realizó a partir del uso de un brazo digitalizador Microscribe G2L digitizer (Immersion Corporation, San José, EEUU). Para el caso de aquellos especímenes que fueron escaneados utilizando TC de rayos $\mathrm{X}$ o fotogrametría, la ubicación de los landmarks 3D se realizó a partir del uso del 
programa Landmark Editor directamente sobre las mallas poligonales obtenidas a partir del análisis de las imágenes.

\begin{tabular}{cc}
\hline Abreviatura & Definición \\
\hline BCB & Ancho de la caja craneana \\
BCL & Largo del basicráneo \\
BZB & Ancho bicigomático \\
LIB & Ancho interorbitario mínimo \\
MFL & Longitud de la fosa mastérica \\
MZL & Longitud del hocico \\
MZH & Altura del hocico \\
MZW & Ancho del hocico \\
NSL & Largo del nasal \\
OCH & Altura occipital \\
ORH & Altura de la órbita \\
ORL & Largo de la órbita \\
PAB & Ancho del paladar \\
PAL & Largo del paladar \\
POC & Constricción postorbitaria \\
PSL & Longitud posterior del cráneo \\
SD & Profundidad del rostro bajo la órbita \\
SE & Largo del proceso paracondilar del exoccipital \\
TSL & Longitud total del cráneo \\
UPL & Largo de la serie dentaria postcanina (exceptuando al P1) \\
\hline \hline
\end{tabular}

Tabla II. 1 Listado de medidas craneanas utilizadas en esta tesis. Ver Cassini 2011 y Cassini et al. 2012a para las fuentes originales de cada una de las medidas.

\begin{tabular}{cc}
\hline \hline Abreviatura & Definición \\
\hline JD & Largo del proceso coronoides \\
JLB & Longitud del diastema \\
JMA & Longitud posterior de la mandíbula \\
JMB & Profundidad del ángulo mandibular \\
JMC & Ancho máximo del ángulo mandibular \\
LMRL & Largo de la serie de molares inferiores \\
LPRL & Largo de la serie de premolares inferiores \\
\hline \hline
\end{tabular}

Tabla II. 2 Listado de medidas mandibulares utilizadas en esta tesis. Ver Cassini 2011 y Cassini et al. 2012a para las fuentes originales de cada una de las medidas. 

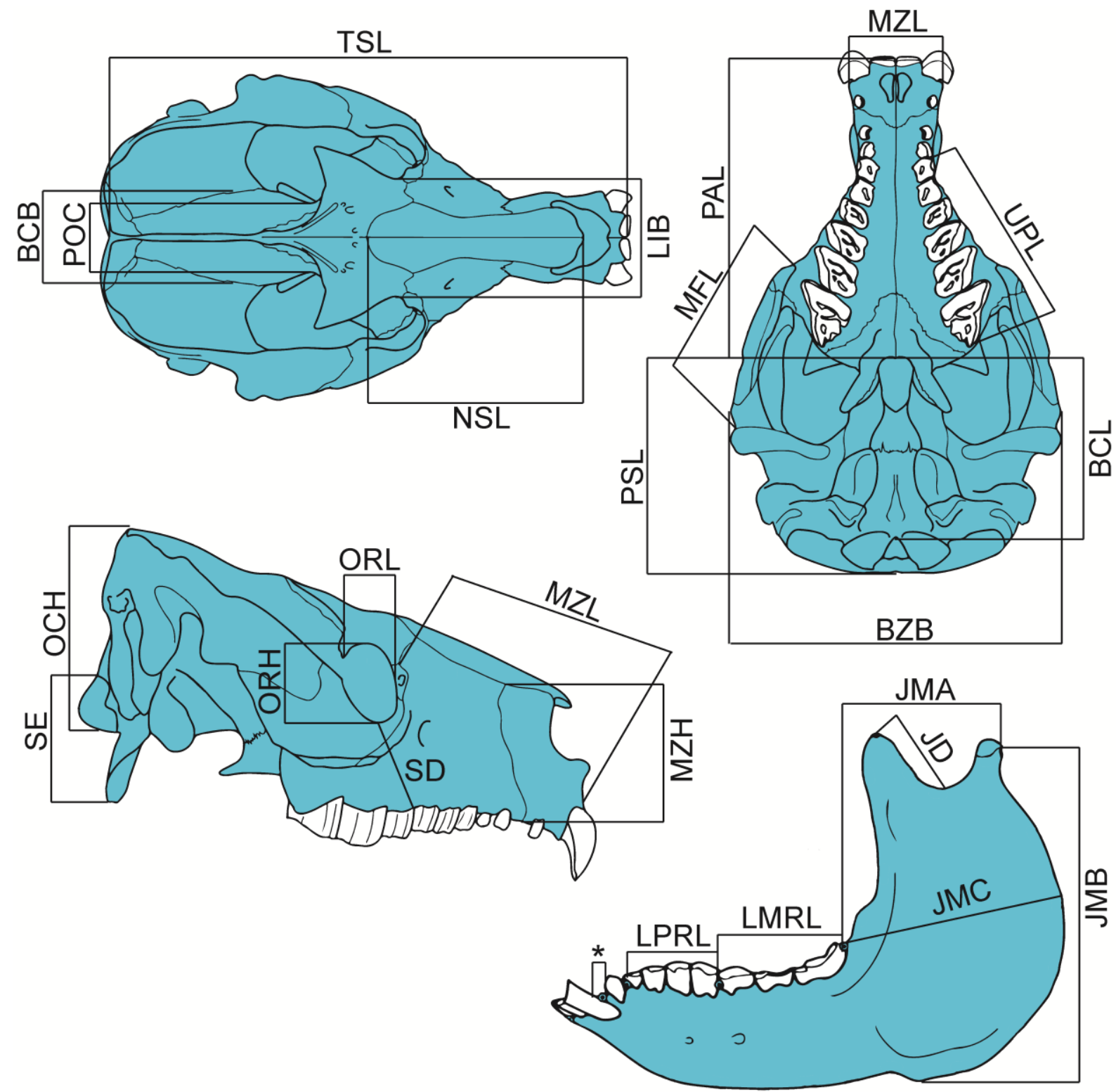

Fig. II. 8. Ubicación de las medidas utilizadas en el análisis morfométrico tradicional (Modificado de Cassini 2011 y Cassini et al. 2012a).

El conjunto de datos craneanos utilizado está compuesto por la base de datos utilizada por Cassini (2013) y la inclusión de tres ejemplares nuevos de Adinotherium ovinum (MPM-PV RB2-SFV-14-9, MPM-PV ELC-NAM-12-6 y MLP 12-1), tres ejemplares del género Nesodon (MPM-PV RBPN-SFV-12-3 y MLP 12-4 de Nesodon imbricatus, y un ejemplar de $N$. taweretus, MHNSR 1004), un ejemplar de Proadinotherium muensteri (FMNH 13590) y cinco ejemplares de Toxodontinae (Xotodon cristatus, MLP 12-1672; Xotodon major, MACN 7708; Trigodon gaudri, MACN 15344; y Toxodon platensis, MACN PV 8598 y MACN 16615); también se incluyeron ejemplares de otras familias de notoungulados como 
isotémnidos (MLP 69-III-24-286, Thomasxuleya externa) y leontínidos (MCNAM-PV 3951, Gualta cuyana, y MACN A 52-573, Leontinia gaudri). Los landmarks 13 y 34 de la lista de Cassini (2013) tuvieron que ser excluidos del análisis debido a una incompatibilidad en la toma de los datos, lo que no posibilitó la comparación de la información tomada de esos landmarks para este trabajo de tesis con la presente en la base de datos de Cassini. En el caso de los landmarks mandibulares, se utilizó la base de datos de Cassini sin modificaciones, dado que los materiales nuevos a disposición no se encontraban lo suficientemente completos como para ser incorporados al análisis.

\begin{tabular}{cc}
\hline \hline Número & Definición Landmark \\
\hline $1 \& 21$ & Intersección entre la sutura fronto-parietal y la línea temporal \\
$2 \& 22$ & Sutura fronto-lacrimal sobre el borde de la orbita \\
$3 \& 23$ & Sutura yugal-lacrimal sobre el borde de la orbita \\
$4 \& 24$ & Punto más anterior sobre el proceso cigomático del escamoso \\
$5 \& 25$ & Sutura yugal-escamoso sobre el borde dorsal del arco cigomático \\
$6 \& 26$ & Sutura escamoso-supraoccipital sobre la cresta supramastoidea \\
$7 \& 27$ & Borde posterior de la cresta facial sobre la sutura yugal-escamoso \\
$8 \& 28$ & Origen del m. masetero, en el punto más ventral del proceso descendente de la mandíbula \\
$9 \& 29$ & Margen alveolar distal del ultimo molar \\
$10 \& 30$ & Margen alveolar mesial del primer diente masticatorio funcional \\
$11 \& 31$ & Foramen infraorbitario \\
$12 \& 32$ & Sutura premaxilar-maxilar sobre el margen interalveolar \\
$13 \& 33$ & Sutura nasal-premaxilar sobre el borde de la abertura nasal \\
$14 \& 34$ & Punto tripartito entre los huesos nasal, frontal y maxilar \\
15 & Sutura entre los parietales y el supraoccipital \\
16 & Sutura fronto-parietal sobre el plano sagital \\
17 & Sutura fronto-nasal sobre el plano sagital \\
18 & Punta rostral del hueso nasal sobre la sutura internasal \\
19 & Sutura interpremaxilar sobre el borde ventral de la abertura nasal \\
20 & Sutura interpremaxilar sobre el margen alveolar \\
\hline \hline
\end{tabular}

Tabla II. 3. Landmarks craneanos utilizados en esta tesis.

La lista completa incluye 34 landmarks craneanos (Tabla II. 2 y Fig. II. 8) y 27 mandibulares (Tabla II. 3 y Fig. II. 8), incluyendo landmarks a ambos lados y sobre la línea media, siguiendo los trabajos de Cassini y Vizcaíno (2012) y Cassini (2013). Entre ellos, se encuentran landmarks de tipo I (anatómicos), de tipo II (matemáticos) y de tipo III (semilandmarks). 


\begin{tabular}{cl}
\hline \hline Número & \\
\hline 1 & Borde posteroventral de la sínfisis mandibular sobre el plano sagital \\
2 & Punto sobre el plano sagital entre ambos alveolos del i1 \\
3 & Borde distal del alveolo del ultimo incisivo inferior \\
4 & Borde mesial del alveolo del primer premolar funcional \\
5 & Margen alveolar entre el p4 y el m1 \\
6 & Borde distal del alveolo dental del m3 \\
$7-10$ & Semilandmarks sobre el proceso ascendente de la mandíbula y el proceso coronoideo \\
11 & Punto dorsal en la inflexión de la curvatura del proceso coronoideo \\
$12-13$ & Semilandmarks sobre el borde posterior del proceso coronoideo \\
14 & Punto más ventral sobre la incisura mandibular \\
15 & Punto más lateral en el cóndilo mandibular \\
16 & Punto más medial en el cóndilo mandibular \\
17 & Centro del borde posterior del cóndilo mandibular \\
18 & Borde posterodorsal de la rugosidad para la inserción del musculo masetero \\
$19-22$ & Semilandmarks sobre el borde posteroventral del ángulo mandibular \\
23 & Borde más anterior de la rugosidad de la inserción del m. masetero \\
$24-27$ & Sobre el margen ventral del cuerpo mandibular \\
\hline \hline
\end{tabular}

Tabla II. 4. Landmarks mandibulares utilizados en esta tesis.

Los datos se analizaron utilizando las aproximaciones del campo de la morfometría geométrica (Dryden y Mardia 1998). Dentro de los especímenes muestreados, y con el objetivo de aumentar el número de la muestra, se consideraron especímenes incompletos, Los landmarks faltantes fueron estimados en dos pasos en el programa estadístico $\mathrm{R}$ 3.4.1 ( $\mathrm{R}$ Development Core Team, 2017). El primer paso consistió en reflejar los landmarks especulares homólogos mediante la función $A M P$, método propuesto por Annat Haber de la Universidad de Chicago (disponible online en http://life.bio.sunysb.edu/morph/; material suplementario en línea 1 de Cassini y Vizcaíno 2012), y demostrada su utilidad en distintos análisis (e.g. Gunz et al. 2009, Prevosti et al. 2013, Segura 2015, Segura et al. 2013, 2017). En aquellos especímenes con ambos landmarks homólogos especulares faltantes, la estimación se realizó mediante la función fixLMtps del paquete Morpho 2.5.1 (Schlager 2017). Para el cráneo, se calcularon dos morfoespacios sobre dos conjuntos de datos: el primer conjunto consiste en los datos tomados ya sea a partir del brazo digitalizador o ubicados en los modelos tridimensionales con el Landmark Editor, para los cuales únicamente se estimaron los datos faltantes (Tabla II. 5) y sin realizar una retrodeformación; el segundo conjunto consiste en los datos retrodeformados resultantes a partir del uso de un algoritmo de resimetrización implementado mediante la función retroDeform $3 d$ del paquete Morpho 2.5.1 (Schlager, 2017). A su vez, para cada conjunto de datos se realizó un análisis de tres muestras 
diferentes: la muestra completa (con todos los ejemplares disponibles), una para el género Nesodon y otra para Adinotherium ovinum.
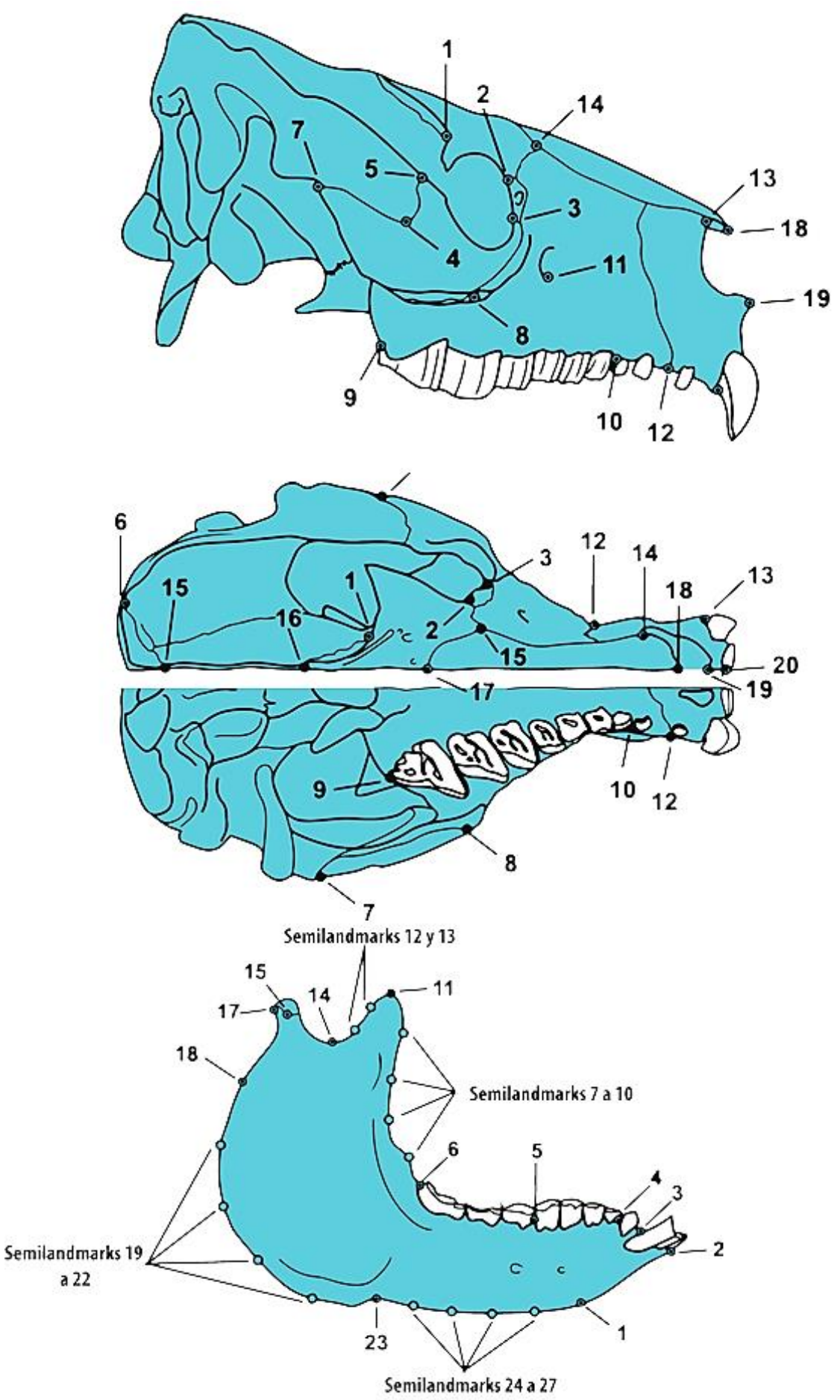

Fig. II. 8. Ubicación de los landmarks utilizados en el análisis morfogeométrico. A. Landmarks craneanos en vista lateral. B. Landmarks craneanos en vista dorsal y ventral. C. Landmarks mandibulares. (Modificado de Cassini 2013). 
En el caso del cálculo de morfoespacio para la mandíbula, debido a la cantidad de datos presentes, se realizó un único análisis a partir de datos sin retrodeformar.

Previo a realizar el análisis, se debe hacer una superimposición de las configuraciones de landmarks de los diferentes especímenes por medio de transformaciónes de rotación, traslación y reflexión, para así poder evitar la variación espacial que no es debida a la forma. Para la realización del alineamiento de las configuraciones de landmarks existen diversos procesos. En esta tesis se recurrio al análisis generalizado de Procrustres (GPA, Rohlf 1990) implementado en el programa MorphoJ. Dichas transformaciones se repiten hasta alcanzar el ajuste por mínimos cuadrados donde los landmarks homólogos de todos los especímenes se acerquen lo más posible (o incluso coincidan) en una "forma consenso" (representada por la media de todas las configuraciones de landmarks; Richtsmeier et al. 2002, Zelditch et al. 2004). Con la finalidad de evaluar si existe una correlación entre los patrones de forma y el tamaño corporal, se almacena el tamaño del centroide para cada configuración de landmarks (Milne y O'Higgins 2002), procedimiento que permitira identificar el componente de variación común para los análisis de las muestras analizadas en esta tesis. En ultima instancia, además, permite observar la posición de los diferentes especímenes en el morfoespacio a lo largo del componente principal de interés (o la combinación de ellos), posibilitando la visualización del cambio morfológico que diferencian a los ejemplares bajo análisis.

Para el caso de los análisis morfogeométricos, todos ellos fueron realizados utilizando el software MorphoJ 1.06b (Klingenberg 2011).

\begin{tabular}{|c|c|c|c|}
\hline Espécimen & $\begin{array}{c}\text { Linea media } \\
\text { (interpolación TPS) }\end{array}$ & $\begin{array}{l}\text { Izquierda } \\
\text { (simetría) }\end{array}$ & $\begin{array}{c}\text { Derecha } \\
\text { (simetría) }\end{array}$ \\
\hline A. ovinum & & & \\
\hline $\begin{array}{c}\text { MPM-PV RB2-SFV-14-9 } \\
\text { N. imbricatus }\end{array}$ & - & 6 & 24,25 \\
\hline $\begin{array}{c}\text { MPM-PV RBPN-SFV-12-3 } \\
\text { N. taweretus }\end{array}$ & 15 & $4,5,6,7,13$ & - \\
\hline $\begin{array}{l}\text { MHNSR-PV } 1004 \\
\text { P. muensteri }\end{array}$ & - & $4,5,7$ & - \\
\hline $\begin{array}{l}\text { FMNH-13590 } \\
\text { X. major }\end{array}$ & 18 & $5,7,13^{*}$ & $33 *$ \\
\hline $\begin{array}{l}\text { MACN } 7708 \\
\text { Toxodon sp. }\end{array}$ & 18 & - & - \\
\hline $\begin{array}{l}\text { MACN PV } 16615 \\
\text { T. platensis }\end{array}$ & 19,20 & $13^{*}$ & $33^{*}$ \\
\hline $\begin{array}{l}\text { MACN PV } 8598 \\
\text { L. gaudryi }\end{array}$ & 18 & 2,6 & - \\
\hline MACN PV 52-573 & - & 6 & - \\
\hline
\end{tabular}

Tabla II. 5. Landmarks faltantes estimados. - indica que ningún landmark fue estimado por ese método, * indica los landmarks en los laterales que fueron estimados por interpolación TPS. 


\section{5. Análisis filogenético}

En este apartado se describen los diferentes métodos utilizados para la realización de los análisis filogenéticos incluidos en esta tesis.

\section{5.1. Morfología y morfometría tradicional}

Para los análisis filogenéticos se confeccionó una matriz de 180 caracteres por 66 taxones, mayormente utilizando caracteres definidos en otros estudios filogenéticos de la familia Toxodontidae (Nasif et al. 2000, Forasiepi et al. 2015, Bonnini et al. 2017) y los Notoungulata (Billet 2011, Shockey et al. 2012, Billet y de Muizon 2013, Cerdeño y Vera 2015, Deraco y García-López 2016). En todos los casos en los que fue posible (i.e. se tuvo acceso al material o las descripciones provistas en la bibliografía lo permitieron), los taxones fueron codificados a nivel específico. Del total de caracteres disponibles, los 19 relacionados con la cavidad endocraneana fueron desactivados y excluidos del análisis debido a que, por los pocos taxones con los que se contaba información, no resultaron útiles para establecer relaciones de parentesco entre los diferentes taxa.

Cabe destacar que Proadinotherium saltoni no fue incluido en los análisis filogenéticos porque no fue posible acceder al material de manera física o a través de fotografías, y la información bibliográfica disponible no fue suficiente para poder codificar al taxón de manera satisfactoria.

La lista de caracteres, los cambios realizados en las codificaciones y la matriz se muestran en el Apéndice II.

El grupo externo del análisis consistió en diversos taxa por fuera del orden Notoungulata (mamíferos mesozoicos, condilartros, astrapoterios y piroterios), así como otros taxa dentro del orden, pertenecientes a los subórdenes Typotheria y Toxodontia. Dentro de este último, se

utilizaron las familias Homalodotheriidae, "Isotemnidae", Leontinidae y "Notohippidae" como sucesivos grupos externos.

El suborden Typotheria se encuentra representado únicamente por dos taxa (Cochilius y Trachyterus), en tal sentido los caracteres que definían arreglos internos dentro de este suborden dejaron de ser informativos y fueron eliminados de la matriz utilizada para el análisis filogenético. La razón de no incluir otros taxa de Typotheria es que no se cuenta con información de configuraciones de landmarks, lo cual hace extremadamente lento el análisis 
de la matriz mixta; por esa misma razón se han eliminado también del análisis filogenético a partir de la matriz morfológica.

Se realizó una búsqueda heurística para encontrar los árboles de máxima parsimonia (AMP) en la matriz, utilizando TNT 1.5 (Goloboff et al. 2008). En primer lugar, se realizó la búsqueda utilizando caracteres con pesos iguales, con 1000 réplicas y salvando 10 árboles por réplica, seguida por una permutación de ramas con los árboles guardados en la memoria usando la variante TBR (Tree Bisection Recconection). A continuación, se calculó el consenso estricto para todos los AMP. Se realizó un segundo análisis utilizando la variante de pesos implicados extendidos (Goloboff 2014), implementada en TNT, utilizando diferentes valores para la constante de concavidad ' $k$ ' a partir de las rutinas creadas por Mirande (2009) y Mirande et al. (2013). A diferencia de los pesos implicados, esta nueva variante previene la asignación artificial de pesos altos a caracteres con demasiadas entradas faltantes (Mirande et al. 2013), razón por la cual resulta más apropiada para analizar la matriz utilizada en este trabajo.

Para los árboles de consenso resultantes del análisis con pesos iguales, se calcularon las frecuencias GC con el algoritmo de jack-knife, bajo 1000 réplicas para asignar valores de soporte para los nodos del árbol. En el caso del análisis bajo pesos implicados extendidos, se calcularon las frecuencias GC con el algoritmo Symmetric resampling bajo 1000 réplicas, ya que este algoritmo es el que mejor se comporta a la hora minimizar la influencia del pesado de caracteres sobre el soporte de los nodos del árbol (Goloboff 2014). Por último, se mapearon las sinapomorfías para ambos árboles de consenso utilizando WinClada (Nixon 2002).

Para todos los AMP obtenidos a partir de los análisis bajo pesos iguales y pesos implicados extendidos, se realizó una estimación del ajuste estratigráfico para poder seleccionar cuáles de esos AMP serían utilizados para la realización del análisis biogeográfico. Para la estimación del ajuste estratigráfico se recurrió al uso del script "MSM.run", diseñado por Pol y Norell (2001) e implementado en el software TNT, y que consiste en la optimización del factor tiempo en la filogenia, dando como resultado árboles filogenéticos cuyo largo de ramas indica el tiempo transcurrido entre cada uno de los eventos de cladogénesis. El script "MSM.run" genera también una tabla de valores donde se pueden apreciar dos índices que indican cuán bueno ha sido el ajuste de cada uno de los árboles analizados con respecto al registro estratigráfico. La matriz utilizada para correr esta rutina de TNT se encuetra disponible en el Apéndice III. 


\section{5.2. Matriz mixta}

El segundo análisis filogenético se basó en una matriz combinada de los caracteres utilizados en el análisis anterior y los datos obtenidos a partir del uso de landmarks 3D. La implementación de algoritmos que permiten el análisis de caracteres continuos (tales como distancias entre puntos anatómicos, índices, etc.) posibilitó la incorporación, en primera instancia, de caracteres derivados de la morfometría clásica (Goloboff et al. 2006). Recientemente, ha sido posible la incorporación de características morfogeométricas a este tipo de análisis (i.e. coordenadas de landmarks) (Catalano et al. 2010). Estos avances permiten la inclusion de rasgos de variación continua de la forma en los análisis filogenéticos, que además ha comenzado a ser incluida en matrices mixtas junto con caracteres morfológicos discretos (e.g. Clouse et al 2010, Carrizo y Catalano 2015), análisis que aun no han sido aplicados para los Notoungulata. La utilización de landmarks para la obtención de filogenias ha sido implementada recientemente en el TNT 1.5 (Goloboff y Catalano 2016). Sobre esta nueva matriz, se realizó una búsqueda heurística para encontrar los AMP, utilizando TNT 1.5 (Catalano et al. 2010, Catalano y Goloboff 2012, Goloboff y Catalano 2016, Catalano y Torres 2017).

TNT reconoce a cada configuración de landmarks como un carácter haciendo que la contribución de cada una de esas configuraciones sea aproximadamente equivalente a un carácter discreto. Para realizar esta "equivalencia" se estandarizan las configuraciones de landmarks de manera tal que su la contribución de cada una de ellas sea similar a un carácter discreto independientemente de la escala y el número de landmarks (Catalano y Goloboff 2018). TNT ofrece diversas maneras de realizar esta estandarización; sin embargo, debido a mi falta de conocimiento en el proceso, se opto por realizar los análisis con estos parámetros por defecto.

En este caso, solo se realizó una búsqueda utilizando caracteres con pesos iguales, con 10 réplicas y salvando 10 árboles por réplica. A continuación, se calculó el consenso estricto para todos los AMP obtenidos.

Los resultados obtenidos en este análisis deben ser interpretados con cautela, en primera instancia, debido a que el número de taxones de los cuales se pudo obtener una configuración de landmarks es bajo y los restantes fueron codificados como entradas faltantes; y en segundo lugar, por el hecho de que varios autores (Adams et al. 2014 y referencias allí citadas) han remarcado que el uso de datos morfogeométricos como base para el armado de filogenias no cumple con los requisitos necesarios para los modelos de Procrustes. 


\section{6. Análisis paleobiogeográfico}

Para llevar a cabo los análisis biogeográficos, se recurrió al uso de uno de los tres subtipos del método basado en eventos, los modelos discretos reticulados (Ronquist y Sanmartín 2011), implementado en el programa RASP-Win (Yu et al. 2015). En los métodos basados en eventos, el costo que se le asigna a la especie depende de varios fenómenos (e.g. vicariancia, dispersión, extinción) y, luego de la búsqueda, se opta por la solución más óptima que tenga el menor costo total (Brooks y McLennan 2001). Los modelos discretos se basan en áreas geográficas determinadas previamente a la realización del análisis y los procesos corresponden a eventos que cambian el "estado biogeográfico" (la distribución) de los organismos. Estos modelos se centran en la transición entre áreas, ignorando cómo se mueven los organismos dentro de las áreas.

El análisis de dispersión y vicariancia (DIVA por sus siglas en inglés) consiste en un método de parsimonia cuyo supuesto principal (si se desconoce la distribución de las áreas en el pasado) es asumir que todas las áreas analizadas se encontraban conectadas y que todas las divisiones posteriores del área ancestral probablemente se debieron a sucesivos eventos vicariantes. En el DIVA, las distribuciones se modelan como unidades de áreas y un linaje puede ocupar una o más de estas áreas. La especiación ocurre por vicariancia o por diversificación dentro de un área. A los eventos de cladogénesis se les asigna un costo de cero, mientras que a la expansión del rango de distribución de un linaje por la adquisición de un área (dispersión) o a la disminución del mismo (extinción) se les asigna un costo de 1 (eventos de anagénesis). Es decir, en este tipo de análisis se prioriza a los eventos vicariantes en detrimento de las dispersiones y extinciones.

Los insumos principales para la realización de los análisis paleobiográficos en el software RASP-Win son: una (o varias) filogenia (s) del grupo en estudio y las distribuciones de los taxones en áreas definidas por el usuario. Para la realización del análisis paleobiogeográfico en esta tesis, se optó por utilizar una de las variantes para modelos reticulados, el análisis BBM (Bayesian Binary Markov Chain Monte Carlo), debido a que el número de áreas definido supera el máximo que puede utilizarse en el S-DIVA. Los parámetros utilizados para el análisis fueron los siguientes: 50.000 generaciones para las cadenas de Markov-Montecarlo, muestreando los estados cada 100 generaciones, y el número máximo de áreas permitidas por nodo fue de 8 . 
Las áreas definidas en el análisis se basan (en parte) en el trabajo de Seoane et al. (2017), agregando algunas localidades del resto de América del Sur y el Caribe conforme ha sido necesario para cubrir los registros de los toxodóntidos analizados.

Para prevenir errores que supongan correlaciones entre los distintos yacimientos en el centro-norte de América del Sur y el Caribe, se seleccionaron áreas pequeñas, que corresponden a yacimientos aislados (Áreas I, J, N y P). El motivo por el que se tomó esta decisión fue debido a la ausencia de referencias bibliográficas que indiquen correlación estratigráfica con otras unidades. En el caso de contar con dicha información los yacimientos correlacionados estratigraficamenet han sido reunidos en una única área (Áreas K, L, M).

El número total de áreas elegidas fue de 16 y corresponden a:

Área A-Localidades fósiles correspondientes a depósitos oligocenos de la Cuenca de San Jorge: Scarrit Pocket (Chubut), Cabeza Blanca (Chubut), La Flecha (Santa Cruz) y Deseado (Santa Cruz). También incluye las áreas de Gaiman (Chubut) y Colhue-Huapi que corresponden a depósitos miocenos de la misma cuenca sedimentaria.

Área B-Localizada en el sur de la provincia de Mendoza, cercana a la localidad de Malargüe. Corresponde a depósitos oligocenos de la cuenca Neuquina y a los depósitos Oligoceno-Miocenos de la localidad de Chucal en Chile.

Área C-Localizada en las provincias de Neuquén y Río Negro. Corresponde a sedimentos del Mioceno temprano de las localidades de Barda Negra (Neuquén) y Paso Córdova (Río Negro).

Área D-Localizada en la provincia de Santa Cruz y las region Aysen en Chile. Corresponde a los depósitos del Mioceno temprano de la cuenca Magallanes.

Área E- Localizada en el centro-norte de la provincia de Mendoza y San Juan. Corresponde a los depósitos del Mioceno temprano de Divisadero Largo (Mendoza) y los depósitos del Mioceno medio-Plioceno de Huayquerías (Mendoza), Puchuzum (San Juan).

Área F-Localizada en el noroeste de Argentina y el sur de Bolivia. Corresponde a los depósitos de las formaciones Corral Quemado, Chiquimil y El Morterito (provincia de Catamarca, Mioceno tardío) y los depósitos de Quebrada Honda (Bolivia, Mioceno medio).

Área G-Localizada en las provincias de Buenos Aires, La Pampa y Entre Ríos. Corresponde a los depósitos del Mioceno tardío de las localidades de Arroyo Chasicó (Buenos Aires), Mar del Plata (Buenos Aires), Chapadmalal (Buenos Aires), Monte Hermoso (Buenos Aires), Quequén Grande (Buenos Aires), Salinas Grandes de Hidalgo (La Pampa) y los depósitos de la Formación Ituzaingó (Entre Ríos). 
Área H-Localizada en las provincias de Córdoba y San Luis. Corresponde a los depósitos de las Formaciones Cura Brochero (Córdoba) y Río Quinto (San Luis), del Mioceno tardío.

Área I- Localizada en el Oeste de Brasil. Corresponde a los depósitos de la Formación Solimöes, del Mioceno de la localidad de Río Acre.

Área J-Localizada en el Norte de Venezuela. Corresponde a los depósitos del Mioceno tardío de la Formación Urumaco.

Área K- Localizada en el Altiplano boliviano en el centro-oeste de Bolivia. Corresponde a los depósitos del Mioceno tardío-Plioceno de la Formación Mauri en las localidades de Umala, La Paz, Pomata Atye y Remedios.

Área L-Localizada en la región del Caribe y Sur de México. Corresponde a los depósitos del Pleistoceno tardío de Panamá, Nicaragua, Venezuela, El Salvador, Costa Rica, Guatemala, Honduras y a las localidades de Hihuitlan y La Estribera en México.

Área M-Localizada en el sur de Colombia, Ecuador y norte de Perú. Corresponde a los depósitos miocenos de Railway Bridge, Villavieja, San Nicolás y La Gaviota (Colombia); los depósitos miocenos de Tambo Viejo y Quebrada Dumapara (Ecuador); y los depósitos miocenos de Inuya-Mapuya (Perú)

Área N-Localizada en la zona nordeste de Brasil. Corresponde a los depósitos del Pleistoceno tardío del parque nacional "Serra da Capivara" en Piauí y los depósitos del Pleistoceno tardío de "Serra do Bodoquena" en Mato Grosso do Sul.

Área O-Localizada en la provincia de Buenos Aires y Uruguay. Corresponde a los depósitos del Pleistoceno (Lujanense) de las localidades de Arroyo Tapalqué, Paso OteroVerde y Luján, en Argentina, y de Pintado y Casil Quarry en Uruguay.

Área P-Localizada en el sur de Bolivia. Corresponde a los depósitos del Pleistoceno temprano de Tarija y del Pleistoceno medio de Nuapua.

La matriz realizada para correr este análisis se encuentra disponible en el Apéndice IV. 


\section{Capítulo III. Revisión taxonómica y estatus nomenclatural de los toxodóntidos del Mioceno de Santa Cruz}

Como se mencionó en el primer capítulo, los ejemplares de toxodóntidos provenientes de la Formación Santa Cruz han recibido una multitud de nombres desde las primeras publicaciones atribuidas al grupo (Owen 1847, 1853). Desde el establecimiento y la descripción de Nesodon imbricatus y dada la enorme cantidad de materiales que se colectaron años más tarde, han sido numerosos los aportes de distintos autores a la taxonomía de los nesodontinos santacrucenses (e.g. Ameghino 1887a, 1891, 1907, Lydekker 1893, Mercerat 1891, Scott 1912). Este capítulo resume los cambios taxonómicos dentro de los Toxodontidae (III. 1.) y, en ese contexto, el de los nesodontinos de la Formación Santa Cruz de forma más detallada (III. 2.), incluyendo sus listas sinonímicas completas (III. 3).

\section{1. Toxodontidae y Nesodontinae}

La familia Toxodontidae Owen 1845 fue fundada a partir de un cráneo encontrado por Charles Darwin en niveles del Pleistoceno de Uruguay, a orillas del arroyo Sarandí, aproximadamente a $193 \mathrm{~km}$ al noroeste de Montevideo (Pasquali et al. 2011). Dicho cráneo había sido descripto por el mismo Owen en el año 1837 como Toxodon platensis, taxón que además fue el primer ungulado nativo de América del Sur en ser descripto (Fernicola et al. 2009). Dado el tamaño del espécimen, Owen lo relacionó con los paquidermos y los "cetáceos herbívoros" (en este último caso, refiriéndose a los sirenios). Entre los rasgos principales a partir de los cuales Owen definió a la familia, se destaca la morfología peculiar de la región occipital y la parte posterior del cráneo, ambas inclinadas en un ángulo de $75^{\circ}$ respecto a la base del cráneo y la posición del foramen magnum. Owen destacó, además, la similitud de la dentición y el aspecto lateral del cráneo de Toxodon con algunos representantes de Rodentia. Todo esto llevó a Owen a pensar que Toxodon constituía una forma transicional que llevaba desde los roedores, pasando por los paquidermos, hacia los cetáceos. A partir de la fundación del taxón, han sido numerosos los aportes de diferentes autores para esta familia en materia de anatomía, aspectos taxonómicos y estratigrafía, siendo algunas de las más importantes las de Ameghino (1887a, 1889, 1891, 1894a y b), Mercerat (1891), Lydekker (1893), Van Frank (1957), Roth (1903, 1908), Pascual y Borrello (1966), Paula Couto (1979, 1981) y Madden 
(1990, 1997), entre muchas otras. Madden (1997) describió a los Toxodontidae como herbívoros de mediano a gran tamaño distinguibles por su dentición anterior especializada, incisivos de crecimiento continuo formando defensas y molares de corona alta, con un registro abundante en América del Sur a partir del Mioceno, aunque la distribución general de la familia abarca desde el Oligoceno tardío hasta la transición Pleistoceno-Holoceno en gran parte de América del Sur.

Diversos autores han señalado la semejanza del cráneo de los toxodóntidos con el de los rinocerontes e hipopótamos (e.g. Owen 1837, Paula Couto 1979, Zurita y Lutz 2002), así como la del esqueleto postcraneano (e.g. Paula Couto 1979, Cartelle 1994). Estas similitudes llevaron a considerar a los toxodóntidos como análogos ecológicos de Rhinocerotidae o Hippopotamidae, haciendo referencia a que estos animales habrían compartido requerimientos ecológicos similares y que deberían hallarse asociados a ambientes relacionados con cuerpos de agua, tales como ríos o lagos.

La familia Toxodontidae incluye más de 40 géneros distribuidos en varias subfamilias (Paula Couto 1979, Frailey 1986, Mones 1986, McKenna y Bell 1997). En primera instancia, se establecieron tres subfamilias (Pascual y Borrello 1966): Nesodontinae, Toxodontinae y Haplodontheriinae; más tarde, Ciffelli (1993) y Bond et al. (1995) consideraron como válida la subfamilia Xotodontinae, fundada por Kraglievich (1934). Por su parte, Madden (1990, 1997) reconoció cinco subfamilias de Toxodontidae: Nesodontinae, como el grupo más basal, formado por Proadinotherium, Adinotherium y Nesodon; Xotodontinae, conformada por Xotodon, Hemixotodon, Nonotherium, Posnanskytherium e Hyperoxotodon; Haplodontheriinae, integrada por Trigodon, Stereotoxodon, Palyeidodon, Paratrigodon, Hoffstetterius y Ocnerotherium; Toxodontinae, con Toxodon, Alitoxodon y Pisanodon; y Dinotoxodontinae, incluyendo a Dinotoxodon, Plesiotoxodon, Gyrinodon y Pericotoxodon. La validez de esta última fue puesta en duda por Saint-Andre (1993).

Si bien las subfamilias mencionadas no se han recuperado como clados en análisis filogenéticos posteriores (Nasif et al. 2000, Billet 2011, Forasiepi et al. 2015, Bonnini et al. 2017), a continuación se resumen las principales características con que se definieron.

Las subfamilia Haplodontheriinae (Pascual y Borrello 1966) se basó principalmente en el material craneodentario del género Trigodon y más tarde se añadieron otros taxones (Madden 1990) de los que, actualmente, solo Paratrigodon y Hoffstetterius cuentan también con material craneano conocido. Esta subfamilia se caracterizó por: cráneo alto y triangular en vista dorsal, con nasales cortos; protuberancia en los frontales; foramen infraorbitario grande; región occipital del cráneo mucho más ancha que alta e inclinada hacia adelante; dientes 
hipsodontes a hipselodontes; incisivos superiores fuertemente arqueados, siendo frecuente la ausencia del I3; molares superiores con un surco posterior al profundo surco lingual; sínfisis mandibular amplia y larga (Patterson y Pascual 1968, Madden 1990). Los haplodonterinos nunca se han recuperado como un grupo monofilético en los análisis realizados hasta la fecha.

La subfamilia Xotodontinae (Kraglievich 1934, Madden 1990, Bond et al. 1995) sería uno de los grupos más fáciles de identificar dentro de los Toxodontidae tanto por la morfología dentaria como de la mandíbula. Entre los rasgos diagnósticos, Madden (1990) destacó: sínfisis mandibular con quilla; márgenes alveolar y ventral de la rama horizontal de la mandíbula divergentes; i1 e i2 procumbentes, triangulares y de crecimiento continuo; últimos premolares ovalados y sin pliegues linguales; molares superiores angostos, con un pliegue lingual simple y sin columna lingual en el protolofo. El único análisis filogenético que ha recuperado esta subfamilia como grupo monofilético es el de Madden (1990).

La subfamilia Dinotoxodontinae se definió por las siguientes sinapomorfías (Madden 1997): rama horizontal de la mandíbula con una sínfisis proyectada ventralmente; pliegue F2 (de acuerdo a Madden 1990 corresponde a un pliegue lingual posicionado en el centro del los molares superiores e inferiores) persistente en los molares superiores; contacto entre el metalofo y el protolofo; M3 alargado mesiodistalmente.

La subfamilia Toxodontinae, nombrada por Trouessart (1899; ver Pascual y Borrello 1966), se basó en el género pleistoceno Toxodon, conocido desde la primera mitad del siglo XIX. Posteriormente, se incluyeron formas del Mioceno y el Plioceno asignadas a los géneros Nesodonopsis, Palaeotoxodon, Alitoxodon y Pisanodon, algunas de las cuales se sinonimizaron después con taxones previos (ver Zetti 1972, Madden 1990, Nasif et al. 2000). La subfamilia Toxodontinae se distingue por la presencia de diastema en la dentición anterior, abertura nasal dirigida dorsalmente, nasales con terminación triangular y extendiéndose más allá del margen lateral de la abertura nasal; m1-m2 con dos pliegues linguales, P4 con un pliegue lingual y M1-M2 con un lóbulo medio (Madden 1990).

Otros géneros y especies incluidos en la familia Toxodontidae se encuentran detallados en el catálogo de Mones (1986). En muchos casos, los taxones se han definido a partir de dientes aislados o material muy fragmentario, tal como señalaron Nasif et al. (2000), por ejemplo, para varias especies de Brasil definidas por Paula Couto (1944, 1982), por lo que sus afinidades no están bien establecidas. La Tabla III. 1 detalla la lista de géneros catalogados por Mones (1986) con el agregado de los taxones descriptos por Paula Couto (1982) y Madden (1997), excluyendo los de Santa Cruz, cuya sinonimia fue establecida por otros autores y se considera válida en esta tesis (III. 3.). 
La subfamilia Nesodontinae, en la que se agrupan los taxones objeto de estudio, fue establecida en primer lugar como familia Nesodontidae por Murray (1866), perteneciente al suborden Toxodontia y solo definida para el género Nesodon. Por su parte, Ameghino (1889) creó los nombres de nivel familia Atryptheridae y Protoxodontidae, para los géneros Atryptherium y Protoxodon, respectivamente. Sin embargo, años más tarde, el propio autor (Ameghino 1891a, 1894a) aceptó la sinonimia de estos taxones con el género Nesodon propuesta por Lydekker (1893), por lo que los nombres de familia pasaron a ser sinónimos de lo que actualmente se conoce como Nesodontinae. Ameghino (1889), dentro de Protoxontidae, había reunido a los siguientes géneros: Protoxodon, Adinotherium, Acrotherium, Phobereotherium, Adelphotherium, Gronotherium, Rhadinotherium y Colpodon. A su vez, Zittel (1893) agrupó en Nesodontidae a: Nesodon, Acrotherium, Adinotherium, Gronotherium?, Phobereotherium?, Nanodus?, Notohippus?, Rhadinotherium, Palaeolithops y Stenostephanos?.

Como aclaró Mones (1993), Murray (1866) es el autor original del taxón supragenérico y Simpson (1945) es quien modificó el rango de familia a subfamilia; por lo tanto, la forma correcta de citar la autoría de este taxón es Nesodontinae (Murray 1866) Simpson 1945. Los trabajos de Madden $(1990$, 1997) reconocieron tres géneros de Nesodontinae, Proadinotherium, Adinotherium y Nesodon, aunque en los análisis filogenéticos subsiguientes (Nasif et al. 2000, Forasiepi et al. 2015, Bonini et al. 2017), Proadinotherium aparece como un taxón basal al resto de los Toxodontidae y no formando un clado con los dos toxodóntidos santacrucenses, que es el concepto seguido en esta tesis.

En el análisis filogenético presentado por Nasif et al. (2000), no se recuperó ninguna de estas subfamilias como grupos monofiléticos, razón por la cual los autores plantearon una nueva clasificación para la familia Toxodontidae, con solo dos subfamilias: Nesodontinae, grupo basal que incluía a los taxones Adinotherium y Nesodon, y Toxodontinae que reunía al resto de los toxodóntidos más derivados. Proadinotherium quedaba como una forma basal sin rango subfamiliar, pendiente de estar mejor caracterizado y poder confirmar su pertenencia a Nesodontinae. 
Hernández Del Pino, S.

\begin{tabular}{|c|c|c|c|c|c|}
\hline Género & Especie tipo & Autor del género y año & $\begin{array}{c}\text { Autor de la especie y } \\
\text { año } \\
\end{array}$ & Subfamilia (según Madden 1990) & $\begin{array}{c}\text { Último registro del } \\
\text { género }\end{array}$ \\
\hline Abothrodon & Abothordon pricei & Paula Couto 1944 & Paula Couto 1944 & Haplodontheriinae & Plioceno \\
\hline Adinotherium & Adinotherium magister & Ameghino $1887 \mathrm{a}$ & Ameghino $1887 \mathrm{a}$ & Nesodontinae & Mioceno inferior \\
\hline Alitoxodon & Alitoxodon vetustus & Rovereto 1914 & Rovereto 1914 & Toxodontinae & Plioceno \\
\hline Andinotoxodon* & Andinotoxodon bolivariensis* & Madden 1990 & Madden 1990 & Toxodontinae & Mioceno superior \\
\hline Calchaquitherium & Calchaquitherium mixtum & Nasif et al. 2000 & Nasif et al. 2000 & Toxodontinae & Mioceno superior \\
\hline Ceratoxodon & $\begin{array}{c}\text { Ceratoxodon corniculatus } \\
\text { Chapalmalodon }\end{array}$ & Ameghino 1907 & Ameghino 1907 & Toxodontinae & Plioceno \\
\hline Chapalmalodon & chapalmalensis & Mercerat 1917 & $\begin{array}{c}\text { Mercerat } 1917 \\
\text { Orbigny y Laurillard }\end{array}$ & Toxodontinae & Plioceno \\
\hline Dinotoxodon & Dinotoxodon paranensis & Mercerat $1895 \mathrm{a}$ & 1837 & Dinotoxodontinae & Plioceno \\
\hline Eutomodus & Eutomodus elautus & Ameghino 1889 & Ameghino 1886 & Toxodontinae & Plioceno \\
\hline Gallardodon & Gallardodon inexcusus & Marelli 1953 & Marelli 1953 & $?$ & $?$ \\
\hline Gyrinodon & Gyrinodon quassus & Hopwood 1928 & Hopwood 1928 & Dinotoxodontinae & Plioceno \\
\hline Haplodontotherium & Haplodontotherium wildei & $\begin{array}{c}\text { Ameghino } 1885 \\
\text { Cabrera y Kraglievich }\end{array}$ & $\begin{array}{c}\text { Ameghino } 1885 \\
\text { Cabrera y Kraglievich }\end{array}$ & Haplodontheriinae & Mioceno \\
\hline Hemixotodon & Hemixotodon chasicoensis & 1931 & 1931 & Xotodontinae & Mioceno \\
\hline Hermoseodon & Hermoseodon excavatus & Mercerat 1917 & (Rovereto 1914) & Toxodontinae & Plioceno \\
\hline Hoffstetterius & Hoffstetterius imperator & Saint-Andre 1993 & Saint-Andre 1993 & Haplodontheriinae? & Mioceno superior \\
\hline Hyperoxotodon & Hyperoxotodon speciosus & Mercerat $1895 \mathrm{a}$ & (Ameghino 1887a) & Xotodontinae & Mioceno \\
\hline Hypotoxodon & Hypotoxodon primigenius & Kraglievich 1928 & (Roth 1927) & Toxodontinae & Mioceno \\
\hline Mesenodon & & Paula Couto 1982 & & Toxodontinae & Plioceno \\
\hline Mesotoxodon & & Paula Couto 1982 & & Haplodontheriinae & Plioceno \\
\hline Minitoxodon & & Paula Couto 1982 & & Toxodontinae & Mioceno \\
\hline Mixotoxodon & Mixotoxodon larensis & Frank 1957 & Frank 1957 & Haplodontheriinae & Cuaternario \\
\hline Nannodus & Nannodus eucaenus & Ameghino 1891c & Ameghino 1891c & $?$ & Mioceno \\
\hline Neoadinotherium & Neoadinotherium triangulatum & Bordas 1941 & Bordas 1941 & $?$ & Mioceno \\
\hline Neotoxodon & & Paula Couto 1982 & & Toxodontinae & Plioceno \\
\hline Neotrigodon & Neotrigodon utoquineae & Spillmann 1949 & Spillmann 1949 & Haplodontheriinae & Plioceno \\
\hline Nesodon & Nesodon imbricatus & Owen 1847 & Owen 1847 & Nesodontinae & Plioceno? \\
\hline
\end{tabular}




\begin{tabular}{|c|c|c|c|c|c|}
\hline Nesodonopsis & Nesodonopsis burckardti & Roth 1898 & Roth 1898 & Toxodontinae & Mioceno \\
\hline Nonotherium & Nonotherium hennigi & Castellanos 1942 & Castellanos 1942 & Xotodontinae & Cuaternario \\
\hline Ocnerotherium & Ocnerotherium intermedium & Pascual 1954 & Pascual 1945 & Haplodontheriinae & Mioceno \\
\hline Pachynodon & Pachynodon validus & Burmeister 1891 & Burmeister 1891 & Haplodontheriinae & Cuaternario? \\
\hline Palyeidodon & Palyeidodon obtusum & $\begin{array}{c}\text { Roth } 1899 \\
\text { Cabrera y Kraglievich }\end{array}$ & $\begin{array}{c}\text { Roth } 1899 \\
\text { Cabrera y Kraglievich }\end{array}$ & ? & Mioceno \\
\hline Paratrigodon & Paratrigodon euguii & 1931 & 1931 & Haplodontheriinae & Mioceno \\
\hline Pericotoxodon & Pericotoxodon platignathus & $\begin{array}{c}\text { Madden } 1997 \\
\text { Zetti en Bondesio et al. }\end{array}$ & $\begin{array}{c}\text { Madden } 1997 \\
\text { Cabrera y Kraglievich }\end{array}$ & Dinotoxodontinae & Mioceno \\
\hline Plesiotoxodon & $\begin{array}{l}\text { Plesiotoxodon tapalquensis } \\
\text { Posnanskytherium }\end{array}$ & Roth 1901 & Roth 1901 & Dinotoxodontinae & Cuaternario \\
\hline Posnanskytherium & & Liendo Lazarte 1943 & Liendo Lazarte 1943 & Xotodontinae & Plioceno \\
\hline Proadinotherium & leptognathum & Ameghino 1894c & Ameghino 1894c & ? & Mioceno inferior \\
\hline Prototrigodon & Prototrigodon rothi & Kraglievich 1930 & Kraglievich 1930 & Haplodontheriinae & Mioceno \\
\hline Pseudotoxodon & Pseudotoxodon formosus & Moreno 1889 & Moreno 1889 & ? & Plioceno \\
\hline Stenosthephanus & Stenosthephanus plicidens & Ameghino 1885 & Ameghino 1886 & Toxodontinae & Mioceno \\
\hline Stereotoxodon & Stereotoxodon tehuelche & Ameghino 1904 & Ameghino 1904 & Toxodontinae & Mioceno \\
\hline Toxodon & Toxodon platensis & Owen 1837 & Owen 1837 & Toxodontinae & Cuaternario \\
\hline Toxodontherium & Toxodontherium compressum & Ameghino 1883 & Ameghino 1883 & Haplodontheriinae & Mioceno \\
\hline Trigodon & Trigodon gaudryi & Ameghino 1882 & Ameghino 1882 & Haplodontheriinae & Pleistoceno \\
\hline Trigodonops & Trigonodops lopesi & Kraglievich 1930 & (Roxo 1921) & Haplodontheriinae & Plioceno? \\
\hline Xotodon & Xotodon foricurvatus & Ameghino 1887b & (Ameghino 1885) & Xotodontinae & Plioceno \\
\hline
\end{tabular}

Tabla III. 1: Listado de los géneros que se incluyen en la familia Toxodontidae basado en el trabajo de Mones (1986) e incluyendo los nuevos taxones descriptos por Paula Couto (1982) y Madden (1990, 1997). *Taxones cuya descripción no se encuentra publicada y por tanto no consituyen nombres válidos. 


\section{2. Toxodóntidos santacrucenses}

A continuación, se comentan brevemente los nombres atribuidos a los taxones de Nesodontinae de la Formación Santa Cruz, incluyendo: autoría del nombre, caracterización y materiales a partir de los cuales se estableció el nombre, y algunos comentarios sobre ellos presentes en las revisiones taxonómicas posteriores. La primera especie que sigue a la breve referencia sobre cada género corresponde a la especie tipo, con la combinación original propuesta por el autor, sin tomar en cuenta las sinonimias posteriores. El resto de las especies de cada género se presentan a continuación, siguiendo un orden alfabético.

En el caso de las abreviaturas correspondientes a los géneros, se siguen utilizando aquellas que ya han sido mencionadas en el texto (i.e. A. para Adinotherium, N. para Nesodon y $P$. para Proadinotherium) para mantener la coherencia, mientras que en el caso de aquellos nombres genéricos que presentan la misma inicial se abrevian añadiendo la segunda letra del nombre (e.g. Ac. para Acrotherium, Ad. para Adelphotherium, Ne. para Nesotherium).

\section{2.1. Acrotherium AMEGHINO 1887a}

Ameghino (1887a, p: 17) caracterizó este género a través de la especie tipo por ser similar a Protoxodon, pero diferente de este por la presencia de un quinto premolar. Mercerat (1891) mantuvo la caracterización genérica propuesta por Ameghino con la formula dentaria I 3/3 C 1/? P 5/? M $3 / 3$ y definio nuevas especies para el género. Mas tarde, Ameghino (1894a) señaló que Acrotherium tenía el cráneo más alargado que Nesodon, el estrechamiento de la región palatina a nivel de los primeros premolares y los nasales convexos en su porción posterior.

La presencia de un quinto premolar definitivo en la dentición, correspondería a una característica muy basal en el contexto de los placentarios (ver O’Leary et al. 2013); sin embargo, esta condición no ha sido constatada en ninguno de los ejemplares a disposición y ni en los asignados originalmente a este género por Ameghino y Mercerat. Es importante destacar que de todos los especímenes asignados a Acrotherium que fueron consultados en esta tesis, el MLP 12-4 es el único que presenta la dentición superior completa, y esta corresponde a la formula dentaria típica de Adinotherium y Nesodon (I 3/3 C 1/1 P 4/4 M $3 / 3)$. 
Para Acrotherium se describieron ocho especies (Ameghino 1887a, Mercerat 1891), que fueron sinonimizadas en años posteriores (Ameghino 1894a, 1902, Lydekker 1893, Scott 1912) con especies de los géneros Nesodon y Adinotherium.

\section{- Acrotherium rusticum AMEGHINO 1887a}

La definición de Ameghino (1887a, p: 17) de Acrotherium rusticum se basó unicamente en la presencia de cinco premolares en los que el autor destacó la presencia de una cresta perpendicular anterolabial. En 1904, Ameghino consideró que la especie correspondía al género Adinotherium, proponiendo la combinación Adinotherium rusticum, pero Scott (1912) la consideró después sinónima de Nesodon imbricatus sin dar mayores precisiones.

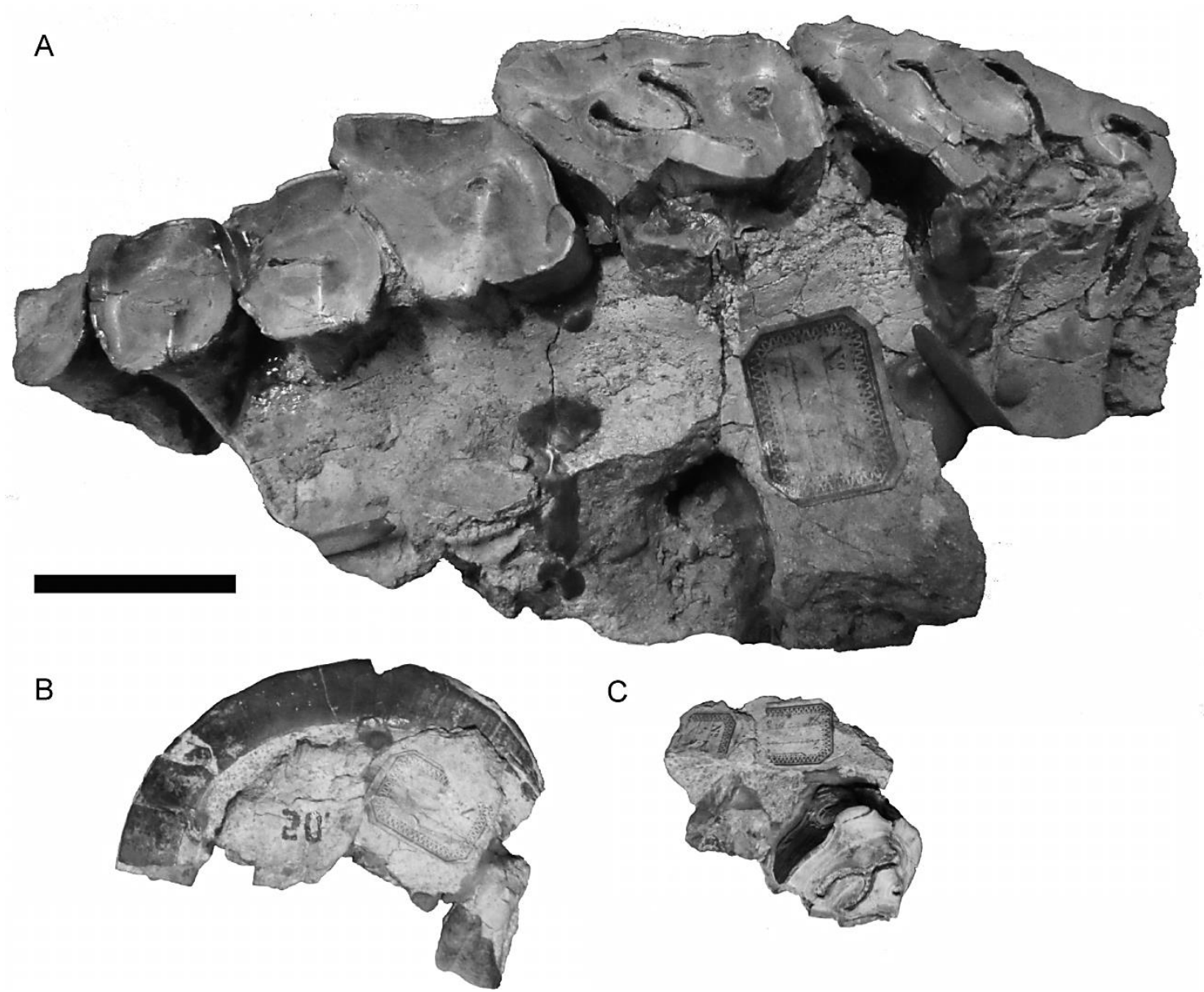

Fig. III. 1: Fragmento de maxilar izquierdo con P2-M3, MLP 12-42 (A), fragmento de premaxilar con I2 y P2 izquierdos (reflejada), MLP 12-50 (B), y fragmento de maxilar con P4, MLP 12-925 (C) utilizados por Ameghino (1887a) para definir Acrotherium rusticum. Escala $5 \mathrm{~cm}$.

Los ejemplares revisados asignados a Acrotherium rusticum son MLP 12-42 (fragmento de maxilar con la serie P2-M3, Fig. III. 1A), MLP 12-50 (fragmento de premaxilar y maxilar 
con I2 y P2, Fig. III. 1B) y MLP 12-925 (fragmento de maxilar con un P4, Fig. III. 1C). En ninguno de los ejemplares a disposición se pudo constatar la presencia del quinto premolar ni tampoco se encontró un premolar cuya morfología sea peculiar y diferente de los restantes ejemplares de Nesodontinae. En cuanto a la caracteristica de una "cresta anterolabial en los premolares superiores", es un rasgo común a todos los Nesodontinae y la morfología y el desarrollo de la misma en los ejemplares de Ac. rusticum no presenta diferencias significativas con los ejemplares aquí atribuidos a Nesodon y Adinotherium.

Ninguno de los ejemplares consultados presenta diferencias con los atribuidos a $N$. imbricatus; en el caso del MLP 12-42, los premolares y el primer molar están muy desgastados (con el valle central prácticamente obliterado), pero no se alejan de la morfología dentaria de especimenes de N. imbricatus con el mismo grado de desgaste. Por ello, se considera válida la sinonimia realizada por Scott.

\section{- Acrotherium australe MERCERAT 1891}

Especie establecida por Mercerat (1891, p: 391-392) a partir de un M2 izquierdo, de talla algo más pequeña que $A c$. rusticum y caracterizado por una depresión labial del diente menos desarrollada que en Ac. patagonicum (ver abajo), pero con un surco longitudinal bien marcado, y el borde distolabial del diente formando una arista más desarrollada.

El material tipo de esta especie, que debería encontrarse en la colección del MLP, no se pudo localizar y, por lo tanto, no se puede constatar adecuadamente la validez de este taxón. Dadas las características proporcionadas por Mercerat (1891), considero válida la sinonimia propuesta por Ameghino (1894a) y Scott (1912) con Nesodon imbricatus, ya que la talla entra dentro del espectro observado para $N$. imbricatus y las diferencias señaladas respecto a $A c$. patagonicum pueden explicarse por el diferente estadio ontogenético del holotipo de esta especie (MLP 12-4), que sin dudas corresponde a un estadio subadulto de N. imbricatus.

\section{-Acrotherium intermedium MERCERAT 1891}

Mercerat (1891, p: 392) describió la especie a partir de dos M2 colectados en las costas del río Santa Cruz, en los que destacó las dimensiones intermedias entre Acrotherium australe y Ac. patagonicum (ver Acrotherium patagonicum), que la depresión labial del diente era menos pronunciada que en $A$. australe, intermedia entre esta última especie y Ac. rusticum, y que el borde distolabial del molar forma una arista más desarrollada que en Ac. patagonicum, pero menos que en Ac. australe. 
En este caso, tampoco se localizó el material tipo de Acrotherium intermedium en la colección del Museo de La Plata y en la bibliografía consultada no existe referencia alguna a ese material o alguna caracterización adicional a la proporcionada por Mercerat. No se puede tomar una decisión definitiva sobre la validez de este nombre, sin embargo, dado que el autor lo describió como una forma intermedia entre dos taxones reconocidos como sinónimos de Nesodon imbricatus, posiblemente se trate de otro sinónimo más de ese taxón.

\section{—Acrotherium karaikense AMEGHINO 1891b}

De acuerdo a la descripción de Ameghino (1891b, p: 131-132), esta especie habría alcanzado un tamaño algo mayor que el de Adinotherium splendidum y se caracterizaba por los siguientes rasgos: los dos primeros incisivos superiores solapados, el I2 algo más grande que el I1 y un tercer incisivo muy pequeño, separado por un pequeño diastema del I2; el canino superior de tamaño similar al último incisivo y también separado de éste por un diastema; el P1 no sería homólogo al del resto de los ungulados conocidos, consistente en una pieza elíptica y cilíndrica, algo más pequeña que el canino, separada de éste por un diastema y seguido por la serie P2-M3 que aumenta progresivamente de tamaño, al igual que en el resto de los nesodontinos (con los cuales Ameghino destacó su gran parecido). Además, Ameghino mencionó que los incisivos inferiores se disponen como los elementos homólogos del resto de los nesodontinos.

Lydekker (1893) fue el primero en considerar a Acrotherium karaikense como sinónimo de Nesodon imbricatus, ya que, a excepción de la presencia de un pequeño premolar suplementario, la morfología del cráneo concordaba perfectamente con la de los ejemplares asignados a la especie tipo de Nesodon. Ameghino (1904), en cambio, consideró que la especie correspondía a Adinotherium, proponiendo la combinación Adinotherium karaikense, mantenida después por Scott (1912).

El material utilizado por Ameghino para fundar Ac. karaikense (MACN A 947) no se pudo localizar. En el trabajo de Vizcaíno et al. (2017, App.1, p: 71) que reproduce el álbum fotográfico realizado por Scott durante sus consultas a las colecciones argentinas, hay dos fotografías etiquetadas como material tipo de Ac. karaikense; una corresponde a un cráneo $\left(\mathrm{n}^{\circ}\right.$ 461) y la otra a un fragmento de mandibula con parte de la sínfisis ( $\mathrm{n}^{\circ} 410$ ), ambos de ejemplares adultos. El cráneo fue fotografiado en vista laterodorsal y por lo que es imposible constatar la presencia del premolar característico descripto. Al no haber revisado directamente un cráneo de $A c$. karaikense, no ha sido posible comprobar la presencia de la base de un cuerno comentada por Scott (1912, p: 233), pero en la fotografía se nota una leve depresión 
justo por detrás de la sutura naso-frontal (rasgo presente en otros ejemplares de Adinotherium ovinum, e.g. MLP 12-1).

La revisión del ejemplar MACN A 5366, el único disponible asignado a este taxón, y lo que se puede observar en las fotografías comentadas permiten constatar que estos ejemplares superan ligeramente el tamaño medio esperable de la mandíbula y el cráneo de Adinotherium ovinum $(250 \mathrm{~mm})$, pero no difieren significativamente de los ejemplares de gran tamaño aquí reconocidos como tal (e.g. MACN A 5346, MLP 12-1, FMNH 13108), que alcanzan 265 mm y $280 \mathrm{~mm}$. Por lo antes dicho, se considera Ac. karaikense como un taxón sinónimo de $A$. ovinum, y no de Nesodon imbricatus.

\section{-Acrotherium mutabile MERCERAT 1891}

Mercerat (1891, p: 393-394) fundó esta especie a partir de dos fragmentos de maxilar del mismo individuo, con las series P1-M3 (MLP 12-55), y otros dos fragmentos maxilares derechos, uno con M2-M3 (MLP sin localizar) y otro con la serie P4-M2 (MLP 12-71). Todos proceden de las costas del río Santa Cruz y el autor no especificó el material tipo, por lo que constituyen sintipos. Mercerat caracterizó Ac. mutabile por su talla menor que Adinotherium magister, un borde distolabial más conspicuo y formando una arista en el "P5", un surco más angosto y profundo que separa esa arista de la columna del diente, y la arista menos conspicua en el borde proximolabial del M2.

Ameghino (1894a) propuso la sinonimia de Acrotherium mutabile con Adinotherium magister, el cual, a su vez, fue sinonimizado (con reservas) años más tarde por Scott (1912) con Adinotherium ovinum.

Tras analizar el material a disposición, MLP 12-55 (Fig. III. 2A) y MLP 12-71 (Fig. III. 2B), se ve que en el primero las series dentarias izquierda (M1-M3) y derecha (P3-M1) no coinciden, aunque no puedo precisar si pertenecen o no al mismo individuo; la porción preservada de la serie dental izquierda sugiere que se trata de un ejemplar subadulto, dado que el valle central en forma de "Y" no se ha cerrado lingualmente ni se ha formado la foseta posterior a él, que en los adultos se ubica en el margen posterolingual de los molares. En el caso del MLP 12-71, se constata la presencia de un premolar deciduo roto (posiblemente un dP4) lo que indica que se trata de un ejemplar juvenil, aunque al no contar con ejemplares con la serie dentaria completa, tampoco se ha podido comprobar la presencia del quinto premolar mencionado por Ameghino. Dadas las caracteristicas del material a disposición y las revisiones realizadas por Ameghino y Scott, se acepta la sinonimia propuesta por este último autor con A. ovinum. 
A

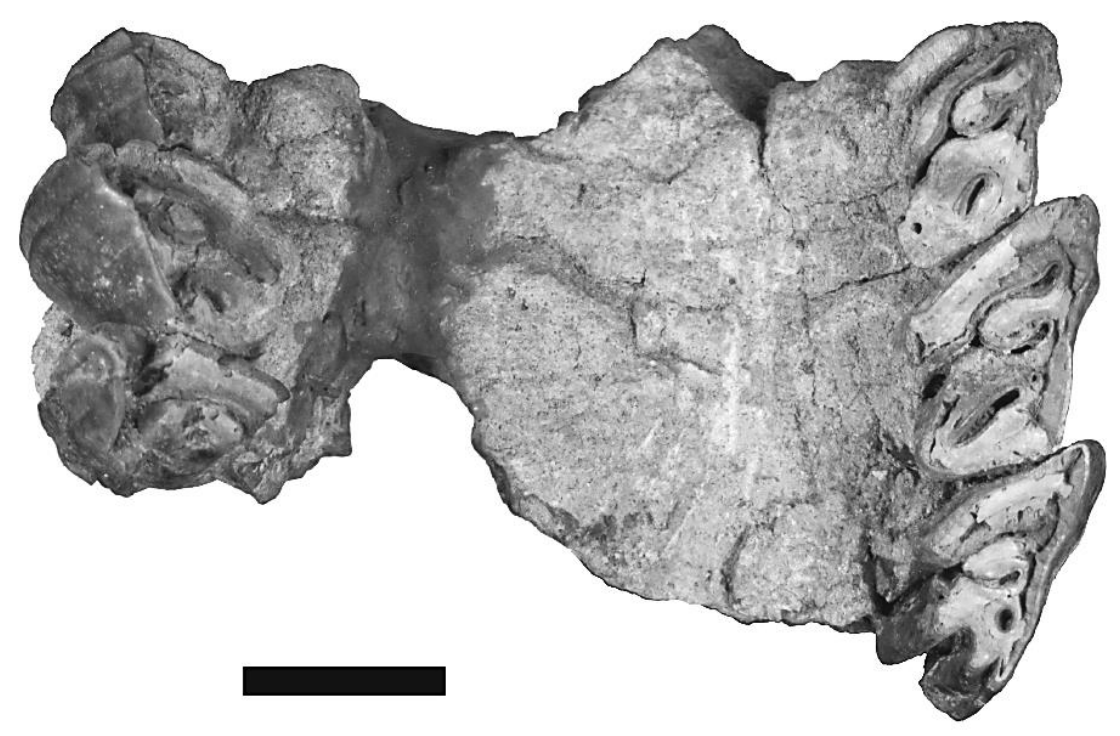

Fig. III. 2: Fragmentos de paladar MLP 12-55 (A) y MLP 12-71 (B) utilizados por Mercerat

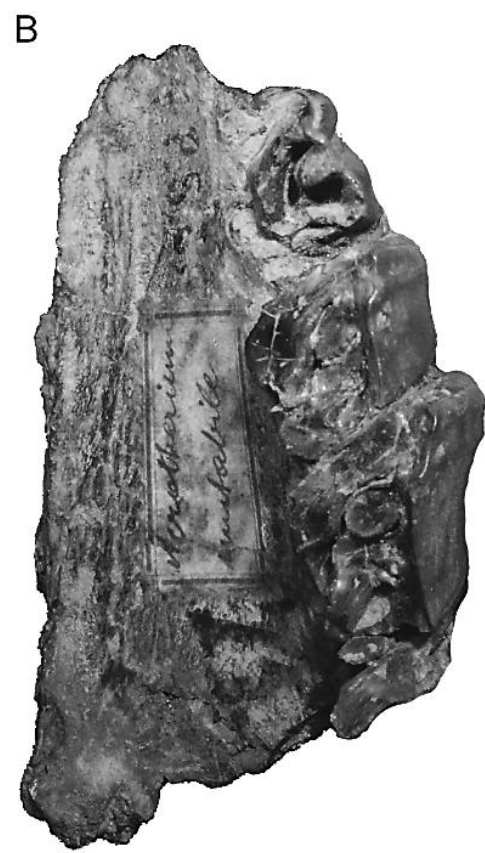
(1891) para definir Acrotherium mutabile. Escala $2 \mathrm{~cm}$.

(1891) para definir Acrotherium mutabile. Escala $2 \mathrm{~cm}$.

\section{-Acrotherium patagonicum MERCERAT 1891}

Esta especie fue establecida por Mercerat (1891, p: 389-391 y 443) a partir de un cráneo en muy buen estado de preservación y un fragmento de mandíbula algo deteriorado correspondiente al mismo individuo (MLP 12-4). De acuerdo al autor, difiere de Acrotherium rusticum por su menor talla, aunque duplica la talla de Adinotherium magister; además, posee una columna proximal más angosta y menos conspicua en el borde labial de los premolares. El autor reconoció que los incisivos, tanto inferiores como superiores, se asemejan en su morfología y disposición a los del género Adinotherium, aunque los distingue por la presencia, en Ac. patagonicum, de una depresión más acentuada en el I1 y el tamaño relativamente menor del I2. Respecto a la serie yugal inferior, Mercerat señaló que representa una forma intermedia entre Adinotherium y Nesodon, sin dar mayores precisiones sobre la morfología. Asimismo, destacó que la sínfisis mandibular se encuentra algo más retraída que en Adinotherium.

Lydekker (1893) consideró esta especie dentro del género Nesodon y propuso la combinación Nesodon patagonicum. Ameghino (1894b) corrigió la grafía original del epíteto específico, Nesodon patagonicus, sin precisar la razón, pero remarcó que este nombre no podría mantenerse, ya que se encontraba ocupado por la derivación del nombre Toxodon patagonense fundado por Moreno (1882, p: 117). Ameghino (1894a) estableció la sinonimia 
de este taxón con Nesodon imbricatus y Scott (1912) propuso la sinonimia con $N$. conspurcatus.
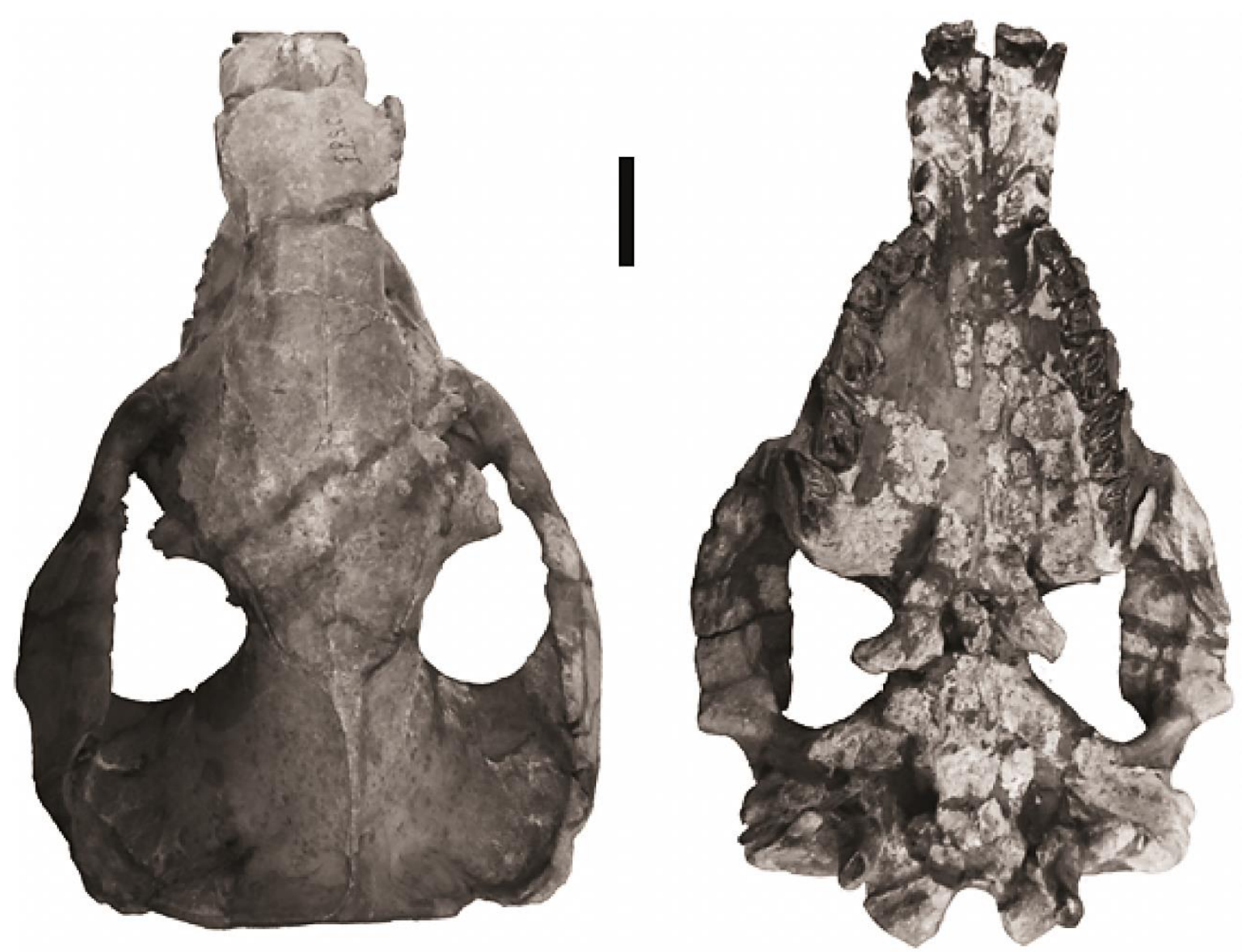

Fig. III. 3: Cráneo (MLP 12-4) utilizado por Mercerat (1891) para definir Acrotherium patagonicum. Vistas dorsal y ventral. Escala $5 \mathrm{~cm}$

Fue posible acceder a los dos ejemplares del MLP que figuran como material tipo de $A c$. patagonicum. Uno de ellos (MLP 12-4, Fig. III. 3) corresponde al cráneo descripto por Mercerat (1891) y el otro (MLP 12-44) es un fragmento de paladar de otro individuo. No se encontró la mandíbula descripta originalmente junto al cráneo. La revisión del cráneo y el maxilar permite comprobar que no existen diferencias significativas ni craneanas ni dentarias con Nesodon imbricatus y que estos ejemplares corresponden a individuos subadultos de dicha especie (en ambos ejemplares el M3 aun no ha erupcionado completamente y en el caso del MLP 12-4 el P4 practicamente no presenta desgaste), cuya morfología no difiere de otros especímenes del mismo estadio ontogenético en $N$. imbricatus (e.g. MPM-PV 3669). Las diferencias observadas por Mercerat en los incisivos se deben al poco desgaste sufrido por 
esas piezas, donde el I1 aún conserva remanentes de una foseta que se oblitera rápidamente en los adultos y el I2 presenta un menor tamaño y una sección mas cónica (Ver Capítulo IV). Por ello, se mantiene la sinonimia propuesta por Ameghino (1894a) para Ac. patagonicum con $N$. imbricatus.

\section{—Acrotherium stygium AMEGHINO 1891b}

Esta especie fue nombrada por Ameghino (1887a) y mencionada años más tarde en la obra de Trouessart (1890, p: 507); sin embargo, dicho nombre no adquirió disponibilidad hasta el año siguiente, cuando se definió y describió el material tipo de la especie (Ameghino 1891, p: 133). Dicho material (MACN A 5358) corresponde a un fragmento anterior de paladar sin dientes y un incisivo suelto, cuyo tamaño Ameghino consideró como intermedio entre Acrotherium rusticum y Ac. karaikense.

Este es el único taxón dentro del género Acrotherium para el que no se han propuesto sinonimias hasta la fecha, aunque ha permanecido completamente ausente de la literatura desde el trabajo de Scott (1912), quien mantuvo la asignación original de Ameghino.
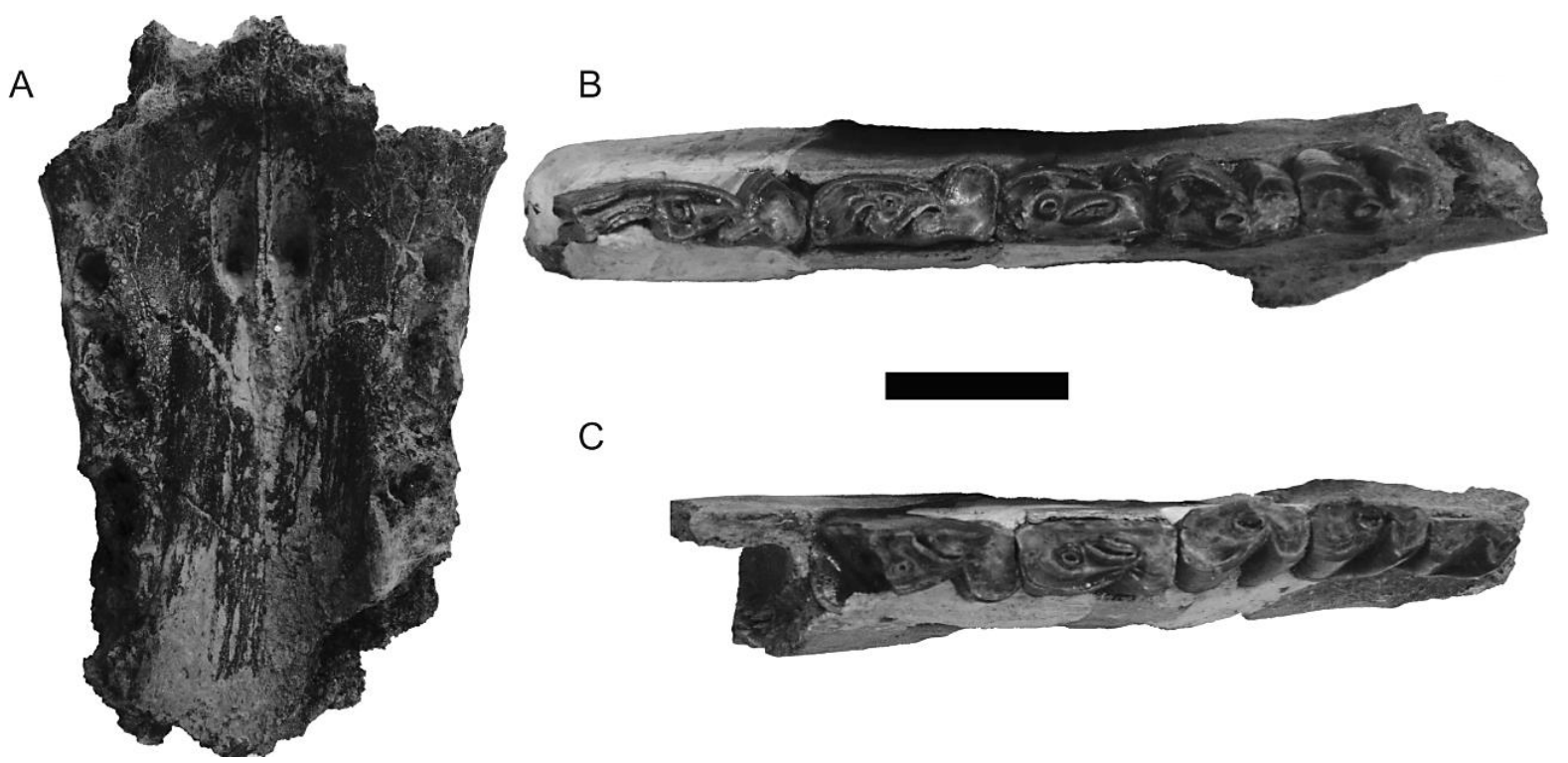

C

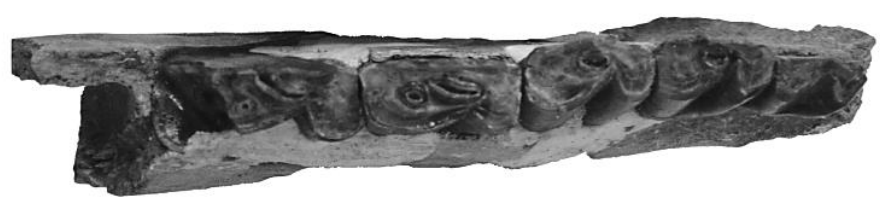

Fig. III. 4: Fragmento de premaxilar MACN A 5358 (A) utilizado por Ameghino (1891) para definir Acrotherium stygium, y fragmentos de mandíbula izquierda (con la serie p3-m3), MACN A 1692 (B), y derecha (con p2-m2), MACN A 1693 (C), atribuidos a esta especie. Escala $2 \mathrm{~cm}$.

Tuve la oportunidad de revisar el material tipo (MACN A 5358 Fig. III. 4A) y dos materiales más asignados a este taxón (MACN A 1692 y MACN A 1693, fragmentos de mandíbula del mismo individuo, Fig. III. 4B y C) y no encuentro diferencias morfológicas ni 
de talla $(M Z W=46,60 \mathrm{~mm}$; $\mathrm{LMRL}=65,24 \mathrm{~mm})$ con otros ejemplares pertenecientes a Adinotherium ovinum (Ver Tablas V.8 y V. 10 en el Capitulo V); por esta razón, establezco la sinonimia de Acrotherium stygium con Adinotherium ovinum.

\section{-Acrotherium variegatum MERCERAT 1891}

Especie fundada por Mercerat (1891, p: 392-393) a partir de un fragmento de maxilar izquierdo con la serie P4-M1 y M2 y M3 sueltos (MLP 12-62). De acuerdo al autor, no alcanzaba el tamaño de Adinotherium splendidum y difería de Acrotherium patagonicum por poseer un surco más profundo y angosto, además de una columna proximal menos saliente, en el margen labial de P4, mientras que, en la serie molar, dicha columna era más pronunciada que en Ac. patagonicum y presentaba una depresión lateral menos desarrollada.

Ameghino (1894a) sinonimizó Acrotherium variegatum con Acrotherium stygium. Scott (1912), en cambio, estableció la sinonimia de Ac. variegatum con Nesodon imbricatus sin mayores precisiones.

La revisión de MLP 12-62 (único ejemplar asignado a $A$. variegatum) permitió comprobar que se trata de un ejemplar joven de Nesodon imbricatus.

\section{2.2. Adelphotherium AMEGHINO 1887a}

Al igual que Acrotherium, este género fue establecido por Ameghino (1887a, p: 16-17) sin proveer una descripción a nivel genérico, destacando su similitud con el género Protoxodon. La especie tipo es Adelphotherium ligatum. Posteriormente, Mercerat (1891) adicionó cinco especies más a este género y amplió la descripción del mismo, caracterizándolo por el mayor tamaño del I1 respecto al I2 comparado con Adinoterium, Nesodon y los restantes Nesodontinae definidos hasta 1890. Años más tarde, Ameghino (1894a) estableció que Adelphotherium era sinónimo de Nesodon, pasando a sinonimia la especie tipo Ad. ligatum con Nesodon imbricatus. Scott (1912) consideró todas las especies asignadas al género Adelphotherium como sinónimos de Nesodon imbricatus.

\section{-Adelphotherium ligatum AMEGHINO 1887a}

Adelpotherium ligatum es la especie tipo del género y de acuerdo al autor (Ameghino 1887a, p: 16-17) presentaba los tres incisivos superiores con base abierta, el I1 ancho y plano, el I2 más pequeño y de sección triangular, y el I3 aún más pequeño y plano; los incisivos 
inferiores con raíz cónica y subiguales; y los molares inferiores con base abierta. Mercerat (1891) estableció años más tarde que la apreciación respecto al crecimiento continuo de los I1 e I3 era errónea y que la única pieza con dicha particularidad en este taxón sería el I2, al igual que en el resto de los nesodontinos.

En las visitas realizadas a la colección del Museo de La Plata, no se pudo localizar el material tipo, razón por la cual no es posible constatar el estatus taxonómico de este taxón.

\section{-Adelphotherium lutarium MERCERAT 1891}

Establecida por Mercerat (1891, p: 438) a partir de cuatro cráneos incompletos, otros fragmentos craneanos y piezas dentarias sueltas, colectados en las barrancas del río Santa Cruz. El autor no precisó cuál era el material tipo y la designación genérica se realizó a partir del tamaño y las características de los molares. Asimismo, mencionó la similitud del I2 con el del género Protoxodon, aunque con un desarrollo menor, cuya altura no supera al I1.

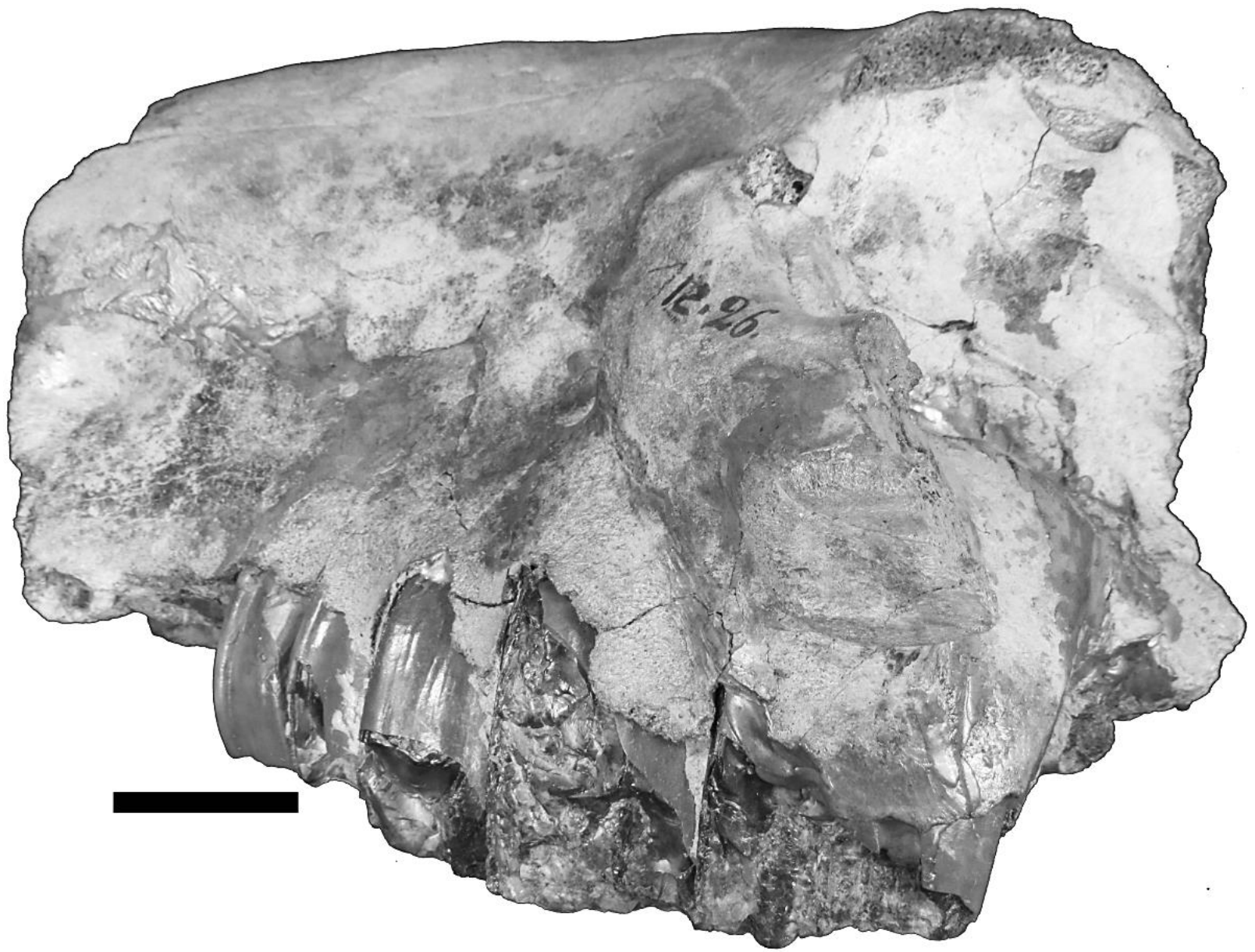

Fig. III. 5: Fragmento anterior de cráneo (MLP 12-26) utilizado por Mercerat (1891) para establecer Adelphotherium lutarium. Escala $5 \mathrm{~cm}$. 
Mones (1986) mencionó cuatro ejemplares tipo asignados a este taxón (MLP 12-20, MLP 12-24, MLP 12-26 y MLP 12-64), de los que solo se pudo localizar el MLP 12-26 (Fig. III. 5). Este ejemplar corresponde a la porción anterior de un cráneo de un individuo subadulto (el M3 tiene muy poco desgaste, aun conserva el valle central abierto lingualmente y no se ha formado la foseta posterior) y conserva parte de la dentición (P3-M3). Aun cuando no fue posible consultar material que contiene la dentición anterior, la similitud de la dentición yugal con Nesodon imbricatus permite validar la sinonimia propuesta por Scott (1912) con dicha especie.

\section{—Adelphotherium pumilum MERCERAT 1891}

Al igual que el caso de Ad. lutarium, esta especie fue definida por Mercerat (1891, p: 440-442) a partir de dos cráneos incompletos colectados en las barrancas del río Santa Cruz. El autor solo mencionó algunas características de los incisivos superiores, como el pequeño tamaño del segundo incisivo y su raíz cerrada.

En la colección del MLP, solo se localizó el ejemplar MLP 12-25 (porción anterior de un cráneo que conserva parte de la dentición molar y que corresponde a un ejemplar subadulto, cuyo M3 aun no ha erupcionado completamente). No he visto en este material ningún rasgo que permita diferenciarlo de otros ejemplares asignados a $N$. imbricatus.

Si bien Mercerat no indicó el número de inventario de los ejemplares utilizados, considero que el material localizado debe corresponder a uno de los asignados a este nombre, dado que ningún otro autor ha vuelto a utilizar el nombre Ad. lutarium en la literatura y el formato de etiquetado es el mismo que el de otros materiales tipo definidos por Mercerat. Al igual que en el caso anterior, a partir del material disponible (que no presenta la dentición anterior), puede constatarse la validez de la sinonimia con Nesodon imbricatus propuesta por Ameghino (1894a) y sostenida por Scott (1912).

\section{-Adelphotherium repandum MERCERAT 1891}

Mercerat (1891, p: 439) estableció esta especie a partir de un fragmento de cráneo colectado en las barrancas del río Santa Cruz. El autor no precisó demasiado sobre los rasgos distintivos del taxón, pero sí mencionó que el segundo incisivo sería similar al presente en el género Protoxodon, aunque menos desarrollado y sin superar la altura del I1. Pocos años después, Ameghino (1894a) sinonimizó Adelphotherium repandum con Nesodon imbricatus. 


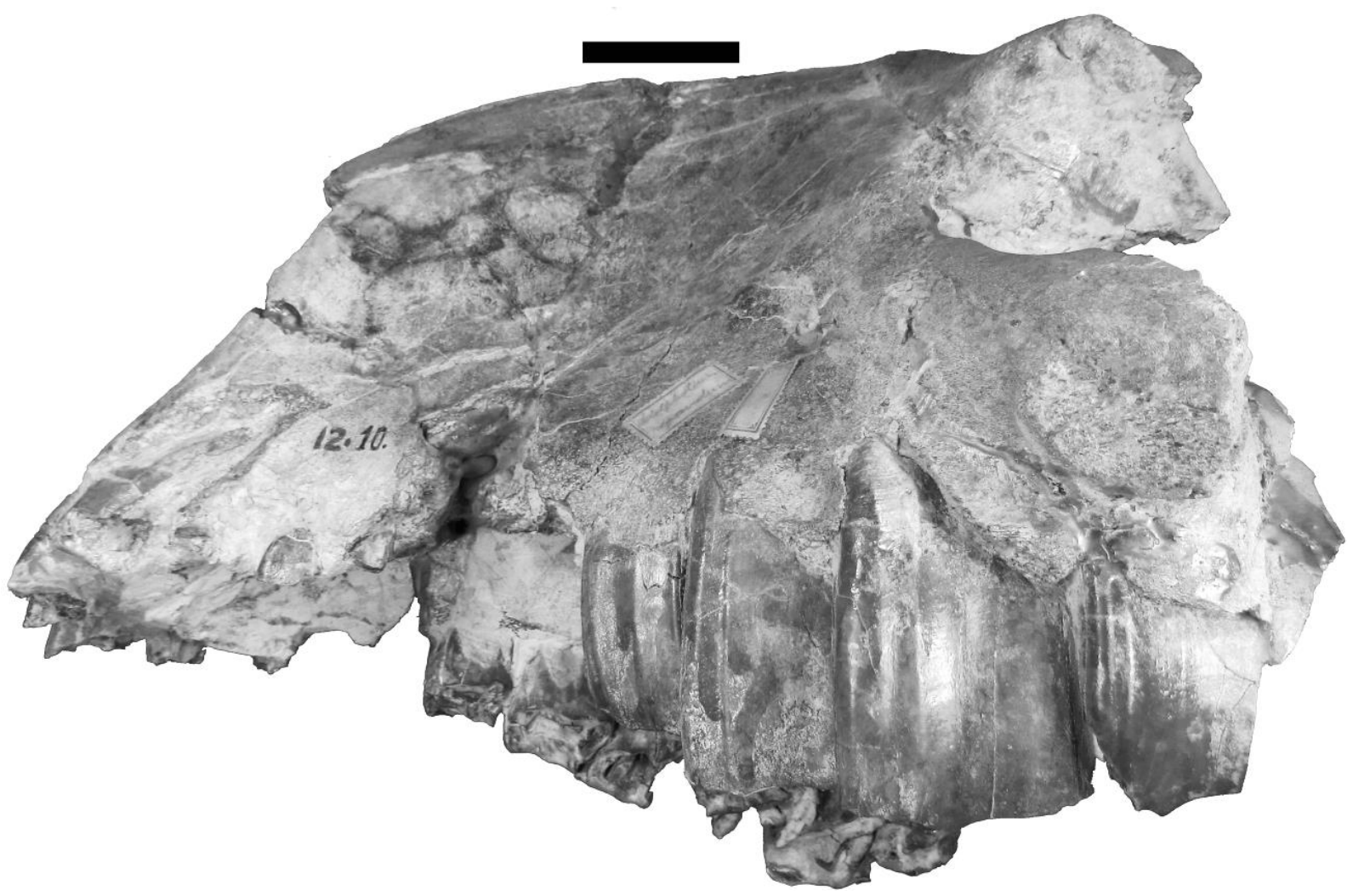

Fig. III. 6: Fragmento anterior de craneo (MLP 12-10) utilizado por Mercerat (1891) para definir Adelphotherium repandum. Escala $5 \mathrm{~cm}$.

Se ha podido revisar el holotipo (MLP 12-10, Fig. III. 6), un fragmento anterior de cráneo de un ejemplar subadulto con P4-M3 izquierdos y P2-M2 derechos, con muy poco o nada (en el caso del M3) de desgaste. A partir de ello, se confirma la sinonimia establecida por Ameghino para Ad. repandum con N. imbricatus.

\section{-Adelphotherium rothi MERCERAT 1891}

Otra especie fundada por Mercerat (1891, p: 440), a partir de un fragmento de maxilar izquierdo, con los últimos dos premolares deciduos y los dos primeros molares definitivos. El autor no dio mayores precisiones sobre el ejemplar. Al igual que en casos anteriores, tanto Ameghino (1894a) como Scott (1912) consideraron a esta especie como un sinónimo más de Nesodon imbricatus.

No se localizó el material tipo durante las visitas al Museo de La Plata y, dado que la descripción original no es diagnóstica, resulta imposible comprobar el estatus taxonómico de esta especie. 


\section{-Adelphotherium trivium MERCERAT 1891}

Esta especie se basó en un fragmento de cráneo y dos maxilares pertenecientes a otro individuo colectados en las barrancas del río Santa Cruz (Mercerat 1891, p: 438-439). El autor mencionó que el I1 es mas bajo que el I2 y que este último presenta una forma similar a la observada en Protoxodon; sin embargo, justifica su asignación a un género diferente por el tamaño de los ejemplares y las características particulares de sus molares. De nuevo, Ameghino (1894a) y Scott (1912) consideraron este nombre como sinónimo de Nesodon imbricatus.

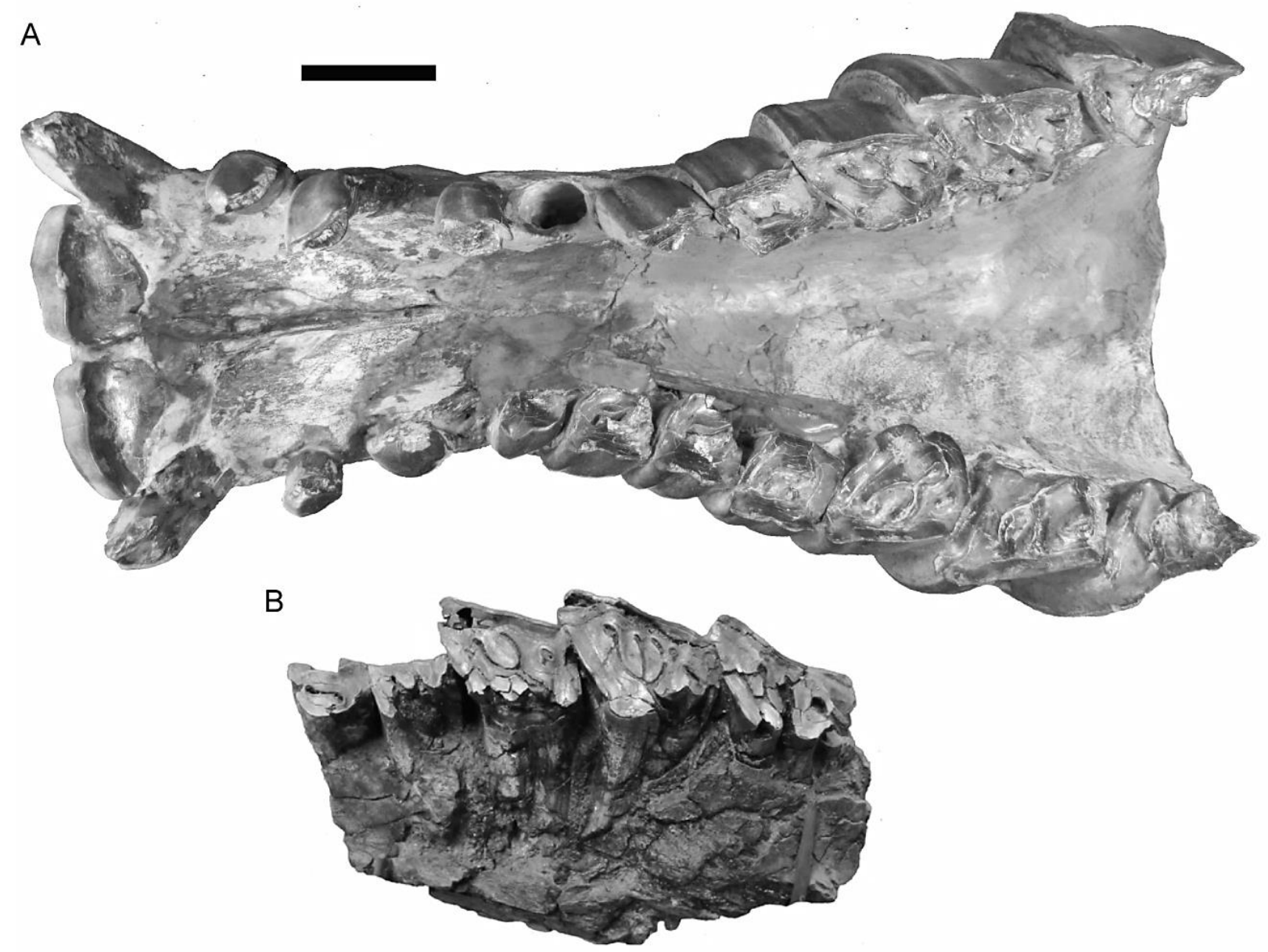

Fig. III. 7: Paladar completo MLP 12-8 (A) y fragmento de paladar MLP 12-40 (B) utilizados por Mercerat (1891) para fundar el nombre Adelphotherium trivium. Escala $5 \mathrm{~cm}$.

El fragmento de cráneo (MLP 12-8, Fig. III. 7A) y los dos maxilares (MLP 12-40-Fig. III. 7B- y MLP 12-41) mencionados presentan las características típicas de la dentición de N. imbricatus. MLP 12-8 corresponde a un adulto joven que conserva toda su dentición a excepción del P2 derecho y el M3 apenas ha comenzando a gastarse. MLP 12-40 presenta el M2 con una tercera rama en la foseta en "Y". Las características mencionadas no justifican la 
creación de otro taxón y por ello se mantiene la sinonimia propuesta por Ameghino y Scott para Adelphotherium trivium con N. imbricatus.

\section{2.3. Adinotherium AMEGHINO 1887a}

Este taxón fue establecido por Ameghino (1887a, p: 17); a pesar de describir cinco especies en el mismo trabajo, el autor no dio una descripción a nivel genérico y definió como especie tipo a Adinotherium magister. Años más tarde, el mismo Ameghino (1889) caracterizó el género Adinotherium y amplió las definiciones de las cinco especies creadas en 1887a (A. magister, A. ferum, A. splendidum, A. proximum y A. nitidum), detallando un poco más los materiales tipo de cada una de ellas. Entre las características mencionadas por Ameghino (1889) para el género Adinotherium, destacan el ancho mayor de la porción posterior del cráneo a nivel de los arcos cigomáticos y el paladar triangular. Lydekker (1893) consideró al género Adinotherium y a todas las especies descriptas como tal, hasta el momento de su publicación, como sinónimos del nombre "Nesodon ovinus" Owen 1853. Sin embargo, Ameghino nunca aceptó esta idea y continuó con la distinción del género Adinotherium (Ameghino 1894a, b).

La revisión realizada por Scott (1912) completó la descripción genérica. De acuerdo a este último autor, las especies de Adinotherium exhiben un tamaño considerablemente menor que las del género contemporáneo Nesodon; destacó que los molares presentan un patrón de la corona más simple, además de que el lóbulo anterior de los molares inferiores es más ancho que el lóbulo posterior; el rostro y la porción anterior de la mandíbula están ensanchados en comparación con Nesodon; además, algunas de las especies atribuidas a Adinotherium presentan rugosidades en el hueso frontal, un rasgo que podría indicar la presencia de pequeños cuernos. Scott (1912) también detalló la existencia de diferencias genéricas claras a nivel de ciertos elementos vertebrales y tarsales, más precisamente el astrágalo y el calcáneo que, si bien muestran una configuración similar, se diferencian claramente en el tamaño y las proporciones de los de Nesodon. Además, reconoció algunos nombres genéricos como sinónimos (total o parcialmente) de Adinotherium; es el caso de Acrotherium (en parte), Nesodon (en parte, ver Lydekker 1893) y Noaditherium Ameghino 1907. Por otra parte, Scott (1912) consideró que la diferenciación realizada por Ameghino entre A. ovinum (= Nesodon ovinum Owen 1853) y A. magister se basaba en caracteres intraespecíficos, razón por la cual las sinonimizó, de forma que $A$. ovinum pasó a ser el nombre valido de la especie tipo del 
género por el principio de prioridad (ICZN, 1999, art. 23). Scott (1912) reconoció cinco especies de Adinotherium: A. ovinum, A. karaikense, A. robustum, A. splendidum y $A$. nitidum. En el catalogo publicado por Mones (1986), se registran un total de trece especies definidas para este género, una de las cuales tiene asignación genérica dudosa (? Adinotherium paranense Ameghino, 1891f).

\section{-Adinotherium magister AMEGHINO 1887a}

Designada como especie tipo del género por Ameghino (1887a, p: 17) y definida a partir de un cráneo completo. Ameghino la caracterizó por ciertas peculiaridades de la dentición: I2 más desarrollado que los demás incisivos; tercer incisivo y canino con escaso desarrollo; i1-2 pequeños, con raíces cerradas; i3 más grande, de sección triangular y sin haber formado la raíz; $\mathrm{m} 3$ grande, mayor que el $\mathrm{m} 2$.

Durante la revisión de la colección del Museo de La Plata, no se pudo encontrar el material tipo de $A$. magister, pero tuve acceso a otros materiales asignados a esta especie por el propio Ameghino en las colecciones del Museo Argentino de Ciencias Naturales (MACN A 923 Fig. III. 8, MACN A 929, MACN A 1666). Al analizar estos materiales, no se encontraron rasgos que los diferenciaran de los ejemplares asignados a A. ovinum y, por ello, se considera que las diferencias en la dentición mencionadas por Ameghino (1894a) corresponden a variación ontogenética, asociada al grado de desgaste de las piezas dentarias. En cuanto al tamaño relativo de los incisivos, es razonable que a medida que progresa la edad del animal (y en consecuencia el desgaste en los dientes) aquellas piezas con crecimiento limitado (I1, I3 y C en la serie superior; e i1, i2 y c en la serie inferior) se hagan relativamente más pequeñas que las que presentan crecimiento continuo (I2 e i3). La variación en la dentición yugal ligada a los diferentes estadios ontogenéticos en Adinotherium se aborda en el capítulo siguiente. Por lo expresado anteriormente, considero válida la sinonimia propuesta por Scott (1912).

Ameghino (1891, 1894a y b, 1904) sostuvo a este taxón como una especie diferente en todos los trabajos en los que abordó aspectos de los Nesodontinae; sin embargo, Scott (1912) consideró a esta especie como un sinónimo de Adinotherium ovinum. 

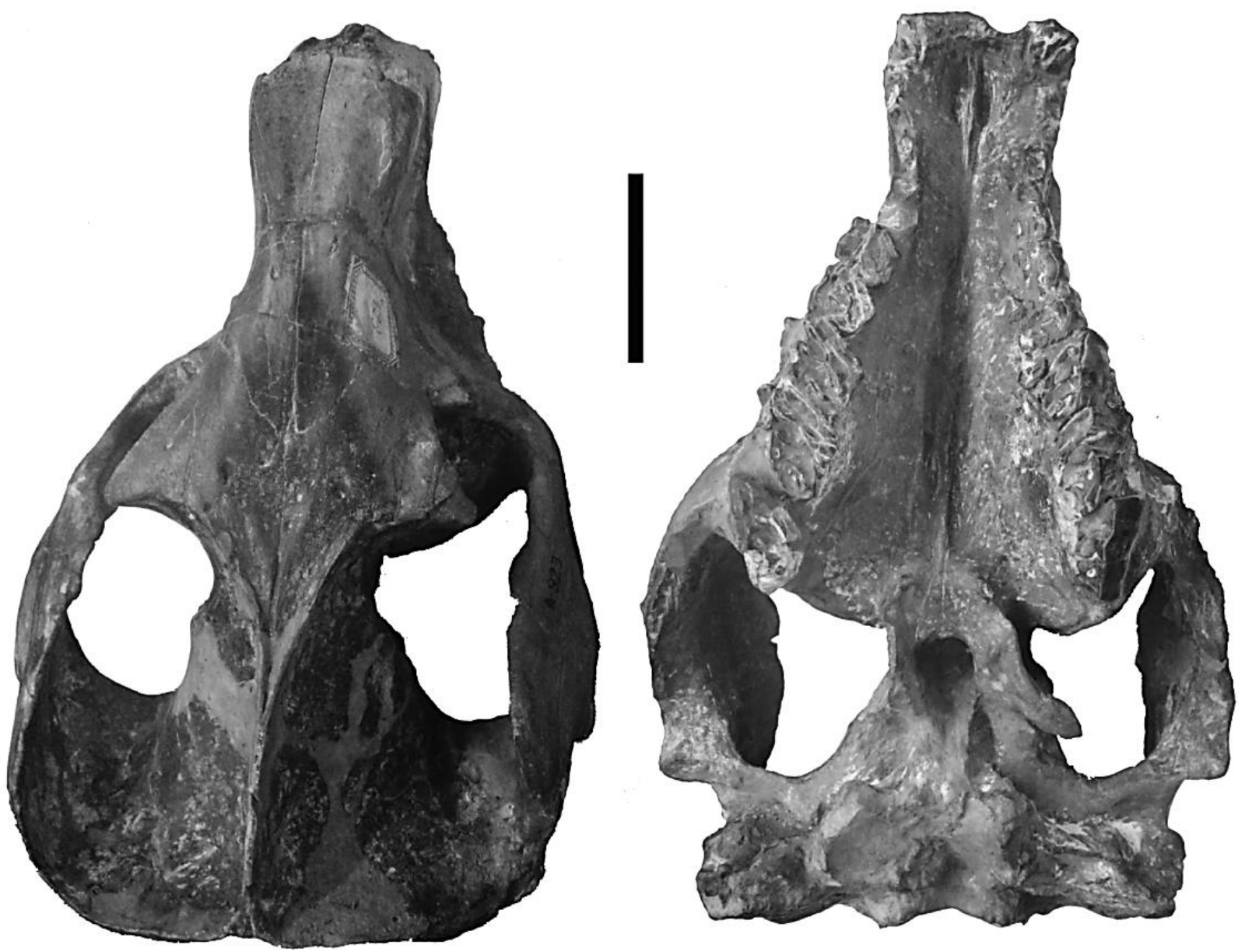

Fig. III. 8: Craneo completo MACN A 923 asignado a Adinotherium magister. Escala $5 \mathrm{~cm}$.

\section{-Adinotherium antiquum MERCERAT 1891}

Definida por Mercerat (1891, p: 410) a partir de maxilares y premaxilares de seis individuos diferentes, dos de ellos procedentes de la localidad de Monte León y los restantes de las barrancas del río Santa Cruz. De acuerdo al autor, esta especie no habría alcanzado el tamaño de Adinotherium pulchrum, de la cual difiere, además, por el menor desarrollo del último molar. Mercerat destacó que $A$. antiquum tenía los mismos rasgos dentarios que $A$. pulchrum, pero menos distintivos.

En la colección del Museo de La Plata, no se ha localizado el material tipo ni otro material atribuido a $A$. antiquum, por lo que resulta imposible constatar el estatus taxonómico de este nombre.

\section{-Adinotherium corriguenense AMEGHINO 1907}

Ameghino (1907, p: 77-79) estableció este taxón a partir de un cráneo encontrado en la zona de Corriguen-Kaike en la costa Atlántica de la provincia de Santa Cruz. El autor remarcó que era un cráneo más pequeño que el de Adinotherium nitidum y de forma completamente 
diferente; además, señaló que los molares presentan una columna lingual bien desarrollada en el interior de un valle medial interno; el área intermaxilar es muy estrecha; los nasales son largos y estrechos, y se unen a los frontales en una sutura en "zig-zag"; la cresta sagital no es tan alta como en otras de las especies y es larga, con su porción anterior convexa transversalmente y de superficie lisa, a diferencia de las restantes especies del género; y los procesos postorbitales son anchos en la base y cortos en dirección lateral. Scott (1912) consideró A. corriguenense un sinónimo de Adinotherium nitidum (ver más abajo).
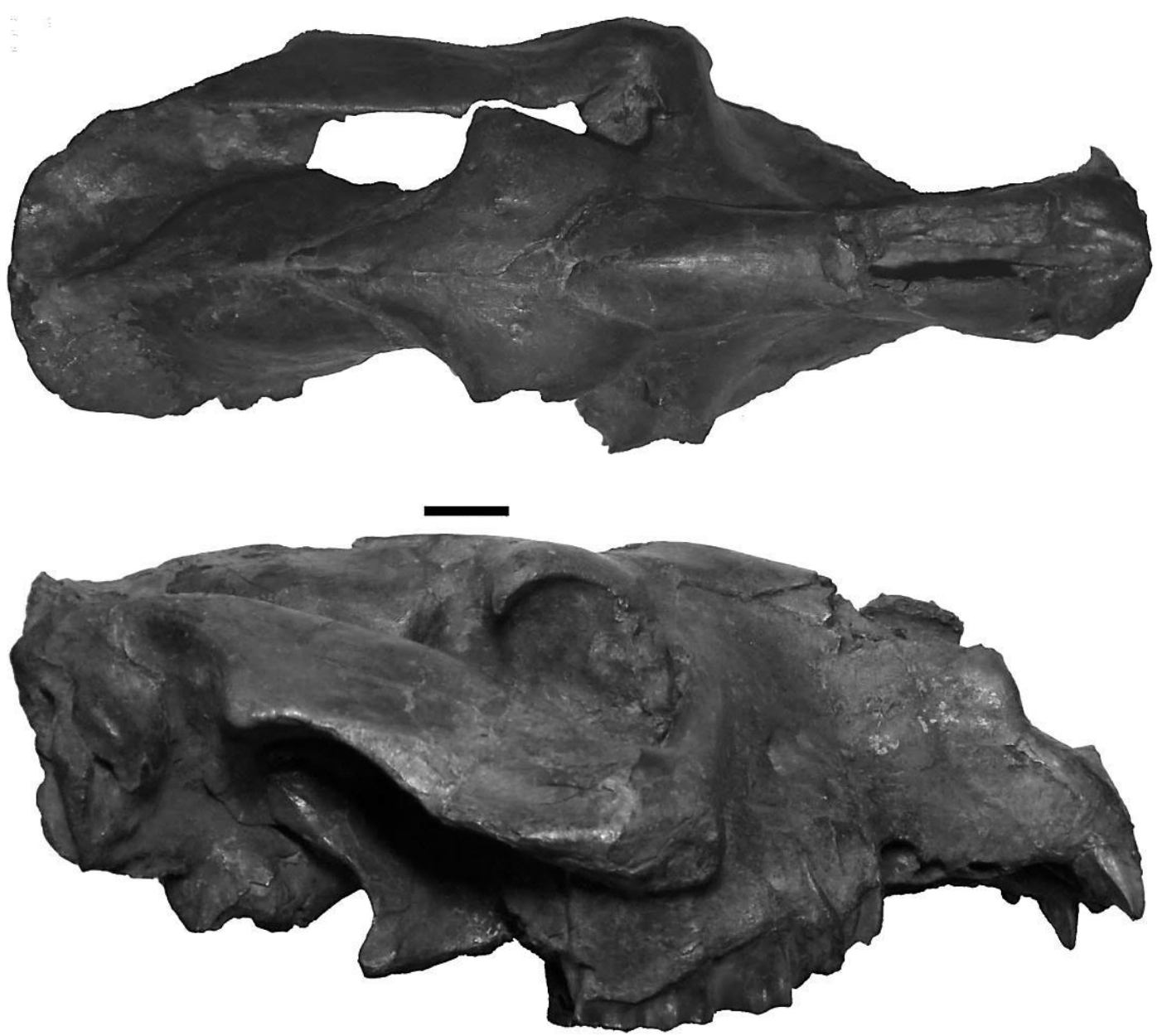

Fig. III. 9: Cráneo MACN A 11689 utilizado por Ameghino (1907) para fundar el nombre Adinotherium corriguenense. Escala $2 \mathrm{~cm}$.

El holotipo (MACN 11689, Fig. III. 9) es un ejemplar subadulto con la dentición típica de dicho estadio en Adinotherium ovinum (i.e. I 3/3 C 1/1 P 4/4 M 3/3, con el último molar a punto de erupcionar). Las diferencias en la cresta sagital y el desarrollo de los procesos postorbitales también pueden atribuirse en parte a la edad del animal, mientras que una parte imporante de la diferencia en el ancho del cráneo de este ejemplar respecto a otros en el 
mismo estadio ontogenético se debe a deformación por aplastamiento y no a diferencias interespecíficas como fue interpretado por Ameghino. Por esta razón, el nombre $A$. corriguenense es considerado en esta tesis como otro sinónimo júnior de A. ovinum.

\section{—Adinotherium ferum AMEGHINO 1887a}

Establecida por Ameghino (1887a, p: 18) y caracterizada por una talla algo menor que la de A. magister, A. proximum y A. splendidum; además, presenta ciertas diferencias en la dentición superior, entre ellas: I2 de sección triangular, angosto, que se proyecta por fuera del alveolo, e I3 más ancho; borde labial de los dientes yugales convexo y perpendicular, formando una columna (Ameghino 1887a, 1891).

Scott (1912, p. 223) estableció la sinonimia de A. ferum con A. ovinum, destacando que podría considerarse como el macho de esta especie, basándose en la presencia de rugosidades que podrían sugerir la presencia de un cuerno, además de tener un cráneo más ancho y bajo. El dimorfismo sexual y la posible existencia de cuernos en Adinotherium se discuten en el capítulo IV.

Mones (1986) indicó que el material tipo de A. ferum se encuentra en la colección del Museo de La Plata; sin embargo, no se localizó ningún espécimen con dicha asignación durante mis visitas a esa institución ni se pudo identificar el material a partir de la descripción original. Fue posible, en cambio, acceder a materiales atribuidos a esta especie por el propio Ameghino (MACN A 5352, Fig. III. 10A y MACN A 5353, Fig. III. 10B) que consisten en un cráneo casi completo, con buen estado de preservación, pero con algo de deformación, y una mandíbula casi completa, que también sirvieron a Scott (1912) para realizar su revisión de los toxodóntidos de Santa Cruz (ver Vizcaíno et al. 2017, App. 1, p: 69).

Si bien el tamaño de este cráneo es ligeramente menor que el de los ejemplares asignados a A. ovinum, no existen rasgos que los diferencien y, por lo tanto, se confirma la sinonimia realizada por Scott (1912) para A. ferum. 


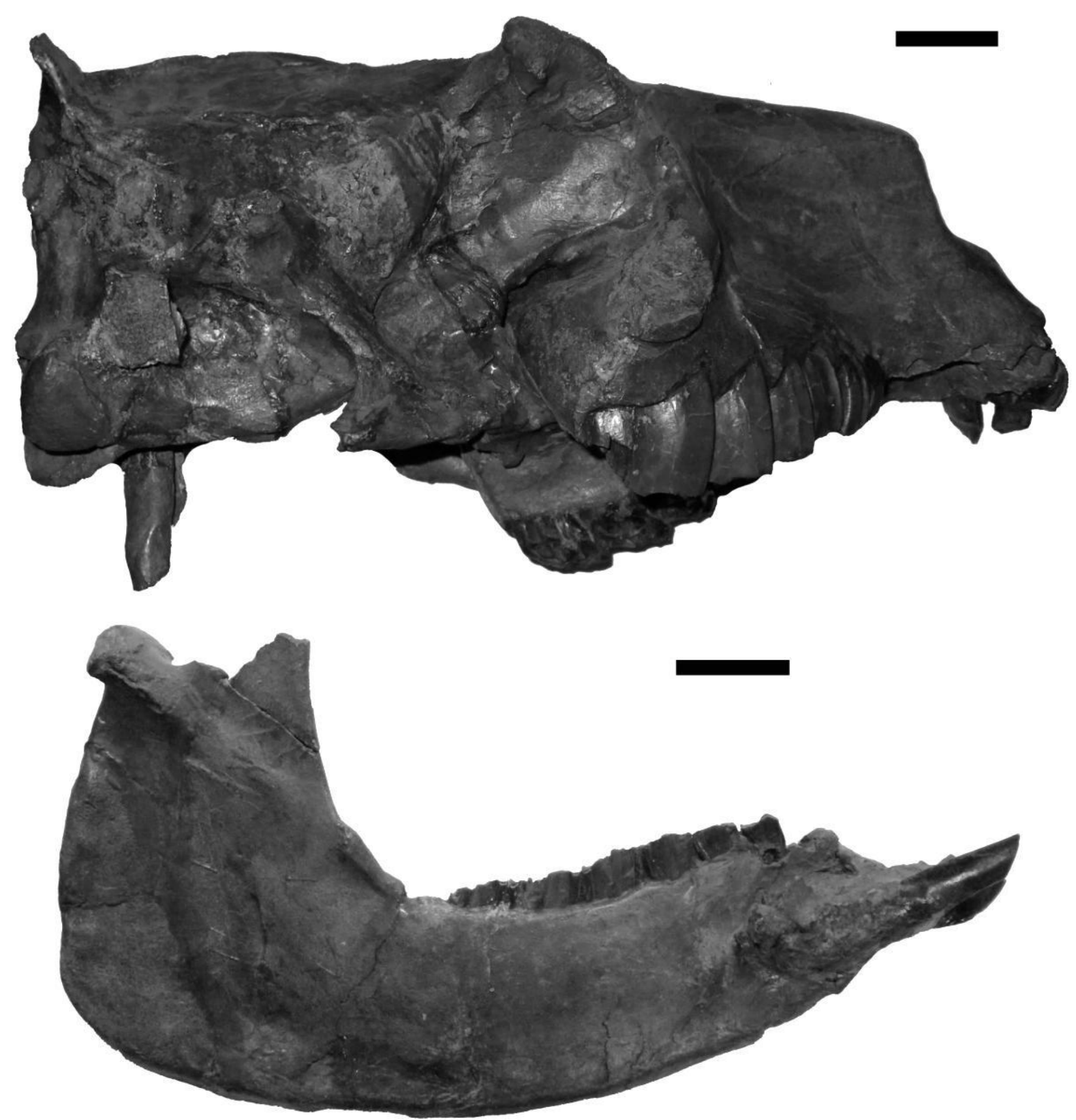

Fig. III. 10. Cráneo MACN A 5352 (A) y mandibula MACN A 5353 (B) atribuidos por Ameghino a Adinotherium ferum. Escala $2 \mathrm{~cm}$.

\section{-Adinotherium haplodontoides AMEGHINO 1891}

Especie definida por Ameghino (1891, p: 129-130) a partir de restos de dentición superior colectada en Patagonia, sin precisar la localidad. Según el autor, esta especie difiere de Adinotherium splendidum y A. magister por su menor tamaño, y su serie yugal se caracteriza por tener las crestas de esmalte unidas tempranamente en los molares superiores, la presencia de un surco lingual perpendicular poco desarrollado y la presencia de una columna lingual. 
Scott (1912) estableció, con ciertas reservas, la sinonimia entre A. haplodontoides y $A$. ovinum.

Aunque no se ha localizado el material sobre el cual se fundó este taxón (que de acuerdo al catálogo de Mones [1986], debería encontrarse en la colección del MACN), no puedo emitir juicio tajante sobre la validez de esta especie, aunque cabe destacar que la semejanza establecida por Scott (1912) entre A. splendidum, A. magister y A. haplodontoides permite asumir que $A$. haplodontoides es otro sinónimo de $A$. ovinum. Sumado a ello, en el álbum fotográfico de Scott (Vizcaíno et al. 2017, App. 1, p: 68), se encuentra la fotografía de un ejemplar identificado por él como material tipo de $A$. haplodontoides $\left(\mathrm{n}^{\circ} 419\right)$, que corresponde a un fragmento de paladar con la serie P3-M3 que no presenta diferencia alguna con la morfología típica de los nesodontinos y que por su tamaño pertenece sin dudas a $A$. ovinum.

\section{-Adinotherium karaikense (MERCERAT 1891)}

Nueva combinación propuesta por Ameghino (1904) para el taxón Acrotherium karaikense (ver más arriba) al realizar la sinonimia a nivel genérico de Acrotherium con Adinotherium.

\section{-Adinotherium kobyi MERCERAT 1891}

Descripta por Mercerat (1891, p: 410-411) a partir de un cráneo incompleto y cuatro fragmentos de maxilares colectados en la localidad de Monte León. De acuerdo al autor, la morfología de las piezas dentarias es similar a la de Adinotherium splendidum y habría alcanzado una talla mayor que la de A. magister. Mercerat distinguió esta especie por el mayor desarrollo del último molar y algunas peculiaridades de ciertas estructuras en los dientes, así como por la sutura naso-frontal en forma de "W".

Ameghino (1894a) se refirió a esta especie como sinónimo de A. splendidum, mientras que Scott (1912) la consideró sinónima de A. ovinum, sin dar mayores detalles al respecto.

No se pudo localizar ninguno de los restos a partir de los cuales fue creado este taxón, aunque cabe destacar que la descripción brindada por Mercerat no expresa caracteres diagnósticos suficientes para mantener la identidad de Adinotherium kobyi separada de la de A. ovinum. 


\section{-Adinotherium nitidum AMEGHINO 1887a}

Definida por Ameghino (1887a, p: 18) como una especie algo más pequeña que Adinotherium ferum y caracterizada por sus molares inferiores muy comprimidos y los dos primeros con escotaduras superficiales en el margen lingual. Ameghino (1894a) extendió la caracterización de esta especie, pero sin brindar rasgos que sirvan realmente para diferenciarla del resto de los toxodóntidos de Santa Cruz. Sin embargo, la validez de esta especie no fue cuestionada por Scott (1912), quien la diferenció por su menor tamaño y comentó que los ejemplares estudiados por Ameghino eran juveniles y, por lo tanto, la definición no sería del todo confiable.
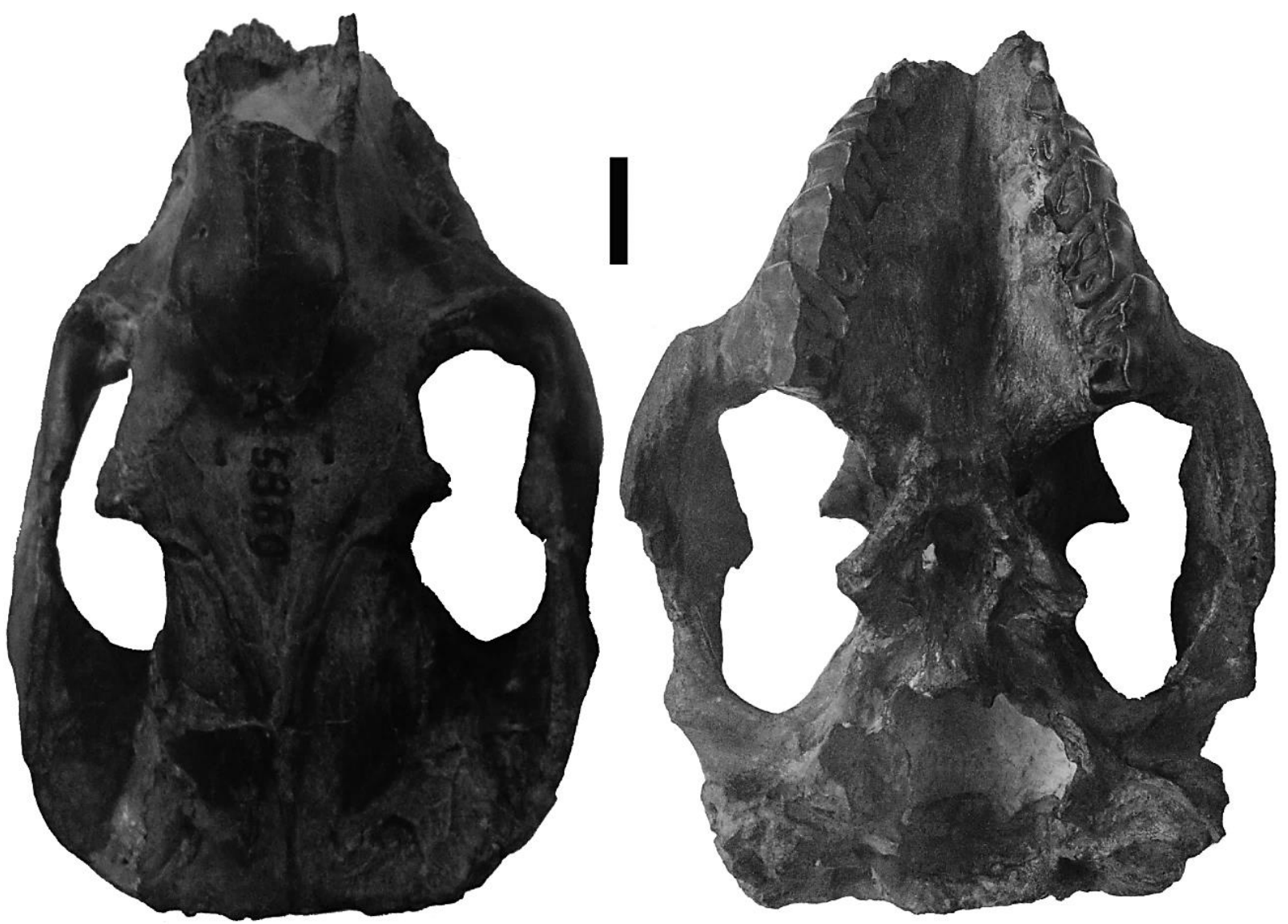

Fig. III. 11: Cráneo MACN A 5360 asignado por Ameghino a Adinotherium nitidum. Escala 2 $\mathrm{cm}$

No se pudo localizar el material tipo de A. nitidum en el Museo de La Plata, donde debería encontrarse según Mones (1986), pero existen dos ejemplares asignados por Ameghino a esta especie en el Museo Argentino de Ciencias Naturales "Bernardino Rivadavia” (MACN A 946 y MACN A 5360, Fig. III. 11). Uno de ellos (MACN A 946) 
corresponde a un individuo juvenil y el restante (MACN A 5360) a un individuo subadulto, lo que justificaría la menor talla de ambos ejemplares respecto a ejemplares adultos. Sin embargo, cabe destacar que MACN A 5360 presenta las dimensiones más pequeñas obtenidas en toda la muestra de ejemplares subadultos de Adinotherium ovinum (ver Tabla V. 12 en el Capitulo V), aunque las diferencias con otros ejemplares son leves (e.g. MPM PV-3667, MLP 84.III.9.10). A pesar de esta diferencia de tamaño, considero a A. nitidum como sinónimo júnior de $A$. ovinum.

\section{-Adinotherium ovinum (OWEN 1853)}

La combinación original propuesta por Owen (1853, p: 318-319) era Nesodon ovinus (ver este taxón), siendo Ameghino (1907) quien la consideró dentro del género Adinotherium. La descripción original de Owen (1853) es una de las más completas de los nesodontinos, refinada después por Scott (1912) quien, además, estudió numerosos ejemplares y precisó cuestiones de variabilidad individual y ontogenética para este taxón.

El material tipo de Adinotherium ovinum no fue localizado pero este taxón es el único perteneciente al género Adinotherium que desde su creación presentó una descripción que contempla características diagnósticas que lo diferencian del resto de los toxodóntidos y que no son atribuibles únicamente a variación individual u ontogenética. Esta es la única especie de Adinotherium que se considera válida para los depósitos de la Formación Santa Cruz en esta tesis. Su diagnosis y la lista sinonímica correspondiente se brindan en el apartado III. 4 y la caracterización de su cráneo y mandíbula se presenta en el capítulo IV.

\section{—Adinotherium proximum AMEGHINO 1887a}

Especie establecida por Ameghino (1887a, p: 17-18) a partir de un fragmento de mandíbula con la serie molar completa. La caracterización brindada por el autor original es bastante concisa y no aporta rasgos distintivos de otras especies del género o de géneros relacionados. El autor describió el material de forma comparativa, pero no queda claro con que taxón estaba realizando dicha comparación. Ameghino señaló: "las muelas inferiores más angostas. m3 más corto y con tres profundas canaletas perpendiculares sobre la cara interna. Premolares anteriores con corona más larga". Tiempo después, Ameghino (1891) amplió la descripción, pero sin aportar características significativas. Años más tarde, Ameghino (1904) reconoció que Adinotherium proximun era un sinónimo de Nesodon ovinus (= Adinotherium ovinum), sinonimia aceptada luego por Scott (1912). 
El examen del material tipo (MLP 12-259), permite reconocer que se trata de un espécimen juvenil de $A$. ovinum.

\section{-Adinotherium pulchrum MERCERAT 1891}

Especie establecida por Mercerat (1891) a partir de tres cráneos incompletos y un fragmento de maxilar izquierdo, procedentes de las barrancas del río Santa Cruz. Esta especie habría tenido una talla mayor a las descriptas para este género y el autor utilizó las dimensiones del M3 para diferenciarla. Además, caracterizó el P4, mencionando que tenía rasgos similares a los del P4 de Nesodon, y señaló la presencia de varios diastemas entre el I2 y el P3, y el progresivo aumento de la longitud de los diastemas hacia el extremo anterior. Ameghino (1894a) estableció la sinonimia de esta especie con Adinotherium splendidum, posición que también adoptó Scott (1912).

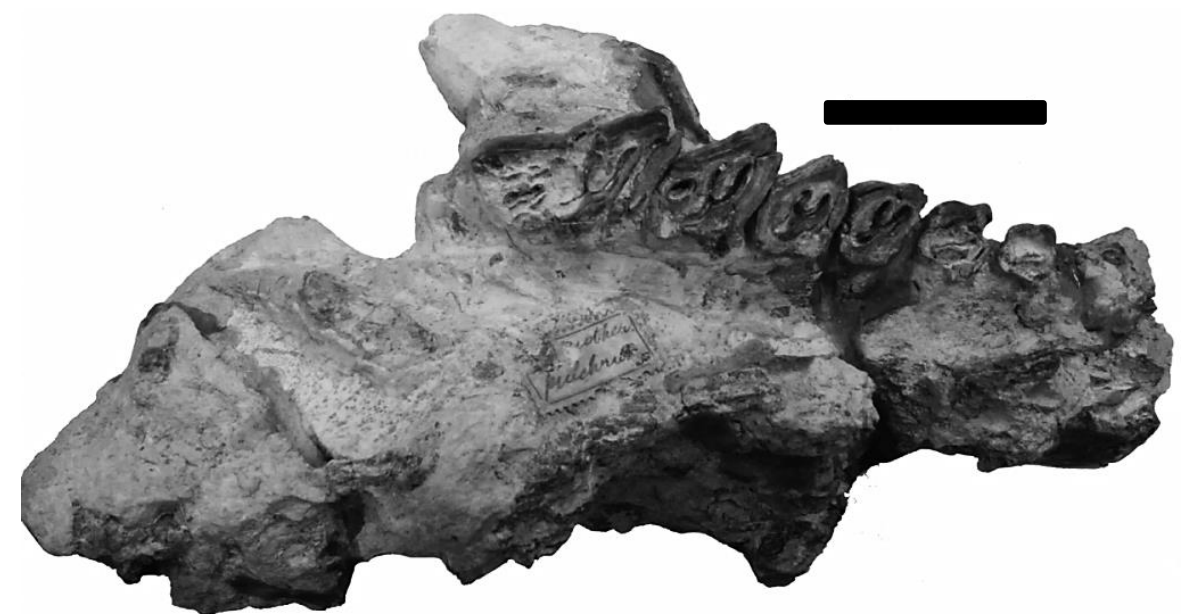

Fig. III. 12: Fragmento de cráneo MLP 12-32 utilizado como tipo por Mercerat para establecer Adinotherium pulchrum. Escala $5 \mathrm{~cm}$.

El material tipo de A. pulchrum (MLP 12-32, Fig. III. 12) es un fragmento anterior de cráneo con la serie P2-M3 de un ejemplar adulto, con los últimos cuatro dientes muy poco gastados. Se considera que se trata de un ejemplar de Adinotherium ovinum, aun cuando su tamaño es mayor (UPL=118,5 mm) que la media de los ejemplares de esa especie (UPL medio=87,31 mm; UPL máximo registrado para la especie $=122,03 \mathrm{~mm}$ ).

\section{-Adinotherium robustum AMEGHINO 1891}

Ameghino (1891, p: 376) estableció esta especie y completó su descripción unos años después (Ameghino 1894b) con los siguientes rasgos: talla mayor que la de Adinotherium 
ferum y un ancho cigomático considerablemente mayor que la longitud anteroposterior del cráneo. Ameghino mencionó una protuberancia a nivel de los frontales más desarrolladas que en A. ferum y similares a la protuberancia frontal presente en el género Trigodon, aunque de mucho menor tamaño y convexidad. Ameghino (1894b) recalcó que los materiales sobre los que creó $A$. robustum fueron colectados en sedimentos asignados al piso Notohippidense, mientras que los de A. ferum procedían del piso Santacrucense, razón que lo llevó a suponer que Adinotherium robustum era estratigráficamente más antiguo que $A$. ferum.

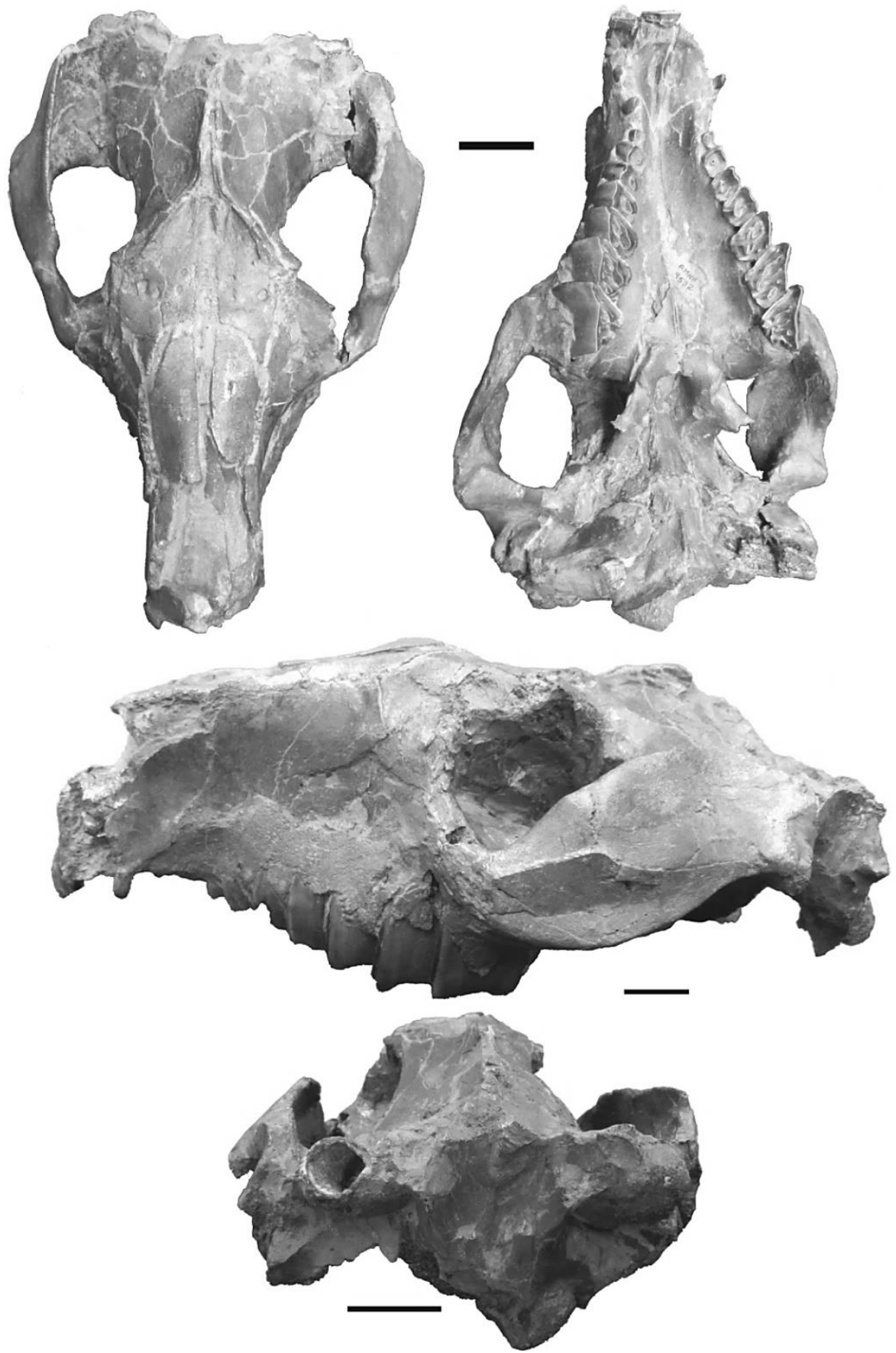

Fig. III. 13: Cráneo AMNH 9532 utilizado por Scott (1912) para describir Adinotherium robustum. 
Scott (1912) mantuvo la distinción de A. robustum, añadiendo características de la región auditiva, tales como el desarrollo de una protuberancia a partir de la expansión de la porción postimpánica del escamoso.

He podido revisar dos ejemplares asignados a A. robustum, un cráneo que no cuenta con la porción posterior (MACN A 407) y el cráneo casi completo descripto por Scott (AMNH 9532), que según él correspondería al tipo de la especie. En el álbum de fotografías de Scott (Vizcaíno et al. 2017), se ilustra otro fragmento anterior de cráneo de $A$. robustum (n $\left.{ }^{\circ} 408\right)$. Las características observables en ambos ejemplares coleccionados por Ameghino corresponden con las de A. ovinum, siendo el paladar de MACN A 407 ligeramente menos ancho $(\mathrm{PAB}=77,39 \mathrm{~mm})$ que la media de la especie $(80,87 \mathrm{~mm})$ y que parece carecer de la protuberancia a nivel de los frontales. El ejemplar AMNH 9532 (Fig. III. 13) corresponde a un individuo subadulto inusualmente grande $(\mathrm{TSL}=249,54 \mathrm{~mm})$, algo más que MPM 3667 $(\mathrm{TSL}=235,2 \mathrm{~mm})$ y MACN A $926(\mathrm{TSL}=234,99 \mathrm{~mm})$, cuya única diferencia radica en las caracteristicas de la porción timpánica mencionadas por Scott, que considero se deben mayormente a la deformación postmortem por aplastamiento (similar a lo que sucede en el ejemplar MPM CV-SHP-15-14 deformado por compresión lateral).

\section{—Adinotherium rotundidens AMEGHINO 1899}

El nombre de este taxón aparece únicamente en el trabajo de Mones (1986, p: 170) quien atribuye la autoría a Ameghino (1899); sin embargo, no he encontrado mención alguna ni en ese trabajo ni en otra bibliografía de la época. Mones (1986) suponía que el material tipo debería encontrarse en el MACN, pero los cuatro ejemplares asignados a este taxón en las colecciones del museo (MACN 5956, MACN A 10377, MACN A 11609. MACN A 11612) no figuran como material tipo de acuerdo al catálogo de colecciones de esta institución. Estos ejemplares no presentan rasgo alguno que puedan diferenciarlos de A. ovinum y, por tanto, considero que no se puede mantener $A$. rotundidens como un nombre válido.

\section{—Adinotherium rusticum (AMEGHINO 1887a)}

Ver Acrotherium rusticum, nominación original de Ameghino (1887a), quien consideró después (Ameghino 1904) que la especie correspondía al género Adinotherium.

\section{-Adinotherium splendidum AMEGHINO 1887a}

Especie definida por Ameghino (1887a, p: 17) a partir de la porción anterior de un cráneo. La comparación que proveyó el autor es concisa y realizada de una forma comparativa 
con las otras cinco especies presentadas en el mismo trabajo. Tiempo después, Ameghino (1891) dio una descripción algo más completa de este taxón, pero sin aportar características distintivas más allá de leves diferencias de proporciones entre elementos o caracteres que varían ontogenéticamente. De acuerdo a Ameghino (1894a), Adinotherium splendidum presentaría los siguientes sinónimos: A. pulchrum, $A$. sylvaticum (en parte, ver Phobereotherium sylvaticum), A. antiquum y A. kobyi. Scott (1912) consideró válidas las sinonimias establecidas por Ameghino.

En esta tesis se considera a A. splendidum y a la combinación propuesta por Ameghino (1907), Noaditherium splendidum, como sinónimos de Adinotherium ovinum. En los materiales tipo asignados a A. splendidum (e.g. MLP 12-10, fragmento de premaxilar, Fig. III. 14A; MLP 12-985, fragmento de mandíbula, Fig. III. 14B), no encontré diferencias significativas con los materiales de A. ovinum. Por ello, se propone la sinonimia de $A$. splendidum (y Noaditherium splendidum) con A. ovinum.
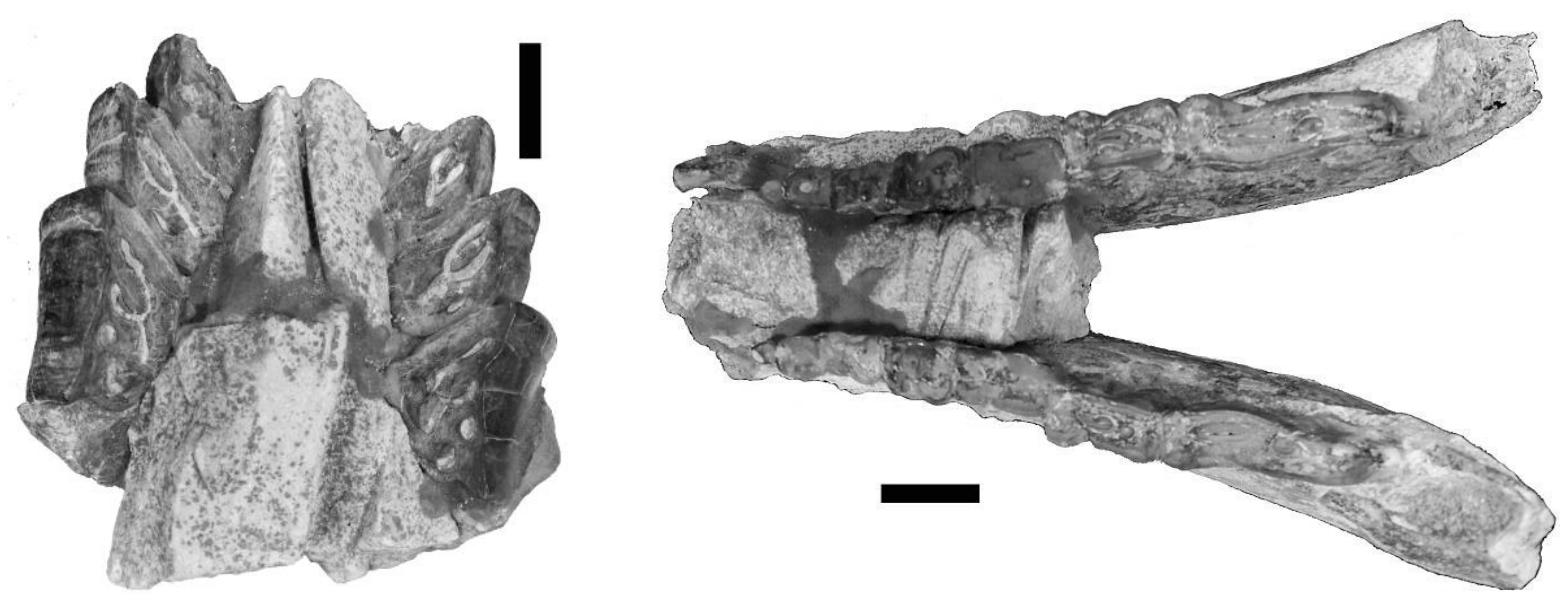

Fig. III. 14: Fragmento de paladar con M1-M3 MLP 12-10 (A) y mandíbula con p1-m3 MLP 12985 com (B) utilizados por Ameghino (1887a) para fundar el nombre Adinotherium splendidum. Escalas $2 \mathrm{~cm}$.

\section{-Adinotherium sylvaticum (AMEGHINO 1887a)}

Esta especie fue descripta como Phobereotherium sylvaticum (ver más abajo) por Ameghino (1887a) y traspasada al género Adinotherium por Mercerat (1891, p: 408). 
Tras observar el ejemplar tipo de Atryptherium bifurcatum (MACN A 926, Fig. III. 15), considero que se trata de un ejemplar subadulto (F.D: I 3/? C 1/? P4/? M3/?) de A. ovinum, donde el M3 aun no ha erupcionado totalmente, cuyas características no difieren de otros ejemplares en el mismo estadio ontogenético (e.g. MPM-PV 3666); por lo tanto, los nombres Atryptherium bifurcatum y la posterior combinación Nesodon bifurcatum (propuesta por Ameghino 1894a) son considerados en este trabajo como sinónimos de A. ovinum.

\section{2.5. Gronotherium AMEGHINO 1887a}

Al igual que en casos anteriores, este género fue definido por Ameghino (1887a, p: 17) sin brindar una descripción para el taxón a nivel genérico. Años más tarde, Ameghino (1891) dio una descripción bastante escueta, dando cuenta de que no logró encontrar características dentarias que le permitieran separarlo de Nesodon. Ameghino atribuyó a Gronotherium la persistencia de las raíces abiertas en estados avanzados de desgaste dentario. La única especie asignada es Gronotherium decrepitum. Scott (1912) estableció la sinonimia de Gronotherium con Nesodon.

\section{-Gronotherium decrepitum AMEGHINO 1887a}

En la descripción original, Ameghino (1887a, p: 17) mencionó la presencia de molares inferiores con base abierta y la diferenciación de dos lóbulos en molares y premolares inferiores. Más tarde, Mercerat (1891) sugirió un cambio de género para esta especie, proponiendo la combinación Protoxodon decrepitum al asignar varios materiales nuevos para este taxón, todos procedentes de las barrancas del río Santa Cruz. A su vez, comentó que este animal no habría sido mayor que Protoxodon marmoratus y añadió algunas características de la morfología mandibular y la posición de los forámenes mentonianos. Ameghino (1891) descartó la propuesta de Mercerat y continuó utilizando la combinación original $G$. decrepitum, convencido de que el taxón constituía una especie diferente a Nesodon imbricatus, aunque Scott (1912) estableció la sinonimia (con reservas) con esta última especie.

El ejemplar tipo de $G$. decrepitum no pudo ser localizado en las colecciones del Museo de La Plata y, aun cuando Ameghino no dio características suficientes que permitan sostener la identidad genérica y específica de este taxón, no se cuenta con los elementos suficientes para evaluar adecuadamente la validez de este nombre. 


\section{2.6. Hyperoxotodon MERCERAT 1895a}

Este género fue fundado por Mercerat (1895a, p: 305) para el fragmento de mandíbula utilizado por Ameghino como tipo para el nombre Stenotephanos speciosus (MLP 12-53, que no se localizó). Mercerat juzgó que el material proveniente de los sedimentos santacrucenses difería en gran medida de las restantes especies asignadas al género Stenotephanos (provenientes de sedimentos mesopotamienses, Entre Ríos) y, por ello, generó la combinación Hyperoxotodon speciosus, que constituye la única especie de este género.

\section{—Hyperoxotodon speciosus (AMEGHINO 1887a)}

Es la combinación resultante del cambio de género propuesto por Mercerat para la especie Stenotephanos speciosus, creada por Ameghino (1887a) a partir de un fragmento de mandibula (MLP 12-53 de acuerdo a Mones [1986]). A partir del ejemplar revisado asignado a este taxón por Mercerat (MLP 12-59, Fig. III. 15) y etiquetado como material tipo en la colección del Museo de la Plata (correspondendiente a un fragmento de maxilar con parte de la dentición yugal), considero que las diferencias comentadas por Mercerat respecto de la morfología del maxilar y los molares de MLP 12-59 (especialmente del M3) con el molar utilizado para crear el género Stenostephanos son válidas y por ello también lo es el taxón Hyperoxotodon speciosus.

Este taxón difiere del resto de los toxodóntidos presentes en la Formación Santa Cruz por la morfología de sus molares, que no presentan el típico patrón de la corona con el valle central en forma de "Y", ni fosetas accesorias. Además, presenta un grado de hipsodoncia mayor que en las especies de nesodontinos del santacrucense.

Cabe destacar que, dado que no pude consultar el material tipo de Stenostephanos speciosus, aun cuando el taxón $H$. speciosus es considerado válido en esta tesis, no puedo emitir juicio contundente sobre la validez del cambio de combinación establecido por Mercerat para S. speciosus, y por ello se seguirá la postura adoptada por Madden (1990) que considera a los nombres $S$. speciosus e $H$. speciosus como sinónimos y a este último como nombre válido.

Para mayores detalles sobre la descripción e historia taxonómica de Stenostephanos speciosus ver el apartado a este especie y el de Nesodonopsis speciosus. 


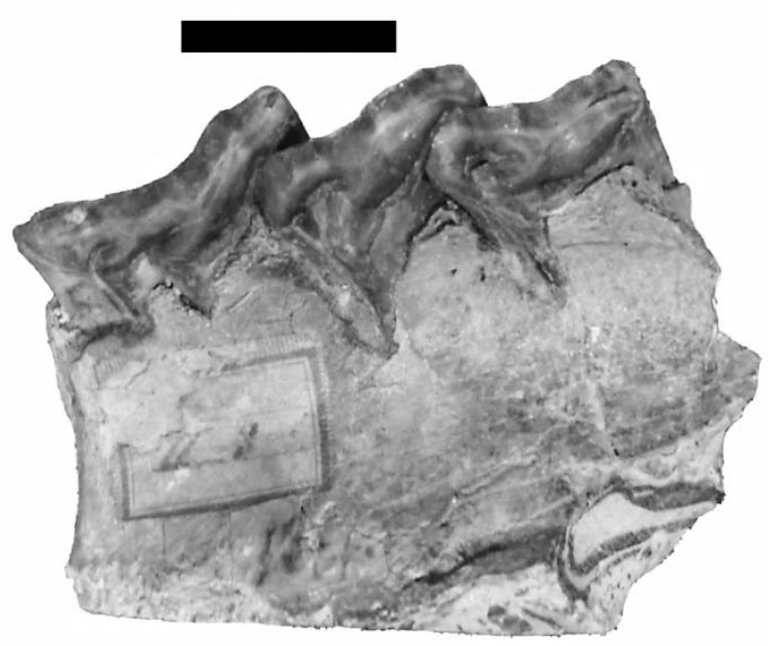

Fig. III. 16: Fragmento de maxilar izquierdo con M1-M3 (MLP 12-59) asignado por Mercerat (1895a) para a Hyperoxotodon speciosus. Escala $2 \mathrm{~cm}$.

\section{2.7. Nesodon OWEN 1847}

El género Nesodon fue fundado por Owen en 1847, con la especie tipo Nesodon imbricatus, cuyos materiales tipo se encuentran perdidos actualmente. Posteriormente, Owen (1853) describió otras tres especies del género: Nesodon sulivani, Nesodon ovinus y Nesodon magnus; esta última corresponde al orden Astrapotheria y más tarde (Ameghino 1889) se consideró Astrapotherium magnum. Luego de la revisión de Scott (1912), Nesodon quedó con tres especies: $N$. imbricatus, $N$. cornutus y $N$. conspurcatus.

De acuerdo al catálogo de Mones (1986), para el género Nesodon se nombró un total de 11 especies que, en gran medida, están definidas por materiales fragmentarios difícilmente comparables, o correspondientes a estadios ontogenéticos diferentes de una misma especie que los autores no lograron discernir en su momento por la escasez de material.

Algunos de los sinónimos que Scott (1912) reconocio para Nesodon son: Toxodon (Moreno 1882, no lo definido por Owen), Colpodon Burmeister (en parte), Astrapotherium Burmeister (en parte), Protoxodon Ameghino 1887a, Atryptherium Ameghino 1887a, Scophotherium Ameghino 1887a, Adelphotherium Ameghino 1887a, Gronotherium Ameghino 1887a, Acrotherium Ameghino 1887a (en parte) y Nesotherium Mercerat 1891.

El género Nesodon fue abundante durante todo el Mioceno temprano y ha sido considerado como taxón guía de estos niveles hasta su registro en niveles correspondientes al Colloncurense en el Mioceno medio (e.g. Kramarz et al. 2011). 


\section{—Nesodon imbricatus OWEN 1847}

Owen (1847, p: 66-67) definió la especie tipo de Nesodon a partir de los materiales enviados por el capitán Sullivan provenientes de las costas del sudoeste de Patagonia, en particular a partir de la mandíbula de un individuo joven con premolares deciduos. Fue la primera especie de la subfamilia Nesodontinae en ser definida y es, junto con Adinotherium ovinum, una de las especies con mayor vigencia en la literatura sobre Toxodontidae. En materia taxonómica, han sido numerosos los aportes dedicados a este taxón y, ya sea por la cantidad de material disponible, la enorme variación ontogenética que presenta o el criterio taxonómico de la época (enfocado más en documentar variaciones de forma que en un criterio más relacionado con la especie como una entidad en la naturaleza), los especímenes de Nesodon imbricatus han recibido una inmensa cantidad de nombres en la literatura zoológica, desde trabajos como los de Owen (1853), Burmeister (1885), Ameghino (1887a y b, 1889, 1894a y b), Mercerat (1890, 1891) y Scott (1912). Es la única especie del género Nesodon reconocida para la Formación Santa Cruz en esta tesis. Por motivos de espacio, las cuestiones nomenclaturales se resumen en la lista sinonímica de Nesodon en el apartado III. 4, junto a la diagnosis de la especie.

\section{—Nesodon andium AMEGHINO 1891a}

Nombre establecido por Ameghino (1891, p: 377) a partir de un fragmento de cráneo de un ejemplar de tamaño similar a Nesodon sulivani, con la única característica distintiva de presentar caninos rudimentarios y caedizos. Ameghino (1894a) reafirmó la identidad de esta especie, pero Scott (1912) estableció su sinonimia con Nesodon conspurcatus, aludiendo a que las diferencias señaladas por Ameghino (primer premolar ausente o rudimentario) podrían deberse a variación individual.

Aun cuando el material tipo de esta especie no pudo ser localizado en el MACN, se revisaron otros materiales asignados a $N$. andium por el propio Ameghino (MACN A 859, Fig. III. 17, MACN A 887, y MACN A 888) que presentan un menor tamaño que Nesodon imbricatus, pero no muestran características que excedan el rango de variación de tamaño en esta especie. Además, a partir de las fotografías tomadas por Scott (ver Vizcaíno et al. 2017, App. 1, p: 63-64) se pudieron observar ejemplares que no se encuentran en la colección del MACN ( $\left.n^{\circ} 377,378,460\right)$. Por esa razón, en esta tesis se considera a $N$. andium como un sinónimo júnior de $N$. imbricatus. 


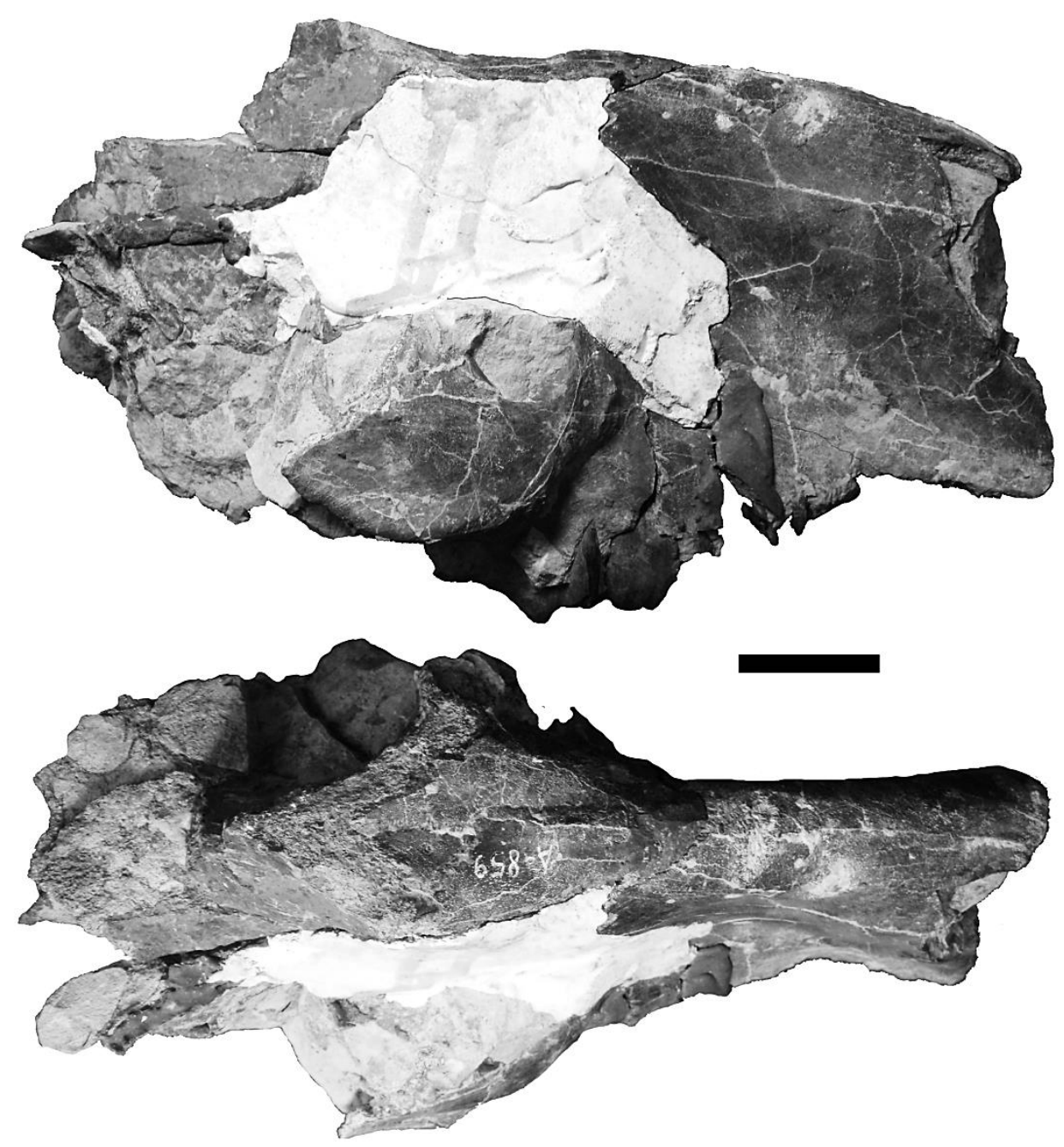

Fig. III. 17: Fragmento anterior de cráneo MACN A 859 asignado a Nesodon andium. Escala 5 $\mathrm{cm}$.

\section{—Nesodon bifurcatum (AMEGHINO 1887a)}

Combinación resultante de la sinonimia del género Atryptherium con el género Nesodon. Para más detalles, ver Atryptherium bifurcatum.

\section{—Nesodon brachycephalus AMEGHINO 1894a}

Especie fundada por Ameghino (1894a, p: 280) a partir de un cráneo en pobre estado de conservación encontrado en Corriguen-kaike. De acuerdo a la breve descripción original, presenta un tamaño mayor que el de Nesodon cavifrons y se distingue porque su cráneo es muy corto, especialmente en la porción posterior. Scott (1912) omitió completamente este taxón en su evaluación de los toxodóntidos de la Formación Santa Cruz. 


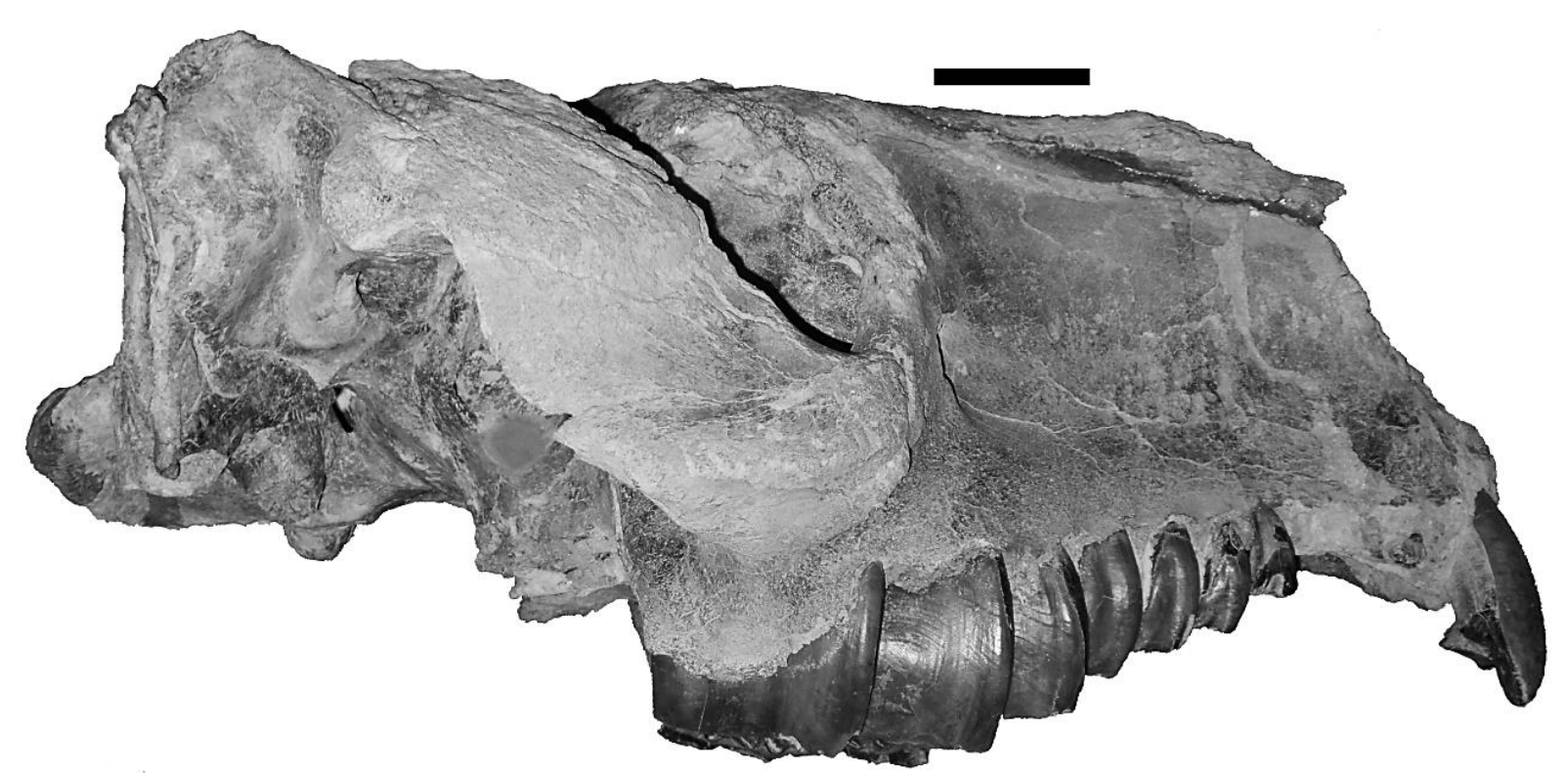

Fig. III. 18: Cráneo MACN A 5305 utilizado por Ameghino (1894a) para fundar el nombre Nesodon brachycephalus. Escala $5 \mathrm{~cm}$.

La revisión del ejemplar tipo (MACN A 5305, Fig. III. 18) y otros especímenes asignados a esta especie confirma la diferencia de tamaño (MACN A 5305, TSL $=421,91 \mathrm{~mm}$ ) con los ejemplares adultos más grandes de Nesodon imbricatus (TSL max $=476,4 \mathrm{~mm}$ ), pero no se aleja demasiado de los valores medios del tamaño total del cráneo (TSL medio $=446,4 \mathrm{~mm}$ ). Esta menor talla y las distintas proporciones se dan en otros ejemplares (Ver Tabla V. 3 para las medidas de tendencia central de ejemplares adultos y V. 5 para subadultos) y se interpretan como variaciones intraespecificas que pueden estar ligadas a diversos factores (e.g. climáticos, ecológicos), por lo que, en esta tesis, se considera a N. brachycephalus como un sinónimo júnior de $N$. imbricatus.

\section{—Nesodon cavifrons AMEGHINO 1894a}

Ameghino (1894a, p: 279-280) basó esta especie en la porción anterior de un cráneo con su mandíbula en oclusión hallado en la localidad de Monte Observación. En la descripción original, solo comentó que se trata de un espécimen de talla aproximada a Nesodon imbricatus y distinguible por poseer frontales profundamente excavados, formando una fosa elíptica, larga y profunda en la porción media del techo craneano. Scott (1912), sin embargo, estableció la sinonimia de $N$. cavifrons con $N$. imbricatus.

El ejemplar tipo (MACN A 5306) presenta, efectivamente, una excavación en el techo del cráneo, pero está lejos de la descripción de Ameghino, siendo tan solo una leve depresión 
anterior a la unión de las líneas temporales. Por ello, se confirma la sinonimia propuesta por Scott para N.cavifrons.

\section{—Nesodon conspurcatus (AMEGHINO 1887a)}

La primera mención de este nombre se encuentra en la publicación de Ameghino (1894a), donde el autor reasignó el taxón Protoxodon conspurcatus al género Nesodon (ver Protoxodon conspurcatus). Más tarde, Ameghino (1894b) lo caracterizó por poseer una talla pequeña, similar a la de Nesodon andium, por poseer un canino inferior incisiviforme e inclinado hacia adelante y por la ausencia del primer premolar (o muy rudimentario).

Scott (1912) mantuvo la validez de este taxón, aun cuando resaltó que los especímenes más pequeños de Nesodon imbricatus se acercaban al tamaño del espécimen tipo de $N$. conspurcatus. $N$. conspurcatus se ha reconocido además para niveles santacrucenses de la provincia de San Juan (López et al. 2011) y tentativamente en la Formación Cullen en Tierra del Fuego (López et al. 2016). Por su parte, Forasiepi et al. (2015, p. 615) hicieron referencia al nombre $N$. conspurcatus como una de las especies dentro del genero Nesodon, pero destacando que dicha especie y Nesodon cornutus Scott 1912 se encuentran pobremente caracterizadas.

Croft (2003) y Croft et al. (2004) comentaron sobre el estatus de este taxón, considerando que las diferencias de tamaño entre éste y $N$. imbricatus son suficientes para considerarlo un taxón distinto.

El material tipo de N. conspurcatus no ha sido localizado en el Museo de La Plata. Existe una fotografía de una mandíbula, en vista lateral, asignada a este nombre en el álbum fotográfico de Scott (Vizcaíno et al. 2017, App. 1, p: 65) que no presenta características que la distingan de $N$. imbricatus, sumado a que tampoco presenta una escala. Considerando la gran variación de talla observada en el material estudiado, las dimensiones publicadas de $N$. conspurcatus (e.g. Ameghino 1887a, Scott 1912, Croft et al. 2003) entran en un espectro continuo de variación de tamaño y no se justifica su separación específica, por lo que se propone su sinonimia con $N$. imbricatus.

\section{—Nesodon cornutus SCOTT 1912}

Esta especie fue creada por Scott (1912) a partir del cráneo YPM PU 16012 en relativamente buen estado de preservación y con la dentición severamente dañada. La describió como un taxón de talla más pequeña que Nesodon imbricatus y ligeramente más grande que $N$. conspurcatus, destacando además la presencia de un abultamiento en el hueso 
frontal, justo por delante de las líneas temporales, y que el extremo dorsal de la región occipital es alto con un diámetro dorsoventral más o menos similar al diámetro transverso, aunque el ancho supera levemente a la altura (en N. imbricatus, el diámetro transverso supera ampliamente al diámetro dorsoventral).

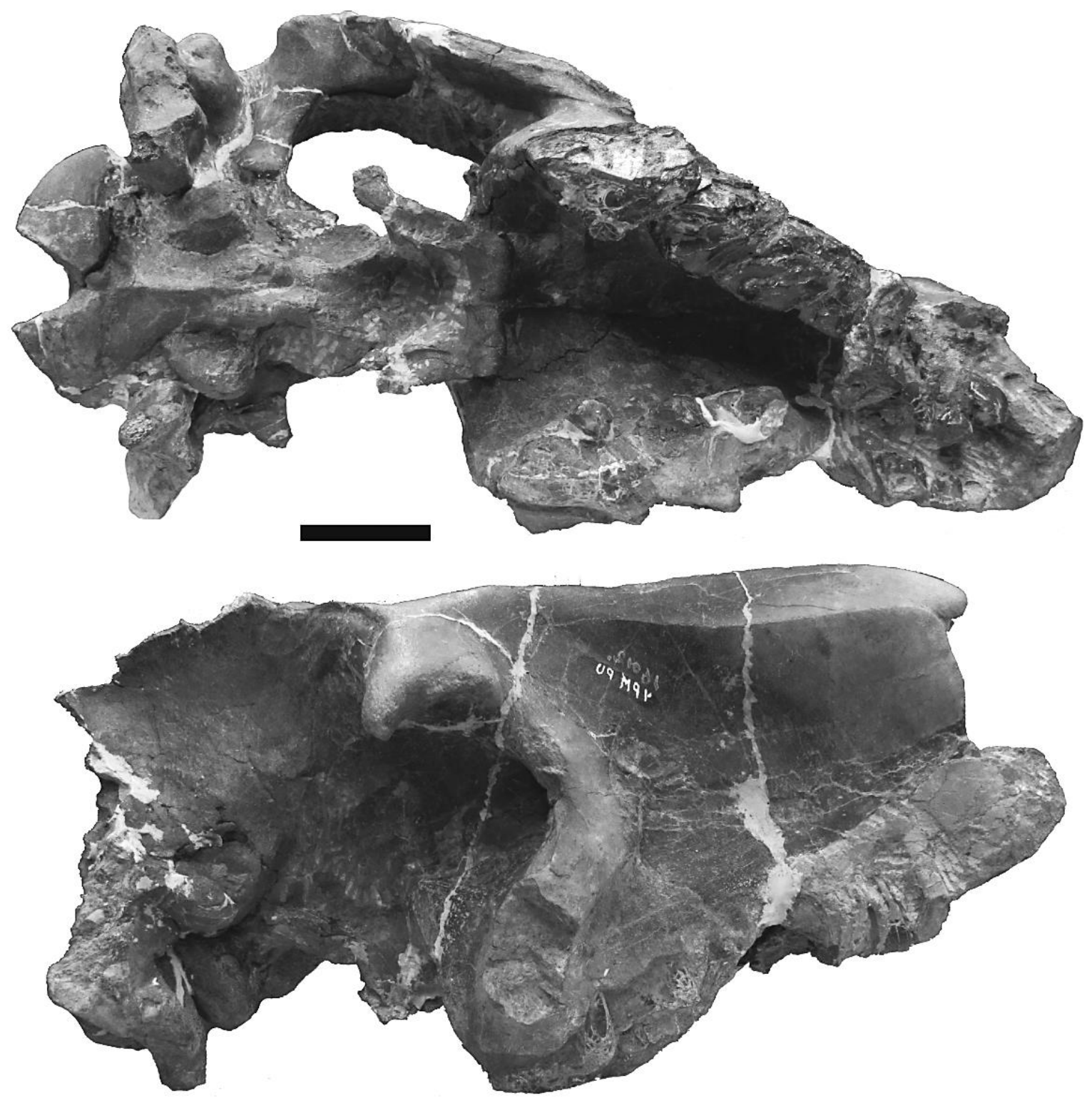

Fig. III. 19: Cráneo YPM-PU 16012 utilizado por Scott (1912) para fundar Nesodon cornutus. Escala $5 \mathrm{~cm}$.

Croft et al. (2004) comentaron sobre el estatus dudoso de $N$. cornutus, refiriéndose a que la supuesta presencia de cuernos dérmicos y las proporciones craneanas comentadas por Scott (1912) solo se encuentran presentes en el holotipo. Al igual que el nombre anterior Forasiepi 
et al. (2015, p. 615) destacan que Nesodon cornutus podría ser una especie válida, pero está pobremente caracterizada.

Al observar el ejemplar YPM PU 16012 (Fig. III. 19), se constata que los huesos frontales no poseen ningún abultamiento y que esta porción del cráneo es esencialmente plana; con respecto a la región occipital, se encuentra severamente dañada, aunque aparenta ser más cuadrada que en la mayor parte de los ejemplares de $N$. imbricatus, pero las diferencias son consideradas como variación individual (ver capítulo IV. 1 y 2), posiblemente ligada a un incipiente dimorfismo sexual, y se registran en otros ejemplares de $N$. imbricatus (e.g. AMNH 9192). Por estas razones, propongo la sinonimia del nombre N. cornutus con $N$. imbricatus.

\section{—Nesodon cyclops AMEGHINO 1887a}

Nueva combinación generada a partir de la sinonimia entre Scophotherium y Nesodon propuesta por Mercerat (1891) y Lydekker (1893). Ver Scophotherium cyclops para más detalles.

\section{—Nesodon imbricatus maior KRETZOI 1941}

La subespecie establecida por Kretzoi (1941, p: 170) se basó en dos fragmentos de paladar (NM-GPA P.V. 21) del mismo individuo, el derecho con la serie I1-C y el izquierdo con P1-M2, procedentes de Patagonia. El autor distinguió esta subespecie por el menor tamaño del espécimen respecto del resto de los ejemplares asignados a Nesodon imbricatus y las restantes especies de Nesodon. Las medidas brindadas por el autor son las siguientes: serie P1-M3 200 mm (no queda claro cómo midió la pieza faltante); serie P1-P4 82,9 mm; serie M1-M3 129,2 mm. Aun cuando la posición del primer premolar superior es variable (así cómo la presencia de diastemas entre el I3 y el P2), no existen grandes diferencias si se comparan estas dimensiones con las presentadas en esta tesis (UPL medio=193,42 mm).

No fue posible acceder al material tipo, el ejemplar no fue figurado y los datos aportados en la publicación son escasos; sin embargo, no existen razones para no aceptar la propuesta de esta subespecie.

\section{—Nesodon impinguatus AMEGHINO 1899}

Al igual que en el caso de Adinotherium rotundidens, no he logrado encontrar ninguna información referida a este taxón, a pesar de que Mones (1986) se refiere a Ameghino (1899) 
como el autor del taxón. Tampoco localicé material designado bajo este nombre en ninguna de las colecciones visitadas, razón por la cual no es posible evaluar el estatus del nombre.

\section{—Nesodon marmoratus (AMEGHINO 1887a)}

Es la combinación propuesta por Ameghino (1891) al establecer la sinonimia del género Protoxon con Nesodon. Para más detalles, ver Protoxodon marmoratus.

\section{—Nesodon ovinus OWEN 1853}

Es el nombre original establecido por Owen (1853, p: 318-319) para esta especie que, después, Ameghino (1907) propuso como perteneciente al género Adinotherium y que se ha mantenido hasta ahora (ver Adinotherium ovinum).

\section{—Nesodon oweni MERCERAT 1891}

Especie creada por Mercerat (1891, p: 399) a partir de dos fragmentos de maxilar del mismo individuo, con P4-M1 izquierdos y P1 derecho, colectados en las barrancas del río Santa Cruz. El autor atribuyó también a esta especie una mandíbula de un individuo adulto. En su escueta descripción, Mercerat se refirió a la posición y el número de los forámenes mentonianos y la diferencia de altura de la mandíbula a nivel del $\mathrm{m} 1$ y el m3. Aludió someramente a diferencias en el desarrollo de ciertas estructuras dentarias con respecto a otras especies, pero no brindó ninguna característica clara que permita distinguirla de otras especies del género Nesodon. Ameghino (1894a) estableció la sinonimia de este nombre con Nesodon imbricatus y Scott (1912) mantuvo la misma opinión.

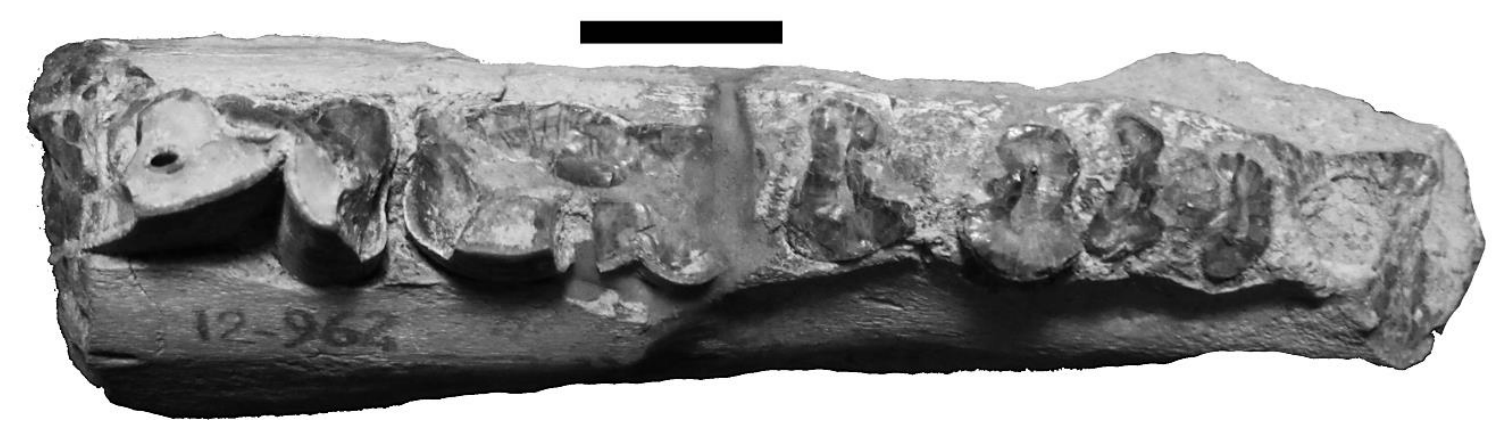

Fig. III. 20: Fragmento de mandíbula derecha con el m2 (MLP 12-962), utilizado por Mercerat (1891) para fundar el nombre Nesodon owenii. Escala $2 \mathrm{~cm}$.

De los materiales mencionados por Mercerat, solo se pudo localizar el fragmento de mandíbula (MLP 12-962, Fig. III. 20). La posición y el número de los forámenes mentonianos 
es un rasgo de variacion individual dentro de las especies de Nesodontinae de Santa Cruz. Ante la ausencia de otras diferencias, considero válida la sinonimia de $N$. oweni con $N$. imbricatus establecida por Ameghino.

\section{—Nesodon patagonicus MORENO fide AMEGHINO 1894b}

Moreno (1882, p: 22) definió esta especie como perteneciente al género Toxodon, a partir de algunos molares hallados durante su viaje a la provincia de Santa Cruz en 1876-1877. Años más tarde, Ameghino (1887a, p: 62) la traspasó al género Protoxodon, cambiando la grafía del epíteto específico (ver Nesotherium patagonense y Protoxodon patagonensis); un tiempo después, Ameghino (1891; 1894b, p: 239) reconoció que Protoxodon era uno de los tantos sinónimos del género Nesodon, estableciendo la combinación $N$. patagonicus. Scott (1912) consideró, con reservas, este nombre (y las otras dos combinaciones) como sinónimo de Nesodon imbricatus.

De acuerdo a Mones (1986) los materiales asignados a este nombre deberían encontrarse en el Museo de La Plata. La búsqueda realizada durante el desarrollo de esta tesis no permitió localizarlos, por lo que me es imposible tomar una decisión con respecto a la validez de este nombre y de los restantes sinónimos objetivos que presenta (Ne. patagonicus y Pr. patagonensis).

\section{—Nesodon patagonicum (MERCERAT 1891) non MORENO 1882}

Esta combinación propuesta por Lydekker (1893) resultó al modificar la asignación genérica de la especie Acrotherium patagonicum creada por Mercerat (1891). Ameghino (1894a) remarcó la invalidez de este nombre, ya que se había utilizado previamente (para mayor detalle, ver Acrotherium patagonicum, Nesodon patagonicus, y Protoxodon patagonicus).

\section{-Nesodon rutimeyeri MERCERAT 1891}

Establecida por Mercerat (1891, p: 402-403) a partir de una mandíbula incompleta y dos fragmentos de maxilar, uno de ellos correspondiente a un individuo joven, todos ellos colectados en la localidad de Monte León, a excepción de uno de los fragmentos de maxilar, proveniente de las barrancas del río Santa Cruz. Mercerat se refirió al tamaño mayor que el espécimen tipo de Nesodon imbricatus (Owen 1847) y a que algunas características de la dentición superior estaban más acentuadas que en otros nesodontinos, así como a los tres 
forámenes mentonianos de la mandíbula y a la falta de diastema entre los incisivos y los molares inferiores.

Ameghino (1894a) estableció la sinonimia de Nesodon rutimeyeri con N. imbricatus, mientras que Scott (1912) lo sinonimizó con N. conspurcatus.

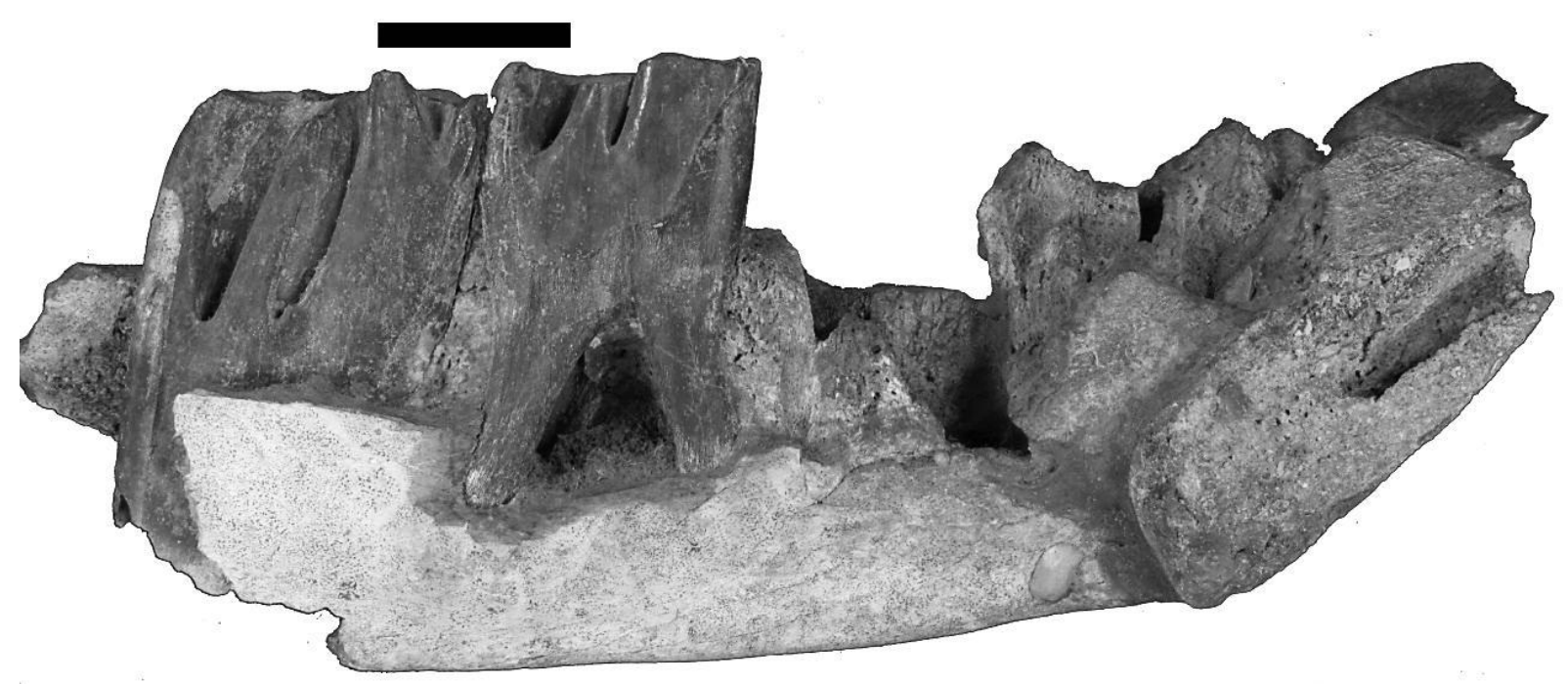

Fig. III. 21: Fragmento de mandíbula con dp4 y el m1 (MLP 12-978) utilizado por Mercerat (1891) para fundar Nesodon rutimeyeri.

El material observado (MLP 12-978, Fig. III. 21) corresponde a un fragmento de mandibula de un espécimen juvenil indiferenciable de otros atribuidos a Nesodon imbricatus, por lo que concluyo que Nesodon rutimeyeri es sinónimo de esta especie.

\section{—Nesodon sulivani OWEN 1847}

Owen (1847) definió esta especie a partir de fragmentos de molares inferiores. Ameghino (1889) consideró que correspondía al género Protoxodon, proponiendo la combinación Protoxodon sulivani; como luego Ameghino (1891) estableció la sinonimia de Protoxodon con Nesodon, se volvió a la combinación original propuesta por Owen, N. sulivani, pero, finalmente, Ameghino (1894a) la sinonimizó con Nesodon imbricatus, concepto que mantuvo Scott (1912).

No se localizó el material tipo y tampoco se encuentra listado en el trabajo de Mones (1986); por ello resulta difícil evaluar el estatus taxonómico de esta especie, pero a partir de las referencias bibliográficas y considerando que el taxón fue fundado únicamente a partir de fragmentos de molares me inclino a aceptar la sinonimia planteada por Ameghino. 


\section{—Nesodon typicus MERCERAT 1891}

Especie fundada por Mercerat (1891, p: 402-403) a partir de un fragmento de maxilar con algunos dientes, otros dientes sueltos y un fragmento de cráneo de un individuo joven (el autor no hace referencia a si pertenecen o no al mismo individuo). Según Mercerat, esta especie habría tenido una talla intermedia entre Nesodon imbricatus y Adinotherium ovinum y la caracterizó por la presencia de una arista anterolingual que se "desprende mejor" del borde del diente.

Ameghino (1894a) no mencionó este nombre en su catálogo de especies, mientras que Scott (1912) presenta a N. typicus como un sinónimo de $N$. imbricatus.

A partir del único material tipo que se localizó, el fragmento maxilar MLP 12-65, se constató que se trata de un ejemplar juvenil de $N$. imbricatus que conserva dos premolares deciduos (dP3 y dP4), el M1 y un M2 roto que no evidencia o presenta muy poco desgaste, por lo tanto, se valida la sinonimia establecida por Scott para N. typicus.

\section{2.8. Nesodonopsis ROTH 1899}

Este género fue establecido por Roth (1899, p: 181-183) a partir de un cráneo no muy bien conservado, con toda la dentadura, y dos mandíbulas. Roth señaló que Nesodonopsis habría tenido una talla menor que la de Adinotherium ovinum y características mandibulares compartidas con todos los nesodontinos.

Algunos de los caracteres que presenta este género son: dos primeros molares superiores provistos de una capa de esmalte sin interrupción; ausencia de columnas sobresalientes; molares completamente lisos, sin ondulaciones ni surcos en la cara lingual; y último molar con dos pliegues. De las cuatro especies asignadas a este género solo se menciona aquí la que procede de la Formación Santa Cruz.

Madden (1990) consideró a Nesodonopsis sinónimo de Hyperoxotodon.

\section{—Nesodonopsis speciosus ROTH 1899}

Una de las especies del género creado por Roth (1899, p: 187-188) a partir de una mandíbula que previamente Ameghino (1887a) había atribuido a Stenotephanus speciosus y que Mercerat (1891) incluyó en Protoxodon. A su vez, el mismo Mercerat (1895a) había creado después el género Hyperoxotodon sobre esta misma especie (Hyperoxotodon speciosus), añadiendo un fragmento de maxilar con algunos molares. Roth (1899) rechazó la propuesta de Mercerat (1895a) y justificó su propia propuesta genérica basándose en las 
grandes diferencias morfológicas entre la mandíbula encontrada en Santa Cruz y el molar sobre el que se basó la especie tipo de Stenostephanos (Ameghino 1885). Pascual (1954) siguió la postura adoptada por Roth y mantuvo a ambos materiales separados en asignaciones diferentes. Madden (1990) consideró a Nesodonopis y a dos de sus especies (Nesodonopsis burchardti y Nesodonopsis speciosus) como sinónimos júnior de Hyperoxotodon e Hyperoxotodon speciosus, respectivamente. Dado que Madden tuvo acceso a más materiales asignados a $H$. speciosus que los disponibles para realizar este trabajo, se acepta la sinonimia que él establece hasta tanto se pueda cotejar la mandíbula usada como tipo de Stenostephanos speciosus.

Ver más comentarios en Hyperoxotodon speciosus.

\section{2.9. Nesotherium MERCERAT 1891}

Este taxón lo estableció Mercerart (1891, p: 411-412) con la especie Nesotherium carinatum, aunque el autor reconoció su incapacidad de establecer caracteres distintivos respecto a Protoxodon, Adinotherium y Adelphotherium; comentó el menor diámetro transversal de los molares respecto a Protoxodon y la presencia de un proceso frontal triangular en los nasales que no sería un carácter de valor genérico. Mercerat describió otras nueve especies de Nesotherium en el mismo trabajo.

Ameghino (1894a) estableció la sinonimia entre Nesotherium y Nesodon, así como de las 10 especies de aquél con Nesodon imbricatus. Scott (1912) mantuvo las sinonimias propuestas por Ameghino para los siguientes nombres: Nesotherium argentinum, Ne. burmeisteri, Ne. nehringi, Ne. patagonense (con reservas), Ne. rufum, Ne. rutilum, Ne. studeri y Ne. turgidum, mientras que a Ne. carinatum y Ne. elegans los consideró sinónimos de Nesodon conspurcatus.

En esta tesis, se aceptan las sinonimias propuestas por Ameghino para todos los nombres asignados a Nesotherium a excepción de Ne. patagonense.

\section{—Nesotherium carinatum MERCERAT 1891}

La especie Nesotherium carinatum fue definida por Mercerat (1891, p: 412-413) a partir de un cráneo y una mandíbula incompleta pertenecientes al mismo individuo, colectados en las barrancas del río Santa Cruz. El autor la caracterizó por su tamaño mayor que Nesodon bifurcatus y la cara anterior de la sínfisis con una cresta medial más acentuada que en otras 
especies de Nesotherium. Además, Mercerat comentó sobre el número de forámenes mentonianos (tres) y su disposición. Respecto a la dentición superior, señaló un patrón bastante similar al de Nesodon, pero más acentuado en los últimos dos premolares.

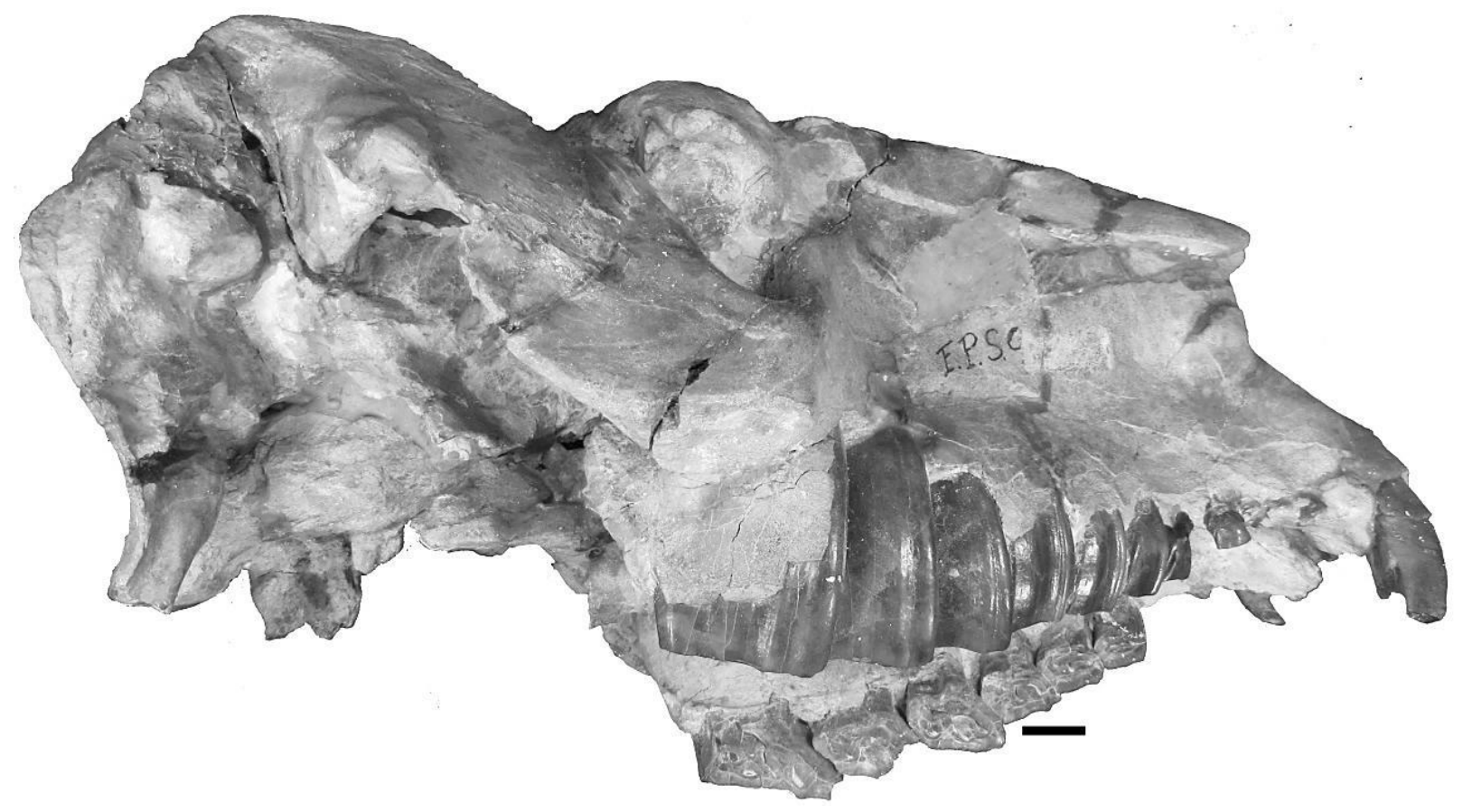

Fig. III. 22: Cráneo (MLP 12-3) utilizado por Mercerat (1891) para fundar Nesotherium carinatum. Escala $2 \mathrm{~cm}$.

El material tipo (MLP 12-3, Fig. III. 22) es de menor tamaño (TSL=373, $35 \mathrm{~mm}$ ) que la mayoría de los ejemplares de $N$. imbricatus (TSL medio adultos $=446,4 \mathrm{~mm}$ ), lo cual se explicaría por ser un individuo subadulto de esta especie (TSL medio subadultos $=387,5 \mathrm{~mm}$ ). Por lo tanto, se confirma la sinonimia propuesta por Ameghino para la especie Nesotherium carinatum y para el género Nesotherium.

\section{—Nesotherium argentinum MERCERAT 1891}

Fundada por Mercerat (1891, p: 421-423) a partir de varios especímenes: un cráneo completo y la mandíbula del mismo individuo, un cráneo y una mandíbula fragmentados, otros dos cráneos incompletos, diez fragmentos de maxilar y cinco mandíbulas. Todos estos materiales se colectaron en la localidad de Monte León y las barrancas del río Santa Cruz. De acuerdo al autor, esta especie presenta un tamaño menor que Protoxodon marmoratus y estaría caracterizada por un surco rudimentario en la columna anterolabial del P4. 


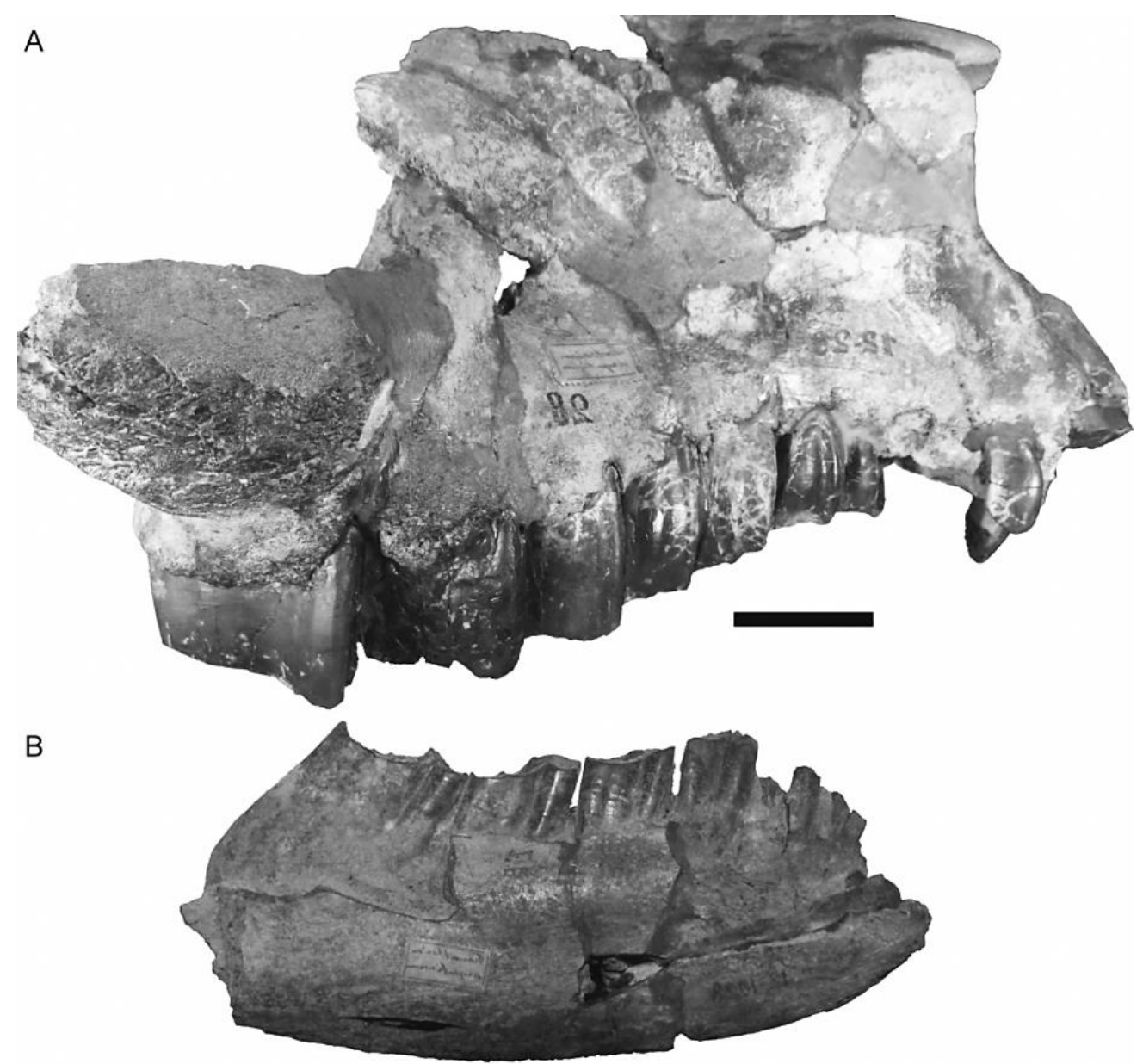

Fig. III. 23: Materiales tipo de Nesotherium artentinum Mercerat (1891). MLP 12-28 Fragmento anterior de cráneo (vista lateral izquierda reflejada), B. Fragmento de mandíbula con p4-m1 (MLP 121028). Escala $5 \mathrm{~cm}$.

De todos los ejemplares mencionados por el autor en su trabajo original, solo se localizaron tres (MLP 12-28, Fig. III. 23A; MLP 12-1028, Fig. III. 23B; y MLP 12-1043), en los que no se observa la característica distintiva brindada por el autor ni ningún otro rasgo que permita diferenciarlo de otros ejemplares de $N$. imbricatus. Por tanto, se confirma la sinonimia propuesta por Ameghino para Nesotherium argentinum con Nesodon imbricatus.

\section{—Nesotherium burmeisteri MERCERAT 1891}

Especie establecida por Mercerat (1891, p: 425) a partir de dos cráneos incompletos, uno de ellos con la serie dentaria derecha completa; ambas piezas fueron colectadas en la localidad de Monte León. De acuerdo al autor, su talla superaría la de Nesotherium nehringi y difiere de esta especie por la presencia de un diastema entre los dos primeros premolares y otro entre el primer premolar y el canino, y por la columna labial del P4 más baja y ancha, 
columna que también está bien desarrollada en el resto de los premolares, mientras que en los molares es más estrecha.

Los especímenes tipo no fueron localizados en la colección del MLP (donde correspondería según Mones [1986]) y tampoco se encontraron otros materiales asignados a este nombre, pero los caracteres señalados por Mercerat (1891) o son muy variables en el grupo (presencia de diastemas) o pueden responder a variación ontogenética ligada al desgaste dentario (columna del P4). Por ello, se confirma la sinonimia propuesta por Ameghino de Nesotherium burmeisteri con Nesodon imbricatus.

\section{—Nesotherium elegans MERCERAT 1891}

En este caso, Mercerat (1891, p: 415-416) se basó en una mandíbula incompleta encontrada en las barrancas del río Santa Cruz. Sus dimensiones eran similares a las de Nesotherium carinatum, pero la cresta de la sínfisis mandibular era menos elevada; el borde posterior de la sínfisis sobrepasaría el nivel del p4, al contrario que en el resto de las especies de Nesotherium, y el alveolo del i3 sería menos prominente. Mercerat nuevamente hizo hincapié en el número (tres) y posición de los forámenes mentonianos. Ameghino (1894a) consideró Nesotherium elegans sinónimo de Nesodon imbricatus.

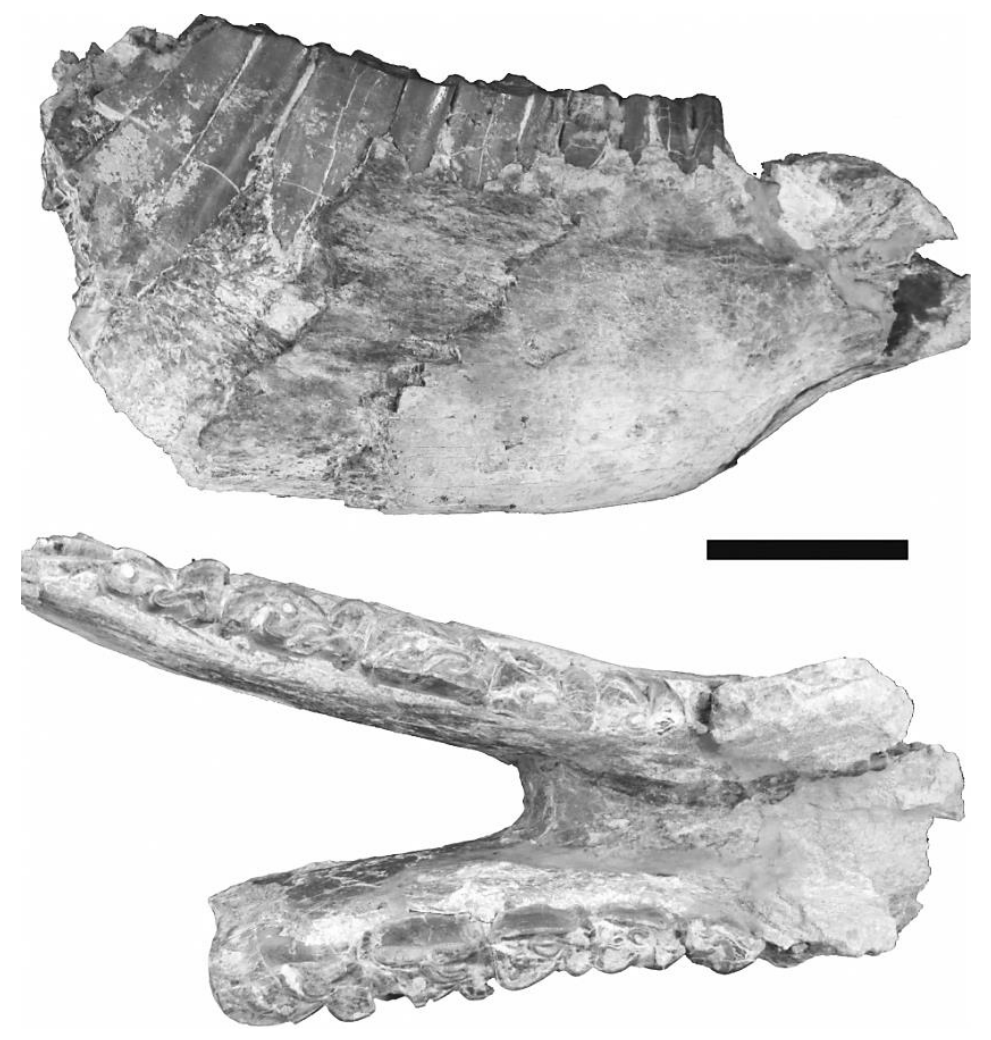

Fig. III. 24: Fragmento de mandíbula con p3-m3 izquierdos y m1-p2 derechos (MLP 12-1050) utilizado por Mercerat (1891) para fundar Nesotherium elegans. Escala $5 \mathrm{~cm}$. 
La revisión del material tipo (MLP 12-1050, Fig. III. 24) permite constatar que el borde de la sínfisis se encuentra a nivel del p4, pero no lo sobrepasa como mencionó Mercerat; además, teniendo en cuenta que la posición y el número de forámenes mentonianos es un factor variable en Nesodon imbricatus, considero que no existen rasgos distintivos para mantener la identidad del nombre Nesotherium elegans y confirmo la sinonimia propuesta por Ameghino (1894a) con N. imbricatus.

\section{—Nesotherium nehringi MERCERAT 1891}

Especie creada por Mercerat (1891, p: 423-424) a partir de un cráneo en buen estado de conservación y varios otros fragmentos de cráneo y mandíbula, casi todos ellos provenientes de la localidad de Monte León, y los restantes de las barrancas del río Santa Cruz. El autor la definió por su tamaño mayor al de Nesotherium argentinum y la elevación y la anchura del pliegue del paracono en los premolares; la mandíbula presentaría tres forámenes mentonianos.

No se pudo localizar el material asignado a Nesotherium nehringi en la colección del MLP (donde se encontraría según Mones [1986]), pero la caracterización presentada por Mercerat (1891) no justifica una especie distinta de Nesodon imbricatus, acorde a lo que expresó Ameghino (1894a).

\section{-Nesotherium patagonense (MORENO 1882)}

Nueva combinación propuesta por Mercerat (1891, p: 417) para materiales que fueron atribuidos por Ameghino (1887a) a las especies Protoxodon patagonensis y Protoxodon sulivani. El material tipo consiste en dos fragmentos de maxilar del mismo individuo y dientes aislados, colectados en las barrancas del río Santa Cruz. El fragmento de maxilar izquierdo fue figurado por Ameghino (1889 pl. XVII, fig. 6) de manera poco exacta, según Mercerat, quien señaló que los rasgos de la cara lateral de los premolares eran iguales que los de Nesodon, pero menos desarrollados que en las demás especies de Nesotherium; además, en los molares, existiría una cresta anterior claramente diferenciada que permitiría separar esta especie del resto de las especies del mismo género. Para más detalles sobre el estatus taxonómico de este nombre, ver Pr. patagonensis y Nesodon patagonicus.

\section{-Nesotherium rufum MERCERAT 1891}

Establecida por Mercerat (1891, p: 416) a partir de un fragmento de mandíbula derecha colectado en las barrancas del río Santa Cruz. De acuerdo al autor, este ejemplar se asemeja a Nesotherium carinatum, la sínfisis mandibular alcanzaría el cuarto premolar y la posición de 
los forámenes mentonianos sería diferente; además, las dimensiones relativas de los dientes diferían del resto de las especies de Nesotherium.

No se localizó el material tipo ni materiales asignados bajo este nombre en las visitas a la colección del Museo de La Plata. A partir de la descripción proporcionada por el autor, no hay razones para dudar de la sinonimia establecida por Ameghino (1894a), ya que la posición de los forámenes mentonianos, la extensión de la sínfisis mandibular y la posición relativa de las piezas dentarias son rasgos variables en los nesodontinos, especialmente los dos últimos rasgos, que también dependen del estadio ontogenético del animal. Por ello, se considera a Nesotherium rufum como sinónimo júnior de Nesodon imbricatus.

\section{—Nesotherium rutilum MERCERAT 1891}

Especie establecida por Mercerat (1891, p: 420) a partir de las series p4-m3 derecha e izquierda de un mismo individuo y otros cinco fragmentos de mandíbula, todos ellos procedentes de la localidad de Monte León. Se trataría de un taxón de mayor tamaño que Nesotherium patagonense; como características, el autor señaló que los molares presentaban una morfología similar a la de Nesodon y no estarían tan desarrollados como en Nesotherium turgidum.

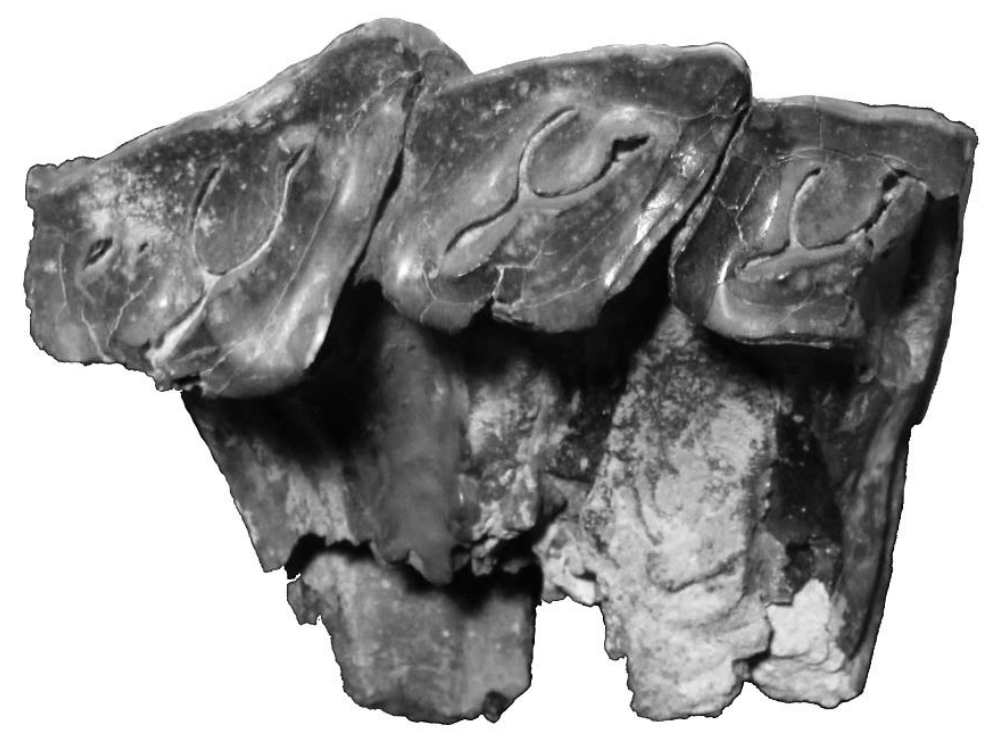

Fig. III. 25: Fragmento de maxilar izquierdo con M1-M3 (MLP 12-58) catalogado como tipo de Nesotherium rutilum Mercerat 1891. Escala $2 \mathrm{~cm}$.

Ameghino (1894a) consideró que Nesotherium rutilum era sinónimo de Nesodon imbricatus, propuesta que respaldo tras haber revisado el único ejemplar localizado asignado 
a este taxón y que figura como tipo en el catálogo de la colección del MLP, el fragmento maxilar MLP 12-58 (Fig. III. 25). Si bien el ejemplar consultado no corresponde a una mandíbula, que fue el elemento sobre el cual se basaron los rasgos distintivos de la especie (que además, no son diagnosticos), MLP 12-58 no presenta diferencias significativas con el resto de los ejemplares de $N$. imbricatus.

\section{—Nesotherium studeri MERCERAT 1891}

Especie fundada por Mercerat (1891, p: 413-415) a partir de un cráneo y una mandíbula del mismo individuo, provenientes de las barrancas del río Santa Cruz. El autor atribuyó, además, otros seis fragmentos de mandíbula de la misma localidad. Nuevamente, Mercerat fue poco claro en las características que diferenciaban este taxón del resto de los nesodontinos; solo comentó que los caracteres dentarios estaban menos acentuados que en Nesotherium carinatum y se refirió a los tres pequeños forámenes mentonianos.

El material tipo no fue localizado en las colecciones del Museo de La Plata y la caracterización brindada por el autor alude a rasgos variables (ya sea de variación individual u ontogenética) en Nesodon imbricatus, Adinotherium ovinum e incluso documentadas en otros grupos de notoungulados (e.g. Sinclair 1909); por ello, considero válida la sinonimia establecida por Ameghino (1894a) entre Nesotherium studeri y N. imbricatus.

\section{-Nesotherium turgidum MERCERAT 1891}

Mercerat (1891, p: 419-420) basó esta especie en fragmentos de cráneo y mandíbula del mismo individuo, en muy mal estado de preservación, procedentes de la localidad de Monte León. De acuerdo al autor, la talla es intermedia entre Nesotherium studeri y Ne. patagonense. Mercerat se limitó a mencionar que este taxón se distingue de los demás por las dimensiones relativas de los dientes y por el menor desarrollo de los rasgos que caracterizan los molares en el género Nesodon.

Pude consultar un único ejemplar asignado a este taxón (MLP 12-29, Fig. III. 26) y no presenta diferencias con los ejemplares de Nesodon imbricatus, por lo que confirmo la sinonimia establecida por Ameghino en (1894a) para Nesotherium turgidum. 


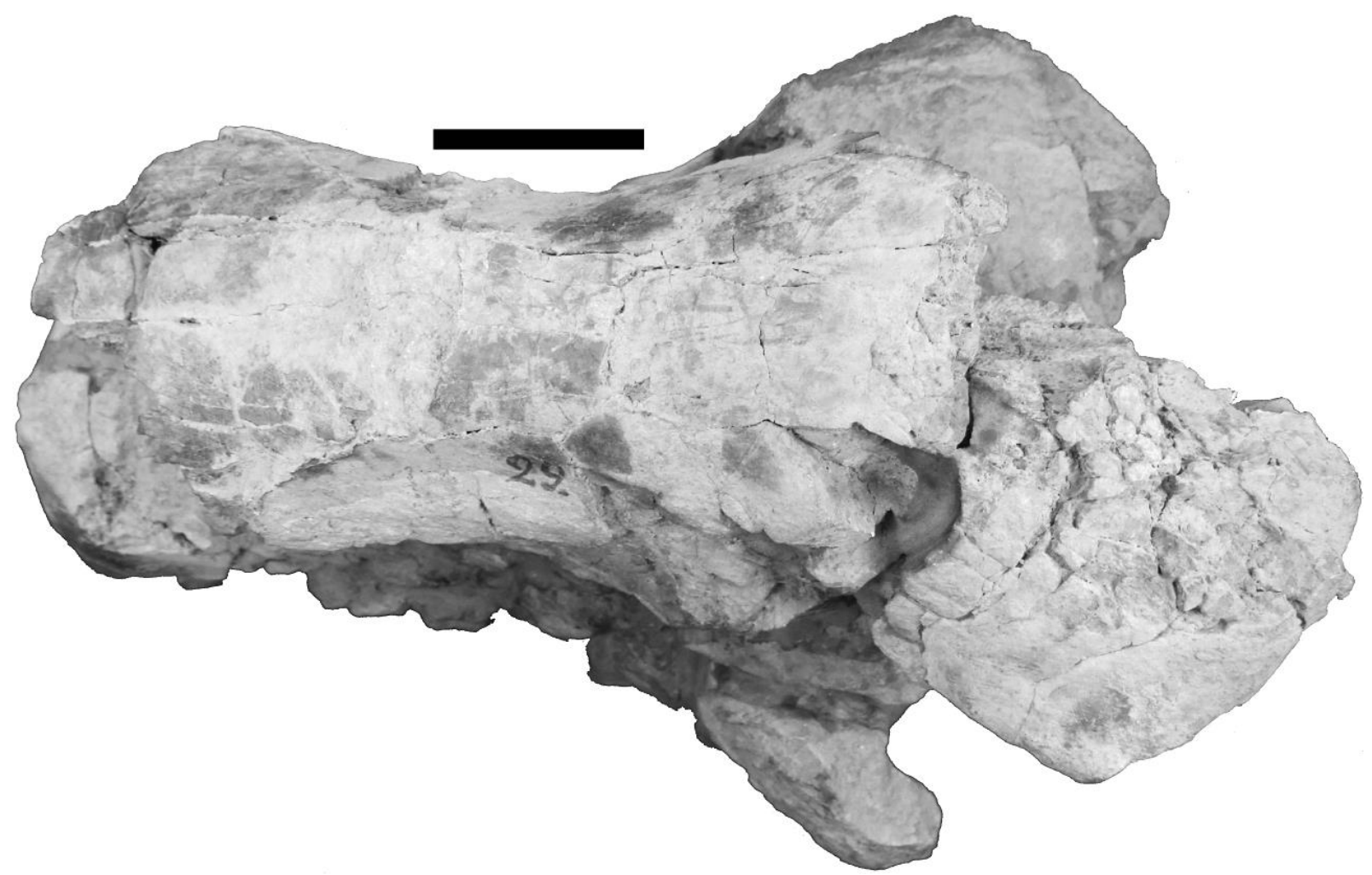

Fig. III. 26: Fragmento de cráneo (MLP 12-29) catalogado como tipo de Nesotherium turgidum Mercerat 1891. Escala $5 \mathrm{~cm}$.

\section{2.10. Noaditherium AMEGHINO 1907}

El género Noaditherium fue establecido por Ameghino (1907) y le atribuyó las siguientes características: procesos postorbitales por delante y encima de las órbitas, transformados en un par de pequeños cuernos; crestas temporales con forma sigmoidea; presencia de dos eminencias frontales; y órbitas mirando hacia adelante. La especie tipo de este género es Noaditherium splendidum, definida originalmente como Adinotherium splendidum (Ameghino 1887a).

Este género fue sinonimizado por Scott (1912) con Adinotherium, propuesta que se adopta en esta tesis, debido a que los materiales revisados no presentan rasgos que diferencien a ambos géneros. Cabe destacar que las características descritas por Ameghino para el techo del cráneo del animal no se pudieron contrastar, ya que solo se localizaron restos de paladar y mandíbula asignados originalmente a Noaditherium. 


\section{-Noaditherium splendidum (AMEGHINO 1887a)}

Como se acaba de comentar, esta combinación la estableció Ameghino (1907) para la especie Adinotherium splendidum, por considerar que difería marcadamente marcadamente del resto de los especímenes asignados al género Adinotherium: cráneo notablemente más alto; líneas temporales fusionadas en una línea sigmoidea; porción de los frontales comprendida entre las crestas temporales de contorno triangular y bastante excavada; protuberancia convexa en el extremo lateral los frontales (que no permitiría ver la órbita en vista dorsal), irregularmente circular y con superficie rugosa. Scott (1912) consideró este nombre como sinónimo de $A$. splendidum y, en esta tesis, se consideran ambos nombres ( $A$. splendidum y Noaditherium splendidum) como sinónimos júnior de Adinotherium ovinum.

\section{2.11. Phobereotherium AMEGHINO 1887a}

Género definido por Ameghino (1887a, p: 18), sin detallar las características a nivel genérico. Más tarde, Ameghino (1891) comentó que se trata de un animal pequeño que difiere del género Adinotherium por la ausencia del primer incisivo superior. Este género solo incluye la especie tipo Phobereotherium sylvaticum. Mercerat (1891) propuso la sinonimia de Phobereotherium con Adinotherium, mientras que Lydekker (1893) consideró que se trataba de un sinónimo del género Nesodon. Scott (1912) prefirió mantener la designación original de Ameghino.

\section{—Phobereotherium sylvaticum AMEGHINO 1887a}

Originalmente, Ameghino (1887a) solo se refirió a la longitud de los últimos "cinco molares superiores" (serie P3-M3) de esta especie. En 1891, Ameghino señaló que tenía una talla similar a la de las especies del género Adinotherium y compartía la ausencia de los P1. El autor también aludió a que los $\mathrm{I} 3$ y los $\mathrm{C}$ se caerían cuando el individuo alcanzaba la madurez, dejando un largo diastema entre el I2 y la serie yugal.

Mercerat (1891) propuso la nueva combinación Adinotherium sylvaticum para este taxón, interpretación desestimada tanto por Ameghino (1891, 1894a y b) como por Scott (1912).

El material tipo no pudo ser localizado en las colecciones del MLP, lo cual, sumado a que la descripción brindada por Ameghino no resulta informativa, impide comprobar la validez de este taxón. Sin embargo, existen en el álbum de Scott (Vizcaíno et al. 2017, App 1. p: 72) unas fotografías de este taxón en donde se puede observar una diferenciacion marcada en los 
surcos de la cara labial de los yugales y la superficie oclusal con un patrón muy similar al de los ejemplares juveniles de los nesodontinos; debido a la ausencia de escala en las fotografías resulta difícil establecer el estatus taxonómico de esta especie.

\section{2.12. Protoxodon AMEGHINO 1887a}

El género Protoxodon fue definido por Ameghino (1887a) con la especie Protoxodon patagonensis, pero no brindó una descripción a nivel genérico. Años más tarde, Ameghino (1889) describió las características dentarias que le daban identidad a este género, refiriéndose principalmente a la forma prismático-triangular de los molares, a la disposición de su esmalte y a la presencia de raíces abiertas. Ameghino (1887a) atribuyó a este género tres especies más (Protoxodon conspurcatus, Pr. marmoratus y Pr. obliteratus) y Mercerat (1891) le sumó otras seis (Pr. americanus, Pr. clemens, Pr. evidens, Pr. henseli, Pr. speciosus y Pr. trouessarti). Años más tarde, tras la crítica realizada por Lydekker (1893), Ameghino (1891, 1894a y b) reconoció a Protoxodon como sinónimo del género Nesodon, justificando su error en la identificación errónea que realizó Owen (1853) en la descripción original de algunas de las especies de Nesodon, unas basadas en dentición definitiva y otras en dentición juvenil.

\section{—Protoxodon patagonensis AMEGHINO 1887a, ex MORENO 1882}

Ameghino (1887a, p: 62) estableció esta combinación a partir de la especie Toxodon patagonense definida por Moreno (1882). Ameghino (1887a) señaló que era un animal de tamaño comparable al de un gran rinoceronte y presentaba muelas menos curvas que la de los verdaderos toxodóntidos (presumiblemente refieriéndose a Toxodon), caracterizando someramente las escasas piezas sobre las que basó esta especie (ver Nesodon patagonicus y Nesotherium patagonense).

\section{-Protoxodon americanus MERCERAT 1891}

Especie establecida por Mercerat (1891) a partir de fragmentos incompletos de mandíbulas colectadas en las barrancas del río Santa Cruz. El autor comparó la talla de este taxón con la de Protoxodon marmomatus y la diferenció de la misma por las dimensiones relativas del cuerpo mandibular y los dientes más anchos, así como por la posición y el número de los forámenes mentonianos. Ameghino (1891, 1894a) estableció la sinonimia de esta especie con Nesodon imbricatus, postura también adoptada por Scott (1912). 
Tras la revisión de dos (MLP 12-982, Fig. III. 27; MLP 12-981) de los materiales tipo asignados a esta especie, se constata que no presentan diferencias significativas. Por lo tanto se acepta la propuesta de Ameghino (1891) y se considera a Protoxodon americanus como sinónimo júnior de $N$. imbricatus.

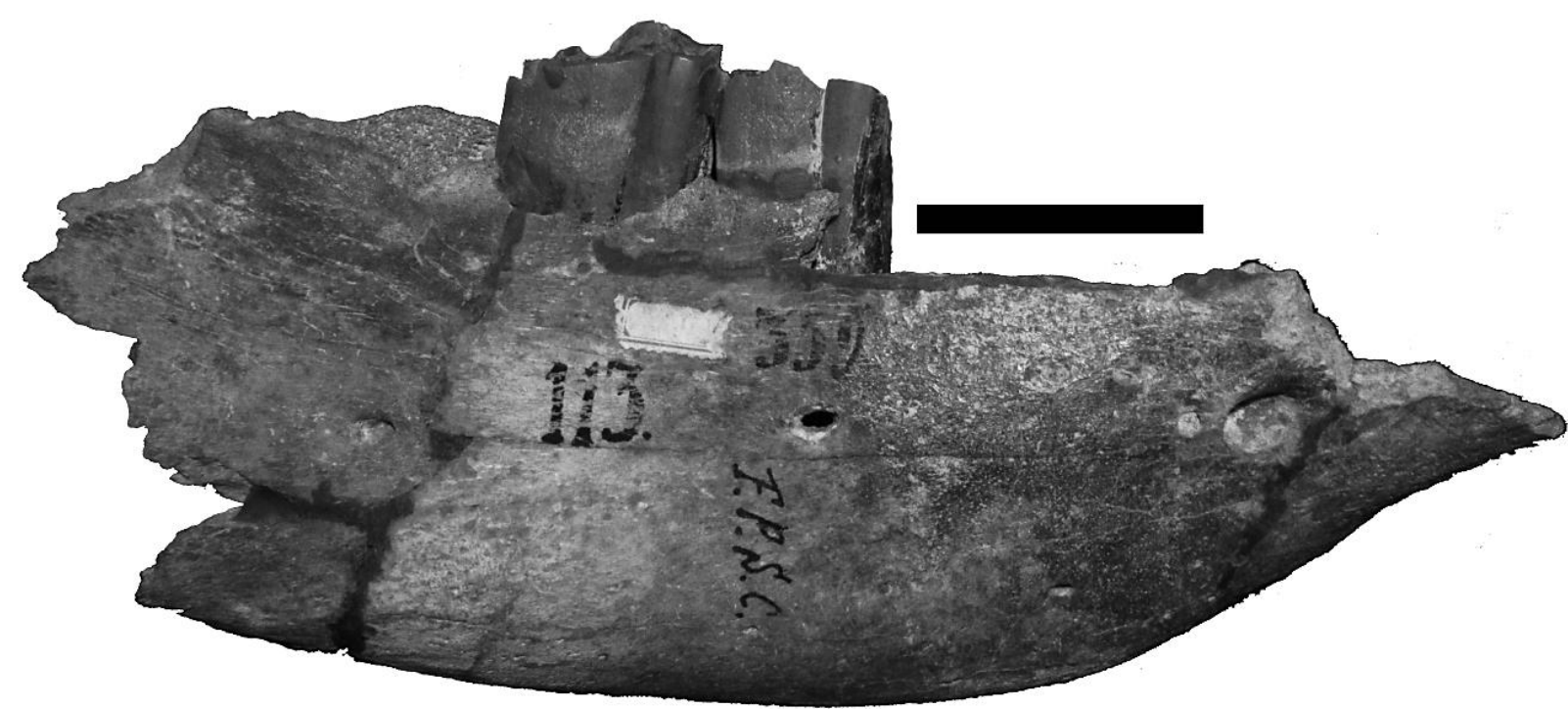

Fig. III. 27: Fragmento de mandíbula con el $\mathrm{m} 1 \mathrm{y} \mathrm{m} 2$ (MLP 12-982) utilizado por Mercerat (1891) para fundar Protoxodon americanus. Escala $5 \mathrm{~cm}$.

\section{-Protoxodon clemens MERCERAT 1891}

Especie establecida por Mercerat (1891) a partir de un cráneo incompleto y tres fragmentos mandibulares colectados en las barrancas del río Santa Cruz. El autor justificó la asignación genérica por el tamaño de los especímenes y las características de la dentición (aunque no las especificó). Al igual que en el caso anterior, Ameghino (1891, 1894a) estableció la sinonimia de esta especie con Nesodon imbricatus, aceptada también por Scott (1912).

Se revisó uno de los materiales tipo de esta especie (MLP 12-847, Fig. III. 28), un fragmento de mandíbula con la serie p2-m1, que no tiene diferencia alguna con los materiales asignados a $N$. imbricatus, por lo que confirmo la sinonimia establecida por Ameghino (1891) entre Protoxodon clemens y N. imbricatus. 


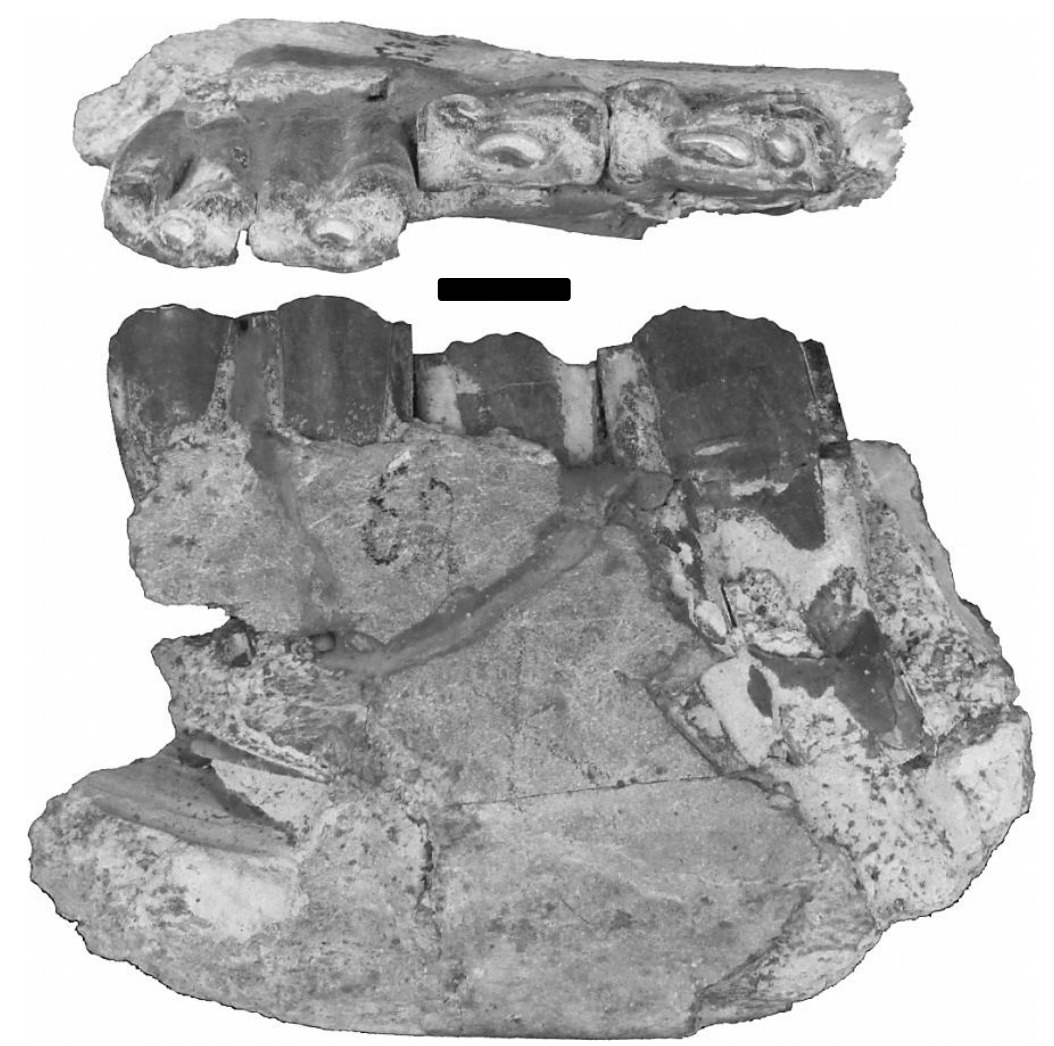

Fig. III. 28: Fragmento de mandíbula con p3-m2 (MLP 12-847) utilizado por Mercerat (1891) para fundar Protoxodon clemens, vistas oclusal (arriba) y labial (abajo). Escala $2 \mathrm{~cm}$.

\section{—Protoxodon conspurcatus AMEGHINO 1887a}

Ameghino (1887a, p: 16) definió esta especie a partir de un fragmento de paladar con las series P3-M3, correspondiente a un individuo de edad avanzada, ya que no había vestigios de los pliegues y fosetas internos de los dientes, excepto en el M3. Ameghino la distinguió por presentar un tamaño menor que Protoxodon sulivani (ver Nesodon sulivani) y por el gran tamaño del M3. La especie se mantuvo en el género Nesodon una vez que Ameghino (1891, 1894a y b) sinonimizó los géneros (ver Nesodon conspurcatus).

\section{_Protoxodon evidens MERCERAT 1891}

Taxón establecido por Mercerat (1891, p: 428-429) a partir de dos cráneos incompletos colectados en las barrancas del río Santa Cruz. Mercerat justificó la asignación genérica de esta especie por las características de la dentición y la talla del animal. El autor atribuyó con reservas algunos materiales más a esta especie, uno de ellos consistente en una mandíbula con solo dos forámenes mentonianos. Ameghino (1891, 1894a) estableció la sinonimia de Protoxodon evidens con Nesodon imbricatus, postura seguida por Scott (1912). 
Considero válida la sinonimia realizada por Ameghino dado que el ejemplar tipo de Protoxodon evidens (MLP 12-23, Fig. III. 29) no presenta características que lo distingan de otros ejemplares de $N$. imbricatus.

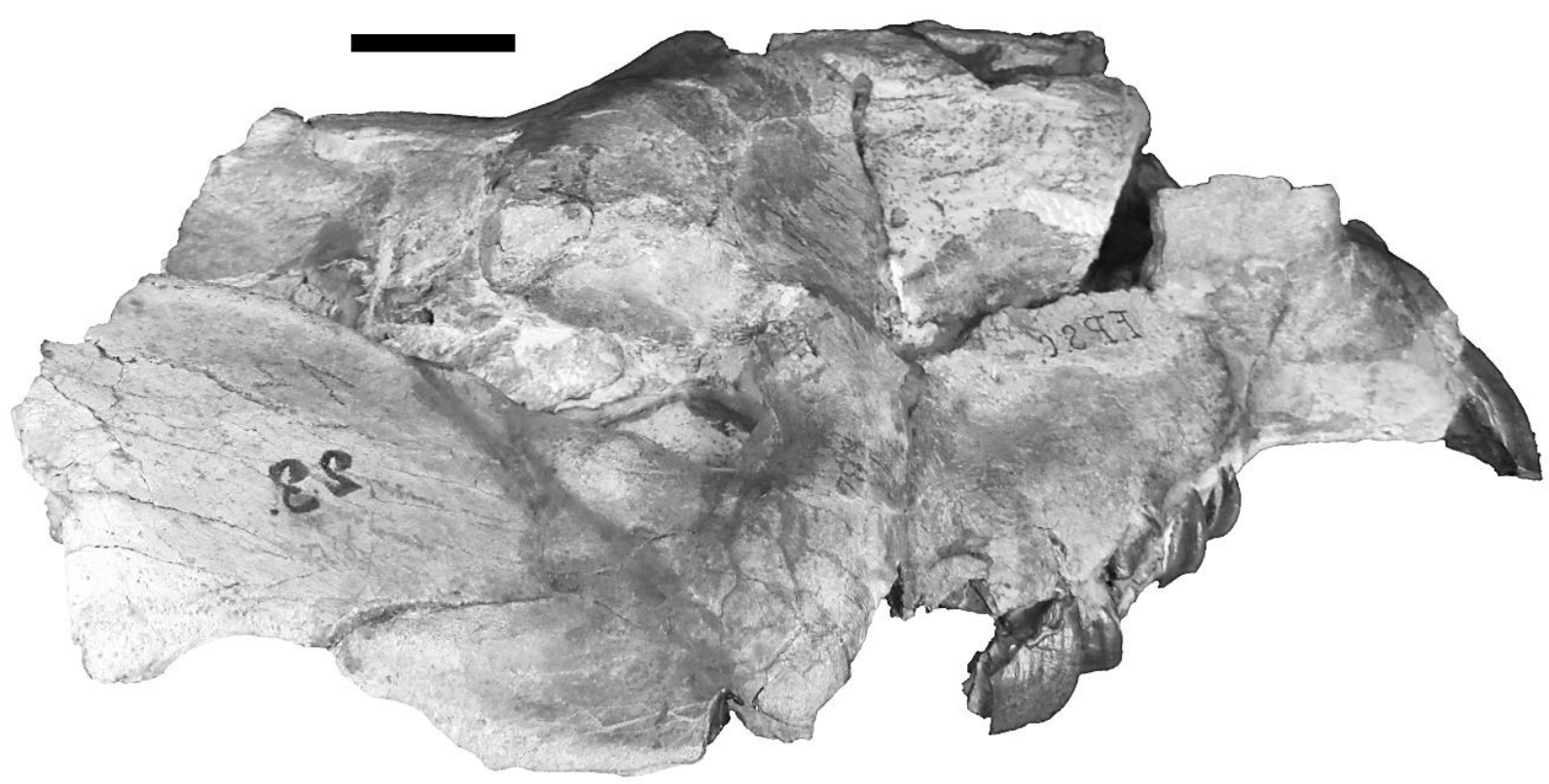

Fig. III. 29: Porción anterior de cráneo (MLP 12-23), preservando I2, P1-P2 y P4-M1 derechos, utilizado por Mercerat (1891) para fundar el nombre Protoxodon evidens. Escala $5 \mathrm{~cm}$.

\section{-Protoxodon henseli MERCERAT 1891}

Definida por Mercerat (1891, p: 435-436) a partir de una mandíbula incompleta y un fragmento de cráneo perteneciente al mismo individuo; también incluyó otro fragmento de cráneo y dientes aislados; todo este material fue colectado en las barrancas del río Santa Cruz. Mercerat basó su diferenciación en el número (cuatro) y la posición de los forámenes mentonianos. Ameghino $(1891,1894 a)$ también estableció la sinonimia de esta especie con Nesodon imbricatus, aceptada después por Scott (1912).

El material tipo no ha sido localizado en las colecciones del MLP, pero, de acuerdo a la descripción brindada por Mercerat (1891), parece justificado aceptar su sinonimia con Nesodon imbricatus, establecida por Ameghino.

\section{_Protoxodon marmoratus AMEGHINO 1887a.}

Especie definida por Ameghino (1887a, p: 16) a partir de un fragmento anterior de cráneo con casi toda la dentadura y la porción anterior de la mandíbula con todos los incisivos, el canino y los premolares, todo correspondiente al mismo individuo. Además, Ameghino 
(1887b) utilizó una mandíbula completa con toda la dentición y otras piezas aisladas para completar la definición de esta especie. De acuerdo al autor, este animal habría tenido un tamaño comparable al de Protoxodon patagonensis. Los huesos frontales carecen de procesos nasales y el M3 habría tenido un tamaño mucho mayor que el M2. Años más tarde, Ameghino (1889) amplió la descripción de este taxón y lo diferenció de Protoxodon sulivani por el mayor tamaño del M3, por presentar un rostro más ancho y bajo, nasales más largos y un prolongamiento internasal de los frontales. El mismo Ameghino (1891, 1894a y b) se refirió después a este taxón como Nesodon marmoratus, indicando su talla similar a la de Nesodon imbricatus. Scott (1912) consideró Protoxodon marmoratus como un sinónimo júnior de Nesodon imbricatus.

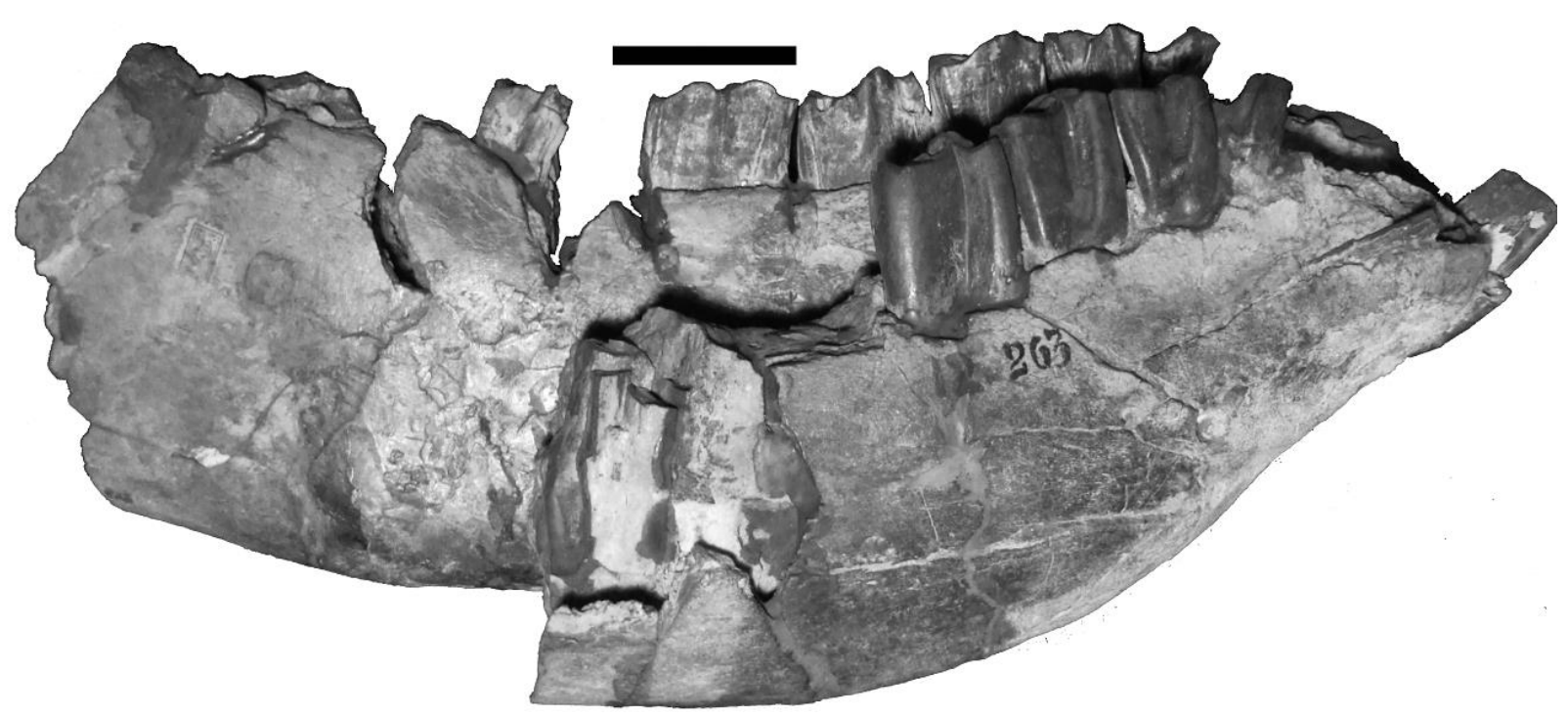

Fig. III. 30: Fragmento de mandíbula (MLP 12-263) atribuido a Protoxodon marmoratus con p1$\mathrm{p} 4 \mathrm{y}$ fragmento de $\mathrm{m} 2$ derechos y $\mathrm{p} 1-\mathrm{m} 1$ izquierdos. Escala $5 \mathrm{~cm}$.

Tras observar el único ejemplar a disposición catalogado como P. marmoratus (MLP 12263, Fig. III. 30), que no corresponde al material tipo de acuerdo al inventario, se considera justificada la sinonimia establecida previamente por Scott. Si bien fue posible cotejar la diferencia de tamaño en los molares, el tamaño relativo de estas piezas puede variar considerablemente dependiendo el grado de desgaste dentario (como fue demostrados por varios autores, ver Ameghino 1907, Scott 1912); y la ausencia de un procesos nasales en los frontales no parece una característica válida para establecer una especie independiente, considerando la variación que presenta la sutura nasofrontal en Nesodon y Adinotherium. 


\section{—Protoxodon obliteratus AMEGHINO 1887a}

Taxón establecido por Ameghino (1887a, p: 16) a partir de una mandíbula con parte de la dentición, aparentemente de un individuo muy viejo. La descripción original no resulta clara y, además, no brinda caracteres distintivos. Tiempo después, Ameghino (1889) completó la caracterización por la forma en que se encuentra implantado el último incisivo, que se dirige hacia arriba de manera más acentuada que en Protoxodon marmoratus. También se refirió al largo de la serie molar, la prematura caída del canino y el contacto del último incisivo con el primer premolar.

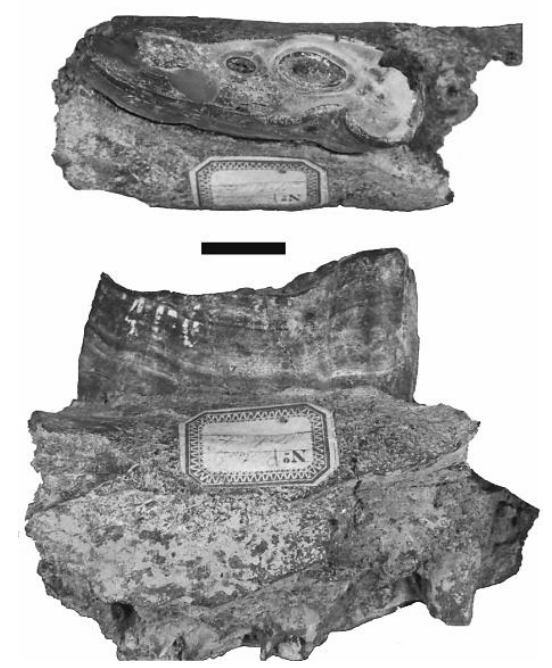

Fig. III. 31: Fragmento de mandíbula con m3 (MLP 12-940) utilizado por Ameghino (1887a) para fundar el nombre Protoxodon obliteratus. Escala $2 \mathrm{~cm}$.

En 1891, Ameghino cambió la combinación nomenclatural de este taxón a Nesodon obliteratus y Scott (1912) lo reconoció como sinónimo júnior de $N$. imbricatus.

Tras la revisión de uno de los ejemplares tipo asignados a este taxón (MLP 12-940, Fig. III. 31), perteneciente a un individuo de edad avanzada, no se encontró ninguna característica que lo distinga de los ejemplares asignados a $N$. imbricatus; por esta razón, considero válida la sinonimia establecida por Scott para Protoxodon obliteratus.

\section{—Protoxodon speciosus MERCERAT 1891}

Especie establecida por Mercerat (1891, p: 436-437) a partir de un fragmento de mandíbula derecha colectada en las barrancas del río Santa Cruz; la diferenció de otras especies por la presencia de cinco forámenes mentonianos, la posición de los mismos y la forma general de la mandíbula (no especificó las diferencias). Además, el autor comentó que 
se parecería más al género Nesotherium que a Protoxodon. Tanto Ameghino (1891, 1894a) como Scott (1912) consideraron Protoxodon speciosus sinónimo de Nesodon imbricatus.

Dicha sinonimia se considera válida en esta tesis a partir de la descripción original de Mercerat (1891), ya que no se pudo localizar el material tipo para realizar una apreciación más adecuada del estatus de este nombre.

\section{-Protoxodon trouessarti MERCERAT 1891}

Otra especie propuesta por Mercerat (1891, p: 430-431) a partir de un cráneo con un fragmento de mandíbula, este último en muy mal estado de preservación, pertenecientes al mismo individuo y colectados en la localidad de Monte León. Según el autor, presenta una talla similar a la de Nesotherium patagonense. Mercerat también se refirió al número (cuatro) y la posición de los forámenes mentonianos para diferenciar esta especie de las demás.

Al igual que en el caso anterior, este nombre fue considerado por Ameghino (1891, 1894a) y Scott (1912) como un sinónimo de Nesodon imbricatus.

No se localizó el material tipo en las colecciones del MLP. Sin embargo, considerando que el número y la posición de los forámenes mentonianos presentan un rango de variación amplio en los nesodontinos, me parece justificada la interpretación de Ameghino y Scott en cuanto a la sinonimia de Protoxodon trouessarti con Nesodon imbricatus.

\section{2.13. Rhadinotherium AMEGHINO 1887a}

Otro de los géneros creados por Ameghino (1887a, p: 18), para los que no aportó características genéricas. La especie tipo es Rhadinotherium limitatum.

Mercerat (1891) y Lydekker (1893) cuestionaron la validez del género Rhadinotherium y sostuvieron que se trataba de un sinónimo más del género Nesodon. Scott (1912) mantuvo la validez, con reservas, de la única especie Rhadinotherium limitatum, considerando únicamente la descripción original de Ameghino.

\section{—Rhadinotherium limitatum AMEGHINO 1887a}

De acuerdo a Ameghino (1887a, p: 18), se trataba de un animal de talla muy pequeña, con el I2 de forma similar a Nesodon y Adinotherium, pero más excavado perpendicularmente; también lo caracterizó por la presencia de muelas inferiores con dos raíces, a excepción de la primera; los yugales aumentando de tamaño desde el primero al último y sin cíngulo; y los verdaderos molares bilobulados. 
No se pudo localizar el material tipo de esta especie en el MLP y, por tanto, no puedo evaluar el estatus taxonómico de este nombre.

\section{2.14. Scophotherium AMEGHINO 1887a}

Al igual que el resto de los géneros establecidos por Ameghino (1887a), Scophotherium no contó con una descripción genérica, sino que describió la especie tipo S. cyclops. Más tarde, Ameghino (1891) lo caracterizó por la ausencia de canino inferior, el tamaño relativamente pequeño de sus incisivos y la presencia de cuatro raíces en p3-4, a la vez que comentó que la dentición molar era similar a la del género Atryptherium. Mercerat (1891) estableció la sinonimia entre Scophotherium y Nesodon, aceptada por Lydekker (1893). Como en otros casos ya comentados, Ameghino (1894a y b) reconoció su error al definir este género y mantuvo la sinonimia con Nesodon.

\section{-Scophotherium cyclops AMEGHINO 1887a}

Ameghino (1887a, p: 18) definió Scophotherium cyclops a partir de dos fragmentos de mandíbula, uno de ellos correspondiente a un individuo joven y el otro a un subadulto, ambos procedentes de las barrancas del río Santa Cruz. Mercerat (1891) y Lydekker (1893) cuestionaron la asignación genérica de la especie, ya que los caracteres utilizados por Ameghino (ausencia del canino inferior, últimos p3-4 y $\mathrm{m} 1$ con cuatro raíces y m2-3 con raíces abiertas) no justificaban una diferenciación genérica, y la atribuyeron a Nesodon, proponiendo la combinación Nesodon cyclops. Lydekker (1893) añadió algunos materiales más de las barrancas del río Santa Cruz y la localidad de Monte León a esta especie.

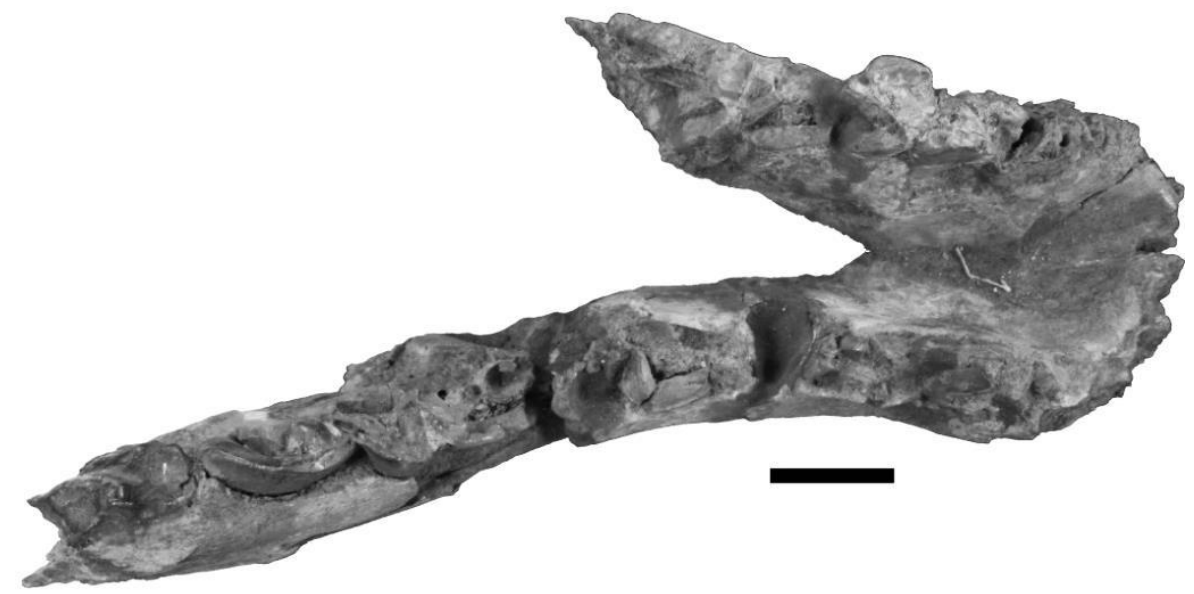

Fig. III. 32: Fragmento de mandíbula con m2 (MLP 12-58) utilizado por Ameghino (1887a) para fundar Scophotherium cyclops. Escala $5 \mathrm{~cm}$. 
Solo se pudo revisar la mandíbula MLP 12-58 (Fig. III. 32), que corresponde a un ejemplar joven (el único molar conservado, m2, presenta muy poco desgaste), y no presenta diferencias sustanciales con el resto de los ejemplares juveniles de $N$. imbricatus analizados en esta tesis.

\section{2.15. Stenotephanos AMEGHINO 1886.}

El género Stenotephanos lo fundó Ameghino (1886) a partir de un molar superior encontrado en Entre Ríos, descripto previamente como Toxodon? plicidens Ameghino 1885. Lydekker (1893, p: 24) modificó la grafía del nombre a Stenostephanus, pero Scott (1912) mantuvo la grafía original y Mones (1986) señaló que la enmienda de Lydekker fue ilegítima (para más detalles sobre este género, ver Schmidt 2013).

La especie de este género creada con materiales de la Formación Santa Cruz fue Stenostephanos speciosus.

\section{-Stenotephanos speciosus AMEGHINO 1887a}

Ameghino (1887a, p: 14-15) basó esta especie en una mandíbula (MLP 12-53) proveniente de la provincia de Santa Cruz y la atribuyó con dudas al género Stenotephanos. Tanto Mercerat (1891) como Roth (1899) propusieron asignaciones genéricas diferentes para la especie (ver Hyperoxotodon speciosus y Nesodontopsis speciosus).

El material tipo de esta especie es el ejemplar MLP 12-53 (Mones 1986), pero no se pudo localizar durante mis visitas al Museo de La Plata, con lo cual no me es posible emitir juicio sobre la validez de este nombre ni sobre las sinonimias establecidas por Mercerat y Roth, pero tal como se ha justificado antes, sigo la propuesta de Madden (1990) de utilizar el nombre Hyperoxotodon speciosus.

\section{3. Estatus taxonómico de las especies de Nesodontinae de la Formación Santa Cruz}

Como pudo apreciarse en las secciones anteriores (III. 1 y III. 2), la historia taxonómica de los Nesodontinae es sumamente compleja y se encuentra plagada de multitud de nombres 
específicos y genéricos que en su mayoría fueron sinonimizados en varios trabajos de finales del siglo XIX y en el de Scott (1912). Los trabajos de Ameghino (1887a) y Mercerat (1891) fueron los que designaron la mayoría de los taxones atribuidos a Nesodontinae y poco después comenzaron las revisiones de los mismos, planteándose ya numerosas sinonimias, como en los trabajos de Lydekker (1893) y el propio Ameghino (1894a), culminando con la revisión más detallada de Scott (1912).

Además del criterio de la época para la definición de especies, la gran cantidad de restos fósiles de los depósitos de la Formación Santa Cruz favoreció la proliferación de nombres que se han recopilado en este capítulo. Los análisis realizados en el marco de esta tesis (ver capítulos siguientes) permiten comprobar que las variaciones en la forma y el tamaño de los restos de toxodóntidos de la Formación Santa Cruz coinciden con las esperadas para algunos perisodáctilos actuales y permiten restringir la diversidad taxonómica de estos toxodóntidos a tres géneros (dos nesodontinos) con una especie cada uno. Al mismo tiempo, los numerosos ejemplares en diferentes estadios ontogenéticos muestran los cambios que se producen a lo largo de la ontogenia y permiten descartar las características diagnósticas utilizadas por Ameghino, Mercerat y Scott para definir muchos de los taxones (Ver Capitulo IV). En los siguientes apartados, se discuten brevemente estas características y se proporcionan, como corolario de todo el análisis taxonómico, las listas sinonímicas para los tres taxones de toxodóntidos de la Formación Santa Cruz que se consideran válidos: Nesodon imbricatus, Adinotherium ovinum e Hyperoxotodon speciosus, seguidas por una breve diagnosis. La descripción anatómica detallada de los dos nesodontinos se presenta en el capítulo IV.

\section{3.1. Consideraciones sobre los caracteres utilizados en la literatura para la diferenciación de especies de Nesodontinae}

A excepción de los dos ejemplares asignados orginalmente a Stenotephanos speciosus, el resto del material de toxodóntidos de la Formación Santa Cruz (particularmente el que pudo ser cotejado) se reconoce como Nesodon imbricatus o Adinotherium ovinum. La enorme cantidad de nombres creados en poco más de 20 años quizás se corresponda con el ingente material fósil proveniente de los depósitos de dicha formación, que mostraba un rango de variabilidad muy grande, no registrado para otros taxones fósiles de la región. La concepción de especie de la época (alejada de un criterio que la considere como un ente real en la naturaleza) habría llevado a los distintos autores a crear nombres específicos para documentar esta variación en la forma, en coincidencia con la búsqueda de las formas transicionales en el 
registro fósil (para mayores detalles sobre la discusión de la concepción de la variación, las especies y la forma a fines del siglo XIX y principios del siglo XX, se recomienda consultar el trabajo de Podgorny 2017). Sin embargo, la mayor parte de los rasgos utilizados corresponden a caracteres cuya variación intraespecifica ya se ha comprobado en taxones actuales; por ejemplo, la variacion en el tamaño de los individuos; la morfología de las suturas entre elementos del cráneo, especialmente la sutura fronto-nasal; o el número y la posición de los forámenes mentonianos en la mandíbula.

Uno de los rasgos más utilizados en la taxonomía de los nesodontinos ha sido el tamaño corporal. Todos los autores antes mencionados se refirieron de una u otra manera al tamaño corporal, utilizándolo como argumento para establecer nuevos nombres aun cuando la morfología era prácticamente idéntica a la de otro taxón. La interpretación más parsimoniosa para ejemplares morfológicamente muy similares, cuya única diferencia es el tamaño corporal (en ausencia de evidencias que indiquen dimorfismo sexual) es la variación individual. Scott (1912), al caracterizar las especies de Nesodon, comentó que los ejemplares asignados a Nesodon conspurcatus presentaban un tamaño similar a los más pequeños de Nesodon imbricatus dejando ver, de alguna manera, que esta diferenciación resultaba insuficiente; y trabajos más recientes (Cassini et al. 2012a, b, Cassini 2013) han llegado a conclusiones similares, dándole un marco cuantitativo más robusto, aunque abordando la problemática a una escala genérica y no específica. En los capítulos siguientes (IV y V) se mencionan aquellos rasgos cualitativos y cuantitativos registrados que aquí se consideran como variación individual.

En los últimos años, se han realizado numerosos estudios (e.g. Monteiro et al. 2005, Cardini y Elton 2009, Cardini et al. 2010, Cerqueira y Webber 2017, Jojić et al. 2017) que demuestran como la asociación entre la morfología y la ecología puede aportar información relevante para interpretar los patrones de expresión fenotípica y que una de las claves de este tipo de estudios no solo consiste en saber si el ambiente tiene una influencia o no en el desarrollo de la forma, sino que también se busca interpretar cómo lo hace. Los resultados de estos estudios sugieren que, en líneas generales, tanto el tamaño como la forma pueden verse altamente influenciados por cuestiones ecogeográficas o por variación a lo largo de una cline. Cardini et al. (2007), a partir del uso de morfometría geométrica, encontraron que gran parte de la variación de forma y tamaño en una muestra de 306 cráneos del primate Cercopithecus aethiops está explicada por la variación clinal, siendo la geografía y la estructura del ambiente las variables que mejor explicaron la variación del tamaño en la muestra. Los estudios como los antes citados son cada vez más comunes en la literatura y, afortunadamente, nos fuerzan a 
modificar la concepción de especie en paleontología para trasladarla al contexto actual de la morfología comparada. En el caso concreto de los nesodontinos de la Formacion Santa Cruz, Tauber (1997a) indicó la presencia de diferentes indicadores climáticos para los depósitos de dicha formación; por un lado, la presencia de primates y roedores equímidos y eretizóntidos indicaría climas húmedos y cálidos, con la presencia de bosques en algunas zonas de la formación; por otro lado, la presencia de cristales de yeso, grietas de desecación, posibles paleodunas y otros rasgos sedimentarios (Tauber 1997a, Bown y Larriestra 1990) sugerirían zonas con climas más secos, hipótesis coherente con la diversidad de armadillos registrada por Vizcaíno et al. (2006). Por otro lado, a nivel estratigráfico, la Formación Santa Cruz presenta niveles de fangolitas de origen volcánico, intercalados con depósitos de toba sin retrabajar (Bown y Fleague 1993), que sugieren que la cantidad de abrasivos presentes en la dieta de los herbívoros podría haber cambiado de manera notable a lo largo del tiempo en que fueron depositados los sedimentos de la formación. Según Barreda y Palazzesi (2007), habrían existido tanto ambientes abiertos como cerrados en la Formación Santa Cruz; estos últimos probablemente hubieran correspondido a bosques en galería, mientras que hacia el final del Mioceno temprano habrían prevalecido condiciones más aridas que posibilitaron el aumento de las floras xerofíticas en la región. Vizcaíno et al. (2012a), proveen muchos argumentos que avalan la interpretación mencionada anteriormente y que, son compilados por Kay et al. (2012) al realizar una reconstrucción del escenario paleoecológico para los niveles fosilíferos 1 a 7 definidos por Tauber.

En ultima instancia, es razonable incluso considerar que las dos especies de Nesodon $(N$. imbricatus y $N$. taweretus) y Adinotherium ovinum compartan identidad genérica, ya que muchas de las características que diferencian ambos géneros probablemente hayan estado correlacionadas con el tamaño corporal.

Las dos especies de nesodontinos de Santa Cruz que se consideran válidas en esta tesis, además de distinguirse por una diferencia discreta de tamaño, presentan un conjunto de características constantes en casi todos los ejemplares asignados a cada una de ellas, que las definen como posibles entidades diferentes en la naturaleza (ver III. 3.2 y III. 3.3). Como se verá en los capítulos siguientes, la muestra analizada en este trabajo demuestra que existe un espectro más o menos continuo de tamaño para cada una de las dos especies y que los únicos ejemplares que se solapan son los adultos de A. ovinum con los ejemplares más jóvenes de $N$. imbricatus (ver capítulo V), resultados que respaldan los obtenidos por Cassini et al. (2012b, Cassini 2013) a partir de morfometría tradicional y geométrica. 
Además de la variación individual, otro de los factores que puede generar variación en la talla es el dimorfismo sexual, tal como ocurre en la mayoría de los ungulados de gran tamaño (actuales y fósiles; e.g. Weckerly 1998, Perez-Barberia et al. 2002, McPherson y Chenoweth 2012). Ejemplos sobre la variación asociada al dimorfismo sexual son recurrentes en la literatura zoológica y aquí solo se ejemplificará utilizando el análogo tradicional para los toxodóntidos, los rinocerontes. Se ha propuesto la existencia de dimorfismo sexual en diversas especies fósiles de Rhinocerotoidea (e.g. Duchesneodus uintensis, Megacerops, Diplacodon elatus), particularmente vinculada al mayor o menor desarrollo de los cuernos y del i2, e incluso al desarrollo de otras estructuras craneanas tales como los nasales y los arcos cigomáticos (e.g. Peterson 1914, Scott 1945, Lucas and Schoch 1989, Mead 2000, Mihlbachler et al. 2004, Mihlbachler 2011).

Si bien se ha especulado con la presencia de un dimorfismo sexual en los nesodontinos, este se definió a partir del desarrollo del I2 e i3, y la posible presencia de cuernos. En los próximos capítulos, se trata con mayor profundidad la hipótesis sobre la presencia de cuernos (IV) y el dimorfismo sexual en Nesodontinae (IV y V).

Otro de los rasgos que ha sido utilizado (especialmente por Mercerat) para establecer nombres dentro del grupo son los forámenes mentonianos. El foramen mentoniano es la estructura que transmite el nervio alveolar inferior (una parte de la rama mandibular del trigémino) y los vasos sanguíneos asociados hacia la encía (Schaller 2007). La forma, el tamaño y la disposición de estos forámenes han sido bien estudiados en diversos taxones de homínidos; incluso, se han detectado casos donde existen tres forámenes mentonianos en los humanos, cuando lo normal es que haya uno (e.g. Sawyer et al. 1998, Ramadhan et al. 2010, Imada et al. 2014). Otro ejemplo encontrado en la litetarua es el del marsupial Lestodelphys halli (Didelphiomorphia) que típicamente presenta dos forámenes (Wible 2003), pero el primero es más conspicuo y estable en su posicion, mientras que el segundo foramen es más variable; además, pueden existir hasta dos forámenes más, pequeños y siempre distribuidos entre las dos aberturas principales (Martin 2005). Los forámenes mentonianos pueden variar, incluso, entre las dos ramas mandibulares del mismo individuo, como se ha observado, por ejemplo, en un ejemplar de Pyrotherium (Cerdeño y Vera, 2017); en Trachytherus y Archeohyrax, el número de forámenes es variable y su posición está relacionada al estadio ontogenético del animal (Billet et al. 2008 y 2009).

En cuanto a la dentición, numerosos autores se han referido a la variabilidad en los nesodontinos (e.g. Ameghino 1891, 1894b, 1907, Scott 1912, Madden 1990, 1997) y hasta en otros Toxodontidae (e.g. Pericotoxodon, ver Madden 1990, 1997). A partir de los ejemplares 
Hernández Del Pino, S.

analizados, puede concluirse que los molares de los adultos de $N$. imbricatus y A. ovinum (dejando a un lado la diferencia obvia de tamaño) no presentan características conspicuas que los distingan, a excepción quizás de la mayor anchura relativa y mayor simplicidad de los molares inferiores en A. ovinum, y el mayor grado de hipsodoncia de los molares inferiores y superiores en esta especie (ver Cassini et al. 2012b, y Cassini et al. 2017). De más está decir que gran parte de los nombres atribuidos a estos dos taxones (principalmente por Mercerat 1891) son el registro de una variación ontogenética y hasta individual dentro de un espectro continuo de formas (especialmente en la dentición molar, que presenta crecimiento continuo durante gran parte de la vida del animal), y que no existen rasgos sustanciales que puedan diferenciar la dentición dentro de los Nesodontinae.

\section{3.2. Nesodon}

En este apartado, se proveen las listas sinonímicas correspondientes al género Nesodon y a la especie reconocida en la Formación Santa Cruz, Nesodon imbricatus, así como la diagnosis de la especie. Aquellos valores indicados con un * fueron tomados de Cassini et al. (2017) y los indicados con ** de Cassini et al. (2012b).

\section{Nesodon Owen 1847}

Nesodon Owen 1847, p: 66.

Astrapotherium Burmeister (en parte) 1879, p: 517.

Toxodon Moreno (non Owen) 1882, p: 22.

Colpodon Burmeister (en parte) 1885, p: 161.

Adelphotherium Ameghino 1887a, p: 16.

Acrotherium Ameghino (en parte) 1887a, p: 17.

Gronotherium Ameghino 1887a, p: 17.

Scophotherium Ameghino 1887a, p: 18.

Protoxodon Ameghino 1887b, p: 62.

Nesotherium Mercerat 1891, p: 386.

\section{Nesodon imbricatus Owen 1847}

Nesodon imbricatus Owen 1847, p: 66.

Nesodon sulivani Owen 1847, p: 66. 
Colpodon propinquus Burmeister (en parte) 1885, p: 66.

Protoxodon conspurcatus Ameghino 1887a, p: 16. Nov. syn.

Protoxodon marmoratus Ameghino 1887b, p: 16.

Protoxodon obliteratus Ameghino 1887b, p: 16.

Adelphoterium ligatum Ameghino 1887a, p: 16.

Acrotherium rusticum Ameghino 1887a, p: 17.

Scophotherium cyclops Ameghino 1887a, p: 17.

Protoxodon sulivani (Owen 1847) Ameghino 1889, p: 443.

Nesodon imbricatus Ameghino 1889, p: 488.

Acrotherium patagonicum Mercerat 1891, p: 389-391.

Acrotherium australe Mercerat 1891, p: 391.

Acrotherium intermedium Mercerat 1891, p: 392.

Acrotherium variegatus (sic) Mercerat 1891, p: 392.

Nesodon oweni Mercerat 1891, p: 392.

Nesodon cyclops (Ameghino) Mercerat 1891, p: 400.

Nesodon rutimeyeri Mercerat 1891, p: 401. Nov. syn.

Nesodon typicus Mercerat 1891, p: 402.

Nesotherium carinatum Mercerat 1891, p: 412.

Nesotherium studeri Mercerat 1891, p: 413.

Nesotherium elegans Mercerat 1891, p: 415.

Nesotherium rufum Mercerat 1891, p: 416.

Nesotherium turgidum Mercerat 1891, p: 419.

Nesotherium rutilum Mercerat 1891, p: 420.

Nesotherium argentinum Mercerat 1891, p: 421.

Nesotherium nehringi Mercerat 1891, p: 423.

Nesotherium burmeisteri Mercerat 1891, p: 425.

Protoxodon evidens Mercerat 1891, p: 428.

Protoxodon clemens Mercerat 1891, p: 430.

Protoxodon trouessarti Mercerat 1891, p: 430.

Protoxodon americanus Mercerat 1891, p: 431.

Protoxodon decrepitus (Ameghino1887b) Mercerat 1891, p: 432.

Protoxodon henseli Mercerat 1891, p: 435.

Protoxodon speciosus Mercerat 1891, p: 435.

Adelphotherium lutarium Mercerat 1891, p: 438. 
Adelphotherium trivium Mercerat 1891, p: 438.

Adelphotherium repandum Mercerat 1891, p: 439.

Adelphotherium rothi Mercerat 1891, p: 440.

Adelphotherium pumilum Mercerat 1891, p: 440.

Nesodon conspurcatus (Ameghino 1887b) 1891, p: 377. Nov. syn.

Nesodon andium Ameghino 1891, p: 377.

Nesodon marmoratus Ameghino 1891, p: 377.

Nesodon patagonicus (Mercerat 1891) Lydekker 1893, p: 36.

Nesodon obliteratus Ameghino 1891, p: 377.

Nesodon cavifrons Ameghino 1894, p: 23.

Nesodon brachycephalus Ameghino 1894, p: 24. Nov. syn.

Nesodon cornutus Scott 1912, p: 196. Nov. syn.

Diagnosis: Toxodóntidos de gran tamaño $\left(\mathrm{mc}_{1 / 2}=1157,76 \mathrm{~kg}^{*}\right.$ a partir de medidas mandibulares; o $\mathrm{mc}_{1 / 2}=637,5 \mathrm{~kg}^{* *}$ a partir de medidas del cráneo), con cráneo largo y relativamente angosto $\left(\mathrm{TSL} / \mathrm{BZB}_{1 / 2}=2,01\right)$, especialmente en su porción anterior; rostro largo $\left(\mathrm{MZL} / \mathrm{BCL}_{1 / 2}=1,43 ; \mathrm{MZL} / \mathrm{TSL}_{1 / 2}=0,47\right)$ y estrecho $\left(\mathrm{MZW}_{\mathrm{MZL}_{1 / 2}}=0,34\right)$ en comparación con los toxodontes más derivados, con los nasales marcadamente convexos; presencia de una constricción postorbitaria; cresta sagital conspicua aunque corta en relación al largo total del cráneo; porción posterior del cráneo estrecha $\left(\mathrm{BCB} / \mathrm{BZB}_{1 / 2}=0,34\right)$; ausencia de constricción palatal; bordes posteriores de las arcadas dentarias poco divergentes $\left(\mathrm{MZW} / \mathrm{PAB}_{1 / 2}=0,58\right)$, resultando en un paladar largo y estrecho $\left(\mathrm{PAL} / \mathrm{TSL}_{1 / 2}=0,58 ;\right.$ y $\left.\mathrm{PAL} / \mathrm{PAB}_{1 / 2}=1,97\right)$, excavado en su porción más anterior. Cavidad del endocráneo larga, estrecha y de poca altura, con bajo ángulo de flexión $\left(31^{\circ}\right)$, con poco espacio respecto al tamaño del animal $(\mathrm{EQ}=0,34)$ y con escasa diferenciación entre la porción que aloja al encéfalo anterior y la del encéfalo posterior; canal orbitotemporal poco desarrollado en comparación con otros Toxodontia (e.g. Homalodotherium, Rhynchippus); fosa hipofisiaria amplia y con poca extensión ventral. Mandíbula sin constricción a nivel de los premolares y ramas mandibulares poco divergentes. P3, P4 y molares superiores con foseta central en forma de "Y"; una o dos fosetas accesorias en los molares poco gastados; molares de crecimiento prolongado durante gran parte de la vida del animal (protohipsodontes, HI M3 ${ }_{1 / 2}=3,24 * *$ ). Molares inferiores protohipsodontes $\left(\mathrm{HI} \mathrm{m} 3_{1 / 2}=3,3^{*}\right.$ ), con trigonido pequeño y triangular, y talónido bilobulado en los individuos adultos jóvenes, dándole un aspecto trilobulado a todo el diente; presencia de fosétida, 
pudiendo haber fosétidas accesorias en los molares con poco desgaste, patrón oclusal de la corona complejo con un grado alto de crenulaciones para el linaje (ECC $\left.\mathrm{m} 3_{1 / 2}=1.21^{*}\right)$.

Diagnosis diferencial: Nesodon imbricatus presenta un mayor tamaño corporal que al menos quintuplica el de Adinotherium y Proadinotherium. Rostro proporcionalmente más largo y basicráneo más corto que en Proadinotherium y Adinotherium. Frontales más largos y estrechos, que raramente presentan rugosidades, y con los procesos postorbitales menos proyectados lateralmente $\mathrm{y}$ una constricción postorbital menos desarrollada (LIB/POC $1 / 2=1,28)$ que en Adinotherium ovinum y Proadinotherium muensteri. Cresta sagital más baja y de menor extensión que en Adinotherium y Proadinotherium. Bulbos olfatorios más largos que en Adinotherium y bajos. Molares superiores menos hipsodontes que en Adinotherium y Proadinotherium; patrón oclusal de la corona de los molares inferiores ligeramente más complejo que en Adinotherium y Proadinotherium, y con un menor índice de hipsodoncia. Nesodon imbricatus difiere de Nesodon taweretus por su mayor tamaño, por poseer una región anterior del cráneo relativamente más larga y angosta, menor desarrollo de los senos frontales y procesos postorbitales más gráciles y conspicuos.

\section{3.3. Adinotherium}

En este apartado, se proveen las listas sinonímicas correspondientes al género Adinotherium y a la única especie reconocida, Adinotherium ovinum, con su correspondiente diagnosis.

\section{Adinotherium Ameghino 1887a}

Adinotherium Ameghino 1887a, p. 17.

Nesodon Owen (en parte) 1853, p: 291.

Adinotherium Ameghino (en parte) 1887a, p: 17.

Acrotherium Ameghino (en parte) 1887a, p: 17.

Atryptherium Ameghino 1887a, p: 18. Nov. syn.

Nesodon Lydekker (en parte) 1893, p: 25.

Noaditherium Ameghino 1907, p: 84

\section{Adinotherium ovinum (Owen 1853) Ameghino 1907}

Adinotherium ovinum (Owen 1853) Ameghino 1907, p: 72-74. 
Nesodon ovinus Owen 1853, p: 291.

Adinotherium magister Ameghino 1887a, p: 17.

Adinotherium proximum Ameghino 1887a, p: 17.

Adinotherium splendidum Ameghino 1887a, p: 17. Nov. syn.

Adinotherium ferum Ameghino 1887a, p: 18.

Adinotherium nitidum Ameghino 1887a, p: 18.

Atryptherium bifurcatum Ameghino 1887a, p: 18. Nov. syn.

Acrotherium karaikense Mercerat 1891, p: 131.

Acrotherium mutabile Mercerat 1891, p: 393.

Nesodon bifurcatus Mercerat 1891, p: 397. Nov. syn.

Nesodon typicus Mercerat 1891, p: 402.

Adinotherium pulchrum Mercerat 1891, p: 407.

Adinotherium antiquum Mercerat 1891, p: 410.

Adinotherium karaikense (Mercerat 1891), p: 410-411.

Adinotherium kobyi Mercerat 1891, p: 410.

Adinotherium haplodontoides Ameghino 1891, p: 129.

Acrotherium stygium Ameghino 1887a, p: 135. Nov. syn.

Adinotherium ovinum (Owen 1853) Ameghino 1891, p: 376.

Adinotherium robustum Ameghino 1891, p: 376.

Nesodon ovinus Lydekker (en parte) 1893, p: 25.

Nesodon imbricatus Lydekker 1893, p: 26.

Adinotherium rotundidens Ameghino 1899, p: 6. Nov. syn.

Adinotherium corriguenense Ameghino 1907, p: 77. Nov. syn.

Noaditherium splendidum Ameghino 1907, p: 84. Nov. syn.

Diagnosis diferencial: Toxodóntido de pequeño tamaño $\left(\mathrm{mc}_{1 / 2}=102.82 \mathrm{~kg} *\right.$; o $\left.\mathrm{mc}_{1 / 2}=113,26^{* *}\right)$ con cráneo más corto $\mathrm{y}$ ancho que en Nesodon imbricatus $\left(\mathrm{TSL} / \mathrm{BZB}_{1 / 2}=1,55\right)$, pero más largo y estrecho que en los toxodontes más derivados, con dos constricciones marcadas: la constricción palatal a nivel de los P1-P2 y la constricción postorbitaria, posterior a los procesos postorbitales del frontal casi a nivel de la sutura frontoparietal, mucho más marcada que en Nesodon imbricatus (LIB/ $\mathrm{POC}_{1 / 2}=1,53$ ). Rostro ligeramente más corto $\left(\mathrm{MZL} / \mathrm{BCL}_{1 / 2}=1,41 ;\right.$ y $\left.\mathrm{MZL} \mathrm{TSL}_{1 / 2}=0,48\right) \quad$ y ancho $\left(\mathrm{MZW} / \mathrm{MZL}_{1 / 2}=0,35\right)$ que en $N$. imbricatus, en una condición similar a los de los toxodóntidos más derivados; sutura fronto-nasal más variable y frontales más cortos y anchos 
que en $N$. imbricatus, a menudo con presencia de rugosidades más conspicuas en las proximidades de las líneas temporales; borde posterior del paladar más ancho que en $N$. imbricatus $\left(\mathrm{MZW} / \mathrm{PAB}_{1 / 2}=0,52 ; \mathrm{PAL} / \mathrm{TSL}_{1 / 2}=0,57 ; \mathrm{PAL} \mathrm{PAB}_{1 / 2}=1,78\right)$; porción posterior del cráneo más larga, con cresta sagital más alta y notablemente más larga que en $N$. imbricatus. Osificación del tentorio en el petroso (rasgo que comparte con algunos Notohippidae, García López [2017] comunicación personal). Cavidad encefálica más voluminosa y globosa que en $N$. imbricatus $\left(\mathrm{EQ}_{1 / 2}=0,51\right)$ y con un ángulo de flexión más grande $\left(39^{\circ}\right)$; con una marcada separación del encéfalo anterior y posterior; bulbos olfatorios más cortos y altos que en $N$. imbricatus y canal orbitotemporal más desarrollado; fosa hipofisiaria amplia y voluminosa. La mandíbula es más corta y presenta una constricción marcada a nivel de los p1, a partir de la cual las ramas divergen en un angulo mayor que en $N$. imbricatus. Dentición superior con la corona más simple que en $N$. imbricatus, con P2, P3 y P4 divididos en dos lóbulos por un surco labial y molares más hipsodontos (HI M3 $\left.3_{1 / 2}=3,24 * *\right)$ que en $N$. imbricatus; molares inferiores con trigónido más amplio, talónido más angosto, mas hipsodontes ( $\mathrm{HI} \mathrm{m} 3_{1 / 2}=4,71^{*}$ ) y con un patrón oclusal ligeramente menos complejo que en $N$. imbricatus (ECC $\mathrm{m} 3_{1 / 2}=$ $\left.1,18^{*}\right)$. Postcráneo mucho más pequeño y más grácil que en $N$. imbricatus.

\section{3.4. Hyperoxotodon}

Es el toxodóntido más enigmático y menos frecuente de los presentes en los depósitos de la Formación Santa Cruz. Si bien se conoce solo por dos restos (de los cuales, solo pude revisar uno), la morfología de los dientes indica que se trataría de un toxodóntido derivado que no se encuentra cercanamente emparentado con los nesodontinos de la Formación Santa Cruz.

En este apartado, se proporcionan las listas sinonímicas para el género Hyperoxotodon y la especie Hyperoxotodon speciosus, seguidas por una breve diagnosis de la especie (a partir de Lydekker 1893 y Madden 1990) basada en el maxilar a disposición. Como fue mencionado en los apartados de los correspondientes nombres sinonimizados, el ejemplar MLP 12-53 que serviría como material tipo para Stenostephanos speciosus y Nesodonopsis speciosus no fue ubicado. Por lo tanto, estas listas sinonímicas (basadas en Madden 1990) están pendientes de una revisión posterior cuando pueda ubicarse el tipo de Stenostephanos speciosus. 


\section{Hyperoxotodon Mercerat 1895a}

Hyperoxotodon Mercerat 1895, p: 305.

? Stenotephanos (en parte) Ameghino 1887a, p: 107.

? Stenosthephanus (en parte) Lydekker 1893, p: 24.

Nesodonopsis (en parte) Roth 1899, p: 181-183.

\section{Hyperoxotodon speciosus (Ameghino) 1887a Mercerat}

Hyperoxotodon speciosus (Ameghino) Mercerat 1895, p: 305.

? Stenotephanos speciosus Ameghino 1887a, p: 14.

? Stenostephanus speciosus (emmend. Illegit pro Stenotephanos) Lydekker 1893, p:

24.

? Nesodonopsis burckardti Roth 1899, p: 183-187

? Nesodonopsis speciosus Roth 1899, p: 187-188.

Diagnosis (modificada a partir de Madden 1990): Molares superiores euhipsodontes, más angostos y curvados en su cara labial que en los nesodontinos de Santa Cruz, rasgo que se vuelve más notorio en el M3. Molares superiores imbricados y dispuestos en una serie oblicua en una condición similar a la de Xotodon; patrón oclusal muy simple, con fosetas accesorias efímeras en estadios tempranos de desgaste (circular y central en los premolares superioires); surco lingual simple en los molares y un segundo surco más corto en el M3, delimitando lóbulos anterolinguales y posterolinguales relativamente más cortos y anchos que en los géneros Xotodon y Toxodon; ectolofo suavemente cóncavo. Molares inferiores euhipsodontes, con fosétidas accesorias efímeras y pliegue ento-hipocónido. Talla menor que en Hemixotodon y M3 proporcionalmente más ancho y con inflexión distolingual más débil. Difiere de Xotodon en los premolares superiores más anchos, con parastilo y foseta central diferenciados, y en los premolares inferiores con pliegues y fosétidas más persistentes; los molares inferiores tienen el paracónido comprimido mesiodistalmente y sin esmalte, que no sobresale lingualmente como en Xotodon, y la cara labial es convexa.

\section{3.5. Nomina dubia}

Todos aquellos nombres sobre los cuales no he podido emitir juicio, debido a la ausencia de los materiales tipo, que además no han sido figurados y cuyas descripciones son 
insuficientes, se proponen como nomina dubia (= nombres dudosos) hasta tanto los ejemplares tipo puedan ser localizados y se pueda cotejar la validez de los mismos.

Toxodon patagonensis Moreno (nomen nudum) 1882, p: 22.

Adelphotherium ligatum Ameghino 1887a, p: 16.

Gronotherium decrepitum Ameghino1887a, p: 17.

Phobereotherium sylvaticum Ameghino 1887a, p. 18.

Rhadinotherium limitatum Ameghino 1887a, p: 18.

Protoxodon patagonensis (Moreno) Ameghino, 1887b, p: 66.

Acrotherium intermedium Mercerat 1891, p: 392.

Adinotherium antiquum Mercerat 1891, p: 410.

Adelphotherium rothi Mercerat 1891, p: 440.

Nesotherium patagonense (Moreno) Mercerat 1891, p: 417.

Paleolithops praevium Ameghino 1891, p: 240.

Nesodon impinguatus Ameghino 1899, p: 6. 


\section{Capítulo IV. Descripción anatómica}

En este apartado se describe, en primera instancia, el cráneo (incluyendo a la mandíbula) de Nesodon imbricatus y luego se describe de forma comparativa el de Adinotherium ovinum. Las descripciones dentarias presentadas aquí son breves, pero se consideran suficientes para atender al problema taxonómico a resolver, ya que la morfología dentaria de las especies santacrucenses está detallada en trabajos previos (e.g. Ameghino 1907, Scott 1912, Madden 1990); sin embargo, sí se brindan figuras de la dentición para diferenciar las distintas clases de edad y mostrar cómo varían en la ontogenía del animal.

Para la confección de las descripciones, se tomó como punto de partida el trabajo de Scott (1912), actualizando la nomenclatura y las interpretaciones sobre los elementos que componen algunas de las estructuras; además, se añade la descripción de varios elementos de la anatomía interna de los Nesodontinae, muchos de los cuales no han sido tratados aún en la literatura. Debido a que esta tesis se enfoca en la descripción de aspectos craneanos no dentarios de los toxodóntidos de Santa Cruz y a que el material disponible de Hyperoxotodon speciosus en un fragmento de paladar con tres molares (holotipo, MLP 12-59) (no se han encontrado nuevos registros en la FSC ni otras localidades santacrucenses), esta especie no se trata en este apartado y se sugiere la consulta de Madden (1990) para mayores detalles que complementen la breve diagnosis brindada en el capítulo anterior (III. 3.4).

Posteriormente, se incluyen las descripciones de otras especies, tanto de toxodóntidos como de otras familias afines ("Notohippidae", Homalodotheriidae), relevantes para la comparación anatómica del craneo, ya sea por afinidad filogenética o por ser contemporáneos, resaltando las diferencias que presentan con los nesodontinos presentes en la Formación Santa Cruz.

\section{1. Nesodon imbricatus}

\section{—Generalidades}

Nesodon imbricatus (Fig, IV. 1) es una de las especies más comunes entre los ungulados de la Formación Santa Cruz (Scott 1912); sus restos se encuentran conservados en diversas colecciones alrededor del mundo y se conoce prácticamente todo el esqueleto del animal; 
incluso, se conocen diversos estadios ontogenéticos postnatales, desde edades tempranas de desarrollo hasta la senilidad (Fig. IV. 2).

En vista dorsal (Fig. VI. 1A), el cráneo es más o menos triangular, alargado en sentido anteroposterior, con su ancho máximo a nivel del arco cigomático, a la altura de la fosa glenoidea. Scott (1912) fue el primero en referirse a la variación del perfil dorsal del cráneo desde levemente plano en la porción más rostral (en la mayor parte de los ejemplares adultos) a un perfil que se eleva abruptamente desde la frente hasta la porción occipital. A diferencia de Adinotherium, Nesodon imbricatus posee una única constricción marcada que se encuentra inmediatamente por delante de la sutura fronto-parietal, desplazada caudalmente detrás de la órbita (constricción postorbitaria). A nivel del maxilar, justo por detrás de la sutura con el premaxilar, hay un leve estrechamiento del hocico, nunca tan marcado como en Adinotherium. El techo craneano es ligeramente convexo y, a nivel de la sutura entre parietales, se desarrolla la cresta sagital que es muy pronunciada y se encuentra delimitada por los bordes bien definidos de las líneas temporales, estando proporcionalmente más extendida que en el género Toxodon, pero de menor extensión que en Adinotherium. El tamaño relativo del hocico respecto de la porción posterior del cráneo es más o menos variable en Nesodon imbricatus $\left(\mathrm{MZL}_{\min } / \mathrm{BCL}_{\min }=1,27\right.$ y $\left.\mathrm{MZL}_{\max } / \mathrm{BCL}_{\max }=1,47\right)$, pero, en líneas generales, presenta un rostro levemente más largo $\left(\mathrm{MZL}_{1 / 2} / \mathrm{BCL}_{1 / 2}=1,43\right)$ y una región posterior del cráneo más angosta que Adinotherium y los toxodóntidos más derivados; respecto de otros taxones de la Formación Santa Cruz, el rostro de $N$. imbricatus es mayor que en Homalodotherium y duplica la extensión del de Notohippus. A pesar del tamaño de la región posterior del cráneo, la cavidad encefálica es relativamente pequeña $(\mathrm{Eq}=0,34)$. El yugal y el escamoso forman el arco cigomático, que es largo y relativamente grande, aunque se encuentra lateralmente comprimido. El arco cigomático se curva ligeramente en su recorrido y encierra una fosa temporal amplia. De acuerdo a Scott (1912), uno de los rasgos más notorios del arco cigomático de los nesodontinos es cómo se eleva desde su margen anterior al posterior, donde contacta con la cresta nucal; la elevación del arco cigomático es un rasgo común a varios Toxodontia, e incluso es usado por Ciffelli (1983, p: 203) en su definición de Notoungulata, pero en el caso particular de los Toxodontidae, la elevación del arco cigomático es mas abrupta y marcada que en los restantes Toxodontia (Fig. IV. 1B y IV. 2B). 
Hernández Del Pino, S.

A

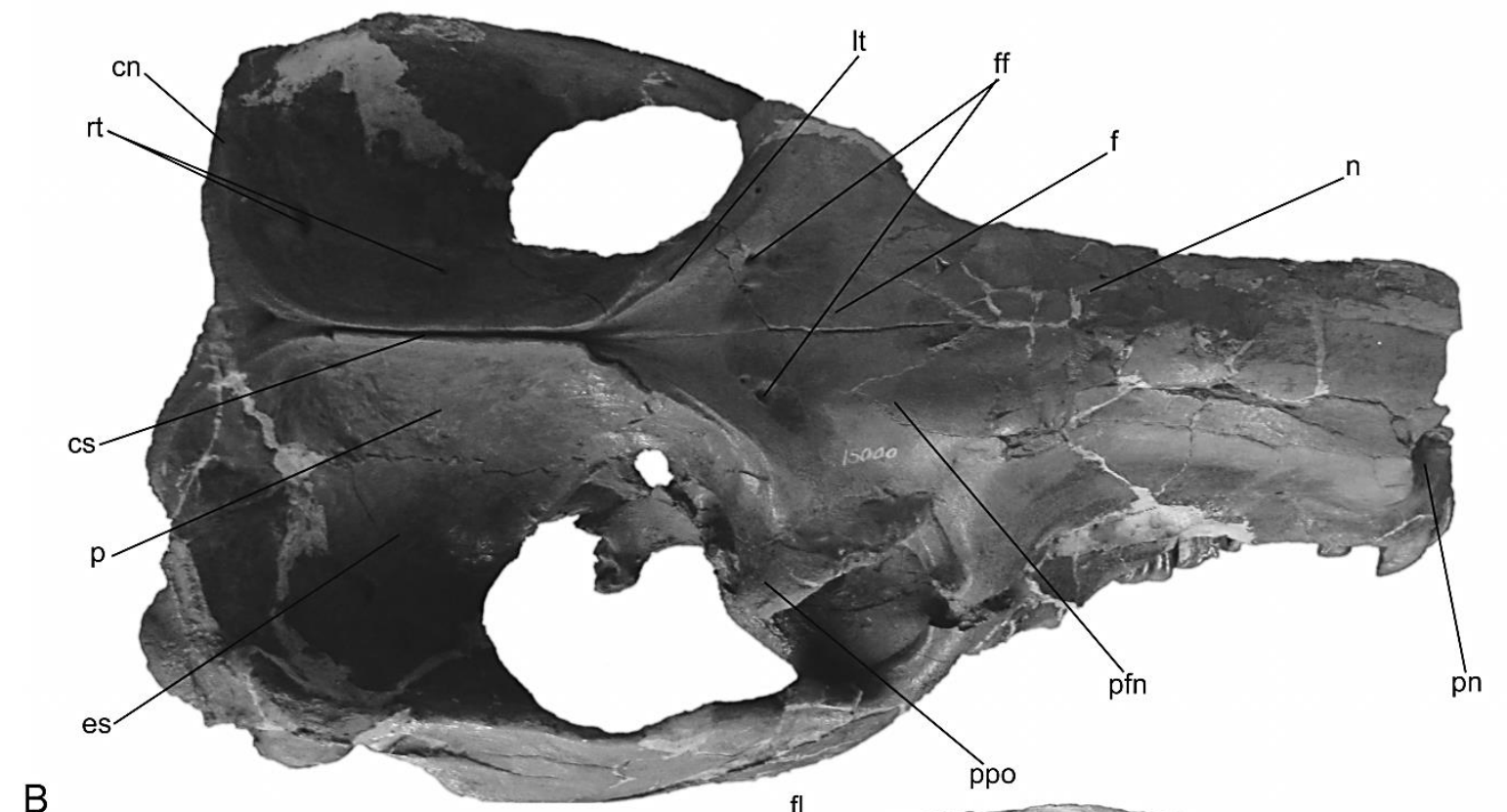

B
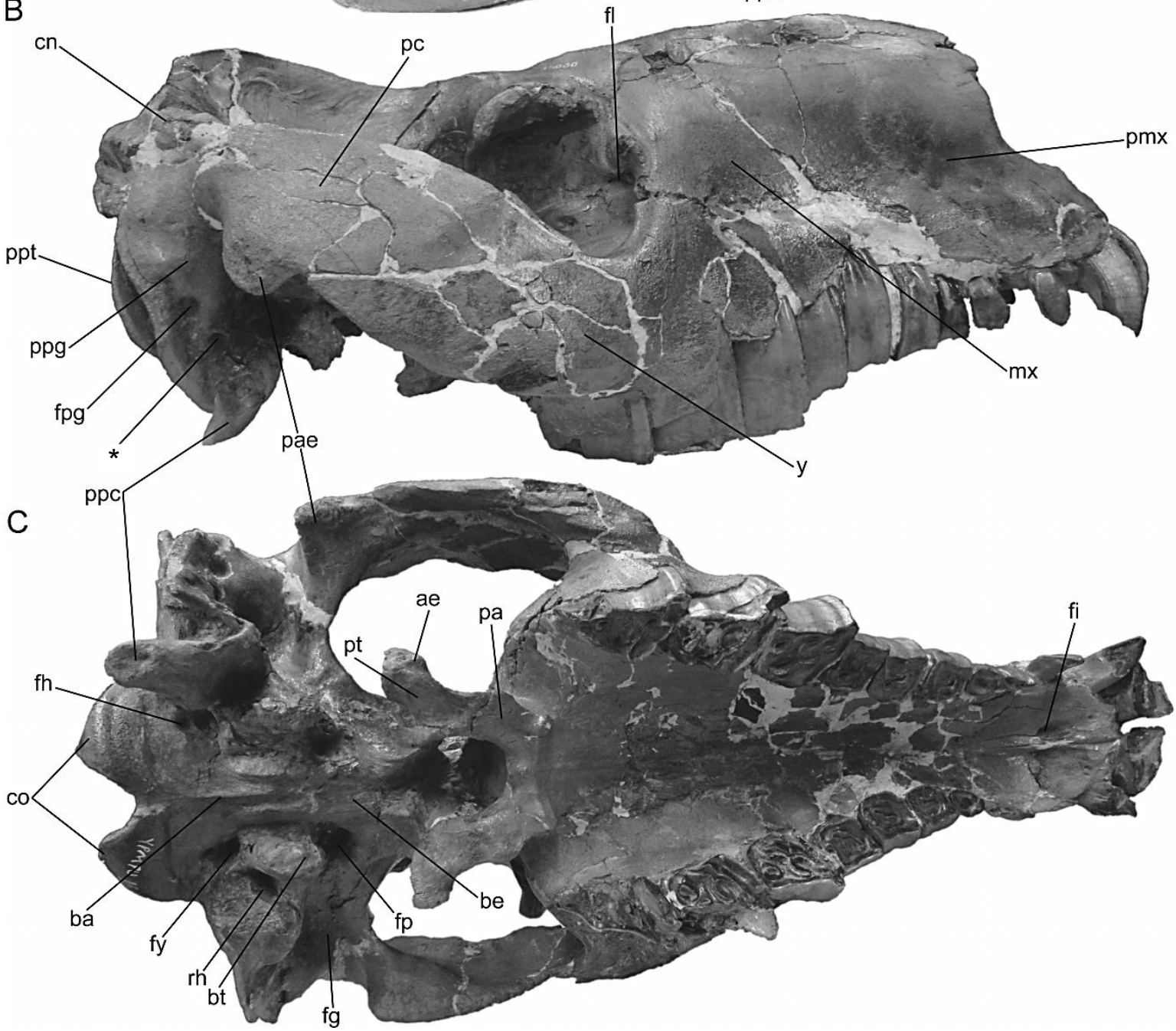

Fig. IV.1: Cráneo de los Nesodontinae indicando las principales estructuras (ejemplificadas a partir de Nesodon imbricatus, YPM-PU 15000): Vistas dorsal (A), lateral derecha (B), ventral (D). * Foramen accesorio del sistema postglenoideo. 

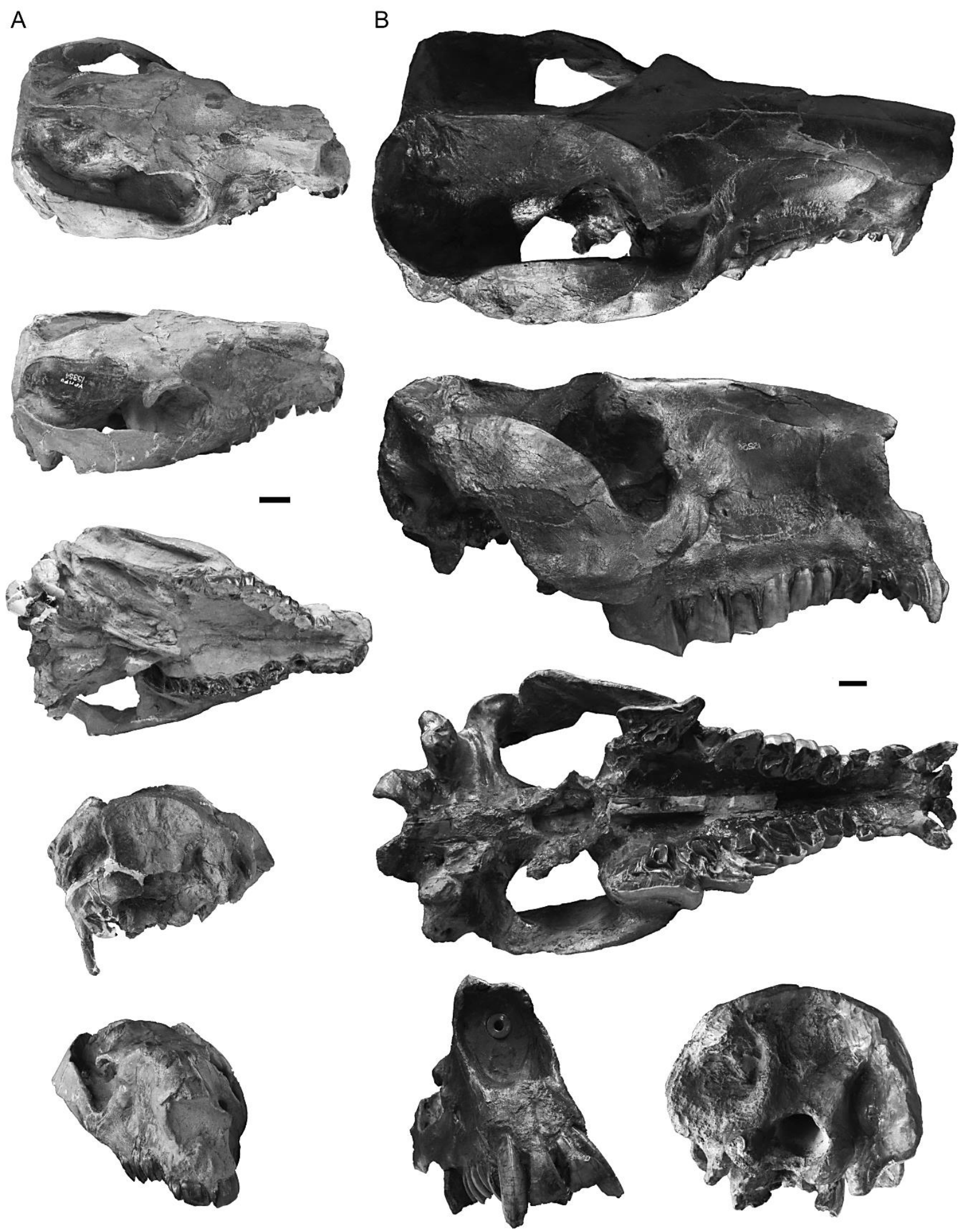

Fig IV.2: Variación ontogenética en los caracteres craneanos de Nesodon imbricatus: Vistas (de arriba hacia abajo) dorsal (reflejada), lateral derecha, ventral (reflejada), posterior y anterior del ejemplar juvenil YPM-PU 15354 (A); vistas dorsal (reflejada), lateral izquierda (reflejada), ventral, anterior y posterior del ejemplar adulto YPM-PU 15256 (B). 


\section{—Región nasofacial y techo craneano}

Esta región está compuesta por los nasales, premaxilares, maxilares, frontales y parietales. Si bien el escamoso participa en la conformación de una porción del techo craneano, su descripción detallada se incluye en la región orbitotemporal, región del cráneo en la que su aporte es mucho más conspicuo.

Los nasales ocupan la porción anterior del techo de la cavidad nasal y contribuyen mínimamente a la formación de una parte de la pared lateral (con mayor aporte en la porción anterior). Son largos y angostos, con ensanchamientos a nivel de sus extremos anterior (donde alcanzan su ancho máximo) y posterior. Los nasales son muy convexos transversalmente; su extremo anterior tiene forma de "U" poco pronunciada y no se encuentran retraídos con respecto al premaxilar; se extienden posteriormente hasta casi alcanzar el nivel de la órbita. Contactan, en sentido anteroposterior, con los premaxilares, maxilares y frontales. La sutura naso-frontal es variable, puede presentar forma de "W" de ángulo agudo (YPM-PU 15000; Fig. IV. 1A; y MLP 12-10, Fig. IV. 3A) o moderadamente angulosa (MLP 12-23; Figs IV. 3B). No se ven forámenes conspicuos.

A

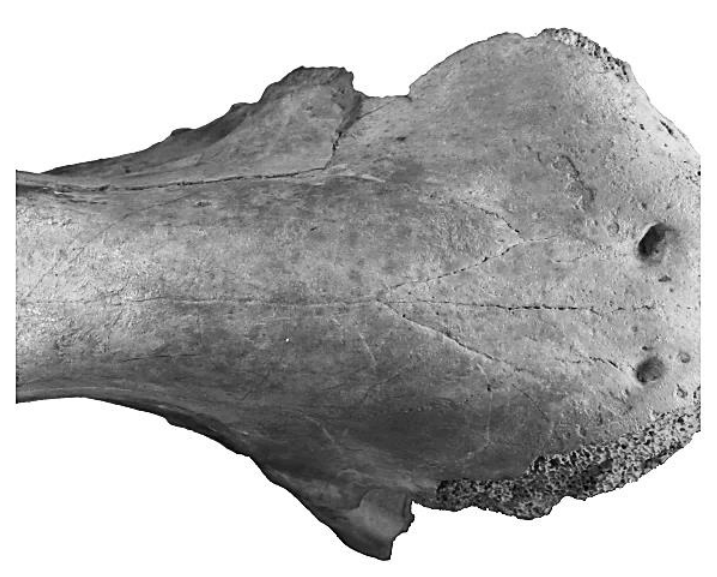

B

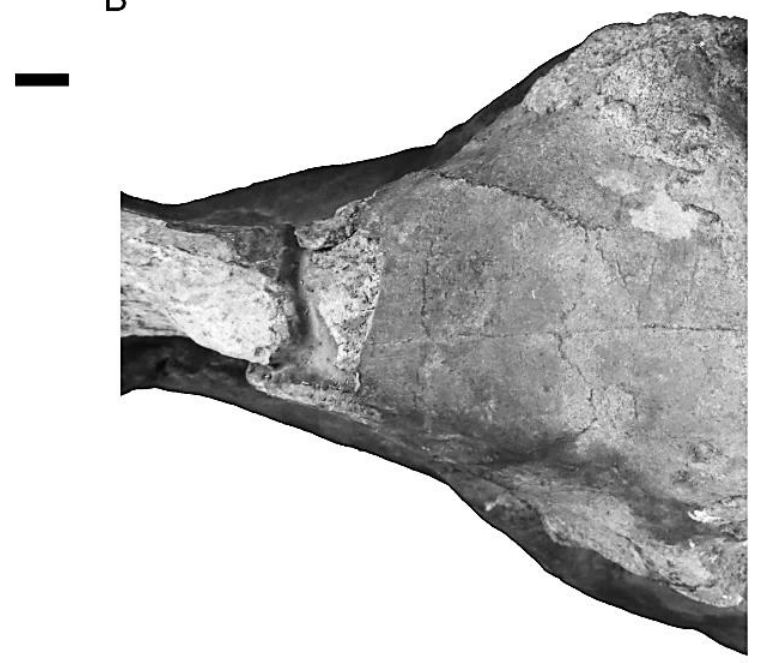

Fig IV. 3: Variación en la sutura fronto-nasal del cráneo de Nesodon imbricatus: MLP 12-10 (A), MLP 12-23 (B). Escala $2 \mathrm{~cm}$.

Los premaxilares son elementos relativamente cortos y altos que, junto a los nasales (techo), forman la porción más rostral de la pared lateral y la base de la cavidad nasal. En sus procesos alveolares, los premaxilares contienen a los incisivos; los procesos faciales de ambos premaxilares forman el piso y las paredes laterales de la abertura nasal externa (Fig. IV. 3A), y la plataforma narial está ligeramente expuesta en vista dorsal y tiene unos procesos pequeños 
a nivel de la sutura entre premaxilares. En vista lateral (Fig. IV. 1B y Fig. IV. 4B), los premaxilares son ligeramente más largos en su porción ventral que en la dorsal; presentan un proceso posterolateral corto que se interpone entre el nasal y el maxilar.

Los maxilares son el componente principal de la pared lateral del hocico y el paladar duro, son altos y contienen los alveolos para los caninos y los siete dientes postcaninos; además, contribuyen a la formación del piso de la porción más anterior de la órbita. Presentan en su extremo posterior, justo antes de la órbita, su máxima altura y se curvan ligeramente hacia la parte medial, generando una constricción conspicua y muy característica para este taxón a nivel a la porción posterior del hocico. Además de contactar con los nasales y premaxilares, los maxilares contactan con los frontales a nivel del M2, a través de una sutura de desarrollo variable y contorno irregular. Ventralmente a esta sutura, el maxilar contacta con el lacrimal y con el yugal a través de suturas ligeramente curvas. Sin duda la estructura más conspicua de la porción facial del maxilar es el foramen infraorbitario; en vista lateral, el foramen presenta una forma ligeramente ovalada, mientras que en vista anterior es bastante circular y abre rostrolateralmente a nivel del contacto entre M1 y M2 en adultos y subadultos, mientras que en los juveniles abre a nivel del dP4 y el M1. El proceso alveolar del maxilar es bastante largo y amplio (Fig. IV. 4B) dado el gran tamaño que presentan los dientes yugales.

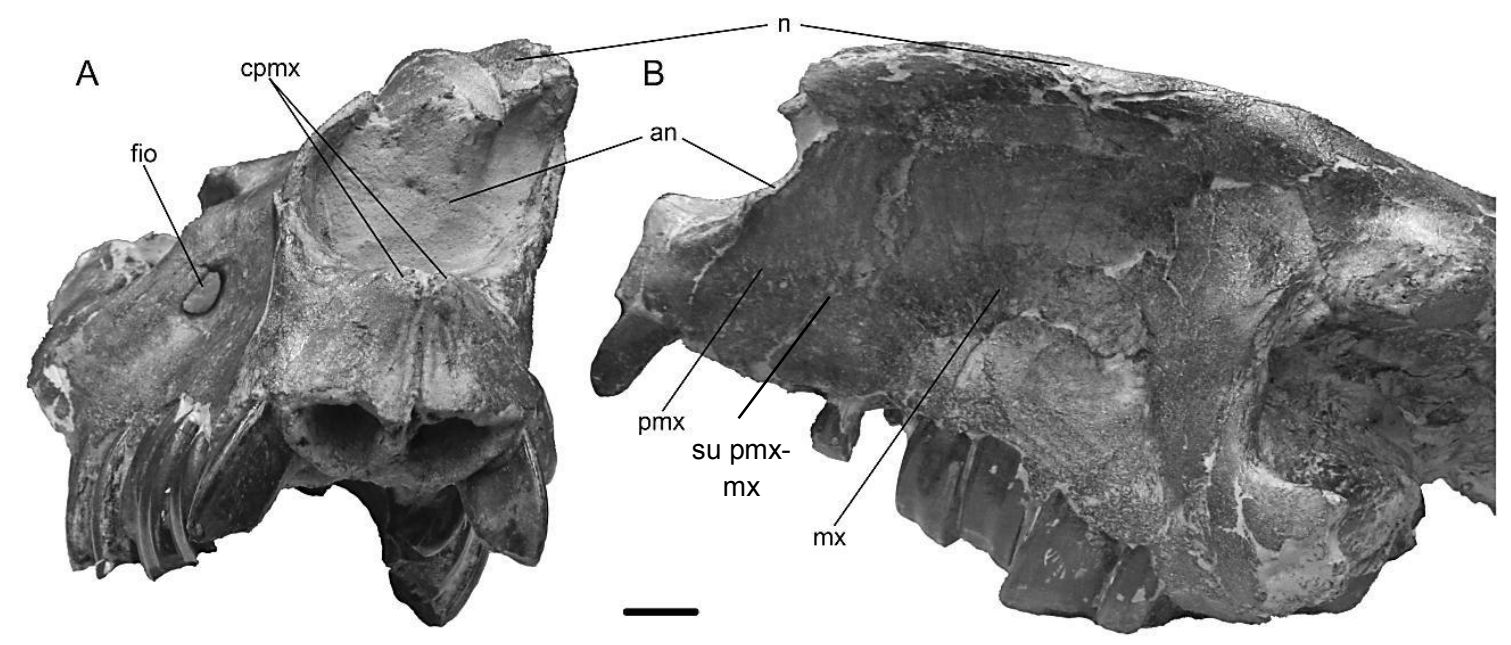

Fig IV. 4: Región rostral del cráneo de Nesodon imbricatus YPM-PU 15135. Vista anterior (A) y vista lateral izquierda (B). Escala $2 \mathrm{~cm}$.

Los frontales son los huesos con mayor desarrollo de toda la bóveda craneana y forman la porción medial, a nivel de las órbitas, del techo craneano. Son cortos en dirección anteroposterior, pero muy anchos y posiblemente sean uno de los elementos que presentan mayor variabilidad a nivel intraespecífico. Los frontales presentan una convexidad algo 
menor que los nasales y hacia su extremo posterior se encuentran bien desarrollados los procesos postorbitales. En los diferentes ejemplares a disposición, tanto en vista dorsal como lateral, se puede notar como estos procesos presentan un desarrollo sumamente variable; en los ejemplares más jóvenes, los procesos postorbitales dan la impresión de ser cortos y no estar proyectados lateralmente, dado que sus extremos se encuentran levemente curvados en dirección posteroventral; en la mayor parte de los ejemplares adultos, los procesos postorbitales tienen sus extremos dirigidos lateralmente y su perfil dorsal es completamente recto. Otro de los rasgos distintivos que presentan los procesos postorbitales es la presencia de rugosidades en su superficie (Fig. IV. 5), que se interpretaron como indicadoras de la presencia de cuernos dérmicos en los nesodontinos (Ameghino 1887a, 1891, 1894a; Mercerat 1891). Scott (1912: 198) también sugirió la presencia de un cuerno, pero basado en un abultamiento medio sobre los frontales, previo a la unión entre las líneas temporales, en el cráneo YPM-PU 16012, rasgo que utilizó para caracterizar la especie Nesodon cornutus. Sin embargo, la revisión del ejemplar YPM-PU 16012 (Fig IV. 5) permite asegurar que no posee ningún abultamiento frontal y que la figura presentada por Scott (1912: fig. 38) no es fidedigna; tampoco se ha observado tal abultamiento en otros ejemplares estudiados. El frontal también contribuye a la formación de las paredes laterales del cráneo y la fosa orbitotemporal. Como se mencionó anteriormente (ver Nasales), la sutura naso-frontal es sumamente variable. Las líneas temporales se encuentran bien desarrolladas y están separadas de manera conspicua al menos en la proximidad de los procesos postorbitales (luego se fusionan hacia el extremo posterior para conformar la cresta sagital a nivel de los parietales); el espacio entre las líneas temporales puede estar profundamente deprimido o presentar una depresión superficial. La presencia de forámenes en el hueso frontal es un rasgo variable, pudiendo existir desde un foramen hasta tres en cada hueso, uno de los cuales presenta una diferencia considerable de tamaño; la perforación de mayor tamaño ha sido identificada en trabajos previos como el canal supraorbital y transmitiría el nervio y los vasos supraorbitales (Martínez et al. 2016).

Los parietales son huesos de escaso desarrollo y especialmente estrechos anteriormente; contribuyen ligeramente a la conformación de la pared lateral del cráneo; se engrosan a medida que se acercan al extremo posterior del cráneo, llegando a ser gruesos y masivos a nivel del contacto con el supraoccipital, en la cresta nucal. Prácticamente a lo largo de todos los parietales, Nesodon imbricatus presenta una cresta sagital corta, delgada y aguda, cuyo origen es posterior al borde orbitario en los frontales; a menudo, especialmente en los individuos jóvenes, las crestas temporales están bien desarrolladas, son filosas y no se unen 
completamente; esto genera que sobre la cresta sagital pueda observarse un surco delgado que recorre toda la extensión de la misma. Otro de los rasgos más notorios de los parietales es la presencia de perforaciones dorsalmente al límite escamoso-parietal; estos forámenes corresponden a las aberturas del pasaje de las rami temporalis de la arteria estapedial, que además habrían transmitido venas desde la región temporal hacia la región cerebral (Gabbert 2004, MacPhee 2014).

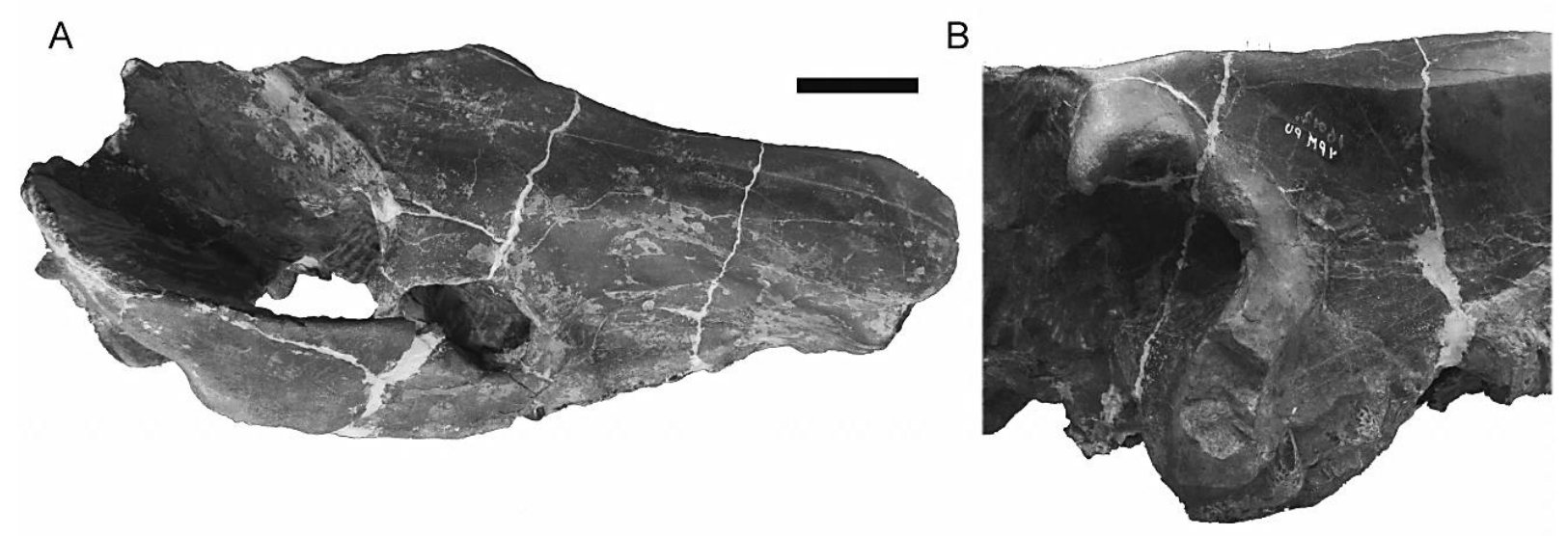

Fig IV. 5. Cráneo de Nesodon imbricatus YPM-PU 16012 (ejemplar tipo de Nesodon cornutus): Vista laterodorsal (A), vista lateral a nivel del comienzo del arco cigomático (B). Escala $5 \mathrm{~cm}$.

Forasiepi et al. (2015) han mencionado la posible presencia de un hueso interparietal en la conformación del techo craneano de otra especie del género Nesodon, N. taweretus; sin embargo, dicha suposición debe referirse a estadios ontogenéticos tempranos del animal y no al ejemplar estudiado (ver Koyabu et al. 2012 y MacPhee 2014 para mayor detalle). El interparietal es un hueso impar que ha sido detectado en estadios de desarrollo postnatal temprano de algunos mamíferos, como por ejemplo los marsupiales Monodelphis domestica (Clark and Smith 1993, Wible 2003) y Didelphis marsupialis (Toeplitz 1920), en los cuales se fusionaría al supraoccipital muy temprano en la ontogenia. La participación del interparietal en la conformación del techo craneano en estadios ontogenéticos tempranos también ha sido evaluada recientemente por Koyabu et al. (2012), quienes no solo detectaron este hueso en casi todos los grandes clados de Mammalia, sino también que está compuesto por al menos cuatro centros de osificación diferentes que o se fusionan tempranamente en la ontogenia y en estadios sucesivos podrían fusionarse a otros huesos de la porción posterior y el techo craneano, o pueden permanecer como un elemento independiente en algún clado. En todos los cráneos revisados (juveniles y adultos) de Nesodon imbricatus fue imposible detectar la presencia de este elemento. 
Hernández Del Pino, S.

Los escamosos contribuyen a la conformación de parte del techo del cráneo de $N$. imbricatus, a partir de un proceso grande de forma irregular; tanto la forma del proceso como el aporte que realiza a la conformación del techo craneano varían durante la ontogenia del animal.
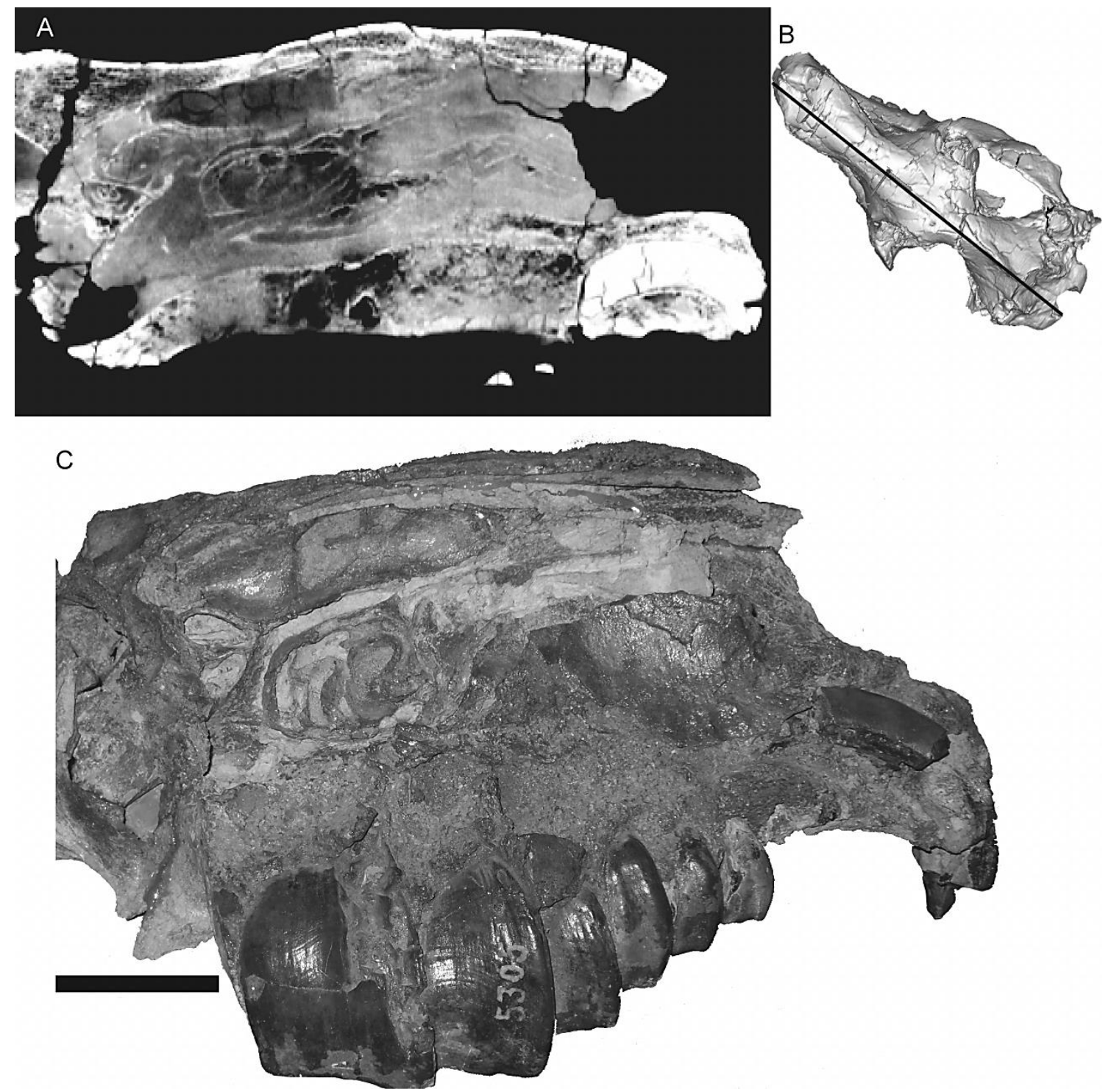

Fig IV. 6. Turbinales de N. imbricatus: Corte sagital virtual de la cavidad nasal del MPM-PV RBPN-SFV-12-3 (A) y su ubicación en el molde tridimensional del cráneo (B); corte sagital del cráneo de Nesodon imbricatus MACN A 5305 (C). Escala $5 \mathrm{~cm}$.

Los turbinales son una de las características típicas del linaje mamaliano y se encuentran mayormente vinculados con el sostén del epitelio olfatorio primario (naso y etmoturbinales) y el epitelio no olfatorio generador de mucosa (maxiloturbinales). Los turbinales se encuentran bien preservados en el ejemplar MPM-PV RBPN-SFV-12-3 (Fig. IV. 6A) y también pueden 
observarse en algunos de los cráneos colectados durante las campañas realizadas por Carlos Ameghino (MACN A 5305 Fig. IV. 6C). Estos ejemplares muestran que el sistema de turbinales en los nesodontinos se encuentra bien desarrollado, y se pudo observar que los maxiloturbinales presentan una sección transveral espiralada, similar a lo reportado para el género Bison (Negus 1958).

\section{-Paladar}

La región del paladar está compuesta por los premaxilares, maxilares y palatinos. El paladar de Nesodon imbricatus es bastante característico dentro de los ungulados sudamericanos; es triangular, relativamente ancho anteriormente, haciéndose más angosto progresivamente desde su extremo anterior hasta la posición del primer premolar, para luego ensancharse nuevamente hacia el extremo posterior; además, es muy cóncavo transversalmente debido al desarrollo de los procesos alveolares del maxilar, mucho más acentuados en los ejemplares adultos debido a la curvatura marcada de la corona de los molares. En la línea media del paladar, existe una cresta leve pero notoria que comienza a la altura del P2 y alcanza el límite con las narinas internas. De acuerdo a Scott (1912), el margen posterior del paladar es oblicuo al eje mayor del cráneo; en los ejemplares a disposición, se comprueba que el borde posterior del paladar está bien inclinado posteromedialmente, y que la coana abre por detrás del borde posterior del último molar.

En vista ventral (Figs. IV. 1C y IV. 7A), los procesos alveolares y palatales del premaxilar conforman el $10 \%$ de la superficie total del paladar duro. Las estructuras más sobresalientes en los procesos palatales son los forámenes incisivos, que se encuentran en una posición media en una depresión de profundidad variable de acuerdo a la edad del individuo, aumentando conforme avanza la edad del animal. El proceso palatal conforma la mayor parte del borde de dichos forámenes, que son angostos y largos, ocupando aproximadamente el $40 \%$ del largo de los procesos palatales. Respecto de los procesos alveolares, de los tres alveolos dentarios presentes, el primero y el tercero presentan un tamaño similar mientras que el segundo es el más desarrollado y el que se encuentra más lateralizado. No existe diastema entre los primeros dos incisivos, puede haber un pequeño diastema entre los I 2 e I3 en algunos individuos (e.g. YPM-PU 15000, YPM-PU 15135), pero este rasgo es sumamente variable y es común que en ejemplares de edad avanzada los diastemas hayan desaparecido.

En vista ventral, los procesos palatales del maxilar son largos, angostos anteriormente y ensanchados progresivamente hacia su extremo posterior, donde duplican el ancho del extremo anterior y, junto con los procesos alveolares, forman aproximadamente un $70 \%$ de la 
superficie total del paladar duro. Los maxilares contactan con los palatinos a través de una sutura en forma de "V" amplia.

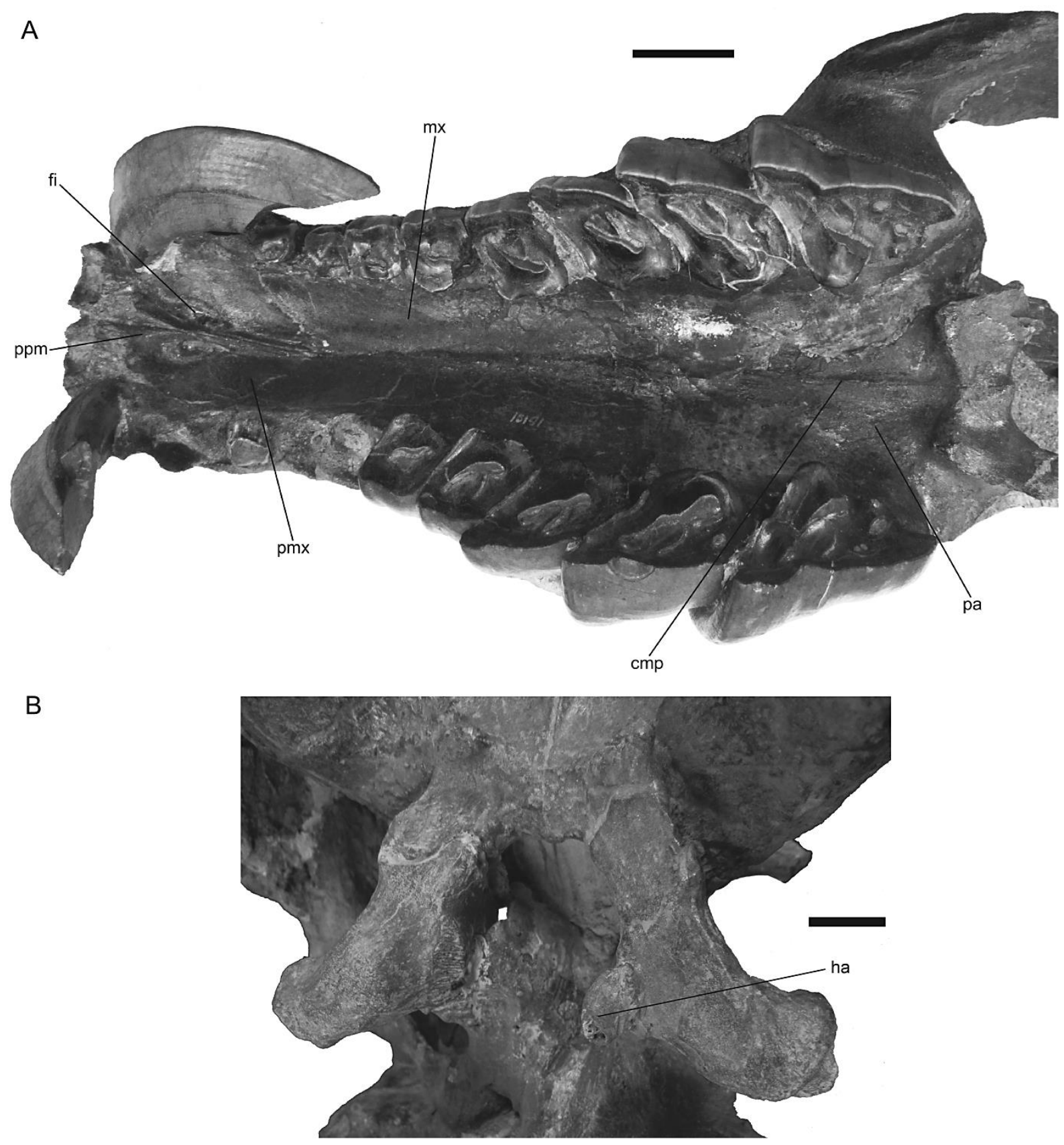

Fig IV. 7: Región palatal del cráneo de Nesodon imbricatus YPM-PU 15141(A); detalle de la porción posterior del paladar del ejemplar FMNH-13901, indicando la ubicación del hamulus (B). Escala $2 \mathrm{~cm}(\mathbf{A}), 2 \mathrm{~cm}(\mathbf{B})$.

Los palatinos tienen un desarrollo importante y conforman prácticamente todo el extremo anterior de las narinas internas; contribuyen en gran medida a la conformación posterior del paladar duro. Son huesos anchos y relativamente cortos. Los procesos postpalatinos son bastante divergentes, pero menos que en Adinotherium ovinum y Nesodon 
taweretus, siendo, sin embargo, relativamente más largos que en estas dos especies.

Los pterigoides contribuyen a la formación de parte del techo y las paredes laterales del conducto nasofaríngeo, por detrás de la coana. Los pterigoides son huesos angostos que cubren al preesfenoides proximalmente. Según Scott (1912), los pterigoides conforman un proceso hamular posterior (Fig. IV. 7B), prominente y curvado lateralmente, pero dicho proceso se encuentra roto en el espécimen figurado por el autor (YPM-PU 15000; ver Fig. IV. 1C) y en la mayor parte de los especímenes consultados, y su posición esta indicada por la existencia de una superficie rugosa que corresponde a la sutura de ese elemento.

La abertura posterior del conducto nasofaríngeo está delimitada dorsalmente por los palatinos, pterigoides, preesfenoides y basiesfenoides, y lateralmente por los palatinos, pterigoides y aliesfenoides. La coana es bastante pequeña en relación al tamaño del cráneo del animal y sus bordes laterales divergen posteriormente.

El vómer no es visible en ninguna de las vistas externas. De acuerdo a las imágenes de $\mathrm{CT}$, es un hueso alargado anteroposteriormente y delgado que se encuentra ubicado en el piso de la porción anterior de la cavidad nasal. Articula con el preesfenoides posteriormente, con el maxilar, anterodorsalmente, y con el premaxilar, anteriormente.

\section{-Región orbitotemporal}

Dado que la cavidad encefálica es bastante estrecha en esta especie (ver Molde endocraneano para más detalles) y los arcos cigomáticos tienen una gran expansión lateral (Fig. IV. 1A), se genera una fosa orbitotemporal de grandes dimensiones.

Los lacrimales se encuentran frecuentemente desarticulados del cráneo y son huesos que, aun cuando no presentan un gran desarrollo, son bastante notorios y tienen una forma que varía desde un ovalo alargado a un trapezoide con base más o menos estrecha. Forman parte del borde anterior de la órbita y cuentan con un proceso facial, uno orbital y uno cigomático. El proceso facial tiene un contorno ligeramente semicircular; contacta con el maxilar anteriormente, con los frontales anterodorsalmente y con los yugales ventralmente; además, presenta una espina prominente y presenta un único foramen lacrimal próximo al borde orbitario. El proceso orbital del lacrimal es amplio y conforma una parte importante de la pared anterodorsal de la órbita. El proceso cigomático del lacrimal es corto y contacta anteroventralmente con el maxilar y ventralmente con el yugal. 


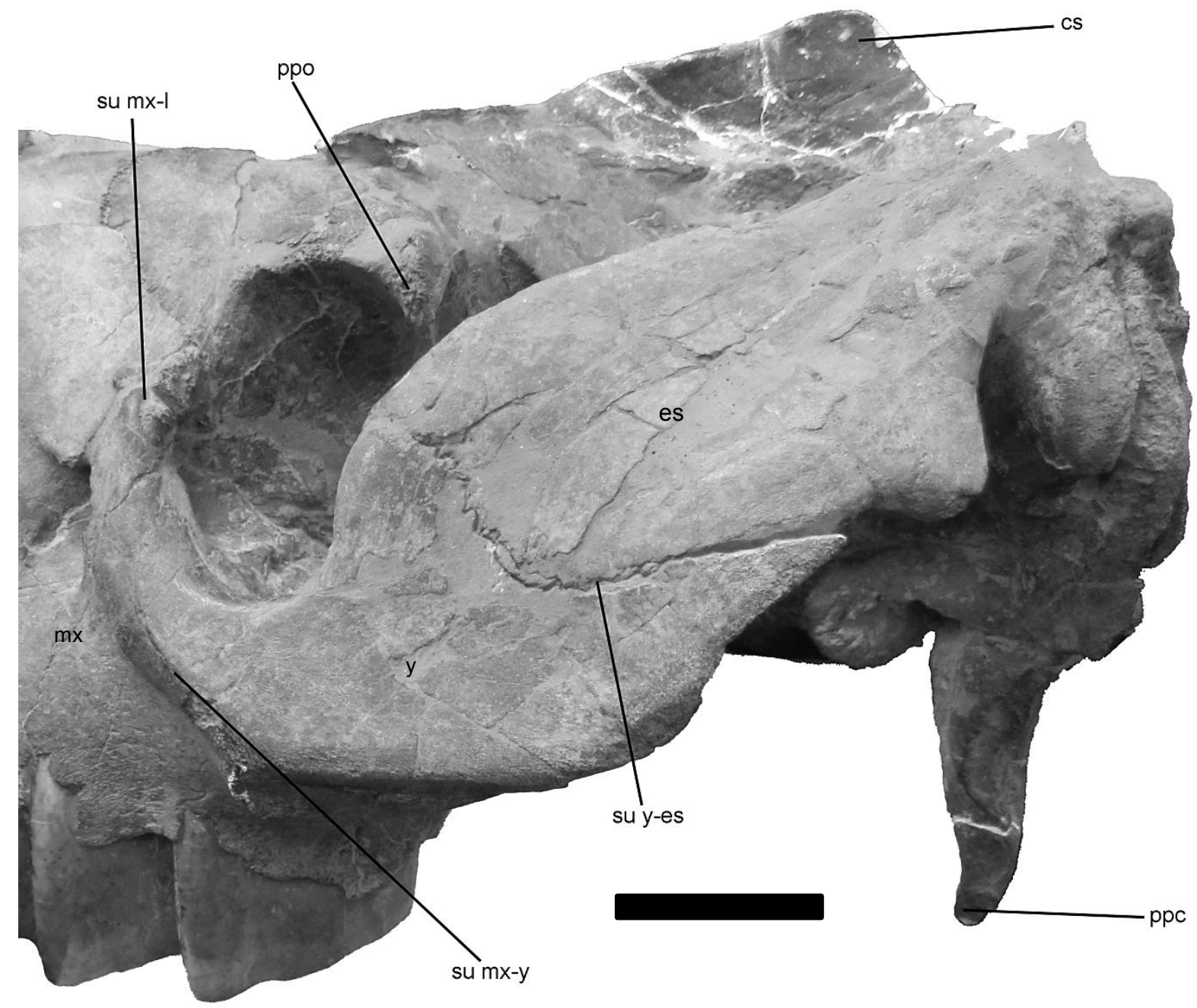

Fig IV. 8: Vista lateral de la región orbitotemporal del cráneo de Nesodon imbricatus FMNH13079. Escala $4 \mathrm{~cm}$.

Los yugales son uno de los principales componentes del arco cigomático (Fig. IV. 8) y además participan en la conformación del borde anteroventral de la órbita, excluyendo a los maxilares de la conformación de la misma. Son huesos largos anteroposteriormente y muy comprimidos lateralmente. Se extienden desde la porción más anterior del arco cigomático (a nivel de la parte posterior del M2 o anterior del M3), donde contactan con el proceso cigomático del maxilar, hasta casi la posición del proceso articular del escamoso, a partir de una prolongación ventral del hueso. La porción anterior del yugal forma, junto al maxilar, la raíz anterior del arco cigomático; el contacto con el maxilar es ventrolateral a través de una sutura ligeramente semicircular en vista lateral; además, en su porción anterior, el yugal contacta dorsalmente con los procesos facial y cigomático del lacrimal. Posteriormente, el yugal contacta con el escamoso, a nivel de la superficie media del arco cigomático, por medio de una sutura convexa (típica de los Toxodontidae, ver Billet [2011]), con ambos extremos 
apuntando posteriormente; el superior es corto, mientras que el inferior casi alcanza la altura de la fosa glenoidea y conforma el proceso glenoideo del yugal.

Los escamosos están muy bien desarrollados y contribuyen en gran medida a la formación de las paredes de la bóveda craneana e incluso participan en la formación de parte del piso del cráneo. En esta sección solo se describe el aporte que realiza el escamoso a la región orbitotemporal, mientras que sus aportes a las regiones del basicráneo y la región occipital se detallan en los apartados siguientes. En vista lateral, el escamoso tiene forma trapezoidal y forma gran parte de la pared lateral del cráneo; además, forma la mitad posterior del arco cigomático $\mathrm{y}$, ventralmente, la totalidad de la fosa glenoidea, el proceso postglenoideo (o retroarticular) y el postimpánico (o retrotimpánico), y su extremo medial conforma parte de la pared lateral de la fisura glaseriana (conformada mayormente por el esfenoides de acuerdo a Gabbert 2004). El proceso cigomático del escamoso es ligeramente alargado, profundo y comprimido lateralmente; contacta con el yugal en la zona anteromedial del arco, en su borde superior, y con la parte anterior del proceso articular del escamoso, en su borde inferior. Dorsalmente, el recorrido del escamoso se eleva progresivamente hacia el margen posterior y es continuo con la cresta nucal. Los escamosos contactan dorsalmente con los parietales, anteroriormente con los yugales y posteriormente con el complejo occipital.

\section{-Basicráneo y región auditiva}

El basicráneo (Fig. IV. 9) está compuesto medialmente por los complejos esfenoidal y occipital, y en los laterales por el escamoso y el ectotimpánico (que conforma la bula timpánica y parte del MAE). El basicráneo en Nesodon imbricatus es relativamente ancho y corto, constituyendo el 39\% del largo total medido a partir de la coana en MPM-PV RBPNSFV-12-3 (ver tabla). La proporción del espacio ocupado por el basicráneo en relación al tamaño total del cráneo varía durante la ontogenia del animal (Fig. IV. 9A y C, ver Tabla V. 1 en el Capítulo V para mayores detalles de cómo varían las proporciones relativas del cráneo entre ejemplares adultos y juveniles); en los ejemplares jóvenes, la región del basicráneo es levemente más larga $\left(\mathrm{BCL} / \mathrm{TSL}_{\mathrm{juv}}=0,34 ; \mathrm{BCL}_{\mathrm{ad} 1 / 2} / \mathrm{TSL}_{\mathrm{ad} 1 / 2}=0,33\right)$, más baja $\left(\mathrm{SB} / \mathrm{TSL}_{\mathrm{juv}}=0,29\right.$; $\left.\mathrm{SB}_{\mathrm{ad} 1 / 2} / \mathrm{TSL}_{\mathrm{ad} 1 / 2}=0,31\right)$ y más ancha que en los adultos $\left(\mathrm{BZB}_{\mathrm{juv}} / \mathrm{TSL}_{\mathrm{juv}}=0,56 ; \mathrm{BZB}_{\mathrm{ad} 1 / 2} / \mathrm{TSL}\right.$ $\operatorname{ad} 1 / 2=0,5)$.

El complejo esfenoidal comparte rasgos similares con el de algunos ungulados actuales y esto puede estar relacionado con el gran desarrollo de la región del paladar, asociada al uso del recurso alimentario (Gabbert 2004). El complejo es corto anteroposteriomente y está 
Hernández Del Pino, S.

confinado anteriormente por los pterigoides y posteriormente por ectotimpánicos, escamosos y basioccipital.
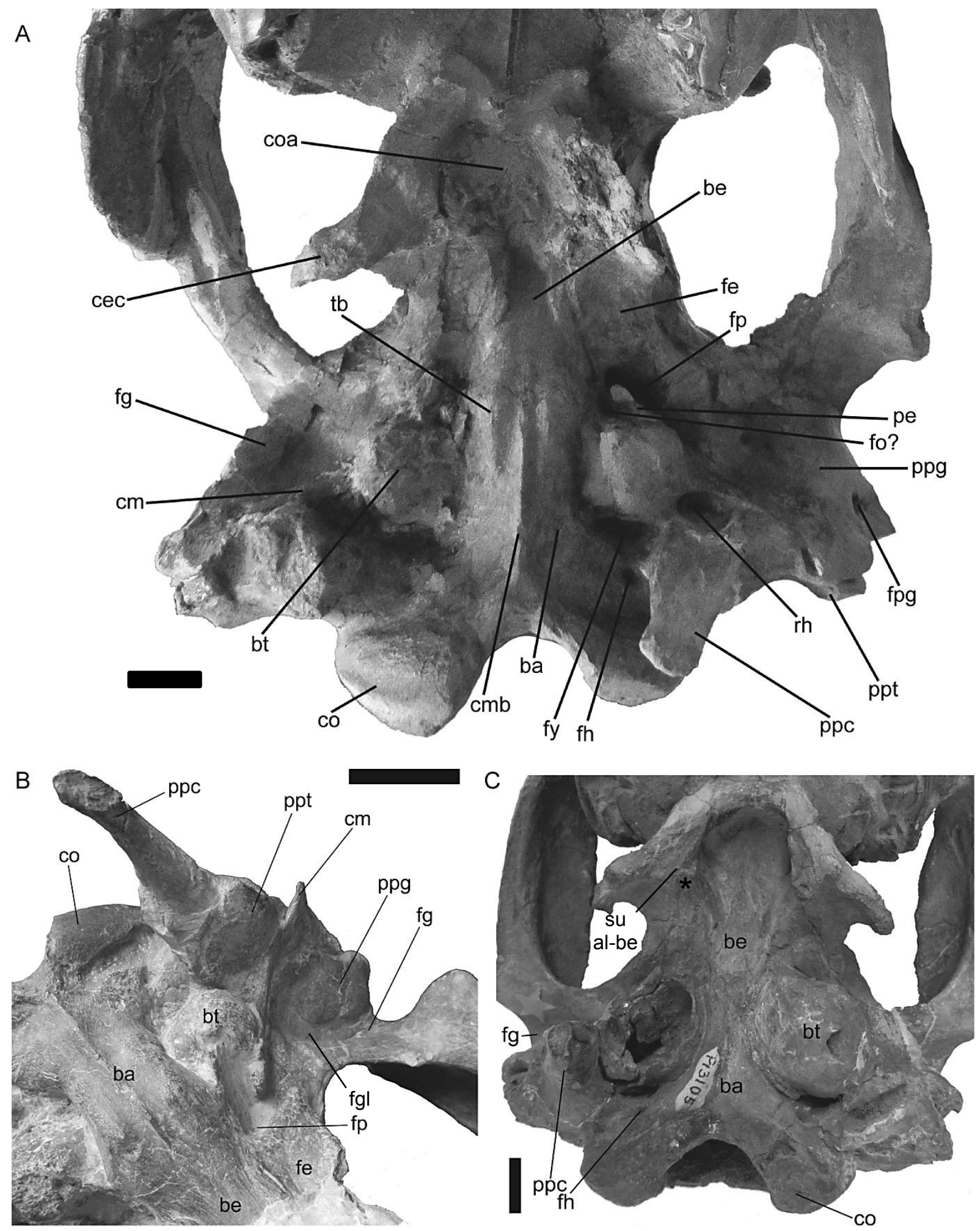

Fig IV. 9. Basicráneos de ejemplares adultos de Nesodon imbricatus, YPM-PU 15336 (A), FMNH-13079 (B) y del ejemplar juvenil FMNH-13105 (C). * indica la proyección lateral del basiesfenoides identificada por Scott (1912). Escala $2 \mathrm{~cm}$. 
El preesfenoides se encuentra prácticamente confinado anteriormente por los pterigoides y es poco visible externamente (Scott 1912). A partir de los tomogramas obtenidos, puede observarse que es un hueso más o menos tubular anteroposteriormente (Fig. IV. 10A), con la sección transversal cuadrada. El preesfenoides es relativamente corto en comparación con el basiesfenoides (que ademas está más expandido lateralmente) y está restringido mayormente a la porción prehipofisiaria de la cavidad encefálica. Las suturas del preesfenoides con los pterigoides no son claramente visibles en los ejemplares tomografiados, pero fue posible identificar la posición del preesfenoides (indicado con una flecha en la Fig IV. 10A) y cómo éste se apoya sobre el basiesfenoides a nivel del plano sagital, aunque la sutura es poco visible en las imágenes obtenidas.

Los aliesfenoides son huesos más o menos largos, más estrechos posteriormente que anteriormente y de forma trapezoidal, cuya exposición es netamente ventral. Colaboran a la conformación del borde posterior de la coana y la pared lateral de la fosa escafoidea, donde contacta con los procesos pterigoideos de los palatinos y con el pterigoides, anteriormente, y con el escamoso, lateralmente. El aliesfenoides se fusiona tempranamente en la ontogenia al basiesfenoides por lo que resulta muy complicada su identificación en los ejemplares adultos.

El basiesfenoides ocupa una posición intermedia entre el preesfenoides y el basioccipital en la línea media del cráneo y, al igual que ellos, presenta una forma más o menos tubular, siendo en este caso más largo que el preesfenoides. El basiesfenoides es ligeramente más estrecho anteriormente y constituye la parte más posterior del techo del conducto nasofaríngeo. En el límite basiesfenoides-basioccipital, se desarrollan dos tuberosidades, de tamaño variable, a los lados o ligeramente anteriores a la cresta media del basioccipital de acuerdo al estadio ontogenético del ejemplar. Como ocurre en otros Notoungulata (e.g. ver Gabbert 2004, MacPhee 2014, Forasiepi et al. 2015), no se encuentran rastros de los forámenes carotideos en el basiesfenoidies; de hecho, este hueso no presenta ningún tipo de perforación conspicua. El basiesfenoides solapa y tapa al preesfenoides anteriormente, extendiéndose en dirección anterior hasta el margen posterior de las narinas y, en su extremo posterior, contactando con el basioccipital. La sutura del basiesfenoides con los aliesfenoides no es perceptible en la mayoría de los ejemplares revisados, pero, según Scott (1912), el basiesfenoides emite proyecciones laterales para contactar con el aliesfenoides, rasgo que podría corresponderse con lo observado en el ejemplar FMNH-13105 (identificado con un * en la Fig IV. 9C).

Los procesos hamulares y el complejo esfenoidal demarcan una fosa conspicua, que recibió el nombre de fosa escafoidea (Gabbert 2004) debido a su morfología y a que no 
presenta una contraparte en la literatura sobre ungulados actuales. Esta fosa se encuentra confinada por crestas altas y delgadas lateral y medialmente, y habría servido como punto de inserción para los músculos tensores del velo palatino. La profundidad y la forma de esta fosa son variables durante la ontogenia, aunque en menor medida que en A. ovinum (ver sección IV. 2.2.).

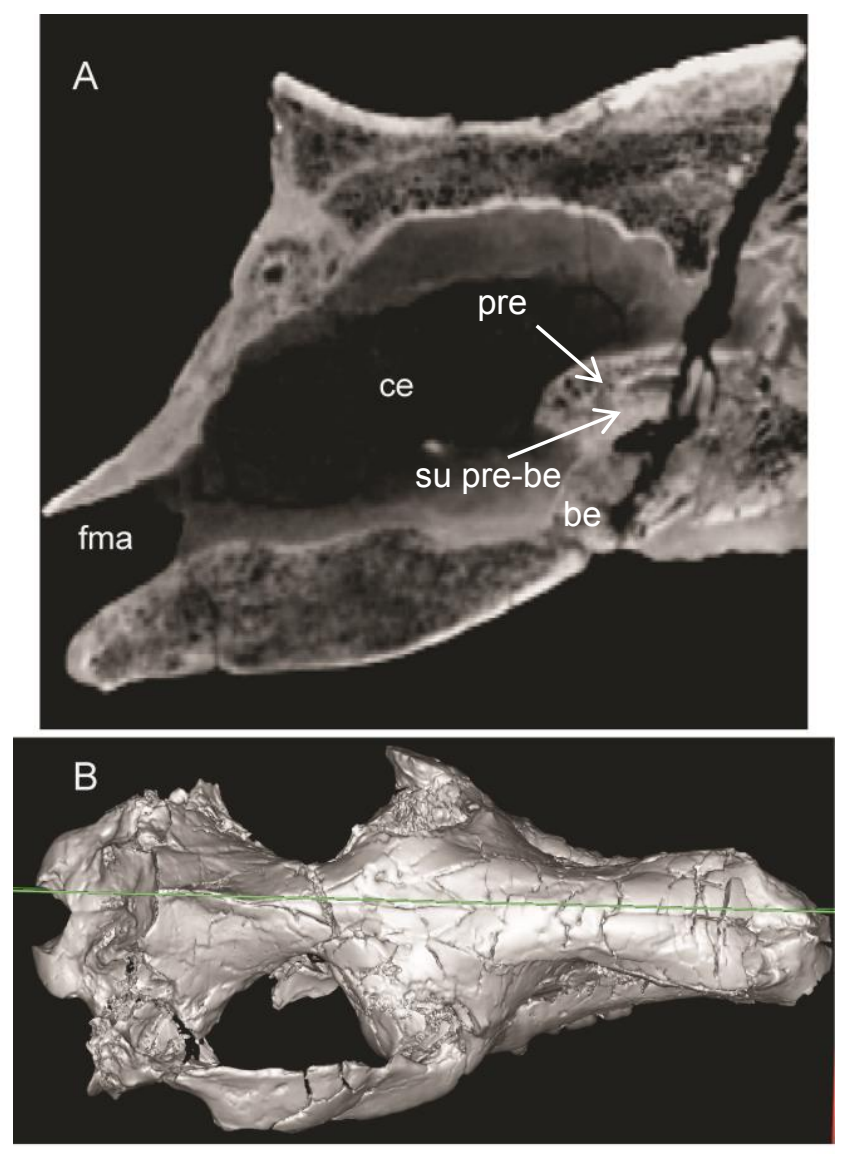

Fig IV. 10. Tomogramas correspondientes un ejemplar de Nesodon imbricatus indicando la ubicación del preesfenoides: Seccion longitudinal del cráneo del MPM-PV RBPN-SFV-12-3 a nivel la porción media del craneo (A) localización del corte longitudinal mostrado en la figura A en el modelo tridimensional del cráneo del MPM-PV RBPN-SFV12-3 (B).

El basioccipital es bastante largo, ancho en sus extremos anterior y posterior, angostándose a nivel de las bullas timpánicas; forma la base del cráneo desde una posición ligeramente anterior a los petrosos, las bullas timpánicas y el foramen magnum. El basioccipital no contribuye a la conformación del foramen magnum, formado únicamente por los exoccipitales. En los ejemplares jóvenes, la mayor parte de la línea media del basicráneo está conformada por el basiesfenoides, mientras que, en el adulto, el basioccipital desplaza notablemente al basiesfenoides (que prácticamente no aumenta su tamaño) a una posición más anterior y es el elemento más conspicuo en la línea media del basicráneo. El basioccipital 
lleva una cresta media prominente, más desarrollada en la porción posterior, que prácticamente alcanza el foramen magnum; este rasgo presenta una variación considerable en la ontogenia, siendo relativamente más corta y prominente en los ejemplares más jóvenes, pasando por una cresta larga y conspicua en los especímenes adultos y reduciéndose a una estructura casi imperceptible en los ejemplares seniles. En el adulto, el basioccipital comparte con el basiesfenoides dos abultamientos laterales de la cresta medial en la porción anterior del hueso; mientras, en los ejemplares más jóvenes, la cresta no alcanza los abultamientos (que se encuentran confinados al basioccipital con su porción anterior en el límite de la sutura basiesfenoides-basioccipital), sino que estos envían proyecciones ligeramente marcadas en dirección posterior hacia la cresta medial. En su extremo anterior, el basioccipital se encuentra separado del basiesfenoides por una sutura poco notoria en los ejemplares adultos, pero que en los ejemplares jóvenes es aproximadamente transversal, contacta anterolateralmente con los ectotimpánicos, a través de una sutura irregular, y con los exoccipitales, posteriormente.

Como se mencionó anteriormente, los escamosos contribuyen a la conformación de los extremos laterales del basicráneo $\mathrm{y}$, en vista ventral, la porción medial de los escamosos conforma parte de las paredes laterales de las fisuras glaserianas, mientras que los rasgos más conspicuos de este hueso en esta vista son la fosa glenoidea y los procesos postglenoideo y postimpánico. La fosa glenoidea es amplia y se encuentra bien delimitada; está representada por una concavidad más o menos triangular, más ancha que larga, conformada únicamente por el escamoso y de posición ventrolateral; además, la fosa glenoidea se encuentra ligeramente proyectada lateralmente y es visible en vista dorsal. En el margen posterior del arco cigomático, en el límite posterior de la fosa glenoidea, se encuentra el proceso postglenoideo conspicuo (Fig. IV. 9), que está constituido por un abultamiento del escamoso, convexo en vista anterior; en el margen posterolateral del proceso postglenoideo se encuentra el foramen postglenoideo, que es notorio y más o menos circular. Medialmente a este foramen y lateral a la crista meatal, se encuentra un foramen accesorio (Figs. IV. 1A y 11A) que es algo más pequeño y ovalado que el foramen postglenoideo y es continuo con el foramen suprameatal y el meato temporal. Posteriormente al foramen postglenoideo, el escamoso se angosta progresivamente y luego se expande ligeramente para conformar el proceso postimpánico (Fig. IV. 11A) que, como ya destacó Scott (1912), su aporte en la conformación de la porción ventral del cráneo y su superficie expuesta varía enormemente a lo largo de la ontogenia de Nesodon imbricatus. En los estadios tempranos del desarrollo, el proceso postimpánico solo se encuentra confinado a una zona pequeña de la superficie lateroposterior del cráneo; en los ejemplares adultos, el escamoso restringe en gran medida el aporte del exoccipital en la 
conformación de la base del cráneo (donde la única estructura formada por este hueso son los procesos paracondilares) y las paredes laterales de la región occipital. El proceso postimpánico del escamoso se encuentra ampliamente expuesto en la porción posterior del cráneo y se encuentra expandido dorsalmente por la presencia de un amplio seno epitimpánico (de variable desarrollo en Notoungulata; ver Gabert 2004, MacPhee 2014). En este trabajo, se sigue la denominación propuesta por MacPhee (2014), quien sugirió que a esta porción de hueso que recubre al seno epitimpánico se la denomine como teca epitimpánica, independientemente de los elementos que la conformen (que en el caso de $N$. imbricatus es solo el escamoso), para evitar la confusión a la hora de describir la cavidad y la pared ósea que la recubre. El seno epitimpánico no presenta hueso esponjoso en $N$. imbricatus, al contrario que en otros notoungulados como algunos Interatheriidae (MacPhee 2014), y contacta con la cavidad timpánica a través del receso epitimpánico. Medialmente al foramen postglenoideo, puede encontrarse un pliegue pequeño y más o menos longitudinal que corresponde a la fisura glaseriana (Fig. IV. 9B). Entre el foramen postglenoideo y el proceso postimpánico del escamoso se forman dos crestas distintivas, paralelas prácticamente a lo largo de toda su extensión. Estas crestas se extienden dorsolateralmente y forman los bordes rostral y caudal (proceso postimpánico) del MAE. Estas crestas van acompañadas en su recorrido por la cresta meatal, que se interpone entre ambas. Ventralmente, los escamosos contactan con el complejo esfenoidal; anteromedialmente, con los ectotimpánicos, y posteromedialmente, con el complejo occipital.

Los ectotimpánicos forman la bula timpánica, la cresta meatal, el proceso estiliforme, el MAE y la pared posterior del foramen postglenoideo (Fig. IV. 9). La estructura más anterior conformada por este hueso corresponde al proceso estiliforme, un proceso bastante grácil dirigido ventralmente y que se ubica en una posición central al margen anterior de la bula timpánica; según Scott (1912), podría tratarse de un timpanohial posiblemente fusionado al estilohial; sin embargo, MacPhee (2014) señaló que el extremo craneal del hioides en Notoungulata es una barra angosta que se aloja en el receso hioideo (ubicado posterolateralmente a la bula timpánica). La bula timpánica consiste en una estructura elipsoidal de gran tamaño, con su eje mayor en dirección dorsoventral, de sección transversal ovalada (cuyo eje mayor es anteroposterior) y una pared ósea muy delgada. La bula recubre la superficie timpánica del petroso y se genera por la expansión lateral y dorsoventral del ectotimpánico (Gabbert 2004), generando una cavidad que, en todos los ejemplares de Nesodon observados, permanece libre de hueso esponjoso (Fig. IV. 11B), coincidiendo con la observación de Scott (1912). En el adulto, la bula timpánica presenta una punta curvada en su 
extremo ventromedial; en cambio, en los ejemplares juveniles, la bula timpánica es menos globosa y presenta una forma mucho más estrecha y aguda en su extremo ventral, que le da una apariencia piramidal, y la punta es mucho más notoria y está dirigida ventral y anteriormente. La bula timpánica se proyecta ventralmente más allá del nivel de la caja craneana y está delimitada por el complejo esfenoidal anteriormente, los procesos paracondilares del exoccipital, posteriormente; y la crista meatal y los procesos postglenoideos y postimpánicos del escamoso, posterolateralmente. De acuerdo a Forasiepi et al. (2015), el extremo medial de la bula timpánica de $N$. taweretus se encuentra fusionado al basiesfenoides; sin embargo, en los especímenes adultos revisados de $N$. imbricatus, no se han observado ejemplares que manifiesten esa condición. El ectotimpánico se extiende lateralmente a la bula timpánica para formar la crista meatal, que es filosa y aumenta drásticamente su altura a medida que se acerca al margen posterolateral del cráneo, donde conforma un proceso bastante más ancho justo a nivel del contacto con el proceso postglenoideo del escamoso. En el contacto entre la crista meatal y el escamoso, posteromedialmente a la fosa glenoidea, existe un pequeño foramen que fue identificado como el foramen estilomastoideo en otros toxodóntidos (Forasiepi et al. 2015); como se mencionó anteriormente, dicho foramen posiblemente corresponda a un foramen accesorio relacionado al sistema postglenoideo, dada su comunicación con el ducto y el foramen suprameatal (Billet 2018, comunicación personal). Tanto en Toxodontia (e.g. Patterson 1932, 1936, Martínez et al. 2016) como en tipoterios (e.g. Billet et al. 2009, MacPhee 2014), este foramen se encuentra ubicado entre la crista meatal y el proceso postimpánico del escamoso, posición que también ocupa en las especies de Nesodontinae. El MAE (Fig. IV. 11C) consiste en un tubo largo, cuyo recorrido es mayormente interno y solo su extremo es visible externamente en vistas dorsal y lateral. Como se mencionó anteriormente, la abertura del MAE tiene una ubicación laterodorsal, es amplia y se encuentra flanqueada rostral y caudalmente por los procesos postglenoideo y postimpánico del escamoso, respectivamente. 

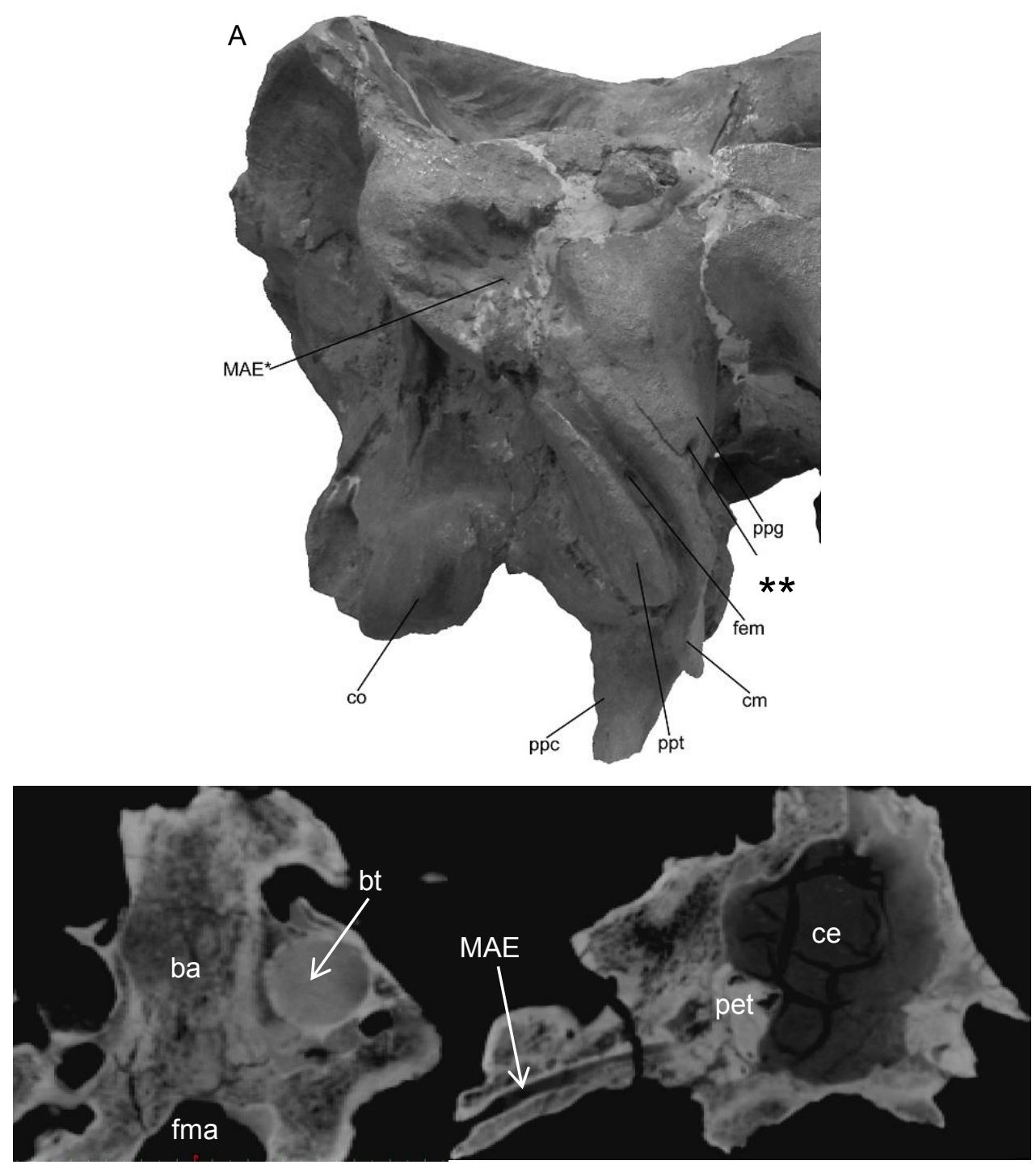

Fig IV. 11 Vista lateral de la región auditiva de Nesodon imbricatus YPM-PU 15000 (A) Tomogramas del ejemplar MPM-PV RBPN-SFV-12-3 de N.imbricatus: sección coronal indicando la bula timpánica hueca, libre de hueso esponjoso (B); sección coronal indicando la morfología tubular del MAE (C). *limites del EAM rotos, ${ }^{* *}$ foramen accesorio del sistema postglenoideo.

\section{—Región occipital}

La región occipital (Fig. IV. 12) está principalmente compuesta por los supraoccipitales en los extremos dorsolaterales, los exoccipitales y los procesos postimpánicos del escamoso, en los extremos ventrolaterales. Su apariencia general es variable, pudiendo tener un contorno, en vista posterior, que varía desde una " $\mathrm{D}$ ", con la curvatura dorsal, de poca altura y con un diámetro transverso que supera ampliamente la altura (Fig. IV. 12A), hasta un perfil más alto, con la altura solo ligeramente menor al diámetro transverso (Fig. IV. 12B). Dicha diferencia sirvió de base a Scott (1912) para la caracterización de un taxón; sin embargo, el 
estudio realizado permite interpretarla como un rasgo de variación individual posiblemente ligado a dimorfismo sexual (ver apartado IV. 4. Discusión).

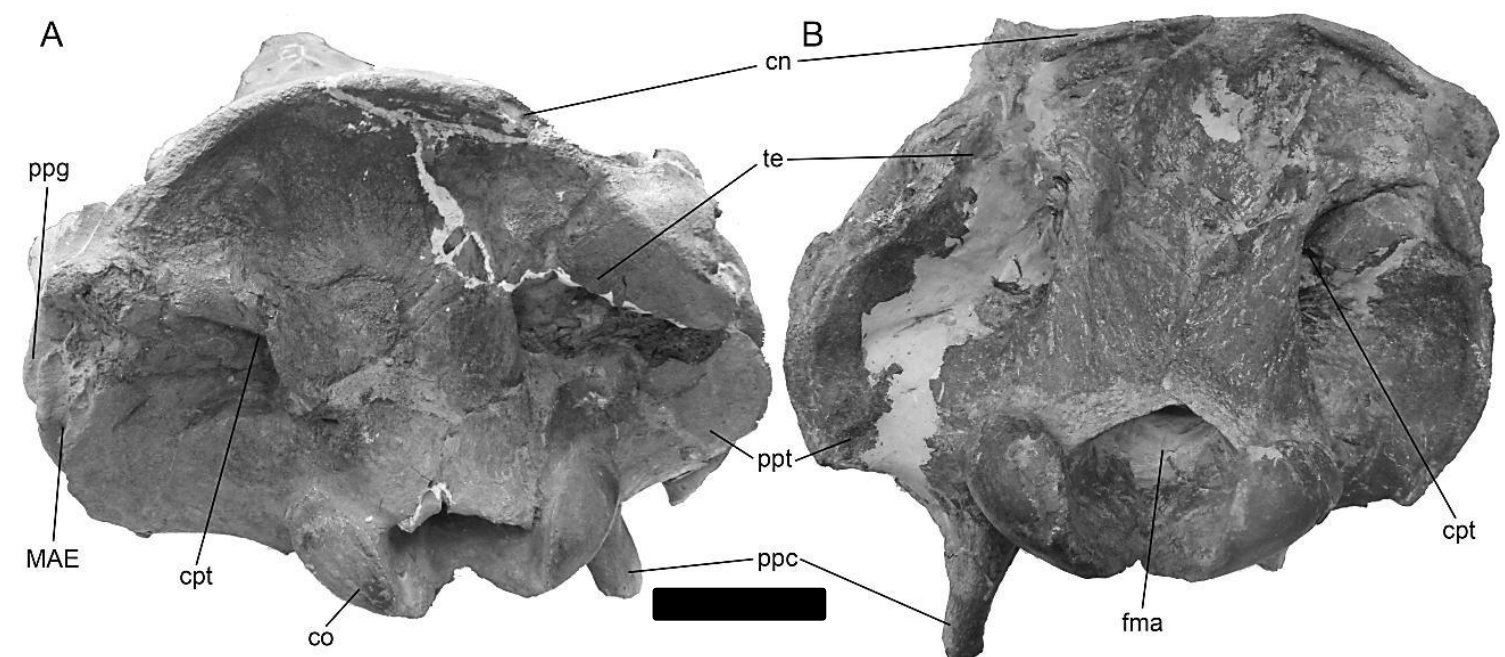

Fig IV. 12. Morfotipos de la región occipital de Nesodon imbricatus: región occipital baja, ancha y con el perfil dorsal redondeado (A, YPM-PU 15000); región occipital alta, angosta y con el perfil dorsal más anguloso (B, AMNH 9192). Escala $5 \mathrm{~cm}$.

Los exoccipitales ocupan una porción del cráneo bastante amplia en los estadios juveniles de Nesodon imbricatus, participando en gran parte de la conformación de la porción posterior del cráneo, pero, al igual que en la región anterior, en los ejemplares adultos, el exoccipital se encuentra desplazado por el desarrollo del proceso postimpánico del escamoso y de los procesos mastoideos (protuberancia petrosa de Roth [1903]). Los exoccipitales conforman dos estructuras muy sobresalientes del cráneo, los cóndilos occipitales y los procesos paracondilares. Los cóndilos occipitales son anchos, bajos y se proyectan considerablemente hacia atrás; divergen dorsalmente, pero se encuentran más próximos el uno con el otro en su extremo ventromedial; en vista ventral, presentan una superficie articular más o menos ovalada, con su extremo medial curvado anteriormente. Los cóndilos delimitan el foramen magnum que, en vista posterior, es amplio y ovalado, con su eje mayor transversal. Los procesos paracondilares son estructuras muy notorias tanto en los ejemplares jóvenes como en los adultos; su extremo dorsal es ancho transversalmente y se angosta progresivamente hacia el extremo ventral, dando un aspecto piramidal. En los ejemplares jóvenes, el eje mayor y la punta de los procesos paracondilares están dirigidos anteroventralmente, mientras que en los adultos el eje es vertical, con su extremo apuntando ventralmente. La superficie de los exoccipitales se encuentra perforada por varios forámenes. Medialmente, el exoccipital conforma la pared posterolateral del foramen yugular 
(medialmente está formado por el basioccipital y anterolateralmente, por el ectotimpánico); lateralmente, conforma el borde posterior del receso hioideo (conformado anteriormente por el ectotimpánico); posteriormente al foramen yugular y justo antes del cóndilo occipital, se encuentra el foramen hipogloso, conformado únicamente por el exoccipital. Tanto el foramen yugular como el receso hioideo presentan un gran tamaño, siendo el segundo más grande que el primero.

El supraoccipital es un hueso amplio que conforma gran parte del extremo dorsal de la región occipital en los adultos y gran parte de los extremos dorsal y laterales en los individuos jóvenes. Además de la extensión, la profundidad del supraoccipital también varía durante la ontogenia, siendo un hueso prácticamente plano en los ejemplares jóvenes y volviéndose fuertemente cóncavo en los adultos. El grosor de este hueso también aumenta progresivamente con la edad del animal. En su extremo dorsal, el supraoccipital se encuentra prácticamente fusionado al extremo posterior de los parietales desde una edad temprana y conforma una cresta nucal prominente; esta cresta presenta una variación individual considerable en cuanto al perfil dorsal, desde un contorno semicircular bajo hasta uno más alto y angular.

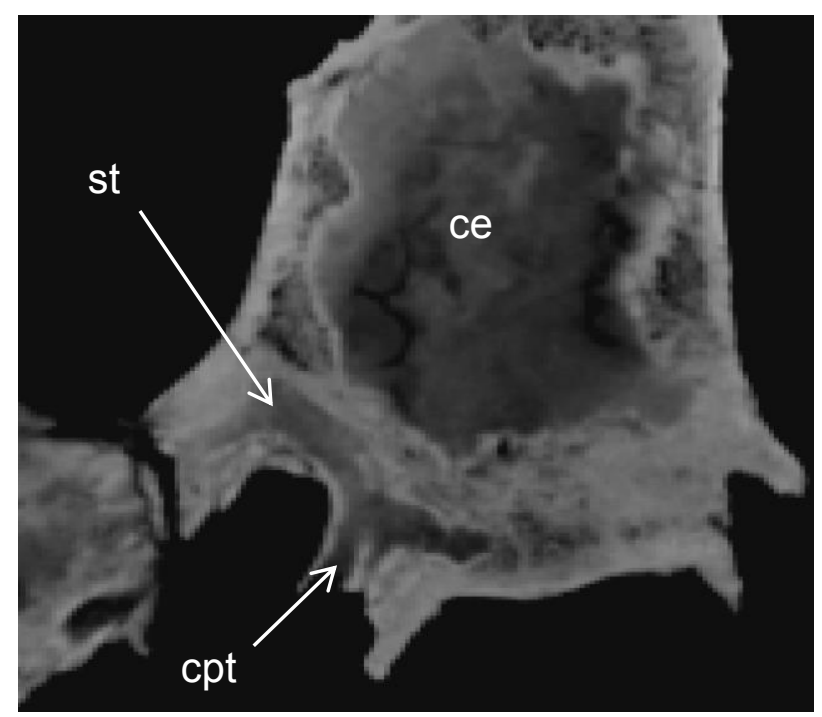

Fig IV. 13. Tomograma del ejemplar MPM-PV RBPN-SFV-12-3 Nesodon imbricatus, sección coronal indicando la abertura posterior del canal postemporal.

En la región occipital de $N$. imbricatus existe una profunda depresión dorsal a los cóndilos occipitales, que abre al interior del cráneo a nivel de la sutura entre escamoso y exoccipital; dicha abertura ha sido interpretada en los Notoungulata como el foramen mastoideo (Gabbert 2004, Billet 2010, Cerdeño y Vera 2015) o como la salida al exterior del 
canal postemporal (Kramarz et al. 2011, MacPhee 2014, Forasiepi et al. 2015) (Fig. IV. 13). Los dos últimos trabajos han puesto de manifiesto que este canal abre intracranealmente en el seno transverso y que correspondería a un sistema venoso (o al menos a un sistema que entre otras cosas portaría venas), aunque la posible presencia de una arteria diploética magna (Billet y De Muizon 2013) sugeriría que esta abertura posterior es el canal postemporal y que no solo transmitiría la arteria diploética magna, sino también las venas asociadas (MacPhee 2014).

De acuerdo a los tomogramas analizados en este trabajo, parece que existe una leve exposición del petroso en vista posterior en los ejemplares adultos (rasgo reconocido también para otros Notoungulados; ver Billet 2011, Fig 8); sin embargo, el material examinado se encuentra severamente dañado en esa región, razón por la cual esta cuestión se trata con más detalle para otras especies (ver región occipital de Adinotherium ovinum).

\section{-Molde endocraneano}

La cavidad endocraneana se encuentra completamente cerrada por la presencia de los huesos occipitales, esfenoidales, parietales y escamosos, con una escasa contribución de los frontales (Scott 1912). En esta descripción, es importante remarcar que las estructuras descriptas (e.g. lóbulos piriformes) no son las que aparecerían en el animal en vida, sino que corresponden a las porciones del molde endocraneano que no coinciden exactamente en forma y tamaño con las correspondientes en el animal vivo. Para realizar esta distinción se añade el subíndice “ $m$ ” detrás de cada estructura. Esta notación será obviada, por ser considerada innecesaria, para las estructuras que no se correspondan con porciones neurales, como por ejemplo los vasos sanguíneos. Para facilitar la descripción, se considera una regionalización del endocráneo, dividiéndolo en diferentes porciones: Encéfalo anterior, Encéfalo posterior, Nervios y Sistema vascular del endocráneo. En la figura IV. 14 se presenta un molde endocraneano de Nesodontinae a modo de ejemplo, detallando las partes que se comentan a continuación.

Las únicas publicaciones previas que han tratado con moldes endocraneanos en toxodóntidos corresponden a moldes que se encuentran depositados en el FMNH (cuyos calcos depositados en el AMNH [AMNH 55969, AMNH 55970, AMNH 55971] pude revisar), descriptos por Patterson (1932, 1937) y Radinsky (1981), y una reconstrucción tridimensional del ejemplar MPM PV-3532, realizada en el marco de la presente tesis (Hernández Del Pino et al. 2014). 
Hernández Del Pino, S.

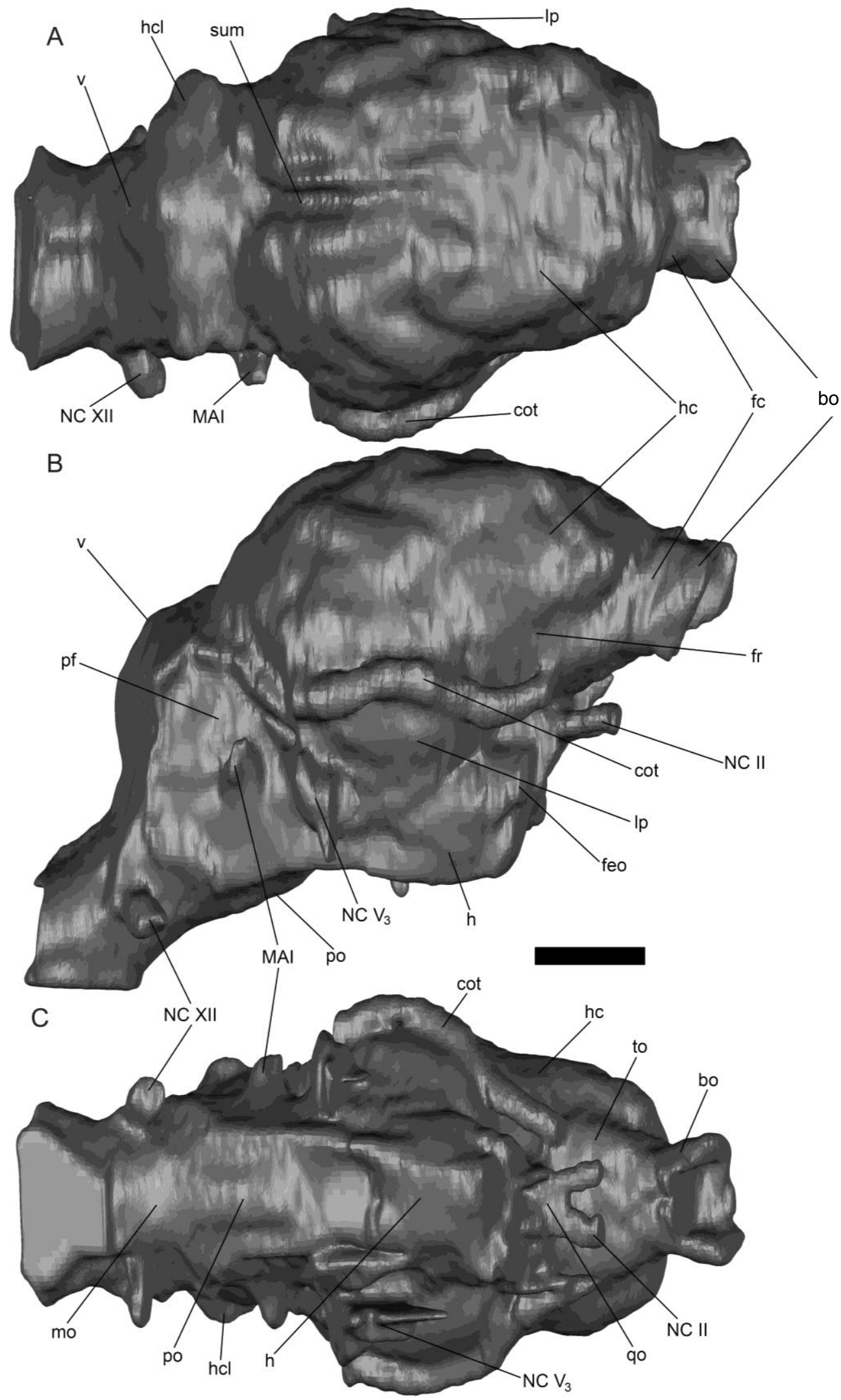

Fig. IV. 14: Cavidad endocraneana de los Nesodontinae (ejemplificada a partir del RB2-SFV-12-

9, ejemplar de Adinotherium ovinum) indicando las principales estructuras: vistas dorsal (A), lateral derecha (B) y ventral (C). Escala $2 \mathrm{~cm}$. 
El molde endocraneano del MPM-PV RBPN-SFV-12-3 (Fig. IV. 15) se caracteriza por ser largo, ligeramente más estrecho y más bajo que en el resto de los nesodontinos, presentando una relación entre el ancho y el largo del molde endocraneano (excluyendo la médula) de 0,52 y una relación entre el alto y el ancho de 0,88 . Otro de los rasgos peculiares de este molde es el grado de flexura, definida como el ángulo entre la línea que va desde el centro de los bulbos olfatorios hasta el centro de la hipófisis y la línea entre este último punto y el centro del foramen magnum (Macrini et al. 2006), que tiene un valor de $31^{\circ}$ y que es relativamente bajo en comparación al resto de los nesodontinos (a excepción del MPM-PV 3479 que se encuentra ligeramente deformado, ver Tabla IV. I).

El encéfalo anterior, en vida, está compuesto por el telencéfalo y el diencéfalo. Las estructuras que corresponden al encéfalo anterior en el molde endocraneano del MPM PV RBPN-SFV-12-3 son los bulbos olfatorios ${ }_{m}$, que en el animal vivo estarían compuestos por la

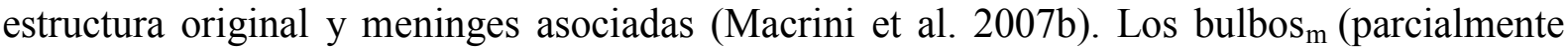
reconstruidos debido a la deformación y daño en el ejemplar) son pequeños, angostos y están alineados con el eje principal ipsilateral de cada hemisferio cerebral $\mathrm{m}_{\mathrm{m}}$, separados el uno del otro en el plano sagital. La fisura circular, que separa a los bulbos olfatorios $\mathrm{m}$ de los hemisferios cerebrales $_{\mathrm{m}}$, es poco notoria, angosta y poco profunda. En los moldes endocraneanos presentados en este trabajo, no se registró evidencia de bulbos olfatorios accesorios $_{\mathrm{m}} \mathrm{y}$ tampoco se mencionan en la literatura disponible. Los tractos olfatorios $\mathrm{m}$ son conspicuos, pero no se proyectan y solo sobrepasan levemente la corteza cerebral $\mathrm{m}$, que representa un total del 5\% del volumen total del molde endocraneano. Los hemisferios cerebrales $_{\mathrm{m}}$ se encuentran separados sagitalmente por un surco medial no muy ancho (desplazado ligeramente hacia el lado izquierdo debido a la deformación), pero en algunos ejemplares dicha separación se encuentra parcial o totalmente oscurecida por el seno sagital superior (ver sección Sistema vascular del endocráneo). Los hemisferios cerebrales ${ }_{\mathrm{m}}$ son ligeramente asimétricos debido a la deformación tafonómica; el hemisferio cerebral $\mathrm{m}_{\mathrm{m}}$ izquierdo, menos deformado, es ovoide, con una relación ancho/largo de 0,51 y una relación alto/largo de 0,82 , contribuyendo a casi el $30 \%$ del volumen total de la cavidad endocraneana. La superficie cortical es girencefálica, con sulci y gyri poco profundos. La fisura rinal está bien demarcada. Los lóbulos piriformes se proyectan levemente hacia los laterales y son poco conspicuos (más notorio el derecho) y son ovoides (más largos que altos). La región hipofisaria $a_{m}$ es enorme (rasgo indicado ya por otros autores, e.g. Patterson 1936, Radinsky 1981), en parte quizá por la deformación tafonómica sufrida por el ejemplar, pero sin duda es la estructura más conspicua del molde endocraneano en vista ventral. Está representada por un 
abultamiento elipsoidal que representa aproximadamente el 5\% del volumen total del molde; está ubicado en medio del piso ventral del molde endocraneano, justo por debajo de los lóbulos piriformes, y ligeramente anterior a la abertura de foramen oval + fenestra piriforme. La hipófisis $\mathrm{m}_{\mathrm{m}}$ posee una quilla media de escaso desarrollo, que probablemente sea una imperfección debida a la deformación postmortem. Como ya se ha indicado para otros notoungulados (Gabbert 2004, Martínez et al. 2016), en la región hipofisaria no hay indicios del pasaje de la rama cerebral de las carótidas internas en el piso de la hipófisis.

El encéfalo posterior de Nesodon imbricatus es bastante más corto y relativamente más estrecho que el encéfalo anterior; estaría compuesto en vida por el cerebelo, la medula oblonga y el puente troncoencefálico (protuberancia anular o pons). La separación entre el encéfalo anterior y el encéfalo posterior está determinada por una depresión profunda en el molde endocraneano del MPM-PV RBPN-SFV-12-3, que podría corresponderse con la ausencia (o presencia sin osificar) del tentorium cerebelli (Macrini et al. 2007b). El cerebelo contribuye con alrededor del $21 \%$ del volumen del molde endocraneano y es bastante angosto (incluso más que cualquier porción del cerebro $_{\mathrm{m}}$ ). En el cerebelo $\mathrm{m}_{\mathrm{m}}$ resulta difícil identificar la vermis $_{\mathrm{m}}$ o los hemisferios cerebelares $\mathrm{m}_{\mathrm{m}}$ pero la primera puede corresponder a un abultamiento, más o menos esférico, que está presente en la porción mediodorsal del cerebelo $_{\mathrm{m}}$. La superficie de los hemisferios cerebelares $\mathrm{m}_{\mathrm{m}}$ es completamente lisa; sin embargo, la presencia de meninges, senos venosos y otras estructuras afectan la morfología del molde endocraneano en esta región y, en consecuencia, no existe una correlación directa de los

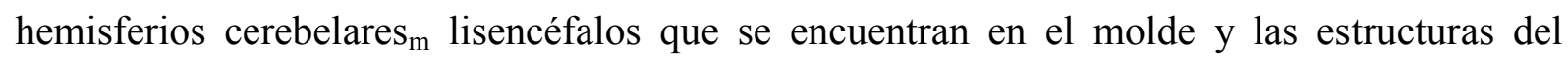
animal en vida (Macrini et al., 2007a). El paraflóculo $\mathrm{m}_{\mathrm{m}}$, ubicado en una posición caudodorsal al $\mathrm{MAI}_{\mathrm{m}}$ en la cara lateral del hemisferio cerebelar $\mathrm{m}_{\mathrm{m}}$, es prácticamente indistinguible, lo cual se correlaciona con la escasa profundidad de la fosa subarcuata (ver Petroso de A. ovinum). En el piso ventral del encéfalo posterior ${ }_{\mathrm{m}}$, la pons $_{\mathrm{m}}$ es indistinguible, mientras que la medula oblonga $_{\mathrm{m}}$ tiene una sección más o menos ovoide (con un gran diámetro transverso posiblemente afectado por deformación) y sale del cráneo por medio del foramen magnum. 


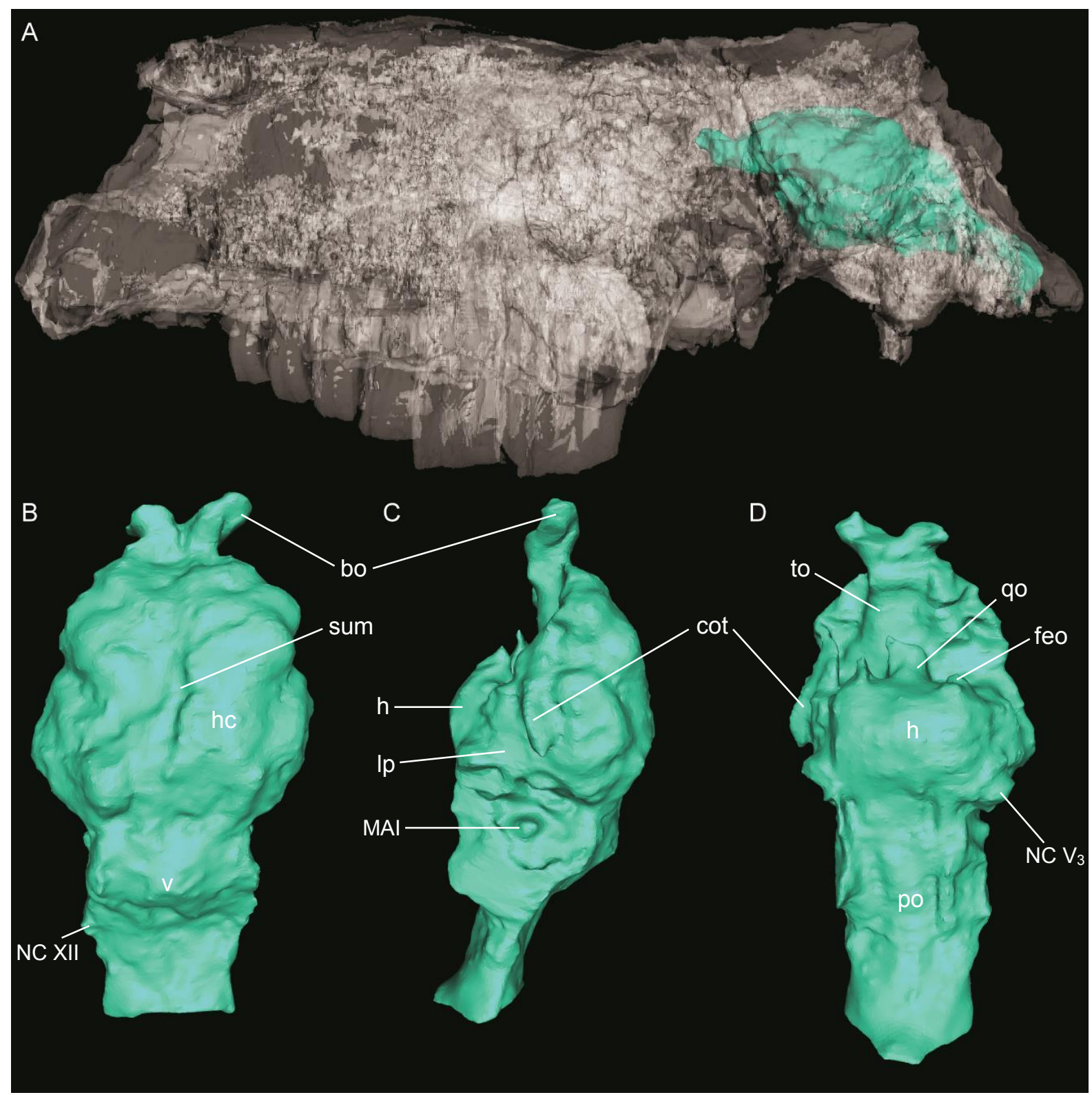

Fig IV. 15. Diferentes vistas del molde endocraneano de MPM PV RBPN-SFV-12-3 de Nesodon imbricatus: Vista lateral del cráneo con el molde endocraneano (A); vistas dorsal (B), lateral izquierda (C) y ventral (D) del molde endocraneano.

A continuación, se detalla la morfología y las salidas de los Nervios craneales localizados en el molde endocraneano. En la porción anterior, en vista ventral, se observa una corta proyección por delante de la hipófisis $\mathrm{m}_{\mathrm{m}} \mathrm{y}$ justo por debajo de los tractos olfatorios $\mathrm{m}_{\mathrm{m}}$, que corresponde al quiasma óptico $\mathrm{m}_{\mathrm{m}}$ (NC II); desafortunadamente, los nervios ópticos $\mathrm{m}_{\mathrm{m}}$ no se pudieron reconstruir, por lo que resulta imposible estimar su diámetro y ángulo de divergencia; sin embargo, dada la morfología del quiasma, parece que ambos nervios habrían divergido en un ángulo bajo. Hacia la parte media del molde endocraneano y justo por detrás del quiasma óptico, se pueden ver los moldes de las salidas de la fisura esfeno-orbitaria 
(=foramen lacerado anterior para Simpson 1933); esta fisura, en la condición típica para los euterios, en vida, habría transmitido los nervios oculomotor (NC III), troclear (NC IV), las ramas oftálmica profunda $\left(\mathrm{NC} \mathrm{V}_{1}\right)$ y maxilar $\left(\mathrm{NC}_{2}\right)$ del trigémino y el abduscens ( $\left.\mathrm{NC} \mathrm{VI}\right)$ (MacPhee 1994). Como se mencionó en la descripción craneana, Nesodon imbricatus no posee un foramen rotundo, por lo que se asume que el $\mathrm{NC}_{2}$ abandona el cráneo por la fisura esfeno-orbitaria. El molde de la rama mandibular del trigémino $\left(\mathrm{NC}_{3}\right)$ abandona el cráneo por el foramen oval (que en los nesodontinos confluye con la fenestra piriforme); en el molde endocraneano del MPM-PV RBPN-SFV-12-3, está representada por un abultamiento conspicuo de posición lateroventral, inmediatamente por detrás del lóbulo piriforme $\mathrm{m}$ y la hipófisis $_{\mathrm{m}}$. En la zona posterior del molde endocraneano, en vista lateral, se observa la posición del $\mathrm{MAI}_{\mathrm{m}} \mathrm{y}$ los orígenes de los nervios facial (NC VII) y vestibulococlear (VIII) en la porción anteromedial de los hemisferios cerebelares $\mathrm{m}_{\mathrm{m}}$. Los tractos correspondientes a los nervios glosofaríngeo (NC IX), vago (NC X) y accesorio (NC XI) se encuentran sugeridos por un abultamiento grueso, dirigido hacia adelante a partir del piso de la porción posterior del hemisferio cerebelar ${ }_{\mathrm{m}}$. En la porción más posterior del molde endocraneano, se registra el canal que transporta el nervio hipogloso (NC XII) y que abre al exterior a través del foramen homónimo.

Con respecto al sistema vascular del endocráneo en los nesodontinos, en vida, la estructura vascular más conspicua habría sido el seno sagital superior, soportado por el surco medial, cuya impresión puede reconocerse en el molde endocraneano. En el molde de MPMPV RBPN-SFV-12-3 no hay resto alguno del seno sagital superior, pero esta estructura se encuentra presente en los nesodontinos y su desarrollo varía con la ontogenia (Ver molde endocraneano de Adinotherium ovinum). El seno transverso no fue reconstruido en este ejemplar debido al daño por compactación que sufrió la cavidad; sin embargo, por lo que puede apreciarse en las secciones obtenidas a partir de TC, el seno transverso conecta con: 1) los forámenes de las rami temporalis; 2) el canal postemporal que transmitiría la arteria diploética magna y un sistema de senos venosos asociados (Wible 1987, 2010; MacPhee 2014); 3) el canal que transporta la vena postglenoidea, con la presencia de un seno sigmoideo de diámetro relativamente pequeño; y 4) el canal orbitotemporal (parcialmente reconstruido) que corre lateralmente sobre la periferia del lóbulo piriforme y que, en vida, transmite la rama supraorbitaria de la arteria estapedial superior y puede o no transmitir una vena (Wible 1987, 2008, de Muizon et al. 2015). El recorrido de este canal se corresponde con el usual registrado para los mamíferos que lo presentan, ya que sigue, aproximadamente, el recorrido de la fisura rinal. A partir de las secciones de las TC, se comprueba que el recorrido del canal 
orbitotemporal es parcialmente intracraneano y se vuelve intramural hacia la porción anterior, aproximadamente a la altura en que comienzan los tractos ópticos. El diámetro del molde de este canal es bastante grande y se pudo registrar en todos los ejemplares de Nesodontinae en los que se realizaron TC.

\section{—Molde oído interno}

En los especímenes analizados de Nesodon imbricatus, la calidad de los estudios de TC y la preservación del material no permitió la realización de modelos tridimensionales donde se pueda apreciar en detalle la morfología del oído interno. Por esta razón, solo se presenta la descripción detallada del oído interno para Adinotherium ovinum, como representante de los nesodontinos de Santa Cruz, y el de Proadinotherium muensteri. 


\begin{tabular}{|c|c|c|c|c|c|c|c|c|}
\hline & $\begin{array}{c}\text { RBPN-SFV } \\
-12-3 \\
\text { N. imbricatus } \\
\end{array}$ & $\begin{array}{c}\text { MPM-PV } \\
3532 \\
\text { A. ovinum } \\
\end{array}$ & $\begin{array}{c}\text { RB2-SFV } \\
-12-9 \\
\text { A. ovinum } \\
\end{array}$ & $\begin{array}{c}\text { MPM-PV } 3541 \\
\text { A. ovinum }\end{array}$ & $\begin{array}{l}\text { MHNSR-1004 } \\
\text { N. taweretus } \\
\end{array}$ & $\begin{array}{c}\text { CV-SHP-15-13 } \\
\text { Homalodotherium }\end{array}$ & $\begin{array}{c}\text { MPM-PV } 3668 \\
\text { A. ovinum }\end{array}$ & $\begin{array}{c}\text { MPM-PV } \\
3479 \\
\text { A. ovinum } \\
\end{array}$ \\
\hline Vol. Total ME & $251361 \mathrm{~mm}^{3}$ & $115376 \mathrm{~mm}^{3}$ & $125817 \mathrm{~mm}^{3}$ & $>79159 \mathrm{~mm}^{3}$ & $285108 \mathrm{~mm}^{3}$ & $257661 \mathrm{~mm}^{3}$ & $76412,33 \mathrm{~mm}^{3}$ & $117066,8 \mathrm{~mm}^{3}$ \\
\hline Flexura ME & $31^{\circ}$ & $38^{\circ}$ & $46^{\circ}$ & $35^{\circ}$ & $59^{\circ}$ & $28^{\circ}$ & $\sim 40^{\circ}$ & $32^{\circ}$ \\
\hline L. máximo ME & $141 \mathrm{~mm}$ & $109 \mathrm{~mm}$ & $105 \mathrm{~mm}$ & $\sim 83 \mathrm{~mm}$ & $130 \mathrm{~mm}$ & $156,35 \mathrm{~mm}$ & $83,3 \mathrm{~mm}$ & $\sim 98 \mathrm{~mm}$ \\
\hline A. máximo ME & $73,7 \mathrm{~mm}$ & $57 \mathrm{~mm}$ & $54,5 \mathrm{~mm}$ & $54,7 \mathrm{~mm}$ & $80 \mathrm{~mm}$ & $78,8 \mathrm{~mm}$ & $\sim 57 \mathrm{~mm}$ & $60 \mathrm{~mm}$ \\
\hline Al. maxima $\mathrm{ME}$ & $65 \mathrm{~mm}$ & $61 \mathrm{~mm}$ & $61,5 \mathrm{~mm}$ & $45 \mathrm{~mm}$ & $71 \mathrm{~mm}$ & $66,6 \mathrm{~mm}$ & $41 \mathrm{~mm}$ & $48,8 \mathrm{~mm}$ \\
\hline Vol. bulbos olfatorios* & $\sim 5646 \mathrm{~mm}^{3}$ & $\sim 3109 \mathrm{~mm}^{3}$ & - & $\sim 1707 \mathrm{~mm}^{3}$ & - & $\sim 3906 \mathrm{~mm}^{3}$ & $\sim 1154 \mathrm{~mm}^{3}$ & $\sim 1771 \mathrm{~mm}^{3}$ \\
\hline L. bulbo olfatorios $* *$ & $17 \mathrm{~mm}$ & $9,6 \mathrm{~mm}$ & - & - & - & $20,2 \mathrm{~mm}$ & $11 \mathrm{~mm}$ & $10,1 \mathrm{~mm}$ \\
\hline A. bulbo olfatorios $* *$ & $13,4 \mathrm{~mm}$ & $9,1 \mathrm{~mm}$ & - & $\sim 8,6 \mathrm{~mm}$ & - & $9,6 \mathrm{~mm}$ & $9 \mathrm{~mm}$ & $8 \mathrm{~mm}$ \\
\hline Al. bulbo olfatorio & $17,6 \mathrm{~mm}$ & $10,3 \mathrm{~mm}$ & - & $11,8 \mathrm{~mm}$ & - & $24 \mathrm{~mm}$ & $10 \mathrm{~mm}$ & $11 \mathrm{~mm}$ \\
\hline Vol. lóbulos piriformes & - & $\sim 14503 \mathrm{~mm}^{3}$ & $\sim 15815 \mathrm{~mm}^{3}$ & $\sim 6225 \mathrm{~mm}^{3}$ & $\sim 9875 \mathrm{~mm}^{3}$ & - & - & $\sim 11115 \mathrm{~mm}^{3}$ \\
\hline L. lóbulos piriformes** & $25 \mathrm{~mm}$ & $25 \mathrm{~mm}$ & $24 \mathrm{~mm}$ & $26 \mathrm{~mm}$ & $37 \mathrm{~mm}$ & $44,7 \mathrm{~mm}$ & $32 \mathrm{~mm}$ & $28 \mathrm{~mm}$ \\
\hline A. lóbulos piriformes** & - & $19 \mathrm{~mm}$ & $17,6 \mathrm{~mm}$ & $17 \mathrm{~mm}$ & $\sim 13 \mathrm{~mm}$ & $9,2 \mathrm{~mm}$ & $\sim 10 \mathrm{~mm}$ & $\sim 11 \mathrm{~mm}$ \\
\hline Al. lóbulos piriformes** & $17,2 \mathrm{~mm}$ & $21 \mathrm{~mm}$ & $16 \mathrm{~mm}$ & $17 \mathrm{~mm}$ & $18,8 \mathrm{~mm}$ & $27,8 \mathrm{~mm}$ & $\sim 21 \mathrm{~mm}$ & $17 \mathrm{~mm}$ \\
\hline Vol. hemisferios cerebrales* & $\sim 71346 \mathrm{~mm}^{3}$ & $\sim 48000 \mathrm{~mm}^{3}$ & $\sim 52303 \mathrm{~mm}^{3}$ & $\sim 45000 \mathrm{~mm}^{3}$ & $\sim 100969 \mathrm{~mm}^{3}$ & $\sim 69885 \mathrm{~mm}^{3}$ & - & $\sim 42505 \mathrm{~mm}^{3}$ \\
\hline L. hemisferio cerebral $* *$ & $75 \mathrm{~mm}$ & $56 \mathrm{~mm}$ & $55 \mathrm{~mm}$ & $45 \mathrm{~mm}$ & $54 \mathrm{~mm}$ & $92,4 \mathrm{~mm}$ & $54,8 \mathrm{~mm}$ & $53,5 \mathrm{~mm}$ \\
\hline A. hemisferio cerebral $* *$ & $38 \mathrm{~mm}$ & $20 \mathrm{~mm}$ & $18 \mathrm{~mm}$ & $22 \mathrm{~mm}$ & $35,7 \mathrm{~mm}$ & $42 \mathrm{~mm}$ & $\sim 25 \mathrm{~mm}$ & $22 \mathrm{~mm}$ \\
\hline Al. hemisferio cerebral ${ }^{* *}$ & $31,3 \mathrm{~mm}$ & $25,5 \mathrm{~mm}$ & $35 \mathrm{~mm}$ & $24 \mathrm{~mm}$ & $38 \mathrm{~mm}$ & $29 \mathrm{~mm}$ & $\sim 29,5 \mathrm{~mm}$ & $25,5 \mathrm{~mm}$ \\
\hline Vol. hipofisis & $\sim 12215 \mathrm{~mm}^{3}$ & $\sim 7235 \mathrm{~mm}^{3}$ & $\sim 8256 \mathrm{~mm}^{3}$ & $\sim 2602 \mathrm{~mm}^{3}$ & $\sim 10548 \mathrm{~mm}^{3}$ & $\sim 2785 \mathrm{~mm}^{3}$ & - & $\sim 5813 \mathrm{~mm}^{3}$ \\
\hline L. hipofisis & $34,5 \mathrm{~mm}$ & $\sim 15 \mathrm{~mm}$ & $20,2 \mathrm{~mm}$ & $\sim 15 \mathrm{~mm}$ & $22 \mathrm{~mm}$ & $18 \mathrm{~mm}$ & $20 \mathrm{~mm}$ & $19,6 \mathrm{~mm}$ \\
\hline A. hipofisis & $42,8 \mathrm{~mm}$ & $24,6 \mathrm{~mm}$ & $25 \mathrm{~mm}$ & $25 \mathrm{~mm}$ & $41 \mathrm{~mm}$ & $14,5 \mathrm{~mm}$ & $26,2 \mathrm{~mm}$ & $18,8 \mathrm{~mm}$ \\
\hline Al. hipofisis & $\sim 18 \mathrm{~mm}$ & $21 \mathrm{~mm}$ & $20 \mathrm{~mm}$ & $13,5 \mathrm{~mm}$ & $28 \mathrm{~mm}$ & $5,4 \mathrm{~mm}$ & $13 \mathrm{~mm}$ & $\sim 14 \mathrm{~mm}$ \\
\hline Vol. puente troncoencefálico & - & $\sim 2586 \mathrm{~mm}^{3}$ & $\sim 3542 \mathrm{~mm}^{3}$ & - & $\mathrm{mm}^{3}$ & $\sim 10535 \mathrm{~mm}^{3}$ & - & - \\
\hline L. puente troncoenfálico & - & - & $15,5 \mathrm{~mm}$ & - & - & $40 \mathrm{~mm}$ & - & - \\
\hline A. puente troncoenfálico & - & - & $8 \mathrm{~mm}$ & - & - & $18,8 \mathrm{~mm}$ & - & - \\
\hline Al. puente troncoenfálico & - & - & $3 \mathrm{~mm}$ & - & - & $13,7 \mathrm{~mm}$ & - & - \\
\hline
\end{tabular}


Anatomía y Sistemática de los

Toxodóntidos de Santa Cruz

\begin{tabular}{|c|c|c|c|c|c|c|c|c|}
\hline Vol. cerebelo & $\sim 52458 \mathrm{~mm}^{3}$ & $\sim 21532 \mathrm{~mm}^{3}$ & $\sim 21845 \mathrm{~mm}^{3}$ & $>8200 \mathrm{~mm}^{3}$ & $\sim 50642 \mathrm{~mm}^{3}$ & $37184 \mathrm{~mm}^{3}$ & - & $\sim 20415 \mathrm{~mm}^{3}$ \\
\hline L. cerebelo & $19,5 \mathrm{~mm}$ & $17 \mathrm{~mm}$ & $18 \mathrm{~mm}$ & $13 \mathrm{~mm}$ & $23 \mathrm{~mm}$ & $38,4 \mathrm{~mm}$ & $\sim 13,5 \mathrm{~mm}$ & - \\
\hline A. cerebelo & $41 \mathrm{~mm}$ & $24,2 \mathrm{~mm}$ & $24 \mathrm{~mm}$ & $\sim 24 \mathrm{~mm}$ & $40 \mathrm{~mm}$ & $40,7 \mathrm{~mm}$ & $\sim 32,3 \mathrm{~mm}$ & - \\
\hline Al. cerebelo & $27 \mathrm{~mm}$ & $\sim 21 \mathrm{~mm}$ & $19,5 \mathrm{~mm}$ & - & $24 \mathrm{~mm}$ & $37,8 \mathrm{~mm}$ & $\sim 26 \mathrm{~mm}$ & - \\
\hline
\end{tabular}

Tabla IV. I. Medidas volumétricas, angulares y lineales de los moldes endocraneanos presentados en esta tesis. A: Ancho, Al: Alto, L: Largo, ME: Molde endocraneano, Vol: Volumen. 
Hernández Del Pino, S.

\section{-Mandíbula}

En líneas generales, la mandíbula (Fig. IV. 16) es un hueso grande y pesado, con una rama ascendente alta y relativamente ancha en su extremo posterior, y una rama horizontal larga y alta. Las hemimandíbulas izquierda y derecha se encuentran firmemente unidas a una edad temprana en una sínfisis mandibular robusta y muy cóncava, cuya extensión varía de manera notable de acuerdo al estadio ontogenético que se esté analizando; en los ejemplares adultos, se extiende desde la raíz de los incisivos hasta el nivel del tercer o cuarto premolar.

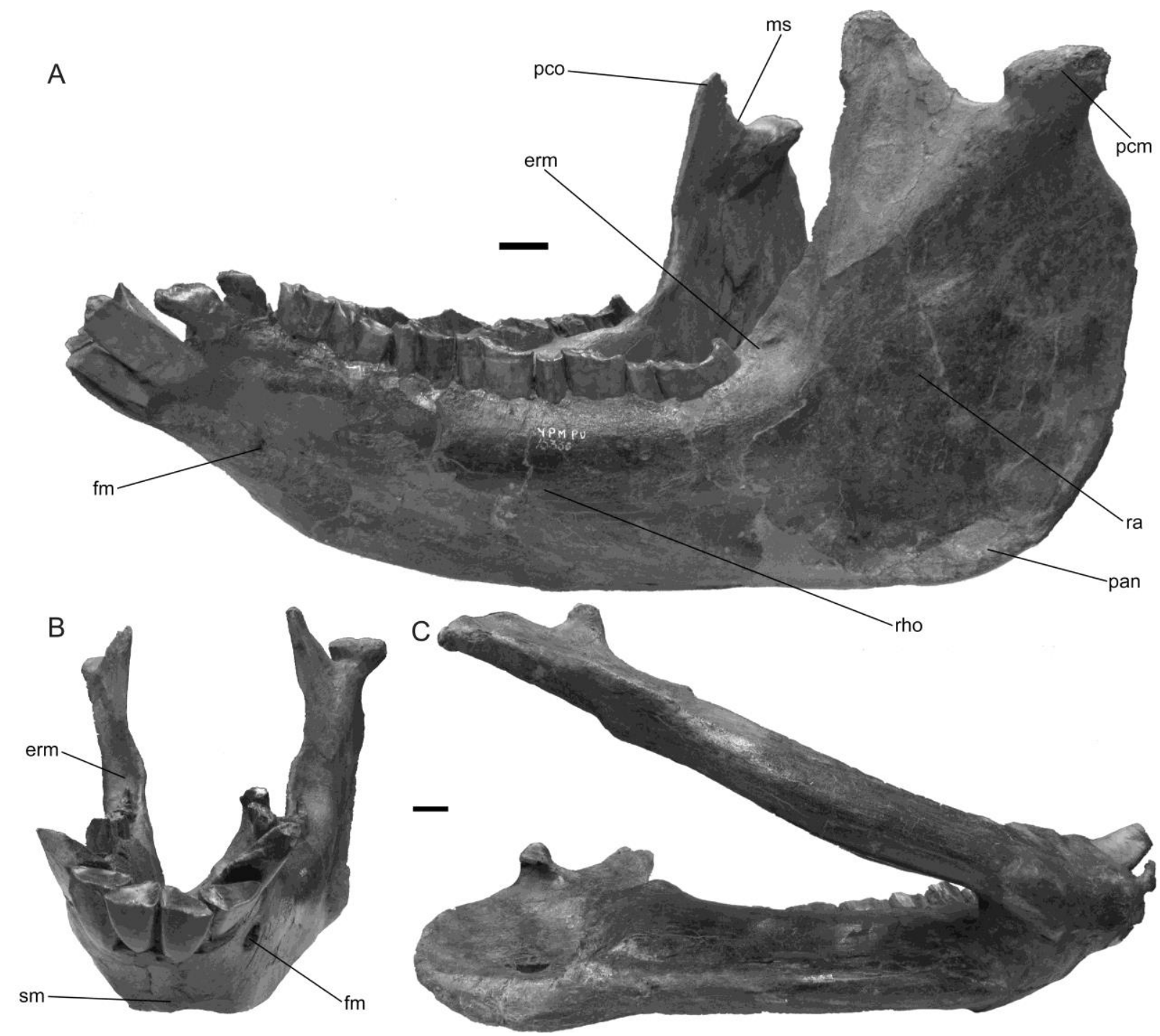

Fig IV. 16. Diferentes vistas de la mandibula de Nesodon imbricatus: A. Vistas lateral izquierda (A), anterior (B) y ventral (C).

La rama horizontal está comprimida lateralmente y adquiere su mayor altura a nivel de m1-m2; hacia el final de la rama existe un espacio retromolar pequeño y angosto entre el m3 y la rama ascendente. Como se mencionó en el capítulo anterior, el desarrollo de forámenes 
mentonianos es variable en $N$. imbricatus, no solo en número, sino también en la posición relativa respecto a la serie dentaria. Es común que haya dos forámenes, el más anterior en la porción lateroventral de la sínfisis mandibular, por debajo del límite p2-p3, y el segundo a nivel del m1, ubicado algo más ventralmente; también pueden presentarse tres y hasta cuatro forámenes mentonianos. Además, pueden existir numerosos forámenes nutricios, más pequeños, a lo largo de toda la rama horizontal.

La rama ascendente de la mandíbula cuenta con tres procesos, el coronoideo, el condilar (o articular) y el angular. El proceso coronoideo es relativamente bajo, aunque supera el nivel de la articulación mandibular, y es convexo en sus bordes anterior y posterior. El proceso condilar es ancho y corto anteroposteriormente, convexo en ambas direcciones. Scott (1912) destacó la presencia de una superficie articular para el proceso postglenoideo en el margen posterior del cóndilo y de una plataforma de hueso con forma de gancho cuya función no es clara; sin embargo dicha estructura no ha sido observada en los ejemplares a disposición. La muesca sigmoidea tiene un desarrollo escaso y es poco profunda. El proceso angular de la rama ascendente está ubicado en la región posteroventral; está ligeramente curvado en su extremo ventral y forma una repisa corta y rugosa fácilmente visible en vista dorsal o ventral.

\section{-Dentición}

La dentición de Nesodon imbricatus es completa (Figs. IV. 17 y IV. 18), con fórmula dentaria I3/3 C1/1 P4/4 M3/3. La morfología oclusal de los dientes yugales cambia de manera notable durante la ontogenia (e.g. Lydekker 1893, Ameghino 1891, 1894a, Scott 1912, Madden 1990). Dada la gran cantidad de ejemplares conocidos de esta especie, se han encontrado casos en los que existen dientes supernumerarios (en general, premolares), que representan ejemplares jóvenes que aún conservan dentición lactal (por ejemplo, MLP 12-4, MLP 12-1, ejemplares originalmente asignados a Acrotherium) o individuos con alguna anormalidad en el desarrollo (e.g. retención de dientes de leche en la edad adulta, teratologías) como el YPM-PU 16031. 
Hernández Del Pino, S.

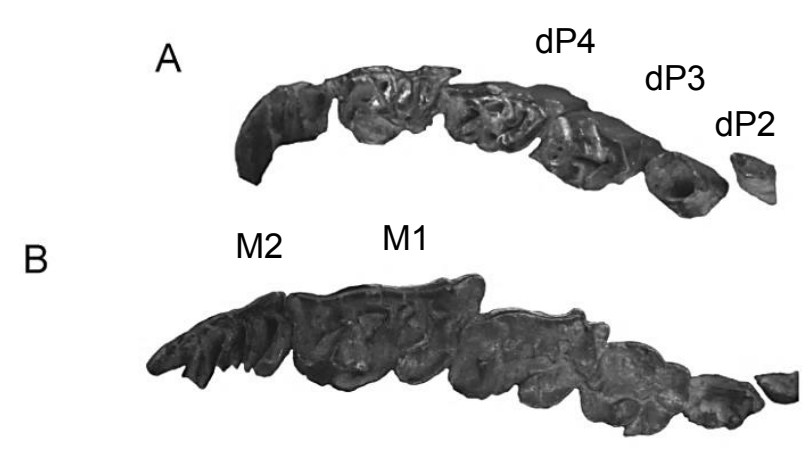

C
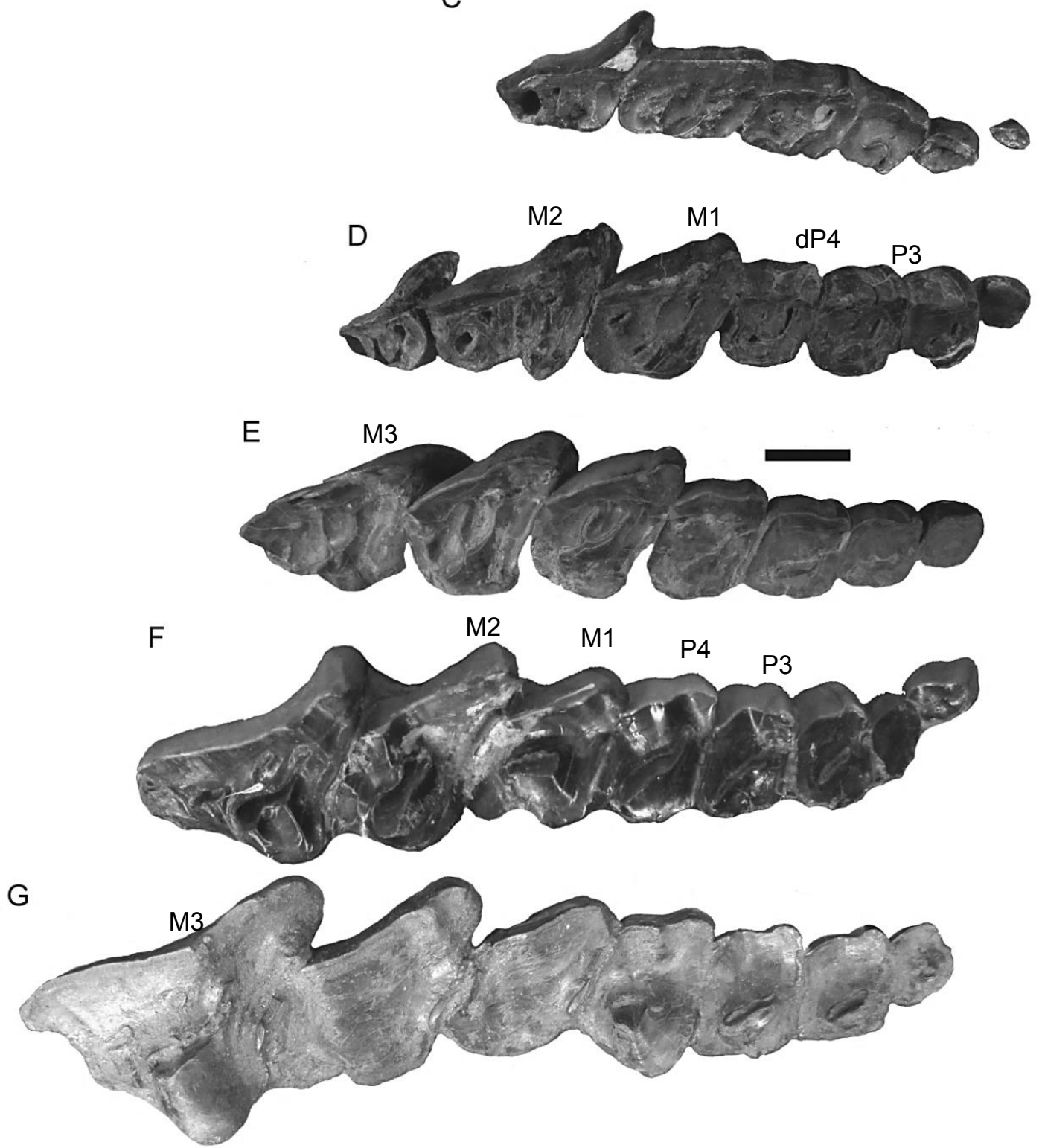

Fig. IV. 17: Variación ontogenética en la dentición yugal superior de Nesodon imbricatus: Ejemplares juveniles YPM-PU 15354 (A) FMNH-13228 (B) y FMNH-13114 (C); ejemplar subadulto FMNH-39739 (D); y ejemplares adultos FMNH-13079 (E), YPM-PU 15256 (F) y FMNH-13084 (G). Escala $2 \mathrm{~cm}$ 
La dentición superior (Fig. IV. 17), en los ejemplares adultos, presenta I1 e I3 convexos labialmente con un contorno lingual biselado debido al desgaste y generalmente no conforman una serie continua con el I2, cuya talla es mucho mayor. El I1 recién erupcionado es un diente ancho y grande, presenta una pequeña foseta superficial en su superficie oclusal que desaparece rápidamente con el desgaste, y en el adulto esta superficie tiene un contorno más triangular con su base apuntando hacia el extremo distal; la cara mesial del diente se encuentra cubierta por una gruesa capa de esmalte, ausente en los bordes laterales y la cara distal (Scott, 1912). El I2 esta hipertrofiado, es el más grande de toda la serie incisiva y tiene una sección triangular; la superficie oclusal del diente es en bisel (debido a la ausencia de esmalte en la cara lingual del diente) y presenta una diferencia grande entre la altura de la porción labial y la lingual del diente, siendo más baja en esta última; el I2 y el I1. Los I3, C y P1 son pequeños en el adulto; I3 y C presentan una forma más espatulada (similar al I1 pero de menor tamaño), el canino ligeramente más grande que el I3, mientras que el P1 tiene una sección cuadrangular. La complejidad y el tamaño de las piezas dentarias aumentan desde P2 a M3. Los P2 presentan una sección subcuadrangular y en su superficie oclusal presentan una foseta central de forma sigmoidea con su eje mayor dirigido mesiodistalmente; progresivamente, a raíz del desgaste, su forma va cambiando hacia una foseta más o menos recta hasta casi desaparecer en los ejemplares adultos. Todos los premolares presentan en un pliegue labial cuyo desarrollo se hace mas notorio a lo largo de la serie yugal. Las diferencias en este pliegue se han usado en la literatura para la fundación de varios nombres atribuidos a Nesodontinae; sin embargo, como fue expuesto en el capitulo III, esta estructura tiene un desarrollo variable dependiendo del desgaste del diente. Los P también presentan un surco lingual, prácticamente imperceptible en los tres primeros premolares y bastante evidente en el cuarto. El P3 presenta las mismas características que el P2, con mayor tamaño. E1 P4 difiere de los anteriores por su mayor talla y las características de la foseta central cuando erupciona el diente, ya que presenta una incipiente forma de "Y", volviendose sigmoidea, como en los otros $\mathrm{P}$, a medida que avanza el desgaste. Los molares son más grandes que los premolares, con parastilo proyectado anterolabialmente. Presentan crecimiento continuo durante gran parte de la vida del animal y las raíces del M3 se cierran en estadios de senilidad. En los molares, la foseta central tiene una clara forma de "Y", con el surco lingual largo, y se encuentra acompañada frecuentemente por fosetas accesorias que desaparecen a medida que progresa el desgaste. Los molares presentan el pliegue del paracono poco marcado y un surco anterior a él superficial, que se acentúa de M1 a M3. Varios autores han remarcado la enorme variación de la forma y las proporciones de los dientes de los nesodontinos en diferentes 
estadios ontogenéticos (Fig. IV. 17), siendo mayor a nivel de los molares. Scott (1912) señaló que al momento de la erupción del M3, el M2 es el diente más grande (Fig. IV. 17. D), pero a medida que progresa la edad, el M3 aumenta considerablemente su tamaño y se convierte en el mayor de toda la serie dentaria (Fig. IV. 17. E-G). En los ejemplares seniles, incluso el M3 pierde casi todas las crestas de esmalte de la corona y el surco del paracono desaparece (Fig. IV. 17G). Los molares presentan esmalte en toda su cara labial, extendiéndose por los extremos mesial y distal, mientras que en la cara lingual se encuentra restringido a una banda angosta. El metalofo se acorta del M1 al M3, siendo en este último donde la diferencia es más notoria, por el mayor desarrollo relativo del ectolofo, que duplica la longitud del protolofo y del metalofo (similares entre sí); además, el M3 presenta un surco posterolingual en el metalofo que le da una apariencia trilobulada a la cara lingual del diente.

A

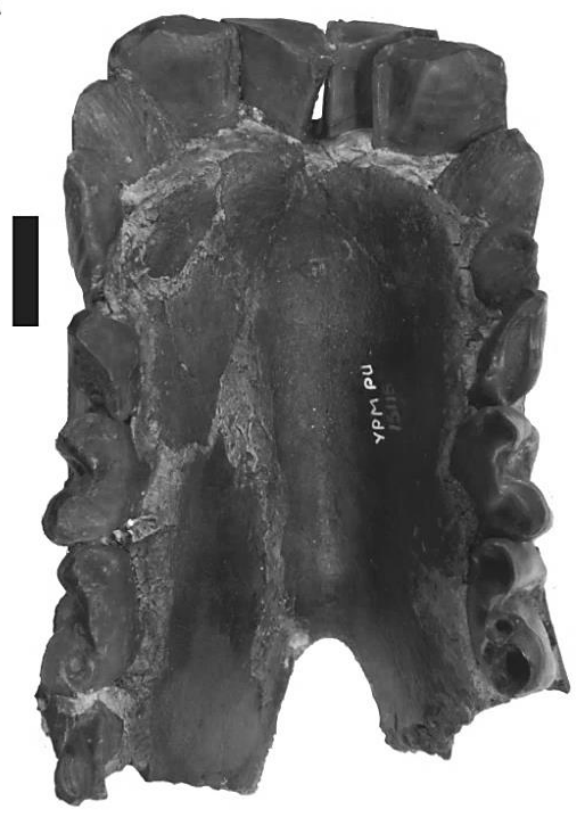

B

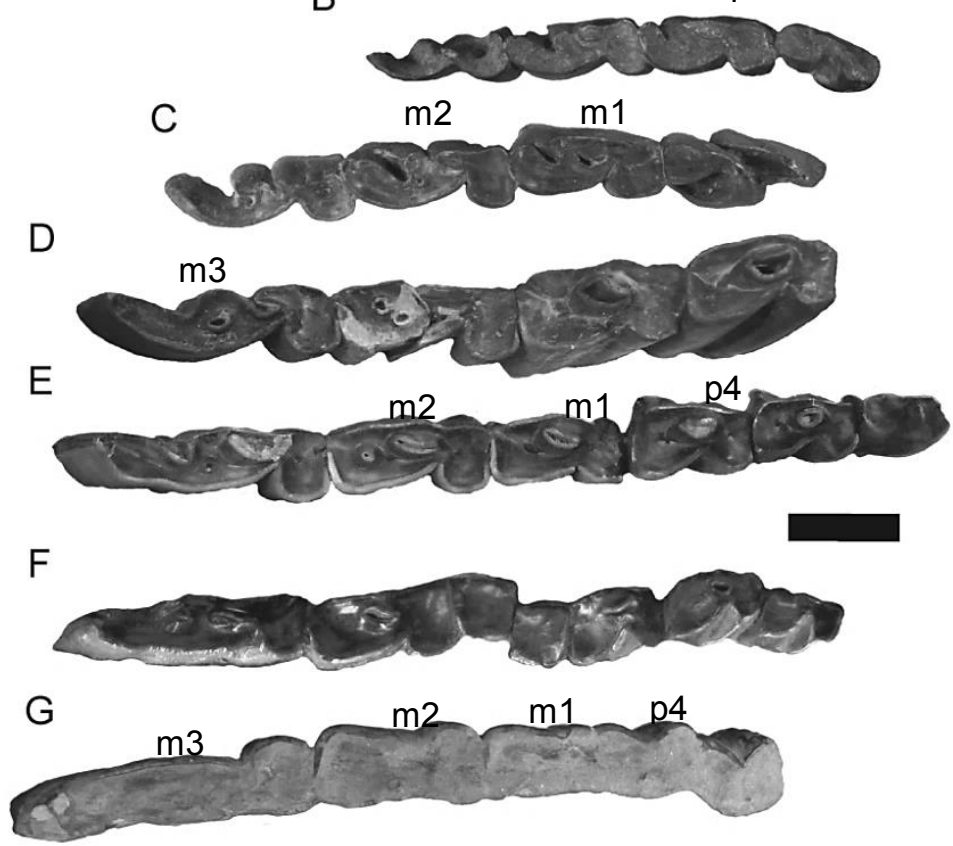

Fig. IV. 18. Variación ontogenética en la dentición inferior de Nesodon imbricatus: sínfisis mandibular de un ejemplar joven YPM-PU 15115 (A) y dentición yugal de un ejemplar juvenil FMNH-13228 (B), de un ejemplar subadulto FMNH-13230 (C), de dos ejemplares adultos jovenes MLP 12-254 (D) e YPM-PU 15000 (E), y de dos ejemplares adultos seniles YPM-PU 15250 (F) y FMNH-13084 (G). Escala $2 \mathrm{~cm}$.

La dentición inferior (Fig. IV. 18) anterior se caracteriza por los dos primeros incisivos insertados en la misma dirección que la cara anterior de la sínfisis, con las coronas orientadas mesialmente. El i3 es hipselodonte y su extremo distal alcanza el nivel del p3, presenta una 
sección triangular y la orientación del extremo mesial de este diente varia desde anterodorsal a anterior; presenta esmalte tanto en la cara lingual como en la labial. El c y el p1 son pequeños y su forma esta bastante simplificada; el c presenta una única raíz y ambos presentan una corona de forma crescentiforme en estadios tempranos de desgaste. En p2 y p3, el trigónido y el talónido tienen más o menos las mismas dimensiones y se encuentran separados por un pligue lingual conspicuo en las piezas con poco desgaste; con el avance del desgaste, este pliegue desaparece y la corona presenta una forma más o menos rectangular. El p4 es el más "molarizado" de la serie premolar y presenta una diferenciación más clara entre el trigónido y el talónido (que casi duplica el tamaño del primero), con un pliegue lingual mas persistente que en p2-3. Cabe destacar que los premolares de Nesodon imbricatus no presentan crecimiento continuo como es el caso de los molares de esta especie y de los premolares de los toxodóntidos del Mioceno medio a tardío (e.g. Pericotoxodon), pero el p3 y p4 son dientes hipsodontes (Cassini et al. 2017). Los molares son hipsodontes (ver Cassini et al. 2017, Tabla 1) y presentan trigónido y talónido bien diferenciados, con pliegues entre metacónido y entocónido, y entre entocónido e hipoconido en las piezas con poco desgaste. En $\mathrm{m} 1$ y m2, el talónido duplica el tamaño del trigónido y, a medida que avanza el desgaste, el pliege ento-hipoconúlido se cierra y forma una fosétida (Fig. IV. 18D, E) que, en los estadios muy avanzados de desgaste, desaparece al igual que el pliegue meta-entocónido (Fig. IV. 18F). El m3 presenta mayor diferencia entre trigónido y talónido (que casi triplica el tamaño del primero) y sus raíces permanecen abiertas hasta estadios de senilidad. En las piezas con poco desgaste (Fig. IV. 18D, E), el $\mathrm{m} 3$ presenta una apariciencia trilobulada lingualmente con conspicuos pliegues meta-entocónido y ento-hipoconúlido, y con dos o tres fosétidas, una de ellas persistente (foseta del entolófido), mientras que las otras desaparecen rápidamente con el desgaste. En estadios ontogenéticos avanzados, el pliegue lingual entohipoconúlido desaparece, mientras que el pliegue meta-entocónido persiste durante toda la vida del animal.

La dentición decidua (Fig. IV. 17A-D y Fig. 18A, B) presenta algunas características generales a todas las piezas: ausencia de defensas con crecimiento continuo, incisivos inferiores imbricados, dentición yugal superior e inferior con patrones de la corona mucho mas complicados, con fosetas y fosétidas más persistentes que en la dentición definitiva, y capas de esmalte mas delgadas. 


\section{2. Adinotherium ovinum}

\section{- Generalidades}

La especie Adinoterhium ovinum, al igual que $N$. imbricatus, es uno de los ungulados más comunes en la Formación Santa Cruz y se conoce prácticamente todo el esqueleto del animal. Scott (1912) ya señaló la existencia de grandes diferencias craneales entre Adinotherium (que en este trabajo reconozco como monoespecífico) y Nesodon, que se pueden resumir en: menor tamaño; diseño oclusal más simple de los premolares superiores, rasgo únicamente identificable en dientes con muy poco desgaste; trigónido de los molares inferiores más ancho y talónido más angosto; rostro y porción anterior de la mandíbula notoriamente más anchos y más similares a la condición observada en Toxodon; y presencia de una convexidad rugosa en los frontales de algunos ejemplares; cresta sagital más larga; y sutura fronto-nasal variable.

En líneas generales, el cráneo de A. ovinum (Fig. IV. 19), dejando de lado la obvia diferencia de tamaño y la mayor gracilidad del cráneo, presenta escasas diferencias con el de $N$. imbricatus y muchas de ellas posiblemente se encuentren relacionadas con la diferencia en las proporciones relativas de los elementos que componen el cráneo (ver IV. 3). En vista dorsal, el cráneo de A. ovinum presenta un contorno pentagonal, a diferencia del contorno triangular del taxón precedente. En vista lateral, el perfil dorsal del cráneo en A. ovinum es ligeramente más sinuoso (debido a la convexidad-concavidad de los frontales) que en Nesodon imbricatus, aunque presenta el mismo patrón de variación, con especímenes que presentan un perfil recto y otros que presentan una elevación anteroposterior más o menos abrupta a nivel de los frontales, dependiendo del ejemplar y la edad del animal; este patrón es similar, pero más notorio que en Proadinotherium muensteri (ver IV. 2.3). 

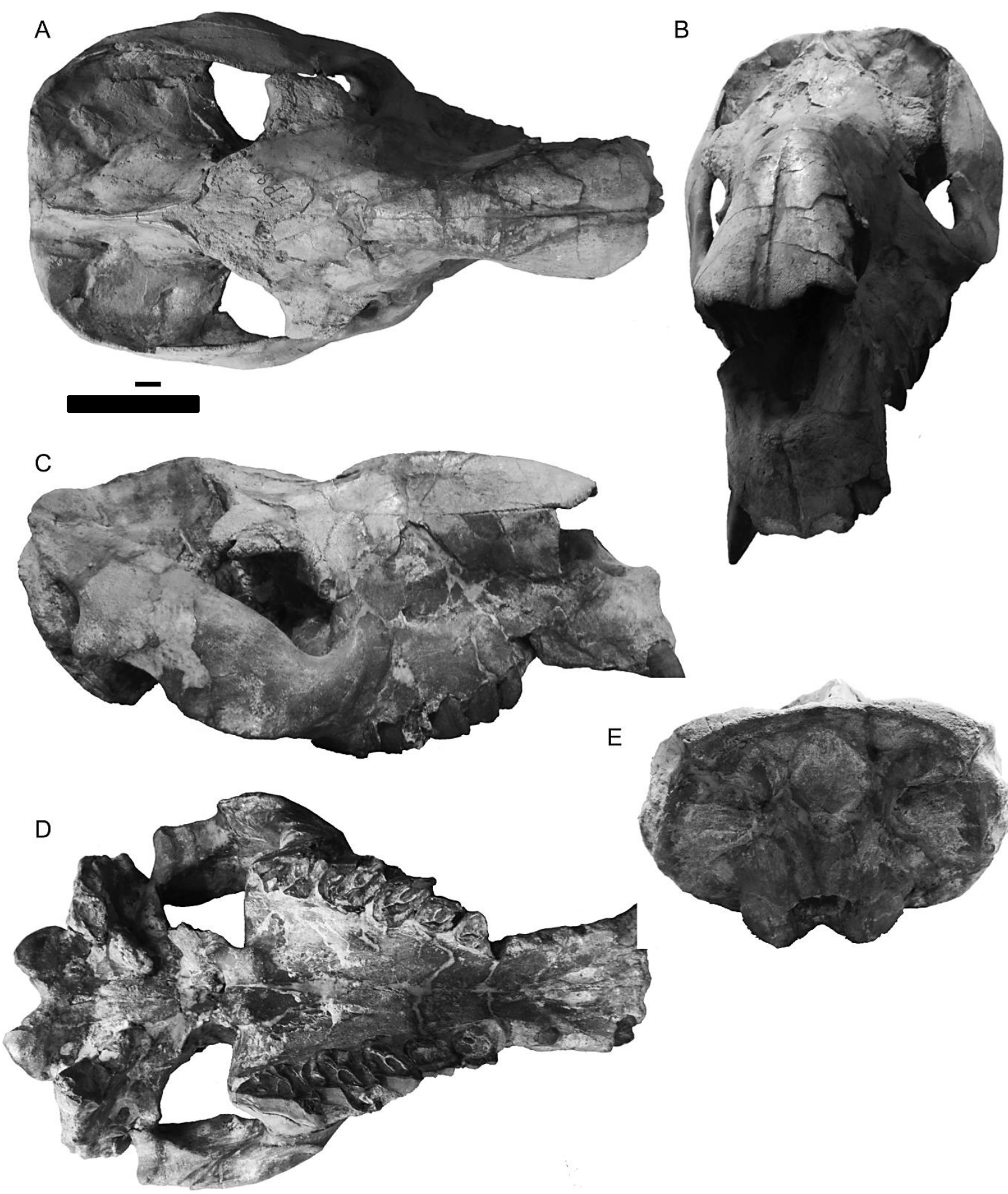

Fig IV. 19: Cráneo de Adinotherium ovinum (MLP 12-1): vistas dorsal (A), anterior (B), lateral izquierda (reflejada, C), ventral (D), posterior (E). Escala $5 \mathrm{~cm}$. 

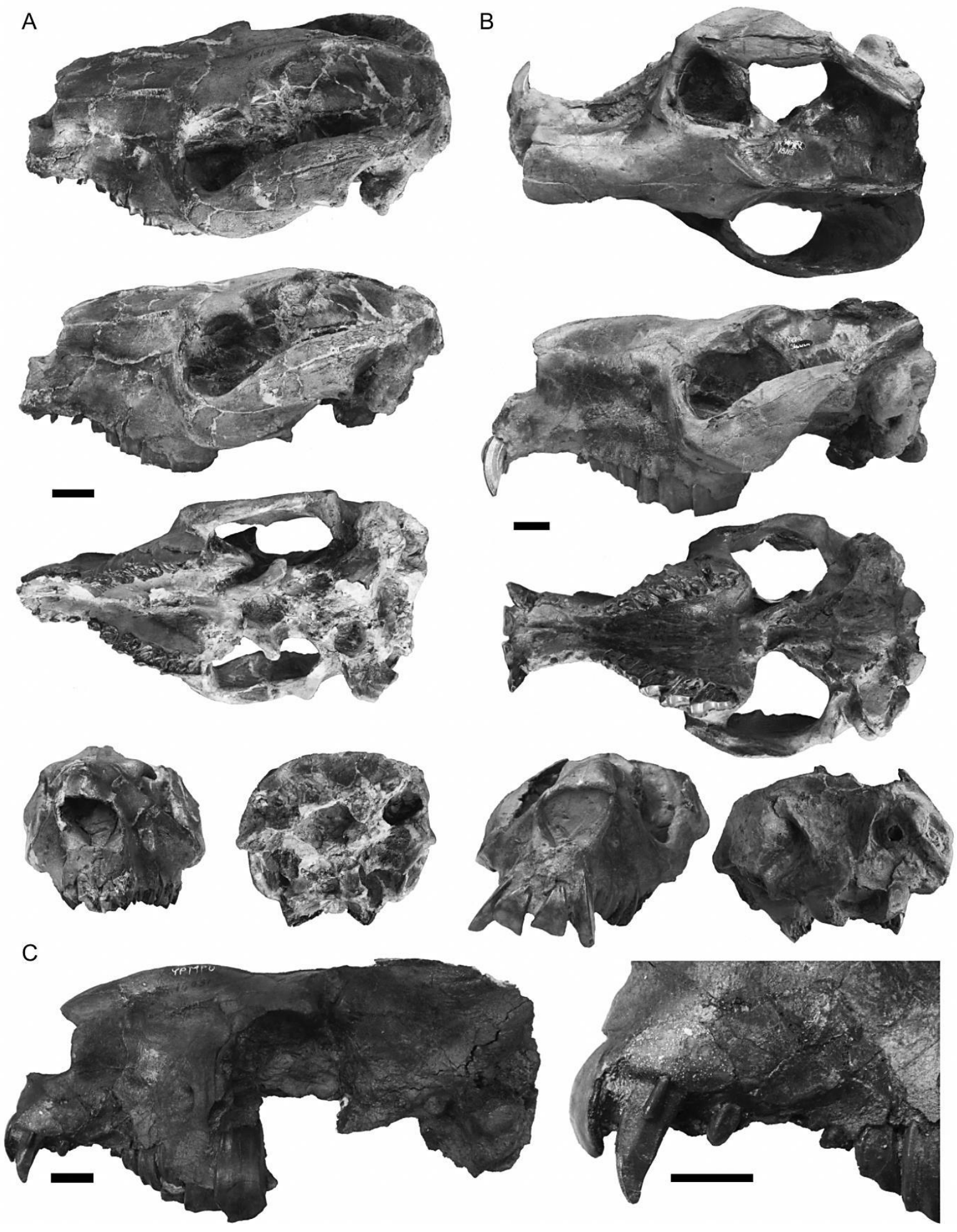

Fig. IV.20. Variación ontogenética en el cráneo de Adinotherium ovinum: de arriba hacia abajo, vistas dorsal, lateral izquierda, ventral, posterior y anterior del ejemplar juvenil YPM-PU 15986 (A); vistas dorsal, lateral izquierda, ventral, anterior y posterior del ejemplar adulto YPM-PU 15118 (B); y vista lateral (y detalle de la misma) del ejemplar YPM-PU 15031. Escala $2 \mathrm{~cm}$. 


\section{—Región naso-facial y techo craneano}

El rostro de $A$. ovinum es relativamente más corto y menos variable en su longitud $\left(\mathrm{MZL}_{\min } / \mathrm{BCL}_{\min }=1,33 ; \mathrm{MZL}_{1 / 2} / \mathrm{BCL}_{1 / 2}=1,41 ; \mathrm{y} \mathrm{MZL}_{\max } / \mathrm{BCL}_{\max }=1,42\right)$ que en $N$. imbricatus y presenta la constricción de la porción posterior de los nasales más pronunciada, justo a nivel del último premolar y el primer molar. Esta constricción genera una mayor exposición de los maxilares en vista dorsal, a pesar de que el ancho de los nasales es mayor en Adinotherium, especialmente en la porción anterior, donde incluso sobrepasan al premaxilar que no es visible en vista dorsal.

Los nasales son largos y angostos (Fig. IV. 21), aunque proporcionalmente más anchos y cortos que en $N$. imbricatus; presentan la típica convexidad anteroposterior y transversal comentada para la especie precedente; sobrepasan anteriormente al premaxilar, pero en menor medida que en $N$. imbricatus, dejando la plataforma narial ligeramente más expuesta. En el margen posterior de los nasales, la sutura naso-frontal es extremadamente variable, tal como comentó Scott (1912), presentando variaciones desde una forma en "V" angosta a una en "W" ancha (Fig. IV. 21); en el caso de la sutura en "W", los procesos frontales del nasal nunca alcanzan el desarrollo que presentan en $N$. imbricatus, siendo más cortos y angostos que en este taxón.

Los premaxilares y maxilares (Fig. IV. 22) son bastante similares a los de la especie precedente, tanto en su desarrollo como en su disposición.

Los frontales (Fig. IV. 19 y 21) son los elementos que presentan mayores diferencias con N. imbricatus, como bien hizo notar Scott (1912). Presentan un desarrollo relativamente mayor, sobre todo transversalmente, las crestas temporales son mucho más notorias y la apariencia general del hueso es bastante más rugosa, incluso en los estadios de desarrollo más tempranos. La variación ontogenética registrada responde al mismo patrón descripto para $N$. imbricatus. En el adulto de A. ovinum, los procesos postorbitales del frontal se encuentran más expandidos lateralmente y son relativamente más robustos que en $N$. imbricatus; además, en diversos ejemplares se pueden observar rugosidades marcadas medialmente a los procesos postorbitales, rodeando una zona que en algunos ejemplares esta ligeramente abultada, un rasgo que llevó a Ameghino (1907) a suponer que esta superficie podría haber servido como zona de inserción para cuernos dermales y que Scott (1912) reconoce como una interpretación probablemente correcta. La excavación posteromedial de los frontales, justo delante de la unión de las crestas temporales, es más profunda que en Nesodon. 


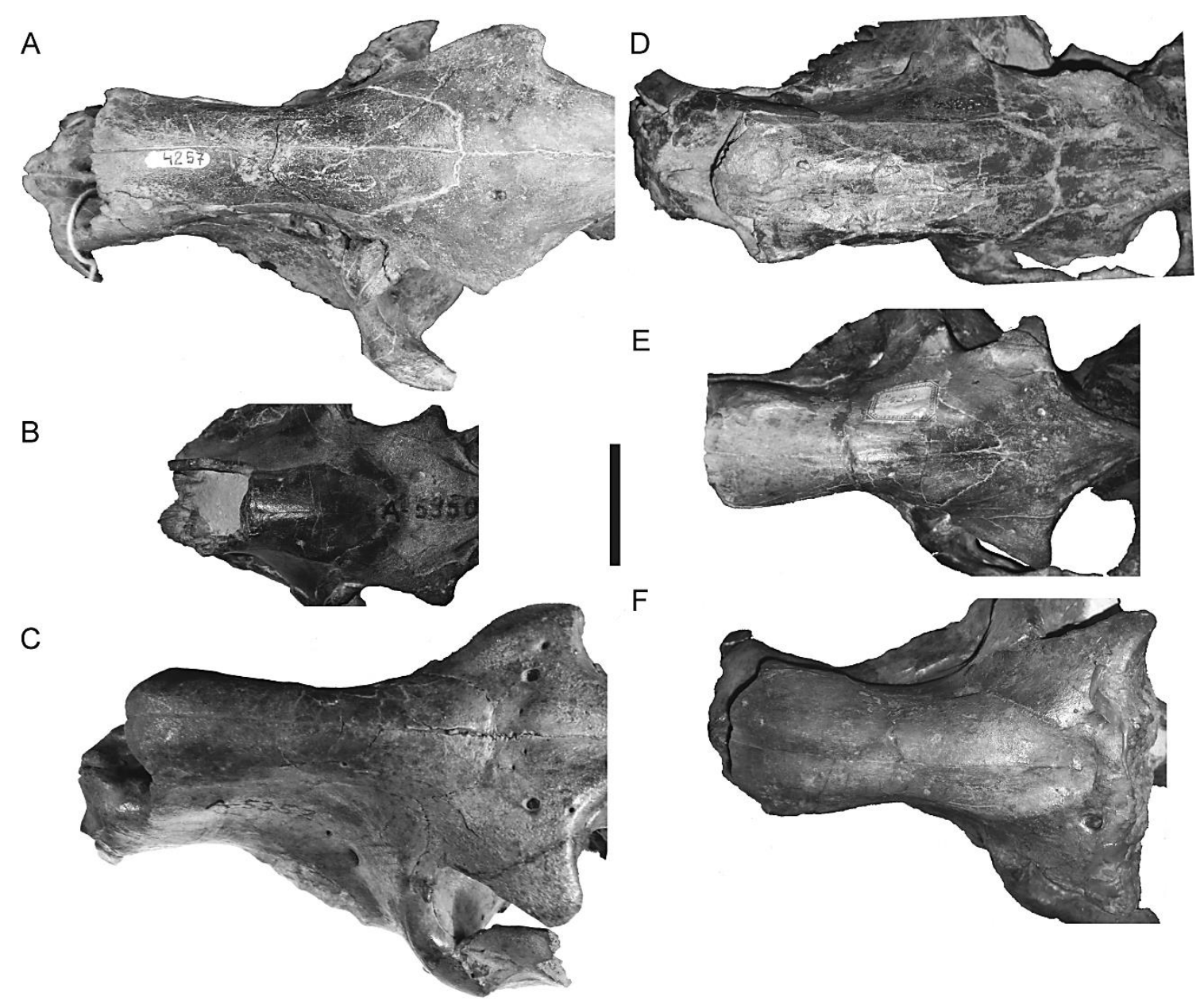

Fig. IV. 21: Variación en la sutura fronto-nasal del cráneo de Adinotherium ovinum en MPM-PV 4257 (A), MACN A 5360 (B), MACN A 5352 (C), MACN A 5354 (D), MACN A 923 (E), MACN A 407 (F). Escala $5 \mathrm{~cm}$.

Los parietales se encuentran más desarrollados, son más largos, anchos y altos que en $N$. imbricatus y, en el adulto, desplazan al escamoso a una posición más ventral. La cresta sagital en los especímenes más jóvenes es ligeramente cóncava y alcanza su mayor altura en la mitad de la bóveda craneana; en los adultos, el perfil dorsal de la cresta sagital puede ser recto o elevado desde la unión de las crestas temporales hacia la región occipital. Los restantes rasgos del parietal son comparables a los de la especie descripta anteriormente.

Los escamosos también participan en la conformación de los laterales del techo craneano justo por debajo de los parietales, aunque su aporte es ligeramente menor que en $N$. imbricatus, debido al mayor desarrollo dorsoventral de los parietales. 

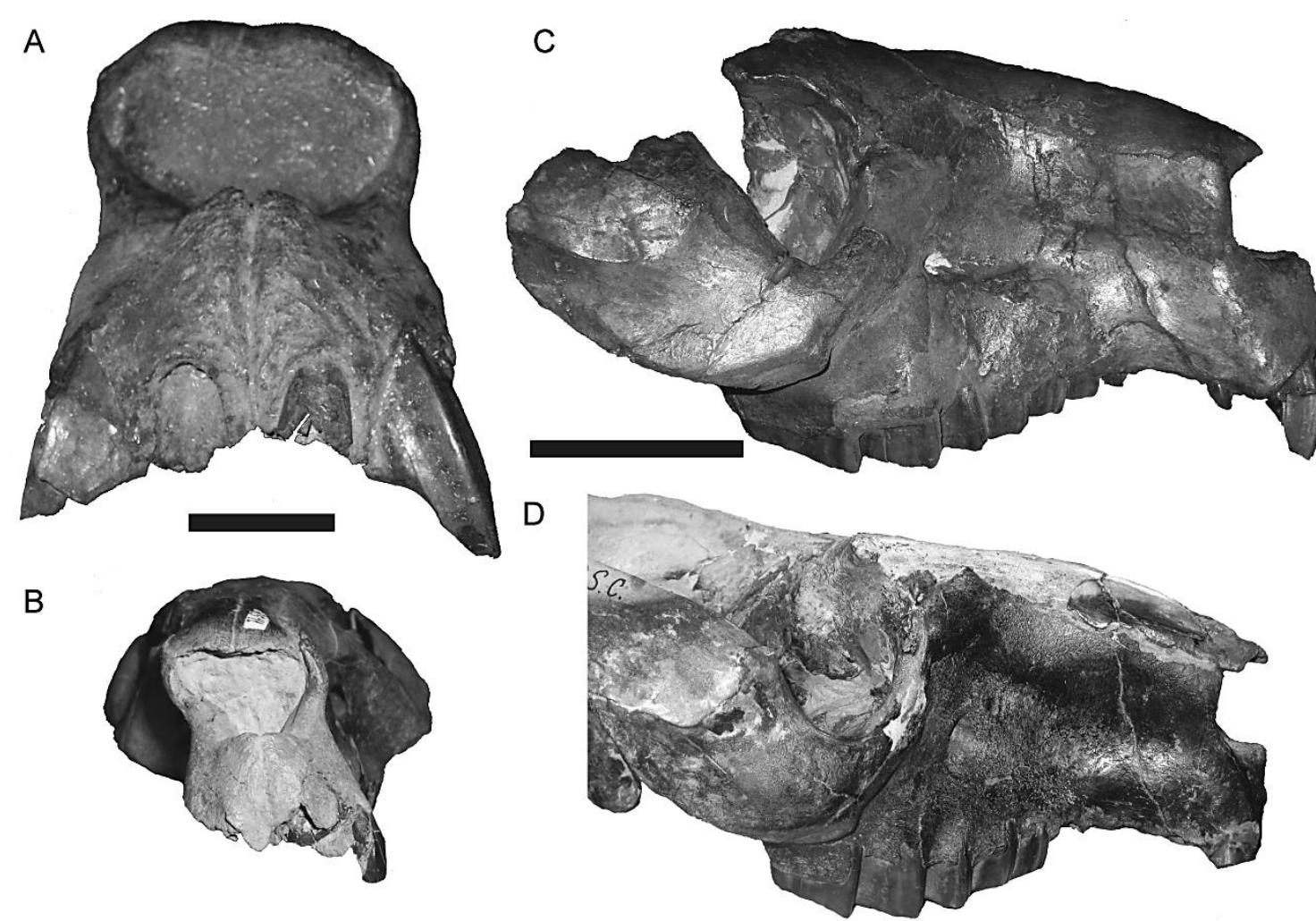

Fig. IV. 22: Región rostral del cráneo de Adinotherium ovinum. Abertura nasal de MACN A 407 (A) y MPM-PV 3541(B), vista lateral derecha de MACN A 407 (C) y MLP 12-2 (D). Escalas, $5 \mathrm{~cm}$.

\section{- Paladar}

En líneas generales, la disposición de los elementos que componen el paladar de $A$. ovinum se corresponde con la condición observada en $N$. imbricatus; por ello, no se brindan descripciones individuales para cada uno de los huesos que componen el paladar, sino que solo se hace hincapié en los rasgos diferenciales de esta región.

Como ya mencionó Scott (1912), el paladar de A. ovinum (Fig. IV. 23) presenta un contorno más triangular que el de $N$. imbricatus y las arcadas dentales convergen fuertemente en la parte anterior; la porción posterior del paladar es más ancha. A estas características puede añadirse, además, que el paladar de $A$. ovinum es relativamente más corto que el de $N$. imbricatus, especialmente en los estadios más avanzados de desarrollo postnatal. Otra diferencia es la constricción de la región palatal a nivel de los primeros premolares, mucho más marcada en Adinotherium que en N. imbricatus.

La porción posterior del paladar y el borde anterior de la coana son bastante similares a los de $N$. imbricatus. Las leves diferencias que presenta $A$. ovinum se refieren a la mayor divergencia de los procesos pterigoideos de los palatinos, que además son ligeramente más cortos que en $N$. imbricatus. 


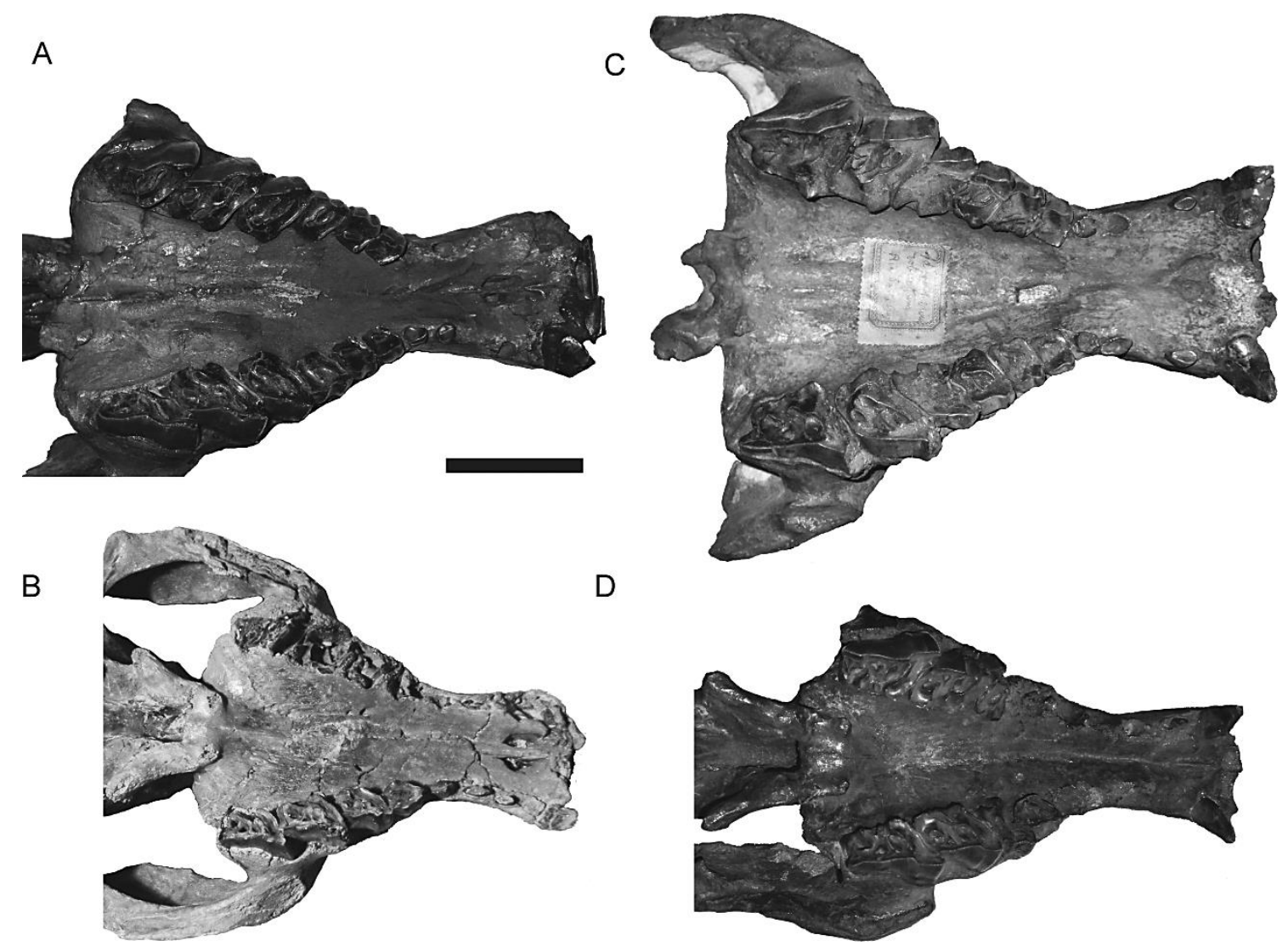

Fig. IV. 23: Región palatal del cráneo de Adinotherium ovinum: MACN A 5352 (A), MPM-PV 3541 (B), MACN A 407 (C), MACN A 11689 (D). Escala, 5 cm.

\section{—Región orbitotemporal}

Al igual que en $N$. imbricatus, las órbitas se encuentran más o menos centralizadas en $A$. ovinum. Se encuentran bien delimitadas y, en vista lateral, su apariencia es más circular que en $N$. imbricatus, además de encontrarse más cerrada por el proceso postorbital del frontal y la elevación del arco cigomático. Por detrás de los procesos postorbitales, como ya se ha mencionado en la caracterización del frontal, existe una constricción transversal marcada que, junto con una cavidad encefálica estrecha y el desarrollo de los arcos cigomáticos en esta especie, genera una amplia cavidad orbitotemporal, ligeramente más amplia que en $N$. imbricatus. La cavidad encefálica, a pesar de ser estrecha, es relativamente más ancha y voluminosa en relación al tamaño corporal del animal (ver Molde endocraneano para más detalles). Los arcos cigomáticos se encuentran ligeramente más expandidos y la diferencia entre el ancho anterior y el posterior varía levemente, lo que le da un aspecto cuadrangular a esta región del cráneo en vista dorsal, mientras que en $N$. imbricatus el ancho anterior es considerablemente menor que el posterior y el contorno del cráneo es más triangular. 


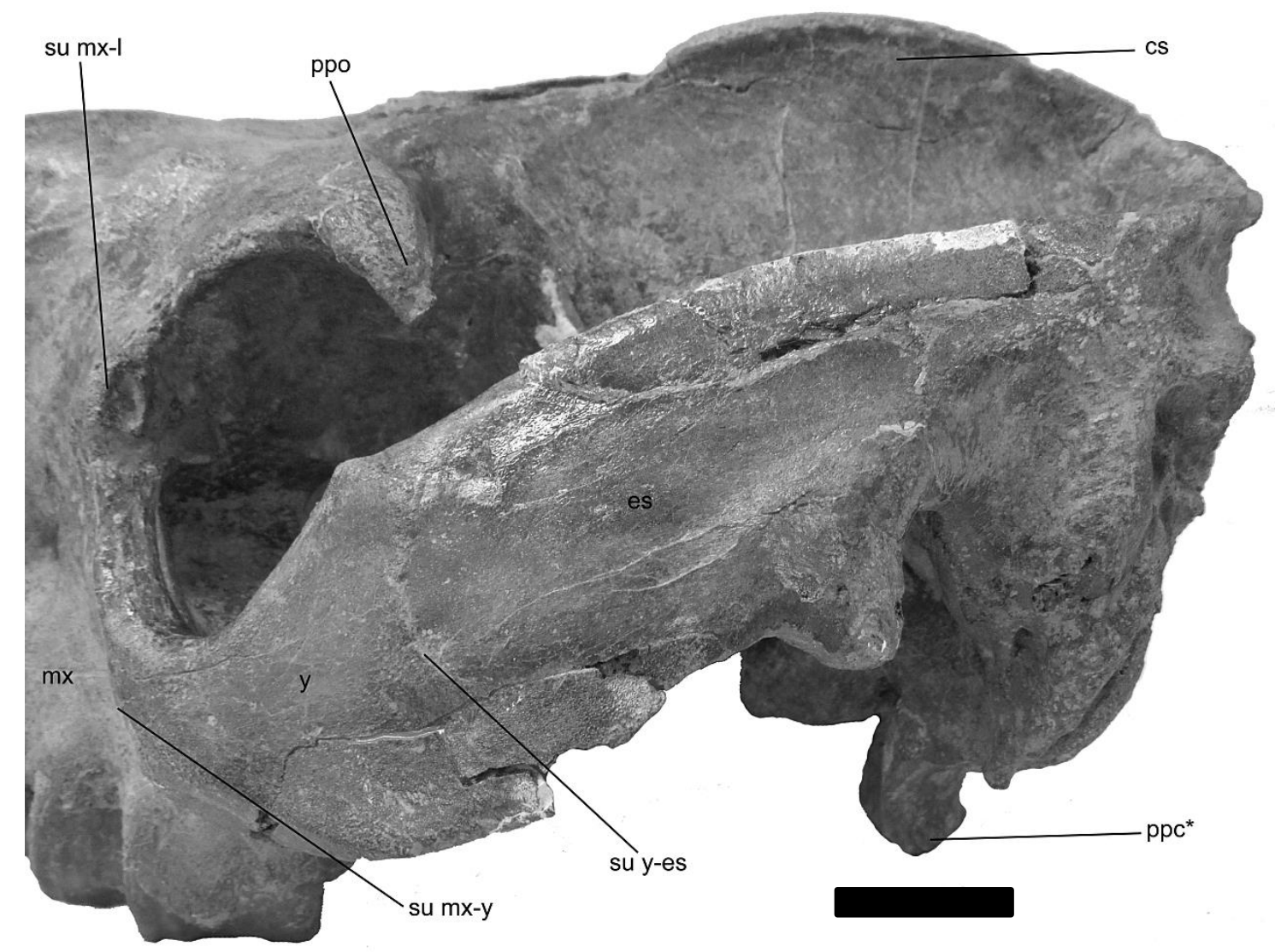

Fig IV. 24: Vista lateral de la región orbitotemporal del cráneo de Adinotherium ovinum FMNH13108. Escala $2 \mathrm{~cm}$.

Los lacrimales ocupan la misma posición que en $N$. imbricatus y presentan una morfología similar, aunque son ligeramente más pequeños y sus procesos son más delgados y afilados; usualmente se desarticulan del resto del cráneo.

El yugal presenta la misma morfología que $N$. imbricatus, pero tiene una posición ligeramente más elevada.

La contribución de los escamosos a la conformación de los elementos de esta región es similar a la expuesta anteriormente para $N$. imbricatus, aunque la extensión del escamoso parece ser menor, especialmente en su porción dorsal, donde está ligeramente desplazado por el parietal. El proceso cigomático del escamoso no presenta diferencias conspicuas con el de $N$. imbricatus, a excepción de la mayor variación de la altura entre la porción anterior y la posterior del proceso.

\section{-Basicráneo y región auditiva}

En el basicráneo de A. ovinum (Fig. IV. 25), el complejo esfenoidal presenta más o menos la misma disposición y desarrollo que en la especie anterior. Ontogénicamente, el 
basiesfenoides conforma la mitad más anterior del basicráneo y, a medida que avanza la edad del animal, es desplazado por el desarrollo del basioccipital hasta ocupar más o menos un tercio del basicráneo.

Al igual que la porción esfenoidal del basicráneo, el basioccipital no presenta grandes diferencias respecto al de N. imbricatus, salvo el menor desarrollo que presentan los tubérculos que se encuentran a nivel de la sutura basiesfenoides-basioccipital. Esta diferencia podría contistuir un carácter de variación individual y a lo largo del desarrollo postnatal del animal, pero debido a que esta porción normalmente se desprende del cráneo de los juveniles no fue posible comprobarlo en diversos ejemplares. Ontogenéticamente, el basioccipital sigue la misma trayectoria descripta para Nesodon, siendo proporcionalmente más corto y pequeño en los ejemplares jóvenes y desplazando notablemente al basiesfenoides hacia la porción anterior del basicráneo en los ejemplares adultos.

Los escamosos presentan escasas diferencias con respecto al patrón observado en $N$. imbricatus. Los procesos postglenoideo y postimpánico presentan el mismo grado de desarrollo y solo son perceptibles pequeñas variaciones de las proporciones relativas de los elementos, que bien podrían reflejar variaciónes ontogenéticas. La fosa escafoidea en los adultos de $A$. ovinum es más profunda que en $N$. imbricatus; sin embargo, las dimensiones de esta depresión varían considerablemente durante la ontogenia, siendo relativamente más larga y menos profunda en los ejemplares más jóvenes que en los ejemplares adultos de A. ovinum.

La contribución del ectotimpánico en la conformación general del basicráneo es la misma que en $N$. imbricatus. La bula timpánica es globosa, con su eje dorsoventral ligeramente apuntado hacia adelante en los ejemplares adultos y bastante más dirigido anteriormente en los ejemplares jóvenes, en los que su extremo ventral es notablemente más anguloso. Al igual que en $N$. imbricatus, la bula timpánica es hueca y no presenta ningún tipo de tabicación o presencia de hueso esponjoso. No se detectó la presencia de un septum bullae en los ejemplares estudiados. El proceso estiliforme es grácil y más laminar en los estadios ontogenéticos tempranos, volviéndose tubular a medida que avanza la edad del animal. En los ejemplares analizados, el ectotimpánico no se encuentra unido al basioccipital, al igual que en Nesodon imbricatus y a diferencia de lo establecido para N. taweretus (Forasiepi et al. 2015).

Los petrosos contienen a los órganos encargados del equilibrio y la audición, y proveen zonas de inserción para los músculos y ligamentos de los huesecillos del oído medio (e.g. Hyrtl 1845, van Kampen 1905). Generalmente, se reconocen dos porciones en este hueso; una de ellas aloja al conducto coclear y al sáculo del oído interno (pars cochlearis) y la otra aloja al utrículo y los canales semicirculares (pars canalicularis). El petroso de los mamíferos 
terios presenta cuatro superficies: timpánica (o ventral), cerebelar (o dorsal), escamosal (o lateral) y mastoidea (o lambdoidea) (MacIntyre 1972, Wible 1990). Para los nesodontinos, Scott (1912) caracterizó este hueso como relativamente grande y remarcó mayormente las características que se pueden ver en vista cerebelar, como la escasa profundidad de la fosa subarcuata (en vista cerebelar), una proyección anterior en forma de gancho (a la que Gabbert 2004 se refiere como osificación tentoria de la cresta petrosa) y el gran tamaño y profundidad del MAI. En vista timpánica, Scott (1912) destacó que el petroso no se encuentra anquilosado a la bula timpánica.

En vista timpánica (Fig. IV. 26A), la característica más representativa del petroso de los notoungulados es la presencia de un flanco medial expandido en forma de abanico (Gabbert 2004) que, en Adinotherium ovinum, no se encuentra tan desarrollado como en otros taxones (e.g. Scarritia) y está representado por una repisa que se extiende a partir del borde medial del promontorio, cuya extensión no se puede comprobar debido al daño del ejemplar. El promontorio está representado por un abultamiento oval conspicuo y voluminoso que encierra al canal coclear y cuya porción más convexa (la más ventral) corresponde al punto de mayor recurvamiento de la cóclea, que presenta alrededor de 2,6 vueltas. En el margen posterior del promontorio, existen dos grandes perforaciones ovales más o menos subiguales (Richany et al. 1975); la anterolateral corresponde a la fenestra vestibular (o ventana oval), donde se ubica, en vida, la plataforma del estribo, y se orienta ventrolateralmente; la segunda abertura abre en el margen posterior del petroso y corresponde a la fenestra coclear (actualmente reconocida como "abertura externa de la fósula coclear", ver Wible et al. 2009) que, en vida, sostiene la membrana timpánica secundaria; ambas aberturas están separadas por la crista interfenestralis. El acueducto coclear (=canalículo coclear, canal que trasporta el ducto perilinfático) no se ve claramente en el ejemplar estudiado (AMNH 9276), pero se ha podido reconstruir parte del molde de la cavidad al realizar el modelo del laberinto óseo del oído interno (ver Oído interno). En el margen ventral de la pars cochlearis, anterior a la fenestra vestibular, debería encontrarse el foramen facial (que trasmite la rama hiomandibular del nervio VII hacia el oído interno), aunque debido al daño en la zona no fue posible precisar su ubicación, pero sí se pudo localizar el surco facial en las cercanías de la fenestra vestibular. Por lo que se puede apreciar en este modelo, el surco facial no formaría un canal, aunque es difícil establecerlo con certeza. La mayor parte de las estructuras presentes en esta vista no se han podido identificar debido a la alteración del material a disposición. En vida, la fosa estapedial sirve como área de origen del musculo estapedial. En el piso de la fosa, se 
encuentra un surco conspicuo que corresponde al recorrido del canal semicircular lateral, que se encuentra al descubierto por daño postmortem.
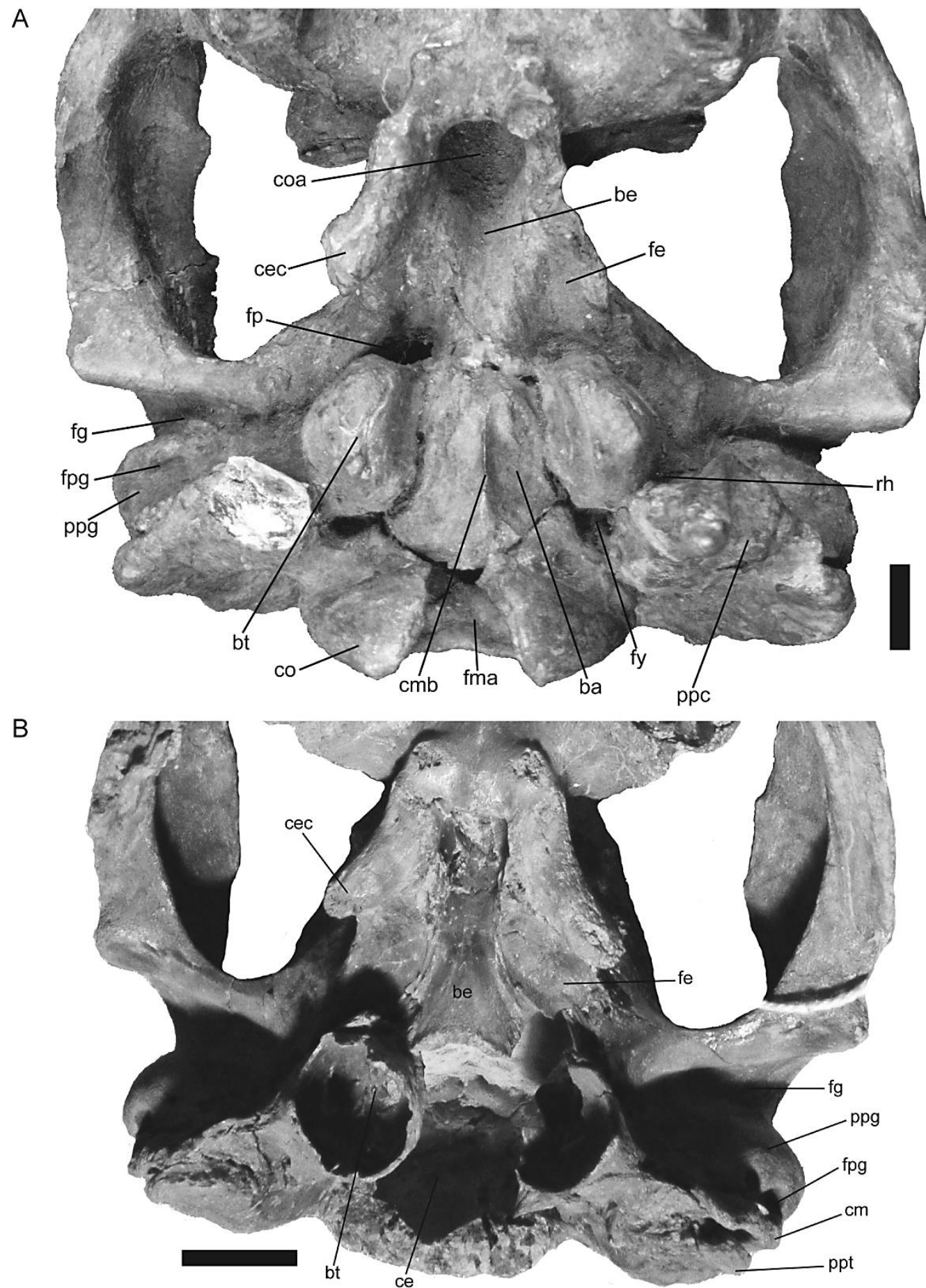

Fig IV. 25. Detalle del basicráneo del ejemplar adulto MLP 12-5 (A) y del juvenil MPM-PV 3541 de Adinotherium ovinum. Escala, $2 \mathrm{~cm}$.

En vista cerebelar (Fig. IV. 26B), la forma de la pars cochlearis es bastante plana y la estructura más representativa es la abertura del MAI para los nervios facial (VII) y 


\section{Anatomía y Sistemática de los \\ Toxodóntidos de Santa Cruz}

vestibulococlear (VIII). Dentro del MAI, existen dos aberturas ovales que presentan un tamaño similar y están separadas por un septo transverso; la abertura más anterior transmite las fibras del nervio facial, mientras que la posterior transmite las del nervio vestibulococlear. La pared lateral del MAI está formada por una barra de hueso conspicua, la comisura prefacial; lateralmente a esta comisura, la pars cochlearis se curva abruptamente y prácticamente no es visible en vista dorsal. En vista dorsal de la pars cochlearis, se ve el acueducto coclear, situado en el flanco opuesto a la comisura prefacial, casi en el extremo anterior del hueso. En la pars canalicularis, el área que se encuentra justo por detrás del MAI aloja el vestíbulo del oído interno y, a partir de él, se proyectan los tres canales semicirculares, estructuras que se describen en detalle en el apartado de Oído interno. La estructura más prominente de la pars canalicularis es la fosa subarcuata, que aloja al paraflóculo del cerebelo y se encuentra localizada en el centro del margen posterior del hueso; en Adinotherium ovinun esta fosa es poco profunda. En el margen lateral, se observa una proyección que fue identificada por Gabbert (2004) como osificación tentoria de la cresta petrosa.

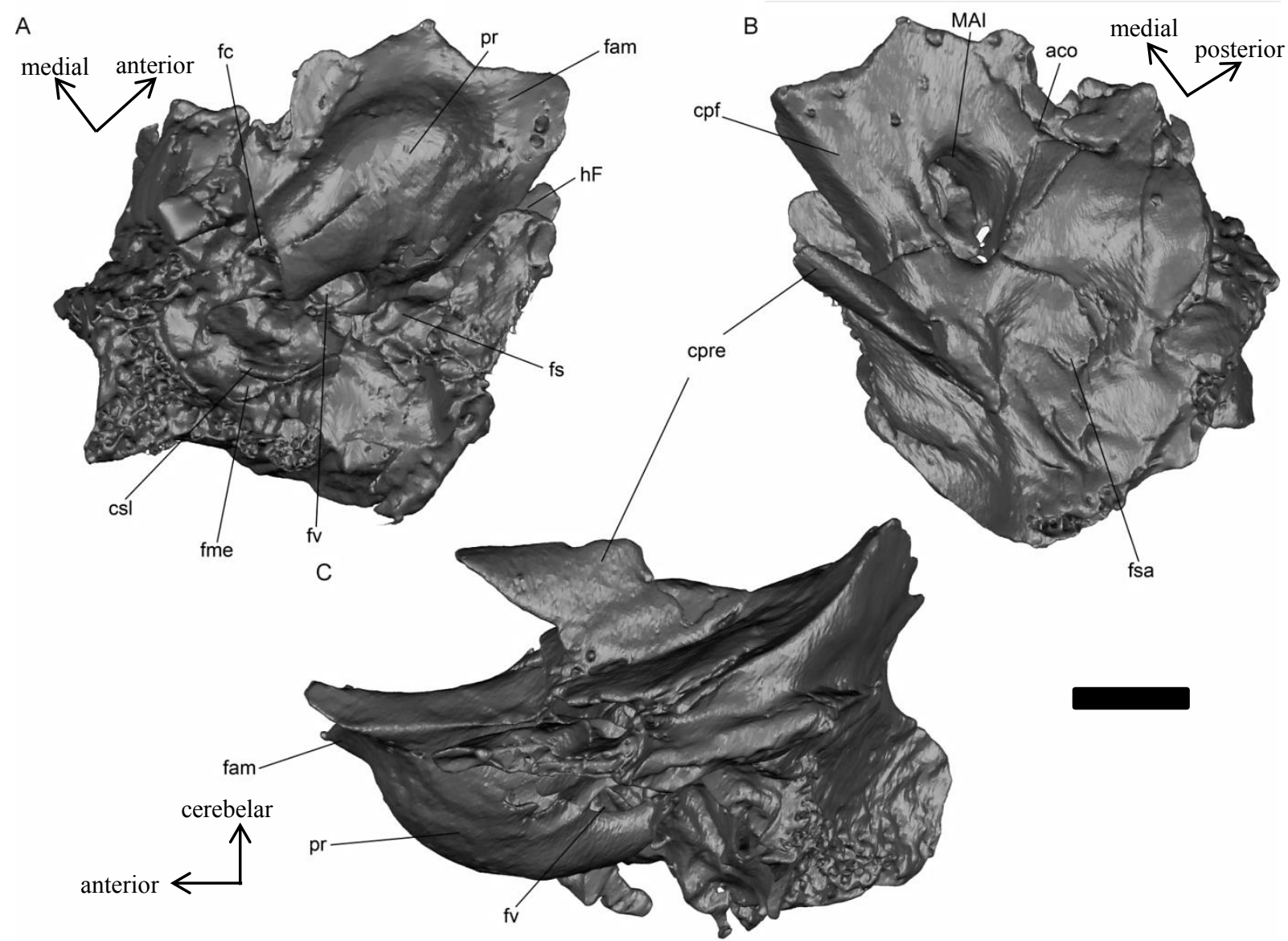

Fig IV. 26. Modelo tridimensional del petroso de Adinotherium ovinum AMNH 9276: Vistas timpánica (A), cerebelar (B) y lateral (C). Escala, 0,5 cm. 
En vista lateral (Fig. IV. 26C), puede observarse el aspecto globoso del promontorio en la porción ventral del petroso, y la osificación de la cresta petrosa; en la porción dorsal.

\section{-Región occipital}

La región occipital en los ejemplares adultos de A. ovinum (Fig. IV. 27) es muy similar a la de $N$. imbricatus, pero la variación del perfil occipital es más amplia, encontrándose occipitales relativamente más bajos y más altos que en $N$. imbricatus. Debido a la mayor altura de los arcos cigomáticos en la porción posterior del cráneo, la cresta nucal es también más alta que en $N$. imbricatus.

A lo largo de más de un siglo, se ha discutido la exposición o no del petroso en la región occipital de los nesodontinos (e.g., Scott 1912, Patterson 1932). A partir de los estudios de TC, se puede asegurar que existe una participación del petroso en la conformación de la pared posterior del cráneo de A. ovinum (al igual que en otros notoungulados, ver Billet 2011, Fig. 8), al menos en los ejemplares juveniles (Fig. IV. 28A y B), donde la exposición es bastante amplia, reduciéndose notablemente en el caso de los ejemplares adultos (MPM-PV CV-SHP15-14 y MPM-PV 3532), en los que la exposición es prácticamente imperceptible (Fig. IV. 28C y D).

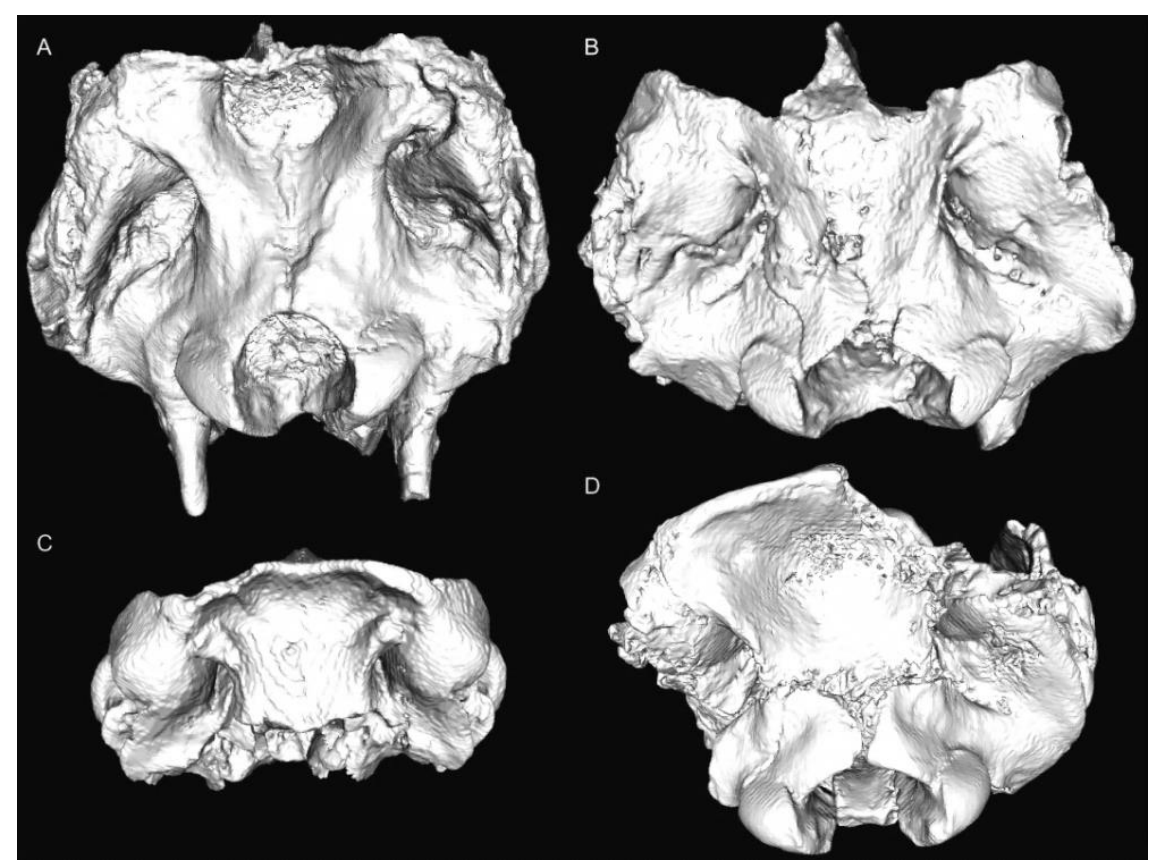

Fig IV. 27. Morfotipos de la región occipital de Adinotherium ovinum: Ejemplares adultos MPMPV CV-SHP-15-14 (A) y MPM-PV 3532 (B), ejemplar juvenil MPM 3541 (C), ejemplar subadulto MPM-PV RB2-SFV-12-9 (D). 


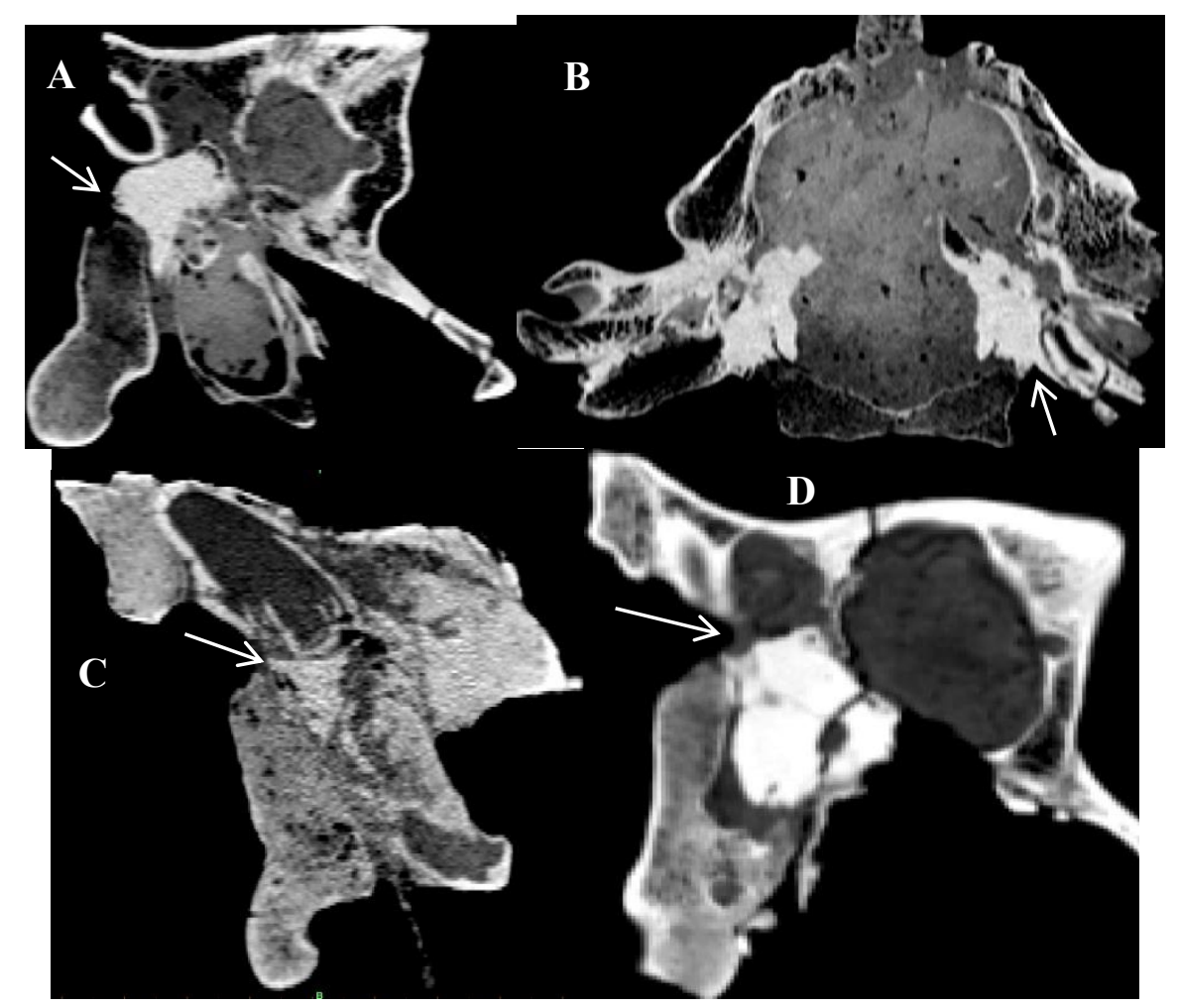

Fig IV. 28: Exposición de la porción mastoidea en la región occipital de Adinotherium ovinum: Sección longitudinal de MPM-PV RB2-SFV-14-9 (A); sección coronal de MPM-PV RB2-SFV-14-9 (B); C. sección longitudinal de CV-SHP-15-14 (C); sección longitudinal de MPM-PV 3532 (D).

\section{-Molde endocraneano}

Los moldes endocraneanos obtenidos para A. ovinum (Figs. IV. 14, IV. 29 y IV. 30) tienen una mejor definición de los rasgos anatómicos que en el caso del ejemplar de Nesodon imbricatus presentado en el apartado anterior. Para la indetificación de las diferentes estructuras ver la figura IV. 14 utilizada como modelo para la cavidad endocraneana de los Nesodontinae.

La flexura del molde endocranenano del MPM-PV 3532 (Fig. IV. 29) tiene un valor de $38^{\circ}$ (tabla IV. I). La relación entre el ancho y el largo del molde endocraneano (excluyendo la médula) es 0,48 y la relación entre el alto y el ancho es de 1,19.

En el encéfalo anterior de MPM-PV 3532,_los bulbos olfatorios ${ }_{\mathrm{m}}$ son pequeños, angostos (ancho/largo $=0,51)$ y altos (alto/ancho $=1,5) \mathrm{y}$, al igual que en $N$. imbricatus, están alineados con el eje principal ipsilateral de cada hemisferio cerebral $\mathrm{m}_{\mathrm{m}}$. Los bulbos olfatorios $\mathrm{m}_{\mathrm{m}}$ contribuyen aproximadamente al 3\% del volumen total del molde endocraneano y están claramente separados el uno del otro en el plano sagital. La fisura circular es más notoria y profunda que en $N$. imbricatus, pero igualmente es angosta. Tampoco se registró evidencia de bulbos olfatorios accesorios m $_{\text {en }}$. ovinum; las estructuras que aparecen por debajo de los 
bulbos olfatorios en el molde endocraneano de MPM-PV 3532 corresponden a artefactos tafonómicos. Los tractos olfatorios $\mathrm{m}_{\mathrm{m}}$ son conspicuos, no se proyectan lateralmente $\mathrm{y}$, a diferencia de lo que ocurre en $N$. imbricatus, no sobrepasan la corteza cerebral $\mathrm{m}_{\mathrm{m}}$, que representa aproximadamente el 7\% del volumen total del molde endocraneano. Los hemisferios cerebrales $_{\mathrm{m}}$ se encuentran separados sagitalmente por un surco medial no muy ancho, desplazado ligeramente hacia el lado izquierdo debido a la deformación; en el caso de algunos ejemplares, dicha separación se encuentra parcial (MPM-PV 3532) o totalmente oscurecida por el seno sagital superior (ver sección Sistema vascular del endocráneo). Los hemisferios cerebrales ${ }_{\mathrm{m}}$ son ligeramente asimétricos debido a la deformación tafonómica sufrida por la mayoría de los ejemplares (e.g., MPM-PV 3668); la forma de los hemisferios cerebrales $_{\mathrm{m}}$ es más o menos ovoide con una relación ancho/largo de 0,37 y una relación alto/largo de 0,45 para el hemisferio cerebral ${ }_{m}$ derecho del MPM-PV 3532. La superficie cortical es girencefálica, con sulci y gyri poco profundos. La fisura rinal está bien demarcada en el molde endocraneano del MPM-PV 3532, pero es menos conspicua en los moldes endocraneanos de MPM-PV 3666 y MPM-PV 3541. Los lóbulos piriformes se proyectan levemente hacia los laterales, son aproximadamente ovoides (más largos que altos), más conspicuos que en $N$. imbricatus (incluso son visibles en vista dorsal) y representan algo mas del 12\% del molde endocraneano. La región hipofisaria ${ }_{m}$ de MPM-PV 3532 es enorme y, al igual que en el ejemplar MPM-PV RBPN-SFV-12-3 de N. imbricatus, en parte puede deberse a la deformación tafonómica sufrida. La hipófisis ${ }_{m}$ se encuentra situada en una posición similar a la comentada para $N$. imbricatus y está representada por un abultamiento elipsoidal (ancho/largo $=1,6 ;$ alto/largo $=1,4)$ que supone más del $6 \%$ del volumen total del molde endocraneano. La hipófisis $\mathrm{m}_{\mathrm{m}}$ no posee una quilla media en ninguno de los ejemplares analizados, rasgo que probablemente se deba a una imperfección por deformación postmortem, tal como se mencionó para $N$. imbricatus. En la región hipofisaria de A. ovinum, al igual que lo observado en $N$. imbricatus y lo indicado para otros notoungulados (Gabbert 2004, MacPhee 2014, Martínez et al. 2016), no hay indicios del pasaje de la rama cerebral de las carótidas internas en el piso de la hipófisis.

En el encéfalo posterior, la separación con el encéfalo anterior en el MPM-PV 3532 está determinada por una depresión algo más profunda que en el molde endocraneano de MPMPV RBPN-SFV-12-3 de $N$. imbricatus e igualmente podría corresponder a la ausencia (o presencia sin osificar) del tentorium cerebelli. El cerebelo $\mathrm{m}_{\mathrm{m}}$ contribuye con alrededor del $18 \%$ del volumen del molde endocraneano, es bastante angosto (incluso más que en $N$. imbricatus) y presenta una forma más o menos cuadrada. En el cerebelo $\mathrm{m}_{\mathrm{m}}$ resulta más fácil identificar el 
vermis cerebelli $i_{\mathrm{m}} \mathrm{y}$ los hemisferios cerebelares $\mathrm{m}_{\mathrm{m}}$ que en $N$.imbricatus. El vermis cerebelli $i_{\mathrm{m}}$ es un abultamiento más o menos esférico presente en la porción mediodorsal del cerebelo $\mathrm{m}_{\mathrm{m}}$. Los hemisferios cerebelares $\mathrm{m}_{\mathrm{m}}$ no se encuentran muy desarrollados ni se expanden lateralmente; su superficie es completamente lisa, aunque, como ya se ha comentado, la presencia de meninges, senos venosos y otras estructuras afecta la morfología del molde endocraneano en esta región y, en consecuencia, no existe una correlación directa de los hemisferios cerebelares $\mathrm{m}_{\mathrm{m}}$ lisencéfalos que se encuentran en el molde y las estructuras del animal en vida. El paraflóculo $\mathrm{m}_{\mathrm{m}}$ tiene la misma localización que en $N$. imbricatus $\mathrm{y}$, al igual que en éste, es prácticamente indistinguible, lo cual se corresponde con la escasa profundidad de la fosa subarcuata (ver Petroso). En el piso ventral del encéfalo posterior ${ }_{\mathrm{m}}$, la pons $\mathrm{m}_{\mathrm{m}}$ está más diferenciada que en $N$. imbricatus, como un leve abultamiento en la porción medial del piso. La medula oblonga $a_{m}$ tiene una sección menos ovoide que en el MPM-PV RBPN-SFV-12-3.

El patrón de distribución de los moldes de las cavidades que transportan los nervios craneales responde al patrón descripto para Nesodon imbricatus, aunque las estructuras se observan con mejor detalle, debido a la mejor preservación y cantidad de ejemplares en que pudo realizarse la reconstrucción, y es posible ampliar la descripción.

El quiasma ópticom (NC II) presenta una morfología y una ubicación similares a $N$. imbricatus; los nervios ópticos $\mathrm{m}_{\mathrm{m}}$ poseen un diámetro pequeño en comparación al tamaño del quiasma y divergen en un ángulo de aproximadamente $60^{\circ}$ en MPM-PV 3532, pero en el ejemplar juvenil MPM-PV 3541 y en el sub adulto MPM-PV RB2-SFV-14-9 (Fig. IV. 30), el ángulo de divergencia es mayor $\left(70^{\circ}\right)$. La salida de la fisura esfeno-orbitaria está indicada por dos proyecciones que parten de la hipófisis $\mathrm{m}_{\mathrm{m}}$ y presenta la misma condición que en $N$. imbricatus (transporta NC III, NC IV, NC $\mathrm{V}_{1}, \mathrm{NC} \mathrm{V}_{2}$ y NC VI). Igualmente, Adinotherium ovinum no posee un foramen rotundo, por lo que se asume que el $\mathrm{NC}_{2}$ abandona el cráneo por la fisura esfeno-orbitaria. El molde de la rama mandibular del trigémino abandona el cráneo por la abertura del foramen oval + fenestra piriforme y en el molde de la cavidad endocraneana de MPM-PV 3532 no se ve claramente, ya que se reconstruyó parcialmente; sin embargo, en el ejemplar MPM-PV RB2-SFV-14-9 (Fig. IV. 14) puede apreciarse el ganglio del trigémino $\mathrm{m}_{\mathrm{m}}$ bien desarrollado e inmediatamente por detrás del lóbulo piriforme $\mathrm{m}_{\mathrm{m}} \mathrm{y}$ la hipófisis $_{\mathrm{m}}$; este nervio abandona la cavidad en dirección anteroventral. Al igual que $N$. imbricatus, en la porción posterior del molde endocraneano, en vista lateral, puede observarse la posición del $\mathrm{MAI}_{\mathrm{m}} \mathrm{y}$ los orígenes de los nervios facial (NC VII) y vestibulococlear (VIII) en la parte anteromedial de los hemisferios cerebelares $\mathrm{m}_{\mathrm{m}}$. Los tractos correspondientes a los nervios glosofaríngeo (NC IX), vago (NC X) y accesorio (NC XI) no se reconstruyeron en el 
Hernández Del Pino, S.

espécimen MPM-PV 3532, pero dichos tractos presentan una posición similar a la del ejemplar subadulto MPM-PV RB2-SFV-14-9 (Fig. IV. 14 y Fig. IV. 30B). En la porción más posterior del molde endocraneano se ve el molde del canal que transporta el foramen hipogloso (NC XII).

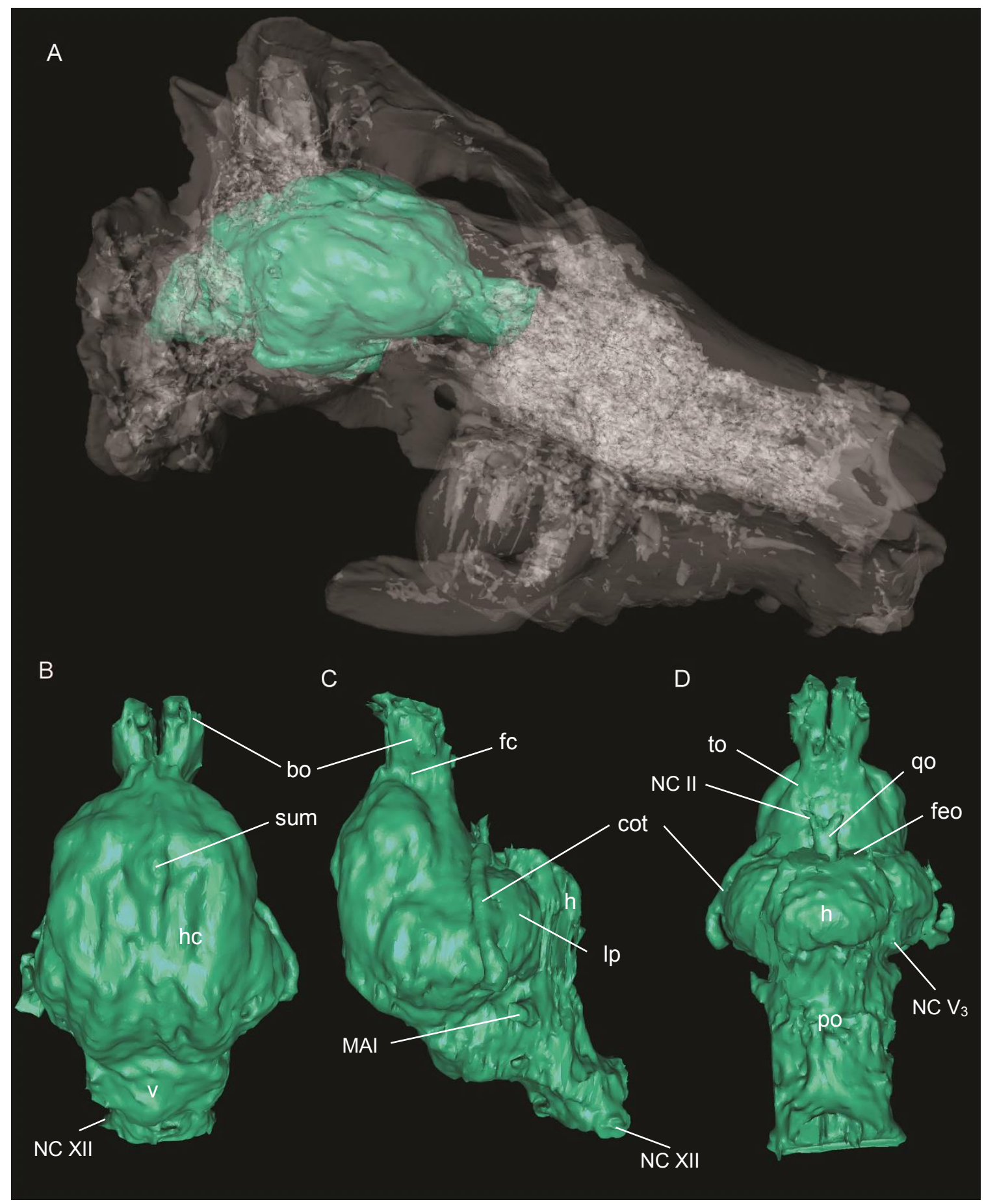

Fig IV. 29. Cráneo MPM-PV 3532 de Adinotherium ovinum con el molde endocraneano en posición (A); molde endocraneano en vistas dorsal (B), lateral derecha (C) y ventral (D). 


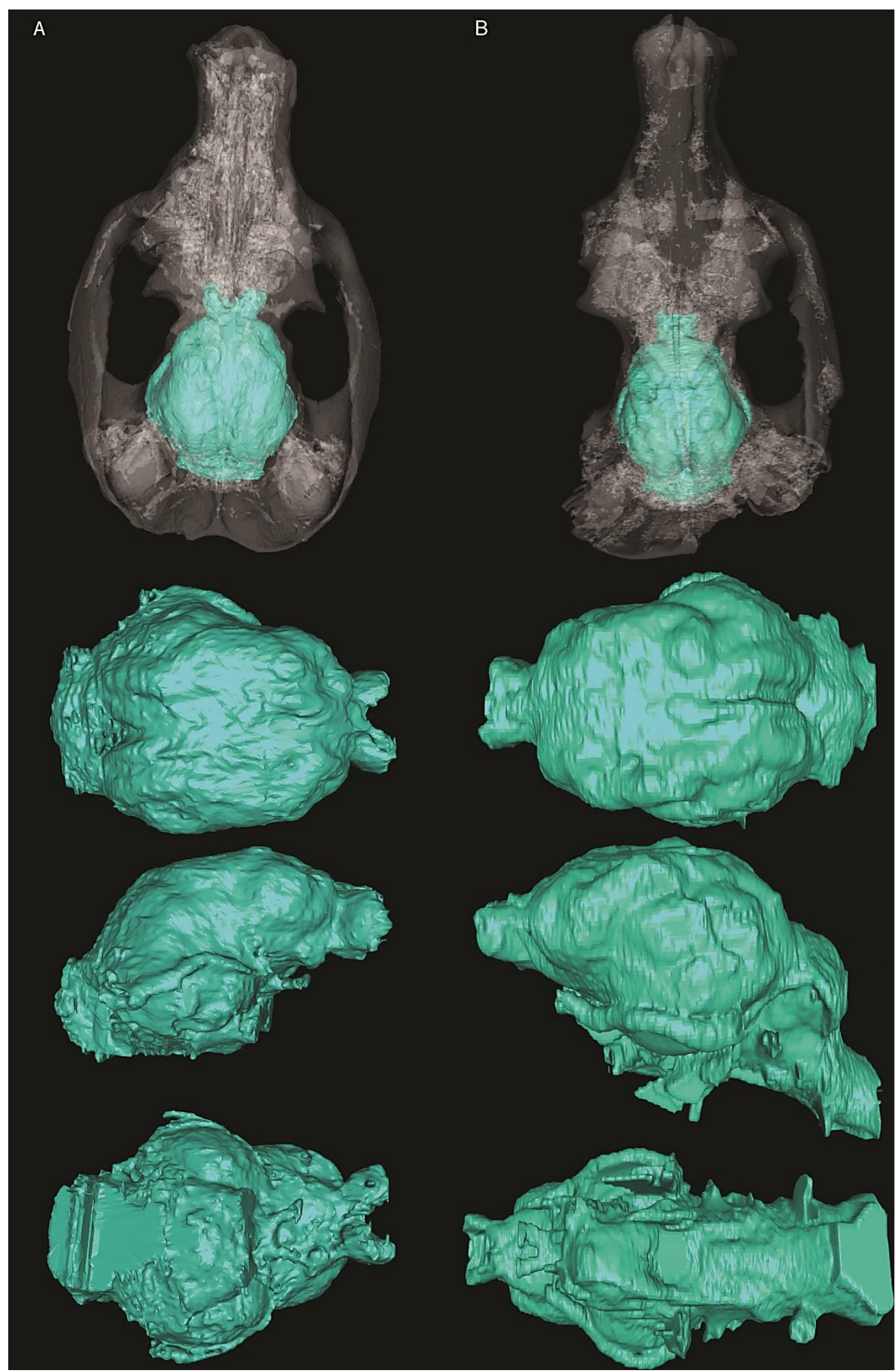

Fig. IV. 30. Variación ontogenética de la cavidad endocraneana en A. ovinum: Moldes endocraneaneos de ejemplar juvenil MPM-PV 3541 (A) y ejemplar adulto joven MPM-PV RB2-SFV14-9 (B). Vistas (de arriba hacia abajo) dorsal dentro el cráneo, dorsal, lateral izquierda (reflejada en A) y ventral. 
Con respecto al sistema vascular del endocráneo, en el molde de MPM-PV 3532, el seno sagital superior se encuentra bien desarrollado, está indicado por una quilla medial y obscurece casi completamente al surco medial. Su recorrido sigue al plano sagital anteriormente, pero hacia su extremo posterior se inclina ligeramente hacia la derecha. $\mathrm{Al}$ igual que en el caso de $N$. imbricatus, el seno transverso no fue reconstruido en este ejemplar, pero presenta las mismas relaciones entre los componentes del sistema venoso que en ese taxón, a excepción del mayor calibre que presenta el canal orbitotemporal y el resto de los vasos asociados al seno transverso.

\section{—Molde del oído interno}

Se pudo reconstruir la totalidad del laberinto oseo del oído interno de uno de los ejemplares de Adinotherium ovinum. Al igual que en el resto de los mamíferos, el laberinto óseo de AMNH 9276 es una combinación de espacios interconectados dentro del petroso, que incluyen al vestíbulo, los canales semicirculares y la cóclea (e.g. MacIntyre 1972, Ekdale 2013, 2016). El canal coclear es la estructura más conspicua de la reconstrucción. Este conducto presenta aproximadamente el mismo ancho que alto y se encuentra enrollado dando alrededor de 2,6 vueltas, un valor más alto que los registrados para otros UNS como Litopterna, cuyo rango va de 2,1 a 2,4 vueltas (Billet et al. 2015, Forasiepi et al. 2016), y Notoungulata, con un rango desde $<2$ a 2,5 vueltas (Simpson 1936, Macrini et al. 2010, 2013). Todas las vueltas de la coclea se encuentran apoyadas la una sobre la otra (al igual que en el ejemplar de notoungulado descripto por Billet y de Muizon [2013]), encontrándose más apretadas hacia la última vuelta. Existe una separación incipiente del canal coclear en un scala tympani y un scala vestibuli evidenciada a partir de la presencia de dos surcos en la vuelta basal del conducto coclear: el interno corresponde a la lámina espiral ósea primaria (que es el más conspicuo), visible en vistas posteromedial y lateral (Fig. IV. 31A y D), mientras que el externo, visible en vista anterior (Fig. IV. 31B), corresponde a la lámina espiral osea secundaria. El acueducto coclear se proyecta más allá del canal semicircular posterior como en otros UNS (Macrini et al. 2010, Billet et al. 2015), aunque no todos estos presentan este patrón (e.g. Pachyrukhos, Macrini et al. 2013). 


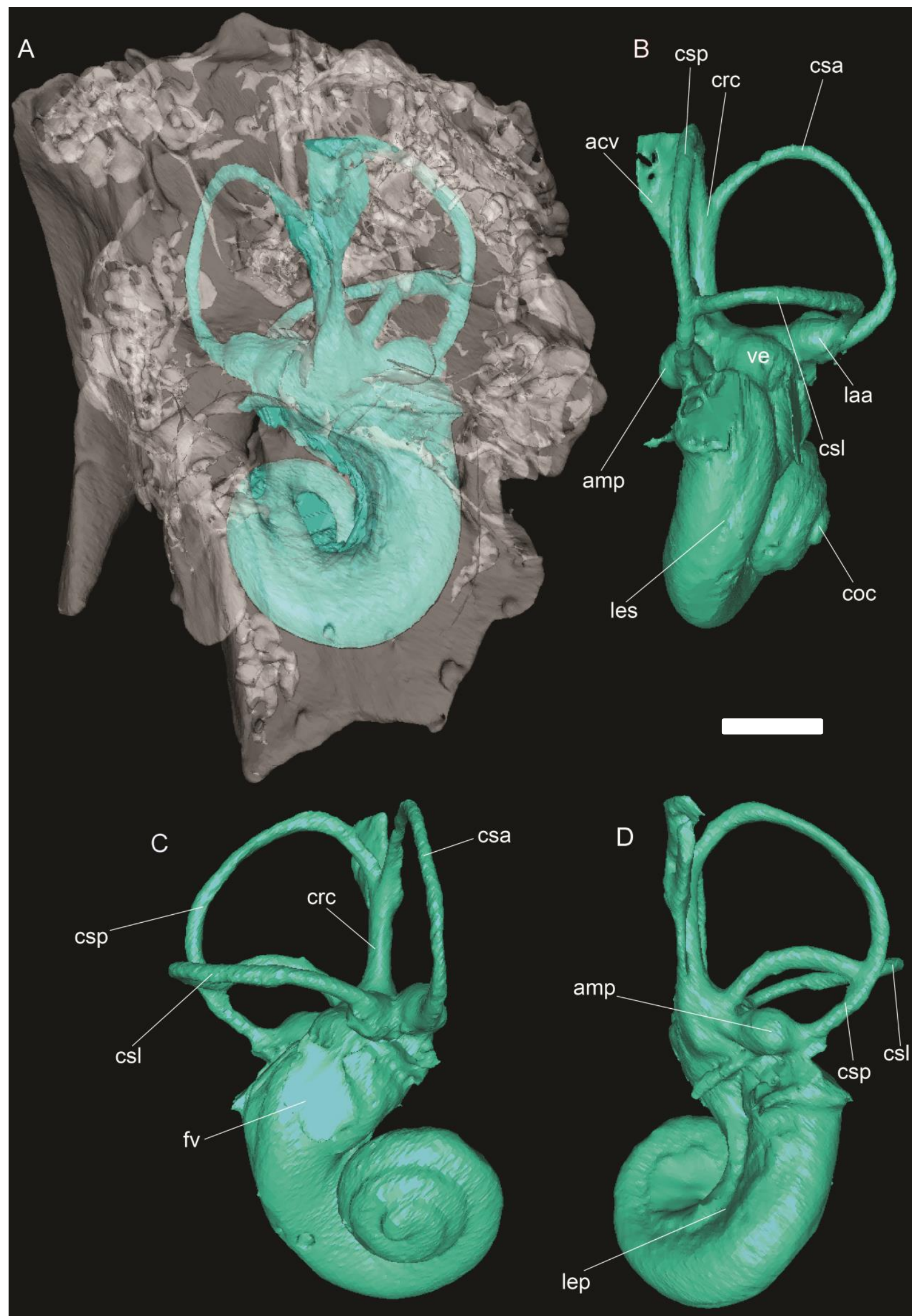

Fig IV. 31. Molde del oído interno de Adinotherium ovinum AMNH 9276: vista posteromedial dentro del petroso (A), vista anterior (B), vista lateral (C) y vista posterior (D). Escala $0,5 \mathrm{~cm}$. 
El vestíbulo es alargado anteroposteriomente, casi paralelo al eje mayor del canal semicircular lateral. En el caso de la pars canalicularis, los canales semicirculares son más gráciles que la crus commune, pero no al grado que se observa en el Litopterna Huayqueriana (Forasiepi et al. 2016). La crus commune presenta la configuración típica mamaliana y está formada por la porción posterior del canal semicircular anterior y la anterior del canal semicircular posterior, y es mas baja que la altura de ambos canales semircirculares.

\section{-Mandíbula}

La mandíbula de Adinotherium ovinum (Fig. IV. 32) presenta algunas diferencias con la de Nesodon imbricatus. Una de las más notorias, ya remarcada por Scott (1912), se encuentra en la sínfisis mandibular, donde existe una constricción transversal algo más marcada a nivel de los primeros premolares (al igual que sucede en el cráneo, Fig. IV. 32B); por delante de la constricción, la mandíbula se ensancha levemente hasta el nivel de los alveolos del tercer incisivo, donde alcanza su máxima anchura anterior; desde la constricción hacia atrás, las hemimandíbulas divergen en un ángulo ligeramente mayor al presente en $N$. imbricatus. Otra diferencia (también señalada por Scott) es la elevación de la sínfisis, con una pendiente mucho más abrupta y menos procumbente que en $N$. imbricatus.

La rama horizontal de la mandíbula presenta leves diferencias de proporciones, ya que, en los ejemplares adultos, es relativamente más corta, más ancha y ligeramente más alta que en $N$. imbricatus. Los rasgos más peculiares de la mandíbula de Adinotherium se encuentran en la rama ascendente, donde la muesca sigmoidea es menos profunda y el proceso coronoideo está menos desarrollado que en $N$. imbricatus.

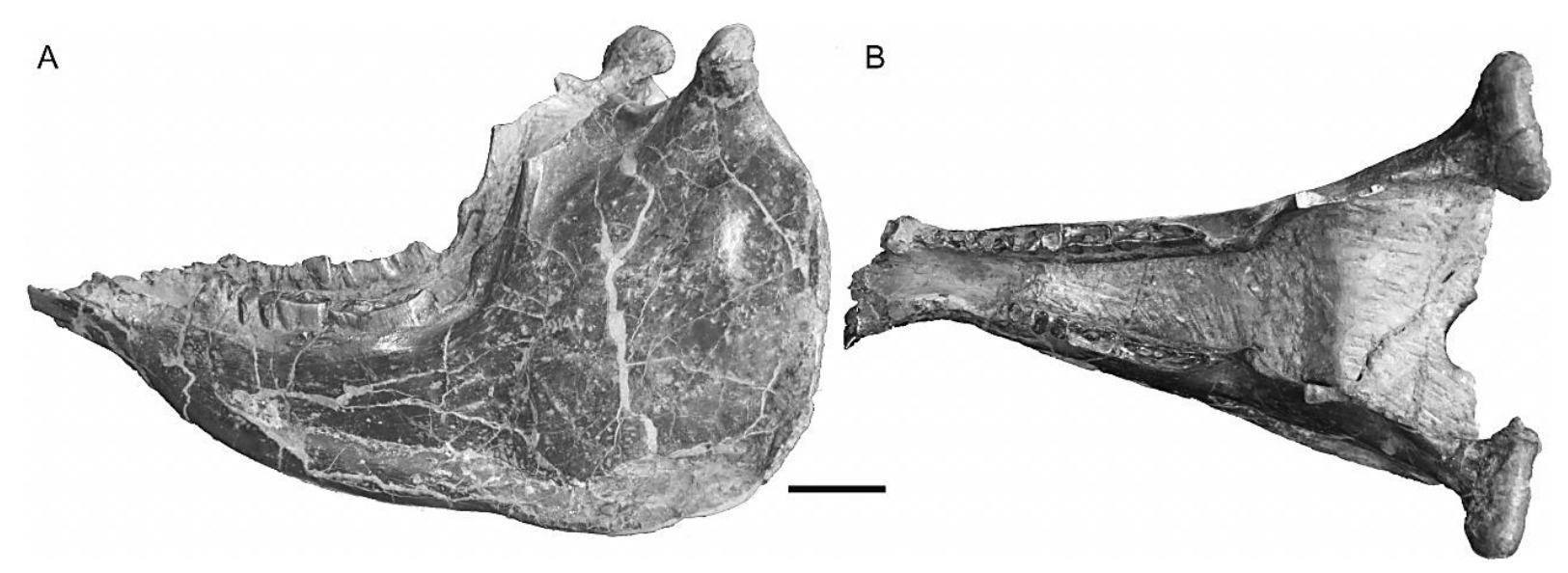

Fig IV. 32. Mandíbula de Adinotherium ovinum AMNH 9141: Vistas lateral izquierda (A) y dorsal (B). Escala $2 \mathrm{~cm}$. 
Cabe aclarar que la cantidad de mandíbulas más o menos completas disponibles de $A$. ovinum es notablemente menor que para $N$. imbricatus.

\section{-Dentición}

Las características generales de la dentición de Adinotherium ovinum (Fig. IV. 33 y Fig. IV. 34) no difieren en gran medida de las comentadas anteriormente para Nesodon imbricatus, a excepción de la clara distinción de tamaño entre ambas especies.

De acuerdo a Scott (1912), las diferencias más importantes entre ambas especies se refieren a los premolares superiores y los molares inferiores, además del menor tamaño relativo de los C y P1 en Adinotherium.

Una diferencia en la dentición superior (Fig. IV. 33) comprobada en este estudio se encuentra en los surcos labiales de P2-P3, que están más desarrollados en Adinotherium ovinum; además, dado el mayor grado de hipsodoncia que presenta la dentición yugal de $A$. ovinum, el valle central en forma de "Y" y la foseta accesoria (o fosetas en algunos casos) de los molares superiores son mas persistentes en la vida del animal. Otro rasgo es la distinta proporción de los molares, relativamente más anchos y cortos que en los ejemplares de $N$. imbricatus.

En la dentición inferior (Fig. IV. 34), los molares de A. ovinum (incluso en estadios de desgaste avanzados) son mucho mas gráciles que en $N$. imbricatus; el trigónido es relativamente más ancho y el talónido notablemente más estrecho y ligeramente más largo que en Nesodon.

En la dentición decidua, no se han encontrado diferencias con respecto a Nesodon imbricatus. 
Hernández Del Pino, S.

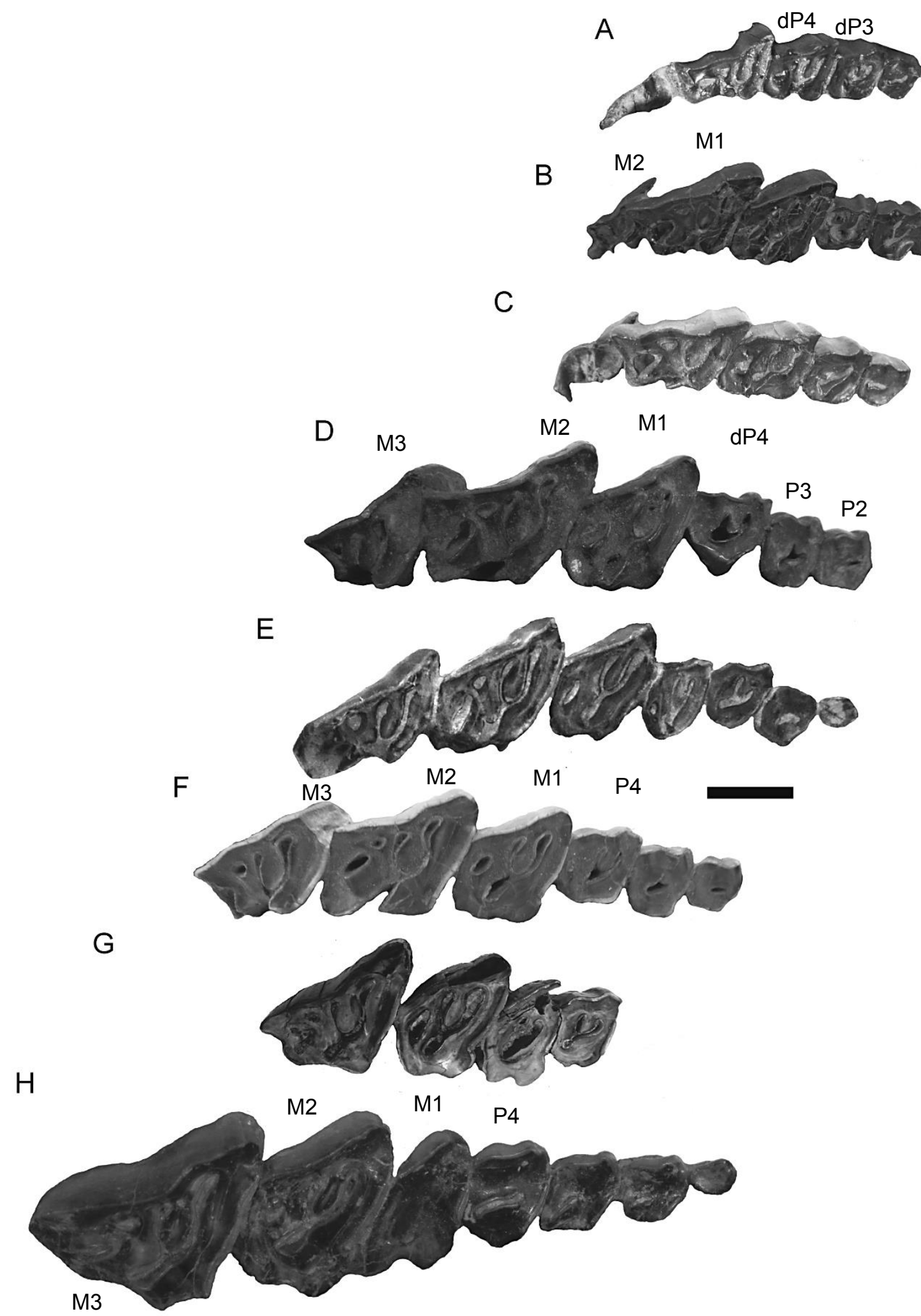

Fig. IV. 33: Variación ontogenética en la dentición yugal superior de Adinotherium ovinum: ejemplares juveniles YPM-PU 15114 (A) FMNH-13098 (B) y FMNH-13109 (C); ejemplares subadultos FMNH-13110 (D), YPM-PU 15538 (E) y FMNH-13231 (F); ejemplares adultos MACN A 1116 (G) y FMNH-13108 (H). Escala $2 \mathrm{~cm}$. 


\section{A}

$\mathrm{dp} 4$

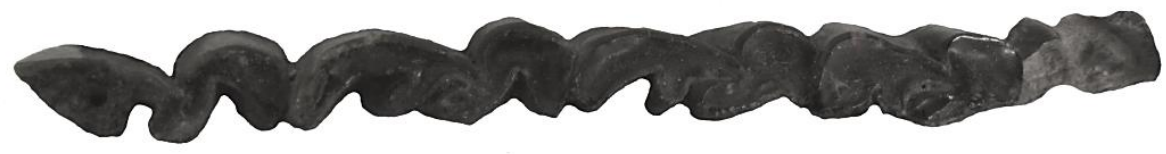

B
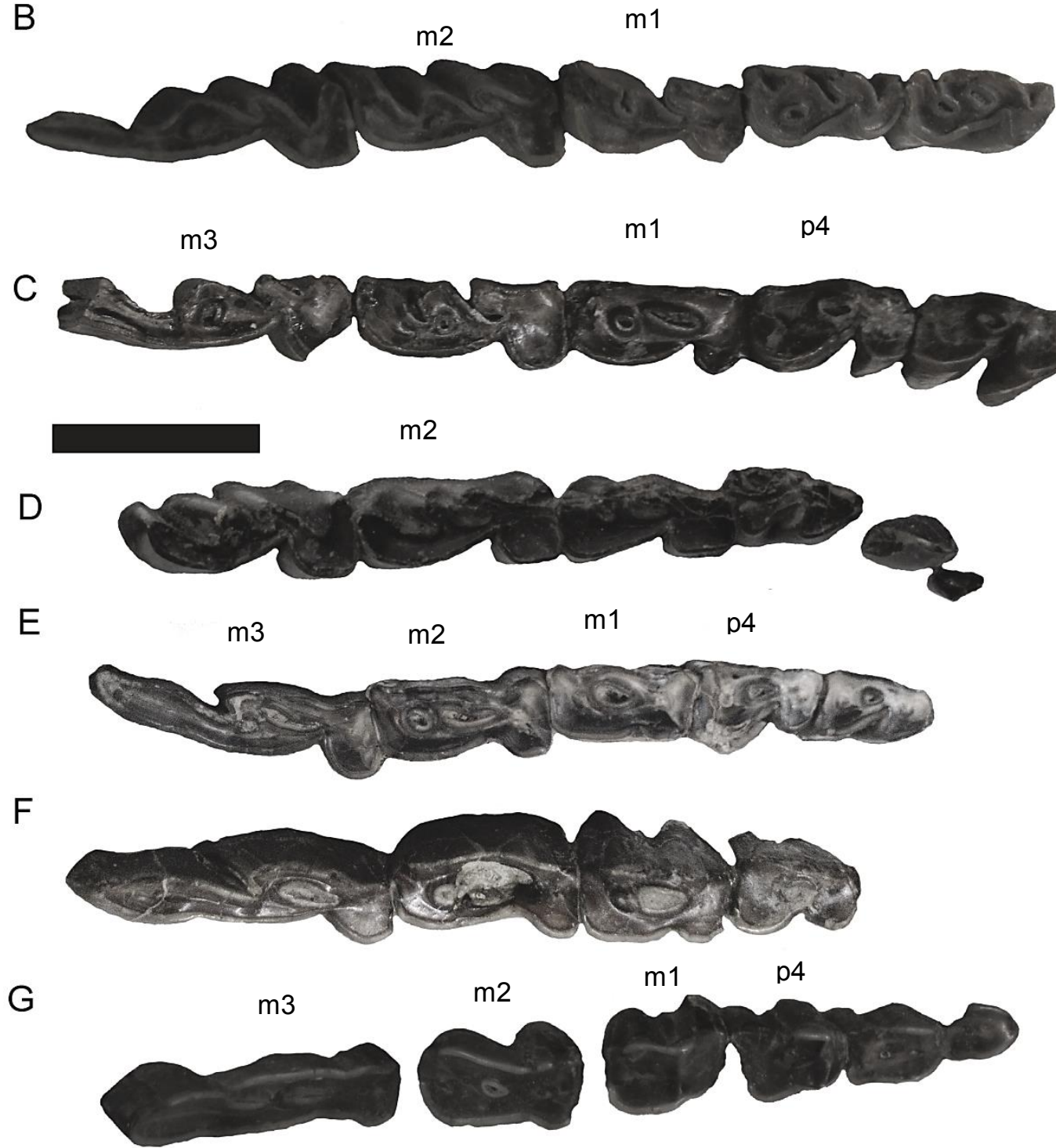

Fig. IV. 34: Variación ontogenética en la dentición yugal inferior de Adinotherium ovinum: Ejemplar juvenil FMNH-13245 (A); ejemplares subadultos FMNH-12066 (B), MACN A 1692 (C) y YPM-PU 15136 (D); ejemplares adultos, MACN A 1117 (E), YPM-PU 15969 (F) y (G) FMNH13104. Escala $2 \mathrm{~cm}$. 


\section{3. Nesodontinos no santacrucenses y otros taxa santacrucenses relacionados con los Nesodontinae}

En el presente apartado se incluyen diversos taxones que o bien son Nesodontinae registrados fuera de la Formación Santa Cruz o son miembros del Suborden Toxodontia contemporáneos o pancontemporáneos de los géneros Adinotherium y Nesodon. En el caso del nesodontino Nesodon taweretus, ya se ha mencionado a nivel comparativo en las secciones anteriores, pero se presenta a continuación la descripción detallada.

\section{3.1 Nesodon taweretus}

\section{-Generalidades}

Este taxón fue fundado a partir del cráneo MHNSR-PV 1004 (Fig. IV. 35), casi completo, con varias de las suturas completamente fusionadas (posible indicador de una edad avanzada o incluso senil), que conserva parte de la dentición izquierda en muy mal estado (M1-M3) y los alveolos de los restantes dientes (Forasiepi et al. 2015). También se ha referido a este taxón un molar superior aislado (MACN-PV 18609), dos restos mandibulares con una parte de la dentición preservada (MNHSR-PV 360 y MHNSR-PV 1000) y algunos fragmentos de postcráneo (MHNSR-PV 1008, MHNSR-PV 1009 y MHNSR-PV 1010).

Forasiepi et al. (2015) caracterizaron a Nesodon taweretus por un cráneo robusto y alto, diferente de $N$. imbricatus por poseer una convexidad dorsal más larga, más que nada a nivel de los frontales, lo que, junto al arco cigomático, otorga al cráneo un aspecto más trapezoidal en vista dorsal, en lugar de triangular; borde anterior de los nasales en forma de W; arcos cigomáticos relativamente más altos y cortos, y alcanzando su ancho máximo en su porción media en lugar de la posterior; basicráneo proporcionalmente más largo que en los ejemplares adultos de N. imbricatus; región occipital baja y ancha(Fig. IV. 35D), de contorno dorsal más o menos circular, similar a uno de los morfotipos de N. imbricatus (Fig. IV. 12A).

La descripción que se brinda a continuación está basada en el trabajo de Forasiepi et al. (2015), a excepción de la descripción de la cavidad endocraneana presentada por primera vez aquí; además, se resumen las principales diferencias que este taxón presenta con los nesodontinos de la Formación Santa Cruz. 


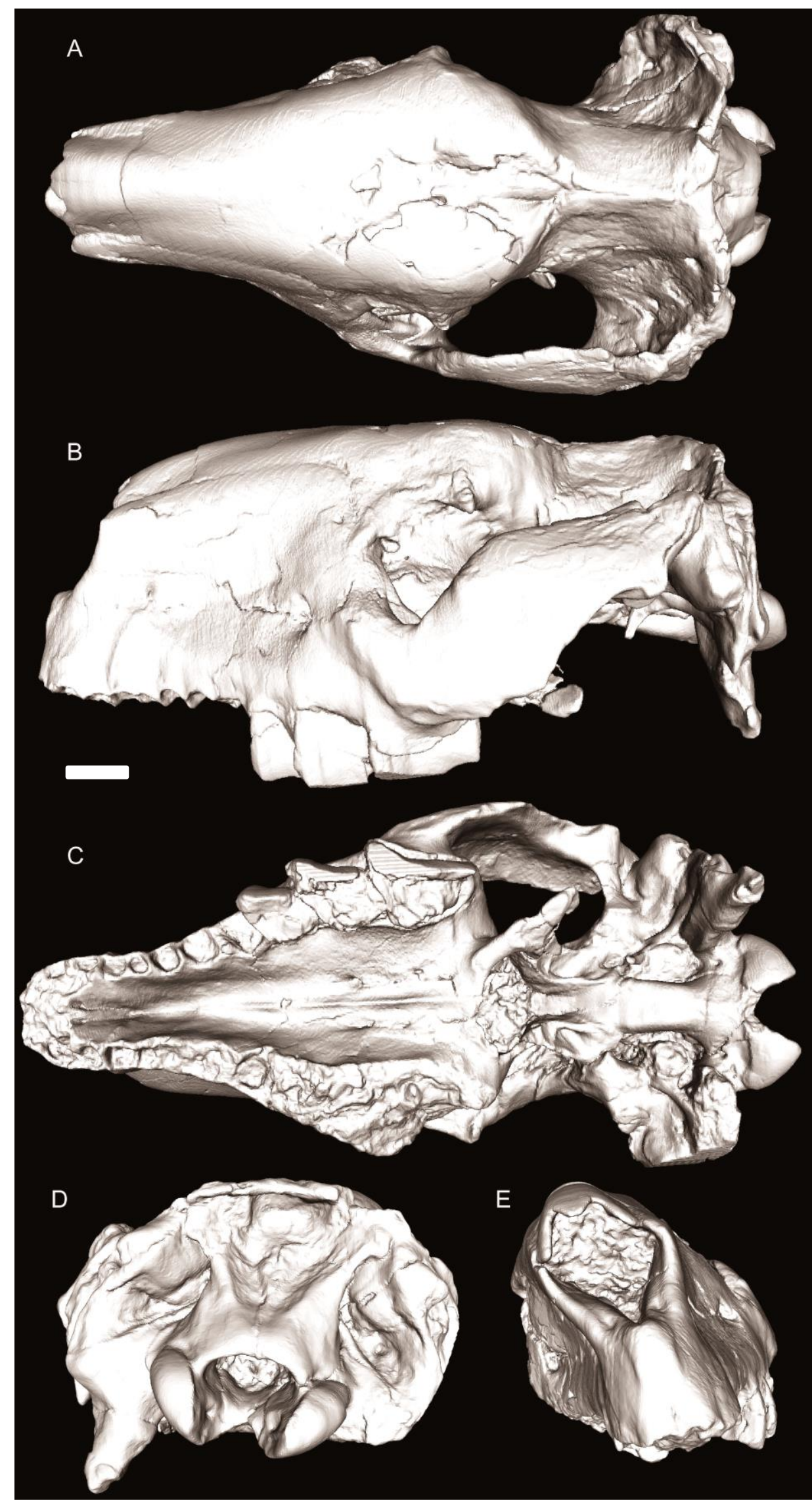

Fig. IV. 35. Reconstrucción tridimensional del cráneo de Nesodon taweretus MNHNSR-PV 1004: Vistas dorsal (A), lateral izquierda (B), ventral (C), posterior (D), anterior (E). Escala $5 \mathrm{~cm}$. 


\section{—Región naso-facial y techo craneano}

El rostro (Fig. IV. 35A y B) es alto, más corto y ancho que en Nesodon imbricatus, e incluso anteriormente más ancho que en Adinotherium ovinum. En vista lateral (Fig. IV. 35B), el perfil del cráneo es convexo a nivel de los nasales y los frontales, algo deprimido a la altura de la región temporal y elevado nuevamente a nivel de la cresta nucal. Esta convexidad a nivel de los frontales es uno de los principales rasgos que lo diferencia de $N$. imbricatus, ya que en este taxón, la convexidad dorsal no incluye la porción posterior de los frontales, en los que el perfil se hace más recto. Los premaxilares presentan una morfología y disposición similar a la de $N$. imbricatus, pero con un proceso posterolateral algo más corto. En $N$. taweretus, la plataforma narial también se encuentra expuesta en vista dorsal y, al igual que en $N$. imbricatus, presenta unos procesos pequeños y romos que se proyectan anteriormente. La abertura nasal es similar a la de $N$. imbricatus, aunque es algo más redondeada. En vista dorsal, los nasales son más cortos (pero también alcanzan el nivel de la órbita), anchos y convexos dorsalmente, con el borde anterior algo más retraído que en la especie cogenérica; sus extremos anterior y posterior tienen forma de "W" y difieren del patrón observado en $N$. imbricatus, en el que la punta anterior de los nasales tiene forma de "U" y la sutura nasofrontal varía desde una "U" hasta una "W" aguda. Al igual que en $N$. imbricatus, el maxilar es el elemento más representativo del rostro, lateralmente, aunque en vista dorsal constituye un elemento más conspicuo que en $N$. imbricatus y A. ovinum.

En el techo craneano, el rasgo más distintivo de $N$. taweretus es el gran desarrollo de los frontales, más precisamente de los senos frontales (Fig. IV. 35A y 36A), cuya pared, en vista dorsal externa, forma sendos abultamientos mediales a los procesos postorbitales del frontal. Los procesos postorbitales tienen un desarrollo escaso en comparación con $N$. imbricatus y $A$. ovinum, y se encuentran dirigidos lateralmente, sin curvarse hacia atrás; las líneas temporales son poco notorias, rasgo posiblemente relacionado con la expansión de los senos frontales y la avanzada edad del animal. Los parietales están menos desarrollados que en $N$. imbricatus y se encuentran restringidos a la porción más posterior del techo craneano; en consecuencia, la cresta sagital de $N$. taweretus es considerablemente más corta que en los toxodóntidos de Santa Cruz. 


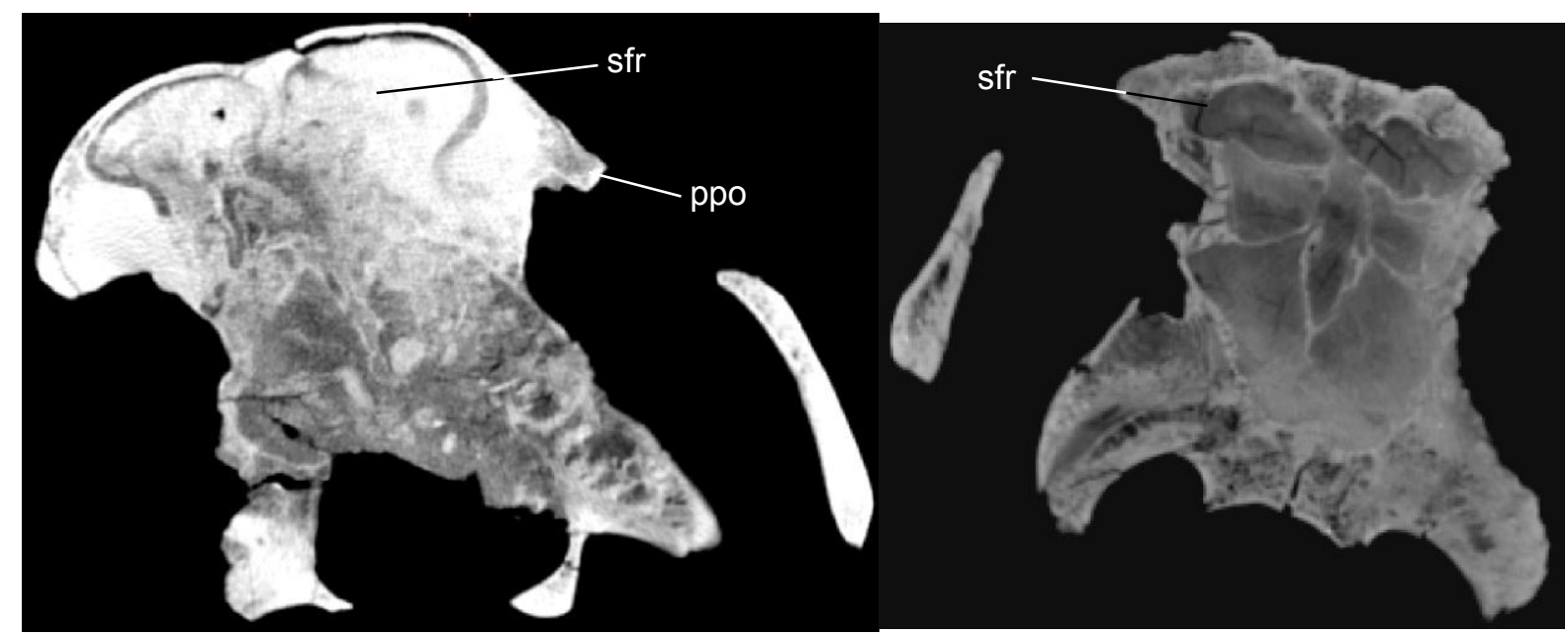

Fig. IV. 36. Corte transversal del cráneo a nivel del desarrollo lateral máximo de los procesos postorbitales: Nesodon taweretus, MHNSR-PV 1004 (A) y Nesodon imbricatus, MPM-PV RBPNSFV-12-3 (B).

\section{_Paladar}

En vista ventral (Fig. IV. 35C), el paladar de Nesodon taweretus es triangular, más angosto que en $N$. imbricatus y Adinotherium ovinum; es muy cóncavo, alcanzando la mayor profundidad a nivel de los P1. Dicha profundidad es mayor que la registrada en todos los ejemplares estudiados de $N$. imbricatus, lo que podría deberse a la edad más avanzada del individuo de $N$. taweretus, ya que este rasgo presenta una variación ontogenética marcada en el cráneo de $N$. imbricatus (Scott 1912), aumentando la profundidad del paladar en los ejemplares más viejos. Las suturas entre los diferentes componentes del paladar son poco distinguibles en MHNSR-PV 1004, a excepción de la sutura maxilopalatina que tiene forma de "V" angosta invertida, similar a lo observado en los ejemplares de N. imbricatus, en donde la "V" suele ser algo más amplia.

En la línea media del paladar, los forámenes incisivos abren en el premaxilar a nivel de los I2-I3; son pequeños en comparación a los presentes en los nesodontinos de Santa Cruz y ligeramente ovales. A nivel de la parte anterior del alveolo del canino, comienza una depresión que llega hasta la porción anterior del P2; la depresión continúa en una cresta conspicua y alta que se eleva progresivamente hasta su extremo posterior, en el margen anterior de la coana. En el maxilar existen dos grandes forámenes a nivel de la porción anterior del M2, identificados por Forasiepi et al. (2015) como los pasajes de la arteria y el nervio palatino mayor, de acuerdo a Evans y de Lahunta (1972).

Los palatinos son notablemente más largos y angostos que en los nesodontinos de Santa Cruz; los procesos palatinos (o crestas ectopterigoideas) son más cortos y divergentes que en 
$N$. imbricatus. Los palatinos presentan tres pequeñas aberturas a nivel del margen anterior del M3 y una cuarta a nivel de la sutura maxilopalatina, en el extremo posterior del M3. De acuerdo a Forasiepi et al. (2015), estas aberturas habrían transmitido manojos del nervio palatino mayor y los vasos acompañantes. A diferencia de $N$. imbricatus, el extremo posterior del paladar y el margen anterior de la coana están alineados con el borde posterior del último molar en $N$. taweretus.

\section{-Región orbitotemporal}

La apariencia general de esta región es similar a la de $N$. imbricatus, aunque la fosa orbitotemporal es ligeramente más amplia en este último.

El lacrimal es más corto y bajo que en los nesodontinos de Santa Cruz, su disposición en el cráneo es similar y presenta un único foramen lacrimal de gran tamaño que abre dentro de la órbita. El lacrimal presenta una espina que se proyecta ventralmente y contacta con el maxilar; el proceso lacrimal está bastante reducido y la sutura naso-lacrimal no se preservó en MHNSR-PV 1004.

El arco cigomático presenta proporciones y disposición bastante similares a $N$. imbricatus, aunque tiene mayor diferencia de altura entre los extremos anterior y posterior; además, la superficie para la inserción del masetero en la zona anteroventral del arco cigomático está ligeramente más desarrollada transversalmente, pero es algo más corta que en los ejemplares analizados de $N$. imbricatus.

\section{—Basicráneo y región auditiva}

El basicráneo de $N$. taweretus es ancho y ligeramente más largo que el de $N$. imbricatus. La región central de la base del cráneo está conformada por los complejos esfenoidal y occipital que, en líneas generales, presentan la misma disposición y morfología en ambas especies. Sin embargo, cabe destacar que las tuberosidades y la cresta media presentes en la zona de transición basiesfenoides-basioccipital presentan un menor desarrollo que en los nesodontinos de Santa Cruz; sin embargo, dada la variabilidad observada en el desarrollo de estas estructuras en $A$. ovinum y $N$. imbricatus, el menor desarrollo en $N$. taweretus posiblemente se deba a la mayor edad del individuo. La fosa escafoidea es más profunda que en $N$. imbricatus, pero algo menos que en A. ovinum, aunque este es otro de los rasgos que presenta un rango de variación amplio de acuerdo al estadio ontogenético (ver Basicráneo de A. ovinum). 
Si bien la morfología de la bula timpánica no puede apreciarse totalmente debido a la condición del ejemplar, se comprueba que es relativamente más pequeña que en los individuos adultos de los nesodontinos de Santa Cruz. Según Forasiepi et al. (2015), la bula timpánica no contacta con el eje lateral del esfenoides a lo largo de la fisura basicoclear, aunque los autores remarcan que esto puede deberse a la rotura del material. El ectotimpánico, al igual que en $N$. imbricatus, emite una proyección a partir de la crista meatal que sobrepasa el extremo anterior de la bula y termina en un proceso estiliforme grácil. El MAE presenta una morfología y disposición similares a las presentes en $N$. imbricatus, pero abre en una posición inferior a la de los especímenes de $N$. imbricatus y A. ovinum. El foramen suprameatal es comparable en las tres especies, aunque en $N$. taweretus tiene una posición anterior al MAE en lugar de anterodorsal.

Al igual que en el resto de los nesodontinos, el escamoso contribuye en gran medida a la conformación del piso del cráneo de $N$. taweretus. En vista ventral, el proceso articular del escamoso, previo a la fosa glenoidea, presenta un desarrollo notablemente menor que en $N$. imbricatus, y la fosa glenoidea es un poco más corta y profunda. Debido a esto, el arco cigomático de $N$. taweretus alcanza su ancho máximo a nivel de su zona media, en una posición similar a la presente en $A$. ovinum, pero más anterior que en $N$. imbricatus, en el que está justo antes de la fosa glenoidea. Los procesos postglenoideo y postimpánico del escamoso son muy similares a los de las especies de Santa Cruz.

Las suturas entre los complejos esfenoidal y occipital, y entre sus respectivos elementos, no son visibles.

\section{—Región occipital}

En vista posterior, la región occipital de $N$. taweretus presenta un contorno más o menos semicircular (Fig. IV. 35D), similar a uno de los morfotipos de N. imbricatus. Asimismo, la cresta nucal tiene un margen dorsal semicircular y no se proyecta por detrás de los cóndilos occipitales que son claramente visibles en vista dorsal. La zona supraoccipital exhibe una morfología similar a la presente en los nesodontinos de Santa Cruz, con una profunda concavidad a nivel de la zona media de este hueso. En los laterales del supraoccipital, la región se abulta notablemente debido al desarrollo de los senos epitimpánicos.

En $N$. taweretus, también existe una profunda depresión dorsal a los cóndilos occipitales, justo a nivel de la sutura escamoso-exoccipital. Como ya se expresó para $N$. imbricatus, esta depresión se ha interpretado como el foramen mastoideo (Gabbert 2004, Billet 2010) o una 
abertura del canal postemporal (Kramarz et al. 2011, MacPhee 2014, Forasiepi et al. 2015), que transmitiría la arteria diploética magna y las venas asociadas.

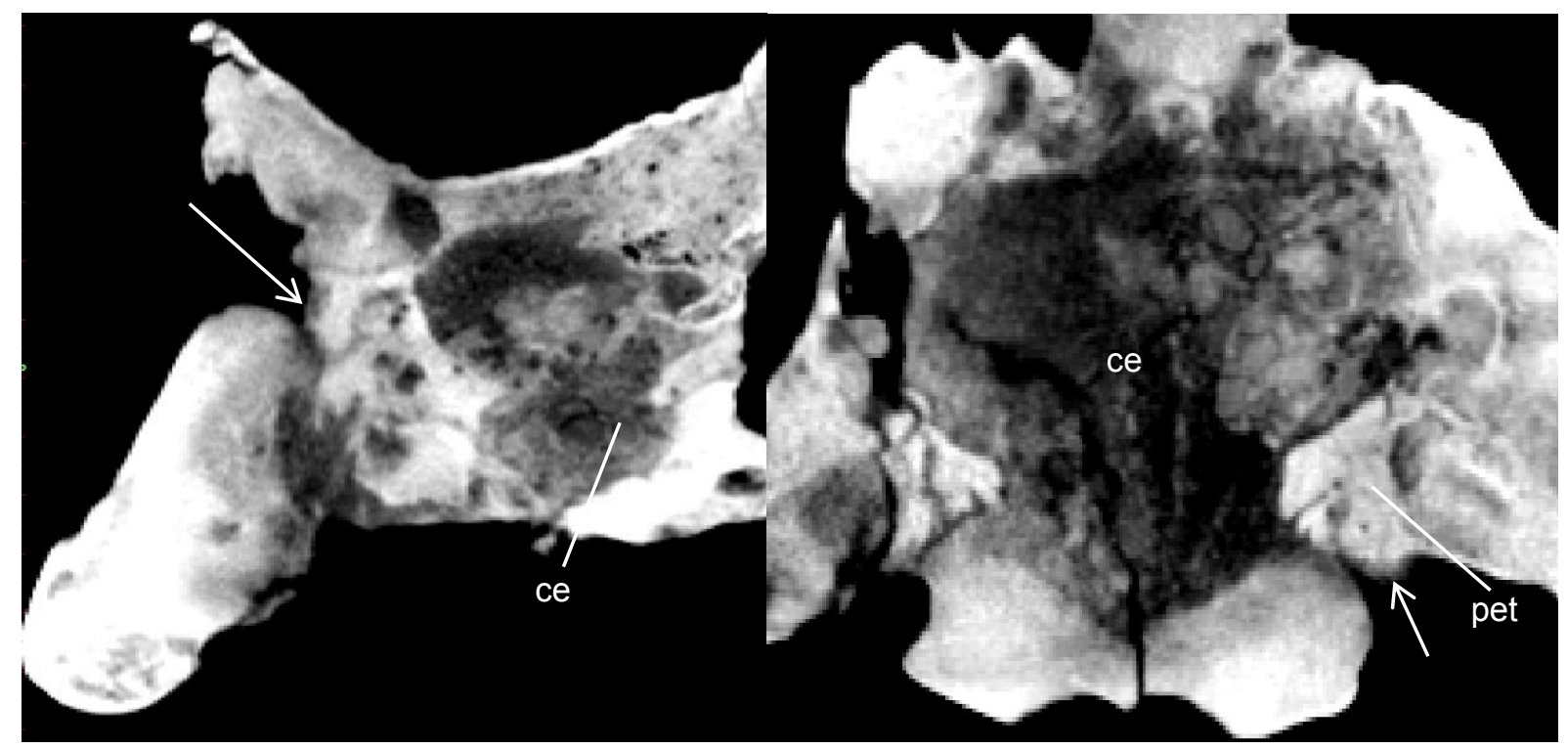

Fig. IV. 37. Exposición de la porción mastoidea (indicada por una flecha) en la región occipital de Nesodon taweretus, MHNSR-PV 1004: Sección longitudinal a nivel del petroso derecho (A); sección coronal a nivel de la exposición de ambos petrosos $(\mathbf{B})$.

Gabbert (2004) manifestó que no existen evidencias de la presencia de un proceso mastoideo en vista posterior del cráneo de algunos Toxodontia y Forasiepi et al. (2015) sugirieron esta condición para el ejemplar de N. taweretus MHNSR-PV 1004; sin embargo, en los tomogramas analizados, puede verse una proyección del petroso que se encuentra expuesta en vista posterior (Fig. IV. 37), lo que estaría en concordancia con las interpretaciones de Roth (1903), Scott (1912) y Patterson (1932); aun así, es difícil discernir si se trata de una proyección natural o un artefacto producto de la deformación y/o la preparación del material.

El foramen magnum es oval, con el eje mayor transversal; su posición en la región occipital es más dorsal que en los ejemplares de N. imbricatus y Adinotherium ovinum, y se orienta posteriormente en lugar de posteroventralmente. Los cóndilos occipitales se disponen de forma similar en que las especies santacrucenses, aunque la superficie articular presenta, en vista ventral, un contorno triangular en $N$. taweretus, en lugar de ovalado.

Posiblemente debido a la avanzada edad del ejemplar MHNSR-PV 1004, las suturas entre los huesos que componen el complejo occipital no se distinguen, con la excepción de la sutura 
escamoso-exoccipital que es ligeramente sinuosa, más conspicua medialmente que hacia los laterales.

\section{-Molde endocraneano}

El molde endocraneano de Nesodon taweretus (Fig. IV. 38) presenta notables diferencias con el molde de $N$. imbricatus, ya que la relación de proporciones dista mucho de las de $N$. imbricatus, siendo más similar a la de Adinotherium ovinum. En general, el molde endocraneano presenta escasa distorsión tafonómica.

La flexura del molde endocranenano tiene un valor de $59^{\circ}$ (Tabla IV. 1). La relación entre el ancho y el largo del molde (excluyendo la medula) es 0,61 y la relación alto/ancho es de 0,89. Comparado con $N$. imbricatus, el molde endocranenano de $N$. taweretus es más corto, más ancho y más alto, con un aspecto mucho más globoso. Respecto a A. ovinum, la cavidad endocraneana es más corta y baja, pero el ancho relativo es similar.

Respecto al encéfalo anterior, a diferencia del ejemplar de $N$. imbricatus, los bulbos olfatorios $_{\mathrm{m}}$ en MHNSR-PV 1004 (parcialmente reconstruidos) parecen ser más cortos y ligeramente más angostos y altos. Al igual que en los Nesodontinae de Santa Cruz, los bulbos están alineados con el eje principal ipsilateral de cada hemisferio cerebral $\mathrm{m}$ y se encuentran separados el uno del otro en el plano sagital. La fisura circular es mucho más notoria, ancha y profunda en $N$. taweretus. En esta especie tampoco se registró evidencia de bulbos olfatorios accesorios $_{\mathrm{m}}$. Los tractos olfatorios $\mathrm{m}$ son poco conspicuos y mucho más cortos que en los toxodóntidos de Santa Cruz, y sobrepasan levemente la corteza cerebral $\mathrm{m}_{\mathrm{m}}$ que representa un $5 \%$ del volumen total del molde endocraneano. La presencia del surco medial que separa los

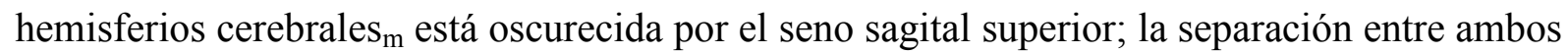
hemisferios $_{\mathrm{m}}$ es notoria únicamente a nivel de la porción posterior del encéfalo anterior. Los hemisferios cerebrales $\mathrm{m}_{\mathrm{m}}$ son simétricos, más o menos ovoides, con la relación ancho/largo de 0,66 y alto/largo de 0,70. Al igual que en los casos anteriores, la superficie cortical es girencefálica; los sulci y gyri, a pesar de la avanzada edad del animal, están más marcados que en $N$. imbricatus. La fisura rinal es bastante conspicua y los lóbulos piriformes se proyectan notablemente hacia los laterales, diferenciándose claramente de la superficie cortical y visibles dorsalmente; son ovoides (más largos que altos) y representan algo mas del $3 \%$ del molde endocraneano.

Al igual que en los casos anteriores, la región hipofisaria $a_{m}$ es muy grande, se encuentra situada en la superficie medial del piso ventral del molde endocraneano, justo por debajo de los lóbulos piriformes, y ligeramente anterior al foramen oval. En N. taweretus, la hipófisis $\mathrm{m}_{\mathrm{m}}$ 
está recorrida medialmente por un surco, en lugar de la quilla registrada en $N$. imbricatus, que la divide en dos abultamientos voluminosos que constituyen las estructuras más conspicuas del molde endocraneano en vista ventral. En su totalidad, la hipófisis $\mathrm{m}_{\mathrm{m}}$ representa aproximadamente un 5\% del volumen de la cavidad endocraneana que se encuentra situada en el medio del piso ventral del molde endocraneano. Como ya se ha indicado para otros notoungulados (e.g. Gabbert 2004, Martínez et al. 2016) y para los ejemplares descriptos anteriormente en este capítulo, en la región hipofisaria no hay indicios del pasaje de la rama cerebral de las carótidas internas en el piso de la hipófisis.

La separación entre el encéfalo anterior y el encéfalo posterior está determinada por una depresión profunda en el molde endocraneano que, como ya se ha mencionado anteriormente, podría corresponder a la ausencia (o presencia sin osificar) del tentorium cerebelli (Macrini et al. 2007b). La reconstrucción de la cavidad en MHNSR-PV 1004 exhibe un encéfalo posterior similar al de $N$. imbricatus y más largo que en A. ovinum, siendo la diferencia de longitud más notoria en vista ventral. Esta mayor longitud del encéfalo posterior en las especies de Nesodon puede deberse a que la porción ventral del encéfalo posterior tiene un recorrido más o menos horizontal en dirección anteroposterior, mientras que en $A$. ovinum la dirección del eje es oblicua y apunta posteroventralmente.

Con respecto a los moldes de los nervios craneanos, la primera estructura discernible corresponde al quiasma óptico ${ }_{\mathrm{m}}$ (NC II), consistente en una corta proyección ubicada en el piso del encéfalo anterior, justo por delante de la hipófisis $\mathrm{m}_{\mathrm{m}}$ e inmediatamente por debajo de los tractos olfatorios $\mathrm{m}_{\mathrm{m}}$. Siguiendo al quiasma óptico $\mathrm{m}_{\mathrm{m}}$, pueden verse dos proyecciones correspondientes a los nervios ópticos $\mathrm{m}$, que divergen notablemente, en un ángulo de aproximadamente $60^{\circ}$, a diferencia de lo observado en los ejemplares de $N$. imbricatus y $A$. ovinum. Hacia la parte media del molde endocraneano y justo por detrás del quiasma óptico, se observa el molde de la salida del canal que abre en la fisura esfeno-orbitaria que, al igual que en los casos anteriores, habría transmitido los nervios oculomotor (NC III), troclear (NC $\mathrm{IV})$, las ramas oftálmica profunda $\left(\mathrm{NC}_{1}\right)$ y maxilar $\left(\mathrm{NC}_{2}\right)$ del trigémino, y el abduscens (NC VI). Similar a la condición presente en N. imbricatus, $N$. taweretus no posee un foramen rotundo y el $\mathrm{NC} \mathrm{V}_{2}$ abandonaría el cráneo por la fisura esfeno orbitaria, cuyas salidas son más divergentes que en los nesodontinos de Santa Cruz. El molde de la rama mandibular del trigémino sale del cráneo por la abertura correspondiente a la confluencia del foramen oval y la fenestra piriforme, que en este ejemplar solo ha sido reconstruido parcialmente debido a la rotura del espécimen en esa zona; sin embargo, dada la morfología que puede apreciarse en los tomogramas, es válido asumir que se condice con la condición observada en el resto de los 
nesodontinos. En la porción posterior del molde endocraneano, en vista lateral, se observa la posición del $\mathrm{MAI}_{\mathrm{m}} \mathrm{y}$ el origen de los nervios facial (NC VII) y vestibulococlear (VIII) en la porción anteromedial de los hemisferios cerebelares $\mathrm{m}_{\mathrm{m}}$. Los tractos correspondientes a los nervios glosofaríngeo (NC IX), vago (NC X) y accesorio (NC XI) se encuentran sugeridos por un abultamiento cuya morfología no se aprecia claramente y que se encuentra dirigido ventralmente a partir del piso de la porción posterior del hemisferio cerebelar ${ }_{\mathrm{m}}$. En la porción más posterior del molde endocraneano, en los laterales del molde de la cavidad, se registran los moldes de los canales que transportan los nervios hipoglosos (NC XII).

Respecto al sistema vascular del endocráneo, el seno sagital superior se encuentra representado por un abultamiento longitudinal que recorre el encéfalo anteromedialmente, siendo más conspicuo en la mitad posterior. El seno transverso no fue reconstruido en este ejemplar debido a la compactación de la cavidad; sin embargo, a partir de las secciones de TC, el seno transverso presenta la misma condición que en los toxodóntidos de Santa Cruz, con las mismas conexiones con las rami temporalis, el canal postemporal, el canal que transporta la vena postglenoidea y el canal orbitotemporal (parcialmente reconstruido) que corre lateralmente sobre la periferia del lóbulo piriforme; a partir de la reconstrucción, se nota que este vaso tiene un calibre ligeramente mayor que en $N$. imbricatus y es similar al del ejemplar MPM PV-3532 de A. ovinum. El canal orbitotemporal en N. taweretus presenta el mismo recorrido que en los otros nesodontinos.

\section{—Molde del oído interno}

Los estudios de TC realizados para la reconstrucción de la cavidad endocraneana no presentan la resolución suficiente para poder reconstruir de forma satisfactoria el laberinto óseo del oído interno de $N$. taweretus.

\section{-Mandíbula}

En el trabajo de Forasiepi et al. (2015), se asignaron, con reservas, dos restos mandibulares a $N$. taweretus. Lamentablemente, no revisé esos materiales y, en consecuencia, no hay comentarios que añadir a la descripción original. El espécimen MHNSR-PV 1000 que es uno de los más completos, presenta una morfología similar a la observada en ejemplares de edad avanzada de $N$. imbricatus, aunque cabe destacar que su longitud es menor que en los ejemplares consultados del taxón de Santa Cruz. 


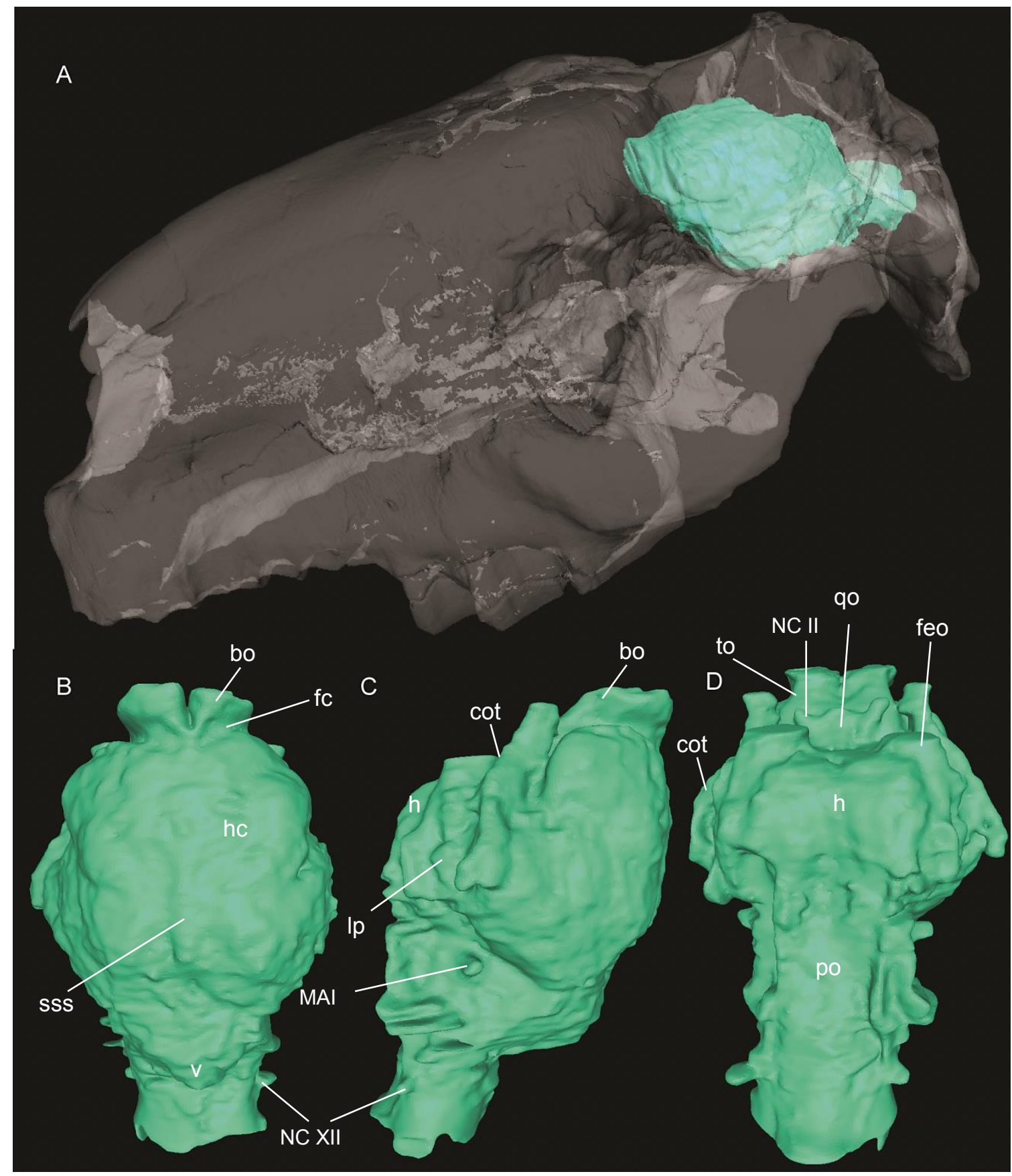

Fig. IV. 38. Molde endocraneano de MHNSR-PV 1004 de Nesodon taweretus: cráneo con el molde endocraneano en posición (A); molde endocraneano en vistas dorsal (B), lateral izquierda (C) y ventral (D).

\section{-Dentición}

En el holotipo de Nesodon taweretus solo se preservó, más o menos completa, la serie M1-M3 derecha. Las restantes piezas dentarias faltan o están rotas a nivel alveolar. $N$. taweretus presenta la misma fórmula dentaria que el resto de los nesodontinos, I3 C1 P4 M3. Un rasgo peculiar que posiblemente se deba a la edad del animal es la proximidad entre los 
alveolos dentarios en la porción anterior del hocico. En las especies de Santa Cruz, es normal que se observe algún diastema, de desarrollo y disposición variables, entre las piezas dentarias anteriores. Los molares conservados en $N$. taweretus presentan un tamaño y un contorno relativamente similar al de $N$. imbricatus. El patrón oclusal en forma de "Y" se ha perdido en M1-2 debido al desgaste, formándose una foseta alargada, más reducida y situada posterolingualmente en M1 y más grande y estrecha en M2; en el M3, aún se puede distinguir un esbozo de la forma en "Y", así como una postfoseta situada posterior y labialmente a la foseta central (Forasiepi et al. 2015: fig. 7A, B).

Con respecto a la dentición inferior, a partir de las ilustraciones de Forasiepi et al. (2015), se comprueba que la morfología de los molares del ejemplar MHNSR-PV 1000 coincide con la de los individuos de edad avanzada de $N$. imbricatus.

\section{3.2 Proadinotherium muensteri Ameghino}

\section{- Generalidades}

El material asignado al género Proadinotherium es bastante escaso. El único cráneo analizado es el ejemplar FMNH-13590, de Colhue-Huapi, asignado a Proadinotherium muensteri (Radinsky 1981). Se trata de un cráneo bastante completo, con parte del rostro y las regiones orbitotemporal y occipital dañadas, siendo el lado izquierdo del ejemplar el que presenta mejor preservación. A este material se accedió únicamente por medio de un estudio de TC y la descripción realizada se basa en la reconstrucción tridimensional del cráneo (sin la mandíbula) generada a partir de los tomogramas (Fig. IV. 39); por esta razón, las suturas y otros rasgos resultan difíciles de observar y solo se describen en la medida en que pudieron diferenciarse nítidamente.

En vida, Proadinotherium muensteri habría sido un animal de tamaño ligeramente mayor que los ejemplares más grandes de Adinotherium ovinum (TSL: 286,24 mm), pero definitivamente menor que Nesodon imbricatus. En vista dorsal, el perfil del cráneo es diferente al de las especies analizadas anteriormente, aunque se acerca más al perfil sinuoso indicado para $A$. ovinum. El ancho máximo del cráneo se sitúa a nivel de la porción media de los arcos cigomáticos $(\mathrm{BZB} *=162,34 \mathrm{~mm}$, estimado por simetría), que estan relativamente menos expandidos lateralmente que en $A$. ovinum. También se observa que el cráneo de $P$. muensteri presenta las dos constricciones (palatal y postorbital) descriptas para A. ovinum 
(Scott 1912; esta tesis), siendo la constricción postorbital mucho más notoria ( $\mathrm{POC}=39,08)$ que en los géneros de Santa Cruz $\left(\mathrm{POC}_{1 / 2}\right.$ Nesodon=68,91; $\mathrm{POC}_{1 / 2}$ Adinotherium=44,41).

En vista lateral, el perfil dorsal del cráneo es rectilíneo hasta la porción media de los frontales, donde comienza a elevarse en dirección posterior, alcanzando su altura máxima justo detrás del límite posterior de la coana (sugerido por los procesos pterigoides del palatino y el aliesfenoides), a nivel de donde debería encontrarse la sutura basiesfenoides-basioccipital. La cresta sagital es alta, incluso más que en A. ovinum, larga y ligeramente convexa.

\section{—Región naso-facial y techo craneano}

El rostro de Proadinotherium muensteri (Fig. IV. 39A y B) es similar al de A. ovinum, a excepción de que los nasales (a partir del área conservada) son relativamente más angostos que en el nesodontino santacrucense. La morfología y el largo de los nasales no pueden precisarse en este ejemplar, dado que solo se ha conservado la porción posterior. La sutura naso-frontal es cóncava en todo su recorrido y similar a uno de los tipos descriptos para $A$. ovinum (Fig. IV. 21C).

En P. muensteri, tanto los premaxilares como los maxilares se encuentran dañados, Caunque parecen tener la misma disposición y forma que en A. ovinum y $N$. imbricatus. El límite dorsal de los premaxilares no puede distinguirse, pero destaca el gran desarrollo que presentan las crestas a nivel de la sutura interpremaxilar en la porción anterior de la plataforma narial. El maxilar no presenta rasgos que difieran de manera considerable de lo expuesto anteriormente para los nesodontinos de Santa Cruz.

Los frontales están más desarrollados que en ambos taxones de Santa Cruz; como se mencionó anteriormente, la constricción postorbital, justo por detrás de los procesos postorbitales, está mucho más marcada y es fuertemente cóncava. Los procesos postorbitales son conspicuos y su extremo está dirigido posterolateralmente; por lo que se distingue en la reconstrucción, carecen de las rugosidades presentes en A. ovinum. Hacia la zona media de los frontales, se encuentra la depresión típica de los nesodontinos, con un desarrollo intermedio entre A. ovinum y N. imbricatus. 


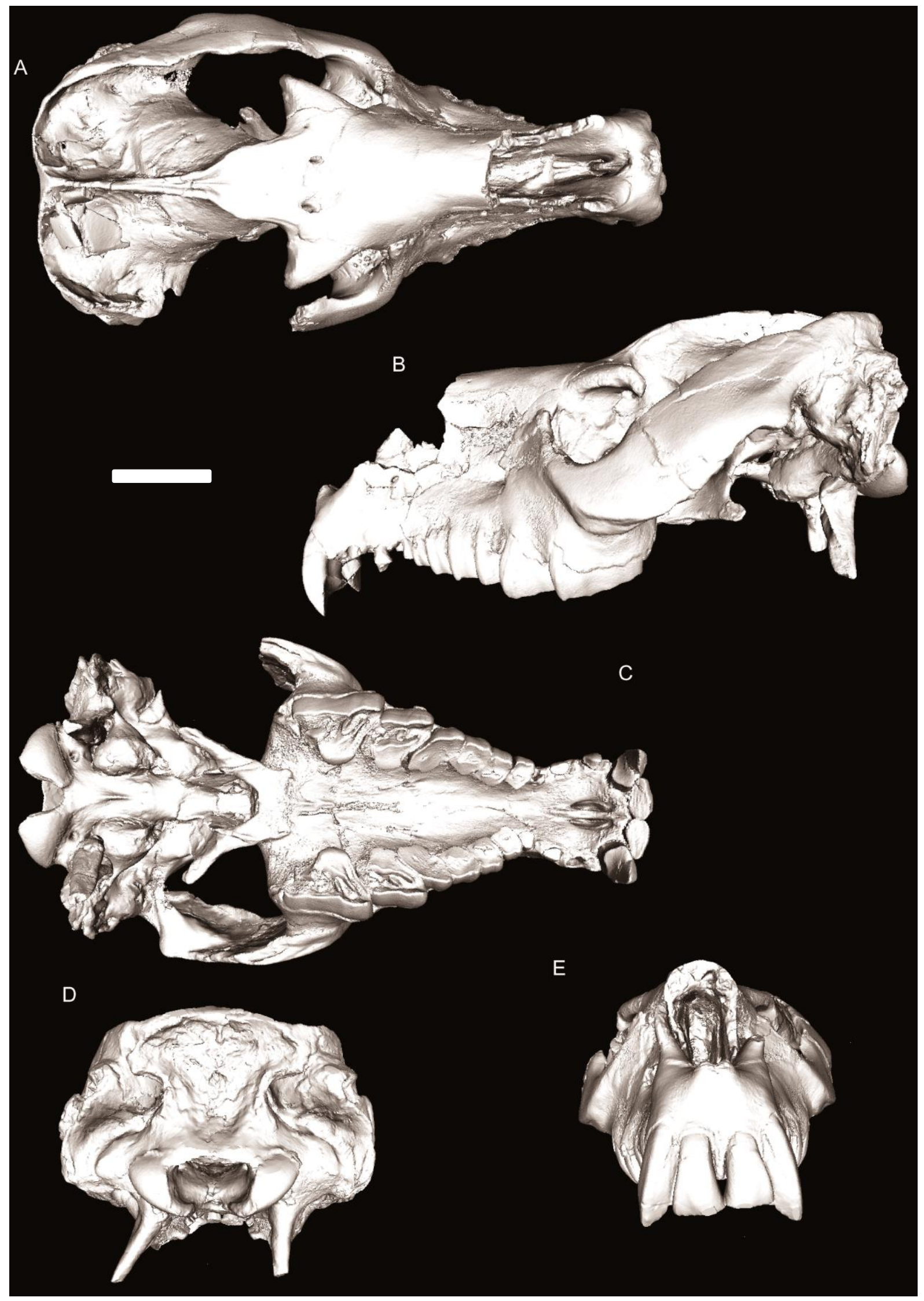

Fig. IV. 39. Reconstrucción tridimensional del cráneo de Proadinotherium muensteri FMNH13590: Vistas dorsal (A), lateral izquierda (B), ventral (C), posterior (D) y anterior (E). Escala $5 \mathrm{~cm}$. 
Los parietales son huesos largos, con una cresta sagital larga y gruesa, donde las proyecciones que la conforman solo están fusionadas posteriormente, dejando un surco conspicuo en la porción anterior de la cresta sagital. Los forámenes para las rami temporales parecen estar restringidos a la porción más posterior del hueso, pero como la sutura escamosoparietal no es distinguible por el daño en la zona, no se puede precisar si perforan el parietal en su límite con el escamoso o más lejos de la sutura. Por el mismo motivo, no se puede precisar si los escamosos contribuyen o no a la conformación del techo craneano.

\section{- Paladar}

Al igual que en Adinotherium, los elementos que componen el paladar (Fig. IV. 39C) no presentan una variación morfológica ni topológica como para realizar una descripción de cada componente, razón por la cual se describe de forma comparativa, remarcando las diferencias más relevantes con las especies antes descriptas.

El paladar de $P$. muensteri presenta características comunes a ambas especies de nesodontinos de la FSC. Anteriormente, presenta la constricción a nivel del P2, como en $A$. ovinum, aunque posteriormente el paladar no se ensancha en la misma proporción, siendo relativamente más angosto, aunque relativamente más ancho que en $N$. imbricatus. Aun cuando el grado de hipsodoncia es menor en $P$. muensteri, el paladar se encuentra profundamente excavado, aunque no alcanza la concavidad presente en los ejemplares de edad avanzada de los otros dos taxones. En la porción posterior del paladar, los procesos palatinos presentan la longitud y el grado de divergencia similares a los de A. ovinum. De hecho, la mayor parte de las estructuras que conforman el piso y el borde posterior de la coana presentan las mismas dimensiones relativas que en A. ovinum.

\section{-Región orbitotemporal}

La fosa orbitotemporal es ligeramente más amplia que en $A$. ovinum, debido al menor desarrollo de la caja craneana y la expansión de los arcos cigomáticos. La caja craneana es estrecha anteriormente y su porción media y posterior no alcanza la expansión transversal presente en Adinotherium; sin embargo, su capacidad craneana (Tabla IV. 1) en relación al tamaño corporal supera la de $N$. imbricatus, siendo la cavidad relativamente más amplia y alta.

El lacrimal no puede observarse en el cráneo FMNH-13590, ya que las suturas no son claras en la reconstrucción tridimensional. 
La delimitación de la órbita parece más marcada en los adultos de esta especie que en los de Santa Cruz. El proceso postorbital se curva levemente en dirección ventral y el yugal es amplio dorsoventralmente, delimitando claramente una órbita algo más circular que en $A$. ovinum y mucho más que en $N$. imbricatus, con proporciones similares a la órbita de $A$. ovinum. La pared lateral del cráneo posterior a la órbita se encuentra bastante dañada y la reconstrucción no permite precisar demasiado.

La contribución de los escamosos a la conformación de la región orbitotemporal es más similar a la de A. ovinum que a la de las dos especies de Nesodon. En vista dorsal, es difícil precisar cómo contribuyen a la conformación del techo craneano, debido a que las suturas no son visibles, pero parecen tener una proporción comparable a la de A. ovinum, estando ligeramente desplazados ventralmente por la mayor contribución de los parietales en la conformación del techo y paredes laterales del cráneo.

\section{—Basicráneo y región auditiva}

El complejo esfenoidal en Proadinotherium (Fig. IV. 39C) es similar a lo descripto para las otras especies de nesodontinos. Es posible observar parte del preesfenoides y el basiesfenoides en vista ventral, aunque resulta difícil precisar su extensión debido a que las suturas no son claramente distinguibles.

La separación entre el basiesfenoides y el basioccipital es poco clara. Tomando como indicador los abultamientos conspicuos de la porción anterior del basioccipital, que en las especies anteriores se encuentran inmediatamente por detrás de la sutura entre ambos huesos, puede inferirse que la condición es similar a la encontrada en A. ovinum.

La contribución de los escamosos a esta región sigue el mismo patrón ya descripto; los procesos postglenoideo y postimpánico tienen un desarrollo similar a lo observado en $A$. ovinum. La fosa glenoidea se encuentra dañada en ambos lados. Anterior a la fosa glenoidea, en el lado izquierdo, puede verse la fosa escafoidea, similar en proporciones a la de $A$. ovinum, pero ligeramente menos profunda. Internamente, los senos epitimpánicos se encuentran bien desarrollados, de forma similar a lo observado en A. ovinum.

El ectotimpánico contribuye de la misma forma que en las especies anteriores, aunque varía levemente en sus proporciones. La bula timpánica en $P$. muensteri es similar a la de $A$. ovinum, menos globular que en $N$. imbricatus y con su extremo ventral más anguloso y dirigido anteroventralmente. Siguiendo el mismo patrón registrado para las otras especies descriptas, la bula timpánica no se encuentra rellena por hueso esponjoso ni presenta tabicaciones conspicuas de ningún tipo. No hay rastros del proceso estiliforme en este cráneo 
y la fenestra piriforme parece tener un calibre relativamente mayor que en $A$. ovinum, aunque esto puede deberse a artefactos provocados por la preparación extensiva que ha sufrido el material. El MAE no presenta rasgos peculiares, siendo más similar en disposición y constitución a lo visto en $A$. ovinum.

Los petrosos de Proadinotherium muensteri (Fig. IV. 40) presentan varias diferencias con el petroso de $A$. ovinun. Las más evidentes son visibles en vista timpánica y se encuentran en el promontorio (y estructuras aledañas), que es menos globoso y el flanco anteromedial del FMNH-13590 parece estar más expandido que en el AMNH 9276; las fenestras coclear y vestibular en $P$. muensteri presentan aproximadamente el mismo tamaño y en este caso fue posible ubicar el surco facial y el hiatus Falopii (Fig. IV. 40A), pero al igual que en el caso anterior, debido a la rotura del cavum supracocleare la posición del foramen facial secundario no pudo identificarse con precisión. En vista cerebelar, las mayores diferencias son el menor desarrollo de la cresta prefacial y la fosa subarcuata menos profunda.

Las restantes estructuras visibles tienen la misma disposición que en A. ovinum.

\section{—Región occipital}

El complejo occipital presenta el perfil dorsal semicircular y bajo descripto anteriormente para algunos ejemplares de los nesodontinos de la FSC (Figs. IV. 12A y IV. 27D). La depresión media del supraoccipital es más profunda que en ellos.

El rasgo más distintivo en la región occipital de FMNH-13590 son las profundas excavaciones del proceso postimpánico del escamoso a nivel de su contacto con el supraoccipital. Estas excavaciones tienen una forma más o menos sigmoidal y recorren la región occipital prácticamente en toda su extensión, desde la base de los laterales hasta el límite dorsal entre el escamoso y el supraoccipital. En las especies antes descriptas, no hay ejemplares que presenten estas excavaciones tan conspicuas y de tanta extensión.

$\mathrm{Al}$ igual que en las otras especies, el petroso está expuesto levemente en vista posterior (Fig. IV. 39D).

Los cóndilos occipitales son similares a los de A. ovinum, aunque ligeramente más expandidos transversalmente. El foramen magnum es ligeramente ovalado, presentando una condición intermedia entre lo observado en las dos especies de la Formación Santa Cruz. 


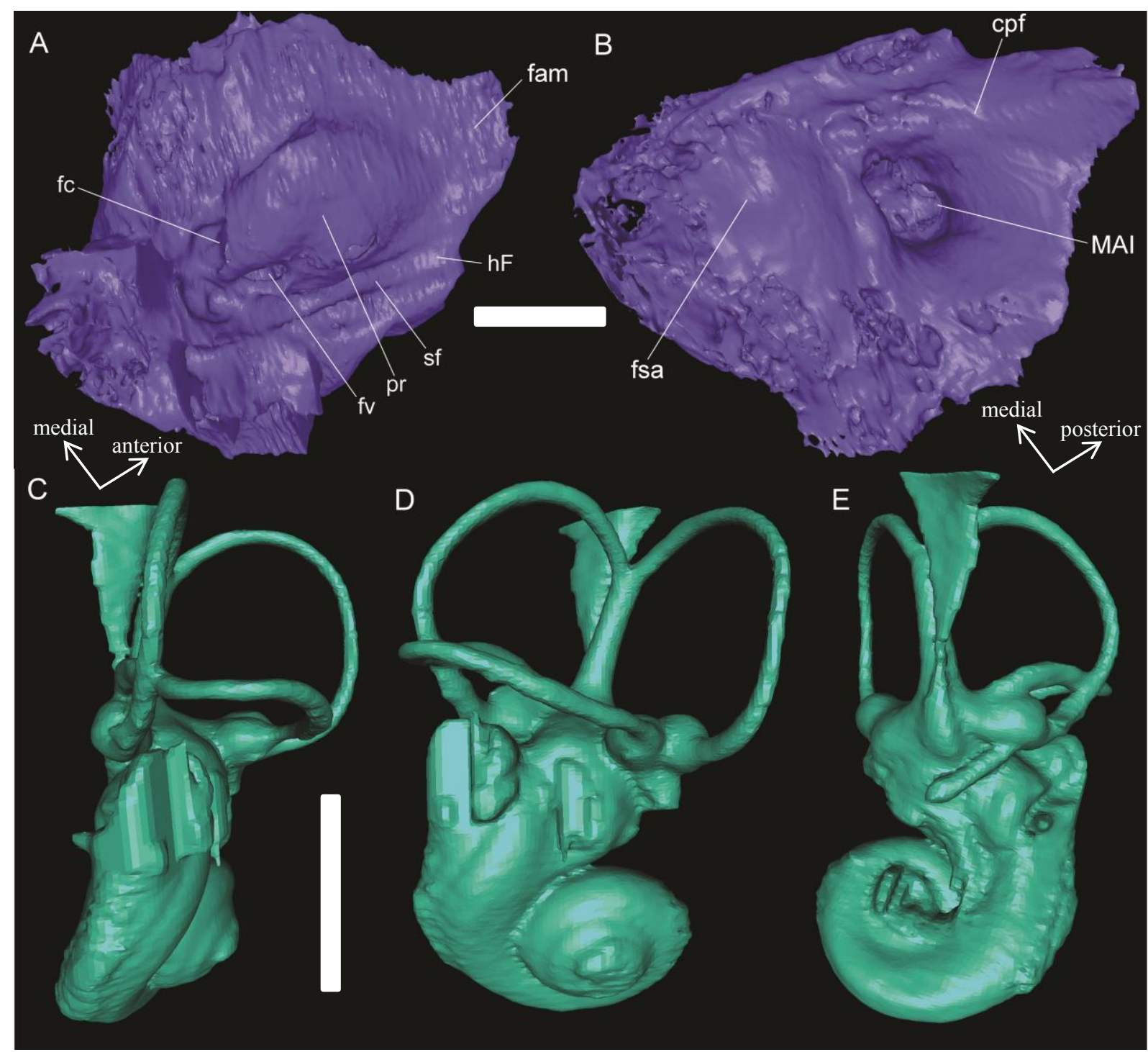

Fig IV. 40. Moldes del petroso y el oído interno de Proadinotherium muensteri FMNH-13590: Petroso en vista timpánica (A) y cerebelar (B), laberinto óseo del oído interno en vista anterior (C), lateral (D) y posterior (E). Escala $0,5 \mathrm{~cm}$.

\section{-Molde endocraneano}

El molde endocraneano de Proadinotherium muensteri fue brevemente descripto por Radinsky (1981) a partir del mismo ejemplar aquí digitalizado. Este molde endocraneano no ha sido reconstruido en su totalidad, pero puede apreciarse que las proporciones de los diferentes elementos son intermedias entre A. ovinum y $N$. imbricatus, aunque ligeramente más similares a las de A. ovinum. La cavidad encefálica en Proadinotherium muensteri es más baja, más larga y ligeramente más ancha que en A. ovinum.

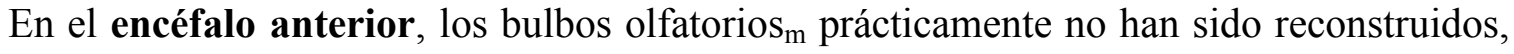
pero se puede constatar que están alineados con el eje principal ipsilateral de cada hemisferio 
cerebral $_{\mathrm{m}}$ y que la fisura circular es más notoria que en $N$. imbricatus y menos que en $A$. ovinum. Los tractos olfatorios ${ }_{\mathrm{m}}$ son menos conspicuos que en $A$. ovinum e incluso menos que en $N$. imbricatus; son ligeramente convexos en dirección dorsoventral en su porción media y no sobrepasan la corteza cerebral. Los hemisferios cerebrales $\mathrm{m}_{\mathrm{m}}$ se encuentran separados en la línea media por un surco medial (más notorio en la porción anterior del molde endocraneano), parcialmente oscurecido por la presencia de un seno sagital superior bien desarrollado a partir de la porción media del encéfalo anterior. Los hemisferios cerebrales $\mathrm{m}_{\mathrm{m}}$ presentan una forma ovoide, intermedia entre las dos especies de la FSC; su superficie cortical es girencefálica, en mayor grado que en $N$. imbricatus, pero los sulci y gyri no alcanzan la profundidad observada en $A$. ovinum. La fisura rinal es conspicua y corresponde al patrón observado en los nesodontinos, aunque es algo menos profunda que en $A$. ovinum. Los lóbulos piriformes se encuentran bien desarrollados y su proyección lateral es menor que en los toxodóntidos descriptos; a pesar de ello, son claramente diferenciables de la superficie cortical. La región hipofisaria es bastante amplia, tiene la misma ubicación y un desarrollo similar y, en su porción posterior, presenta una depresión conspicua, similar a la que se encuentra presente en la hipófisis $\mathrm{m}_{\mathrm{m}}$ de Nesodon taweretus. El piso de la hipófisis está ligeramente deformado, pero, en las zonas donde la cavidad se ha conservado, no hay indicios de la presencia de conductos para el pasaje de la rama cerebral de las carótidas internas.

En el encéfalo posterior una de las características más distintivas se encuentra en la zona de transición entre el encéfalo anterior y el posterior. A diferencia de los taxa descriptos anteriormente, la depresión que separa ambas partes es muy poco notoria y el perfil dorsal del molde endocraneano es prácticamente recto y continuo en esa zona. El encéfalo posterior de FMNH-13590 es corto anteroposteriormente y bastante más bajo que en A. ovinum. El cerebelo $_{\mathrm{m}}$ es angosto en comparación al encéfalo anterior, pero es bastante similar a $A$. ovinum en este aspecto. El vermis $\mathrm{m}_{\mathrm{m}}$ es poco distinguible, aún menos que en los nesodontinos descriptos, y los hemisferios cerebelares $\mathrm{m}_{\mathrm{m}}$ son completamente lisos. El paraflóculo $\mathrm{m}_{\mathrm{m}}$ está bien desarrollado y es largo anteroposteriormente, aunque no sobresale mucho de la superficie cerebelar. Otro de los rasgos distintivos de este molde endocraneano es la presencia de un pons $_{\mathrm{m}}$ bien desarrollado en el piso ventral. La medula oblonga $\mathrm{m}_{\mathrm{m}}$ presenta una sección ovoide y es transversalmente más ancha que en $A$. ovinum.

Los nervios craneanos y el sistema vascular en FMNH-13590 no se pudieron completar, por lo que no se brindan caracterizaciones detalladas de estas estructuras. A grandes rasgos, se corresponden con el patrón observado en Nesodontinae. 


\section{—Molde oído interno}

Como puede verse en la Figura IV. 40C-E, el laberinto oseo del oído interno de Proadinotherium muensteri no difiere en gran medida del de Adinotherium ovinum. Cabe destacar que, al igual que en Adinotherium, FMNH-13590 presenta una crus commune que no alcanza la altura de los canales semicirculares y un acueducto vestibular bien desarrollado; el conducto coclear tiene la misma cantidad de vueltas $(2,6)$, aunque se encuentra más inclinado que en AMNH 9276; la vuelta basal del conducto presenta los surcos correspondientes a las láminas espirales principal y secundaria, aunque éstas son menos notorias que en A. ovinum.

\section{-Dentición}

La dentición superior de $P$. muensteri es similar, en líneas generales, a la de Adinotherium ovinum, tanto en sus proporciones como en la morfología general. El rasgo más distintivo, sin dudas, es el menor grado de hipsodoncia de los dientes yugales. Incluso en ejemplares que no parecen tener una edad avanzada (e.g. FMNH-13590), la morfología oclusal se oblitera rápidamente por el desgaste (ver el M1 en Fig. IV. 39C). Al contrario que en Adinotherium y Nesodon, la foseta central en forma de "Y" persiste en el P4 y está esbozada en el P3, mientras que en el M1 ha desaparecido ya casi por completo. Además, la presencia de numerosas fosetas accesorias en el M3 sugeriría que se trata de un adulto joven.

\section{3.3 Notohippus toxodontoides Ameghino 1891 (Familia "Notohippidae")}

\section{- Generalidades}

Esta descripción está basada en el material tipo de la especie, representado por un $\mathrm{m} 2$ (MACN A 1813) y un m3 (MACN A 1814) con algunos restos de hueso mandibular, así como en los ejemplares asignados a esta especie recientemente (Hernández Del Pino et al. en revisión): MPM PV-18806, fragmentos de cráneo y mandíbula asociados de un ejemplar subadulto, donde los M/m3 aún no han erupcionado totalmente, y MPM PV-18807, un fragmento de paladar de un individuo adulto con parte de la dentición. Se incluye la descripción de este taxón en este apartado, porque se trata de un Toxodontia estrechamente relacionado filogenéticamente a Toxodontidae (Ver Capitulo VI) y es coetáneo de los géneros de toxodóntidos de Santa Cruz.

En vista dorsal, el cráneo de Notohippus toxodontoides (Fig. IV. 41A) tiene una apariencia más cuadrangular que en las especies de toxodóntidos de la FSC, debido a la 
expansión lateral de los arcos cigomáticos a nivel de la zona del contacto entre frontales y parietales. En este caso, si bien el ancho máximo del cráneo también se alcanza en la región posterior, el ancho a nivel del nacimiento de las crestas temporales y a nivel del proceso glenoideo es similar. Además, presenta un rostro mucho más corto y ancho que en los nesodontinos. En vista lateral, el perfil dorsal del cráneo es convexo en la parte anterior de los frontales, se vuelve cóncavo a nivel de la órbita y se eleva hacia atrás donde las crestas temporales se unen en la cresta sagital en una posición relativamente anterior (a nivel del M3). El perfil dorsal es similar al de Proadinotherium muensteri y algunos ejemplares juveniles de Nesodon imbricatus (como MLP 12-4), aunque en estos últimos la variación de altura entre las diferentes partes del techo craneano es más pronunciada.

\section{—Región naso-facial y techo craneano}

En vista dorsal, los nasales de $N$. toxodontoides son largos y angostos comparados con otros notohípidos, algo más anchos en su porción anterior que en la posterior, y llegan al nivel de la parte anterior del P4. En comparación con los nesodontinos, los nasales son relativamente más cortos y algo más anchos. La sutura fronto-nasal es moderadamente sinuosa y no presenta forma de "W" ni proyecciones hacia los frontales como en algunos ejemplares de Adinotherium y Nesodon. En vista lateral, los premaxilares ocupan alrededor del primer tercio de la región nasal y forman una pequeña cresta en su margen más anterior, a nivel de la sutura interpremaxilar justo sobre el borde anteroventral de la plataforma narial. Los premaxilares presentan un desarrollo similar al observado en los nesodontinos, pero carecen del proceso maxilar presente en este grupo. La abertura nasal, en vista lateral, tiene un perfil ligeramente cóncavo, más suave que en el género deseadense Rhynchippus (que además presenta premaxilares más largos), y el contorno anterior es algo más redondeado que en los nesodontinos. El maxilar conforma la mayor parte del hocico, el borde anterior y parte del piso de la órbita; el proceso facial es más o menos cuadrangular y en él la única estructura visible es el foramen infraorbitario, del cual solo se ha preservado la porción ventral que se encuentra por encima del límite entre el M1 y el P4. En vista lateral, se puede ver que el maxilar de $N$. toxodontoides es un hueso relativamente corto (al igual que el rostro del animal), condición que comparte con otros "Notohippidae", pero que lo diferencia fácilmente de los Nesodontinae, que presentan un maxilar bastante largo. La sutura premaxilar-maxilar, en vista lateral, es irregular, y las suturas del maxilar con los elementos que componen el borde anterior de la órbita no son visibles. 
En vista dorsal, resulta notoria la formación de dos abultamientos en la porción anterior de los frontales, a los que le siguen, posteriormente, unas depresiones en el hueso; este rasgo se encuentra en Rhynchippus, menos desarrollado, pero está ausente en otros notohípidos (e.g. Eurygenium y Mendozahippus). Aun cuando los procesos postorbitales se encuentran incompletos, se nota que no se proyectan lateralmente tanto como en los ejemplares adultos de Adinotherium y Nesodon, y que tienen una forma curvada más similar a lo observado en los ejemplares juveniles de ambos géneros. Las aberturas del canal supraorbital en los frontales no se distinguen en el cráneo de $N$. toxodontoides.

Las crestas temporales convergen rápidamente en la cresta sagital, aunque no se fusionan completamente, sino que dejan dos bordes finos adosados (al menos en la porción preservada en MPM PV-18806). Los parietales son los huesos más largos del techo craneal de $N$. toxodontoides; aunque se encuentra dañado, su extensión puede estimarse a partir del inicio de la cresta sagital hasta la cresta nucal.

\section{-Paladar}

El paladar se encuentra comprimido lateralmente, mejor preservado en su lado derecho; puede apreciarse que es relativamente más ancho y claramente más corto que en Adinotherium y Nesodon. La serie dentaria superior de MPM PV-18806 muestra un diastema conspicuo entre el I3 y la dentición yugal, de la cual se ven los alveolos correspondientes a los primeros dos premolares, pero no hay evidencias de un alveolo para el canino (tal como señalaron preliminarmente Ribeiro y Bond [1999]). Como se describió anteriormente, el desarrollo de las piezas dentarias por detrás del I2 es bastante variable en los nesodontinos y, en algunos casos, se encuentran diastemas breves entre los incisivos (I2 e I3), entre los incisivos y caninos, y entre los caninos y premolares, aunque nunca alcanzan el desarrollo que presenta $N$. toxodontoides. La existencia de diastema en los "Notohippidae" solo se ha registrado en los géneros neógenos, Argyrohippus y Notohippus. El paladar presenta una constricción anterior, similar a la condición presente en Eurygenium y los nesodontinos. Las contribuciones de los premaxilares y maxilares a la conformación del paladar responden al mismo patrón observado para los taxones anteriores, siendo los maxilares los que tienen mayor contribución al paladar duro. La arcada dentaria es más ancha que en los nesodontinos y Rhynchippus, y es casi transversal, en una condición más similar a la presente en Eurygenium. El área donde se encontrarían los forámenes incisivos está rota, pero en la región más anterior del paladar se observa una depresión larga y angosta, más o menos elíptica, que podría corresponder a dichos forámenes. Aparentemente, cada foramen comenzaría en el 
margen anterior del I3 y alcanzaría su extremo más posterior. En la porción más posterior del paladar, están preservados algunos restos del proceso palatino izquierdo y del hamulus. No se reconocen otras estructuras en el paladar del ejemplar MPM-PV 18806 debido al daño que presenta toda esta zona, a excepción de unos pequeños forámenes nutricios en las porciones preservadas del premaxilar y el maxilar. La sutura premaxilar-maxilar en vista ventral esta levemente marcada y el resto de las suturas entre los distintos huesos del paladar duro no se observan.

\section{—Región orbitotemporal}

Esta región del cráneo está alterada e incompleta en el lado derecho y falta casi totalmente en el izquierdo (Fig. IV. 41A y C). No han quedado remanentes del hueso lacrimal y la sutura maxilo-lacrimal no es observable. Los bordes anterior y posterior de la órbita se encuentran muy destruidos; el piso de la misma está conformado mayormente por el maxilar que forma una plataforma relativamente ancha, desplazando al yugal al extremo más lateral del piso orbital. El arco cigomático comienza a nivel del primer molar, es amplio y alcanza su mayor ancho hacia la porción más posterior del cráneo, a la altura del proceso glenoideo; al contrario de lo que sucede en los nesodontinos, no aumenta sustancialmente su separación lateral hacia atrás, por lo que apenas varía el ancho cigomático total del cráneo. Además, el arco cigomático de Notohippus es algo más largo, de recorrido más recto y con menor diferencia de altura entre la porción anterior y la posterior que en los nesodontinos. El borde ventral del arco es algo más ancho que en Rhynchippus, Adinotherium y Nesodon. Tanto el yugal como el escamoso contribuyen en proporciones muy similares a la conformación del arco cigomático; el primero es un hueso alto y relativamente corto que se extiende desde el borde lateral del piso de la órbita hasta prácticamente alcanzar el proceso articular del escamoso; la porción preglenoidea del escamoso es más larga y más baja que el yugal y su borde anterior alcanza el borde posterior del piso de la órbita. El contacto entre los tres componentes del arco cigomático se da a nivel del M2.

La porción posterior del escamoso forma parte de la pared lateral y el techo del cráneo, pero el estado de preservación de la zona no permite dar mayores precisiones morfológicas. 

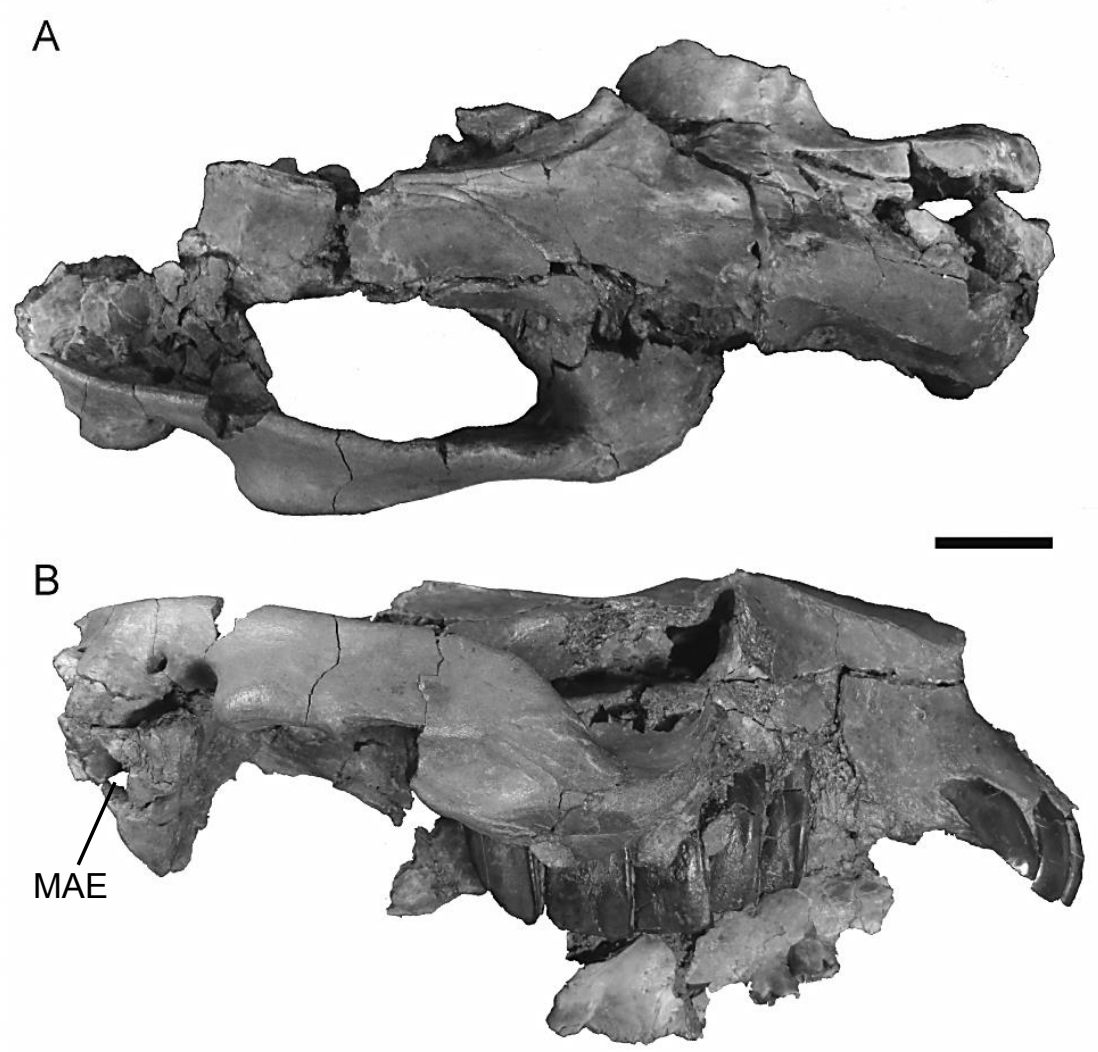

C
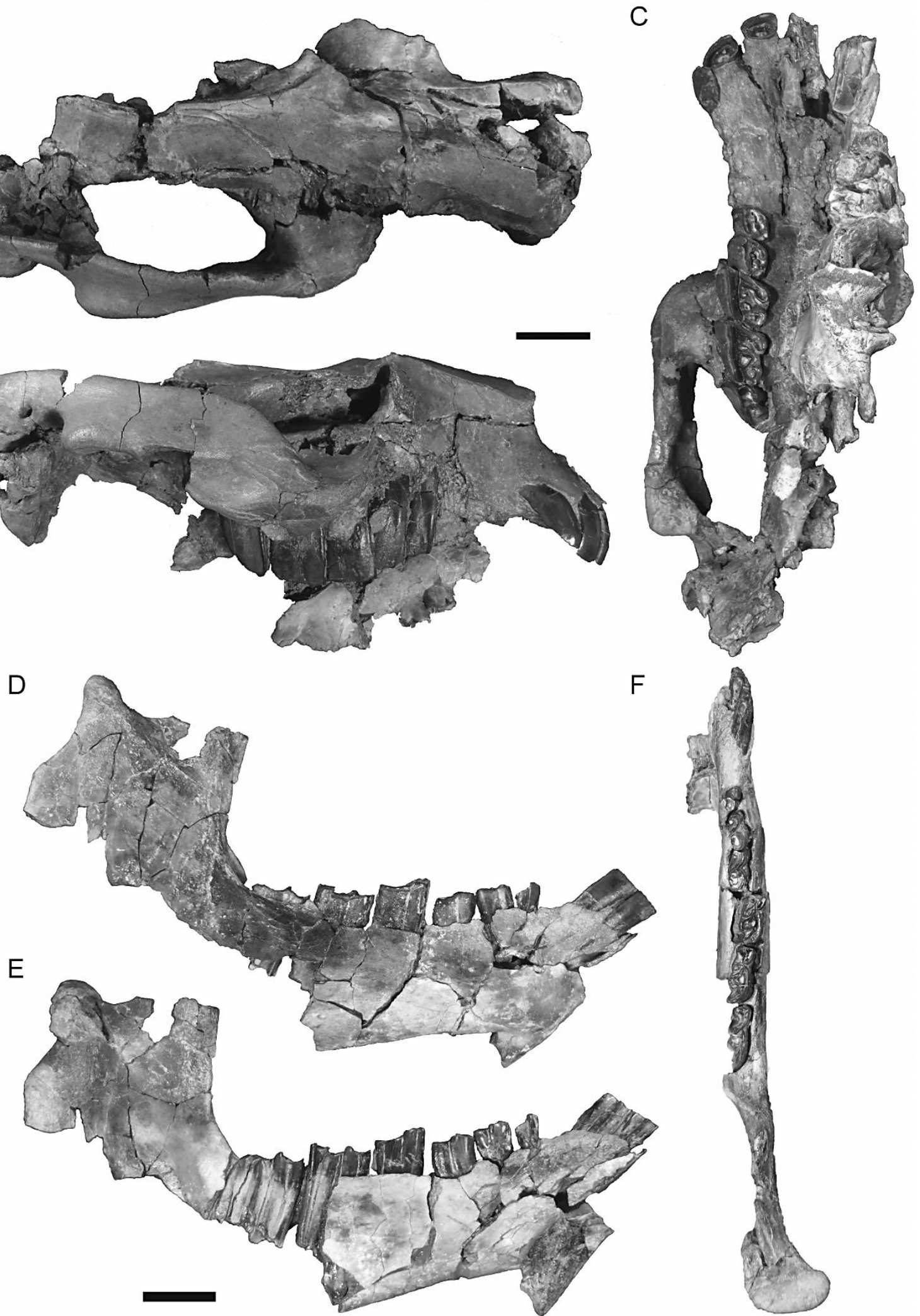

Fig. IV. 41. MPM-PV 18806 Notohippus toxodontoides: cráneo en vistas dorsal (A), lateral derecha (B) y ventral (C); mandíbula en vistas labial (D), lingual (E) y oclusal (F). Escala $5 \mathrm{~cm}$. 


\section{-Basicráneo y región auditiva}

El basicráneo de MPM PV-18806 apenas se ha preservado (Fig. IV. 41C), presentando remanentes de la región mastoidea del escamoso y el proceso postglenoideo completo. En vista ventral, la fosa glenoidea es una concavidad ancha y triangular, mal delimitada. Dicha fosa se proyecta lateralmente, al contrario de lo que sucede en Rhynchippus, Eurygenium y Mendozahippus, pero similar a lo observado en los nesodontinos, en los que además la fosa es algo más ancha. En vista ventral, el foramen postglenoideo se encuentra ubicado en el margen lateral del proceso postglenoideo, justo por detrás de la fosa glenoidea.

El MAE se encuentra localizado en el margen lateroposterior del cráneo y puede observarse tanto en vista ventral como lateral, aun cuando el área circundante se encuentra severamente dañada. El MAE es una abertura grande y conspicua, alojada en una depresión formada por el solapamiento de los procesos postimpánico y postglenoideo del escamoso (ambos severamente dañados, aunque conservan parte de su porción ventral en buen estado), y se encuentra ubicado en el margen lateroposterior del cráneo. En vista lateral, además del MAE, se observa un foramen grande, redondeado y muy bien delimitado por detrás de la fosa glenoidea; este foramen postcigomático probablemente corresponda a un sistema venoso y no hay registro de su presencia en los nesodontinos.

\section{-Región occipital}

No se ha conservado la región occipital del cráneo asignado a Notohippus toxodontoides.

\section{-Molde endocraneano}

Debido a la preservación y lo fragmentario del material disponible, no es posible la realización de un molde endocraneano.

\section{—Molde oído interno}

Aun no se cuenta con material de petroso para la realización de un molde del oído interno.

\section{-Mandíbula}

El holotipo de Notohippus toxodontoides (MACN 1813 y 1814) solo preserva un pequeño fragmento de mandíbula; por el contrario, el ejemplar MPM PV-18806 (Fig. IV. 41 D-F, y Hernández Del Pino et al. en rev.) mantiene la sínfisis y las ramas horizontal y ascendente incompletas. MPM PV-18806 muestra que no hay p1 (como señalaron preliminarmente 
Ribeiro y Bond [1999]) y esto se refleja en un corto diastema. El borde posterior de la sínfisis alcanza el nivel del trigónido del p3. La rama horizontal es bastante recta, similar a la condición de los nesodontinos, aunque algunos especímenes de Adinotherium presentan un perfil ventral más o menos convexo. El cóndilo mandibular es tres veces más ancho que largo y la incisura mandibular es poco profunda, al igual que en los nesodontinos. Debido al daño en el material, no se pueden apreciar otros rasgos morfológicos.

\section{-Dentición}

En la dentición superior de Notohippus toxodontoides (Fig. IV. 42A y B), los incisivos son convexos labialmente y con un contorno lingual biselado debido al desgaste, con un valle en forma de $\mathrm{V}$; forman una serie continua, con los dos primeros incisivos ubicados transversalmente al plano sagital y el I3 en una posición casi perpendicular al I2. El I2 es un poco más largo que los otros dos incisivos. El I3 es más angosto y elíptico. Existe un pequeño diastema entre el I3 y el alveolo del P1. Los premolares incrementan su tamaño desde el primero al último. El P1 es redondeado, con pequeños remanentes del paracono y el parastilo. El P2 está poco gastado y es más o menos cuadrado, con el parastilo poco desarrollado y separado del paracono por un surco pequeño y poco profundo; el protolofo es largo, delgado y curvado distolingualmente; el metalofo está dirigido mesiolingualmente y el hipocono está bien desarrollado. Un gancho se extiende desde el metalofo hacia el ectolofo y un pequeño postcíngulo se origina desde la base distolingual del metalofo. Los P3 y P4 están poco gastados, pero más que el P2; ambos son más o menos cuadrados, con el surco entre parastilo y paracono poco profundo; el pliegue del paracono se proyecta labialmente, estando más destacado en el P3 debido a la posición más mesiolingual del parastilo. En ambos dientes, el protolofo es largo y está curvado distolingualmente; el protocono está bien desarrollado y presenta un surco vertical suave en su cara distal; el metalofo está dirigido mesiolingualmente; en el P3, el protocono y el hipocono están fusionados casi completamente y solo se diferencian por un surco lingual superficial; tiene gancho y postcíngulo bien desarrollados y la crista media se proyecta distolingualmente desde el ectolofo. En el P4, la separación entre hipocono y protocono está más acentuada que en el P3, al igual que la separación entre la crista principal y el gancho; en ambos premolares, estos pliegues se unirían con algo más de desgaste, formando una foseta; en el P4 hay una crista más anterior y menos desarrollada que se uniría al protolofo formando una prefoseta. Los molares son más grandes y relativamente más largos que los premolares, de contorno más trapezoidal. El surco entre el parastilo y el pliegue del paracono es poco profundo; el parastilo está proyectado 
mesialmente. El protolofo es largo, ancho y está curvado distolingualmente; el protocono está bien desarrollado y presenta un surco vertical suave en su cara distal; el metalofo es más angosto que el protolofo y está curvado mesiolingualmente, formando un ángulo marcado con el hipocono. Hay dos cristas dirigidas distolingualmente que se unen en su extremo, generando una foseta mesial, y también se unen al gancho formando una foseta labiodistal más grande. Hay una tercera foseta, de tamaño similar a la mesial, en una posición linguodistal. El M1 es más corto que el M2, pero ambos tienen un ancho similar. El M3 aún no ha terminado de erupcionar y está casi sin desgastar; en la parte que puede verse, el ectolofo incrementa su longitud a medida que aumenta el alto de la corona; el protolofo es largo y esta curvado distolingualmente; hay dos cristas y un gancho largo fusionados, sin desgaste.

Un rasgo distintivo de la dentición de Notohippus toxodontoides, que lo separa tanto de notohípidos paleógenos como de los nesodontinos, es la presencia de una gruesa capa de cemento alrededor de los dientes; labialmente, dicha capa deja al descubierto el borde oclusal de esmalte.

A
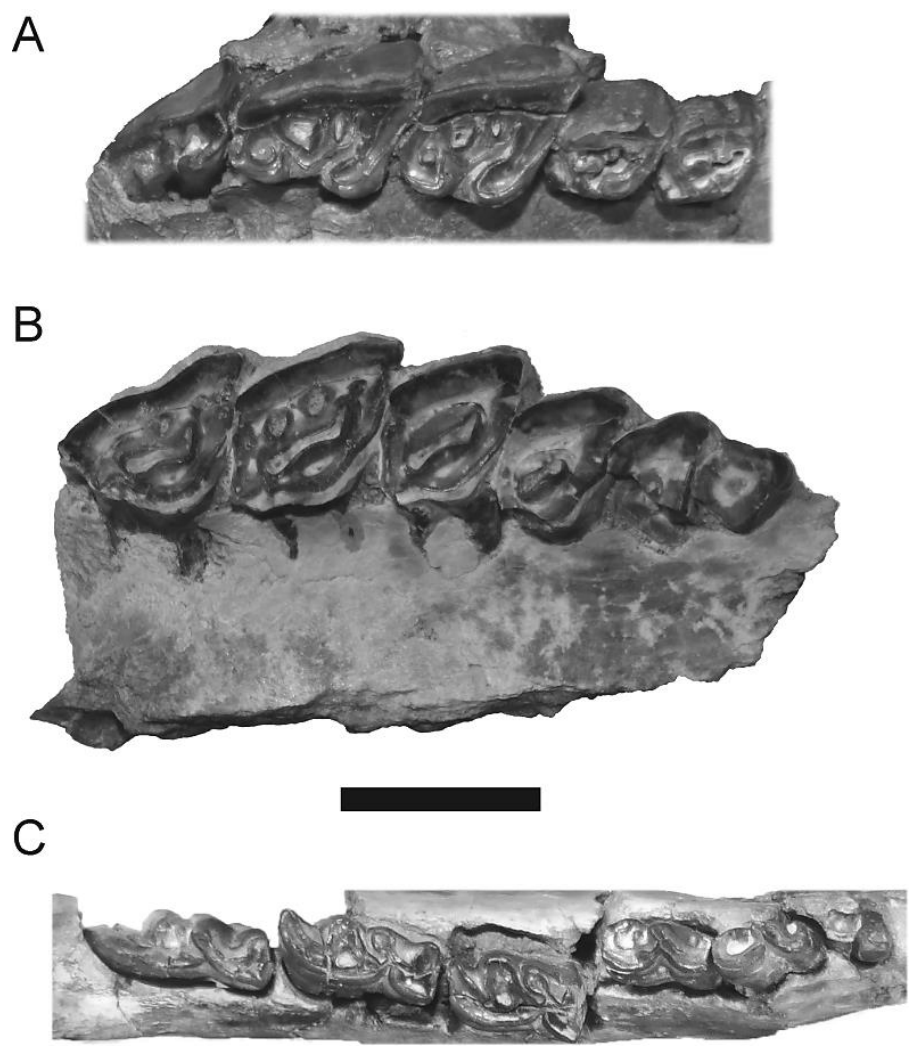

Fig. IV. 42: Dentición de Notohippus toxodontoides. Detalle la serie P3-M3 del MPM-PV 18806 (A), fragmento de maxilar MPM-PV 18807 con la serie P2-M3 (B), detalle de la mandíbula del ejemplar MPM-PV 18806 con la serie p2-m3 (C). Escala $2 \mathrm{~cm}$. 
En el paladar MPM PV-18807 (Fig. IV. 42B), un individuo de edad más avanzada que el MPM PV-18806, se observa la superficie oclusal más simplificada debido al desgaste; la ondulación del ectolofo es aún más suave, con el surco parastilo-paracono más superficial; el protolofo y el metalofo se encuentran fusionados lingualmente; la foseta central del P2 ha desaparecido completamente, es muy pequeña en el P3 y está bien desarrollada en el P4, corta, angosta y orientada mesiolabial-distolingualmente. En los molares, las fosetas son más anchas y largas; M2 y M3 presentan fosetas adicionales que ya habrían desaparecido en el M1 por el mayor desgaste; en el M2 hay dos fosetas de gran tamaño, labiales a la foseta central, y otra más distal y más pequeña; el M3 solo presenta una foseta adicional en posición media, labialmente a la foseta central. El M3 es subtriangular, con metalofo corto; su cara lingual es fuertemente convexa mesiodistalmente; el surco distolingual es más profundo que en M1-2 y situado más distalmente; la cara distal del metalofo es corta y presenta una concavidad leve; el ectolofo es más ondulado que en el M1 y M2, con una concavidad marcada por detrás del paracono.

En la dentición inferior de MPM PV-18806 (Fig. IV. 41D-F, Fig. IV. 42C), los incisivos y el canino son subiguales, procumbentes, ligeramente convexos labialmente y angostos labiolingualmente. Presentan una cresta vertical lingual que desaparece hacia la base y una capa de cemento labial y lingual. El primer premolar está ausente y existe un corto diastema entre el c y el p2. Los dientes yugales incrementan su tamaño gradualmente desde el p2 al m3. Al igual que en los nesodontinos, el trigónido de los premolares es algo más pequeño que el talónido, mientras que en los molares la diferencia es mucho más acusada, sobre todo en el m3. Todos los yugales presentan una capa gruesa de cemento alrededor de la corona y en los valles y fosétidas, manteniéndose el borde oclusal del esmalte sin cemento.

El p2 es corto y angosto, con la pared labial del trigónido y el talónido ligeramente convexa en sentido mesiodistal; el paracónido y el metacónido se encuentran separados por un surco corto y profundo que forma un pliegue pronunciado; la crístida oblicua está casi fusionada al metacónido. El p3 y el p4 tienen mayor desgaste; en el p4, la crístida oblicua ya está fusionada al metalófido. El paralófido es corto y esta curvado lingualmente; el metalófido está alargado distalmente y el metacónido está bien desarrollado; el paracónido y el metacónido limitan un valle anterior profundo; el hipolófido tiene forma de espuela (más en p3); el profundo surco meta-entocónido desparece hacia el borde oclusal en el p3 y hacia la base en el p4. En el p4, existe una crístida que se extiende desde la cara lingual del talónido hasta el entocónido; se observa un conúlido en el extremo lingual de esta crístida, que 
permanece separada del entocónido a nivel oclusal, pero se fusiona con él unos pocos milímetros más abajo, encerrando una fosétida.

En los molares, el trigónido tiene su cara labial ligeramente convexa e inclinada distolingualmente; el hipofléxido está bien desarrollado, pero no es muy profundo; la cara labial del talónido es convexa mesiodistalmente, con un ángulo distal marcado en el m1, algo más suave en el m2 y apenas marcado en el $\mathrm{m} 3$, en el que el talónido es más largo. Lingualmente, el metacónido se encuentra bien desarrollado y se dirige distolingualmente. En el talónido, los surcos meta-entocónido y ento-hipocónido son profundos y curvados mesialmente, delimitando un lóbulo amplio en el que se encuentra una fosétida.

\section{3.4 Homalodotherium Flower 1873 (Familia Homalodotheriidae)}

\section{-Generalidades}

En el caso del género Homalodotherium, se presenta una descripción somera de algunas de las características craneanas que lo diferencian de los toxodóntidos estudiados, añadiendo la descripción del molde endocraneano realizado para este trabajo de Tesis. El detalle morfológico de los elementos que componen el cráneo de Homalodotherium se puede consultar en los trabajos de Scott (1912), para la morfología general, y Patterson (1932, 1934, 1936) y Gabbert (2004), para el basicráneo en particular.

En vista dorsal, el contorno del cráneo de Homalodotherium tiene una apariencia ovalada, con su extremo anterior algo más estrecho que el posterior, marcadamente diferente del contorno triangular de Nesodon imbricatus. El ancho máximo del cráneo se alcanza a nivel de la zona media de los arcos cigomáticos, justo por detrás de los procesos postorbitales del frontal. Los rasgos más distintivos en el techo craneano consisten en: nasales muy cortos, planos y retraídos; frontales muy anchos, más que en los toxodóntidos de la FSC, y sin la presencia de líneas temporales bien desarrolladas; parietales relativamente más cortos que en A. ovinum y $N$. imbricatus; y cresta sagital conspicua. La caja craneana es relativamente más grande que en el género Nesodon, pero significativamente más pequeña y alargada que en Adinotherium.

En vista lateral, el perfil dorsal del cráneo de Homalodotherium es aproximadamente recto; el hocico es notoriamente más corto que en los nesodontinos, mientras que la porción posterior del cráneo es relativamente más grande; y es un cráneo notablemente más bajo que en aquellos. El acortamiento del rostro genera una diferencia importante en las proporciones 
de los premaxilares y maxilares con respecto a los toxodóntidos estudiados, siendo mucho más pequeños en Homalodotherium. La órbita es más alargada y más baja; el arco cigomático presenta una leve variación en su altura, aunque no se eleva tanto como en los nesodontinos para contactar con la cresta nucal.

En vista ventral, los rasgos más destacables se encuentran a nivel de la abertura de la coana, rodeada por las plataformas formadas por la porción posterior de los palatinos y de los pterigoides, y por el aliesfenoides, que presentan un arreglo similar, pero son relativamente más cortas y mucho más divergentes lateralmente que en los Nesodontinae, además de encontrarse divididas por una placa conspicua. El basioccipital es notablemente más largo y ancho que en Adinotherium y Nesodon. La bula timpánica es más grande, especialmente en dirección anteroposterior, y no presenta la condición hueca descripta anteriormente, sino que se encuentra tabicada en casi toda su extensión. A diferencia de los nesodontinos, el basicráneo se angosta notablemente a nivel de los procesos paracondilares del exoccipital, y la región occipital también presenta una condición relativamente más angosta. Los procesos paracondilares son relativamente más grandes, más anchos en su base y con mayor altura que en los Nesodontinae, y su extremo ventral es ligeramente más grácil.

En vista posterior, la región occipital es bastante diferente de lo observado en los Nesodontinae por ser relativamente más alta y notablemente más angosta. El aporte del proceso postimpánico del escamoso es mucho más limitado y el supraoccipital es el elemento más conspicuo en vista posterior, extendiéndose incluso dorsalmente.

\section{-Molde endocraneano}

La descripción presentada en este trabajo se basa en el único molde endocraneano generado a partir del material disponible de Homalodotherium, correspondiente al ejemplar MPM-PV CV-SHP-15-13 (Fig. IV. 43). En líneas generales, este molde es más largo, más estrecho y más bajo que los descritos anteriormente y, además, es bastante rectilíneo (la flexura del molde endocraneano es de de $28^{\circ}$ ). La relación entre el ancho y el largo del molde (excluyendo la médula) es 0,5 y la relación alto/ancho es 0,84 . 


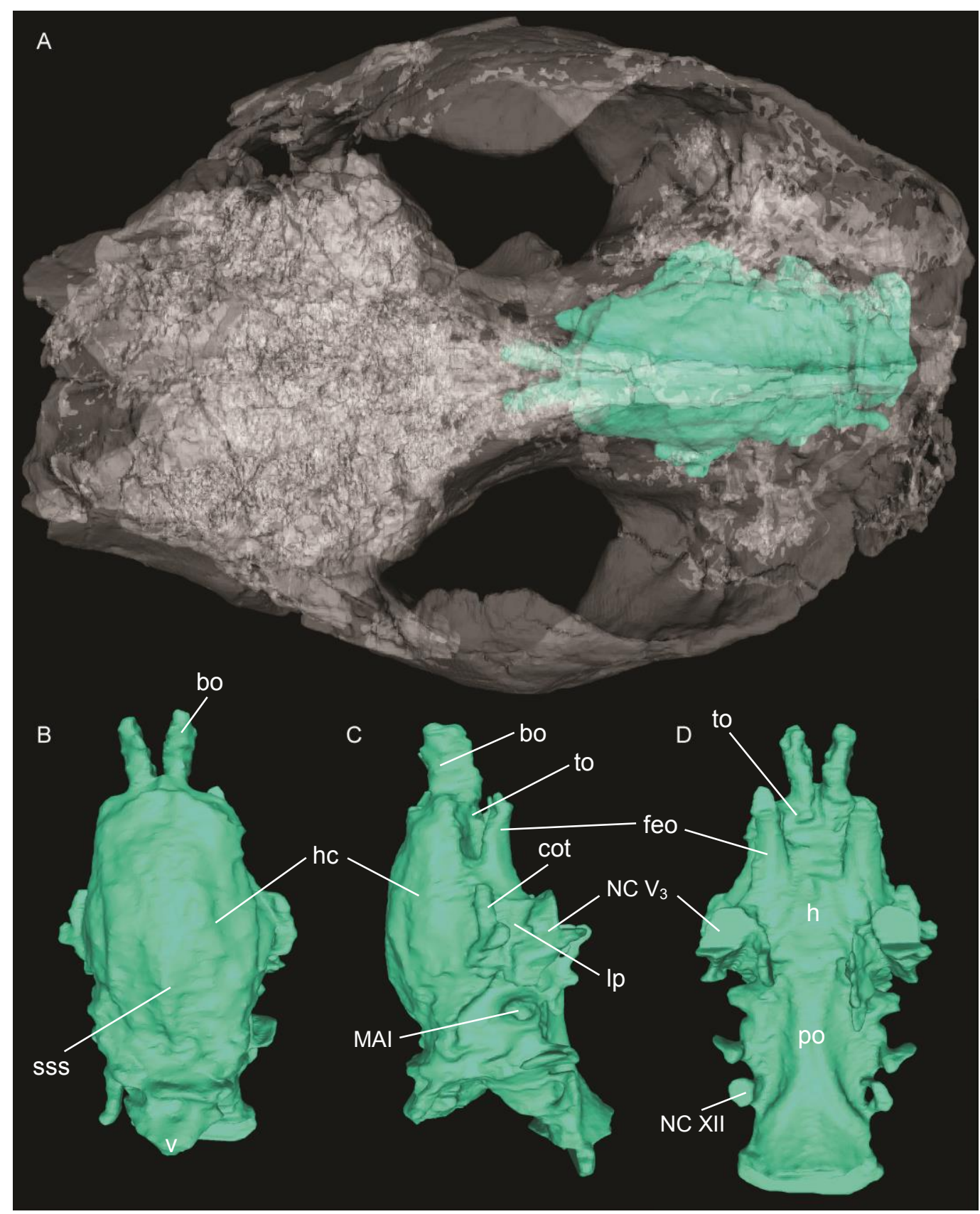

Fig. IV. 43. Molde endocraneano de MPM-PV CV-SHP-15-13 de Homalodotherium: cráneo con el molde endocraneano en posición (A), molde endocraneano en vistas dorsal (B), lateral derecha (C) y ventral (D).

En el encéfalo anterior de Homalodotherium, los bulbos olfatorios ${ }_{m}$ son más pequeños, angostos (ancho/largo, 0,48) y altos (alto/ancho, 2,5) que en Adinotherium ovinum, más similares a los de Nesodon imbricatus, de los que se diferencian por ser más largos y altos. Contribuyen aproximadamente al 1,5\% del volumen total del molde endocraneano y están separados entre sí en el plano sagital. La fisura circular es indistinguible. No se registró evidencia de bulbos olfatorios accesorios $\mathrm{m}_{\mathrm{m}}$ Los tractos olfatorios $\mathrm{m}_{\mathrm{m}}$ son conspicuos, siendo 
bastante más cortos que en los nesodontinos, y no sobrepasan la corteza cerebral $\mathrm{m}_{\mathrm{m}}$, que representa aproximadamente el 9\% del volumen total del molde endocraneano. Los hemisferios cerebrales $\mathrm{m}_{\mathrm{m}}$ no se encuentran separados sagitalmente por un surco medial como en los nesodontinos, sino que presentan una cresta conspicua en su margen posterior (que posiblemente corresponda al molde del techo del canal por donde pasa el seno sagital superior). Los hemisferios cerebrales $\mathrm{m}_{\mathrm{m}}$ son bastante simétricos, ovoides, con una relación ancho/largo de 0,44 y una relación alto/largo de 0,31. La superficie cortical parece ser lisencefálica. La fisura rinal está bien demarcada en este molde endocraneano, pero es menos conspicua que en los taxones descriptos anteriormente. Los lóbulos piriformes son apenas visibles, no se proyectan hacia los laterales (no superan en ningún momento el ancho de los hemisferios cerebrales) y son mucho menos conspicuos que en los nesodontinos. La región hipofisaria $_{\mathrm{m}}$ es minúscula en comparación con los taxones anteriores; está representada por un pequeño abultamiento (ancho/largo $=0,77$; alto/largo $=0,3$ ) que representa solo un poco más del 1\% del volumen total del molde endocraneano; está ubicado en la región medial del piso ventral del molde, justo por detrás de la salida de la fisura esfeno-orbitaria. La hipófisis $\mathrm{m}_{\mathrm{m}}$ no posee una quilla media en el ejemplar analizado. No hay indicios del pasaje de la rama cerebral de las carótidas internas en el piso de la hipófisis.

La separación entre el encéfalo posterior y el encéfalo anterior en MPM-PV CV-SHP15-13 es mucho menos conspicua que en los nesodontinos, debido a que la depresión observada en éstos está poco desarrollada en Homalodotherium. El cerebelo $\mathrm{o}_{\mathrm{m}}$ contribuye con alrededor del 18\% del volumen del molde endocraneano; es bastante angosto, pero es la parte más alta del molde endocraneano. En el cerebelo $\mathrm{m}_{\mathrm{m}}$ resulta fácil identificar el vermis cerebell $i_{\mathrm{m}}$, que se extiende mucho posteriormente; sin embargo, los hemisferios cerebelares $_{\mathrm{m}}$ no se encuentran muy desarrollados ni se expanden lateralmente (incluso puede notarse la presencia de parte del seno transverso que no pudo ser completamente diferenciado del cerebelo en la reconstrucción). El vermis cerebelli $i_{\mathrm{m}}$ se aprecia como un abultamiento más o menos ovoide (con su eje mayor en dirección dorsoventral), presente en la porción mediodorsal del cerebelo $_{\mathrm{m}}$. La superficie de los hemisferios cerebelares $\mathrm{m}_{\mathrm{m}}$ es completamente lisa. El paraflóculo $_{\mathrm{m}}$ tiene la misma localización que en $N$. imbricatus y es prácticamente indistinguible, pero ligeramente más desarrollado que en los nesodontinos. En el piso ventral del encéfalo posterior ${ }_{\mathrm{m}}$, la pons $_{\mathrm{m}}$ se distingue mejor que en los nesodontinos, como un abultamiento (ligeramente mayor al de la hipófisis $\mathrm{m}_{\mathrm{m}}$ ) en la porción medial del piso ventral del molde endocraneano, mientras que la médula oblonga $a_{m}$ tiene una sección ovoide, similar a la 
de N. imbricatus, y está recorrida por dos crestas romas que divergen del plano sagital, posterolateralmente, justo por detrás de la salida del nervio XII.

Con respecto a los nervios, el ejemplar de Homalodotherium sigue un patrón similar al descripto para Nesodon imbricatus. El quiasma óptico ${ }_{m}$ (NC II) no pudo reconstruirse debido a la preservación del material, pero se ubicaría en una posición similar. La salida de la fisura esfeno-orbitaria, indicada por dos proyecciones que parten de la hipófisis ${ }_{\mathrm{m}}$, es bastante notoria; tiene un diámetro menor, pero el ángulo de divergencia entre ambas es mayor que en los nesodontinos de Santa Cruz. Debido a la ausencia de un foramen rotundum en el cráneo, Homalodotherium presenta la misma condición descripta para los nesodontinos, es decir la fisura esfeno-orbitaria transporta NC III, NC IV, $\mathrm{NC} \mathrm{V}_{1}, \mathrm{NC} \mathrm{V}_{2}$ y NC VI. El molde de la rama mandibular del trigémino abandona el cráneo por el foramen oval, cuyo molde posee un diámetro anteroposterior mayor que en los Nesodontinae; este nervio abandona la cavidad

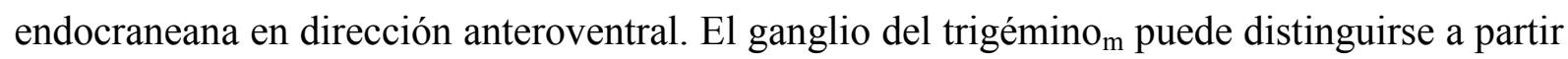
de un abultamiento en la cara lateral del molde, justo por debajo de la porción reconstruida del canal orbitotemporal del MPM-PV CV-SHP-15-13. En la porción posterior del molde endocraneano, en vista lateral, se sitúa el $\mathrm{MAI}_{\mathrm{m}}$, más voluminoso y situado algo más ventral que en los nesodontinos. Los moldes de los NC VII y NC VIII fueron reconstruidos en conjunto en este ejemplar y su separación no es visible. Los tractos correspondientes a los NC IX, NC X y NC XI están bien representados en este espécimen y mantienen una posición y un desarrollo similares a la condición en los nesodontinos. En la porción más posterior del molde endocraneano, se registra el molde del canal que transporta el NC XII.

Con respecto al sistema vascular del endocráneo, en el molde endocraneano de MPMPV CV-SHP-15-13, el seno sagital superior parece estar bien desarrollado, como lo sugiere la presencia de una quilla notoria en la porción más posterior de los hemisferios cerebrales $\mathrm{m}_{\mathrm{m}} \mathrm{Su}$ recorrido sigue el plano sagital sin inclinarse hacia la derecha como en el MPM-PV 3532 de Adinotherium (Fig. IV. 20B). Al igual que en las especies anteriores, el seno transverso se reconstruyó totalmente, pero en MPM-PV CV-SHP-15-13 está sugerido por una prolongación bien diferenciada y lateral al cerebelo. El canal orbitotemporal y los vasos relacionados con el seno transverso presentan un calibre menor al registrado en MPM-PV 3532 y MPM-PV RB2SFV-14-9 de A. ovinum. 


\section{4. Discusión}

En este apartado se realizan algunos comentarios de los aspectos morfológicos novedosos incorporados en esta tesis, que básicamente involucran rasgos de la cavidad encefálica y de la anatomía interna de los nesodontinos de Santa Cruz, además de abordar algunos aspectos que han podido estudiarse a partir del uso de tomografías computadas.

Asimismo, se profundiza un poco más en los rasgos que fueron utilizados en la literatura para sugerir un incipiente dimorfismo sexual tanto para Nesodon como para Adinotherium, aun cuando en esta tesis no se ha corroborado la existencia de rasgos que lo indiquen.

\section{4.1 Anatomía interna de los nesodontinos}

Se pueden destacar varios rasgos peculiares para los Nesodontinae a partir de los moldes endocraneanos obtenidos en esta tesis. El más representativo de ellos consiste en el gran tamaño de la fosa hipofisaria, muy voluminosa en ambas especies de Santa Cruz. Otros de los rasgos notorios de la cavidad son la presencia de un canal orbitotemporal de gran calibre, la presencia de un paraflóculo pobremente desarrollado y la escasa diferenciación en el cerebelo de hemisferios cerebelares. Como fue mencionado a lo largo de este capítulo (y recalcado por diversos autores, e.g. Patterson 1937, Radinsky 1981), en ninguno de los modelos obtenidos se pudo encontrar una entrada independiente para las carótidas internas al cráneo.

En todas las especies de Nesodontinae estudiadas, las cavidades del endocráneo presentan una morfología que difiere notablemente de una a otra; aun cuando se encuentran presentes las mismas estructuras, la diferencia en las proporciones y la topología de las mismas es bastante notoria, especialmente entre ambas especies del género Nesodon. Esto podría sugerir que las presiones de selección que actúan sobre esta estructura están más influenciadas por las variaciones del tamaño corporal y no por una componente filogenética, al menos para el caso de los Nesodontinae; sin embargo, no puede establecerse concretamente hasta que no se evalúe la variación de estas características en un contexto filogenético mas amplio.

Respecto de las variaciones de la cavidad a lo largo de la ontogenia, solo se pudo contar con diversos ejemplares de $A$. ovinum, observándose que las diferencias más marcadas se refieren a las proporciones, siendo una cavidad mucho más globosa y más equidimensional en los ejemplares jóvenes (más corta, alta y ancha), mientras que en subadultos y adultos se observa un claro predominio del largo frente al ancho y el alto de la cavidad. En los ejemplares subadultos y adultos, las diferencias en la forma de la cavidad y disposición de las 
estructuras son poco evidentes; es decir, la cavidad encefálica de los subadultos es similar a la de los ejemplares adultos, solo que más pequeña en términos absolutos. Otros de los rasgos que destacan en los ejemplares juveniles son: fosa hipofisaria menos voluminosa; menor desarrollo de sulci y gyri en los hemisferios cerebrales y encéfalo anterior; y mayor ángulo de divergencia de los nervios ópticos.

Debido a la escasez general de información respecto de la estructura interna del cráneo de la mayoría de los notoungulados y a la aparente variabilidad presente en los nesodontinos, los rasgos de la cavidad endocraneana parecen no constituir fuentes útiles de caracteres filogenéticos, pero de todas maneras serán utilizados para realizar algunos de los análisis y poder testear la hipótesis de homología primaria propuesta para ellos (ver capítulo VI). En términos comparativos, la cavidad encefálica de los nesodontinos y Proadinotherium muensteri es más alta y corta que la presente en Homalodotherium. No ha sido posible evaluar adecuadamente el tamaño relativo de la cavidad en Homalodotherium debido a que el cráneo se encuentra incompleto y el resto de los materiales disponibles no resultaron adecuados para ello; sin embargo, las proporciones obtenidas de las estructuras sugieren que la cavidad encefálica sería ligeramente mayor a la de ambas especies de Nesodon y de tamaño similar a la de Proadinotherium.

Uno de los aspectos que se ha discutido durante mucho tiempo en la literatura asociada a la paleoneurología es el coeficiente de encefalización (EQ). Este coeficiente relaciona el volumen de la cavidad encefálica con el tamaño corporal del animal y fue propuesto por Jerison (1973) como un estimador del tamaño relativo del cerebro, asociado directamente a la capacidad cognitiva del animal. Este índice fue modificado años más tarde por Einsenberg (1981) al ampliar la muestra a partir de la cual se formuló la ecuación original. Si bien diversos autores han recalcado que el tamaño relativo del encéfalo no es un buen indicador de la capacidad cognitiva del animal (Deaner et al. 2007), este coeficiente es ampliamente utilizado en paleontología y ha servido para documentar los diferentes pulsos en los que se ha dado la encefalizacion en los mamíferos (Rowe et al. 2011). Como mencionó Radinsky (1981), el coeficiente de encefalización para los nesodontinos (0,5-0,7 para Adinotherium, por debajo de 0,4 en Nesodon) y para todos los UNS analizados en su muestra es notablemente menor que para los ungulados actuales ( $>0,85$, Perez Barberia et al. 2002, Boddy et al. 2012). Si bien el coeficiente de encefalización no ha sido uno de los objetivos en esta tesis, a partir de las estimaciones de masa para los nesodontinos presentes en la literatura, se pudo corroborar que lo expresado por Radinsky para nesodontinos coincide con los datos obtenidos aquí, aunque los valores de EQ para Adinotherium y Nesodon son menores que los publicados 
por Radinsky (Hernandez Del Pino et al. 2014, Dozo y Martínez 2015) debido a que las estimaciones de masa utilizadas por este autor eran menores a las reportadas recientemente (Ver Cassini 2011 y Cassini et al. 2012c).

\section{4.2 Dimorfismo sexual}

Antes de abordar la problemática del dimorfismo sexual en los nesodontinos, es importante establecer algunas clarificaciones sobre el uso de ciertos términos. Una especie presenta dimorfismo sexual cuando se puede establecer una diferenciación clara entre ambos sexos; en todas las especies de vertebrados existe dimorfismo sexual. Los caracteres sexuales secundarios son aquellas características que facilitan la selección de parejas (Darwin 1871) aun cuando no traigan aparejado beneficio alguno para la supervivencia del animal. Estas características pueden definirse entonces como rasgos físicos o del comportamiento que aparecen en los individuos sexualmente maduros y que permiten establecer una diferenciación entre los sexos de una especie.

Los caracteres sexuales secundarios físicos en los mamíferos incluyen la presencia de crecimiento diferencial de ciertas estructuras en el cuerpo (e.g. piezas dentarias, estructuras en el cráneo), variaciones en el tamaño del animal, diferencias en el pelaje e incluso el desarrollo de estructuras peculiares en machos (e.g. probóscides, cuernos o astas) (McPherson y Chenoweth 2012). Este tipo de diferenciación tiende a ser más pronunciada en el caso de las especies polígamas y es común que los machos presenten caracteres sexuales secundarios más acentuados que las hembras. En paleontología, el dimorfismo sexual puede ser identificado mayormente a partir de tres fuentes de caracteres: el tamaño corporal, la composición esqueletal y la presencia de estructuras accesorias utilizadas para la competencia entre machos de la misma especie o para la protección contra los depredadores.

Entrando algo más en los rasgos que han sido mencionados como posibles caracteres sexuales secundarios en los nesodontinos, uno de los que ha tenido más aceptación en la literatura ha sido la posible presencia de cuernos en los machos de ambas especies (Ameghino 1907, Scott 1912). En el caso de Nesodon, Scott (1912) postuló la posible presencia de un cuerno sobre un abultamiento del hueso frontal, justo por delante de la zona de unión de las crestas temporales para conformar la cresta sagital. Scott comentó que a los lados de dicha protuberancia el hueso frontal era más rugoso y ornamentado que en el resto de la frente y propuso una especie aparte, dado que esta superficie era muy diferente de la observable en 
todos los ejemplares a disposición de Nesodon imbricatus. Como se mencionó a lo largo de este capítulo, no se encontraron evidencias de la protuberancia mencionada por Scott ni las rugosidades en el ejemplar utilizado por ese autor para definir Nesodon cornutus; cabe destacar que, en el caso de haber estado presentes, no consistirían en un indicador suficiente de la presencia de cuernos dérmicos para esta especie. Un ejemplo de la posible base de un cuerno entre los toxodóntidos se ha determinado en Trigodon gaudryi, de Monte Hermoso, pero el ejemplar tipo, MACN 15344, presenta es un abultamiento redondo y muy notorio en el frontal, no unas rugosidades superficiales del hueso descripto para N. cornutus. Algo similar ocurre en los rinocerontes, por ejemplo, ya sean actuales o fósiles, en los que la base del cuerno constituye una superficie abultada y más o menos rugosa, bien definida incluso si los cuernos son pequeños (e.g., Tanner 1972, Cerdeño 1990). Los restantes ejemplos de cuernos en las especies actuales de mamíferos tampoco se ajustan a la caracterización brindada por Scott para justificar la presencia de un cuerno en Nesodon.

En el caso de Adinotherium ovinum se ha sugerido (Ameghino 1907) la existencia de un cuerno incipiente por la presencia de las mismas estructuras utilizadas por Scott (1912) para la fundación de $N$. cornutus. A lo ya comentado para esta última especie, hay que sumarle la enorme variabilidad que presenta la zona frontal en A. ovinum. En los diferentes ejemplares a disposición, puede verse una gran variación en la sutura fronto-nasal, la extensión, curvatura y desarrollo de los procesos postorbitales, cuya superficie puede variar desde una completamente lisa a una ligeramente ornamentada con rugosidades, y la presencia de una superficie lisa, deprimida o ligeramente abultada justo antes de la unión de las líneas temporales. Todos estos rasgos no forman parte de morfotipos discretos, sino que se presentan con diferente desarrollo de acuerdo al ejemplar consultado y posiblemente correspondan a variación individual y no a rasgos asociados con caracteres sexuales secundarios; al menos, no en el marco propuesto por Ameghino y Scott.

En coincidencia con lo expuesto anteriormente, no existen razones para sostener la presencia de un cuerno de ningún tipo en las especies de Nesodontinae de la Formación Santa Cruz.

Con respecto a otros aspectos que podrían atribuirse a caracteres sexuales secundarios, de existir en los taxones bajo estudio en esta tesis, se trataría de características cuya diferencia es sumamente leve en los distintos sexos. Posiblemente, algunos rasgos que puedan atribuirse a caracteres sexuales secundarios en los nesodontinos puedan observarse en diferencias en el desarrollo de estructuras en el techo craneano, tales como: altura y longitud de la cresta sagital; desarrollo de los procesos postorbitales y del hueso frontal en general; ancho del 
hueso nasal en su porción más anterior; y ancho y largo relativo del paladar, pero resultaría necesario realizar un análisis cuantificando los rangos de variación de estas estructuras en una muestra amplia, objetivo que excede ampliamente la finalidad de esta tesis.

Por último, con respecto al tamaño corporal, los extremos observados podrían sugerir la diferenciación de los sexos a partir de su tamaño (Ver Capitulo V), aunque estos índices deben ser tomados con cautela, dado que en las diferencias de tamaño registradas por los distintos autores (Croft 2001, Elissamburu 2004, Vizcaíno et al. 2010, Cassini et al. 2012b) es imposible discriminar si se trata de variaciones ligadas al ambiente u otros factores (variación individual) o a características sexuales secundarias. De acuerdo a Weckerly (1998), pueden establecerse tres categorías para la relación del tamaño corporal entre machos y hembras de una misma especie, tomando cómo eje la proporción tamaño corporal de los machos/tamaño corporal de las hembras: 1) proporción baja (índices entre 1,22 y 1,37), 2) proporción moderada $(1,38-1,77)$ y 3$)$ proporción alta $(1,78-1,81)$. Tomando las estimaciones de masa propuestas por Cassini (2011) a partir del tamaño del centroide del cráneo para las dos especies del género Adinotherium consideradas en ese trabajo (A. ovinum y A. robustum, reconocidas como sinónimos en esta tesis), el rango de variación de la masa para los ejemplares adultos es de 1,72 (145,3/84,2) para la estimación máxima, de 1,68 (91,2/54,2) para los valores medios y de $1,57(45,5 / 28,9)$ para los valores mínimos; el promedio de estos tres valores $(1,65)$ posicionaría a $A$. ovinum en la categoría intermedia propuesta por Weckerly (1998), grupo donde se encuentran los primates catarrinos y los elefántidos. En el caso de Nesodon imbricatus, los valores de variación son notablemente menores (aunque también es menor el número de ejemplares a partir de los cuales se pudo estimar la masa corporal), siendo $1,28(618,6 / 486,8)$ para los valores de tamaño corporal máximos, 1,26 $(363 / 288,8)$ para los valores intermedios y 1, $22(152 / 124,5)$ para los valores mínimos, dando un promedio de 1,25 que ubicaría a Nesodon en la categoría más baja, junto a los platirrinos, rumiantes y mustélidos.

En conclusión, en el caso de Adinotherium ovinum podría postularse la existencia de un dimorfismo sexual moderado a partir del tamaño corporal, mientras que, en el caso de Nesodon imbricatus, se trataría de un dimorfismo mucho más leve; sin embargo, esto no es del todo concluyente. Como se verá en el capítulo siguiente (Ver Capítulo V. 1 y V. 4), la variación de tamaño en ambas especies se da en un rango más o menos continuo y si bien existen grupos discretos a partir de los cuales se podría establecer la presencia de una diferenciación en el tamaño corporal debida a dimorfismo sexual (Ver Capitulo V. 1, 
Hernández Del Pino, S.

especialmente adultos de Adinotherium ovinum), no todas las varibales se comportan de esta manera. 